\title{
Feasibility Study of Medical Isotope \\ Production at Sandia National Laboratories
}

Charles D. Massey, Dennis L. Miller, Susan D. Carson, Timothy A. Wheeler, Susan W. Longley, Richard L. Coats, Edward J. Parma, Marion McDonald, Milton E. Vernon, Susan C. Bourcier Scott G. Mills, Anthony J. Trennel, Kenneth R. Boldt

\section{Prepared by}

Sandia National Laboratories

Albuquerque, New Mexico 87185 and Livermore, California 94550

for the United States Department of Energy

under Contract DE-AC04-94AL85000

Approved for public release, distribution is unlimited.

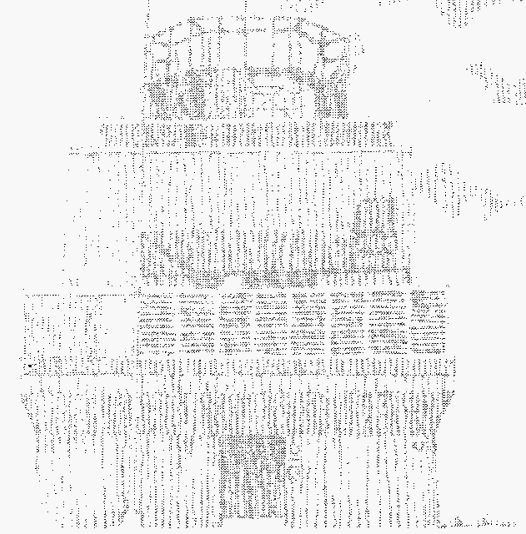


Issued by Sandia National Laboratories, operated for the United States Department of Energy by Sandia Corporation.

NOTICE: This report was prepared as an account of work sponsored by an agency of the United States Government. Neither the United States Government nor any agency thereof, nor any of their employees, nor any of their contractors, subcontractors, or their employees, makes any warranty, express or implied, or assumes any legal liability or responsibility for the accuracy, completeness, or usefulness of any information, apparatus, product, or process disclosed, or represents that its use would not infringe privately owned rights. Reference herein to any specific commercial product, process, or service by trade name, trademark, manufacturer, or otherwise, does not necessarily constitute or imply its endorsement, recommendation, or favoring by the United States Government, any agency thereof or any of their contractors or subcontractors. The views and opinions expressed herein do not necessarily state or reflect those of the United States Government, any agency thereof or any of their contractors.

Printed in the United States of America. This report has been reproduced directly from the best available copy.

Available to DOE and DOE contractors from

Office of Scientific and Technical Information

PO Box 62

Oak Ridge, TN 37831

Prices available from (615) 576-8401, FTS 626-8401

Available to the public from

National Technical Information Service

US Department of Commerce

5285 Port Royal Rd

Springfield, VA 22161

NTIS price codes

Printed copy: A14

Microfiche copy: A01 


\section{DISCLAMMIER}

Portions of this document may be illegible in electronic image products. Images are produced from the best available original document. 
SAND95-2703 Rev. 0

Distribution

Unlimited Release

UC-527

Printed December 1995

Feasibility Study of Medical Isotope Production at Sandia National Laboratories

\author{
Charles D. Massey, Dennis L. Miller, Susan D. Carson, \\ Timothy A. Wheeler, and Susan W. Longley \\ Environmental Regulatory Assessment Department
}

Richard L. Coats, Edward J. Parma, Marion McDonald

Milton E. Vernon, and Susan C. Bourcier

Isotope Program and Compliance Initiatives

Scott G. Mills

Transportation Systems Analysis Department

Anthony J. Trennel,

Transportation Systems Department

Kenneth R. Boldt

Nuclear Safety and Systems Analysis

Sandia National Laboratories

Albuquerque, NM 87185

\begin{abstract}
In late 1994, Sandia National Laboratories in Albuquerque, New Mexico, (SNL/NM), was instructed by the Department of Energy (DOE) Isotope Production and Distribution Program (IPDP) to examine the feasibility of producing medically useful radioisotopes using the Annular Core Research Reactor (ACRR) and the Hot Cell Facility (HCF). Los Alamos National Laboratory (LANL) would be expected to supply the targets to be irradiated in the ACRR. The intent of DOE would be to provide a capability to satisfy the North American health care system demand for ${ }^{99} \mathrm{Mo}$, the parent of ${ }^{99 \mathrm{~m}} \mathrm{Tc}$, in the event of an interruption in the current Canadian supply. ${ }^{99 m} \mathrm{Tc}$ is used in 70 to $80 \%$ of all nuclear medicine procedures in the US. The goal of the SNL/NM study effort is to determine the physical plant capability, infrastructure, and staffing necessary to meet the North American need for ${ }^{99} \mathrm{Mo}$ and to identify and examine all issues with potential for environmental impact.
\end{abstract}




\section{TABLE OF CONTENTS}

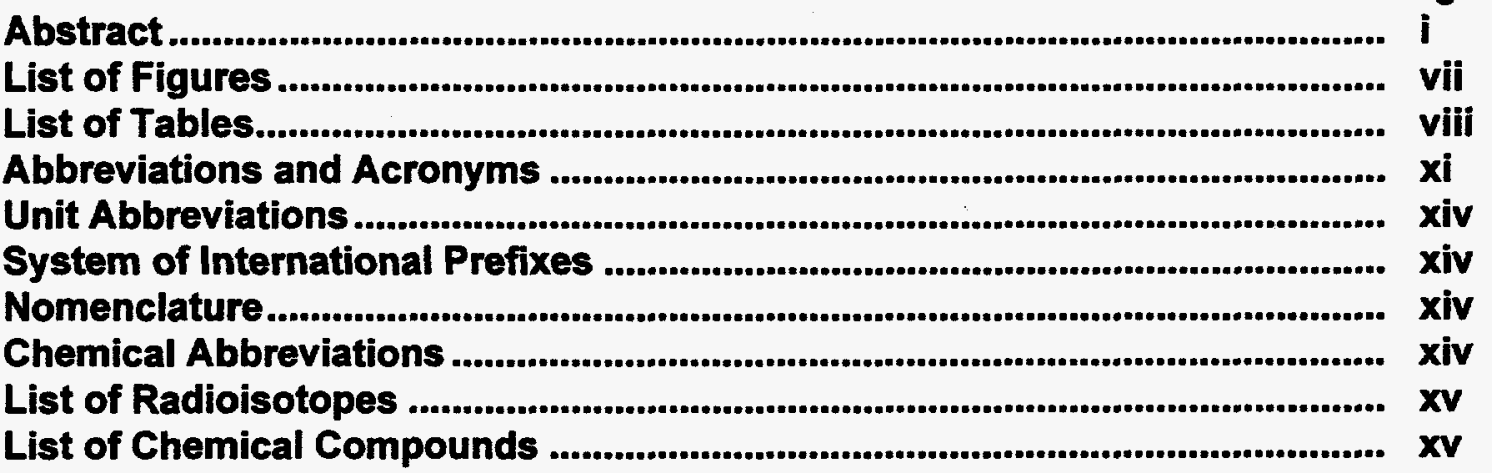

1.0 JUSTIFICATION FOR STUDY .......................................................... 1-1

1.1 Background .................................................................................. 1-1

1.2 Purpose and Need ...................................................................... 1-2

2.0 PRODUCTION PROGRAM CONCEPTS ................................................... 2-1

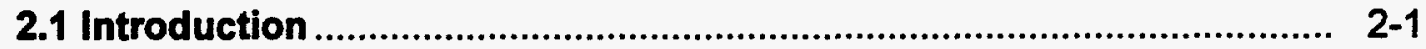

2.1.1 Pre-Production Activities............................................................ 2-5

2.1.1.1 Required CMR Facility Modifications at LANL...................... 2-5

2.1.1.2 Required ACRR Facility Modifications at SNL/NM ............... 2-5

2.1.1.3 Required HCF Facility Modifications .................................. 2-7

2.1.1.4 Prototype and Proof-of-Principle Testing ........................... 2-8

2.1.1.5 Availability for Conversion to Support

2.1.2 Target Fabrication ............................................................ 2-11

2.1.2.1 Target Fabrication at LANL ........................................... 2-11

2.1.2.2 Target Shipment to SNL/NM ........................................... 2-14

2.1.2.3 ACRR Operations at SNL/NM ....................................... 2-15

2.1.2.4 Target Transfer to HCF................................................. 2-18

2.1.2.5 Isotope Extraction at HCF ............................................... 2-19

2.1.2.6 Product Shipment ............................................................. 2-21

2.1.2.7 Other Isotope Production ................................................. 2-21

2.1.2.8 Waste Management........................................................ 2-22

2.1.3 Routine Maintenance.............................................................. 2-23

2.2 Alternative Production Concepts................................................ 2-23

2.2.1 Target Fabrication Site Options ............................................... 2-24

2.2.2 Waste Disposal Site Options .................................................... 2-24

3.0 AFFECTED ENVIRONMENTS ............................................................... 3-1

3.1 Introduction ................................................................................ 3-1

3.2 SNLNM Site Facilities.................................................................... 3-1

3.2.1 Hydrology and Water Usage.................................................... 3-6

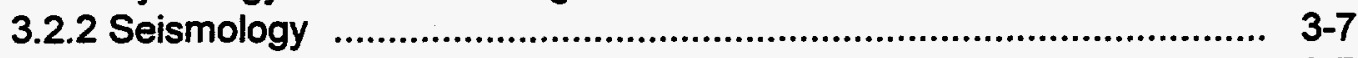

3.2.3 Climatology ........................................................................ 3-7

3.2.4 Population Characterization................................................... 3-9

3.2.5 Current Conditions.................................................................. $\quad 3-10$

3.2.5.1 ACRR Site ............................................................. $3-10$ 
3.2.5.2 Current Radiation Environment

3.2.5.3 Waste Management...................................................... 3-16

3.3 LANL Facilities

3.3.1 Location and Description of LANL Facilities.

3.3.2 Hydrology and Water Resources.

3.3.3 Seismology

3.3.4 Climatology

3.3.5 Population Distribution.

3.3.6 Current Conditions.

3.3.6.1 Site of Proposed Action

3.3.6.2 Environmental Quality and Monitoring Program.................. 3-22

3.3.6.3 Current Radiation Environment........................................ 3-22

3.3.6.4 Waste Management.................................................. 3-22

3.4 Transportation Routes.

4.0 ENVIRONMENTAL IMPACTS .......................................................... 4-1

4.1 Normal Operations ........................................................................ 4-1

4.1.1 Pre-Operational Impacts.......................................................... 4-1

4.1.1.1 CMR Activities ........................................................... 4-1

4.1.1.2 ACRR Activities......................................................... 4-2

4.1.1.3 HCF Activities ............................................................. 4-2

4.1.2 Operational Impacts ............................................................ 4-2

4.1.2.1 CMR Target Fabrication Normal Operations ....................... 4-2

4.1.2.2 ACRR Normal Operations............................................... 4-3

4.1.2.2.1 Water Consumption............................................ 4-4

4.1.2.2.2 Radiological Impacts ...................................... 4-5

4.1.2.3 HCF Operations ............................................................ 4-11

4.1.2.3.1 HCF Radiological Impacts ................................... 4-11

4.1.2.4 Cumulative ACRR and HCF Emissions............................. 4-16

4.1.3 Waste Management .............................................................. 4-18

4.1.4 Transportation Impacts ............................................................. 4-19

4.1.4.1 Pre-Operational Transportation Impacts ............................. 4-19

4.1.4.2 Unirradiated Target Shipment Impacts............................... 4-20

4.1.4.3 Isotope Product Shipment Impacts ................................... 4-22

4.1.4.3.1 Isotope Product Shipments Associated
With Full Purification of Isotopes at SNL/NM ......... 4-22

4.1.4.3.2 Isotope Product Shipments of Unpurified

${ }^{99}$ Mo Between SNL/NM and Ottawa, Canada .......... 4-24

4.1.4.4 Waste Shipments............................................................. 4-25

4.1.4.5 Total Radiological Impacts ............................................ 4-27

4.1.4.6 Nonradiological Transportation Impacts ............................. 4-27

4.2 Target Fabrication Site Options ................................................... 4-29

4.3 Alternative Waste Facilities.......................................................... 4-29

4.4 Cumulative Impacts ................................................................... 4-30

4.4.1 Cumulative Production Impacts .................................................. 4-30

4.4.2 Cumulative Waste Management Impacts ..................................... 4-31

4.4.3 Cumulative Transportation Impacts ........................................... 4-31

4.4.3.1 NUREG-0170 and Other Studies on Population Exposures... 4-31

4.4.3.2 Summary of Estimated Individual Radiological Doses .......... 4-32 


\subsubsection{Estimated Individual Doses From Other Proposed}

Activities at SNL/NM

4.4.3.4 Summary of Cumulative Transportation Effect Evaluation .....

4.5 Environmental Justice.

4.6 Spin-off Industries

4.7 Summary of Radiological Impacts for A Medical Isotope Production Program

5.0 POTENTIAL ENVIRONMENTAL IMPACTS OF ACCIDENT SITUATIONS ....

5.1 CMR Target Fabrication Accident Analysis

5.2 ACRR Accident Analysis

5.3 Target Transfer Accident Analysis .

5.4 HCF Accident Analysis

5.5 Transportation Accident Analysis

5.5.1 Introduction

5.5.2 Pre-Operational Waste Transportation

5.5.3 Unirradiated Target Shipments. 5-10

5.5.4 Isotope Product Shipments.

5.5.4.1 Isotope Product Shipments Associated With Full

Purification of Isotopes at SNLNM

5-12

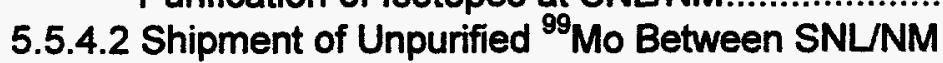
and Ottawa, Canada

5.5.5 Waste Shipments

5-13

5.5.6 Nonradiological Impacts

5.5.7 Total Radiological Impacts.

5-15

5.6 Simultaneous Accidents.

APPENDIX A DESCRIPTION OF MEDICAL ISOTOPE PRODUCTION PROCESS

A.1 Target Fabrication

A.1.1 Waste Management

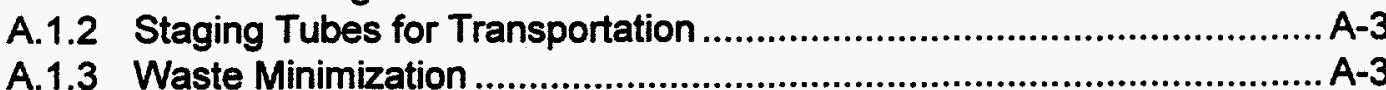

A.1.4 Criticality Safety and Hazard Category ...........................................A-3

A.2

ACRR Operations

A-4

A.3

A.4

Transfer to HCF

Isotope Extraction at HCF

A.6.1 Trash, Chemical Waste, and Wastewater

A.6.2 Low-Level Radioactive Waste

A.6.2.1 PPE and Contaminated Equipment.

A.6.2.2 ${ }^{99}$ Mo Extraction Process Wastes. 
A.6.2.4 Wastewater

A.6.3 Spent Nuclear Fuel.................................................................

A.6.4 Mixed Waste ................................................................................. A

A.6.5 Waste Management at LANL ........................................................ A-19

A.7 Transportation Shipping Campaign ............................................................A-19

APPENDIX B DESCRIPTION OF CONTAINERS USED FOR TRANSPORTING TARGETS, PRODUCTS, AND WASTES ……........................................... B-1

B.1 Pre-Production Activity ....................................................................................

B.2 Product Transportation to Customer ................................................................B-2

B.3 Waste Transportation and B-3 Package Status/Plans ................................. B-3

APPENDIX C REACTOR NEUTRONICS................................................................................

C.1 Reference Target Design..................................................................................... C-2

C.2 Neutronic Analysis Techniques............................................................................

C.2.1 Preliminary Neutronic Results .........................................................

C.2.2 Optimal Core/Target Configuration Results ......................................... C-11

C.3 Critical Heat Flux Analyses ......................................................................................15

C.4 ACRR Capability Summary ..................................................................................C-16

APPENDIX D ENVIRONMENTAL DATA ........................................................................... D-1

D.1 Methods for Determining Meteorological Dispersion Parameters.............. D-7

D.2 Site Geology....................................................................................................... D-9

D.3 Site Seismic Considerations............................................................................. D-19

APPENDIX E LEAKING TARGETS AND FUEL ELEMENTS - OFF SITE ACTIVITY RELEASES ......................................................................................................... E-1

APPENDIX F ANALYSIS AND CONSEQUENCES, ACRR DESIGN BASIS ACCIDENT ..... F-1

F.1 Limiting Event..................................................................................................F-2

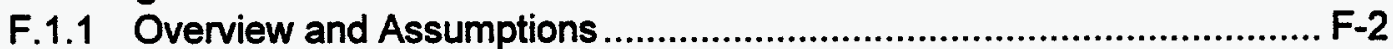

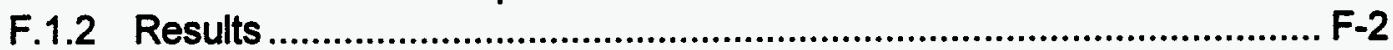

APPENDIX G HCF RADIONUCLIDE RELEASE CALCULATIONS.........................................-1

APPENDIX H CHEMICALS USED IN THE HCF ........................................................................ H-1

APPENDIX I ACCIDENT ANALYSIS ............................................................................... I

I.1 Methodology ...................................................................................................... 1-2

I.1.1 Operational Accidents ..................................................................... I-2

1.1.1.1 Accident-Sequence Initiating Event (IE) Analysis ..................... 1-3

I.1.1.2 Plant-System Analysis ............................................................ I-3

I.1.1.3 Accident-Sequence Analysis .................................................. I-4

I.1.1.4 Source-Term Analysis ........................................................... I-5

I.1.1.5 Consequence Analysis ..........................................................

I.1.1.6 Risk Analysis and HCF Comparison to Guidelines .................. I-11

1.1.2 Natural Phenomena and External Events........................................ $\mid-11$

I.1.2.1 Design-Basis Events ........................................................ I-12

I.1.2.2 Frequency of Occurrence or Return Periods .......................... I-12

I.1.2.3 Facility and Equipment Response .......................................... I-12 
I.1.2.4 Source-Term Analysis ................................................... I-12

I.1.2.5 Consequence Analysis .................................................. I-13

I.1.2.6 Risk Analysis ..................................................................... I-13

I.1.3 External Events ........................................................................ I-13

1.1.3.1 Identification of External Events ....................................... I-13

I.1.3.2 Event-Frequency Estimation............................................ $1-13$

1.1.3.3 Facility-Damage Assessment .......................................... I-13

1.1.3.4 Source-Term Analysis ...................................................... I-13

1.1.3.5 Consequence Analysis .................................................... I-13

I.1.3.6 Risk Analysis .............................................................. 1-14

1.2 ACRR Accident Analyses .......................................................................... 1-14

1.2.1 ACRR Operational Accidents .................................................. I-14

1.2.2 ACRR Natural Phenomena Accidents .......................................... I-20

1.2.3 ACRR External Event Accidents.................................................. I-21

1.3 HCF Accident Analyses.............................................................................. I-22

1.3.1 HCF Operational Accidents ...................................................... I-22

1.3.2 HCF Natural Phenomena Accidents .......................................... I-27

1.3.3 HCF External Event Accidents ...................................................... I-28

1.4 Accident Analysis for Worker Impact......................................................... I-29

APPENDIX J HOT CELL FACILITY EVALUATION............................................................ J-1

APPENDIX K CHEMICAL DISPERSION ANALYSIS FOR A RELEASE FROM THE HCF DURING ${ }^{99}$ MO PROCESSING .............................................................. K-1

APPENDIX L INPUT PARAMETERS FOR TRANSPORTATION RISK ANALYSIS.............. L-1

L.1 Potentially Exposed Population Groups ............................................... L-2

L.2 Handler Dose Models ........................................................................... L-3

L.3 Accident Severity Category Data ........................................................ L-3

L.4 Highway Routes................................................................................ L -4

L.5 Radionuclide Inventory For Waste Shipments ...................................... L-5

APPENDIX $M$ IMPACT AND RISK ASSESSMENT METHODOLOGY ................................. M-1

M.1 Measurements of Radiation Exposure .................................................. M-2

M.2 Operations Dose Calculations and Risk Assessment................................ M-3

M.3 Incident-Free Transportation................................................................ M-4

M.4 Highway Accidents............................................................................ M-5

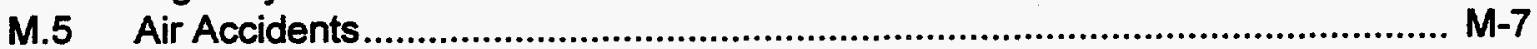

M.6 Nonradiological Health Effects and Risks............................................. M-8

\section{List of Figures}

Figure 2.1 Coordination of Existing ${ }^{99}$ Mo Production Capabilities with SNL Based Production..

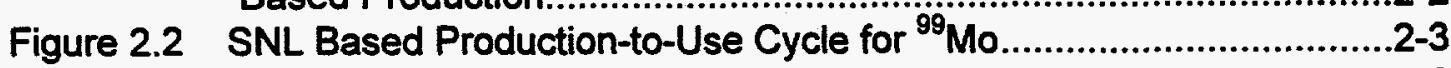

Figure 2-3 Target Fabrication Area in the CMR Facility at LANL .......................2-6

Figure 2-4 Proposed Modified Lowbay Configuration........................................2-11

Figure 2-5 The Isotope Production Process ....................................................2-12 
Figure 2-6

Figure 2-7

Figure 2-8

Figure 2-9

Figure 3-1

Figure 3-2

Figure 3-3

Figure 3-4

Figure 3-5

Figure 3-6

Figure 3-7

Figure 3-8

Figure 3-9

Figure 3-10

Figure 3-11

Figure 4-1

Figure 4-2

Figure 4-3

Figure 4-4

Figure A-1

Figure A-2

Figure A-3

Figure A-4

Figure A-5

Figure A-6

Figure $\mathrm{C}-1$

Figure $\mathrm{C}-2$

Figure C-3

Figure $\mathrm{C}-4$

Figure $\mathrm{C}-5$

Figure C-6

Figure C-7

Figure $\mathrm{C}-8$

Figure C-9
Figure C-10

Fuel Elements

Figure C-11 19 Targets in Flooded ACRR Central Cavity with No Liner and 129

Fuel Elements.

Figure C-12 37 Targets in Flooded ACRR Central Cavity with No Liner and 129

Fuel Elements. .C-14

Figure G-1 Model for Estimating Noble Gas Release During Normal Process

Operations G-2

Figure $\mathrm{G}-2$

Figure $\mathrm{J}-1$
Decay Paths that Produce Noble Gases During ${ }^{9}$ Mo Processing....G-6

Radiological Dose Criteria
.2-13

2-16

.2-16

.2-18

3-2

3-3

3-5

$3-6$

3-8

3-12

3-13

3-14

3-18

3-20

3-21

4-4

4-5

4-12

4-13

A-7

A-7

A-8

A-8

A-9

A-15

C-3

c-4

..C-5

C-6

C-7

C-8

C-9

C-10

C-11

C-13

C-14 


\section{List of Tables}

Table 2-1 HCF Systems Powered by Standby Diesel Generator .........................2-20

Table 3-1 Average Annual Ambient Radiation Levels .....................................3-14

Table 3-2 Estimated Public Radiation Exposure from SNL/NM Activities .............3-15

Table 3-3 Radiation Doses Received by Personnel Working at ACRR/HCF

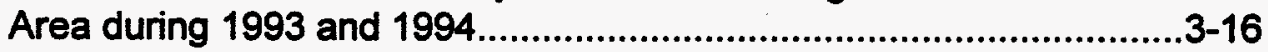

Table 4-1 Annual Waste Stream Increases Due to Target Fabrication at LANL..4-3

Table 4-2 Potential Radiological Hazards Associated with Normal ACRR

Operations ..................................................................................4-6

Table 4-3 Estimated Annual Doses for Continuous ACRR Operation for ${ }^{99}$ Mo Production.

Table 4-4 Average Historical and Expected Annual ACRR Radioactive Effluent Releases...........................................................................4-8

Table 4-5 Annual Downwind Dose Estimates for Leaking Targets and Fuel Elements in the ACRR ................................................................4-9

Table 4-6 Potential Radiological Hazards Associated with Normal HCF Operations ..................................................................................15

Table 4-7 Estimated Dose Rates and Occupational Exposures for Continuous HCF Operation and $200 \%{ }^{99}$ Mo Production .....................4-15

Table 4-8 Estimated Annual Dose for Normal HCF Operations at 200\% Production (2080 Targets/yr) ...............................................................4-15

Table 4-9 Estimated Individual Doses for HCF Incidents ................................4-17

Table 4-10 Estimated Total Annual Population Dose and Risk Data for Normal HCF Operations.

Table 4-11 Cumulative Radiological Doses from ACRR and HCF Operations at 200 Percent Production...............................................................4-17

Table 4-12 Cumulative Radiological Risks from ACRR and HCF Operations at $200 \%$ Production.......................................................................18

Table 4-13 Shipment Types, Origins, and Destinations.......................................4-19

Table 4-14 Pre-Production Hot Cell Cleanup Waste Shipment Impacts ................4-20

Table 4-15 Incident-Free Radiological Transportation Impacts Unirradiated Targets Shipped to SNL/NM from LANL ...........................................4-21

Table 4-16 Incident-Free Radiological Transportation Impacts Unirradiated Targets Shipped to Ottawa ..............................................................4-21

Table 4-17 Incident Free Radiological Transportation Impacts Unirradiated Targets Shipped from Lynchburg, VA to SNL/NM Via Air Cargo ..........4-22

Table 4-18 Incident Free Radiological Transport Impacts Unirradiated Targets Shipped by Lynchburg, VA to SNL/NM Via Truck

Table 4-19 Incident Free Radiological Transportation Impacts Isotope Product Shipments.

Table 4-20 Incident Free Radiological Transportation Impacts Waste Shipments to NTS.

Table 4-21 Incident Free Radiological Transportation Impacts Waste Shipments to Hanford

Table 4-22 Incident Free Radiological Transportation Impacts (NTS) .................4-22

Table 4-23 Incident Free Radiological Transportation Impacts (Hanford)..............4-28

Table 4-24 Incident Free Non radiological Transportation Impacts 
(LCF's Due to Diesel Emissions)

Table 4-25 Cumulative Individual Annual Radiation Dose for Maximally

Exposed Individuals

Table 4-26 Summary of Radiological Impacts for a Medical Isotope

Production Program

Table 5-1

Table 5-2

Table 5-3

Estimated Dose Conse

Estimated Risk Data for ACRR Accident Scenarios

Downwind Dose Estimates for a Target Rupture During

Transport to the HCF

Table 5-4 Estimated Risk Data for Target Rupture During Transport to the HCF

Table 5-5 Estimated Maximum Individual and Population Risks for Aircraft Crash into HCF

Table 5-6 Estimated Individual Doses for HCF ${ }^{99}$ Mo Spills, SCB Ventilation

Filter Not Isolated, Processing Starts 6 hours after Irradiation ............5-9

Table 5-7 Pre-Operational Hot Cell Cleanup Waste Shipment Accident Risks....5-10

Table 5-8 Total Accident Radiological Transportation Dose-Risks for Shipping:

Unirradiated Targets Fabricated at LANL

Table 5-9 Total Accident Radiological Transportation Dose-Risks:

Unirradiated Target Shipments form B\&W, Lynchburg, VA to SNL/NM 5-11

Table 5-10 Accident Radiological Transportation Risk: Purified Isotope Product Shipment $.5-12$

Table 5-11 Accident Radiological Transportation Risk: Waste Shipments

Table 5-12 Accident Non-radiological Transportation Fatality Risk-Annual Risk....5-14

Table 5-13 Accident Non-radiological Transportation Fatality Risk:

Life of Program

Table 5-14 Total Accident Radiological Transportation Risk.

Table 5-15

Table A-1

Simultaneous Accident Risks: Airplane Crash into ACRR \& HCF

5-16

Table A-2

Approximate Yearly Process Chemical Usage

Table A-3

Isotope Extraction Process Waste Estimates

A-15

Table A-4

Table A-5

Summary of SNL/NM Mixed Waste Treatability Groups

Annual Waste Stream Increases Due to Target Fabrication at LANL .A-19

Table D-1

Transportation Risk Assessment Shipping Campaign

Meteorological Data for Albuquerque, 1991

D-2

Table D-2

Meteorological Data for Albuquerque, 1940-1991

D-3

Table D-3

Precipitation, 1960-1991.

D-4

Table D-4

Snowfall, 1960-1991.

D-5

Table D-5

Average Temperatures, 1960-1989.

D-6

Table D-6

Table D-7

Values of Empirical Constants.

D-7

Table D-8

Dispersion Parameters and Coefficients

D-8

Dispersion Factors $(\chi / Q)$ as a Function of Distance from the HCF .....D-8

Table D-9

Formations Present in the Area Near TA-V

D-12

Table D-10

Log of Well

D-13-16

Table D-11 Mechanical Compositions and lon-Exchange Capacity.

Table D-12 Mineralogy of Silt and Clay Fractions

D-18

Table D-13 Noninstrumentally Located Earthquakes in NM, 1868-1959

Table D-14 Instrumentally Located NM Earthquakes, 1960-1986

Table E-1

Table E-2

Solubility of Some Noble Gases and Halogens in Water E-2

ACRR Highbay Release Rates for a Leaking Target Following a 
$21 \mathrm{~kW}, 7$-day Irradiation

Table E-3 ACRR Highbay Release Rates for a Leaking Target Following a

$25 \mathrm{~kW}, 5$-Yr Irradiation

Table E-4

Downwind Dose Estimates for a Leaking Target

Table E-5

Downwind Dose Estimates for a Leaking Fuel Element.

E-6

Table F-1

Calculated Results for $\$ 10.25$ Reactivity Insertion

Table F-2

Centerline Total Life Commitment Consequences for Individuals as a Function of Distance From the ACRR

Table F-3 ORIGEN2 PC Fission Product Inventory (Ci) for the ACRR

Limiting Event Scenario

Table F-4 ORIGEN2 PC Actinides Inventory (Ci) for the ACRR Limiting

Event Scenario

Table F-5 Summary of Building Concentration and Dose Consequences to Radiation Workers

Table G-1 Dose to an Individual per Curie of Radionuclide Released from the HCF Stack, NW Direction.

Table G-2

Table G-3

Table H-1

Table H-2

Table $1-1$

Partitioning of Significant Noble Gases and Their Precursors

Downwind Dose Estimates at $3000 \mathrm{~m}$ for Sample Case.

Chemicals Stored for ${ }^{99} \mathrm{Mo}$ Purification and Target Coating.

Exposure Limits for ${ }^{99} \mathrm{Mo}$ Chemicals.

EDE-Dose Conversion Factors and Specific Activities for

Representative Radionuclides.

Table I-2

Estimated Annual Probability of Occurrence and Mechanical

Consequences for ACRR Accident Scenarios.

Table 1-3

Table 1-4

Estimated Probability of Occurrence for HCF Accidental Scenarios...1-22

Time Required to Reach TLV and IDLH in HCF Rooms 106, 203 and the Chemical Storage Area (CSA) after a 2.5 Liter Chemical Spill, Assuming 473ml Evaporates

Table J-1

Event Categorization

Table J-2

Radiological Safety-Decision-Threshold Criteria..

Table J-3

Toxicological Exposure Criteria

Table K-1

Dispersion Characteristics of HCF Chemicals

Table L-1

Highway and Air Accident Probability Data by Mode.

Table L-2

RADTRAN Accident Severity Category Conditional Probability

Data by Mode

Table L-3

RADTRAN Source Term Parameters

Table L-4 A Representative Transportation Route From TA-V, SNL/NM to

Albuquerque International Airport..

Table L-5 Highway Route for Shipments of Unirradiated Targets from LANL to SNL/NM and Albuquerque

Table L-6 Highway Route for Shipments of HCF Wastes from SNL/NM to NTS L-10

Table L-7 Highway Route for Shipments of HCF Wastes from SNL/NM to Hanford.

Table L-8 EPA Nonattainment Counties Along a Representative Route from SNL/NM to the NTS

Table L-9 EPA Nonattainment Counties Along a Representative Route from SNLINM to the Hanford Site.

Table L-10 HCF Waste Shipment Radionuclide Inventory for RADTRAN 4 Accident Analysis. 


\section{Abbreviations and Acronyms}

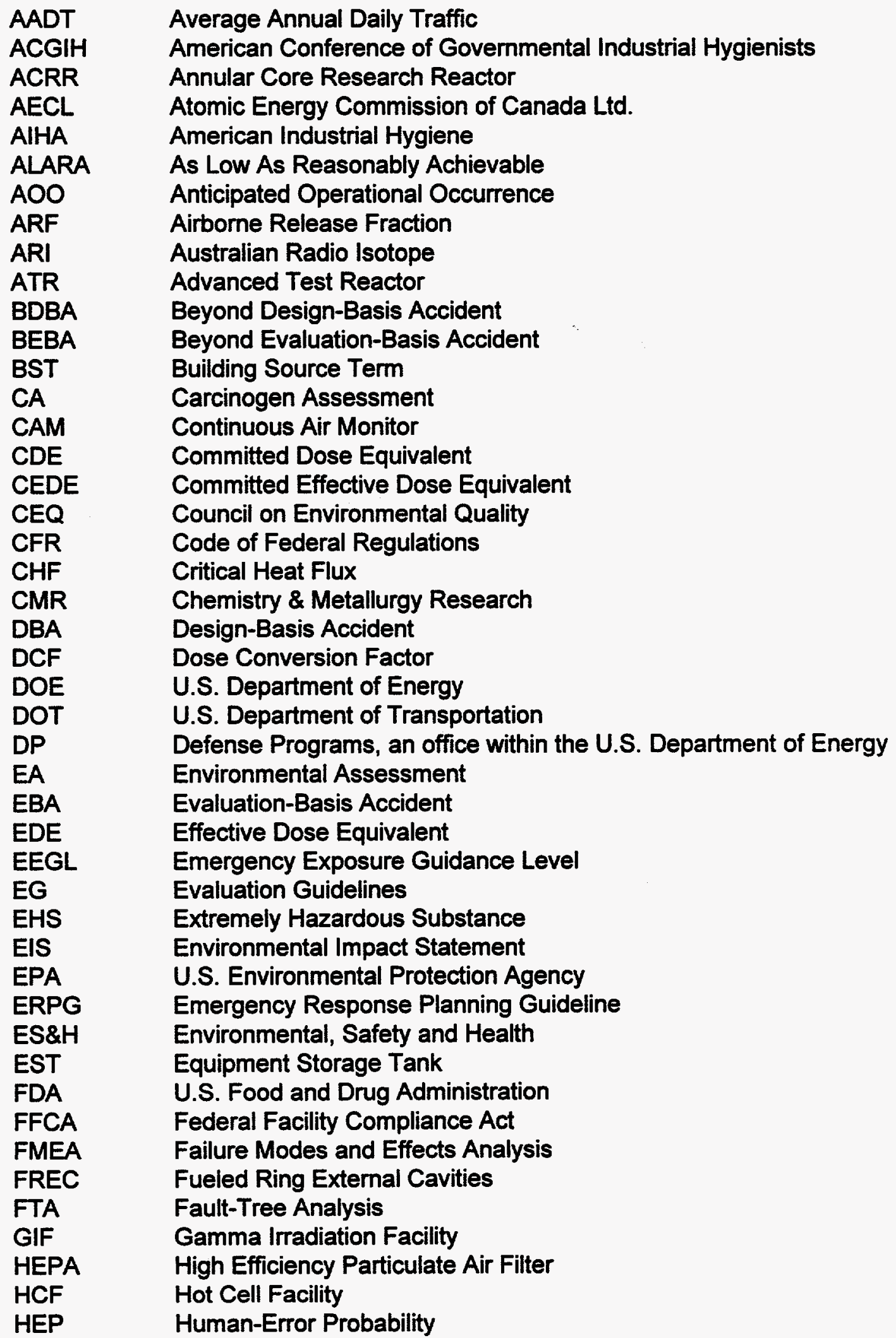




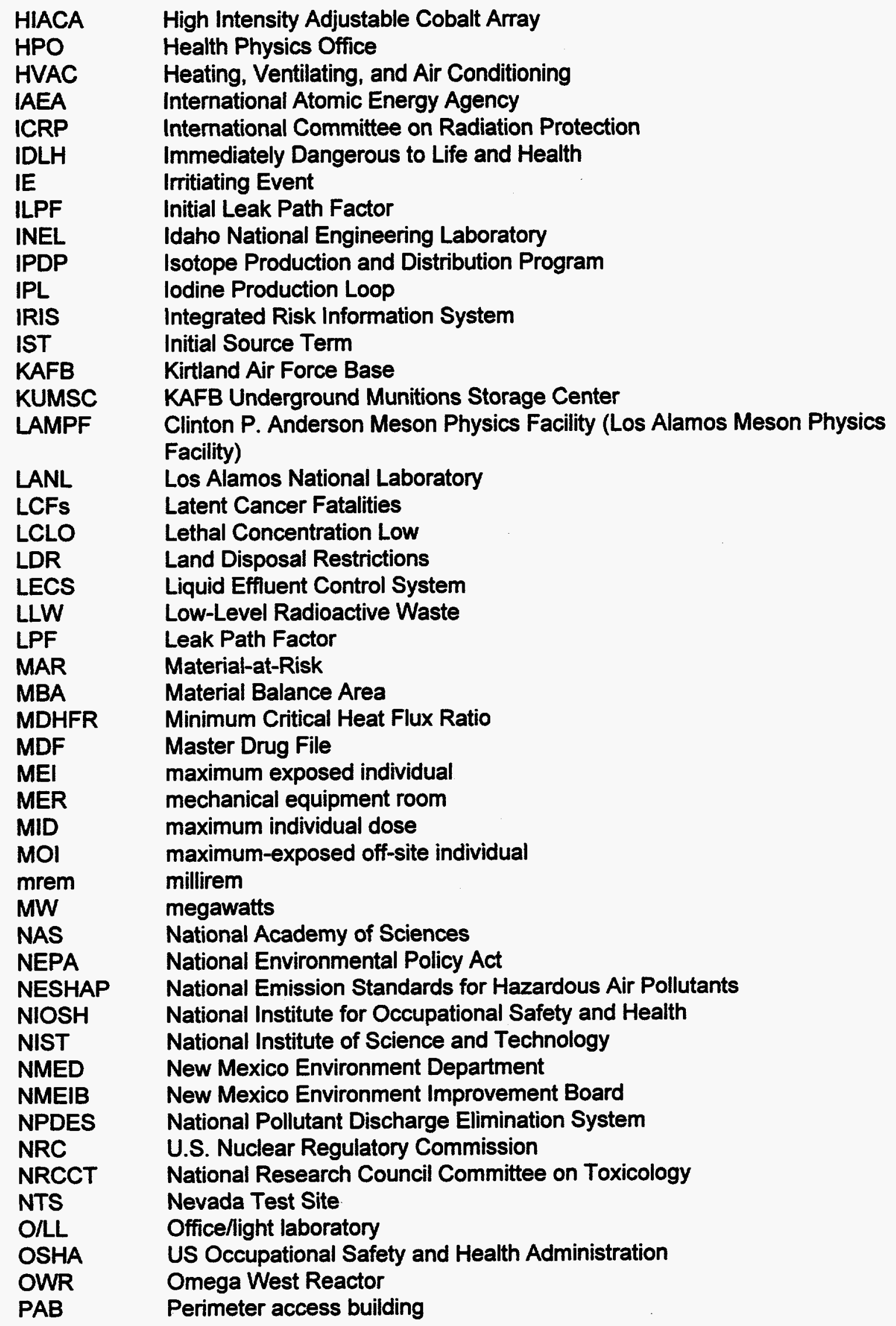




$\begin{array}{ll}\text { PC } & \text { Plant Conditions } \\ \text { PEL } & \text { Permissible Exposure Limit } \\ \text { PET } & \text { positron emission tomography } \\ \text { PHA } & \text { Preliminary Hazard Assessment } \\ \text { PHC } & \text { Preliminary Hazard Checklist } \\ \text { P\&ID } & \text { Piping and Instrumentation Drawing } \\ \text { PPE } & \text { Personnel Protection Equipment } \\ \text { PRA } & \text { Probabilistic Risk Assessment } \\ \text { QA } & \text { Quality Assurance } \\ \text { QC } & \text { Quality Control } \\ \text { QF } & \text { Quality Factor } \\ \text { RAMs } & \text { Radiation Area Monitors } \\ \text { RCRA } & \text { Resource Conservation and Recovery Act } \\ \text { R\&D } & \text { Reference Dose } \\ \text { RF } & \text { Respirable Fractions } \\ \text { RLWTF } & \text { Radioactive Liquid Waste Treatment Facility } \\ \text { RMTC } & \text { Regional Medical Technology Center } \\ \text { RWMS } & \text { Radioactive Waste Management Site } \\ \text { SA } & \text { Specific Activity } \\ \text { SAR } & \text { Safety Analysis Report } \\ \text { SCB } & \text { Steel Containment Box } \\ \text { SEIS } & \text { Site-wide Environmental Impact Statement } \\ \text { SHEBA } & \text { Solution High Energy Burst Assembly } \\ \text { SIRAS } & \text { Sandia Independent Review and Appraisal System } \\ \text { SNL/NM } & \text { Sandia National Laboratories/New Mexico } \\ \text { SNM } & \text { Special Nuclear Material } \\ \text { SPEGL } & \text { Short-Term Exposure Guidance Level } \\ \text { SPR } & \text { Sandia Pulsed Reactors } \\ \text { SRS } & \text { Savannah River Site } \\ \text { SSC } & \text { Structured Systems and Components } \\ \text { STEL } & \text { Short-Term Exposure Limit } \\ \text { STP } & \text { Site Treatment Plan } \\ \text { TA } & \text { Technical Area at SNL/NM or LANL } \\ \text { TI } & \text { Transportation Index } \\ \text { TLD } & \text { Thermoluminescent Dosimeter } \\ \text { TLV } & \text { Threshold Limit Value } \\ \text { TSD } & \text { Transportation Surety Department } \\ \text { TWA } & \text { Time-Weight Average } \\ \text { UBC } & \text { Uniform Building Code } \\ \text { UCRL } & \text { University of California Research Laboratory } \\ \text { USAF } & \text { United States Air Force } \\ \text { USQ } & \text { Unreviewed Safety Question } \\ & \end{array}$

\section{Unit Abbreviations}

$\begin{array}{ll}\text { ac } & \text { acre } \\ \mathrm{Ci} & \text { curie } \\ \text { cc } & \text { cubic centimeter }\end{array}$




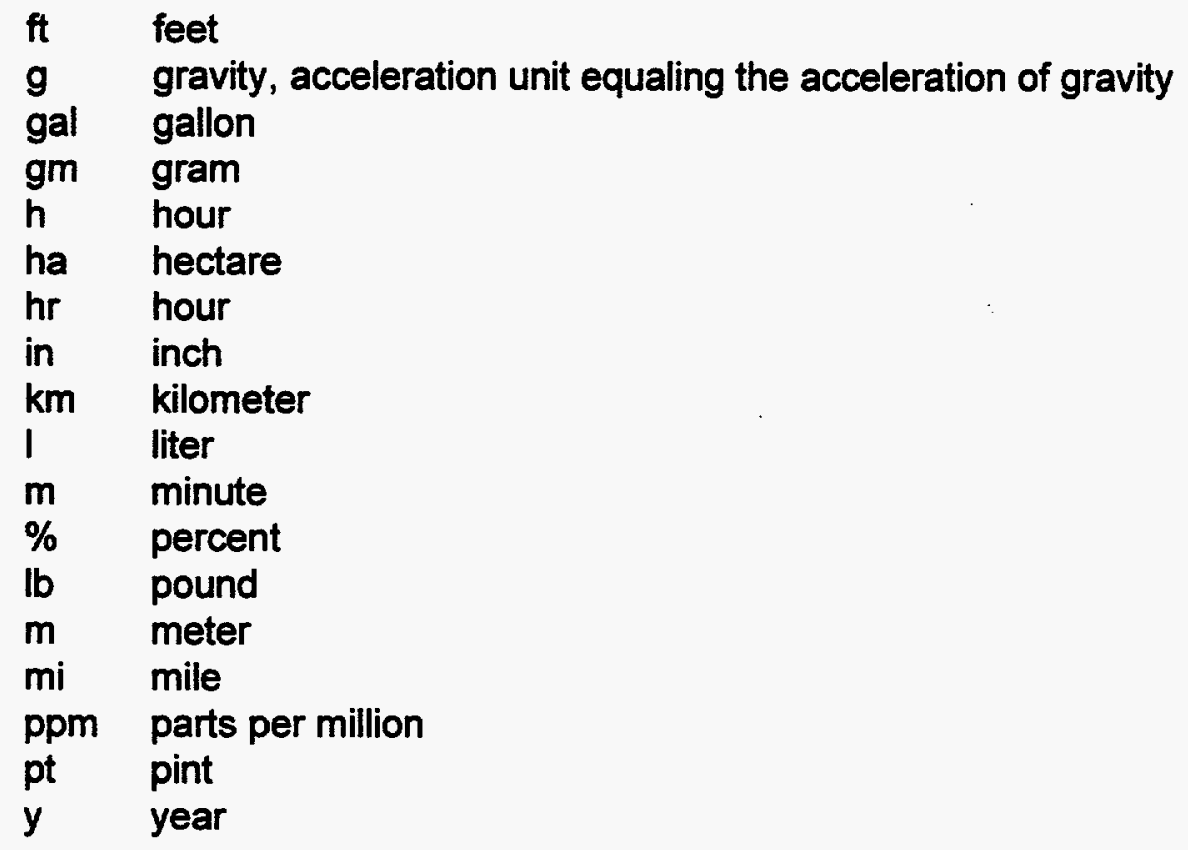

\section{System of International Prefixes}

\begin{tabular}{clc} 
Exponent & Prefix & Symbol \\
\hline $10^{6}$ & mega & $\mathrm{M}$ \\
$10^{3}$ & kilo & $\mathrm{k}$ \\
$10^{-2}$ & centi & $\mathrm{c}$ \\
$10^{-3}$ & milli & $\mathrm{m}$ \\
$10^{-6}$ & micro & $\mu$ \\
$10^{-9}$ & nano & $\mathrm{n}$
\end{tabular}

Nomenclature

Some numbers are expressed in an exponential shorthand as follows:

2.1e-03 represents $2.1 \times 10^{-3}$, which can also be written as 0.0021

\section{Chemical Abbreviations}

Chemical elements are characterized in the Periodic Table by the number of protons ( $Z$ ) contained in the atoms. The mass of these elements results from the number of nucleons (combined number of protons [Z] and neutrons [N]) in the atom. In the early part of this century it was discovered that not all of the atoms of a particular element have the same mass. Since the number of protons $(Z)$ is constant for a particular element, this implies that the number of neutrons $(\mathrm{N})$ could vary. These different varieties of the same element are called isotopes and are identified by their nucleon number $A(A=Z+N)$. The common way of identifying isotopes is to use the chemical element abbreviation preceded by the nucleon number $A$ as a superscript. For example ${ }^{99} \mathrm{Mo}$ is the isotope of molybdenum that contains 42 protons and 57 neutrons in each atom. While some isotopes are stable, others decay by emitting particles and/or electromagnetic radiation. The latter isotopes are referred to as radioisotopes. The time it takes for half of the atoms of a radioisotope sample to decay is called its half-life. 
List of Radioisotopes

\begin{tabular}{|c|c|c|c|c|}
\hline Symbol & Chemical name & Protons & Neutrons & Half-life \\
\hline & Cobalt & 27 & 33 & $5.271 \mathrm{yr}$ \\
\hline Mo & Molybdenum & 42 & 57 & 2.448 days \\
\hline${ }^{99 m} \mathrm{Tc}^{*}$ & Technetium & 43 & 56 & 6.01 hours \\
\hline & lodine & 53 & 72 & 60.1 days \\
\hline${ }^{131}$ & lodine & 53 & 78 & 8.04 days \\
\hline${ }^{133} \mathrm{Xe}$ & Xenon & 54 & 79 & 5.243 days \\
\hline${ }^{192} \mathrm{Ir}$ & Iridium & 77 & 115 & 73.83 days \\
\hline & Uranium & 92 & 143 & 7.04E8 yr \\
\hline
\end{tabular}

${ }^{*}$ The $\mathrm{m}$ in ${ }^{99 \mathrm{~m}} \mathrm{Tc}$ refers to a metastable state of the isotope ${ }^{99} \mathrm{Tc}$.

\section{List of Chemical Compounds}

\begin{tabular}{ll} 
Chemical Formula & Chemical Compound \\
\hline $\mathrm{U}_{3} \mathrm{O}_{8}$ & Uranium oxide \\
$\mathrm{HCl}$ & Hydrochloric acid \\
$\mathrm{H}_{2} \mathrm{SO}_{4}$ & Sulfuric acid \\
$\mathrm{HNO}_{3}$ & Nitric acid \\
$\left(\mathrm{NH}_{4}\right)_{2} \mathrm{C}_{2} \mathrm{O}_{4} \mathrm{H}_{2} \mathrm{O}$ & Ammonium oxalate \\
$\mathrm{HCOOH}$ & Formic acid \\
$\mathrm{NaOH}$ & Sodium hydroxide \\
$\mathrm{H}_{2} \mathrm{O}_{2}$ & Hydrogen peroxide \\
$\mathrm{NH}_{4} \mathrm{OH}$ & Ammonium hydroxide \\
$\mathrm{H}_{2} \mathrm{O}$ & Water
\end{tabular}




\subsection{Justification for Study}

\subsection{Background}

For more than forty years, the Department of Energy (DOE) and its predecessor agencies have produced and distributed isotopes through its national laboratories. In 1990, Congress established the Isotope Production and Distribution Program (IPDP), bringing together under one program all DOE isotope production activities.

Among other activities, the IPDP has taken responsibility for ensuring a stable supply of molybdenum-99 $\left({ }^{99} \mathrm{Mo}\right)$, the most widely used medical radioisotope. For use in medical diagnosis and treatment, ${ }^{99} \mathrm{Mo}$ is provided to private bulk radiopharmaceutical product manufacturers who, in turn, use ${ }^{99} \mathrm{Mo}$ as a source for the production of technetium-99m $\left({ }^{99 m} \mathrm{Tc}\right)$, which is provided to medical personnel in shielded containers called generators. Because these isotopes are highly perishable and have a lifetime of a few days (half-life of ${ }^{99}$ Mo is only 66 hours, and that of ${ }^{99 \mathrm{~m}} \mathrm{Tc}$ only six hours), the need to provide a continuous and stable supply of ${ }^{99}$ Mo for medical use is critical.

As an example of the extensive use of radioisotopes in the U.S., during 1993 the following nuclear medicine applications were performed (U.S. Council for Energy Awareness, 1993):

- 36,000 diagnostic procedures each day (most procedures using ${ }^{99 \mathrm{~m}} \mathrm{TC}$ );

- 50,000 nuclear medicine therapies during the year, and

- $100,000,000$ laboratory tests during the year.

Prior to $1989,{ }^{99}$ Mo was produced in the U.S. by a single supplier, Cintichem, Inc. In 1989, because of problems associated with operating its Nuclear Regulatory Commission (NRC) licensed facility, Cintichem elected to decommission the facility rather than incur the costs to repair it. The demise of the ${ }^{99} \mathrm{Mo}$ production capability at Cintichem left the U.S. totally reliant upon a single foreign source, Nordion International, located near Ottawa, Canada. Nordion receives their raw ${ }^{99}$ Mo from Atomic Energy of Canada, Ltd (AECL).

Prior to 1991, AECL operated two reactors capable of producing ${ }^{99}$ Mo. In 1991, one of the Canadian reactors was shut down. For nine days there was no source of ${ }^{99}$ Mo for North America and the supply was quickly exhausted. Fortunately, the Canadians were able to switch production to the second reactor and the supply of ${ }^{99}$ Mo resumed. However, in 1993, the first reactor was closed permanently, leaving only one operating. This reliance on a single production reactor increases the likelihood of an interruption of the supply of ${ }^{99}$ Mo to the U.S. medical community.

Recognizing the impact that a shutdown of their only reactor would have on isotope production, the Canadians investigated the option of building a second reactor, but these plans were abandoned in late 1993. As a result, any shutdown of the single operating Canadian reactor would again jeopardize the U.S. supply of ${ }^{99} \mathrm{Mo}$, causing a drastic effect on the nation's health care. 
Because the medical radioisotope market is influenced by forces other than traditional market forces (i.e., national interest and government subsidies), full cost recovery of investment is often infeasible. In addition to market vagaries, the uncertainty and liabilities of constructing and operating a nuclear reactor have prevented and will likely continue to prevent private companies from providing a domestic source of ${ }^{99} \mathrm{Mo}$. In hearings on the condition of the IPDP before the Congressional Environment, Energy, and Natural Resources Subcommittee of the Committee on Government Operations, the "need for DOE to re-enter the molybdenum supply business" was reaffirmed and the "peril of dependence on a single source for such a critical isotope" was addressed (Committee on Government Operations, 1992).

\subsection{Purpose and Need}

Because the North American medical community has been without a reliable backup supply of medical isotopes since the shutdown of the second Canadian reactor in 1993, SNL has investigated the feasibility of using existing DOE facilities to provide a reliable backup supply of medical isotopes for use in North America. In addition, because it is essential to establish a backup capacity as soon as possible, the SNL's feasibility study is focused on existing and proven processes, specifically the Cintichem process and its associated Food and Drug Administration (FDA) Master Drug File (MDF). 


\subsection{PRODUCTION PROGRAM CONCEPTS}

\subsection{Introduction}

SNL/NM has assessed the feasibility of using existing DOE facilities at Los Alamos National Laboratory (LANL) and Sandia National Laboratories, New Mexico (SNLNM) to produce medical isotopes for North American medical care use. The feasibility analysis focused on production requirements for meeting the current and future North American demand for radioisotopes in the event that the Canadian supply is interrupted. The assessment analyzed a number of production activity options. For any option, a baseline production goal of about 30 percent of current North American demand (about 5,000 curies of ${ }^{99}$ Mo per week) would be required. This baseline production is needed to ensure that production could be increased quickly to meet 100 percent of demand, if needed. The demand for ${ }^{99} \mathrm{Mo}$ increases each year; hence, the feasibility assessment includes production levels up to 200 percent of the current level of demand to meet this increase.

The principle activities assessed on this study include:

- fabricating uranium targets at the LANL Chemistry and Metallurgy Research (CMR) facility and then shipping the targets to Technical Area V (TA-V) at SNL/NM;

- irradiating targets in SNL/NM's Annular Core Research Reactor (ACRR);

- $\quad$ processing irradiated targets in SNL/NM's Hot Cell Facility (HCF) to produce medical radioisotopes;

- $\quad$ shipping medical radioisotopes to radiopharmaceutical companies; and

- $\quad$ shipping wastes to disposal facilities.

Variations of these principal activities, which are included in this assessment, include shipping unirradiated targets from LANL to Canada and shipping unpurified ${ }^{99} \mathrm{Mo}$ from Canada to SNL/NM or vice versa for further processing. An overview of the production process is depicted in Figure 2-1.

The process depicted in Figure 2-1 is an overview from a system perspective. Many activities would be involved in establishing and operating such a system. Figure 2-2 describes the activities that would be involved in such an isotope production program. The entire productionto-use cycle is described in Appendix A. 
Figure 2-1. Coordination of Existing ${ }^{99}$ Mo Production Capabilities with SNLNM Based Production

\section{Proposed U.S. Backup Program}

\author{
Existing Canadian \\ Production Program
}

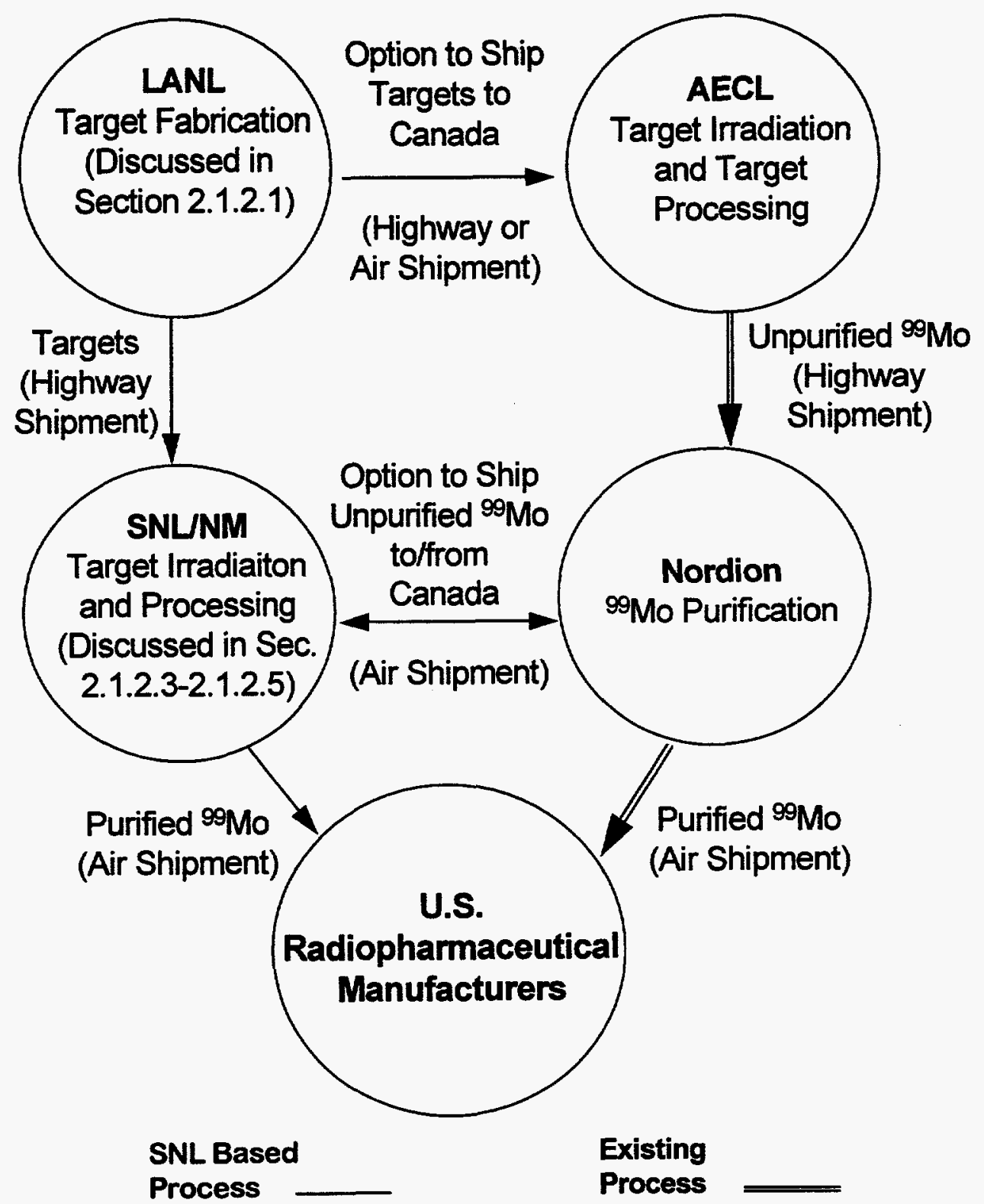




\section{Figure 2-2. SNL/NM Based Production-to-Use Cycle for ${ }^{99}$ Mo}

\section{LANL}

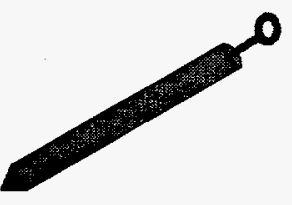

1

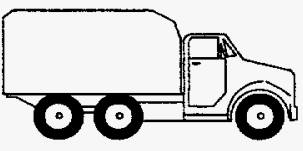

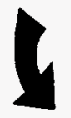

SNL

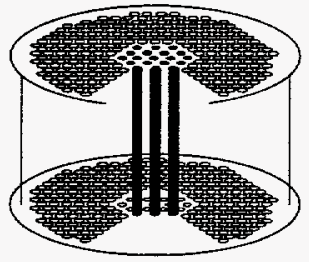

1

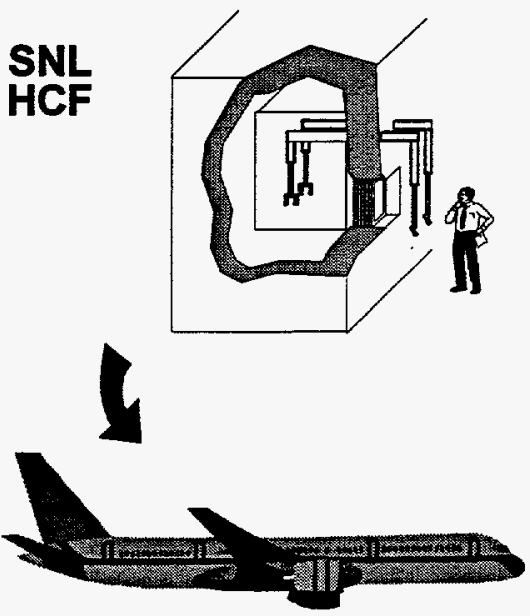

TARGET FABRICATION (CMR FACILITY, LANL)

Target elements would be manufactured by electrocoating enriched $\mathrm{U}_{3} \mathrm{O}_{8}$ (up to $20 \mathrm{~g}$ [0.7 oz.] of ${ }^{235} \mathrm{U}$ per target) on the inner wall of stainless steel tubes. The tubes would be welded closed with end caps. They would undergo QA and leak checks before shipment to SNL/NM.

\section{TARGET TRANSPORT (LANL $\rightarrow$ SNLNM) \\ Unirradiated targets (up to 24 per shipment) would be transported by truck from the CMR Facility at LANL to TA-V at SNLNMM.}

\section{IRRADIATION (ACRR FACILITY, SNLNM TA-V)}

Target elements would be loaded in the central core region of the ACRR in SNL/NM's TA-V. Irradiation would be performed around the clock. Targets would be loaded and removed from the core on staggered schedules to provide daily batches of isotopes for processing.

\section{EXTRACTION (HCF FACILITY, SNLNM TA-V)}

Irradiated targets would be transferred in a shielded cask by manned transport to the HCF in SNLINM's TA-V. In the HCF, the isotopes would be extracted in shielded hot cells equipped with remote manipulators. For each irradiated target about 600 curies of ${ }^{99}$ Mo would be extracted from the approximately 20,000 curies of fission products using a chemical dissolution and precipitation process approved by the FDA. Strict quality control (QC) would be performed on the product before shipping the product in shielded casks.

\section{TRANSPORT (SNLNM $\rightarrow$ PHARMACEUTICAL COS)}

The containers of medical radioisotopes would be shipped by commercial air freight express to radiopharmaceutical companies throughout the country. 
Uranium-loaded targets would be fabricated at the CMR facility at LANL. In glove boxes at the CMR facility, highly enriched uranium oxide $\left(\mathrm{U}_{3} \mathrm{O}_{8}\right)$ would be electrocoated on the inner walls of hollow cylindrical tubes. The clean unirradiated targets would be transported to SNL/NM's TA-V by truck in shipments of up to 24 targets. The targets would then be irradiated for several days in SNL/NM's ACRR. On a staggered daily schedule, one or more irradiated targets would be removed from the ACRR and transferred in a shielded cask via a manned transport vehicle to SNL/NM's HCF, located adjacent to the ACRR facility in TA-V.

The irradiated targets containing almost 20,000 curies of fission products would be processed in dedicated, shielded confinement boxes located in the HCF. Within the boxes, the isotopes of interest would be extracted from the fission product inventory by chemical dissolution and precipitation procedures (see Appendix A). The isotopes would be further refined and would undergo strict quality control procedures to meet FDA Master Drug File (MDF) standards. The isotopes would then be shipped in shielded casks by air freight to radiopharmaceutical companies.

The process would use technology previously employed by Cintichem, Inc. Cintichem is a private company and was the last U.S. producer of ${ }^{99} \mathrm{Mo}$. The process used by Cintichem was approved by the FDA and is described in a MDF. DOE obtained the rights to the patented process and the MDF in 1991 and is proposing to use this process to save the time and expense of developing a new MDF. As a result, the proposed production process would be very similar to the Cintichem process and produce similar medical isotopes. While ${ }^{99}$ Mo is the "workhorse of nuclear medicine" (U.S. Council for Energy Awareness, 1993) and would be the primary focus of the program, other isotopes which are generated by fission or activation would be produced. These isotopes include iodine-131 $\left({ }^{131} \mathrm{I}\right)$, xenon-133 $\left({ }^{133} \mathrm{Xe}\right)$ and iodine-125 $\left({ }^{125} \mathrm{I}\right)$ (see Appendix A).

SNL/NM's TA-V facilities would be used for this isotope production for the following reasons (DOE, 1994):

- The ACRR is a modern facility and is presently in an operational state.

- The ACRR can be dedicated to continuous isotope production, which is necessary to meet the demands for short-lived medical use isotopes.

- TA-V facilities (a reactor and hot cell facility) are present and can be modified relatively easily.

- The DOE Defense Programs (DP) and other mission needs for the ACRR and HCF have decreased. While the ACRR must be available for future DP activities in the event of a national emergency, DP does not currently have a full-time mission for the reactor; therefore, the facilities are available for continuous isotope production (See Section 2.1.1.5).

Other reasons that support this concept are:

- facility capability to handle and store Special Nuclear Material (SNM) such as enriched ${ }^{235} \mathrm{U}$

- collocated reactor and hot cell facilities; 
- a reactor with operating characteristics that are compatible with radioisotope production; and

- close proximity to air transportation facilities (Albuquerque International Airport) for radioisotope shipments.

\subsubsection{Pre-Production Activities}

Some modification of existing facilities/operations would be required to implement a medical isotope production process at SNL/NM. The following sections provide a description of these modifications.

\subsubsection{Required CMR Facility Modifications at LANL}

Targets would be made in the CMR facility, Wing 9 . Some interior walls would be removed and doors would be relocated to form a single-point access suite of five rooms (Figure 2-3). The CMR facility is particularly adaptable to interior reconfigurations of this type because interior walls are non-load-bearing metal panels, which can be readily relocated.

Nine glove boxes would be custom fabricated to contain the apparatus for the process steps as two parallel, duplicate production lines. Each glove box exhaust would be fitted with a high efficiency particulate air (HEPA) filter. Apparatus in glove boxes would include:

- dissolution tanks,

- introduction boxes,

- electrocoating lines,

- pyrolyzing and welding equipment, and

- quality assurance and assay equipment.

Additional exhaust ducting and fans would connect the glove box ventilation systems to the existing CMR Wing 9 ventilation system.

\subsubsection{Required ACRR Facility Modifications at SNLNM}

Procurement/installation of Heat Exchangers - The ACRR currently operates in either a pulsed or steady-state mode. The current steady-state power limit is 2 megawatts (MW). This limit is due to the combined heat rejection limitations of the heat exchanger/cooling tower system. Installation of additional heat exchanger/cooling tower heat rejection capacity would allow the reactor to run at $4 \mathrm{MW}$ and maintain a pool water temperature of $40^{\circ} \mathrm{C}\left(104^{\circ} \mathrm{F}\right)$ for desired performance of the reactor and the pool water treatment system.

Removal of Central Cavity - The central cavity was used in past operations to provide a dry, high neutron flux location in the core. The central cavity is shown in Figure 2-7 later in this section. Removal of the central cavity would allow targets to be placed in this central core 
Figure 2-3. Target Fabrication Area in the CMR Facility at LANL

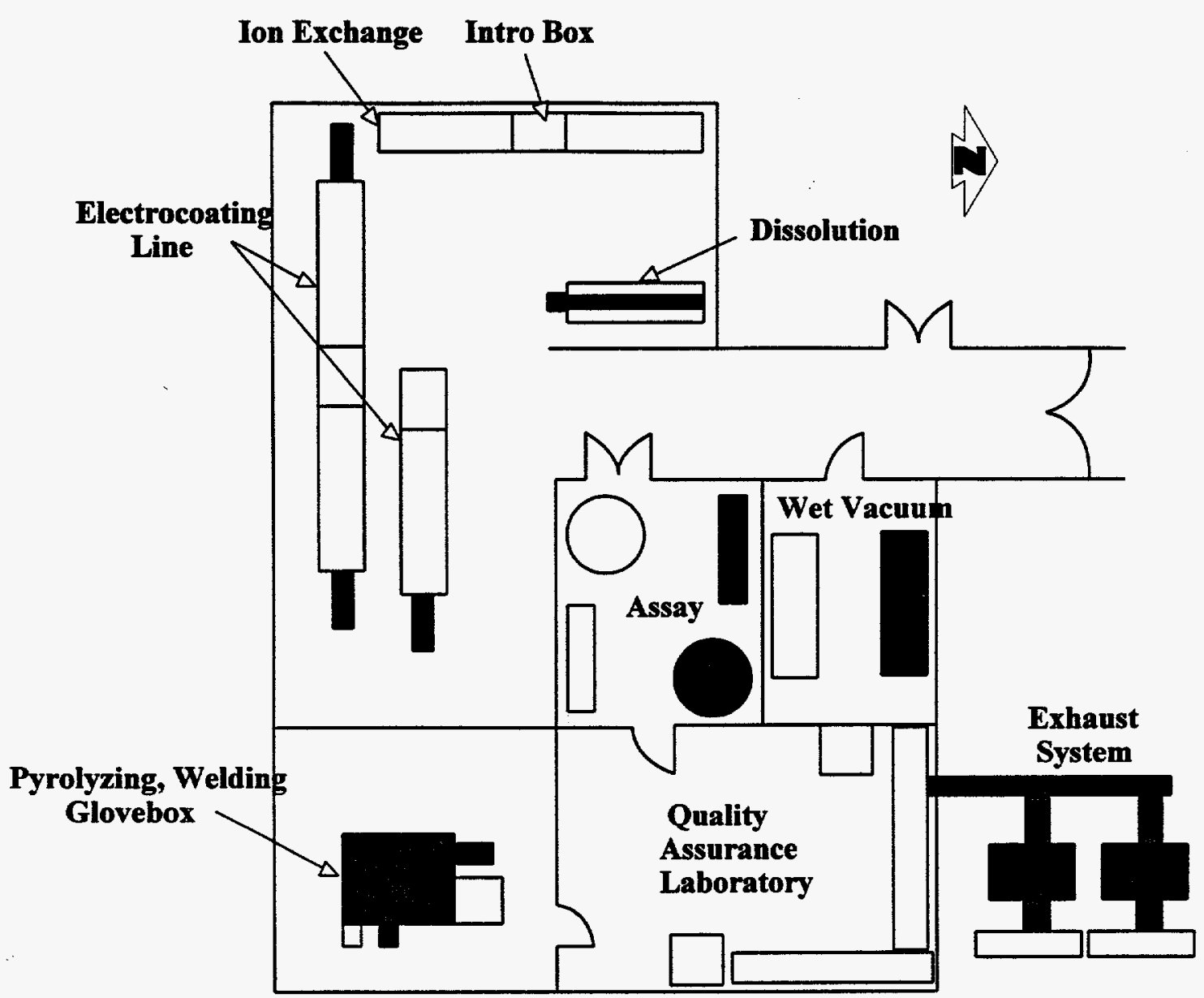

region. Removal of the central cavity for isotope production also has the benefit of reducing argon-41 ( ${ }^{41} \mathrm{Ar}$ ) production and subsequent release to the environment (See Section 2.1.1.5).

Hardware Upgrades and Redundancy - Because a medical isotope production program would require continuous operation, redundancy features would be required to increase and sustain the performance of the ACRR. Redundancy features include redundant reactor control subsystems and rod drives. All upgrades and redundancy modifications should retain the objective of reliable and continuous operation. Minimizing personnel exposure is a driving consideration for these upgrades.

Removal of Extraneous Hardware - There may be extraneous hardware that would be removed from the ACRR and/or core tank in order to make the reactor as flexible as possible for isotope production (see Section 2.1.1.5). The extraneous hardware includes the central cavity, a neutron radiography tube, and external cavities.

Ventilation and Environmental Monitoring Upgrade and Redundancy - The ventilation and radiation monitoring systems should be upgraded if required for continuous operation and/or redundancy. 
Special Handling Equipment - Fuel racks, transfer casks, and target handling equipment would be required to meet isotope production needs.

Air Lock Addition - Operation of the ACRR currently does not require use of an air lock. For isotopic production, however, delivery or removal of materials without an air lock would require shutdown of the reactor in order to minimize the potential for airborne emissions. Therefore, an air lock would need to be installed so that a negative pressure differential relative to the atmosphere could be maintained in the ACRR high-bay. Materials could then be transferred into and out of the ACRR facility with a minimum of shutdown time. Installation of the airlock would require construction of a small $(3.65 \mathrm{~m} \times 3.65 \mathrm{~m}$ [about $12 \mathrm{ft} \times 12 \mathrm{ft}$ ) addition to the building to enclose the airlock space.

Backup Electrical Power - In order to minimize interruptions of continuous production operations, backup electrical power may be needed to ensure continuous production. Backup power is not a safety requirement. Backup electrical power may be provided by a diesel generator purchased and installed in TA-V.

Material Balance Area (MBA) - A new MBA should be established at TA-V to specifically handle the receipt of targets. This is primarily an administrative procedure and would require only minimal modification of an existing facility.

The ACRR is designed so that it can be operated with a number of different fuel configurations and various numbers of fuel elements. In the proposed program, the ACRR core would have between 130 and 180 fuel elements. Current estimates indicate that the current core would be replaced somewhere between the years 1997 and 2001. The replacement core could produce 100 percent or more of the current North American demand for ${ }^{99}$ Mo and last between 6 and 24 years depending on core configuration and power levels. For a ${ }^{99}$ Mo production program lasting 30 years, the proposed program would use between two and five complete core loadings consisting of 130 to 180 fuel elements.

When removed from service, any irradiated fuel would be moved to the Gamma Irradiation Facility (GIF) pool for temporary storage. The spent fuel would be kept in the GIF pool until it is placed in dry storage at SNL/NM or shipped for final disposition.

If dry storage is desired, the spent fuel would be removed from the pool and placed in specially designed containers called "storage casks" or "dry storage casks". These passive casks would reside in a storage facility, likely in TA-V, and would be monitored to verify the integrity of the spent fuel and the casks. Enough spent fuel ( 9 to 30 elements per year) could be generated to fill one small dry cask (approximately $1.2 \mathrm{~m} \times 1.2 \mathrm{~m} \times 0.6 \mathrm{~m}[4 \mathrm{ft} \times 4 \mathrm{ft} \times 2 \mathrm{ft}$ ] high) per year. These small casks would be stored in a small storage area.

\subsubsection{Required HCF Facility Modifications}

HCF Ventilation Upgrade - A major upgrade to the ventilation system would allow improved ventilation for the HCF and adjacent spaces. The upgrade would improve safety and reliability. Addition of more accessible filtration and radiation monitoring equipment would also improve the system. 
${ }^{99} \mathrm{Mo}$ Process Line Installation - Processing equipment unique to isotope production would have to be procured and installed prior to production. Examples include extraction process equipment and waste processing equipment.

Quality Control Laboratory - This would be required by the approved FDA procedure. The Quality Control Laboratory requires a minimal amount of space and equipment such as ventilated, shielded glove boxes and detection equipment. Additionally, small shielding enclosures would need to be installed around selected equipment. Floor space in the HCF has been identified and no significant construction is anticipated for this laboratory.

Reconfiguration of HCF to Streamline Process - Modifications to the east wall, entry door location, and internal overhead crane may be required. Wall modifications would involve providing cut-outs for additional manipulators, leaded glass windows, and a pass-through. Moving the entry doors would make more space available and thus minimize crowding and facilitate remote replacement of containment boxes. Overhead handling equipment modifications would facilitate movement of materials, supplies, and containment boxes.

Steel Containment Boxes (SCBs) - Proposed replacement SCBs would result in safer, more reliable, and more versatile hot cell operations to service isotope production. The new SCBs should be designed to provide complete process control, including waste minimization and management. The units should be designed to collect by-products from the radioisotope extraction, process the by-products, and package them into waste containers. The design of the SCBs should be modular to allow easy replacement of components. Replacement of SCBs would require the removal of existing steel containment boxes and/or interior walls.

Waste Storage Area - Existing rooms should be modified to manage waste from the process line efficiently. Minimal upgrades over what currently exists and installation of floor railing and/or motorized remotely operated moving equipment would be required.

\subsubsection{Prototype and Proof-of-Principle Testing}

Some activity would be devoted to reactor physics experiments and process prototyping prior to production. Such activity would require the procurement of some equipment and/or hardware. Activities would include:

- Process Prototyping - One or more prototype SCBs and prototype processing equipment would be set up for examination of equipment performance, reliability, and adequacy of design.

- Reactor Physics Experiments - Existing data on isotope production would be verified in the ACRR. This would aid in determining configurations, reactor power, and reactor operations.

- Prototype Target Fabrication - Test targets would be fabricated and tested to verify processes.

These activities are characterized as "proof-of-principle" studies that would support design and operational activities related to medical isotope production. 


\subsubsection{Availability for Conversion to Support Defense Program (DP) Mission}

Under the transfer terms of the ACRR from DP to Nuclear Energy, the ACRR must be available to support DP missions in times of emergency to address national security concerns. Consequently, this study considered the feasibility of maintaining capabilities to return the ACRR to its current DP mission, operating under conditions similar to the ones that presently exist. The ability to convert the ACRR to DP activities requires retaining the capability for a pulsed-mode operation, the capability to install irradiation cavities, and access to a steel containment box (SCB) to support DP activity. Any requirements to use the ACRR for DP activities would have to be weighed against the need and demand for medical isotopes.

Since only minor modification of the facilities is required, the ACRR facilities could be returned to DP initiatives, if needed. The ACRR is currently fueled with $\mathrm{BeO}-\mathrm{UO}_{2}$ fuel elements that were developed specifically for DP testing and are irreplaceable. As a result, the fuel currently in the ACRR would systematically be replaced and stored on site for possible use in the future.

The current ACRR core has 236 fuel elements of a beryllium oxide $(\mathrm{BeO})$ design that are approximately $74 \mathrm{~cm}(29 \mathrm{in})$ long and $4 \mathrm{~cm}(1.5 \mathrm{in})$ in diameter. These fuel elements are of a specialized design that can be used for both steady-state and pulsed operation. The pulsedmode operational capability is not needed for isotopic production; therefore, a replacement uranium fuel element design (not containing $\mathrm{BeO}$ ) suitable for steady-state operation would be used. It is estimated that the current core of fuel elements could be used for one to five years and still be usable for pulsed-mode operation to meet potential DP needs; the fuel element lifetime would depend primarily on the amount of ${ }^{99} \mathrm{Mo}$ production required.

To ensure that the ACRR could be quickly reconfigured for pulse testing of nuclear weapons components in an emergency related to maintaining the nuclear stockpile, much of the hardware currently in the ACRR pool would be stored in a configuration which would guarantee its long-term integrity and usability. The storage of hardware would be in a new tank accessible by overhead crane. This equipment storage tank (EST) would be installed in the south part of the ACRR building. The hardware stored in the EST would include only non-fuel components required for this activity such as the fuel-ringed external cavities (FREC-I and FREC-II) without the fuel, control elements and drives, support hardware, the central cavity, and the radiography system. The EST would only be used for storage. There would be no on-going or sporadic operations involving movement of materials into or out of the tank, unless the decision is made to move the stored hardware back into the ACRR to support a DP mission in a national emergency.

Since the FREC-II tube is approximately $25 \mathrm{ft}$ in length, the tube must be stored vertically to prevent distortion. Any distortion would destroy the precision tooling of the tube, which was designed for precise radiation streaming control. The deep EST proposed would make possible vertical storage of the hardware. The water in the tank would shield personnel from the radiation emitted by the activated hardware during inspections of the hardware during storage.

The modified ACRR facility layout is shown in Figure 2-4. The final size and shape of the EST would be based on cost and hardware integrity needs. Additionally, the tank would be sized only for storage of ACRR DP hardware. 
Figure 2-4. Proposed Modified Low Bay Configuration
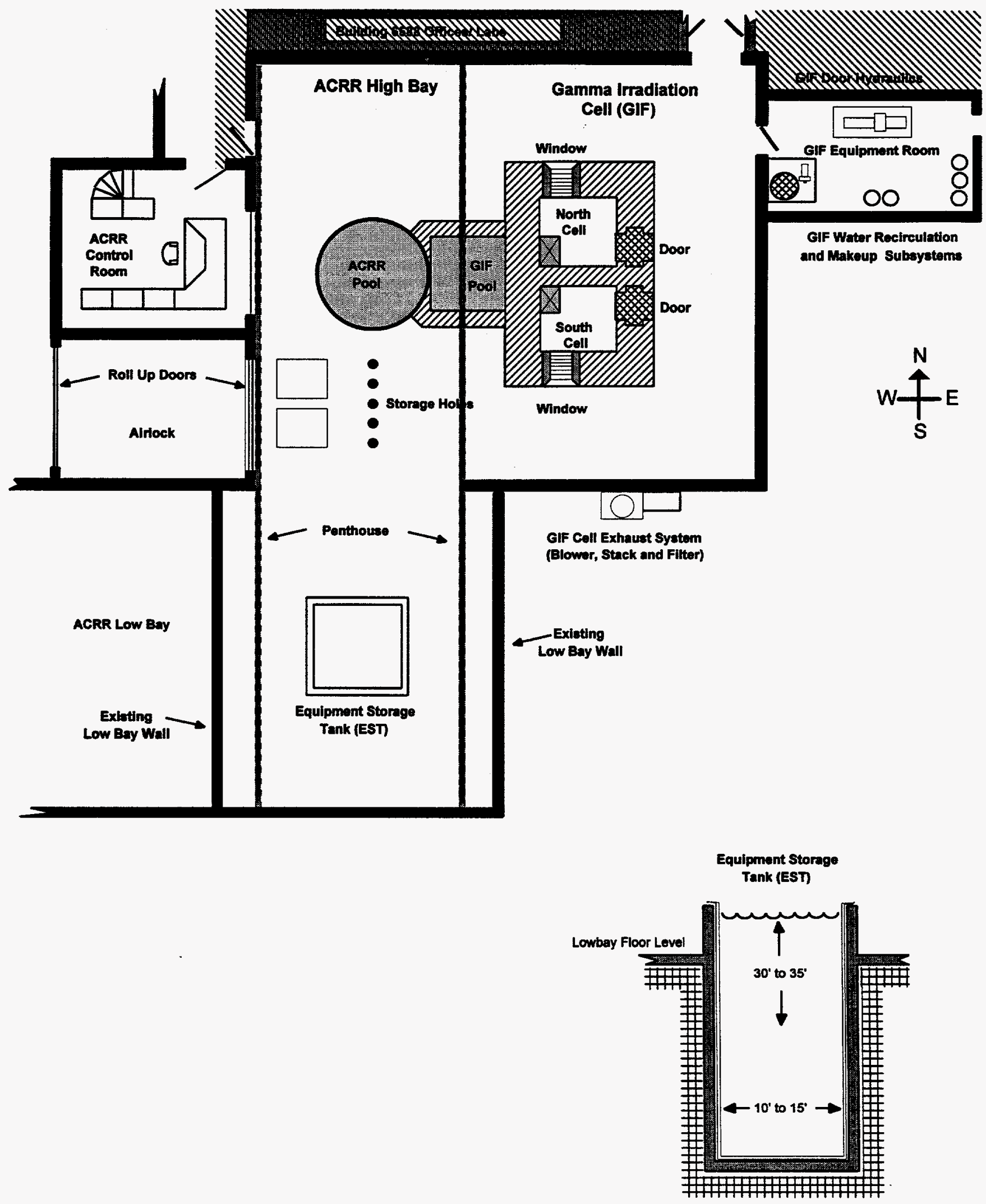
The construction and installation of the EST would include:

- Relocation of the existing cavity purge system from the Building 6588 lowbay to the highbay roof.

- Extension of the $5.5 \mathrm{~m}$ wide by $15.2 \mathrm{~m}$ high (18-feet by 50 -feet) penthouse a distance of $9.1 \mathrm{~m} \mathrm{(30} \mathrm{ft)} \mathrm{to} \mathrm{the} \mathrm{south.}$

- Installation of a double-walled steel storage tank of approximately $13.4 \mathrm{~m}^{2}\left(145 \mathrm{ft}^{2}\right)$ surface area by $10.7 \mathrm{~m}$ (35 ft) deep in the low bay.

- Provision for maintaining water quality suitable for storage of equipment in the storage tank.

- Upgrading the HVAC, power, and lighting, as needed for the storage area.

- Relocating utilities and removing a portion of the wall between the existing high bay and the new high bay extension.

There would be no radioactive material emissions to the atmosphere from the EST.

\subsubsection{Target Fabrication at LANLTarget Irradiation at SNLNM}

A flow chart of the SNL/NM-based production process is presented in Figure 2-5. Uraniumloaded targets would be fabricated in the CMR facility at LANL and transported by truck to SNLNNM'S TA-V.

The targets would be irradiated in the ACRR, transferred to the GIF pool, and loaded into transfer casks at the ACRR. The casks would be transferred to the HCF for processing where the radioisotopes of interest would be separated from the fission product inventory. The product would then be transported to the airport for air shipment to radiopharmaceutical manufacturers. Waste generated during the production process would be temporarily stored on site and then disposed of at proper waste facilities. The following sections provide the details for each of these steps.

\subsubsection{Target Fabrication at LANL}

A typical target would be constructed of stainless steel tubing approximately $45 \mathrm{~cm}$ (18 in) long and $3.18 \mathrm{~cm}(1.25 \mathrm{in})$ in diameter, as shown in Figure 2-6. A layer of uranium oxide $\left(\mathrm{U}_{3} \mathrm{O}_{8}\right)$ 
Figure 2-5. The Isotope Production Process
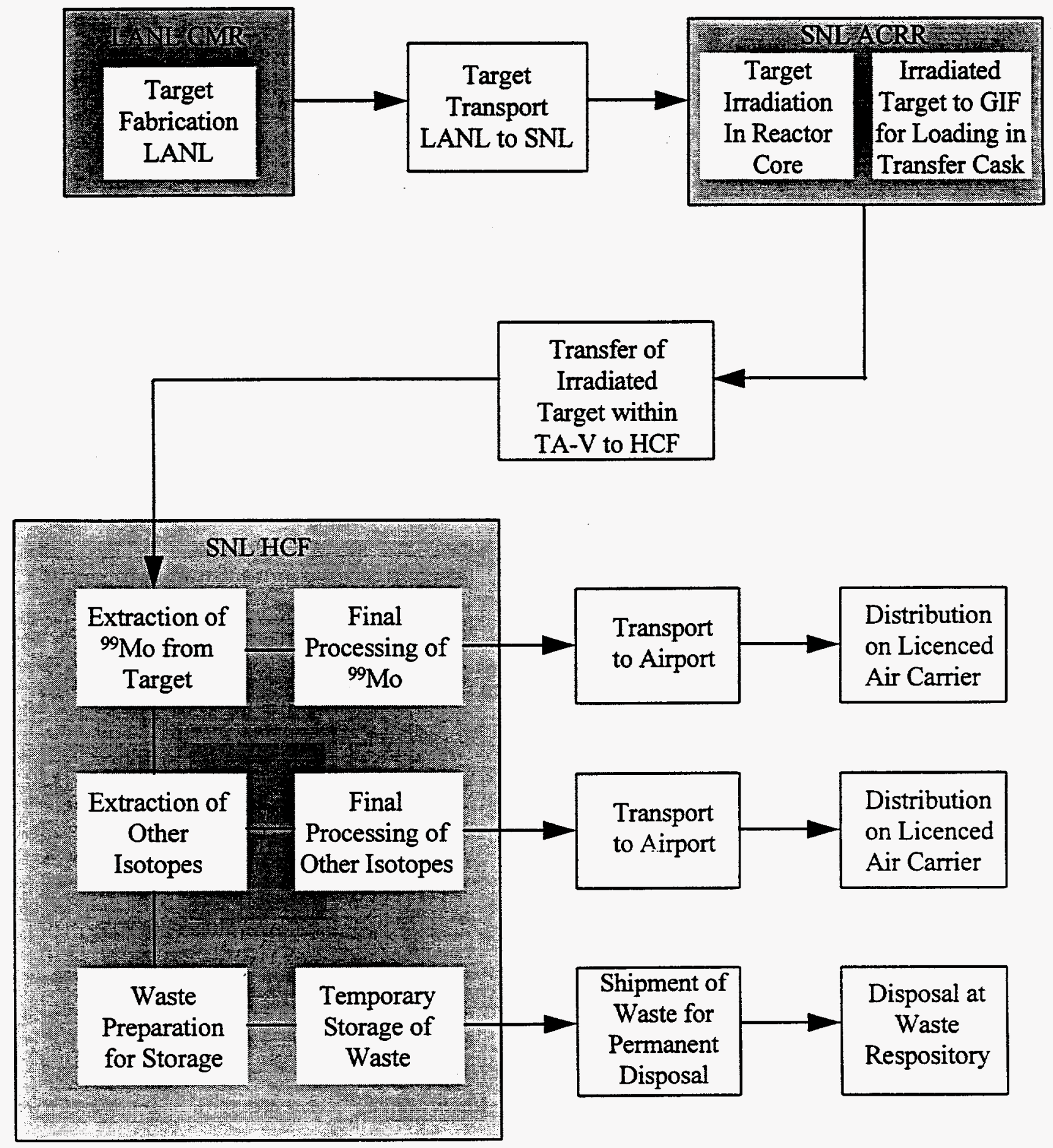
Figure 2-6. Target Design

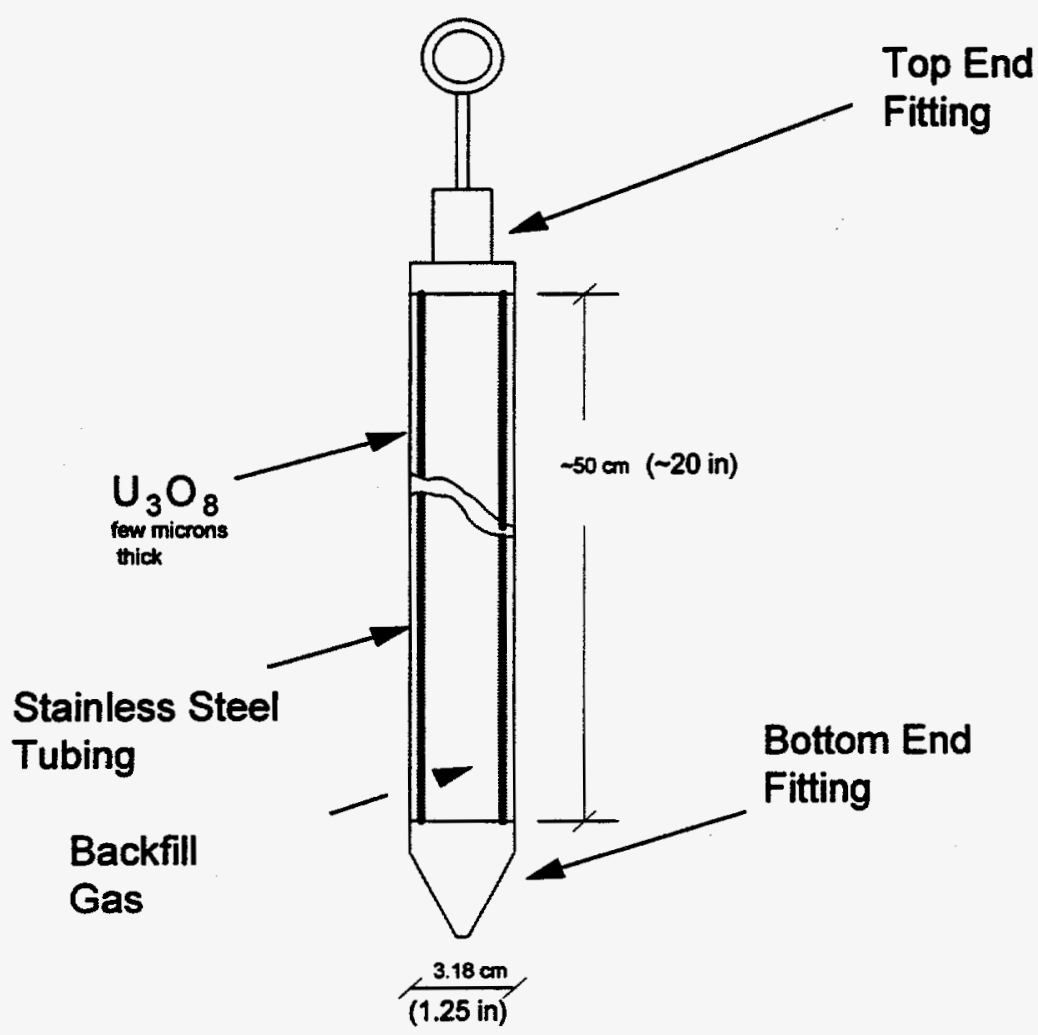

approximately 50 microns (1.6e-08 in) thick would be electrocoated onto the inside surface of the tube. The uranium used in the electrocoating process would be prepared by LANL personnel in the CMR facility. Caps would be welded to close the top and bottom. The end fittings would be designed to facilitate installation and removal from the reactor core. The top fitting would include a thin diaphragm, which provides containment of the tube contents until it is punctured in the fission product recovery process. Appendix A contains a detailed description of the target fabrication and electrocoating process.

The materials and dimensions of targets may be modified as the process is refined. Target specifications for the Canadian reactor, if targets were supplied by LANL to the Canadians, would probably be different from the targets proposed for use in the ACRR, but the ${ }^{235} \mathrm{U}$ content of a target would not exceed $25 \mathrm{gm}(0.9 \mathrm{oz})$.

At present there are sufficient inventories of highly enriched ${ }^{235} \mathrm{U}\left(\mathrm{U}_{3} \mathrm{O}_{8}\right)$ to supply the target fabrication process for several years at 200 percent production. Future sources of supply would be determined by DOE decisions on where within the DOE complex enriched uranium would be stored. 


\subsubsection{Target Shipment to SNLNM}

Targets would be fabricated, tested, and packaged for shipment in the CMR facility at LANL. Targets would be packaged in Department of Transportation (DOT)-approved Type A containers designed to hold 24 targets each. The target packages would comply with DOT regulations for fissile materials, 49 CFR 173.417. The route of shipment from LANL to SNL/NM would likely be via NM 4, U.S. 285, and Interstate 25. Target shipments would occur about once a week and would likely pass through Santa Fe. Based on the nature of the Type A packaging proposed for use, each shipment would be limited to $500 \mathrm{gm}(17.5 \mathrm{oz})$ of ${ }^{235} \mathrm{U}$. Thus, only one package would be allowed on a single truck or air shipment.

The shipments would be required to comply with DOT regulations for the transportation of Fissile Class III packages as specified in 49 CFR 173.457. 49 CFR 173.457 (b) (1) and 175.703 (c) (1) state that Fissile Class III packages must be shipped in exclusive-use conveyances. Fissile Class III shipments must incorporate controls designed to ensure that:

- nuclear criticality safety is provided for,

- loading, storing, or transporting a shipment of Fissile Class III material with any other fissile material is prevented, and

- the shipping papers include the descriptions required in 49 CFR 172.203 (d).

Each shipment of unirradiated targets would involve the transportation of less than $500 \mathrm{gm}(1.1 \mathrm{lb})$ total of highly enriched ${ }^{235} \mathrm{U}$. Under NRC regulations, the material would be classified as "Special Nuclear Material of Low Strategic Importance" (10 CFR 73.2). However, the target shipments would not be exempt from the NRC's safeguards and physical protection requirements for transportation, such as armed escorts, route selection, and performance standards for physical protection systems and procedures as specified in 10 CFR 73.25, 73.26, and 73.27.

An alternative method for packaging the unirradiated targets would be to use specific Type B containers, such as the DOT Specification 6M container, as specified in 49 CFR 173.417 . Twelve targets could be packaged into each such container, for a total of $240 \mathrm{gm}(8.5 \mathrm{oz})$ of ${ }^{235} \mathrm{U}$ per package. Use of this type of container would qualify the packages of targets to be classified as Fissile Class I packages. This would remove any criticality-based limit to the number of packages that could be transported in any shipment.

The targets would be received at SNL/NM and then processed through the normal special nuclear material receiving procedures of SNL/NM where special nuclear material accountability would confirm the ${ }^{235} \mathrm{U}$ loading. Establishment of a separate receiving MBA is planned at TA-V for direct receipt of the target shipments. The targets would then be assigned to the TA-V MBA where they would be stored awaiting use in the reactor. A six month supply of targets is expected to be stored in TA-V. Each target would be identified with a sequential serial number and controis would include identifying target locations while in the reactor. 


\subsubsection{ACRR Operations at SNLNM}

The ACRR facility, consisting of the reactor and all support systems required for its operation and conduct of experiments, is located in TA-V at SNL/NM. The ACRR became operational in 1978 and was originally designed with characteristics suitable to support weapons programs (Reuscher, 1982). The ACRR's capability to have large-volume, thermal-flux traps makes it a viable resource for producing radioisotopes, especially for those isotopes produced in the fission process.

Sketches of the ACRR are shown in Figures 2-7 and 2-8. The reactor currently uses a uranium-oxide/beryllium-oxide fuel material. The reactor core is installed in a large open tank filled with about $10 \mathrm{~m}(33 \mathrm{ft}$ ) water to provide both core cooling and radiation shielding.

The current ACRR configuration consists of an annular array of $236 \mathrm{UO}_{2}-\mathrm{BeO}$ fuel elements having an active fuel length of $52 \mathrm{~cm}(20.5 \mathrm{in})$ submerged in the open water pool. This configuration would be changed to accommodate between 130 to 180 fuel elements. A modified central region about $22.8 \mathrm{~cm}(9$ in) in diameter would be used for irradiation of targets. The core is cooled by natural convection in a water pool; the water pool is cooled by an external heat exchanger.

The ACRR would be operated in the steady-state mode. Operations would be at or below 4 MW. Although provisions were made when constructing the ACRR tank to have the potential for forced cooling, (by using the bottom coolant return line), this feature has never been used, nor would it be needed for the isotope production program.

The target irradiation level needed to meet North American demand for ${ }^{99}$ Mo could be achieved with relatively minor modifications to the core. A sufficient amount of margin and flexibility exists in the core to allow for a high degree of confidence that the full North American demand can be met. The actual target fuel configuration to be employed would depend on the production goal (fraction of North American demand) at any given time. However, the target/core configurations could easily cover the possibilities for 20 percent to 200 percent and greater shares of the North American market.

Because the ACRR is a pool reactor (see Figure 2-7), targets and fuel elements would be readily accessible for removal. Irradiated targets would be removed from the core and transferred via the pass-through ports to a rack in the GIF pool (see Figure 2-8). A transfer cask would be lowered into the GIF pool and the irradiated target(s) would be loaded into the cask. The cask would then be removed from the pool using the bridge crane, surveyed for contamination, and moved using a manned transport vehicle.

\section{Anticipated Events}

During the normal operation of any facility, there are certain anticipated events, which, while not accidents, are mechanical failures that have the potential to disrupt operations. At the ACRR, events which fall into this category include power outages, a mechanical failure of the ventilation system, and leaking fuel elements or targets. These events are discussed in the following paragraphs. 
Figure 2-7. ACRR Reactor Tank and Pool Cooling

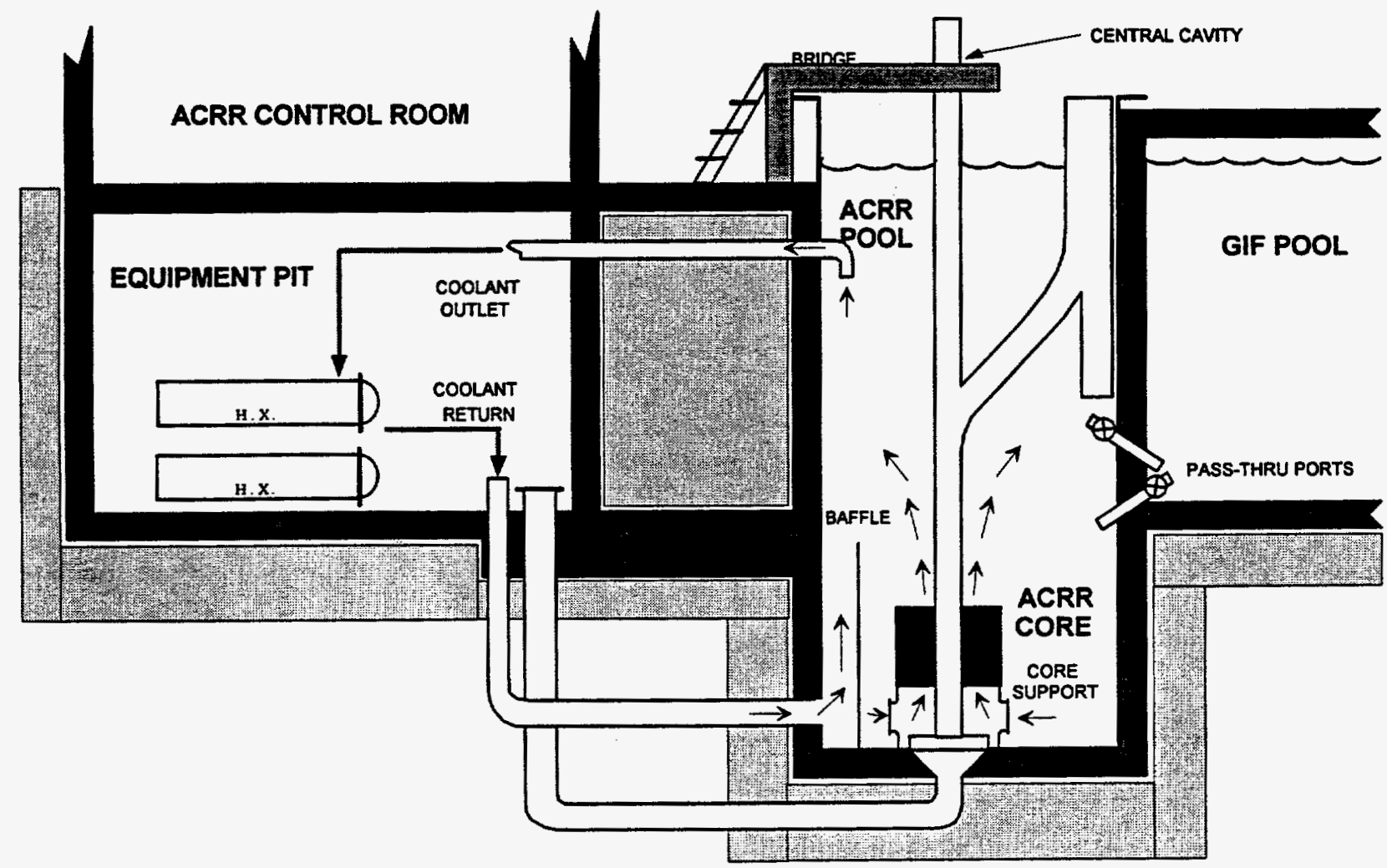

Figure 2-8. ACRR High Bay Layout.

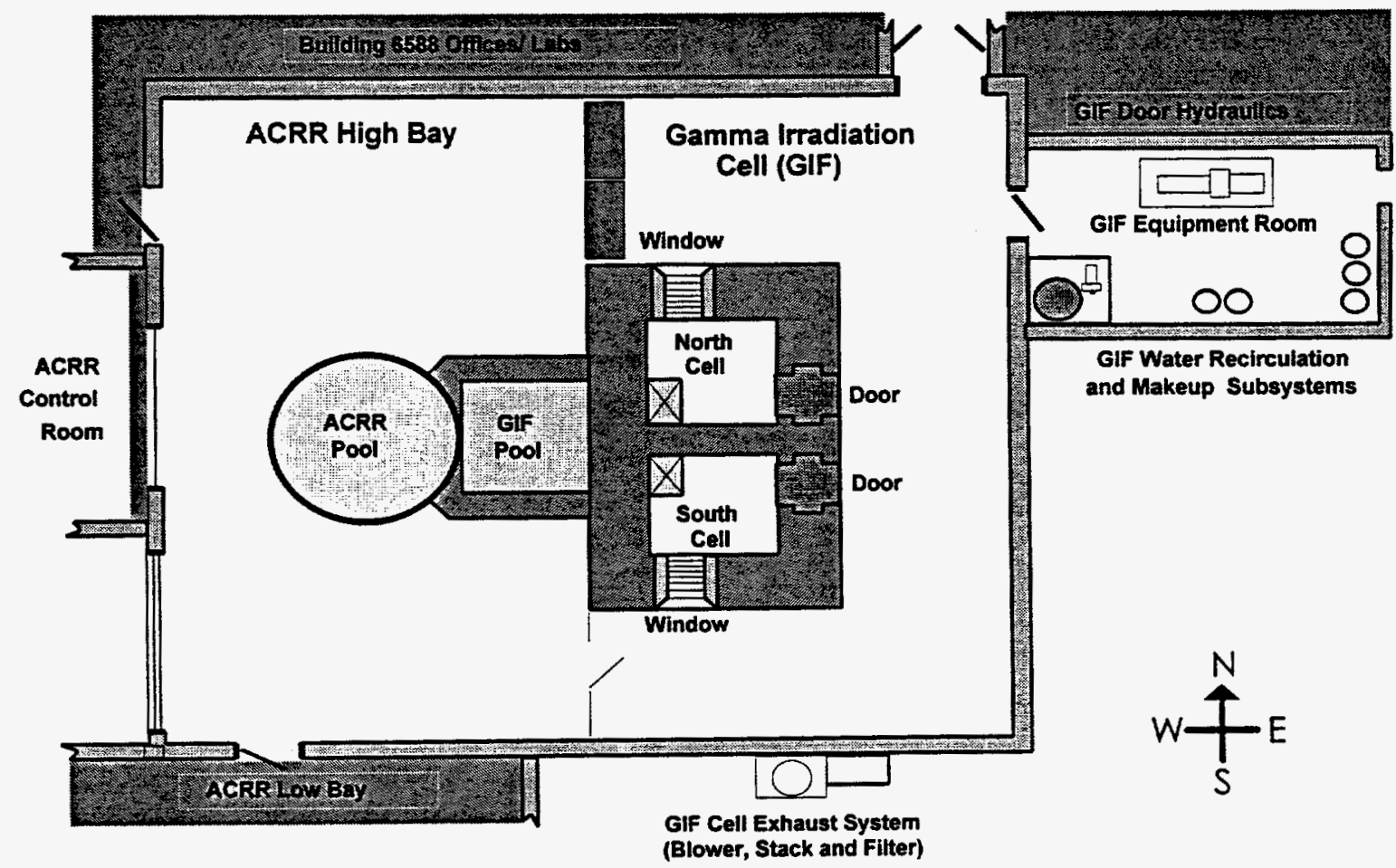


Power Outages - All TA-V utilities are derived off site. All utility systems have redundant supply paths and have demonstrated a high degree of reliance over the years. However, since all control circuits are fail-safe, loss of power to the ACRR facility simply results in reactor shutdown. Once the reactor is shut down, the residual heat generated by the reactor core is dissipated into the water in the ACRR pool. An electric power failure at any point in the TA-V network would have no detrimental effect on the ACRR, since all vital and selected emergency equipment, such as emergency lighting and radiation area monitors (RAMs), are batterypowered.

Ventilation System Failure - The high bay supply and exhaust ventilation system is designed to provide conditioned air to the facility and exhaust the air to the environment at a rate that maintains the reactor high bay at a negative pressure relative to all other manned spaces and the outside environment. Releases of radioactive material to the environment are controlled through two exhaust systems, the high bay exhaust system and the cavity purge system. Currently, the high bay exhaust system contains one HEPA filter which is bypassed unless the Continuous Air Monitor (CAM) units sense high levels of airborne radioactive material and automatically switch the air flow through the HEPA filter. The cavity purge system exhausts air from the reactor experiment facilities through a bank of two HEPA filters and two charcoal filters. As part of the proposed facility redesign, the new ventilation system would continuously exhaust through the filters of the high bay ventilation system.

Leaking Targets or Fuel Elements - If a target or fuel element were to develop a leak, all the noble gases could be released into the pool water, as well as some iodine. Leaking targets are expected to be minimized through leak-testing in the final fabrication steps (estimated annual probability of occurrence $=1$ to $1 \mathrm{e}-02$ ). Drop tests performed at LANL have also shown the targets to be mechanically robust. Although fuel element leaks are also expected to be rare, they are expected to occur.

Element and target leaks would probably first be detected in either the cleanup loop system or by the high bay CAM or reactor pool CAM. There are no direct safety consequences of having a leaking element or target other than pool contamination, which would be handled by the cleanup loop. Water ingress into a fuel element has been analyzed and has no effect on the ability to cool the element under steady-state conditions. The same would hold true for a target.

Radiation detection equipment would be used that would sample the water exiting the flow channels between elements and targets in order to identify potential leaks. The reactor would continue to be operated under full power conditions during this time period. Once a suspect (potentially leaking) target or fuel element has been identified, the reactor would be shut down, the suspect item removed and replaced, and the reactor restarted. Fuel element replacement, like target replacement, should only take a few minutes to perform. Leaking ${ }^{125}$ I targets would be handled in the same manner.

Targets that are leaking would be removed for normal processing or prepared and packaged as radioactive waste. Leaking fuel elements would be removed from the core and placed in the GIF pool awaiting final disposition along with any other spent fuel. These fuel elements would be marked so that they would not be placed back in the ACRR core. When these fuel elements were removed from the GIF pool, appropriate handling procedures (possibly including packaging in a sealed container) would be followed to minimize or eliminate potential releases of radioactive materials. 


\subsubsection{Target Transfer To HCF}

A manned transport vehicle would be used to move the targets to the adjacent HCF. The transporter would exit the reactor facility through the proposed airlock, which would permit the continued operation of the reactor, and proceed down the ramp of the HCF (see Figure 2-9). The transporter would enter the HCF through the rollup door at the west end of the HCF, then proceed to the HCF transporter airlock. Once through the airlock, the cask would be moved to the far north end of the HCF where it would be placed within the shielded region of Zone $2 A$. Zone $2 \mathrm{~A}$ is a long central room within the HCF with remote manipulators and lead-glass windows, as shown in Figure 2-9. The cask would then be moved below one of the dedicated processing boxes designed to conduct the initial steps of the isotope extraction process. Once emptied of targets, the transfer cask would be removed from Zone $2 \mathrm{~A}$ and returned to the reactor facility to await the next movement of targets.

Figure 2-9. Transfer of Irradiated Targets Within the HCF

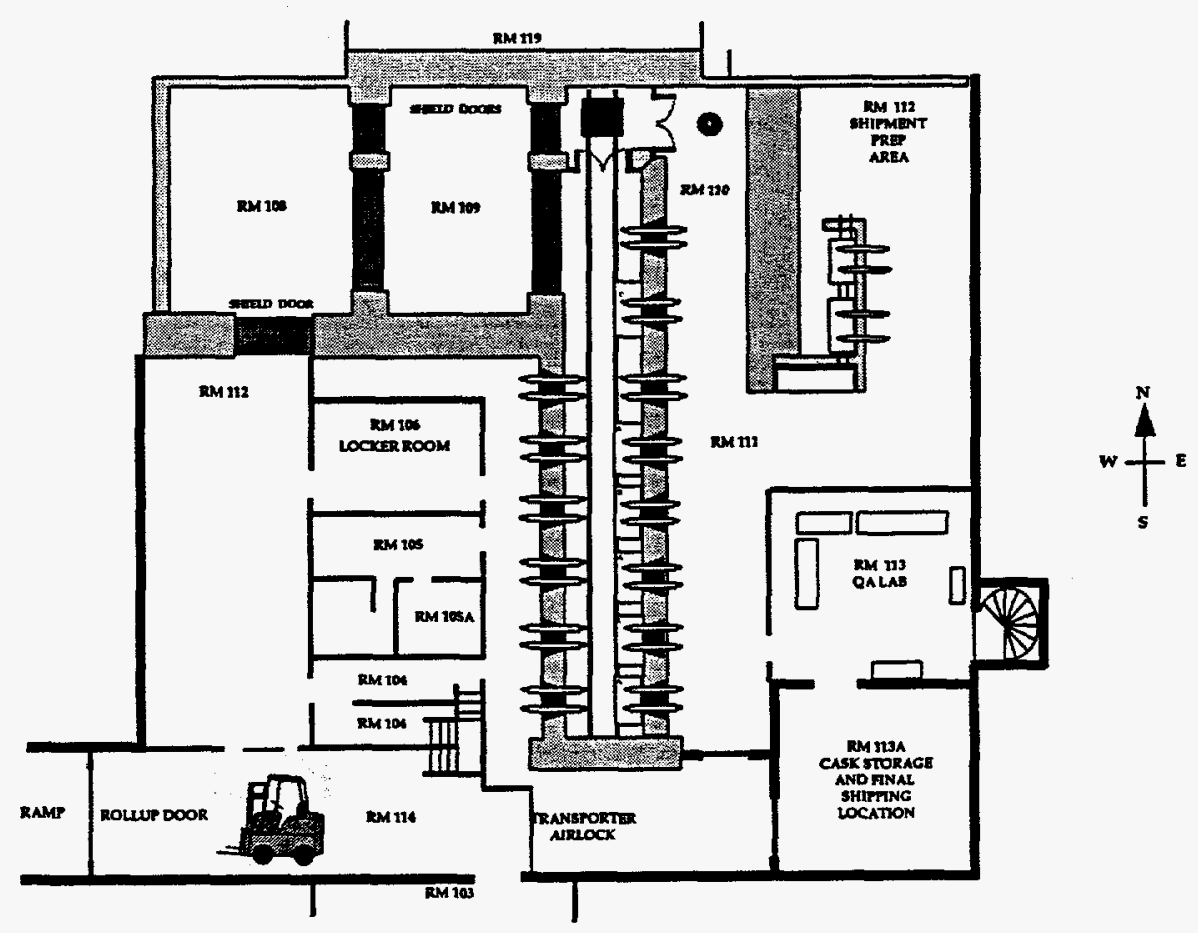

The movement of targets from the ACRR building to the HCF would be anticipated to be conducted up to three times per day, five days of the week, 52 weeks of the year. The number of targets transported would depend upon the required production rate, but should be between one and eight targets per day. 


\subsubsection{Isotope Extraction at HCF}

The isotope extraction process for ${ }^{99} \mathrm{Mo}$ would be a combined chemical/distillation process in which:

- the noble gases and iodine would be condensed from the target fill gas;

- the fuel and fission products would be dissolved from the inside of the target;

- chemicals would be added to maintain specific fission products in solution;

- the molybdenum would be precipitated, filtered, and cleansed; and

- the precipitated molybdenum would be redissolved for shipment to pharmaceutical companies.

The extraction process would provide necessary radioisotopes of xenon, iodine, and molybdenum.

Each target would yield approximately 600 curies of ${ }^{99} \mathrm{Mo}, 200$ curies of ${ }^{131} \mathrm{I}$, and 600 curies of ${ }^{133} \mathrm{Xe}$ one day after discharge from the reactor. Approximately, one-half liter (about $1 \mathrm{pt}$ ) of neutralized process liquid (waste) would be generated per target. This liquid would be neutralized, stabilized, allowed to decay, and then shipped to an approved low-level waste disposal facility. Although shipments to the disposal site could be made as soon as six months after generation, sufficient storage exists within the HCF to allow up to two years storage of waste generated as a result of meeting 100 percent of North American demand. At production levels to meet 200 percent demand, 1 year's worth of storage would be available. At less than 100 percent demand production, more than 2 years storage is available.

\section{Electrical Failure}

If Building 6580 should experience a loss of commercial power, a standby power system consisting of a diesel generator and an uninterruptible power supply located in Building 6581, Room 222, is automatically activated. The essential systems powered by this secondary source of electricity are listed in Table 2-1. This system is normally tested weekly by simulating an interruption of the normal power source and allowing the generator to start and pick up the critical loads. Sufficient diesel fuel is stored to run the generator for 90 to 110 hours. The generator comes up to speed and picks up the backup circuit loads in less than one minute.

Based on past experience, a loss of electrical power can occur because of storm, wind, lightning, or equipment malfunction. Data on power outages for the 10 years 1977 through 1986 show a total of 32 unscheduled outages with a frequency of $0-10 / y r$ and a duration ranging from "momentary" to 17 hours (only 8 outages were greater than 2 hours in duration; Restrepo, 1994). The TA-V backup power system successfully compensated for all outages with no radiological releases or mechanical failures.

In the event of a long-term shutdown from a complete power failure, processing of targets in the process line at the start of the outage would be completed using the backup power system. Further processing would then be delayed until commercial power was restored. 
Table 2-1. HCF Systems Powered by Standby Diesel Generator

\begin{tabular}{|l|l|}
\hline \multicolumn{1}{|c|}{ System } & \multicolumn{1}{c|}{ Description } \\
\hline Blister, Glove Box 3, Fume Hoods & Standby power to control working atmosphere \\
\hline Nitrogen Inerting System & $\begin{array}{l}\text { Power system and SCB/hot cell heat detectors } \\
\text { and fire alarms }\end{array}$ \\
\hline Area V Stack System & Fans and interlocks \\
\hline Ventilation System Zones 1, 2A, and 2 & $\begin{array}{l}\text { Blowers, interlocks and temperature and } \\
\text { pressure monitoring instrumentation }\end{array}$ \\
\hline $\begin{array}{l}\text { Room 112 Glove Box and Fume Hood } \\
\text { Ventilation Systems }\end{array}$ & Blowers and interlocks \\
\hline Radiation Monitoring System & $\begin{array}{l}\text { All criticality monitors, central monitor display } \\
\text { panel and selected CAMs }\end{array}$ \\
\hline
\end{tabular}

\section{Ventilation System Failure}

Upon loss of commercial power, the backup diesel generator would automatically provide power to the HCF ventilation system blowers. In addition, all HCF ventilation systems would be designed and constructed to fail safe; i.e., supply dampers fail closed and exhaust dampers fail open. The latter would still vent through their HEPA filters and confinement would be maintained so long as the physical barriers maintained their integrity. Electrical failure of the ventilation system would not result in a release of radioactive material.

\section{Spills During Isotope Processing}

The possibility of a spill during ${ }^{99}$ Mo purification would be minimized through the use of syringes for all reagent additions and the requirement that all transfer containers be fastened together and tied down prior to solution transfers. However, because of the large number of targets that could be processed (up to approximately $2080 / y r$ for $200 \%$ of North American demand) and the fact that the ${ }^{99}$ Mo purification process involves multiple reagent additions and solution transfers, the probability of a spill during the process is estimated to be between $1 \mathrm{e}-02$ and 1 per year.

The most probable initiating spill event during purification would be a filled reagent container knocked over and spilled during remote handling. One of the container seals would have to be dislodged for a spill to occur, since reagent containers would be metal or plastic. There would be no release of radioactivity with a reagent spill. In terms of a potential radiation release to the atmosphere, the worst-case spill scenario in a process SCB would be if a target were to be dropped and breached prior to entrapment of volatile gases on the cold finger. This would result in the complete loss of noble gases from that target to the atmosphere. Halogens $(\mathrm{Br}, \mathrm{I})$ not retained by the target material would be captured by treated charcoal filters in the SCB filter system. Only a negligible amount of halogens would be lost through gradual decay to krypton and xenon because the SCB would be isolated from the exhaust system and a redundant filter system would be used in the rest of the process train until the contaminated filter could be replaced. In terms of time lost due to process line shutdown to clean up the SCB, the worst scenarios would be if the dissolved target solution or the acid waste bottle were spilled. 
A QA sample of the ${ }^{99} \mathrm{Mo}$ solution from one target (volume about $10 \mathrm{ml}[0.3 \mathrm{oz}]$ ) would contain about $1 \mathrm{Ci}$ of radioactivity. This solution would be transported from the process SCBs to the quality assessment/quality control (QAQC) laboratory in a sealed glass vial packaged in a shielded container. A sample spill during transit would require the container to be dropped, the seal on the container to break, and the sealed vial to break. This series of events has an annual probability of occurrence of less than 1e-07. If the sample were spilled in a glove box during removal from the container, the glove box would be isolated from the ventilation system, resulting in no significant release to the atmosphere.

\section{Spills During ${ }^{125}$ LProcessing}

Processing of ${ }^{125}$ I would not begin until at least 3 days after removal of the target from the reactor. Even if the entire contents of a target were lost during processing, the dose to the closest member of the public located $1610 \mathrm{~m}(1 \mathrm{mi})$ away is a small fraction of the dose expected from normal operations (see Tables 4-8 and 4-9).

\subsubsection{Product Shipment}

${ }^{99}$ Mo decays at the rate of about 1 percent per hour. Therefore, shipment of the product must be expedited to prevent needless decay of the product. Nordion, which is the only company presently shipping bulk ${ }^{99} \mathrm{Mo}$, uses a combination of commercial and chartered air flights using Syracuse, NY, as the U.S. hub. The SNLINM product shipment plans assume a similar distribution system originating at Albuquerque International Airport.

Initially, ${ }^{99}$ Mo would be shipped by air freight on a daily basis to any of the following three locations. The initial locations and corresponding radiopharmaceutical companies would be as follows:

\section{Company Location}

DuPont-Merck Amersham Mediphysics Mallinckrodt
Boston, Massachusetts

Chicago, Illinois

St. Louis, Missouri

The ${ }^{99} \mathrm{Mo}$ would be packaged in Type B accident-resistant packaging for shipment from SNL/NM to the radiopharmaceutical companies. Air express class of shipments would be used with direct routing, if possible, to the customer city. Passenger aircraft could not be used since the Transport Index of the ${ }^{99}$ Mo package exceeds that allowed on passenger aircraft. If a stop is required, the shortest time of routing from Albuquerque to the customer city is preferable. Product movement would be directly from TA-V to the airport transfer point using Kirtland Air Force Base access roads or off-base routing.

\subsubsection{Other Isotope Production}

In addition to ${ }^{99} \mathrm{Mo}$, a number of other isotopes could be generated in the ACRR. These isotopes can be grouped into two categories based on their means of generation:

- those generated as additional fission products in the ${ }^{99} \mathrm{Mo}$ targets (fission targets); and 
- those generated by other reactions (e.g. neutron absorption) in special targets.

The first category includes two isotopes $\left({ }^{131} \mid\right.$ and ${ }^{133} \mathrm{Xe}$ ) which are initially planned for extraction from the ${ }^{99}$ Mo-target fission product stream. The second category includes ${ }^{125}$, of which up to $750 \mathrm{Ci}$ per year would be produced in separate irradiation elements loaded with ${ }^{124 \mathrm{Xe} \text {, a }}$ non-radioactive isotope of xenon. Even with the three additional isotopes, only a small fraction of the isotope production capacity of the ACRR would be utilized. The additional capacity would make possible advanced research and process development of these and other isotopes.

\subsubsection{Waste Management}

Trash, chemical waste, radioactive waste, and mixed wastes would be generated at SNL/NM as a result of the medical isotope production program. The trash generated would consist primarily of office trash and lab trash. Some chemical waste from process verification activities or from expired, contaminated, or otherwise unusable chemicals would also be generated. This trash and chemical waste would be handled through the established waste management processes at Sandia in accordance with all applicable federal, state, local, DOE, and Sandia requirements.

The radioactive wastes that would be generated consist of LLW and spent nuclear fuel. The LLW stream would include protective clothing, contaminated process and facility hardware, solidified waste from the isotope extraction process, and resins that are used to remove contaminants from the reactor pool and the GIF pool. Approximately $214 \mathrm{~m}^{3}\left(7600 \mathrm{ft}^{3}\right)$ of LLW would be generated per year, assuming 200 percent production. The LLW would be stored on site until shipment for disposal. All waste and spent fuel would be managed in accordance with all other applicable federal, state, local, DOE, and Sandia requirements.

The disposal sites being considered for the LLW are the DOE disposal facilities at the Nevada Test Site and the Hanford site near Richland, Washington. Certain low-level waste streams, such as the solidified waste from the isotope extraction process, would be stored on site for 6 to 12 months to allow for the decay of most of the short-lived fission products in the waste. After decay, this waste would be transported to the LLW disposal site.

Spent fuel elements would be generated at a rate of approximately 9 to 30 per year starting after the year 2000. After removal from the ACRR, the spent fuel elements would be stored in the GIF pool for an initial cooling period that would range from a minimum of one year to possibly as long as $\mathbf{2 5}$ years, depending on the space available in the GIF pool. After removal from the GIF pool, the spent fuel elements would be transferred to dry storage in one of the existing TA-V buildings or in one of the lined underground storage shafts. The TA-V buildings are constructed of reinforced concrete with concrete floors. The storage shafts range from 20 to 30 feet deep. Shaft liners are constructed of welded carbon or stainless steel $1 / 6$ to $1 / 4$ inches thick with caps made of steel with poured lead shielding. The openings are above grade and include gutters to divert rainwater from the shafts.

If placed in the storage shafts, the sturdy stainless steel spent fuel elements would first be placed in an inner container of welded steel to provide an additional barrier to water. If stored in one of the existing TA-V buildings, the elements would be placed in shielded containers designed specifically for spent fuel storage at SNLNM. These containers would consist of an 
welded steel liner at least $0.6 \mathrm{~cm}(1 / 4 \mathrm{in})$ thick surrounded by a minimum of $15.25 \mathrm{~cm}(6 \mathrm{in})$ of concrete or lead shielding so that the external exposure rate would be reduced to contacthandled levels (below $200 \mathrm{mR} / \mathrm{hr}$ ). The concrete or lead shielding would then be packaged in an outer layer of steel of sufficient thickness to support the shielding, i.e., at least $0.6 \mathrm{~cm}(1 / 4$ in) thick.

The spent fuel elements would consist only of solids; no liquids would be present. Primary containerization would be in a sealed and shielded container. The containers would be shielded for handling and storage. Secondary containment would be in a building or a lined storage shaft after removal from the GIF pool. The primary containerization and secondary containment would serve to prevent any damage to the element during storage at SNLNM. The spent fuel containers in a storage building or storage shaft would be able to withstand any credible accident scenarios, such as fires, aircraft crashes, tornadoes, or earthquakes. The storage facilities would be inspected regularly to ensure the integrity of the containers.

Mixed wastes (wastes that are hazardous and radioactive) would be generated in the isotope extraction process would only be hazardous because they are corrosive. This characteristic would be removed through waste neutralization, leaving only low level liquid waste to be stabilized. However, some mixed waste would be produced by facility operations that are incident to the manufacturing process. Examples of the mixed wastes that could be generated include absorbent wipes, batteries, spent solvents, solvent rags, vacuum pumps, electronics containing heavy metals, and lubricants that become contaminated with radioactive materials. These mixed waste streams would be managed in accordance with applicable requirements.

A decontamination capability would be part of the medical isotope production support programs. A decontamination program would be required as part of routine operations, facility maintenance, work planning, worker dose reduction, and emergency response capability. This program would assist in ensuring control and monitoring of radioactive contamination and waste and would employ clean-up and handling techniques to ensure that facilities and equipment operate within required regulatory limits. Radioactive waste would be managed as part of the SNL/NM Radioactive Waste Management Program.

\subsubsection{Routine Maintenance}

Equipment may be modified or replaced during the course of operations. Regular maintenance, including interim decontamination, would be performed as needed. If and when operations were terminated, the affected facilities would be decontaminated and decommissioned in accordance with the applicable DOE Orders or federal regulations. Currently decontamination and decommissioning activities are covered under DOE Order 5820.2A. This Order states that "radioactively contaminated facilities for which DOE is responsible shall be managed in a safe, cost-effective manner to assure that release of, and exposure to, radioactivity and other hazardous materials comply with Federal and State standards. Facilities, equipment, and valuable materials shall be recovered and reused when practical" (DOE, 1988).

\subsection{Alternative Production Concepts}

Section 2.2.1 discusses other potential target fabrication sites. Other potential waste disposal sites are discussed in Section 2.2.2. 


\subsubsection{Target Fabrication Site Options}

Target fabrication could be performed at a number of sites other than LANL. For example, DOE facilities at SNL/NM or Oak Ridge, Tennessee or commercial facilities such as Babcock and Wilcox (B\&W) in Lynchburg, Virginia could be used. The alternate fabrication site options were assessed for the same manufacturing process that was assessed for the LANL option.

The target transportation risk for transportation routes from these fabrication sites to SNLNM is bounded by the transportation analyses conducted for truck shipments of targets from B\&W to SNL/NM as presented in Section 4.0. In regard to transportation risk, fabrication at SNL/NM facilities could be advantageous because the transportation of targets from the fabrication site to SNL/NM would be eliminated.

\subsubsection{Waste Disposal Site Options}

Other DOE disposal sites exist at INEL, Oak Ridge Reservation, and the Savannah River Site (SRS). SNL/NM low-level waste could be disposed at any of these sites. However, none of these sites currently accepts low-level waste generated at off-site facilities. The potential impacts and risks associated with transport to these sites would be comparable to or less than the transport of LLW to the site at the Hanford Reservation in the State of Washington as presented in Section 4.0.

Commercial disposal facilities could also be potential sites for disposal of at least some SNL/NM low-level waste. These sites include Envirocare in Clive, Utah, and U.S. Ecology which is on land within the boundaries of the Hanford Reservation. The risks of shipping to these facilities would be bounded by the risks associated with the transportation of waste to the DOE disposal facility at Hanford. 


\subsection{AFFECTED ENVIRONMENTS}

\subsection{Introduction}

This section contains a description of environments that could be affected by a program to produce medical isotopes at SNL/NM. The environments include the sites at SNL/NM and LANL, the highway and air corridors to and from SNLNM, and the radiopharmaceutical market.

The production concept would involve modifications to existing buildings, but not the construction of new buildings. A number of environmental resources would not be impacted by this action. The potentially affected buildings are less than $\mathbf{5 0}$ years old and are not eligible for listing on the historic properties list. Several other environmental resources that would not be affected by the production concept can be eliminated from further discussion. These resources are listed below:

- recreation resources,

- agricultural resources,

- wetlands and floodplains,

- historic preservation, and

- endangered and threatened species.

\subsection{SNL/NM Site and Facilities}

The city of Albuquerque and Kirtland Air Force Base (KAFB) are located in Bernalillo County. SNL/NM is located on the KAFB installation immediately southeast of Albuquerque as shown in Figure 3-1. Major transportation services are provided by the Albuquerque International Airport and Interstates 40 and 25. The Sandia Mountains are northeast of KAFB and the Manzano Mountains are to the southeast of the base. Directly east of SNL/NM are the foothills which comprise the northern portion of the Manzano range.

The production concept would use the ACRR, HCF, and GIF facilities located in the TA-V complex at SNL/NM. Other major TA-V facilities include the Sandia Pulsed Reactors (SPR IIISPR III). In addition to these major facilities, small research laboratories, machine shops, plant support facilities, and offices for operational personnel are located throughout the area. The location of SNL/NM's Technical Areas with respect to the KAFB and the city of Albuquerque is shown in Figure 3-2. TA-V is located $5.4 \mathrm{~km}$ (about $3.4 \mathrm{mi}$ ) south of the major SNL/NM installation, TA-I.

SNL/NM is operated by Sandia Corporation, a wholly owned subsidiary of Lockheed Martin Corporation, for the DOE. The area in which SNLNM is located is administratively known as KAFB East and comprises the facilities necessary to conduct research consistent with the SNL/NM mission. DOE-owned land situated within KAFB covers approximately 21,053 ha (about $52,000 \mathrm{ac}$ ). The total land occupied by the SNL/NM facilities is about 1134 ha $(2,800 \mathrm{ac})$ of DOE-owned land and another 8500 ha $(21,000$ ac) leased from the 
Figure 3-1. Location of Sandia National Laboratories/New Mexico

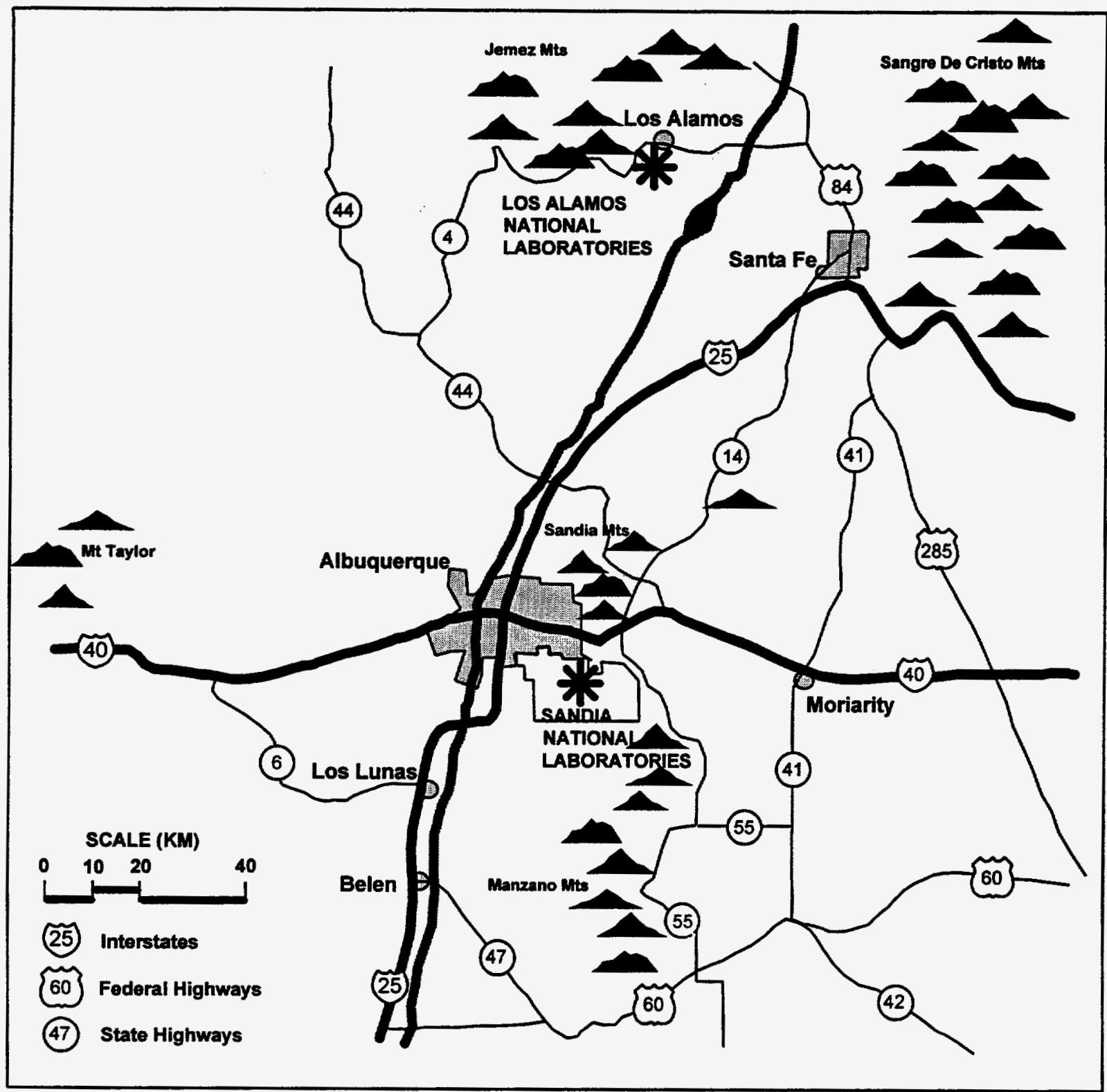

U.S. Air Force (USAF), the U.S. Forest Service, the state of New Mexico, and the Isleta Indian Reservation. Other facilities within the KAFB East area include the DOE's Albuquerque Operations Office, the Defense Nuclear Agency Field Command, the USAF Air Force Operational Test and Evaluation Center, the KAFB administrative offices, the KAFB Underground Munitions Storage Center (KUMSC), and other smaller agencies. SNLNM's facilities are spread over the 9636 ha $(23,800$ ac) of leased and owned land and are organized by function. The functions are typically centered in various Technical Areas that have been established. There are five Technical Areas and one test area. The areas and their uses include:

- Technical Area I: Administration, site support, technical support, component development, research, energy programs, microelectronics, defense programs, and exploratory systems. 
Figure 3-2. TA-V Location within SNL/NM and the KAFB/Albuquerque

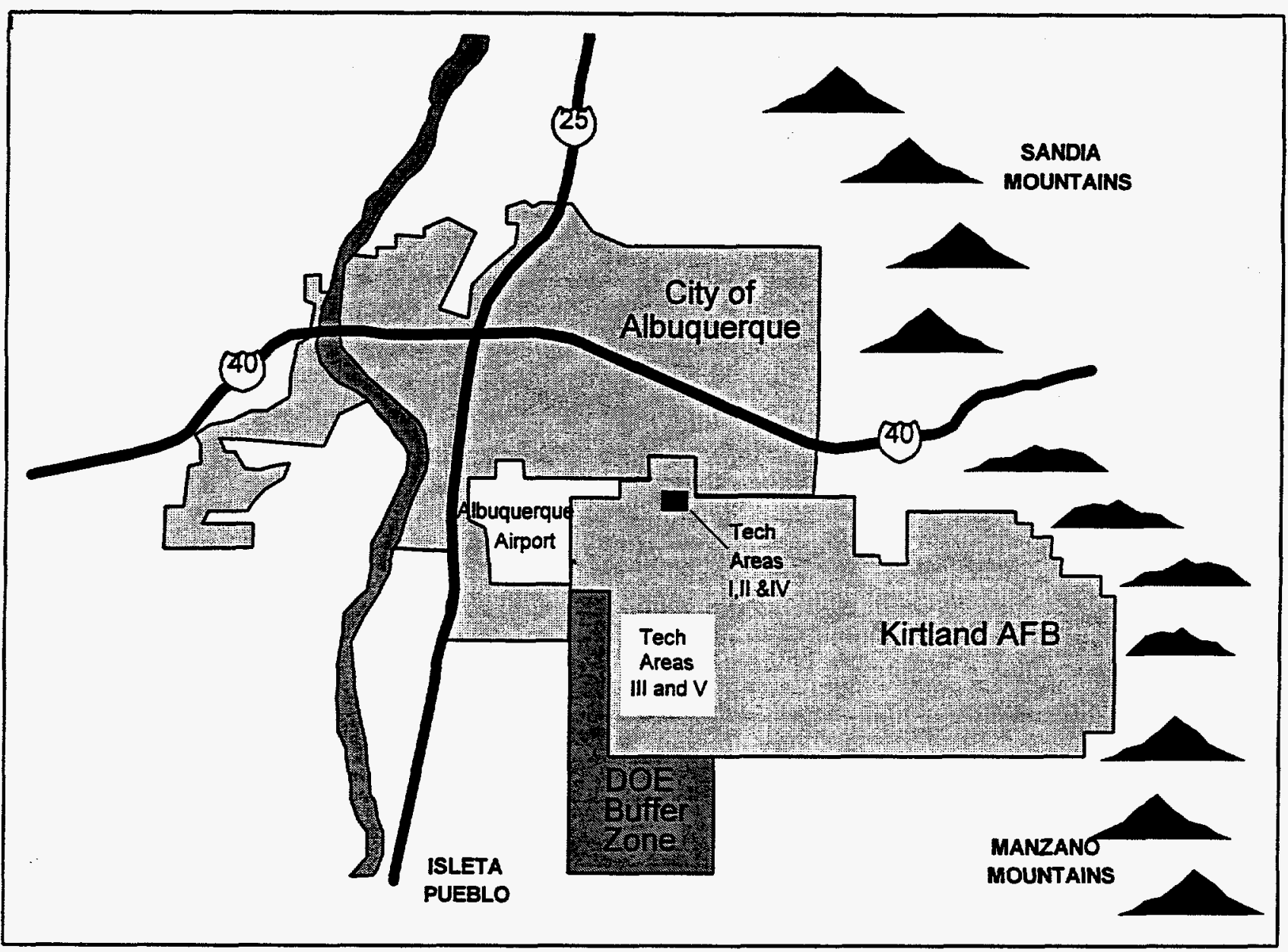

- Technical Area II: Testing explosive components.

- Technical Area III: Testing and simulating a variety of natural and induced environments, including two rocket-sled tracks, two centrifuges, and a radiant-heat facility. TA-III has a use permit for the rocket-sled tracks, including land to the north of TA-III, plus a strip of property on the west boundary of the base.

- Technical Area IV: Applied pulsed-power sciences such as x-ray, gamma-ray, and particle-beam fusion accelerators which are used to simulate nuclear weapon effects; research on inertial-confinement fusion and particle-beam weapons.

- Technical Area V: Research and testing of various materials, such as electronics, in a nuclear environment provided by low power nuclear reactors.

- Coyote Test Field: Various test activities on land parcels scattered throughout Coyote Test Field. These parcels are on 1- to 5-year land-use permits from the USAF. 
The majority of the medical isotope production activities would be centered in TA-V. TA-V lies west of the Manzano Mountains and east of the Rio Grande. The slope of the terrain is characterized by a consistently gradual decline toward the river. The terrain is characterized by numerous small canyons that have been cut through the mesa by drainage from the mountains.

Routine access to the TA-V complex is over a paved access road, from Pennsylvania Street, which passes near the main facilities in TA-I (Figure 3-3). Normal access to the area could be restricted by traffic accidents or military convoys which occasionally travel the main paved roads.

TA-V (Figure 3-4) is a discrete area, completely enclosed by two standard security chain-link fences, except for the Office/Light Laboratory (O/LL), Building 6587 on the west side. All regular entries and exits to or from TA-V are through a Perimeter Access Building (PAB, Building 6577) manned by the SNLNM Security Force. Nuclear facilities in the TA-V complex are the:

- ACRR housed in Building 6588,

- Sandia Pulse Reactors II and III (SPR-II/III),

- HCF housed in Building 6580, and

- Gamma Irradiation Facility (GIF) housed in Building 6588.

The main technical activities are housed in Buildings $6580,6588,6590,6591,6593,6594$, and 6597. Building 6582 contains a large conference room and serves as the assembly point for potential emergency evacuations of TA-V. Other buildings provide laboratory and support services for the nuclear facilities in TA-V. The O/LL, Building 6587, immediately to the west of TA-V houses the administrative, analytical, and experiment support personnel for the nuclear facilities. TA-V is bordered to the west and south by TA-III. To the north is the access road to TA-V and a vacant area controlled by KAFB.

Control of all personnel and equipment entering or leaving TA-V is maintained at one central point, the PAB, Building 6577, which contains both personnel portals and a vehicle gate. Security inspectors are assigned to the PAB at all times the site is open for business. Personnel control is maintained by a computer-based personnel accountability system. This provides the security inspectors with an up-to-date and accurate count of the total number of people in the area at all times.

All activities in TA-V are currently under the administrative control of the Reactor Engineering Technology Center. Direct operational and safety responsibility for the HCF and ACRR is assigned to the Nuclear Facilities and Diagnostics Department. During an emergency, physical access to TA-V by vehicles such as fire trucks and ambulances, is coordinated through the on Scene Commander. TA-V ingress and egress is normally through the PAB. If use of the PAB portals is not possible or practical, there is another vehicle gate in the west fence and a personnel gate in the north fence that are normally locked but which can be opened. Use of these gates must be coordinated with the on-site security and health physics personnel. 
Figure 3-3. Location of Technical Area $V$ and Nearby Facilities

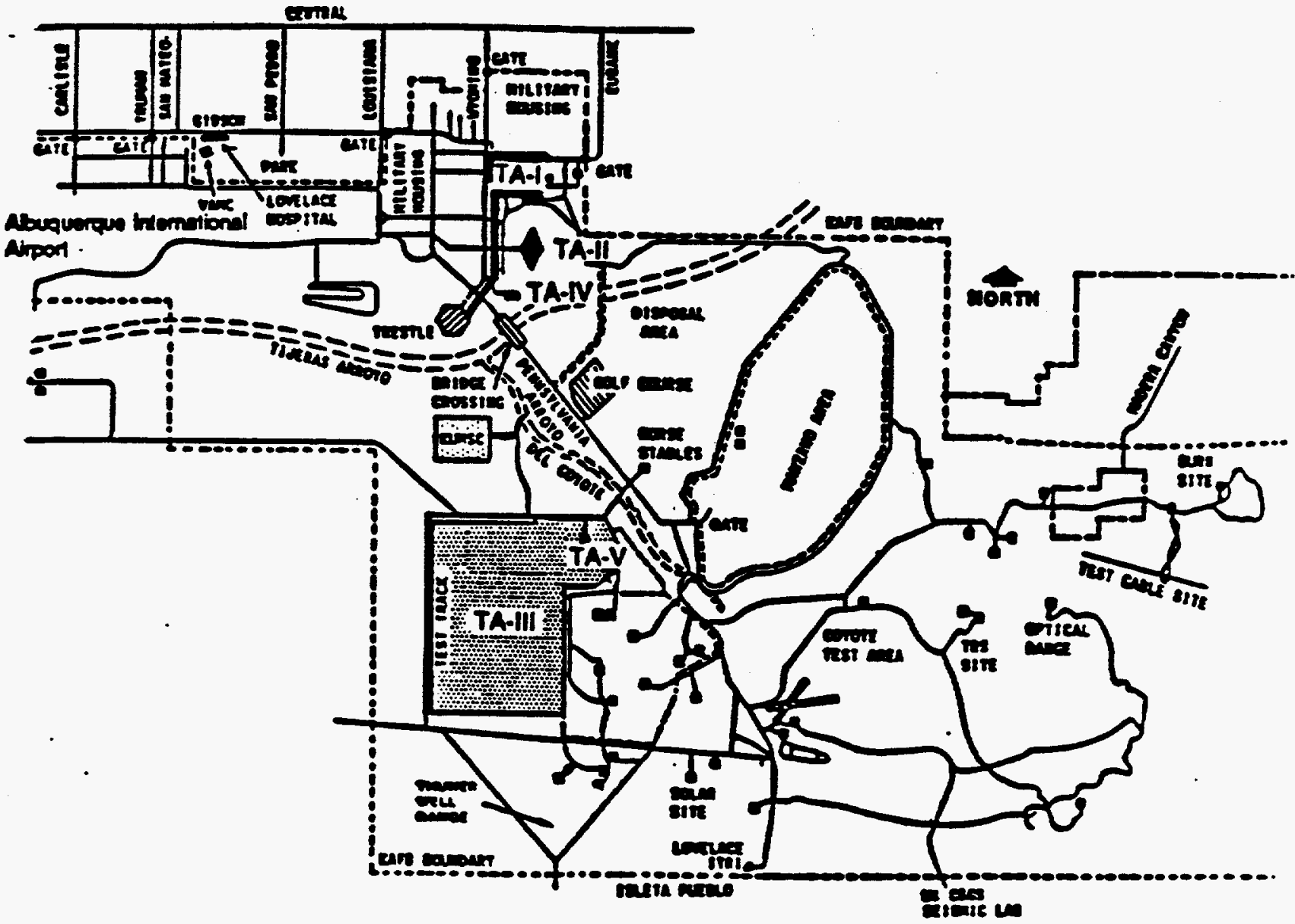


Figure 3-4. Technical Area V Complex

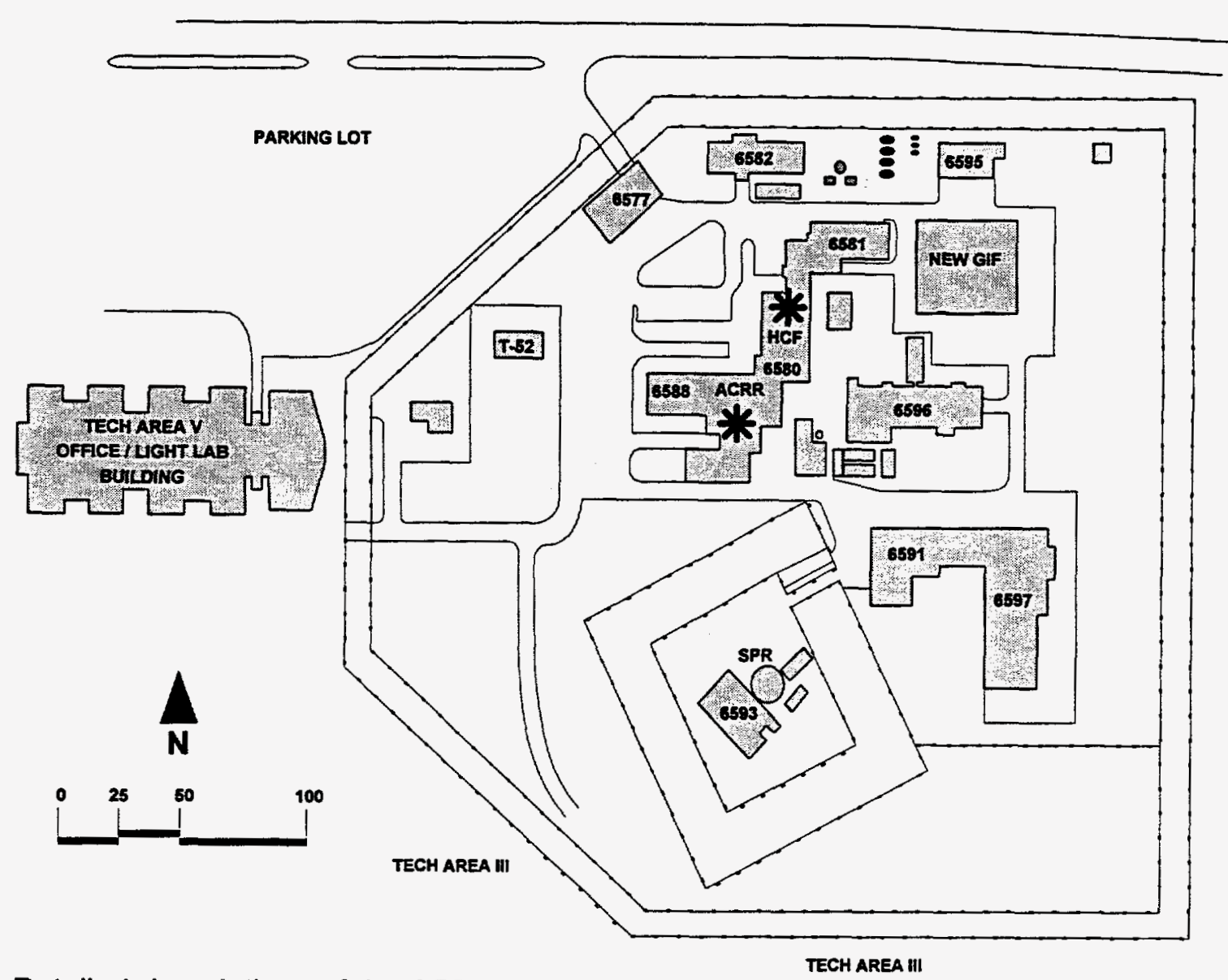

Detailed descriptions of the ACRR and associated facilities are given in Section 3.2.5.1, ACRR site.

\subsubsection{Hydrology and Water Usage}

There are no naturally occurring permanent surface waters in the immediate vicinity of the TA-V facilities.

Topography near TA-V is dominated by Tijeras Canyon, about $3 \mathrm{~km}(1.9 \mathrm{mi})$ to the north. TA-V is situated on a slight ridge of high ground that has several small drainage cuts (arroyos) through the area. One arroyo of significance, Arroyo del Coyote, is about $0.8 \mathrm{~km}(0.5 \mathrm{mi})$ east of the complex, running southeast to northwest and emptying into Tijeras Arroyo.

During heavy precipitation the arroyos effectively collect runoff from the mountains and divert surface flow away from the area. Therefore, surface flows that could affect the area are limited to that amount collected between TA-V and the arroyos. The heaviest precipitation to date in this area has not produced general flooding in TA-V, although some localized flooding has occurred outside the HCF since it is below grade. All precipitation occurring to the north, south, and west is drained away from the complex by the natural surface slope and therefore does not constitute a problem. General flooding of the site is extremely unlikely, and, on the basis of historical evidence, is not apt to result from natural phenomena. 
The SNL/NM water system is connected to the KAFB water system, which in turn is supplied from both KAFB wells and additional water purchased from the city of Albuquerque. Water consumption at SNL/NM is approximately $3,790,000$ V/day $(1,000,000$ gl/day) out of the $341,100,000 \mathrm{l} /$ day $(90,000,000 \mathrm{gl} /$ day) used in the Albuquerque area. A single $254 \mathrm{~mm}(10 \mathrm{in})$ pipe transports water, normally by gravity feed, from TA-I to TA-III. At TA-III a system of valves, pumps, intermediate tanks, and an additional deep well, forward this water, also primarily by gravity feed, to a large ground tank east of TA-III through a $355.6 \mathrm{~mm}$ (14 in) pipe. It is then ordinarily drawn from the large ground tank through the same 355.6-mm (14 in) pipe to supply the water needs of TA-III and TA-V. Current water consumption in TA-V is approximately $9500 \mathrm{~V} /$ day $(2,500 \mathrm{gl} /$ day).

Should the main 254-mm (10 in) line from TA-I rupture, the large ground tank will continue to provide water without interruption. The deep well and an intermediate tank at TA-III, together with the two auxiliary pumps, would be activated to replenish the large ground tank water supply, though at a reduced rate. Another large elevated tank at TA-III would supply emergency water in the event of a break in the 355.6- $\mathrm{mm}$ (14 in) line between the large ground tank and TA-III/TA-V. No normal operations in TA-V use the TA-III water supply.

\subsubsection{Seismology}

TA-V is located on the eastern portion of the Albuquerque-Belen Basin, which is part of the Rio Grande trough complex. The entire trough in the Albuquerque region is classified as a Seismic Zone 2, as indicated by the Uniform Building Code's Seismic Risk Map of the United States dated 1985 (Figure 3-5). This classification implies that the area will be frequently subjected to moderate damage, that in terms of magnitude, corresponds to a Richter magnitude of M5 to M6 (Appendix D). Horizontal accelerations that are typical of these magnitudes range from $0.07 \mathrm{~g}$ to $0.3 \mathrm{~g}$.

Seismically, the Albuquerque area is characterized as a region of high activity but relatively low magnitude and intensity. Seismic records indicate that the most active seismic segment of the Rio Grande trough (for that portion in New Mexico) extends southward from Albuquerque to slightly beyond Socorro [100 km (62 mi)]. Historical evidence indicates that the largest earthquake expected within this zone in a 100-year period would be of magnitude M6 on the Richter scale.

In general, geological evidence indicates that the area has been relatively stable for a long period of time and that strong earthquakes have not affected the area within the last 300 years. Available recorded information indicates that about 600 earthquakes have occurred in New Mexico since 1855. About 90 percent of them have originated in a narrow belt in the Rio Grande trough between Albuquerque and Socorro, and shocks have been felt in at least 30 different years.

\subsubsection{Climatology}

\section{Temperature, Humidity, and Precipitation}

The average daily temperature range is relatively high. Normal daily minimum temperatures for winter months are about $-5^{\circ} \mathrm{C}$ to $-3^{\circ} \mathrm{C}\left(23^{\circ} \mathrm{F}\right.$ to $\left.27^{\circ} \mathrm{F}\right)$ and for the summer months, $14^{\circ} \mathrm{C}$ to $19^{\circ} \mathrm{C}$ 
Figure 3-5. Seismic Risk Map of the United States

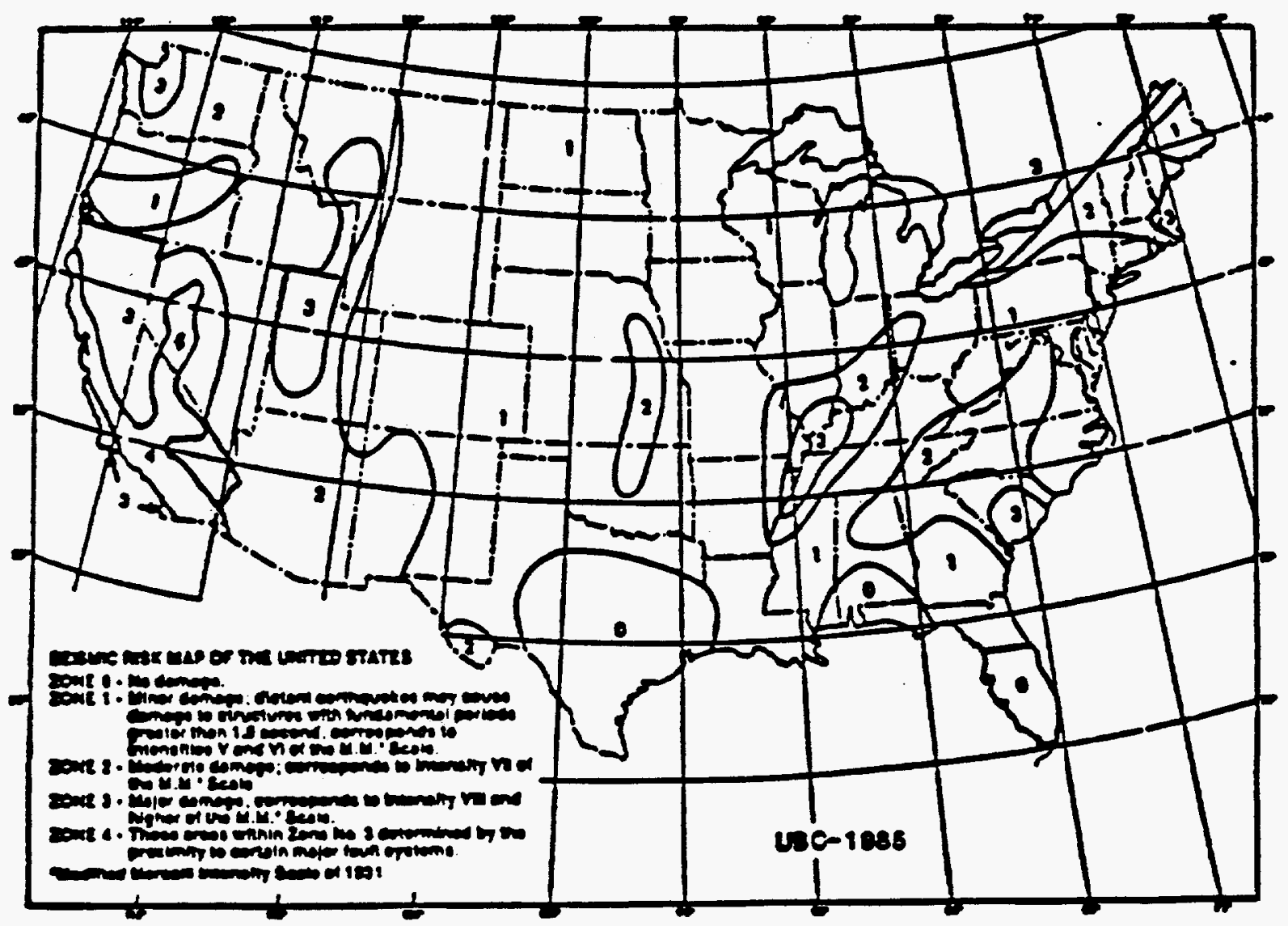


$\left(57^{\circ} \mathrm{F}\right.$ to $\left.66^{\circ} \mathrm{F}\right)$. Normal daily maximum temperatures for the same periods are $8^{\circ} \mathrm{C}$ to $11^{\circ} \mathrm{C}$ $\left(46^{\circ} \mathrm{F}\right.$ to $\left.52^{\circ} \mathrm{F}\right)$ and $28^{\circ} \mathrm{C}$ to $33^{\circ} \mathrm{C}\left(82^{\circ} \mathrm{F}\right.$ to $\left.91^{\circ} \mathrm{F}\right)$, respectively.

The average annual rainfall for the Albuquerque area is just over $206 \mathrm{~mm}$ (8.2 in). The lowest monthly precipitation occurs in the winter, with less than $13 \mathrm{~mm}(0.5 \mathrm{in})$. The highest average monthly precipitation occurs from July to September, and accounts for about half of the annual amount. Summer precipitation is usually the result of highly localized heavy thundershowers that typically last an hour or less at any given location. The maximum observed precipitation in a 24-hour period occurred in September 1955, when $49 \mathrm{~mm}$ (2 in) was recorded.

\section{Tornadoes}

Tornado occurrences in the state of New Mexico vary from a mean annual frequency of 0.2 to a maximum of 1.1. Statistically, the highest frequency has been observed in the eastern half of the state. For the western half of the state, generally demarcated by the Rio Grande and the mountain ranges that parallel it on the east side, there is approximately one tornado every 3 years. In the Albuquerque area, which lies west of the Sandia and Manzano Mountains, only two tornadoes have been reported in the last 20 years. These occurred in Albuquerque in 1985 and 1987, and are officially listed in the climatological records of the National Weather Service as "small tornadoes." Damage was very light, and no official wind readings were recorded.

\subsubsection{Population Characteristics}

The major population center in the vicinity is metropolitan Albuquerque. The city of Albuquerque is adjacent to KAFB, occupying all land from the southwest quadrant clockwise through the northeast quadrant. The 1990 U.S. Census figures indicates that 385,000 people live within the city limits, and over 480,000 live in the metropolitan statistical area.

\section{TA-V}

Normal work activities in TA-V are scheduled for Monday through Friday, 8:15 am to 4:15 pm. The Nuclear Facilities and Diagnostics Department is responsible for ACRR and HCF operations, and normally consists of about 30 people, including a Department Manager, a secretary, and an operations staff. This department is part of a total TA-V work force of about 100 people, about half of whom are located in the West Annex outside the double fence.

TA- $V$ residents are assigned access badges that automatically activate the personnel accountability system computer. Other SNL/NM employees with work assignments that require them to be in TA-V are issued temporary badges to record them into the personnel accountability system. Approximately 40 temporary badges are available for issue. The expected average population inside the fence at TA-V during regular working hours is about 85 persons. All personnel are required to receive an emergency procedures briefing before being allowed unescorted access to TA-V.

\section{KAFB Areas Outside TA-V}

The major locations whose population would be of immediate interest are SNL/NM Technical Areas I, III, and IV, DOE Albuquerque Operations, KAFB underground munitions storage centers (KUMSC), KAFB Housing, and the KAFB Headquarters. The TA-I and KAFB 
Headquarters are located about $5.4 \mathrm{~km}(3.4 \mathrm{mi})$ north of the TA-V radiation facilities, and have a population of about 10,000 persons during normal working hours. This is the largest single concentration of people in the SNLIUSAF complex on KAFB East. Of this number, about 8000 are employees and contractors. The remainder are associated with or attached to various military and civilian government organizations.

TA-IV is located $4.0 \mathrm{~km}(2.5 \mathrm{mi})$ north of TA-V, and has a normal work-day population of about 500 personnel, most of whom are SNL/NM employees.

TA-III is adjacent to TA-V on the west and south sides, and has a population that may vary from 200 to 300 at any given time because of the nature of the diverse testing operations for which this area exists; for the same reason, these people may be widely dispersed throughout the area.

KUMSC is the nearest USAF facility with a significant population and is $1.7 \mathrm{~km}(1.1 \mathrm{mi})$ northeast of TA-V. This facility has a work-day population of about 150 persons, and is equipped with its own environmental control system. Operations at this facility have no impact on TA-V. All other special areas or zones in KAFB East (including military facilities) either have a small population or are located in a low meteorological probability zone (that is, a zone in which winds from TA-V have a very low frequency of occurrence).

\section{General Area}

The KAFB East/lsleta Indian Pueblo boundary is $6.1 \mathrm{~km}(3.8 \mathrm{mi})$ south of the TA-V facilities; there are no permanent residences along the boundary. A private cattle company occupies the land bordering the western boundary of KAFB East, $3.1 \mathrm{~km}(1.9 \mathrm{mi})$ from TA-V. All other areas within a radius of $6.0 \mathrm{~km}(3.7 \mathrm{mi})$ are under the control of SNL/NM, except a small area immediately east of TA-I, which is within the Albuquerque city limits. The Four Hills development is approximately $7.0 \mathrm{~km}(4.3 \mathrm{mi})$ northeast of the TA-V facilities.

Another zone of interest, because its population is transient, is the Albuquerque International Airport. The airport shares runways and other flight facilities with KAFB, forming an integral unit, and consists of all the private and commercial facilities located at the western-most part of the airfield complex. Two drivers and two handlers would be directly involved with loading products at the airport, and approximately 10 additional people would be in the general area during loading. An exact analysis of the number of persons in the terminal and surrounding facilities is not available, but peak occupancy may be several thousand people. The airport terminal and maintenance facilities are located $9.3 \mathrm{~km}(5.8 \mathrm{mi})$ northwest of the TA-V complex. This area is controlled by civil authorities, and the SNL/NM Emergency Plan provides for proper and timely cooperation with those authorities.

\subsubsection{Current Conditions}

\subsubsection{ACRR Site}

\section{Annular Core Research Reactor}

The ACRR facility, consisting of the reactor and all support systems required for its operation and conduct of experiments, is located in TA-V at Building 6588. Sketches of the ACRR are 
shown in Figures 3-6 and 3-7. The ACRR became operational in 1978 and was originally designed with characteristics suitable to support weapons programs (Reuscher, 1982). The ACRR's capability to have large-volume, thermal-flux traps makes it a viable resource for producing radioisotopes, especially for those isotopes produced in the fission process.

\section{Gamma Irradiation Facility}

The GIF pool is a rectangular stainless steel lined pool that has a portion open to the Building 6588 high bay, and a portion covered by heavily shielded dual confinement boxes. The GIF contains high activity cobalt and cesium sources that are used for gamma irradiation experiments. Construction on a new and separate GIF facility located in the TA-V complex is scheduled to begin shortly. The GIF sources are scheduled to be moved to this new facility within two years.

The GIF pool would be used in the isotope production program to transfer irradiated targets from the ACRR tank to the transfer cask for movement to the HCF. The GIF pool could also store spent fuel elements generated during the isotope production process. The GIF has its own separate cleanup loop to control contamination and water purity.

\section{Hot Cell Facility}

The HCF is located in Buildings 6580 and 6581 in TA-V. The HCF is composed of the mechanical equipment room, the monorail system and associated debris-bed cask, the liquid nitrogen holding tank, the hydraulic system housed in Building 6581 , and the central facility housed in the basement of Building 6580. Generally, however, the term HCF is used to designate the Building 6580 basement. The HCF is constructed to allow safe remote handling of nuclear (fissile) and radioactive materials. It is primarily a research laboratory with limited facilities for experiment assembly and disassembly and small-sample preparation for microscopic, radiological, and chemical analyses.

The underground part of the HCF is a robust concrete-shielded structure that contains 3 laboratories: the hot cell laboratory, the glove box laboratory, and the analytical support laboratory. The HCF walls are massive, 0.3 to $1.1 \mathrm{~m}$ ( 1 to $3.5 \mathrm{ft}$ ) thick depending on location, to provide shielding for handling highly radioactive materials. The basement location offers considerably more protection. The earth surrounding the outer walls and ceiling varies from about $1.5 \mathrm{~m}$ ( $5 \mathrm{ft})$ to essentially infinite thickness. Thus the radiation hazard to the surrounding area is very low.

The HCF has multiple ventilation zones. Differential air pressure is maintained between these zones to ensure that air flows from areas of lower potential contamination to areas of higher potential contamination. 
Figure 3-6. ACRR Reactor Tank and Pool Cooling

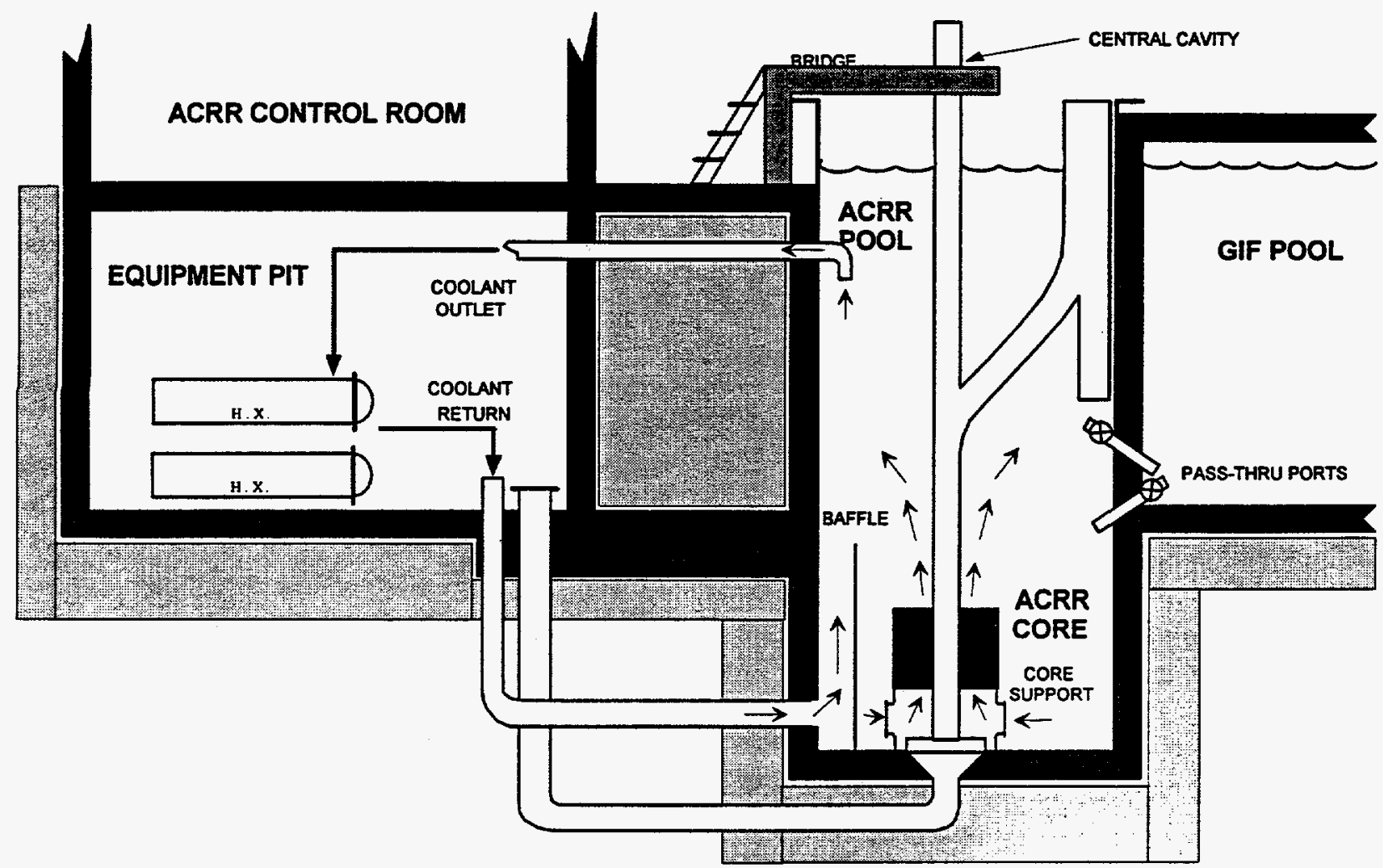

Figure 3-7. ACRR High Bay Layout.

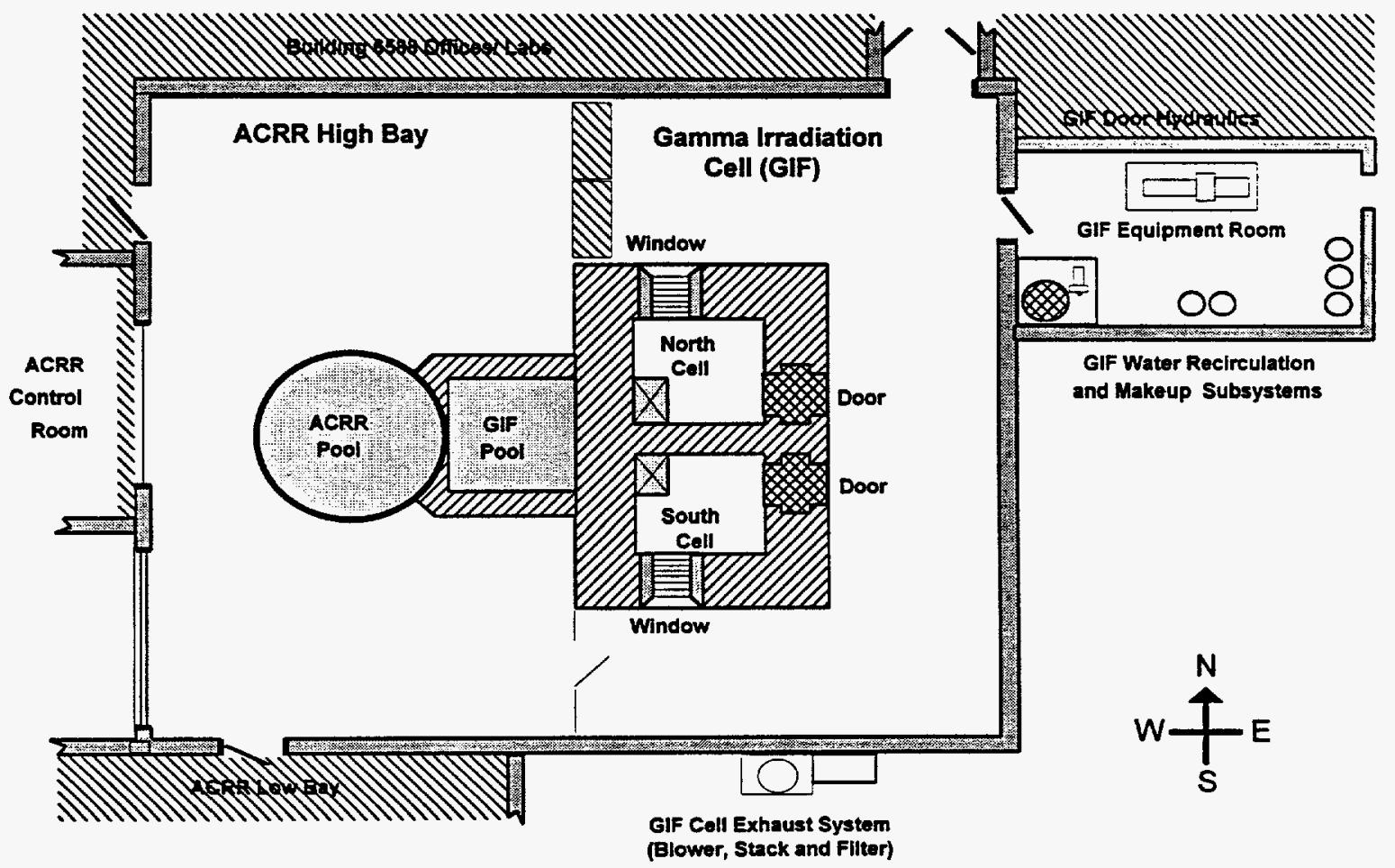




\section{Auxiliary Facilities}

The ACRR high bay, central and the Fuel Ring External Cavities, and the GIF cells each have their own ventilation system. Each ventilation system has flow rates sufficient to maintain the serviced area at a negative pressure differential relative to the outer environment. Each system contains HEPA filters to ensure that all air released to the environment during upset conditions is filtered prior to release.

The current location of the ACRR control room is shown in Figure 3-7. During the past several years, a new computer-aided control room has been designed and constructed that is more remotely located than the current configuration. This new control room is awaiting final checkout and approval by the Sandia safety committees and DOE before being used. Using the new control room would part of the proposed production.

Rooms 109 and 108 (Figure 3-8) in the HCF are available for storing process waste containers. These rooms are shielded by thick concrete walls. The minimum wall thickness in these rooms is $1.45 \mathrm{~m}$ ( $4.8 \mathrm{ft})$ for the interior walls and $0.6 \mathrm{~m}(2 \mathrm{ft})$ for exterior walls which are backed by earth. Room 109 would be used as the primary waste container storage area. Room 108 is potentially available for backup storage capacity. The preferred approach would be to use Room 109 for waste storage and to use Room 108 to load waste containers into shipping casks for transportation to the disposal site. The benefit of this approach is having ample process shielding while loading unshielded waste containers into shipping casks.

Room 109 has approximately $61 \mathrm{~m}^{2}\left(660 \mathrm{ft}^{2}\right)$ of floor space, $6.7 \mathrm{~m} \mathrm{x} 9.1 \mathrm{~m}$ ( $22 \mathrm{ft}$ by $30 \mathrm{ft}$ ). This room could store approximately 160 waste containers. Room 108 has approximately $68.5 \mathrm{~m}^{2}$ $\left(740 \mathrm{ft}^{2}\right)$ of floor space, $7.5 \mathrm{~m} \times 9.1 \mathrm{~m}(24.6 \mathrm{ft}$ by $30 \mathrm{ft})$. This space could store approximately 180 waste containers.

\subsubsection{Current Radiation Environment}

SNL/NM has maintained an Environmental Radiological Monitoring Program since 1959. The program staff collects soil, arroyo sediment, vegetation, and water samples that are analyzed according to established plans and procedures. In addition to these sampling and monitoring activities, another program that began in 1981 uses thermoluminescent dosimeters (TLDs) to measure ambient levels of external gamma radiation at each major facility. TLD monitoring locations are also present around the SNL/NM perimeter and at locations in the surrounding community.

Background radiation originates from cosmic (extraterrestrial), terrestrial (radioactive elements in the earth's crust) and internal (radionuclides in food and water) sources, as well as from radon. The average total dose to the general population in the U.S. is about $360 \mathrm{mrem} / \mathrm{yr}$ (NAS, 1990). Radon, cosmic, and terrestrial sources contribute to the external gamma exposure. The external gamma exposure from background radiation levels, however, is affected by many environmental factors, including elevation and seasonal variations. In the U.S., the external exposure rates range from 50 to $125 \mathrm{mR} / \mathrm{yr}$. In Albuquerque and the surrounding community, this rate is estimated to be about $105 \mathrm{mR} / \mathrm{yr}$.

The results of TLD measurements for SNL/NM, the SNL/NM perimeter (within Kirtland Air Force Base boundaries), and the community or background (17 locations around Albuquerque and 
within an 80-km radius of SNL/NM) are summarized in Table 3-1. These averages are based on 1991 and 1992 SNL/NM environmental monitoring data (Culp et al., 1992; Culp et al., 1993a), and are within expected exposures for Albuquerque and vicinity.

Table 3-1. Average Annual Ambient Radiation Levels (mR/Yr)

\begin{tabular}{|c|c|c|}
\hline LOCATION & 1991 & 1992 \\
\hline SNL/NM & $92.5 \pm 11.8$ & $103.0 \pm 9.4$ \\
\hline SNL/NM Perimeter & $89.4 \pm 20.0$ & $100.6 \pm 19.8$ \\
\hline Community & $90.7 \pm 17.6$ & $100.5 \pm 19.0$ \\
\hline
\end{tabular}

Figure 3-8. Building 6580 (Basement)

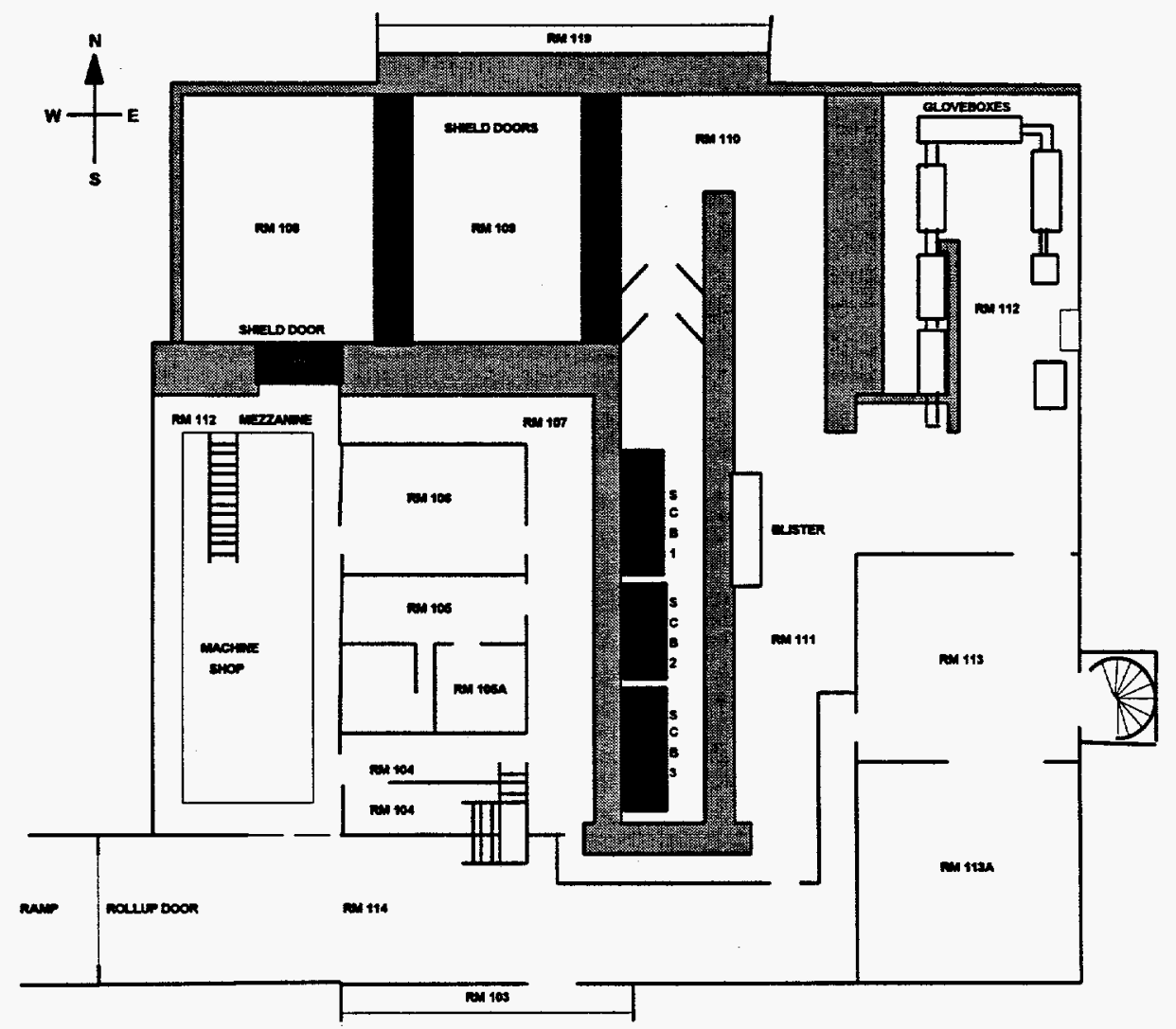

Eight facilities at SNL/NM reported releases of airborne radionuclides during 1993 (Culp et al., 1993b). A total of $3.2 \mathrm{Ci}$ of argon- $41,0.62 \mathrm{Ci}$ of nitrogen-13, $0.012 \mathrm{Ci}$ of oxygen-15 and $1.9 \mathrm{Ci}$ of H-3 were released as a result of SNL/NM activities in 1993. The National Emission Standards for Hazardous Air Pollutants (NESHAP) maximally exposed individual (MEI) was determined to be located at the Kirtland Underground Munitions Storage Complex (KUMSC) facility on KAFB. As shown in Table 3-2, the maximum effective dose equivalent calculated for this location was $0.02 \mathrm{mrem} / \mathrm{yr}$, or 20 percent of the $0.1 \mathrm{mrem} / \mathrm{yr}$ dose that would require continuous monitoring by NESHAP. SNL conducts continuous monitoring as a management practice, rather than by NESHAP requirement. The total population dose within the $80.5 \mathrm{~km}$ (50 
mi) radius surrounding SNL/NM was calculated to be 0.027 person-rem during 1993 from SNUNM operations, compared with 57,000 person-rem from external exposure to natural background radiation.

Radionuclides are produced and released at the ACRR as a result of operating the facility. It is estimated that the ACRR could generate a maximum reactor power of $1.06 e+07 \mathrm{MJ} / \mathrm{yr}$. Power production at that rate would release $218 \mathrm{Ci} / \mathrm{yr}$ of ${ }^{41} \mathrm{Ar}$ (LATA, 1991). Although the ACRR is not expected to operate at maximum capacity, the dose calculated for maximum capacity is less than $0.1 \mathrm{mrem} / \mathrm{yr}$ to the maximally exposed individual at the KUMSC closest to the source.

Table 3-2. Estimated Public Radiation Dose from SNLNM Activities (Population Within $80.5 \mathrm{~km}$ [50 Mi] of SNL/NM)

\begin{tabular}{|c|c|c|c|}
\hline & 1991 & 1992 & 1993 \\
\hline *MEl Effective Dose Equivalent & $0.0014 \mathrm{mrem}$ & $0.0034 \mathrm{mrem}$ & $0.002 \mathrm{mrem}$ \\
\hline$\%$ of $10 \mathrm{mrem} / \mathrm{yr}$ Dose Limit & $0.01 \%$ & $0.03 \%$ & $0.02 \%$ \\
\hline $\begin{array}{c}\text { Total Population Collective Dose } \\
\text { from Operations }\end{array}$ & 0.018 person-rem & 0.020 person-rem & 0.027 person-rem \\
\hline \hline $\begin{array}{c}\text { Total Population Collective Dose } \\
\text { from Natural Background }\end{array}$ & 57,000 person-rem & 57,000 person-rem & 57,000 person-rem \\
\hline
\end{tabular}

- MEI - Maximum Exposed Individual

Current emissions from the HCF result from disassembling nuclear components. Only gases are released on a routine basis. A potential release is based on a release fraction of 1 e- 06 for bulk solids, 1e-03 for particulate, and 1.0 for gaseous materials. For the HCF, it is assumed that all of the fuel material is solid except for gaseous iodine, tritium, and krypton. For maximum capacity, the calculated dose for the maximally exposed individual at the KUMSC, located $1610 \mathrm{~m}$ (1 mi) northwest of TA-V, is 2.1e-03 mrem/yr (LATA, 1991).

\section{Present Radiological Exposures of Workers in Area V}

Table 3-3 shows the radiological doses received by personnel working in the ACRR/HCF area in the years 1993 and 1994 . For comparison, the annual allowable dosages for a radiological worker are set at 5 rem and 50 rem for full body and extremity dosages, respectively, by DOE. SNL has set an administratively controlled limit of $500 \mathrm{mrem} / \mathrm{yr}$ for a radiation worker. 
Table 3-3. Radiation Doses Received by Personnel Working at ACRR/HCF Area during 1993 and 1994 (Data from Monthly Exchange Dosimetry Reports, Radiological Protection Department, Dept. 6521, SNL/NM)

\begin{tabular}{|l|l|l|l|l|l|l|l|}
\hline $\begin{array}{l}1994 \text { Dose } \\
\text { (9 months) }\end{array}$ & \multicolumn{3}{|c|}{ Rem } & $\begin{array}{c}1993 \text { Dose } \\
\text { (12 months) }\end{array}$ & \multicolumn{3}{c|}{ Rem } \\
\hline 13 Workers & $\begin{array}{c}\text { Whole } \\
\text { Body }\end{array}$ & Skin & Extremity & 12 workers & $\begin{array}{c}\text { Whole } \\
\text { Body }\end{array}$ & Skin & Extremity \\
\hline Min & 0.010 & 0.010 & 0.010 & Min & 0.034 & 0.034 & 0.096 \\
\hline Max & 0.519 & 0.748 & 1.695 & Max & 0.418 & 0.677 & 1.465 \\
\hline Average & 0.177 & 0.231 & 0.351 & Average & 0.112 & 0.182 & 0.474 \\
\hline \multicolumn{3}{|c|}{4 workers with no dose } & \multicolumn{3}{c|}{1 worker with no dose } \\
\hline
\end{tabular}

\subsubsection{Waste Management}

\section{Low-Level Waste}

SNL/NM currently generates approximately $70.8 \mathrm{~m}^{3}\left(2500 \mathrm{ft}^{3}\right)$ of uncompacted LLW each year. Currently, the SNLNM ACRR and HCF generate about 35 percent $\left(24.4 \mathrm{~m}^{3}\right.$ or $860 \mathrm{ft}^{3}$ uncompacted) of this LLW (Seylar, 1994). When compacted, this waste would fill about thirtynine 55-gallon drums. Much of this LLW is personnel protection equipment (PPE) and wipes, with the remainder consisting of discarded items that are contaminated with radioactive materials. This waste is packaged in a form acceptable for disposal at a designated LLW disposal site.

\section{Wastewater Effluents}

SNL/NM currently discharges about $3,790,000$ I $(1,000,030 \mathrm{gl})$ of sanitary sewage each day. TA-V has two separate connections to the sanitary sewage lines. One is a direct connection for non-radioactively contaminated wastewater generated in offices, including sink drains, lavatories, toilets, etc. The other connection is to the recently installed Liquid Effluent Control System (LECS). All discharges from the process drains (including the ACRR and HCF) are routed to the LECS and monitored for radioactive contamination before the tank contents are pumped into the sewer system. The LECS contains three $18,950 \mathrm{I}(5,000 \mathrm{gl})$ tanks used for fill, sampling, and backup capacity. The LECS ensures that all facility effluents are monitored to verify that there are no discharges of radioactive materials in excess of the established legal limits.

Water discharges into the LECS system from the TA-V facilities currently average less than 380 I (100 gl) per day. It is not possible to quantify separately the total amount of sanitary sewage discharged directly into the sewer system from TA-V alone, since the closest monitoring station provides combined data from both TA-III and TA-V. This combined sewage discharge ranges from 189,500 to 265,300 I ( 50,000 to $70,000 \mathrm{gl}$ ) per day, or about 6 percent of the SNLINM total. 


\subsection{LANL Facilities}

\subsubsection{Location and Description of LANL Facilities}

LANL is a DOE facility located on 111 square $\left.\mathrm{km} \mathrm{(43} \mathrm{mi}^{2}\right)$ of land in Los Alamos County in north-central New Mexico, approximately $100 \mathrm{~km}(62 \mathrm{mi})$ north-northwest of Albuquerque. LANL is on the Pajarito Plateau, a series of mesas and canyons, at an elevation of about 2,200 $\mathrm{m}(7,200 \mathrm{ft})$ above sea level. The LANL site contains prehistoric and historic cultural resources, flood plains, wetlands, and habitat that is highly suitable for several state and federal threatened and endangered species (Bowen 1990; LANL 1994). However, since all target fabrication activities would take place in existing buildings, none of these resources would be adversely affected by the proposed action.

Detailed descriptions of LANL environs, its climatology, meteorology, hydrology, flood plains, wetlands, cultural resources, and habitat suitable for threatened and endangered species are presented in the site-wide Environmental Impact Statement (DOE, 1979). The annual surveillance reports prepared by LANL Environmental Protection Group in the Environment Safety and Health Division, describe the LANL environment, including archaeology, geology, seismology, geographic setting, land use, hydrology, climatology, meteorology, and population distribution of Los Alamos and surrounding areas (LANL, 1994). These are incorporated by reference. Relevant information is summarized below. The general location of LANL in the county and New Mexico is shown in Figure 3-9.

\subsubsection{Hydrology and Water Resources}

There are no naturally occurring, permanent surface waters at LANL. The nearest source of permanent water is the Rio Grande, which flows through White Rock Canyon $10.4 \mathrm{~km}$ (6.4 mi) to the southeast. All surface flows within LANL originate from storm water runoff or from National Pollutant Discharge Elimination System (NPDES) permitted outfalls from LANL facilities. Intermittent flows and storm water runoff infiltrate the alluvium of the canyon bottoms until their downward movement is impeded by less permeable tuff and volcanic sediment. This results in shallow alluvial groundwater bodies.

Water use rate for all of Los Alamos County is about 5.5 billion I ( 1.43 billion gl) annually (LANL, 1994). This represents 79 percent of the total diversion rights available to DOE under its permit. LANL uses about 1.9 billion I ( 0.5 billion gl) of water annually.

\subsubsection{Seismology}

LANL is on the western edge of the Rio Grande Rift. Evidence suggests that only one earthquake of Richter scale magnitude 5.5 has occurred in the vicinity of Los Alamos in the past 150 years. This is based on geologic studies of motion along faults and on seismic monitoring. Los Alamos lies on the boundary between Zones 1 and 2 designated by the Uniform Building Code of 1991. LANL facility designs are based on the more restrictive Zone 2 criteria. In the event of an earthquake typical of Zone 2, the buildings would be expected to remain intact and the distribution systems for water, gas, and other utilities would not be expected to rupture. Evaluating the earthquake risk at Los Alamos is based on the results of a study of seismic 
Figure 3-9. Location of Los Alamos National Laboratory

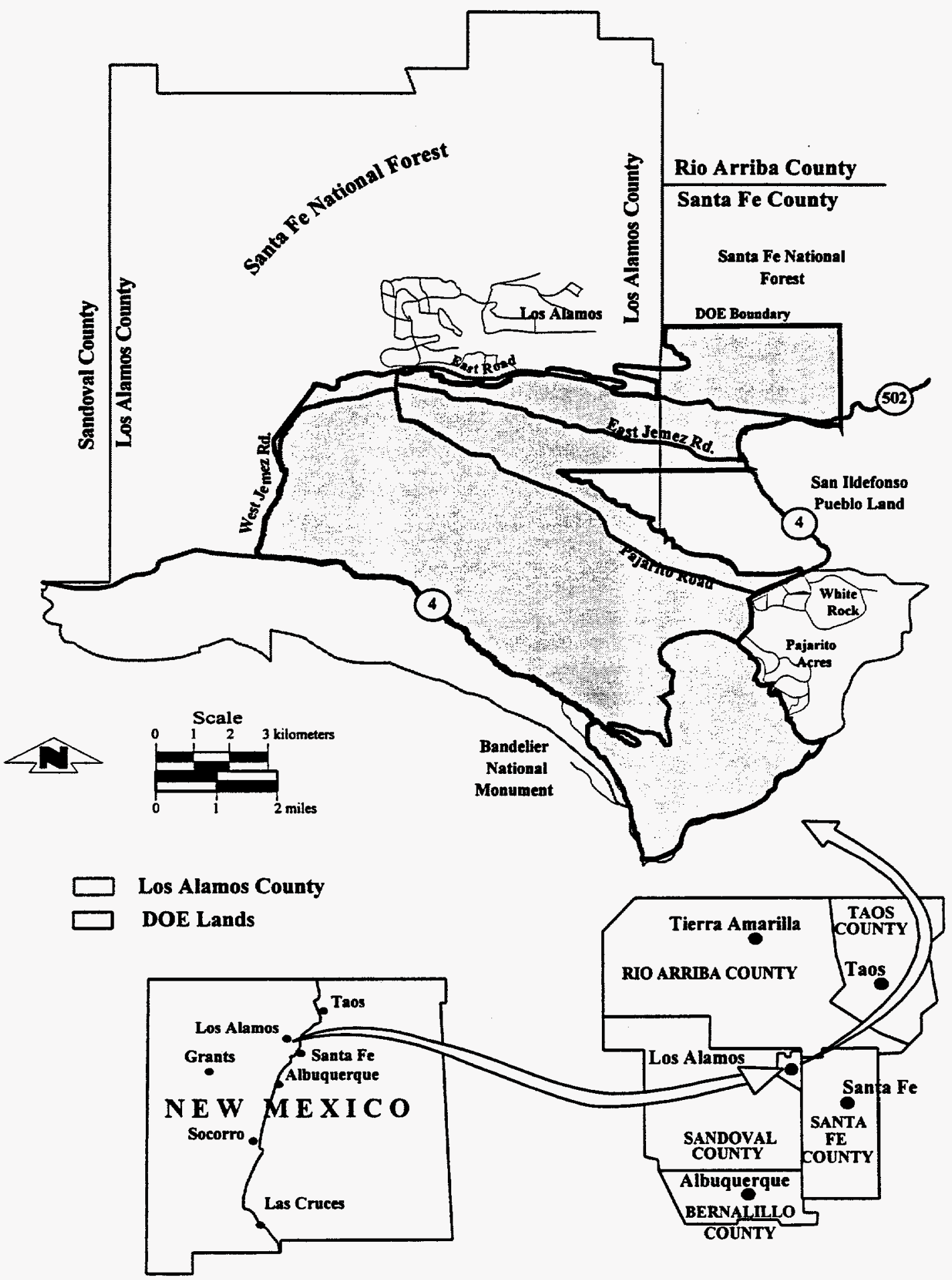


hazard for DOE sites (Coats, 1984). The design basis earthquake has a ground surface acceleration of $0.30 \mathrm{~g}$ (gravity force) and a predicted occurrence of once every 5,000 years.

Additional seismic studies were made in 1992 and 1993; seismic criteria are being re-evaluated in light of the results.

\subsubsection{Climatology}

Los Alamos has a semi-arid, temperate mountain climate with about $45 \mathrm{~cm}$ (18 in.) of annual precipitation.

\subsubsection{Population Distribution}

In 1992, Los Alamos County had an estimated population of approximately 18,200 (based on the 1990 U.S. census adjusted to July 1, 1992). Two residential and related commercial areas exist in the county. The Los Alamos town site has an estimated population of 11,400 . The White Rock area, including the residential areas of White Rock and Pajarito Acres, has about 6,800 residents. Approximately one-third of the 7,550 people employed by the University of California at LANL commute from other counties. The 1990 census conducted by the U.S. Census Bureau indicates that approximately 215,000 people live in Los Alamos County and the adjoining counties of Rio Arriba, Santa Fe, and Sandoval.

The place nearest to the CMR facility continuously occupied by a member of the public is the edge of Los Alamos townsite, about $1 \mathrm{~km}(0.6 \mathrm{mi})$ north. The nearest public access road, Diamond Drive, is $100 \mathrm{~m}$ ( $330 \mathrm{ft}$ ) away. The community of Los Alamos lies to the north, and the community of White Rock lies to the east-southeast. These are shown on Figure 3-10. The prevailing wind path at TA-3 is to the northeast, which favors transport of emissions toward the Los Alamos townsite (LANL, 1994).

LANL is $32 \mathrm{~km}$ ( $20 \mathrm{mi})$ northwest of the city of Santa Fe [56 km (35 mi) by road], $32 \mathrm{~km}$ (20 mi) southwest of Espanola, and $80 \mathrm{~km}(50 \mathrm{mi})$ north of the city of Albuquerque (150 km $93 \mathrm{mi}$ by road).

\subsubsection{Current Conditions}

\subsubsection{Site of Proposed Action}

\section{Chemistry and Metallurgy Research Building}

The CMR at LANL TA-3 (Fig. 3-11), is a large $\left(50,505 \mathrm{~m}^{2}, 545,000 \mathrm{ft}^{2}\right.$ ) reinforced-concrete structure with a basement, a first floor, and an attic (the administrative wing and Wing 1 contain second-floor office areas). The building is centered on a spinal corridor oriented in a northsouth direction; the administrative wing and seven laboratory wings (wings 1, 2, 3, 4, 5, 7, and 9) extend from the corridor. The spinal corridor is a three-story, reinforced-concrete structure providing access to all wings. The building contains a waste assay facility at the loading dock between wings 1 and 4 and a nuclear material storage vault between wings 1 and 5 . 


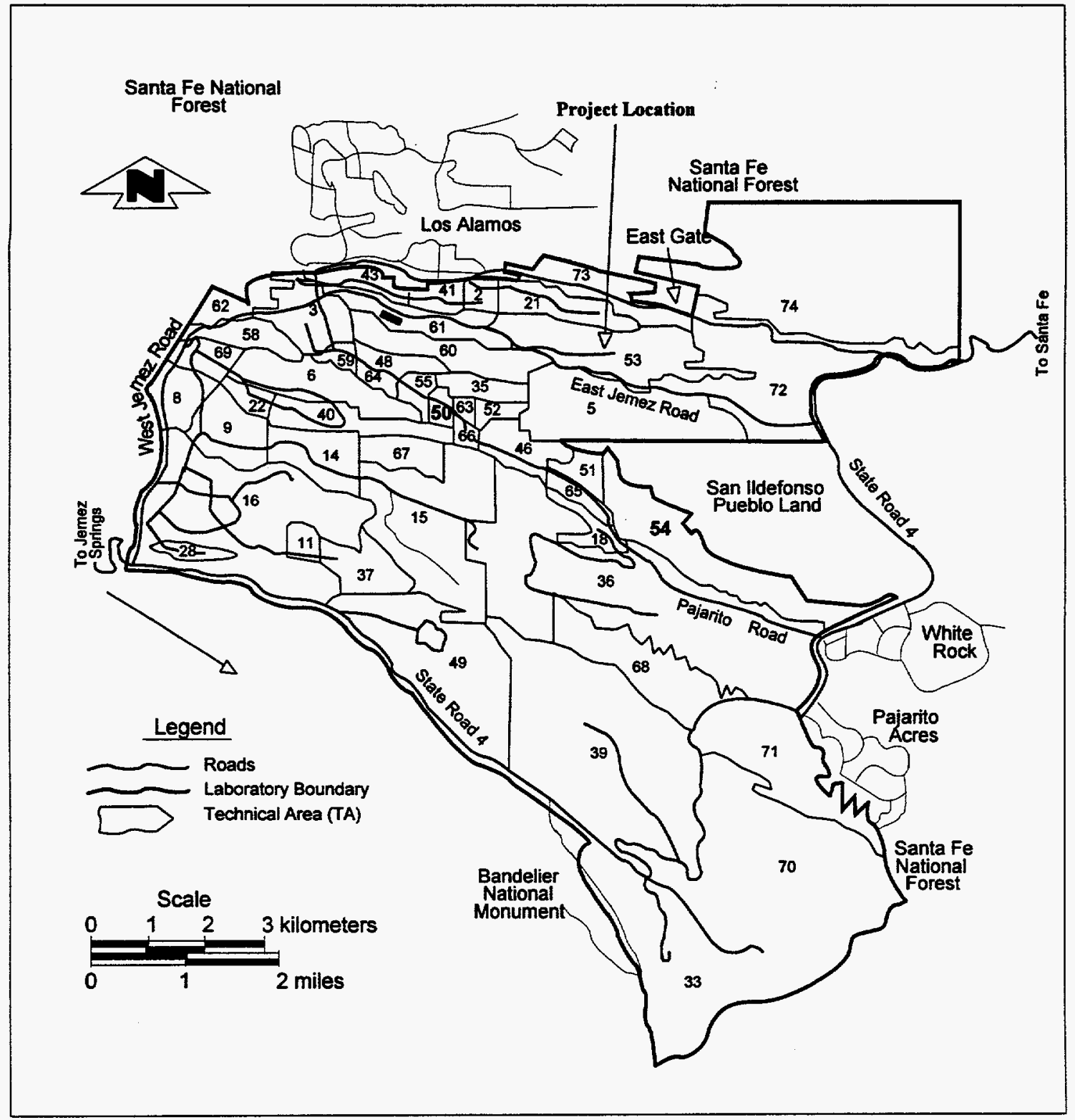

Wing 9 was added in 1959 and is of different construction from the rest of CMR. Wing 9's roof consists of a long span of metal deck supported by steel roof beams. The total area of the first floor of Wing 9 is approximately $2,045 \mathrm{~m}^{2}\left(22,000 \mathrm{ft}^{2}\right)$. The first and second floors are constructed of a cast-in-place concrete slab and joist system of flat slabs $112.7-27.9 \mathrm{~cm}[5-11$ in.] thick). The floor systems are supported on concrete beams and columns. Wing 9 was constructed to the Uniform Building Codes (UBC) of 1960 for Seismic Zone II. The wing would maintain structural integrity in an earthquake with a horizontal acceleration of $0.02 \mathrm{~g}$. Laboratory space in Wing 9 would be used for the target fabrication process and the vault would be used to stage highly enriched ${ }^{235} \mathrm{U}$ for electrocoating and to accumulate prepared targets before they 
are shipped. Figure 3-11 shows the floor plan of CMR with the position of Wing 9 and the proposed target fabrication area.

The heating, ventilating, and air conditioning (HVAC) system for Wing 9 allows for one air change per hour for the areas normally occupied by personnel. Air is exhausted through an atmospheric protection system equipped with a HEPA filter bank. The pressure drop across the HEPA filter is tested routinely to ensure that the HEPA is intact. In addition to the HEPA filter, there is a roughing filter at the stack through which the hot cell and general Wing 9

Figure 3-11. CMR Floor Plan

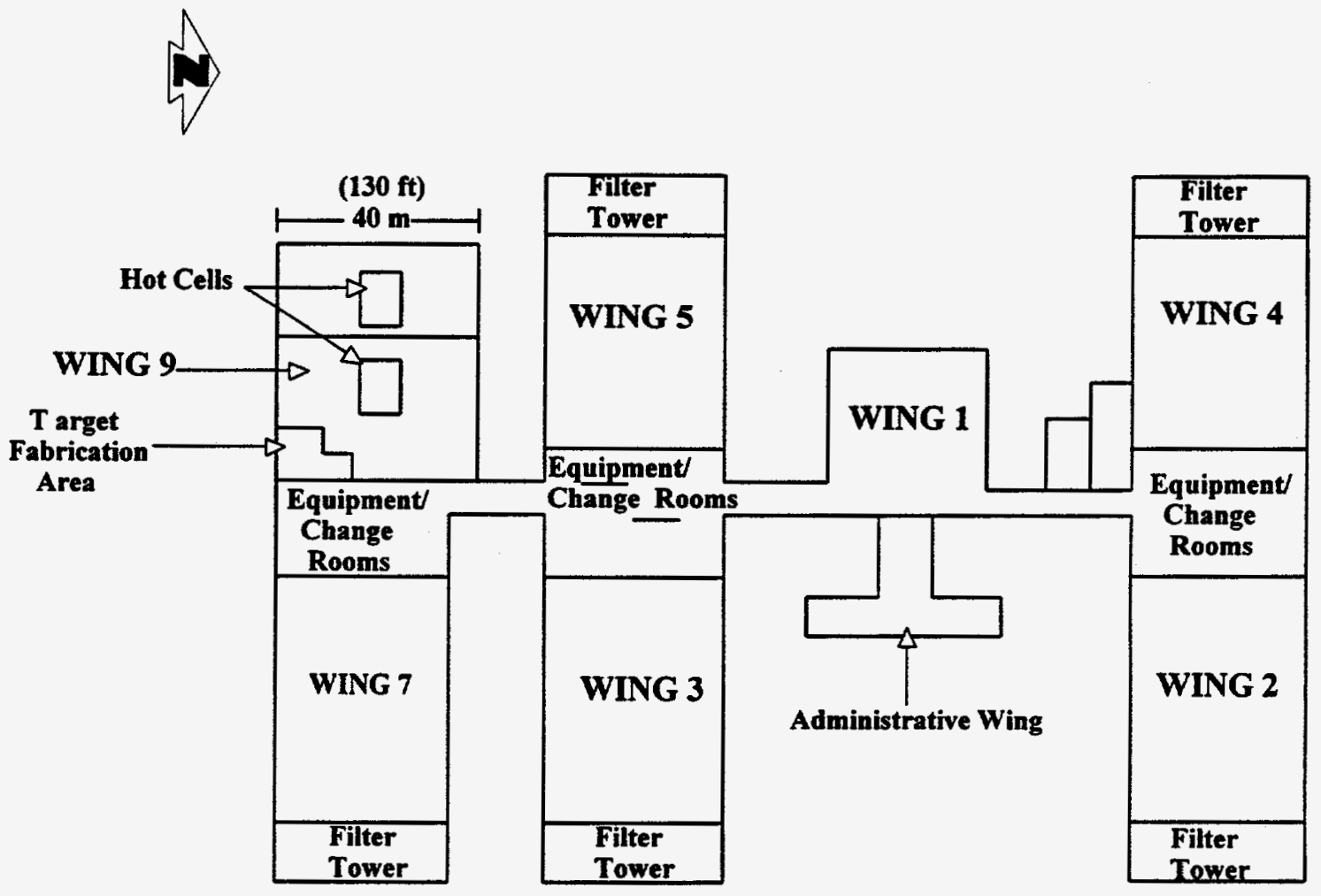

exhaust air flow. The HEPA filter has an efficiency rating of 99.95 percent for particles greater than 0.3 microns, and the roughing filter has an efficiency rating of 90 percent. Ahead of these filters is a sodium hydroxide $(\mathrm{NaOH})$ bubbler, which neutralizes any acid fumes.

Most of the low-level radioactive aqueous wastes from CMR drain directly into the industrial waste main. The industrial waste lines are also known as acid drain lines. These lines transfer the wastes from lab sinks, the duct washdown system, and overflow from the circulating chilled water system. The waste lines tie into a main line that exits from the southwest corner of the basement and discharges to the Radioactive Liquid Waste Treatment Facility (RLWTF) at the TA-50 main industrial waste line. Radioactive liquid wastes may also be drained into the stainless steel holding tanks at SM-154 (a separate structure just west of Wing 9). The system includes monitoring capability for $\mathrm{pH}$, flow, and valve and pump status (which are transmitted to a computer at TA-50). From the tanks, the waste is pumped into the same industrial waste main. RLWTF discharges treated effluent to Mortandad Canyon. 


\subsubsection{Environmental Quality and Monitoring Program}

LANL supports an ongoing environmental surveillance program, as required by the DOE Orders. This program includes routine monitoring programs for radiation, radioactive emissions and effluents, and hazardous materials management at LANL. The results are published annually (LANL, 1994).

\subsubsection{Current Radiation Environment}

Normal operations at LANL produce radioactive air emissions (LANL, 1994). Air emissions are routinely sampled from 88 release points. The major source of radioactive emissions isthe Los Alamos Mason Physics Facility (LAMPF), which releases short-lived ( 8 second to 20 minute half-life) air activation products. The quantity released depends on the amount of time the facility is in operation. In 1992, LAMPF released $71,950 \mathrm{Ci}$ of mixed air activation products, a 25 percent increase over the previous year. The maximally exposed individual, located across a canyon north of LAMPF received a dose of $6.1 \mathrm{mrem}$ in 1992 (LANL, 1994). The average Los Alamos resident's dose was 0.12 mrem.

In $1992,0.014 \mathrm{mCi}$ of ${ }^{235} \mathrm{U}$ were released from all TA-3 stacks including CMR. The total ${ }^{235} \mathrm{U}$ release from LANL was $0.022 \mathrm{mCi}$. An individual located about 1,000 meters north of CMR, in Los Alamos townsite, receives about $5 \times 10^{-6}$ mrem annually due to CMR operations.

Consequences of the doses can be expressed as risk of excess fatal cancer cases. DOE has adopted the Nuclear Regulatory Commission's (NRC's) recommended risk conversion factors. The assumed risk is $\mathbf{4 0 0}$ cancer fatalities per million person-rem for workers and 500 cancer fatalities per million person-rem for the general public (NRC, 1991).

In 1992, the average individual's dose of $0.12 \mathrm{mrem}$ from LANL operations increased that individual's chance of premature death from cancer by less than 1 in one million (LANL, 1994). Normal background radiation dose in Los Alamos is 340 mrem. The TLD reading on 48th Street, the neighborhood nearest to CMR, was 105 mrem, compared with readings in Santa Fe, Espanola, and Pojoaque of 92-97 mrem (LANL, 1994).

\subsubsection{Waste Management}

\section{Sanitary Wastewater}

LANL's NPDES permit includes nine sanitary wastewater treatment facilities. During 1992, the effluent exceeded the permit limits in one of the 266 samples collected.

\section{Radioactive Wastewater}

LANL's radioactive wastewater is collected at RLWTF at TA-50, where it is treated by ferric chloride precipitation (LANL, 1991). The solids are filtered, dewatered, and collected in drums for disposal as LLW. RLWTF processes about 20 million I (5.2 million gl) of waste water annually. The effluent is discharged into Mortandad Canyon. This discharge infiltrates a thick section of unsaturated alluvium in the lower reaches of the canyon, which is monitored annually. Treated effluents do not generally flow beyond the LANL boundary. The liquid infiltrates and recharges a shallow body of groundwater in the alluvium (LANL, 1994). This 
shallow aquifer is of limited extent and lies completely within LANL boundaries. Most of the radionuclides in the effluent are absorbed or bound to sediments in the stream channel. $A$ series of sediment traps constructed in the canyon, in the 1970's were re-excavated in 1992 to restore their original sediment retention volumes. In 1991 and 1992 the 20 million liters (5.2 million gallons) of effluent contained no ${ }^{235} \mathrm{U}$ (LANL, 1993, 1994).

\section{Solid Waste - General}

LANL has established procedures to be in compliance with all applicable laws and regulations for collecting, storing, processing, and disposing of routinely generated solid wastes at established facilities, on- and off-site. Waste minimization programs are being implemented to decrease the quantities of waste generated.

\section{Solid Waste - Industrial Waste}

Noncontaminated solid wastes are salvaged if they have value or they are sent to the Los Alamos County sanitary landfill if they do not. LANL disposed about one-third of the total waste discarded in 1992. LANL contributed 121 metric tons (133 tons) of construction rubble and 11,000 metric tons $(12,100$ tons) of other rubble and trash to the total 33,700 metric tons $(37,100$ tons) of waste accepted at the county landfill.

\section{Solid Waste-Low-Level Radioactive Wastes}

LLW is collected by LANL's waste management personnel and taken to TA-54, Area G, which is the on-site burial area. LANL generates about $4,500 \mathrm{~m}^{3}\left(160,000 \mathrm{ft}^{3}\right)$ of LLW annually (LANL, 1991).

\subsection{Transportation Routes}

Overland transportation of radioactive materials is normally achieved by commercial truck in containers that are approved by DOT, NRC, and DOE. The transportation activities associated with the production concept would follow this procedure. In addition, most transportation activities would be along interstate or other primary highways well suited to truck transport. Appendix $L$ contains descriptions of representative routes. 


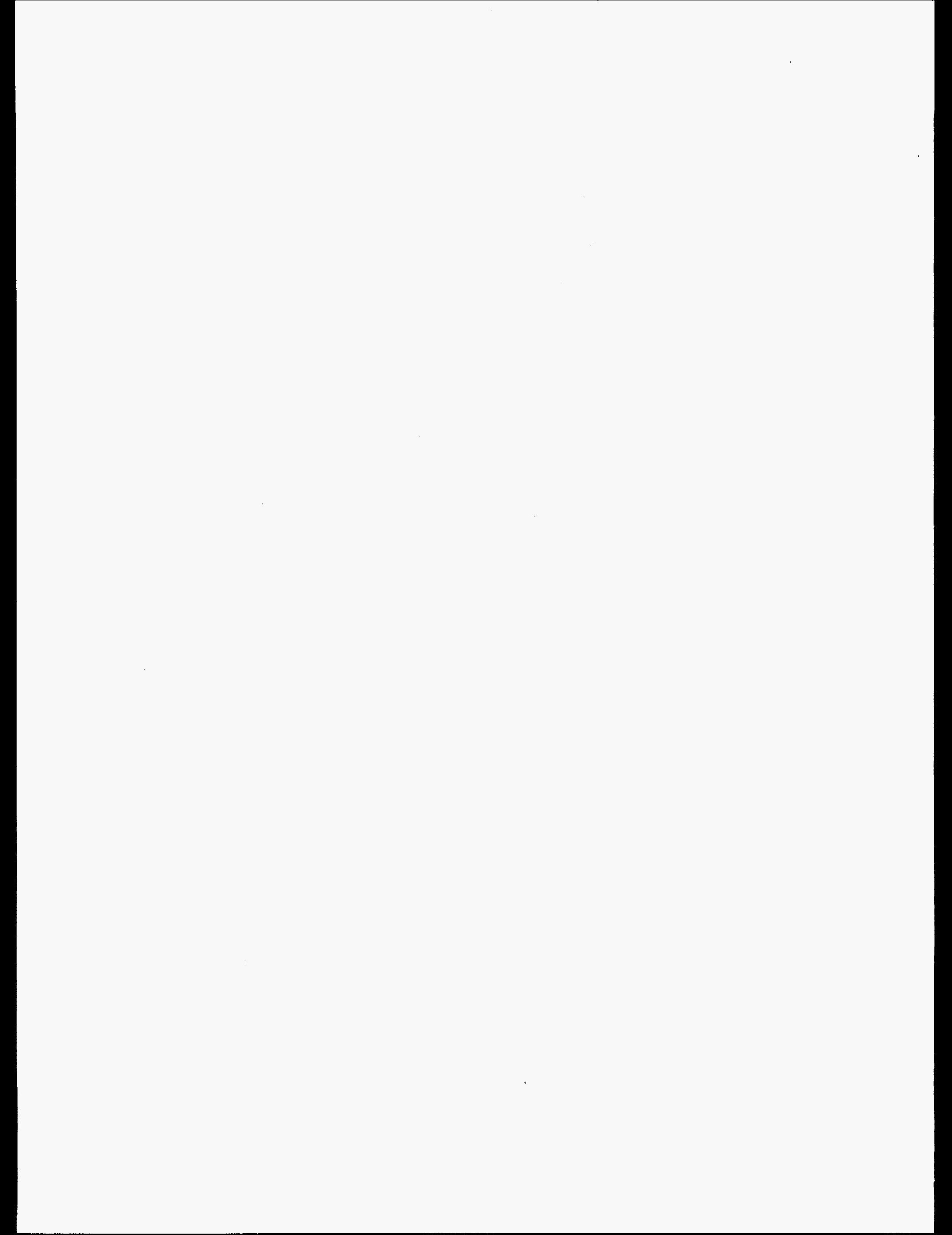




\subsection{ENVIRONMENTAL IMPACTS}

This section examines the potential environmental impacts from routine activities associated with the production of medical radioisotopes at SNL/NM with target fabrication at LANL. The section also discusses the impacts from routine shipments of unirradiated targets from LANL to SNL/NM, and as backup supply to AECL at Chalk River, Ontario. The transportation impacts include shipments of ${ }^{99}$ Mo from SNL/NM to pharmaceutical suppliers in the U.S. and waste shipments. Potentially affected groups of people include target fabrication personnel, ACRR personnel, HCF personnel, transportation crews, and members of the general public. A summary of these potential impacts is found in Table 4-26.

Since the construction activities associated with the production concept would be limited to modifications of existing buildings, a number of environmental resources would not be impacted. These buildings are less than $\mathbf{5 0}$ years old and are not eligible for listing on the historic properties list. Several other environmental resources would not be affected. These resources are listed below:

- recreation resources,

- agricultural resources,

- wetlands and floodplains,

- historic preservation, and

- endangered and threatened species.

Normal operations were evaluated for mechanical, radiological, and toxicological (chemical) impacts. Except for diesel fume emissions from transportation activities, the evaluation concluded that there would be no toxicological impacts on workers, the environment, or the public as a result of normal operations. As a result, toxicological impacts are discussed only for the transportation activity.

\subsection{Normal Operations}

\subsubsection{Pre-Operational Impacts}

As discussed in Section 2, the production concept would require some construction and modification activities at both LANL and SNLNM. The environmental impacts associated with these activities would result primarily from construction and clean-up worker doses and transportation risks for waste disposal. Individual annual worker doses would be maintained below a 500 mrem administrative exposure limit which is one-tenth of the 5,000 mrem limit established by DOE.

\subsubsection{CMR Activities}

At LANL, modifications to the CMR facility would include some room configurations. The room reconfiguration process would generate some LLW from the removal of existing walls and floor coverings as well as some uncontaminated construction trash. Preliminary estimates are $10 \mathrm{~m}^{3}$ 
(353 $\left.\mathrm{ft}^{3}\right)$ of LLW and $5 \mathrm{~m}^{3}\left(177 \mathrm{ft}^{3}\right)$ of uncontaminated trash. LLW would be taken to the LLW disposal site at TA-54, Area G. Uncontaminated trash would be recycled if possible or discarded in the Los Alamos County sanitary landfill.

\subsubsection{ACRR Activities}

At SNLNM, the installation of the EST in the ACRR building would require building modifications. The south wall of the low bay would be partially demolished to accomplish the construction and would be rebuilt on completion of the work. Approximately $183 \mathrm{~m}^{3}\left(6500 \mathrm{ft}^{3}\right)$ of non-contaminated earth below the existing low bay floor would be excavated for the storage tank. The penthouse would be extended over the low bay and the 3-ton penthouse crane rails extended to provide coverage over this area. A non-load-bearing portion of the wall between the high bay and low bay would be removed so that hardware can be moved between the ACRR and the EST. A small amount of low-level radioactive waste may be generated in cleaning up the cavity purge system prior to disassembly for relocation to the high bay roof. Less than $1 \mathrm{~m}^{3}\left(35 \mathrm{ft}^{3}\right)$ of such waste, including gloves and wipes, is anticipated. If charcoal filters and HEPA filters are replaced rather than reused, the volume of low-level radioactive waste would double. The low-level waste would be stored and then disposed at the Nevada Test Site (NTS) or Hanford. A preliminary estimate is that about $10 \mathrm{~m}^{3}\left(353 \mathrm{ft}^{3}\right)$ of nonradioactive construction trash would be generated and recycled or disposed of in the Bernalillo County landfill.

The construction of the EST would have no effect on the medical isotope production proposed action. Additionally, the maintenance of the EST would have no effect on isotope production. There would be no emissions to the atmosphere from equipment storage. Since the EST would be installed inside an existing facility no new land areas would be disturbed. For these reasons there are no further discussions in this study of the environmental impacts associated with the tank and hardware storage.

\subsubsection{HCF Activities}

At SNL/NM, modification activities potentially include replacement of the steel confinement boxes and ventilation systems within the HCF. Radioactive wastes accumulated by the cleanup and decontamination of the HCF would be packaged and shipped to a disposal facility. Up to $212 \mathrm{~m}^{3}$ $\left(7500 \mathrm{ft}^{3}\right)$ of radioactive waste would be generated by the pre-production activities. It is expected, as with the HCF wastes generated from production activities, that the pre-production generated wastes would be shipped to NTS or Hanford for disposal.

\subsubsection{Operational Impacts}

\subsubsection{CMR Target Fabrication Normal Operations}

\section{Radiological Impacts}

Expected radiation doses to involved personnel would result from external contact with ${ }^{235} \mathrm{U}$ rather than from inhalation because all operations would be carried out in glove boxes. The doses are not expected to exceed $150 \mathrm{mrem} /$ person/year. Less than ten individuals would potentially be exposed. The worker population dose would not exceed 1.5 person-rem 
annually. Using the NRC dose conversion factor, this dose could be correlated with a 1 out of 1,666 chance that one of the 10 workers would get a fatal cancer as a result of working in the facility for a year.

Other workers in Wing 9, in adjacent facilities, and members of the public would not be expected to receive a dose from target fabrication.

\section{Mechanical Risk Impacts}

No mechanical risks have been identified.

\section{Waste Management}

Anticipated additions from target fabrication to the LANL waste streams are summarized in Table 4-1 below, which shows a slight increase ( 2.5 percent) in treated effluent that would not exceed treatment capacity at LANL.

Table 4-1. Annual Waste Stream Increases Due to Target Fabrication at LANL

\begin{tabular}{|l|c|c|c|}
\hline \multicolumn{1}{|c|}{ Waste Stream } & $\begin{array}{c}\text { LANL Normal } \\
\text { Operations }\end{array}$ & $\begin{array}{c}\text { Target } \\
\text { Fabrication }\end{array}$ & $\begin{array}{c}\text { Percent } \\
\text { Increase }\end{array}$ \\
\hline Uranium air emissions & $0.022 \mathrm{mCi}$ & none expected & 0 \\
\hline $\begin{array}{l}\text { Radioactive Liquid } \\
\text { Waste Effluents } \\
\text { (treated) } \\
{ }^{235} \mathrm{U} \text { in Effluent }\end{array}$ & 20 million liters & 0.5 million liters & 2.5 \\
\hline $\begin{array}{l}\text { Uncontaminated Solid } \\
\text { Waste }\end{array}$ & $\begin{array}{c}11,121 \text { metric } \\
\text { tons }\end{array}$ & $\begin{array}{c}5 \text { cubic meters } \\
\text { (< } 10 \text { metric ton) }\end{array}$ & $<<1$ \\
\hline LLW & $\begin{array}{c}4,500 \text { cubic } \\
\text { meters }\end{array}$ & $\begin{array}{c}\text { Pre-production: } \\
5 \text { cubic meters } \\
\text { Operational: } \\
5 \text { cubic meters }\end{array}$ & $<1$ \\
\hline
\end{tabular}

\subsubsection{ACRR Normal Operations}

The ACRR would operate in the steady-state mode 24 hours per day, 7 days per week, in order to meet the full North American demand for ${ }^{99} \mathrm{Mo}$. For $200 \%$ of North American demand, up to eight targets would be removed for processing daily. Other configurations, irradiation times, and power levels are possible depending upon production requirements. The irradiated targets would be removed from the ACRR central cavity and moved underwater to the GIF pool through ports that connect the ACRR and GIF pools. Once this transfer is complete, the reactor would be brought back to operating conditions. The targets would be stored in the GIF pool for several hours to allow for decay of very short half life fission products before transfer to the HCF. At least six hours will pass after the targets are removed from the reactor before they are processed. The six-hour waiting period is a requirement in the MDF. The radioactivity associated with a 21-kW, 7-day irradiated target is shown in Figure 4-1 and the decay power in 
Figure 4-2. Assuming a six-hour delay before processing in the HCF, the target activity for a $21-\mathrm{kW}, 7$-day target is approximately $15,000 \mathrm{Ci}$ and the decay power is about 100 watts.

Figure 4-1. Target Activity Following a 21-kW, 7-day Irradiation

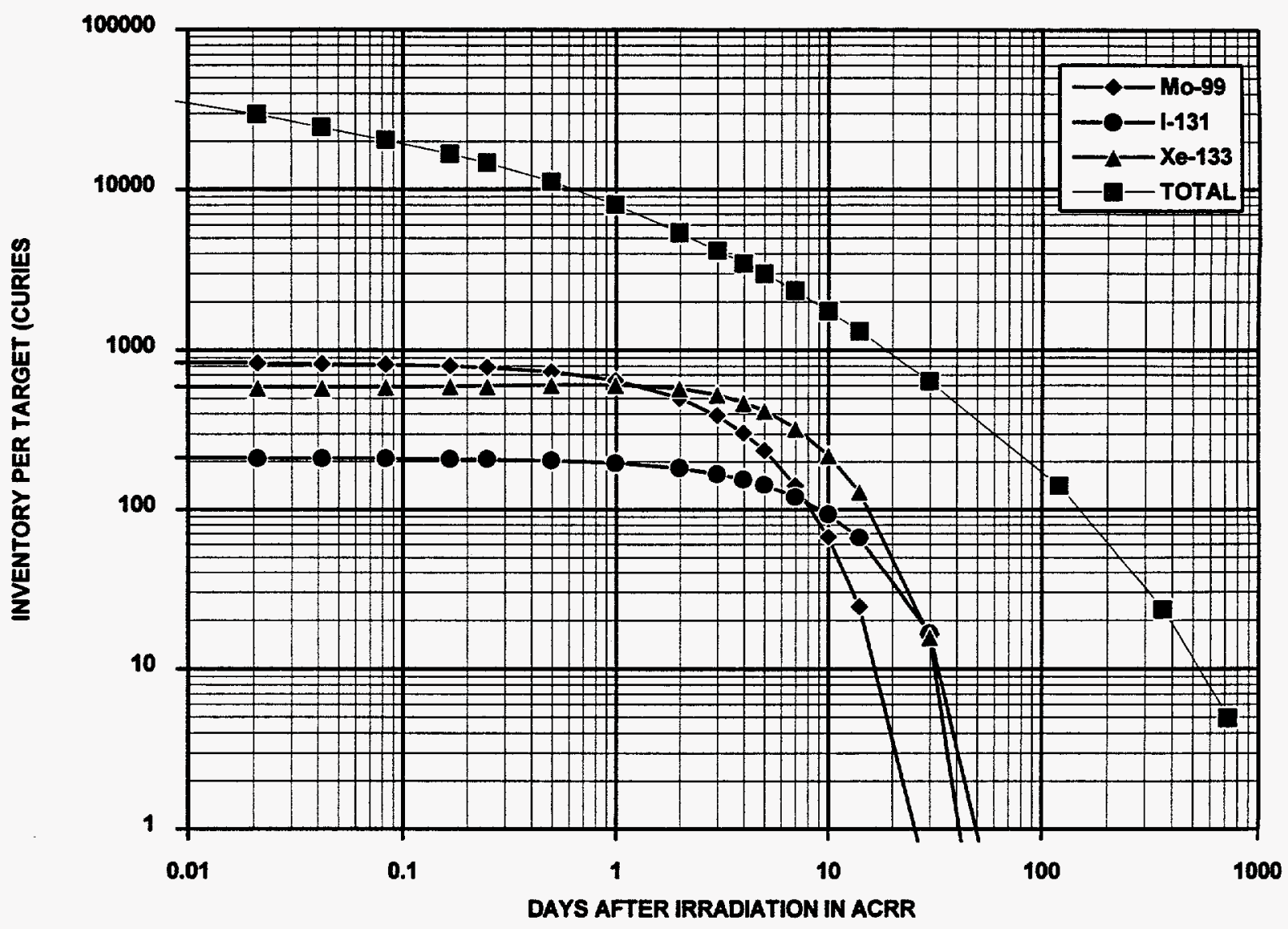

\subsection{Water Consumption}

Installation of the proposed heat exchangers/cooling tower heat rejection capabilities would enable the ACRR to operate continuously at 2 to $4 \mathrm{MW}$ while maintaining the reactor pool temperature below $40^{\circ} \mathrm{C}\left(104^{\circ} \mathrm{F}\right)$. At the upper level of $4 \mathrm{MW}$ continuous power expected for isotope production, the cooling system would increase the water consumption at TA-V by about $110,000 \mathrm{l} /$ day $(29,000 \mathrm{gal} /$ day $)$. The total water use by SNL/NM is about $3,790,000 \mathrm{l} /$ day $(1,000,000 \mathrm{gal} / \mathrm{day})$, current TA-V total water use is about $9,500 \mathrm{~V} /$ day $(2,500 \mathrm{gal} / \mathrm{day})$, and the Albuquerque area water use is about $340,000,000 \mathrm{~V} /$ day $(90,000,000 \mathrm{gal} /$ day $)$. Therefore, the water consumption due to operating the reactor at $4 \mathrm{MW}$ would represent a 1160 percent increase in TA-V use, 3 percent in SNL/NM water use and 0.03 percent in Albuquerque area water use over present levels. 
Figure 4-2. Target Decay Power Following a 21-kW, 7-day Irradiation

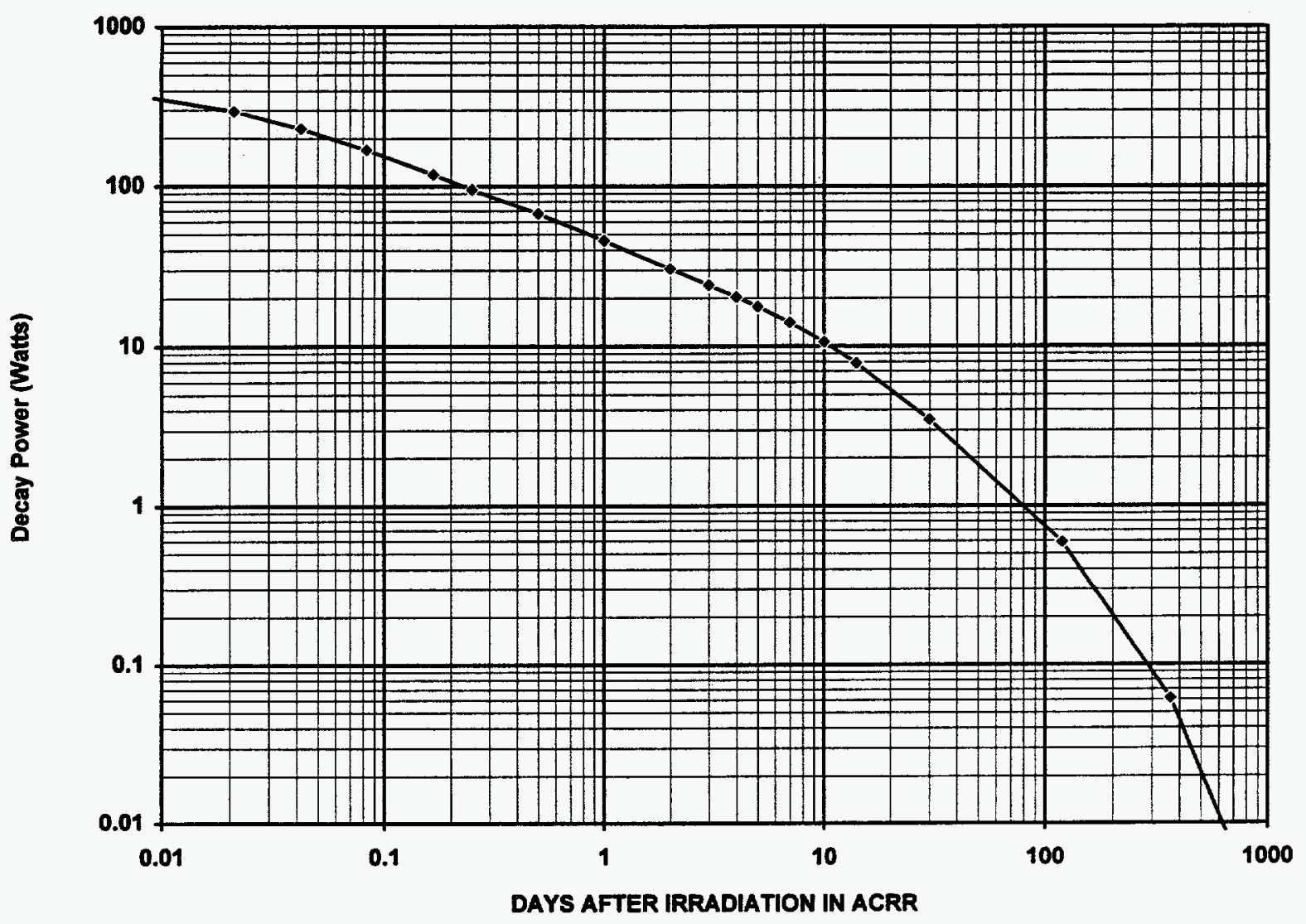

\subsection{Radiological Impacts}

The primary radiation source in the ACRR facility is the reactor core. Fission products produce high levels of radiation; however, the radiation levels are reduced by the reactor tank cooling water. Table 4-2 lists examples of potential radiation sources.

ACRR design features that provide shielding include:

- Approximately $6 \mathrm{~m}(20 \mathrm{ft})$ of water over the reactor core.

- Concrete shell for the reactor tank.

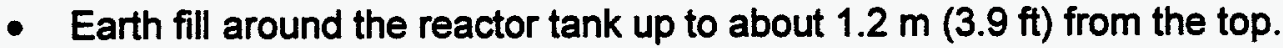

Only reactor personnel who have successfully completed radiation worker safety training are permitted unescorted access into controlled radiation areas. Workers undergo extensive operations and safety training prior to beginning hands-on activities in the ACRR. Facility access is controlled by doors that can be electronically locked via the reactor control panel. Doors can also be padlocked to prevent access. 
Table 4-2. Potential Radiological Hazards Associated with Normal ACRR Operations

\begin{tabular}{|c|c|}
\hline Potential Hazard & Description of Operation \\
\hline Direct exposure to radiation & $\begin{array}{l}\text { - Transfer of incoming targets from shipping } \\
\text { - } \text { Tantainers to storage vaults } \\
\text { - Fuel element movements } \\
\text { - Maintenance activities involving reactor } \\
\text { coolant system } \\
\text { - Maintenance activities involving control rod } \\
\text { drive systems. }\end{array}$ \\
\hline $\begin{array}{l}\text { Release of radioactive material to the high bay } \\
\text { or the high bay ventilation system }\end{array}$ & $\begin{array}{l}\text { - Transfer of incoming targets from shipping } \\
\text { containers to storage vaults; fuel element } \\
\text { movements }\end{array}$ \\
\hline $\begin{array}{l}\text { Release of loose surface radiological } \\
\text { contamination into work area, ventilation } \\
\text { system, or the environment }\end{array}$ & $\begin{array}{l}\text { - Maintenance activities in and around } \\
\text { reactor tank and bridge structure }\end{array}$ \\
\hline
\end{tabular}

Radiological areas, as defined in 10 CFR 835 , are posted and labeled with the dose equivalent a worker could receive in that area, the concentration of airborne radioactive material, and, where appropriate, the amount of surface contamination present consistent with the SNL Radiological Control Manual. Radiation monitoring equipment, located throughout the facility, consists of the Radiation Air Monitor (RAMs) for gamma radiation and the CAMs for gross alpha, beta, and gamma activity. Portable radiation survey equipment is routinely used by health physics personnel to monitor and survey the facility, materials movement, and facility personnel. Action levels on the radiation alarm systems are typically set at about 10 percent of the allowed external dose annual limit for air monitors and $10 \mathrm{mrem} / \mathrm{hr}$ for area monitors.

The design basis for all ACRR facility modifications and operational procedures is the SNL/NM ALARA requirement that the maximum annual radiation dose to any individual worker will not exceed 500 mrem. To meet this criterion, based on a 2000-hour work year, the maximum permissible radiation level in the new ACRR control room would average $0.25 \mathrm{mrem} / \mathrm{hr}$. The principal operation that would provide the maximum worker exposure to radiation is the removal of the loaded transfer cask from the GIF pool and onto the forklift for transport to the HCF. During this operation, if necessary to achieve the ALARA goal, reactor power may be reduced or completely shut down, and the crane operator would be protected to reduce radiation exposure to acceptable levels. Personnel exposure may be further limited through job rotation. Formal operating procedures would be developed to ensure that the ALARA goal is met.

\section{Normal Operations - Exposure to Workers}

For normal operating conditions, including exposure from leaking targets and fuel elements, radiation exposure of operations and maintenance personnel would include direct radiation from 
the reactor and effluents in the pool, i.e., volatile radionuclides released into the high bay, $\left({ }^{16} \mathrm{~N}\right.$, ${ }^{41} \mathrm{Ar}$ and ${ }^{3} \mathrm{H}$ ), and direct radiation from targets in the transfer cask.

The dose rate levels and occupational exposure for performing the ACRR functions would stay within the goals of ALARA. The design goal of $500 \mathrm{mrem} / \mathrm{yr}$ for operations and maintenance personnel would be met by reducing exposure levels where possible through actions such as: 1) decreasing the time requirements to perform tasks by using operating procedures, 2) limiting access to areas to required personnel, and 3 ) increasing the shielding where possible and practical. Table 4-3 presents the estimated dose rates, time requirements, and dose commitments for workers involved in the ACRR operations. These estimates are tentative and would vary depending on the actual dose rates in the areas where a required task is performed. Exposure levels would be monitored continuously using detection equipment and by monitoring personnel dosimetry. For tasks where the design limits would be exceeded, ALARA principles would be examined to determine if the levels can be lowered. If the dose levels cannot be lowered, other personnel would be utilized on a rotating basis.

SNL/NM uses administrative controls based on individual dosimetry data to ensure that no individual worker exposure exceeds 500 mrem $(0.5 \mathrm{rem})$ per year. A minimum of 20 workers would be required in order to maintain the dose levels below the $0.5 \mathrm{rem} / \mathrm{yr}$ design limitations. Of these, 15 would be required to perform the operational duties for the reactor (including health physics support). The other five would be required for target handling, transfer, and online maintenance and surveillance. This latter group may also be utilized in other non-radiation areas for maintenance and/or surveillance. Total annual worker population dose for reactor operations would be 10 person-rem (20 persons $\times 0.5$ rem per person). Current annual total worker population dose is approximately 2.3 person-rem.

Table 4-3. Estimated Annual Doses for Continuous ACRR Operation for ${ }^{99}$ Mo Production

\begin{tabular}{|l|c|c|c|c|}
\hline Function & $\begin{array}{c}\text { Est'd Dose Rate } \\
\text { (mrem/hr) }\end{array}$ & $\begin{array}{c}\text { Total Time in } \\
\text { Exposure Field }\end{array}$ & $\begin{array}{c}\text { Required } \\
\text { Personnel for All } \\
\text { Shifts }\end{array}$ & $\begin{array}{c}\text { Est'd Annual } \\
\text { Worker Dose } \\
\text { (mrem) }\end{array}$ \\
\hline Reactor Operator & $<0.25$ & $24 \mathrm{hr} / \mathrm{d}, 7 \mathrm{~d} / \mathrm{wk}$ & 10 & $<500$ \\
\hline $\begin{array}{l}\text { Health Physics } \\
\text { Support }\end{array}$ & 5 & $1 \mathrm{hr} / \mathrm{d}, 7 \mathrm{~d} / \mathrm{wk}$ & 5 & 360 \\
\hline $\begin{array}{l}\text { Target Transfer \& } \\
\text { Cask Prep. }\end{array}$ & 5 & $1 \mathrm{hr} / \mathrm{d}, 5 \mathrm{~d} / \mathrm{wk}$ & 3 & 430 \\
\hline $\begin{array}{l}\text { Surveillance \& } \\
\text { Maintenance }\end{array}$ & 5 & $0.5 \mathrm{~h} / \mathrm{d}, 5 \mathrm{~d} / \mathrm{wk}$ & 2 & 325 \\
\hline
\end{tabular}

\section{Normal Operations - Offsite Dose Estimates}

Downwind dose calculations for continuous releases were performed using CAP88-PC (Parks, 1992). MACCS (Chanin, 1990) used to model instantaneous releases. The dose values presented represent the individual effective dose equivalent at the location given. A distance of $1610 \mathrm{~m}$ (1 mi) NW represents the location of KUMSC, an underground munitions storage site that contains the closest population group. An exclusion zone is an area surrounding TA-V 
where access is controlled in the event of an emergency at TA-V. A radius of $3000 \mathrm{~m}$ (1.9 mi) was chosen as the exclusion zone for TA-V after an evaluation of locations of worker populations, general members of the public, and road access points. A distance of 5400 to $6000 \mathrm{~m}$ ( 3.4 to $3.7 \mathrm{mi})$ north is representative of the closest public living area, and $20,000 \mathrm{~m}$ $(12.4 \mathrm{mi})$ northwest is a representative distance for the population centers of Albuquerque.

Radioactive effluent releases from ACRR operations are currently dominated by the release of ${ }^{41} \mathrm{Ar}$ through the neutron bombardment of air in the central cavity. With the central cavity removed for ${ }^{99}$ Mo production, the ${ }^{41} \mathrm{Ar}$ release would be substantially reduced. The dominant releases to the atmosphere would be through evaporation and diffusion of the pool water containing ${ }^{3} \mathrm{H}$ (tritium) and ${ }^{41} \mathrm{Ar}$. No routine operational releases of pool water to the sewer system would occur.

The average historical and expected radioactive effluent releases through the high bay exhaust are shown in Table 4-4. Historical releases are based on past operating conditions and assume that the reactor is operated continuously at $11.5 \mathrm{~kW}$, which is equivalent to a yearly average of the total energy produced. Expected releases assume the reactor is operated continuously at $4 \mathrm{MW}$.

Results indicate that the downwind doses would be lower than the dose from current operations. Lower ${ }^{41} \mathrm{Ar}$ emissions would result from the removal of the central cavity. Tritium release would increase due to higher evaporation rates as a result of continuous reactor operation. Overall the total dose from ACRR air emissions associated with medical isotope production would be less than current doese. The decrease in dose from reduced ${ }^{41} \mathrm{Ar}$ emissions would offset the increase associated with tritium emissions.

Table 4-4. Average Historical and Expected Annual ACRR Radioactive Effluent Releases

\begin{tabular}{|l|c|c|c|c|c|c|}
\hline \multirow{2}{*}{ Isotope } & Ci/yr & \multicolumn{5}{|c|}{ Annual Dose (mrem) at Distances $(\mathbf{m})$ from ACRR } \\
\cline { 3 - 7 } & & $300 \mathrm{~m}$ & $1610 \mathrm{~m}$ & $3000 \mathrm{~m}$ & $6000 \mathrm{~m}$ & $20,000 \mathrm{~m}$ \\
\hline $\begin{array}{l}\text { AVERAGE } \\
\text { HISTORICAL }\end{array}$ & & & & & & \\
\hline Ar-41 & 14.8 & $1.30 \mathrm{e}-02$ & $4.44 \mathrm{e}-03$ & $1.92 \mathrm{e}-03$ & $6.44 \mathrm{e}-04$ & $6.36 \mathrm{e}-05$ \\
\hline Tritium & $6.33 \mathrm{e}-05$ & $9.50 \mathrm{e}-09$ & $3.48 \mathrm{e}-09$ & $1.65 \mathrm{e}-09$ & $6.96 \mathrm{e}-10$ & $1.65 \mathrm{e}-10$ \\
\hline TOTAL & 14.8 & $1.30 \mathrm{e}-02$ & $4.44 \mathrm{e}-03$ & $1.92 \mathrm{e}-03$ & $6.44 \mathrm{e}-04$ & $6.36 \mathrm{e}-05$ \\
\hline $\begin{array}{l}\text { EXPECTED } \\
\text { Ar-41 }\end{array}$ & 2.2 & $1.91 \mathrm{e}-03$ & $6.60 \mathrm{e}-04$ & $2.86 \mathrm{e}-04$ & $9.46 \mathrm{e}-05$ & $9.46 \mathrm{e}-06$ \\
\hline Tritium & 2.2 & $3.30 \mathrm{e}-04$ & $1.21 \mathrm{e}-04$ & $5.72 \mathrm{e}-05$ & $2.42 \mathrm{e}-05$ & $5.72 \mathrm{e}-06$ \\
\hline TOTAL & 4.4 & $2.24 \mathrm{e}-03$ & $7.81 \mathrm{e}-04$ & $3.43 \mathrm{e}-04$ & $1.19 \mathrm{e}-04$ & $1.52 \mathrm{e}-05$ \\
\hline
\end{tabular}


The latent cancer fatality risk associated with normal ACRR operations during ${ }^{99}$ Mo production at the 200 percent production level would be $3.9 \mathrm{e}-10$ per year for the maximum individual located at the KUMSC facility located $1610 \mathrm{~m}(1 \mathrm{mi})$ from TA-V. At 200 percent production, total annual dose for the entire general population would be 15.1 person-rem with an associated LCF risk of $7.6 \mathrm{e}-03 / \mathrm{yr}$. This leads to the estimate that the average annual probability of any one individual in the general population of Albuquerque of developing a fatal cancer from ACRR operations would be about 1 in $60,000,000$. This would also mean an increase in one's average annual fatal cancer risk from all causes from approximately 0.003 per year to 0.00300001 per year.

\section{Leaking Targets and Fuel Elements - Off-Site Estimates}

Even though rigorous design and thorough testing of all fuel elements and targets would be used, the structural integrity of fuel elements and targets is expected to fail on a basis of 1 per year at a 200 percent production level. To estimate the expected doses which would result from leaking targets and fuel elements, downwind dose estimates were calculated by conservatively assuming that 50 percent of all noble gases and halogens potentially produced in a target or fuel element were immediately released into the pool and then released to the ventilation system (Powers, 1991). The ${ }^{99}$ Mo target leak was assumed to occur following a 21 $\mathrm{kW}, 7$-day target irradiation, and the fuel element leak after a 25-kW, 5-year fuel irradiation (maximum target and fuel element activity). $A^{125}$ I target leak was also assumed to occur at the end of a 7.5-hr irradiation. Using ORIGEN2, the total activity released from the high bay stack was calculated for each of the noble gas and halogen species (see Appendix $E$ for details).

Using the stack release values from Appendix E, dose estimates can be calculated and are shown in Table 4-5. These results assume that one ${ }^{99} \mathrm{Mo}$, one ${ }^{125} \mathrm{I}$ target, and one fuel element leaks per year. Data indicate that the major contributor to the downwind doses for leaking targets and fuel elements is ${ }^{133} \mathrm{Xe}$. The water cleanup loop would remove most of the iodine from the pool, making it unavailable for release, but for conservatism 50 percent of all iodine was assumed to be released to the ventilation system.

Table 4-5. Annual Downwind Dose Estimates for Leaking Targets and Fuel Elements in ACRR

\begin{tabular}{|l|c|c|c|c|c|c|}
\hline \multicolumn{1}{|c|}{ Event } & Stack & \multicolumn{5}{c|}{ Individual Dose (mrem) at Distance from ACRR } \\
\cline { 3 - 7 } & Release (Ci) & $300 \mathrm{~m}$ & $\mathbf{1 6 1 0} \mathrm{m}$ & $\mathbf{3 0 0 0} \mathrm{m}$ & $\mathbf{6 0 0 0} \mathrm{m}$ & $\mathbf{2 0 , 0 0 0} \mathrm{m}$ \\
\hline $\begin{array}{l}\text { Leaking fuel } \\
\text { element }\end{array}$ & 76.6 & 0.16 & 0.038 & 0.0085 & 0.0011 & 0.000065 \\
\hline $\begin{array}{l}\text { Leaking } \\
\text { target }\end{array}$ & 48.5 & 0.14 & 0.33 & 0.0074 & 0.00099 & 0.000056 \\
\hline $\begin{array}{l}\text { Leaking } \\
\text { target }\end{array}$ & 1.5 & 0.01 & 0.0029 & 0.0007 & 0.0003 & 0.0001 \\
\hline Total & 126.6 & 0.31 & 0.074 & 0.017 & 0.0024 & 0.00022 \\
\hline
\end{tabular}


The maximally exposed offsite individual located at $1610 \mathrm{~m}$ (1 mi) from the ACRR would receive an estimated dose of 7.4e-5/yr rem from all leaking targets and fuel elements. The corresponding LCF risk would be $3.7 e-8 / y r$. For the general population, total annual dose would be 0.05 person-rem, with an LCF impact of $2.5 e-5 / y r$. This means that the annual probability of an individual developing a fatal cancer within the general population of Albuquerque resulting from a leaking target or fuel element is 1 in $18,240,000,000$.

\section{Cooling Tower Blow Down}

As described in Section 4.1.2.2.1, Water Consumption, the proposed heat exchanger/cooling tower heat rejection would allow for continuous operation at 2 to $4 \mathrm{MW}$. The maximum water consumption for the cooling towers during the hottest part of the year would be about 109,900 I/day $(29,000 \mathrm{gal} /$ day), the average would be about $87,000 \mathrm{l} /$ day $(23,000 \mathrm{gal} /$ day). In order to maintain sufficient water purity on the cooling tower side, chemicals must be added to control scale, corrosion, bacteria, and algae. Also in order to keep the dissolved minerals in the tap water from plating on the piping, heat exchangers, valves, etc., some of the water must be discharged throughout the day. This water is called blow down. The blow down requirements are a function of the amount of water used and the solubility of the minerals in the water. If water chemistry is maintained on the system, for a usage of $109,900 \mathrm{l} /$ day $(29,000 \mathrm{gal} /$ day $)$, the blow down would be about $15,900 \mathrm{l} /$ day $(4,200 \mathrm{gal} /$ day $)$, for a usage of $87,000 \mathrm{l} /$ day $(23,000$ gal/day), the blow down would be about $12,500 \mathrm{l} /$ day $(3,300 \mathrm{gal} /$ day). Before the water can be released to the sewer, it must be monitored to ensure that it was not radioactive. The possibility for radioactive contamination of the water on the cooling tower side is very remote. First a breach would have to occur in the heat exchanger, but with the cooling tower water side operating at a higher pressure than the pool side, water would flow from the cooling tower towards the pool. Hence, although the possibility for having any radioactive contamination in the cooling tower water is very unlikely, the water in the cooling tower will be monitored as good engineering practice.

\section{Cooling Tower Water Chemistry}

The pool water that cools the reactor is continually cycled through resin beds to remove any contamination or impurities. However, this is not true for the cooling tower water. Since thousands of gallons of water are evaporated each day in the cooling process, removing dissolved minerals and other agents found in normal tap water would be very costly and unnecessary. Instead, the system chemistry is maintained by adding chemicals and discharging water (blow down).

Sulfuric Acid (commercial product example Nalco 2597) is used for lowering the tower water alkalinity to make the silica in the water more soluble and allow a reduction in the amount of blow down water. The water will remain basic ( $\mathrm{pH}$ of 7.2 will be maintained), and hence the acid will be fully neutralized.

Scale and corrosion are also controlled by adding phosphates and phosphonates. The orthophosphate will be maintained at $10 \mathrm{ppm}$, the phosphonate at $6 \mathrm{ppm}$. For a 15,200 $\mathrm{V} /$ day ( 4,000 gal/day) blow down rate, only one third of a pound of phosphate will be discharged per day. The other ingredients in the product example are a non-hazardous polymer and an organic tracer used to simplify water testing. Both of these will degrade. 
Bacteria and algae are controlled using an isothiazoline based biocide. It is added at a rate of about one half of a gallon per week to the system. Most of the product is consumed during contact with micro-organisms. The small amount that remains, approximately $0.02 \mathrm{~kg},(0.05$ $16 \mathrm{~m}$ ) degrades to harmless byproducts within 18 hours.

This chemistry control for cooling tower systems is accepted worldwide. None of the chemicals involved pose a risk to the users or the environment.

\subsubsection{HCF Operations}

In the normal operations section which follows, the expected operations (i.e., work processes) within the HCF are generally described along with personnel requirements and the anticipated time necessary to complete each operation.

Activities associated with ${ }^{99}$ Mo processing include preparation of chemical reagents used in ${ }^{99}$ Mo extraction, precipitation, and purification; and QAQC testing of the final product from each target. There are a number of confinement systems that would be used during normal operations. These systems include the SCBs, and, in the Room 106 laboratory, glove boxes and a fume hood. The glove boxes may be operated with an argon atmosphere to eliminate or minimize the possibility of a reaction of water vapor or oxygen and sensitive materials. The fume hood in Room 106 is a standard chemical hood with a prefilter/HEPA filter system. The blower provides exhaust air to the Area V stack system.

The HCF ventilation zones with their corresponding air flow patterns and filtration systems are shown in Figure 4-3. Differential air pressure is currently maintained between various regions within the hot cell to ensure air flow always occurs from a higher zone designation (higher pressure) to a lower zone designation (lower pressure). Zone 1 is the inside of the dedicated processing boxes; Zone $2 \mathrm{~A}$ is the region between the shielding walls, Zone 2 includes the remaining region inside the airlock located at the entrance ramp; and Zone 3 includes the airlock, west manipulator bay, changing room and scanning electron microscope areas. As part of the facility modifications, the ventilation system would be re-designed to ensure that there would be no activity buildup in areas not protected by radiation shielding.

\subsection{HCF Radiological Impacts}

All HCF facility modifications would be engineered to meet the $500 \mathrm{mrem} / \mathrm{yr}$ dose limit. HCF operations would comply with the dose limit structure in the administrative procedures and also work closely with the SNLINM ALARA Committee to ensure that operations have been stringently reviewed to assure compliance with the regulations and ALARA.

\section{Target Transfer to HCF}

A shielded transfer cask would be used for the transfer of irradiated targets from the GIF pool inside the ACRR facility to Zone 2A of the HCF. Figure 4-4 shows the expected dose rates $1 \mathrm{~m}$ $(3.3 \mathrm{ft})$ from the centerline of the transfer cask as a function of the shielding thickness. For a $16-\mathrm{cm}$ (6.3 in) thick depleted uranium cask, an irradiated target with a 6-hour decay would produce a dose rate of $3 \mathrm{mrem} / \mathrm{hr}$ at 1 meter from the centerline of the cask. A two-person team would conduct the transfer of irradiated targets from the GIF pool to the HCF. If the same 
team members were in direct contact with the transport cask every day, each person could

Figure 4-3. HCF Ventilation Zones
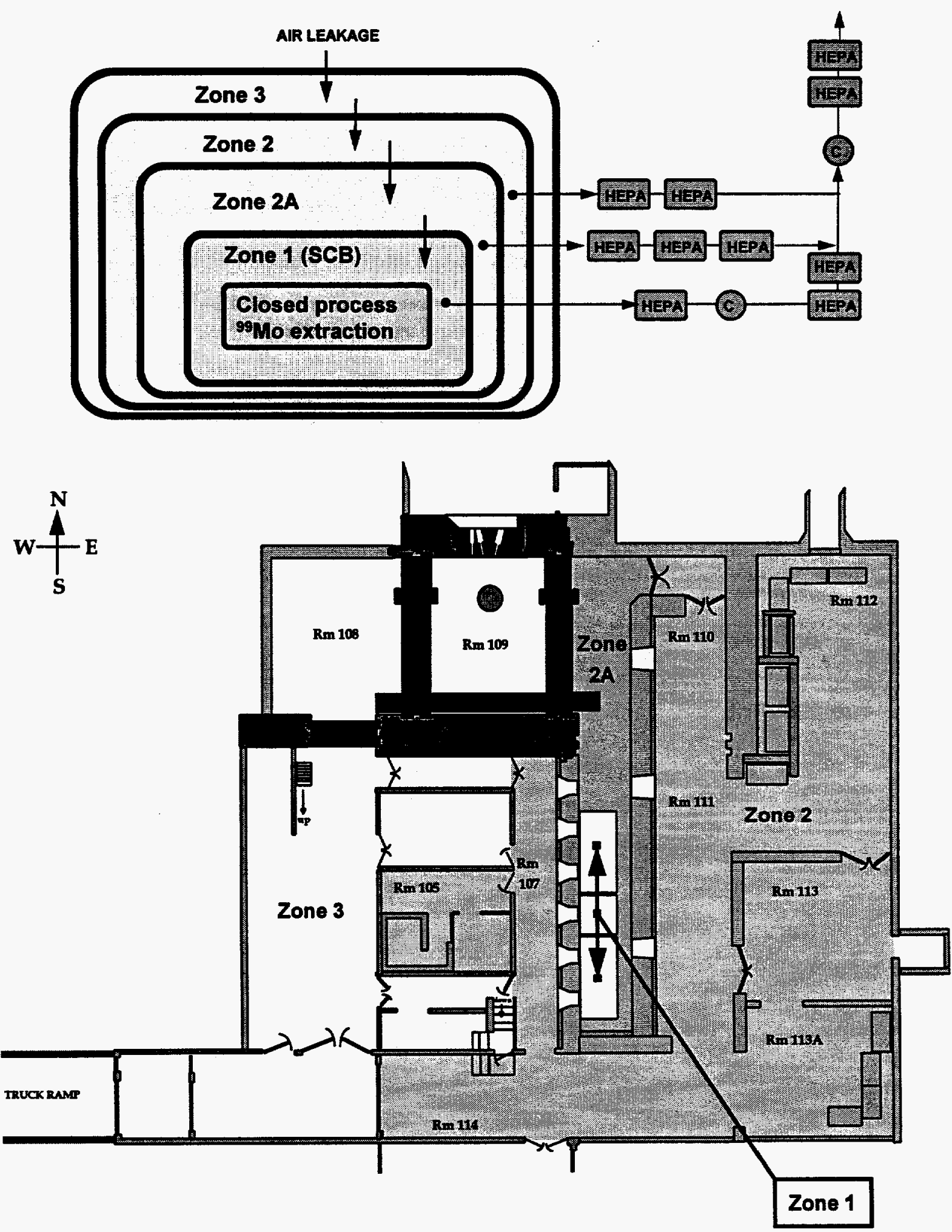
Figure 4-4. Dose Rate as a Function of Shield Thickness for an Irradiated Target Loaded in the Transfer Cask

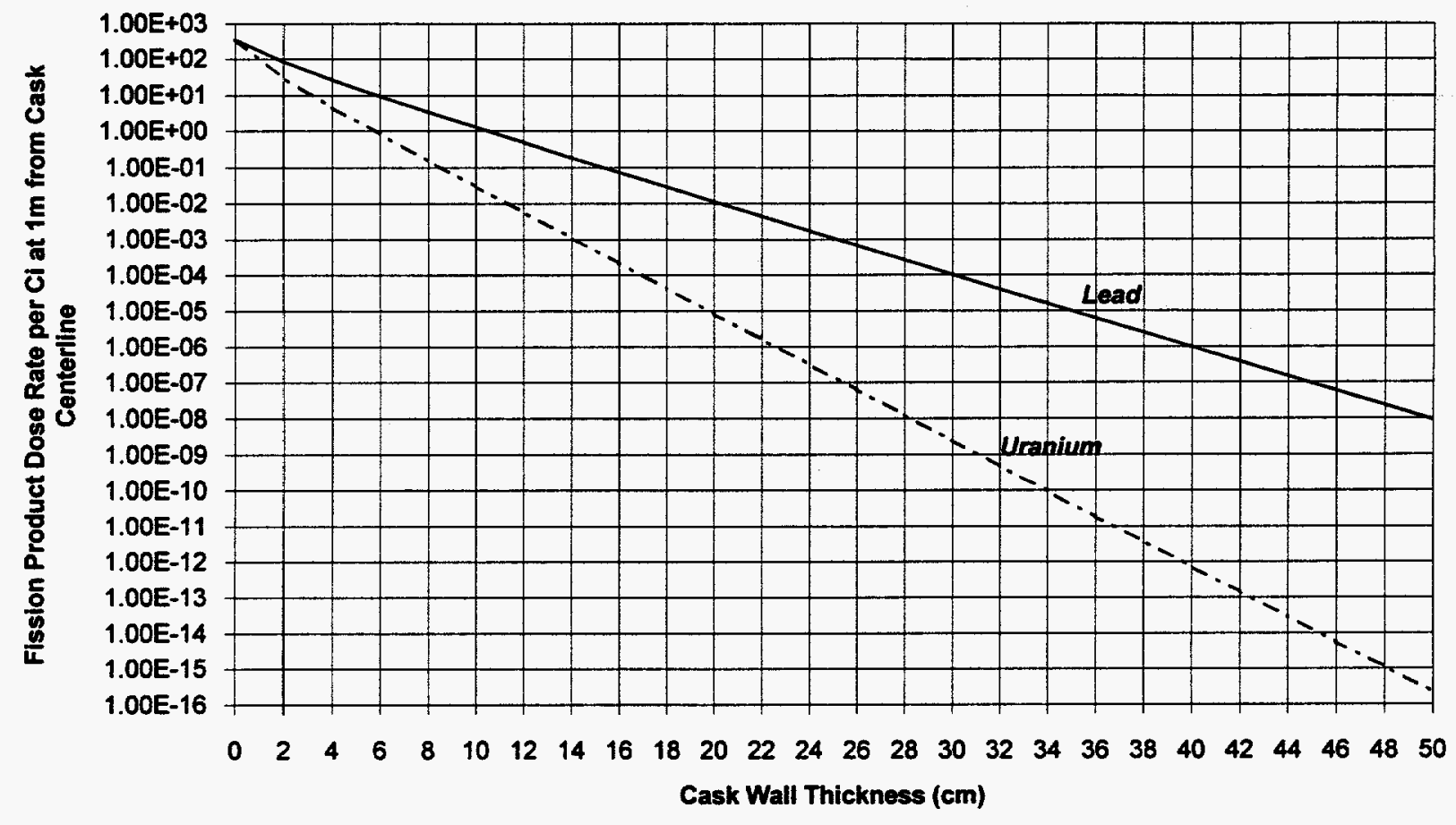


receive more than the 500 mrem per year dose allowed by the SNL administrative dose control limit from this single operation. However, several teams would be used as a normal part of the operations plan to control individual doses. A maximum of three teams would be needed for transfer of enough irradiated targets to produce 200 percent of the current North American demand for ${ }^{99} \mathrm{Mo}$. It is estimated that the rotation of teams would reduce exposure over a year to approximately 325 mrem per person for this task. Hence, the total worker dose would be bounded by approximately 2 person-rem ( 6 × 0.325 rem [325 mrem] per person).

Direct worker exposure to radiation would be reduced once the transfer cask is inside the shielded Zone 2A of the HCF. There would be no impact to the general population as a result of normal target transfer operations.

\section{Normal Operations - Exposure to Workers}

Operations in addition to target transfer that could have radiological impact are listed in Table 4-6. Estimated worker doses for HCF activities with the potential for radiation exposure are summarized in Table 4-7.

\section{Normal Operations - Off Site Dose Estimates}

Under normal operations, the only radioactive discharge to the environment would be the noble gases krypton and xenon. In addition, any noble gas precursors such as iodine and bromine released from the process line would either remain within the box or be trapped in the charcoal filters, but would eventually decay to a noble gas which would then escape. Estimated maximum annual doses (200\% production, 2080 targets/yr) at $300 \mathrm{~m}$ (984 ft), $1610 \mathrm{~m}$ (1 mi), $3000 \mathrm{~m}(1.9 \mathrm{mi}), 6000 \mathrm{~m}(3.7 \mathrm{mi})$ and $20,000 \mathrm{~m}(12.4 \mathrm{mi})$ from atmospheric radionuclide releases during normal HCF ${ }^{99}$ Mo processing are presented in Table 4-8. Doses were calculated assuming a 6-hour interval between the end of target irradiation and the start of target processing. The following additional assumptions were also applied:

- The target has been irradiated at approximately $21 \mathrm{~kW}$ for 7 days.

- The extraction of nobles and halogens occurs after 6 hours and the purification process is complete 8 hours later.

- 5 percent of the nobles and halogens initially present are not extracted by the cold trap. This is a very conservative number because the actual amount present after extraction would likely be less than 1 percent.

- 0.1 percent of the nobles and halogens are estimated to be in the piping connecting the cold trap and the target. These would be released into the SCB (and ultimately the atmosphere through the ventilation system) when the sealed cold trap is disconnected from the sealed target.

- The 0.1 percent of halogens released into the SCB are not cleaned up and eventually decay into krypton and xenon that is released into the atmosphere. 
Table 4-6. Potential Radiological Hazards Associated with Normal HCF Operations

\begin{tabular}{|c|c|}
\hline Potential Hazard & Description of Operation \\
\hline Direct exposure to radiation & $\begin{array}{l}\text { - Loading transfer cask into first process } \\
\text { SCB } \\
\text { - Transfer of QAVQC sample to lab } \\
\text { - } \text { QAVQC testing } \\
\text { - Transfer of product to shipping }\end{array}$ \\
\hline $\begin{array}{l}\text { Release of radioactive material to the } \\
\text { ventilation system }\end{array}$ & $\begin{array}{l}\text { Valve movement to separate target and } \\
\text { cold trap ( } \leq 0.1 \% \text { fission gases lost) } \\
\text { - }{ }^{99} \text { Mo processing steps }\end{array}$ \\
\hline $\begin{array}{l}\text { Gradual decay of } \mathrm{I}, \mathrm{Br} \text { in charcoal filters and } \\
\mathrm{SCB} \text { to } \mathrm{Kr}, \mathrm{Xe} \text {. Nobles released through } \\
\text { ventilation system }\end{array}$ & $\begin{array}{l}\text { Valve movements to separate target and } \\
\text { cold trap ( } \leq 0.1 \% \text { halogens released) } \\
\text { - }{ }^{99} \text { Mo processing steps }\end{array}$ \\
\hline
\end{tabular}

Table 4-7. Estimated Dose Rates and Occupational Exposures for Continuous HCF Operation and $200 \%{ }^{99}$ Mo Production*

\begin{tabular}{|l|c|c|c|c|}
\hline Function & $\begin{array}{c}\text { Est'd Dose Rate } \\
\text { (mrem/hr) }\end{array}$ & $\begin{array}{c}\text { Total Time in } \\
\text { Exposure Field }\end{array}$ & $\begin{array}{c}\text { Required } \\
\text { Personnel for All } \\
\text { Shifts }\end{array}$ & $\begin{array}{c}\text { Est'd } \\
\text { Dose/Worker } \\
\text { (mrem/yr) }\end{array}$ \\
\hline $\begin{array}{l}\text { Move targets into } \\
\text { SCB }\end{array}$ & 10 & $0.15 \mathrm{hr} / \mathrm{d}, 5 \mathrm{~d} / \mathrm{wk}$ & 6 & 325 \\
\hline Processing in HCF & $<0.25$ & $10 \mathrm{hr} / \mathrm{day}, 5 \mathrm{~d} / \mathrm{wk}$ & 27 & 3 \\
\hline $\begin{array}{l}\text { Sample transport } \\
\text { to QC lab }\end{array}$ & 1 & $0.15 \mathrm{hr} / \mathrm{d}, 5 \mathrm{~d} / \mathrm{wk}$ & 300 \\
\hline QC testing & 1 & $1 \mathrm{hr} / \mathrm{d}, 5 \mathrm{~d} / \mathrm{wk}$ & 3 & 65 \\
\hline $\begin{array}{l}\text { Product transfer to } \\
\text { shipping }\end{array}$ & 10 & $0.33 \mathrm{hr} / \mathrm{d}, 5 \mathrm{~d} / \mathrm{wk}$ & 6 & 260 \\
\hline
\end{tabular}

* $200 \%$ of North American demand would require irradiation and processing of up to 2080 targets per year (40 targets per week).

Table 4-8. Estimated Annual Doses for Normal HCF Operations at $200 \%$ of Production (2080 targets/yr)

\begin{tabular}{|c|c|c|c|c|c|}
\hline $\begin{array}{c}\text { Hrs After } \\
\text { Irradiation }\end{array}$ & \multicolumn{5}{|c|}{ Maximum Individual Dose (mrem) } \\
\hline & $300 \mathrm{~m}$ & $1610 \mathrm{~m}$ & $3000 \mathrm{~m}$ & $6000 \mathrm{~m}$ & $\mathbf{2 0 , 0 0 0} \mathbf{~ m}$ \\
\hline $6^{*}$ & 10 & 3.5 & 2.1 & 0.9 & 0.3 \\
\hline
\end{tabular}

*At 100 percent production, doses would be one-half of those reported. For example, at $6000 \mathrm{~m}$ (location of closest residents) the annual dose would be a maximum of $0.5 \mathrm{mrem}$. 
- 50 percent of nobles and halogens remaining in the process liquid at six-hours after irradiation are released into the ventilation system. This is very conservative since the sealed process liquid containers should release a maximum of only 1 percent.

- Conservatively assume that there exists only a 90 percent efficiency for each charcoal filtration exhaust stage in a 3-stage filter system. Since 5 percent of the total halogen inventory is assumed to remain with the process liquid, then only 0.0025 percent of the target halogen inventory would escape to the environment.

Appendix $G$ provides a detailed description of the model and data used to estimate potential normal radionuclide releases. The doses presented here are expected to overestimate the actual doses by about a factor of 50 to 250 , due to the low estimate of cold trap extraction efficiency and retention in process solution containers. It is anticipated that, during the initial process equipment implementations, design features would be introduced which would minimize release to the environment. For example, additional charcoal filters could be added to the HCF ventilation system to minimize any release of iodine and bromine. All releases would also be continuously monitored to determine releases from operations and would be strictly controlled. It is also anticipated that, with operating experience, experience-based process design improvements would be implemented to further reduce emissions to levels as low as reasonably achievable.

\section{Anticipated Operational Occurrences - Off-Site Dose Estimates}

Table 4-9 summarizes the estimated doses for the anticipated SCB spill scenarios discussed in Section 2.1.2.5. At an estimated maximum probability of occurrence of once per year, the event with the highest release, loss of all cold trap nobles and halogens, would increase the annual dose shown in Table 4-8 by about 2 percent. The anticipated spill scenarios would have minimal impact on the general public and no anticipated impact on workers.

The risks associated with normal HCF processing of ${ }^{99} \mathrm{Mo}$ are summarized in Table 4-10. Data incorporate all of the assumptions used to generate the dose data for a processing rate of 2080 targets/yr. As a basis of comparison, total population dose in the Albuquerque metro area during 1993 from natural background radiation was 57,000 person-rem (Culp et al, 1993b).

\subsubsection{Cumulative ACRR and HCF Emissions}

The medical isotope production activities at SNL/NM involving the ACRR and HCF would result in radioactive emissions simultaneously from both facilities. The impacts associated with the cumulative emissions from the ACRR and HCF are presented in Tables 4-11 and 4-12.

SEN-35-91 states that "the risk to the population in the area of a DOE nuclear facility for cancer fatalities that might result from operations should not exceed one-tenth of one percent $(0.1 \%)$ of the sum of all cancer fatality risks resulting from all other causes. For evaluation purposes, individuals are assumed to be located within 10 miles of the site boundary." (DOE, 1991). In order to determine if ${ }^{99} \mathrm{Mo}$ production would meet this requirement, it is necessary to consider the average annual cancer fatality rate for the Albuquerque metropolitan area. According to the University of New Mexico School of Medicine, New Mexico Tumor Registry, the annual death rate from cancer in Bernalillo county is 150 deaths per 100,000 persons, and has been at this level for more than 30 years (Key, 1995). Total population within a $16 \mathrm{~km}(10 \mathrm{mi})$ radius of the 
Table 4-9. Estimated Individual Doses for HCF Incidents

\begin{tabular}{|l|c|c|c|c|c|}
\hline \multirow{2}{*}{ Incident } & \multicolumn{5}{|c|}{ Dose (mrem) } \\
\cline { 2 - 6 } & $300 \mathrm{~m}$ & $1610 \mathrm{~m}$ & $3000 \mathrm{~m}$ & $6000 \mathrm{~m}$ & $20,000 \mathrm{~m}$ \\
\hline $\begin{array}{l}\text { Target spill, all nobles and } \\
\text { halogens released 6 hrs } \\
\text { after irradiation }\end{array}$ & 0.148 & 0.0523 & 0.034 & 0.015 & 0.0024 \\
\hline $\begin{array}{l}\text { Cold trap release of } \\
\text { nobles and halogens from } \\
2 \text { targets, processing } \\
\text { starts } 6 \text { hrs after } \\
\text { irradiation }\end{array}$ & 0.28 & 0.099 & 0.064 & 0.028 & 0.0046 \\
\hline $\begin{array}{l}\text { Process solution spill, 5\% } \\
\text { of nobles and halogens } \\
\text { released 6 hrs after } \\
\text { irradiation }\end{array}$ & 0.0074 & 0.00262 & 0.00088 & 0.00075 & 0.000122 \\
\hline $\begin{array}{l}\text { Complete release of 125!* } \\
\text { during processing }\end{array}$ & 0.07 & 0.027 & 0.022 & 0.009 & 0.0004 \\
\hline
\end{tabular}

* Does not take credit for any charcoal filter.

Table 4-10. Estimated Total Annual Population Dose and Risk Data for Normal HCF Operations, 2080 Targets/Yr Processed Per Year

\begin{tabular}{|c|c|c|c|c|}
\hline Activity & \multicolumn{2}{|c|}{$\begin{array}{c}\text { Maximum Individual } \\
\text { Dose (1610 m) }\end{array}$} & \multicolumn{2}{c|}{ Total Population } \\
\hline & $\begin{array}{c}\text { Dose } \\
\text { (rem) }\end{array}$ & LCF & $\begin{array}{c}\text { Dose } \\
\text { (person-rem) }\end{array}$ & LCF \\
\cline { 2 - 5 } $\begin{array}{c}\text { HCF Processing } \\
\text { Operations }\end{array}$ & 0.0035 & $1.75 e-6$ & 140 & 0.07 \\
\hline HCF Incidents & 0.00018 & $9 e-8$ & 7.2 & 0.0036 \\
\hline Total & 0.0037 & $1.84 e-6$ & 147 & 0.074 \\
\hline
\end{tabular}

${ }^{A}$ At 100 percent production, doses would be one-half of those reported in this table for the HCF Processing Activities.

Table 4-11. Cumulative Radiological Doses from ACRR and HCF Operations at 200 Percent Production

\begin{tabular}{|c|c|c|c|c|}
\hline \multicolumn{5}{|c|}{ Dose to Individual (mrem) } \\
\hline $300 \mathrm{~m}$ & $1610 \mathrm{~m}$ & $3000 \mathrm{~m}$ & $6000 \mathrm{~m}$ & $20,000 \mathrm{~m}$ \\
\hline 12.9 & 4.28 & 2.66 & 0.97 & 0.31 \\
\hline
\end{tabular}


Table 4-12. Cumulative Radiological Risks from ACRR and HCF Operations at 200 Percent Production

\begin{tabular}{|c|c|c|c|}
\hline \multicolumn{2}{|c|}{ Maximum Individual Public Dose } & \multicolumn{2}{c|}{ Total Population } \\
\hline Dose (mrem) & Risk (LCF) & Dose (Person-Rem) & Risk (LCF) \\
\hline 4.3 & $2.2 \mathrm{e}-6$ & 163 & 0.08 \\
\hline
\end{tabular}

HCF and ACRR is approximately 386,000 ; therefore, total annual deaths from cancers from causes other than medical isotope production would be approximately 600 . In the case of ${ }^{99} \mathrm{Mo}$ production there would be less than a one in ten chance that there would be one additional cancer fatality in addition to the 600 expected in the Albuquerque area or 0.01 percent increase in annual deaths due to cancer.

\subsubsection{Waste Management}

\section{ACRR Operations}

Spent fuel elements that would eventually be generated as a result of continuous ACRR operation would be first stored in the GIF pool. Between 9 and 30 spent fuel elements would be generated annually. After a sufficient time period ( $\sim 6$ months) to allow for decay of fission products, the spent fuel elements could be loaded into dry storage casks and stored on-site at SNLNM for final disposition.

\section{HCF Operations}

The waste management activities associated with the process wastes would be conducted in Zone $2 \mathrm{~A}$ of the HCF alongside the isotope extraction processes. These activities would include neutralization and stabilization of the liquid process wastes and the packaging and containerization of contaminated process hardware and the stabilized wastes. Once a full container of waste is accumulated, the waste container would be moved into Room 109 of the HCF for storage for at least six months prior to transportation to the LLW disposal site. All of these activities would be conducted remotely; therefore, there are no mechanical risks to facility workers. The radiological risk and the public doses calculated for the isotope extraction processes bound the risk associated with process waste management operations. In addition, since these operations would take place in the HCF, the HCF accident scenarios and facilityrelated event frequencies also apply to the process waste management operations. 


\subsubsection{Transportation Impacts}

The potential impacts associated with transporting radioactive materials related to the isotope production are estimated for the following types of shipments shown in Table 4-13.

Table 4-13. Shipment Types, Origins and Destinations

\begin{tabular}{|c|c|c|}
\hline Shipment Type & Origin & Destination \\
\hline \multirow{3}{*}{ Unirradiated Targets } & LANL & SNL/NM \\
& LANL & Ottawa, Ontario \\
& & \\
Radioisotopes & SNL/NM & Boston \\
& SNL/NM & Chicago \\
& SNL/NM & St. Louis \\
& SNL/NM & Ottawa, Ontario \\
& Ottawa, Ontario & SNL/NM \\
& SNL/NM & NTS \\
Hot Cell Facility & SNL/NM & Hanford \\
Wastes &
\end{tabular}

Incident-free impacts and accident risks are estimated for two time regimes, 1) annually, and 2) life of program (assumed to be 30 years). Appendix A, Section A.7 describes the shipping campaigns used in the analysis completed for this section.

\subsubsection{Pre-Operational Transportation Impacts}

A bounding estimate for impacts associated with the transportation of the pre-operations wastes was derived by assuming that the entire inventory of these wastes would have the same specific activity as the HCF wastes modeled in the transportation risk assessment in Section 4.1.4.4 and would be shipped in the same container as the production HCF wastes. In order to establish a very conservative estimate, the radionuclide inventory model of pre-operations HCF waste was based on the inventory of a $21 \mathrm{~kW} 7$-day irradiated target, 180 days out the of reactor. Waste shipments were modeled as B-3 waste casks containing a radionuclide inventory equivalent to 14 such targets. However, not all pre-operations waste would need B-3 packaging. This conservative assumption for HCF pre-operations construction waste over-estimates actual impacts by a factor of at least one hundred. The waste capacity of the B-3 is essentially equivalent to that of a 55-gallon drum, $0.2 \mathrm{~m}^{3}\left(7.5 \mathrm{ft}^{3}\right)$. Thus, the pre-operations waste transportation campaign was modeled as 1000 B-3 cask shipments, each shipment having an inventory equal to that of fourteen $21 \mathrm{~kW}, 7$-day irradiated targets (This inventory is documented in Appendix L.). The estimates of incident-free impacts are summarized in Table 4-14. The incident-free dose estimates are dominated by exposure to the public, particularly exposure to the public at rest stops during shipments. The total public dose estimates from the pre-production waste shipments (12 person-rems for the NTS waste disposal option, and 21 person-rem for the Hanford option) would be about one quarter of the estimated dose to the public from the production HCF waste shipments over the entire anticipated life of the program at a production level of 200 percent of the current North American demand for ${ }^{99} \mathrm{Mo}$ (see Section 4.1.4.4). 
Table 4-14. Pre-Production Hot Cell Cleanup Waste Shipment Impacts

\begin{tabular}{|c|c|c|c|c|c|}
\hline \multicolumn{2}{|c|}{ Waste Repository Location } & \multicolumn{2}{|c|}{ NTS } & \multicolumn{2}{|c|}{ Hanford } \\
\hline \multicolumn{2}{|c|}{ Shipments } & \multicolumn{2}{|c|}{1000} & \multicolumn{2}{|c|}{1000} \\
\hline \multicolumn{2}{|c|}{ Incident-Free Impacts } & Person-Rem & LCF & Person-Rem & LCF \\
\hline \multicolumn{2}{|c|}{ Truck Crew } & 1.7 & $6.8 \mathrm{e}-04$ & 2.9 & $1.2 \mathrm{e}-03$ \\
\hline \multirow[t]{4}{*}{ Public } & Off Link & 0.098 & $4.9 e-05$ & 0.15 & $7.5 e-05$ \\
\hline & On Link & 0.90 & $4.5 e-04$ & 1.1 & $5.5 e-04$ \\
\hline & Stops & 9.6 & $4.8 e-03$ & 17.0 & $8.5 e-03$ \\
\hline & Public Total & 11.0 & $5.3 e-03$ & 18.0 & $9.1 \mathrm{e}-03$ \\
\hline \multicolumn{2}{|l|}{ Total } & 12.0 & $6.0 \mathrm{e}-03$ & 21.0 & $1.0 e-02$ \\
\hline \multicolumn{2}{|c|}{ Maximum Individual (rem) } & $1.8 \mathrm{e}-05$ & $9.0 e-09$ & $1.8 \mathrm{e}-05$ & $9.0 e-09$ \\
\hline
\end{tabular}

\subsubsection{Unirradiated Target Shipment Impacts}

Transportation impacts associated with shipments of unirradiated targets were estimated for two sets of target shipments. The first is the set of target shipments from LANL to SNL/NM to support the production of radioisotopes at SNLNM's TA-V. The second is the set of target shipments from LANL to Ontario, Canada, to support the production of radioisotopes at Nordion in Chalk River, Ontario. Shipment of unirradiated targets to SNLINM were modeled as exclusive-use truck shipments where a single package of 24 targets would be shipped per truck. Shipments to Nordion were modeled as two-stage shipments - exclusive-use shipments from LANL to Albuquerque International Airport (AIA), and then exclusive-use air cargo from AIA to Ottawa, Ontario.

Tables 4-15 and 4-16 show transportation dose estimates for various population groups. For shipments to SNL/NM the dose to the public (persons sharing the route with the shipments and living along the route), $1.9 \mathrm{e}-02$ person-rem/yr, dominates the total dose estimate of $2.5 \mathrm{e}-02$ person-rem/yr. The remaining dose is attributed to the truck crew. No worker dose was estimated for the handling of the target packages during loading and unloading. Worker doses associated with the loading and unloading of the unirradiated targets was incorporated into the impact assessment of the LANL target production operations and the SNLNM ACRR operations. For shipments to Ottawa, Ontario, the total dose estimate of $6.3 \mathrm{e}-02$ person-rem/yr is evenly distributed among crew, air cargo handlers, and the public. The dose estimates for public are the same as for the shipments from LANL to SNLNM since the public would receive no dose during air cargo operations. The crew dose for shipments to Ottawa included both the truck crew dose and the aircraft crew.

An alternative to fabricating the targets at LANL would be to fabricate the targets at Babcock and Wilcox in Lynchburg, Virginia. The targets could be transported directly from Lynchburg to 
Table 4-15. Incident-Free Radiological Transportation Impacts Unirradiated Targets Shipped to SNLNM from LANL

\begin{tabular}{|c|c|c|c|c|c|c|}
\hline \multicolumn{7}{|c|}{ Annual Impacts } \\
\hline Market Share & \multicolumn{2}{|c|}{30 percent } & \multicolumn{2}{|c|}{100 percent } & \multicolumn{2}{|c|}{200 percent } \\
\hline Shipments/yr & \multicolumn{2}{|c|}{13} & \multicolumn{2}{|c|}{44} & \multicolumn{2}{|c|}{87} \\
\hline Impact & $\begin{array}{c}\text { Person- } \\
\text { Rem }\end{array}$ & LCF & $\begin{array}{c}\text { Person- } \\
\text { Rem } \\
\end{array}$ & LCF & $\begin{array}{c}\text { Person- } \\
\text { Rem }\end{array}$ & LCF \\
\hline Crew & $9.0 e-04$ & $3.5 e-07$ & $3.0 e-03$ & $1.2 e-06$ & $6.0 e-03$ & $2.4 \theta-06$ \\
\hline Workers & 0.0 & 0.0 & 0.0 & 0.0 & 0.0 & 0.0 \\
\hline Public & $2.8 \mathrm{e}-03$ & $1.4 e-06$ & $9.6 \mathrm{e}-03$ & $4.8 e-06$ & $1.9 \mathrm{e}-02$ & $9.5 e-06$ \\
\hline Total & $3.7 e-03$ & $1.8 e-06$ & $1.3 e-02$ & $6.0 e-06$ & $2.5 e-02$ & $1.2 e-05$ \\
\hline Maximum Individual (rem) & $3.1 e-08$ & $1.6 e-11$ & $1.1 e-07$ & $5.3 e-11$ & $2.1 e-07$ & $1.0 \mathrm{e}-10$ \\
\hline \multicolumn{7}{|c|}{ Total Life of Program Impacts (30 years) } \\
\hline Market Share & \multicolumn{2}{|c|}{30 percent } & \multicolumn{2}{|c|}{100 percent } & \multicolumn{2}{|c|}{200 percent } \\
\hline Impact & $\begin{array}{c}\text { Person- } \\
\text { Rem }\end{array}$ & LCF & $\begin{array}{c}\text { Person- } \\
\text { Rem }\end{array}$ & LCF & $\begin{array}{c}\text { Person- } \\
\text { Rem }\end{array}$ & LCF \\
\hline Crew & $2.7 e-02$ & $1.1 e-05$ & $9.1 \mathrm{e}-02$ & $3.6 e-05$ & $1.8 e-01$ & $7.2 e-05$ \\
\hline Workers & 0.0 & 0.0 & 0.0 & 0.0 & 0.0 & 0.0 \\
\hline Public & $8.5 e-02$ & $4.3 e-05$ & 2.9e-01 & $1.4 \mathrm{e}-04$ & $5.7 e-01$ & $2.9 \mathrm{e}-04$ \\
\hline Total & $1.1 \mathrm{e}-01$ & $5.3 e-05$ & $3.8 \mathrm{e}-01$ & $1.8 \mathrm{e}-04$ & $7.5 e-01$ & $3.6 e-04$ \\
\hline Maximum Individual (rem) & $9.4 e-07$ & $4.7 e-10$ & $3.2 e-06$ & $1.6 e-09$ & $6.3 e-06$ & $3.1 e-09$ \\
\hline
\end{tabular}

Table 4-16. Incident-Free Radiological Transportation Impacts Unirradiated Targets Shipped to Ottawa (Combination of Truck and Air Shipment)

\begin{tabular}{|c|c|c|c|c|c|c|}
\hline \multicolumn{7}{|c|}{ Annual Impacts } \\
\hline Market Share & \multicolumn{2}{|c|}{30 percent } & \multicolumn{2}{|c|}{100 percent } & \multicolumn{2}{|c|}{200 percent } \\
\hline Shipments/yr & \multicolumn{2}{|c|}{13} & \multicolumn{2}{|c|}{44} & \multicolumn{2}{|c|}{87} \\
\hline Impact & $\begin{array}{l}\text { Person- } \\
\text { Rem }\end{array}$ & LCF & $\begin{array}{c}\text { Person- } \\
\text { Rem }\end{array}$ & LCF & $\begin{array}{c}\text { Person- } \\
\text { Rem }\end{array}$ & LCF \\
\hline Crew & $2.5 e-03$ & $1.0 \mathrm{e}-06$ & $8.5 e-03$ & $3.4 e-06$ & $1.7 e-02$ & $6.8 \mathrm{e}-06$ \\
\hline Workers & $4.0 \mathrm{e}-03$ & $1.6 \mathrm{e}-06$ & $1.4 \mathrm{e}-02$ & $5.5 e-06$ & $2.7 e-02$ & $1.1 \mathrm{e}-05$ \\
\hline Public & $2.8 \mathrm{e}-03$ & $1.4 e-06$ & $9.6 e-03$ & $4.8 e-06$ & $1.9 e-02$ & $9.5 e-06$ \\
\hline Total & $9.4 e-03$ & $4.0 e-06$ & $3.2 e-02$ & $1.4 e-05$ & $6.3 e-02$ & $2.7 e-05$ \\
\hline Maximum Individual (rem) & $3.2 \mathrm{e}-08$ & $1.6 \mathrm{e}-11$ & $1.1 \mathrm{e}-07$ & $5.3 e-11$ & $2.1 e-07$ & $1.0 e-10$ \\
\hline \multicolumn{7}{|c|}{ Total Life of Program Impacts ( 30 years) } \\
\hline Market Share & \multicolumn{2}{|c|}{30 percent } & \multicolumn{2}{|c|}{100 percent } & \multicolumn{2}{|c|}{200 percent } \\
\hline Impact & $\begin{array}{c}\text { Person- } \\
\text { Rem }\end{array}$ & LCF & $\begin{array}{c}\text { Person- } \\
\text { Rem }\end{array}$ & LCF & $\begin{array}{l}\text { Person- } \\
\text { Rem }\end{array}$ & LCF \\
\hline Crew & $7.6 \mathrm{e}-02$ & $3.0 e-05$ & $2.6 e-01$ & $1.0 e-04$ & $5.1 e-01$ & $2.0 e-04$ \\
\hline Workers & $1.2 \mathrm{e}-01$ & $4.8 e-05$ & 4.1e-01 & $1.6 e-04$ & $8.1 \mathrm{e}-01$ & $3.2 \mathrm{e}-04$ \\
\hline Public & $8.5 e-02$ & $4.3 e-05$ & $2.9 e-01$ & $1.4 \mathrm{e}-04$ & $5.7 e-01$ & $2.9 e-04$ \\
\hline Total & $2.8 \mathrm{e}-01$ & $1.2 e-04$ & $9.5 e-01$ & $4.1 \mathrm{e}-04$ & $1.9 e+00$ & $8.1 e-04$ \\
\hline Maximum Individual (rem) & $9.4 e-07$ & $4.7 e-10$ & $3.2 e-06$ & $1.6 e-09$ & $6.3 e-06$ & $3.1 \mathrm{e}-09$ \\
\hline
\end{tabular}


Albuquerque via exclusive-use air cargo and then transported by truck from Albuquerque International Airport to SNLNM TA-V. Table 4-17 shows the incident-free transportation impacts associated with this concept. However, the targets could also be shipped from Lynchburg to SNL/NM by truck. Transportation impacts associated with truck shipments of unirradiated targets from Lynchburg, Va. to SNL/NM are shown in Table 4-18.

Table 4-17. Incident-Free Radiological Transportation Impacts Unirradiated Targets Shipped From Lynchburg, Va. to SNLINM Via Air-Cargo

\begin{tabular}{|c|c|c|c|c|c|c|}
\hline \multicolumn{7}{|c|}{ Annual Impacts } \\
\hline Market Share & \multicolumn{2}{|c|}{30 percent } & \multicolumn{2}{|c|}{100 percent } & \multicolumn{2}{|c|}{200 percent } \\
\hline Shipments/yr & \multicolumn{2}{|c|}{13} & \multicolumn{2}{|c|}{44} & \multicolumn{2}{|c|}{87} \\
\hline Impact & $\begin{array}{l}\text { Person- } \\
\text { Rem }\end{array}$ & LCF & $\begin{array}{c}\text { Person- } \\
\text { Rem }\end{array}$ & L.CF & $\begin{array}{c}\text { Person- } \\
\text { Rem }\end{array}$ & LCF \\
\hline Crew & $1.7 e-03$ & $6.7 e-07$ & $5.6 e-03$ & $2.3 e-06$ & $1.1 e-02$ & $4.5 e-06$ \\
\hline Workers & $4.0 \mathrm{e}-03$ & $1.6 e-06$ & $2.9 \mathrm{e}-04$ & $1.4 \mathrm{e}-07$ & $2.7 e-02$ & $1.1 \mathrm{e}-05$ \\
\hline Public & $7.0 e-04$ & $3.5 e-07$ & $2.4 e-03$ & $1.2 e-06$ & $4.7 e-03$ & $2.3 e-06$ \\
\hline Total & $6.4 e-03$ & $2.6 e-06$ & $2.2 e-02$ & $8.9 e-06$ & $4.3 e-02$ & $1.8 e-05$ \\
\hline Maximum Individual (rem) & $3.1 e-08$ & $1.6 \mathrm{e}-11$ & $1.1 \mathrm{e}-07$ & $5.3 e-11$ & $2.1 e-07$ & $1.0 e-10$ \\
\hline \multicolumn{7}{|c|}{ Life of Program Impacts ( 30 years) } \\
\hline Market Share & \multicolumn{2}{|c|}{30 percent } & \multicolumn{2}{|c|}{100 percent } & \multicolumn{2}{|c|}{200 percent } \\
\hline Impact & $\begin{array}{c}\text { Person- } \\
\text { Rem }\end{array}$ & LCF & $\begin{array}{l}\text { Person- } \\
\text { Rem }\end{array}$ & LCF & $\begin{array}{l}\text { Person- } \\
\text { Rem }\end{array}$ & LCF \\
\hline Crew & $5.0 e-02$ & $2.0 \mathrm{e}-06$ & $1.7 \mathrm{e}-01$ & $6.8 \mathrm{e}-05$ & $3.3 e-01$ & $1.3 \mathrm{e}-04$ \\
\hline Workers & $1.2 \mathrm{e}-01$ & $4.8 e-05$ & $4.1 \mathrm{e}-01$ & $1.6 e-04$ & $8.1 e-01$ & $3.2 \mathrm{e}-04$ \\
\hline Public & $2.1 e-02$ & $1.0 \mathrm{e}-05$ & $7.1 \mathrm{e}-02$ & $3.5 e-05$ & $1.4 e-01$ & $7.0 \mathrm{e}-05$ \\
\hline Total & $1.9 \mathrm{e}-01$ & $7.9 \mathrm{e}-05$ & $6.5 e-01$ & $2.7 e-04$ & $1.3 e+00$ & $5.3 e-04$ \\
\hline Maximum Individual (rem) & $9.4 e-07$ & $4.7 e-10$ & $3.2 e-06$ & $1.6 e-09$ & $6.3 e-06$ & $3.1 e-09$ \\
\hline
\end{tabular}

\subsubsection{Isotope Product Shipment Impacts}

\subsection{Isotope Product Shipments Associated With Full Purification Of Isotopes At SNLNM}

Table 4-19 shows the incident-free transportation impact estimates of shipping the fully purified isotope products from SNL/NM to three locations, Boston, Chicago, and Saint Louis. In the transportation model it was assumed that each package of ${ }^{99} \mathrm{Mo},{ }^{133} \mathrm{Xe},{ }^{131} \mathrm{I}$, and ${ }^{125} \mathrm{I}$ was shipped individually with one third of the packages shipped to each of the three locations. For incident-free analysis there is minimal impact on dose estimates whether packages are shipped individually or together, since the impacts from shipping each package would be assessed regardless of the configuration of multiple package shipments. In fact, this approach does not account for possible radiation shielding from packages placed in close proximity to each other.

Two different worker doses were estimated for isotope product shipments: 1) dose to handlers and 2) dose to conveyance crew members. The maximum exposure for a package handler involved in transporting radioactive material packages associated with the proposed production is predicted to occur with air cargo handlers. The dose would result from the loading, inter-flight transfer, and unloading of isotope product packages during air transport. The annual worker dose estimate of 56 person-rem would be largely attributable to the handling of the ${ }^{99}$ Mo packages 
Table 4-18. Incident-Free Radiological Transport Impacts Unirradiated Targets Shipped From Lynchburg, VA to SNLINM Via Truck

\begin{tabular}{|c|c|c|c|c|c|c|}
\hline \multicolumn{7}{|c|}{ Annual Impacts } \\
\hline Market Share & \multicolumn{2}{|c|}{30 percent } & \multicolumn{2}{|c|}{100 percent } & \multicolumn{2}{|c|}{200 percent } \\
\hline Shipments/yr & \multicolumn{2}{|c|}{13} & \multicolumn{2}{|c|}{44} & \multicolumn{2}{|c|}{87} \\
\hline Impact & $\begin{array}{c}\text { Person- } \\
\text { Rem }\end{array}$ & LCF & $\begin{array}{c}\text { Person- } \\
\text { Rem }\end{array}$ & LCF & $\begin{array}{c}\text { Person- } \\
\text { Rem }\end{array}$ & LCF \\
\hline Crew & $1.2 \mathrm{e}-02$ & $4.6 e-06$ & $3.9 e-02$ & $1.6 \mathrm{e}-05$ & $7.7 e-02$ & $3.1 e-05$ \\
\hline Workers & 0.0 & 0.0 & 0.0 & 0.0 & 0.0 & 0.0 \\
\hline Public & $3.4 \mathrm{e}-02$ & $1.7 e-05$ & $1.2 e-01$ & $5.8 e-05$ & $2.3 e-01$ & $1.1 e-04$ \\
\hline Total & $4.6 \mathrm{e}-02$ & $2.2 e-05$ & $1.5 e-01$ & $7.4 e-05$ & $3.1 e-01$ & $1.5 e-04$ \\
\hline Maximum Individual (rem) & $3.1 \mathrm{e}-08$ & $1.6 \mathrm{e}-11$ & $1.1 \mathrm{e}-07$ & $5.3 e-11$ & $2.1 e-07$ & $1.0 \mathrm{e}-10$ \\
\hline \multicolumn{7}{|c|}{ Life of Program Impacts ( 30 years) } \\
\hline Market Share & \multicolumn{2}{|c|}{30 percent } & \multicolumn{2}{|c|}{100 percent } & \multicolumn{2}{|c|}{200 percent } \\
\hline Impact & $\begin{array}{c}\text { Person- } \\
\text { Rem }\end{array}$ & LCF & $\begin{array}{c}\text { Person- } \\
\text { Rem } \\
\end{array}$ & LCF & $\begin{array}{c}\text { Person- } \\
\text { Rem } \\
\end{array}$ & LCF \\
\hline Crew & $3.5 e-01$ & $1.4 \mathrm{e}-04$ & $1.2 e+00$ & $4.7 e-04$ & $2.3 e+00$ & $9.3 e-04$ \\
\hline Workers & 0.0 & 0.0 & 0.0 & 0.0 & 0.0 & 0.0 \\
\hline Public & $1.0 e-00$ & $5.10-04$ & $3.5 \mathrm{e}+00$ & $1.7 \mathrm{e}-03$ & $6.9 e+00$ & $3.4 e-03$ \\
\hline Total & $1.4 e+00$ & $6.5 \mathrm{e}-04$ & $4.6 e+00$ & $2.2 e-03$ & $9.2 e+00$ & $4.4 e-03$ \\
\hline Maximum Individual (rem) & $9.4 e-07$ & $4.7 e-10$ & $3.2 \mathrm{e}-06$ & $1.6 e-09$ & $6.3 e-06$ & $3.1 e-09$ \\
\hline
\end{tabular}

Table 4-19. Incident-Free Radiological Transportation Impacts Isotope Product Shipments

\begin{tabular}{|c|c|c|c|c|c|c|}
\hline \multicolumn{7}{|c|}{ Annual impacts } \\
\hline Market Share & \multicolumn{2}{|c|}{30 percent } & \multicolumn{2}{|c|}{100 percent } & \multicolumn{2}{|c|}{200 percent } \\
\hline Shipments/yr & \multicolumn{2}{|c|}{967} & \multicolumn{2}{|c|}{3224} & \multicolumn{2}{|c|}{6448} \\
\hline Impact & $\begin{array}{c}\text { Person- } \\
\text { Rem } \\
\end{array}$ & LCF & $\begin{array}{c}\text { Person- } \\
\text { Rem }\end{array}$ & LCF & $\begin{array}{c}\text { Person- } \\
\text { Rem } \\
\end{array}$ & LCF \\
\hline Crew & $1.8 e+00$ & $7.4 \mathrm{e}-04$ & $6.1 \mathrm{e}+00$ & $2.5 e-03$ & $1.2 \mathrm{e}+01$ & $4.9 e-03$ \\
\hline Workers & $8.4 e+00$ & $3.4 e-03$ & $2.8 \mathrm{e}+01$ & $1.1 \mathrm{e}-02$ & $5.6 e+01$ & $2.2 e-02$ \\
\hline Public & $5.7 e-01$ & $2.7 e-04$ & $1.9 \mathrm{e}+00$ & $9.5 e-04$ & $3.8 \mathrm{e}+00$ & $1.9 e-03$ \\
\hline Total & $1.1 e+01$ & $4.4 \mathrm{e}-03$ & $3.6 \mathrm{e}+01$ & $1.5 e-02$ & $7.2 e+01$ & $2.9 e-02$ \\
\hline Maximum Individual (rem) & $2.6 e-05$ & $1.3 e-08$ & $8.6 e-05$ & $4.3 e-08$ & $1.7 e-04$ & $8.6 \mathrm{e}-08$ \\
\hline \multicolumn{7}{|c|}{ Total Life of Program Impacts ( 30 years) } \\
\hline Market Share & \multicolumn{2}{|c|}{30 percent } & \multicolumn{2}{|c|}{100 percent } & \multicolumn{2}{|c|}{200 percent } \\
\hline Impact & $\begin{array}{c}\text { Person- } \\
\text { Rem }\end{array}$ & LCF & $\begin{array}{c}\text { Person- } \\
\text { Rem }\end{array}$ & LCF & $\begin{array}{c}\text { Person- } \\
\text { Rem }\end{array}$ & LCF \\
\hline Crew & $5.5 e+01$ & $2.2 e-02$ & $1.8 e+02$ & $7.4 e-02$ & $3.7 e+02$ & $1.5 e-01$ \\
\hline Workers & $2.5 e+02$ & $1.0 \mathrm{e}-01$ & $8.4 e+02$ & $3.4 e-01$ & $1.7 e+03$ & $6.7 \mathrm{e}-01$ \\
\hline Public & $1.7 e+01$ & $8.6 e-03$ & $5.7 e+01$ & $2.9 e-02$ & $1.1 \mathrm{e}+02$ & $5.7 \mathrm{e}-02$ \\
\hline Total & $3.2 \mathrm{e}+02$ & $1.3 e-01$ & $1.1 \mathrm{e}+03$ & $4.4 e-01$ & $2.2 e+03$ & $8.8 e-01$ \\
\hline Maximum Individual (rem) & $7.7 e-04$ & $3.9 e-07$ & $2.6 \mathrm{e}-03$ & $1.3 e-06$ & $5.2 e-03$ & $2.6 e-06$ \\
\hline
\end{tabular}


during loading and unloading to and from aircraft and ground transportation. Of this total, 45 person-rem is attributable to loading, unloading, and short-term storage of isotope packages at air cargo terminals. The remaining 11 person-rems of the total worker dose estimate would be incurred predominantly by handlers at SNLNM TA-V who would load the isotope packages onto trucks for shipment to Albuquerque International Airport.

Conveyance crew members would receive a total annual dose of 12 person-rem from isotope product packages. This would be distributed between air crew ( 7 person-rem) and ground transportation crew (5 person-rem) for the shipments from SNLNM TA-V to AIA.

\subsection{Isotope Product Shipments of Unpurified ${ }^{99}$ Mo between SNL/NM and Ottawa, Canada}

\section{Transportation Shipping Model}

If unpurified ${ }^{99}$ Mo were to be shipped between SNL/NM and Ottawa instead of shipment of purified ${ }^{99}$ Mo to St. Louis, Chicago, and Boston, it would be packaged in Type B containers (such as the 20WCO and transported by air cargo carrier. The shipments of unpurified ${ }^{99}$ Mo would be essentially the same as shipments of purified ${ }^{99} \mathrm{Mo}$. Thus, the transportation model for this variation of the proposed action is almost identical to the transportation model that was used to develop the incident-free impact estimates discussed in Section 4.1.4.3.1. Certain specific features of the transportation model were adjusted to model the transportation of unpurified ${ }^{99} \mathrm{Mo}$ between Albuquerque and Ottawa. The transportation impact and risk assessment for this concept were modeled with the following important assumptions:

- The ${ }^{99}$ Mo produced from each irradiated target would be packaged in a single Type B package such as the 20WC;

- Each package of unpurified ${ }^{99} \mathrm{Mo}$ would contain a radioactive inventory that would be equivalent to the inventory of packages of purified ${ }^{99}$ Mo modeled for the isotope product shipments in section 4.1.4.3.1 (1000 Ci., which is the certification limit for the 20WC packaging, was the value used in the RADTRAN 4 analyses);

- Each package ws assumed to be shipped individually (this is consistent with the transportation analysis in Sections 4.1.4.3.1);

- The ${ }^{99}$ Mo would be shipped via an overnight air cargo express service through a central air cargo hub between Albuquerque, New Mexico and Ottawa, Ontario;

- All other shipments associated with this variation of the proposed action (i.e., unirradiated target shipments, isotope product shipments of ${ }^{133} \mathrm{Xe},{ }^{131} \mathrm{I}$, and ${ }^{125} \mathrm{I}$, and waste shipments to NTS or Hanford) would be the same as if purified ${ }^{99}$ Mo were to be shipped to Boston, Chicago, and St. Louis.

The effect of these assumptions is that the transportation impact models would be virtually the same whether the isotopes were to be purified at SNL/NM or at Nordion in Canada. The only difference would be that instead of shipping all containers of ${ }^{99} \mathrm{Mo}$ from Albuquerque to a central air cargo hub and then splitting the shipments evenly between the air cargo hub and Boston, Chicago, and St. Louis, all of the ${ }^{99} \mathrm{Mo}$ containers would be air shipped from Albuquerque to Ottawa. 


\section{Transportation Impacts}

Estimates of transportation impacts associated with shipping unpurified ${ }^{99}$ Mo from SNL/NM to Ottawa are bounded by the estimates presented in Sections 4.1.4.3.1. Indeed, the estimates for impacts are essentially the same for the two variations. For example, the annual incidentfree dose estimate for the unpurified ${ }^{99}$ Mo shipment variation is 70 person-rem ( 0.028 LCFs) for 200 percent of the market, as compared to 75 person-rem ( 0.03 LCFs) for the variation involving shipment of ${ }^{99}$ Mo product from Albuquerque to Boston, Chicago, and St. Louis (see Section 4.1.4.5, Table 4-23). The small decrease in incident-free impact estimates would be associated primarily with lower handler dose estimates. For the purified ${ }^{99}$ Mo shipments from Albuquerque to Boston, Chicago, and St. Louis, dose estimates to handler and air cargo terminal personnel were calculated for three different sets of handlers; at the origin air terminal (Albuquerque International Airport, the air cargo hub terminal, and the three destination air terminals (Boston, Chicago, and St. Louis). For the unpurified ${ }^{99}$ Mo shipments from Albuquerque to Ottawa dose estimates to handlers and air terminal personnel were calculated only for the point of origin (Albuquerque) and the air cargo hub. The handling of radioactive material packages in Canada does not fall under DOE, NRC, or Council on Environmental Quality (CEQ) regulations. Since this action would be conducted in cooperation with the Canadian government, exposure to the Canadian public and Canadian workers would be regulated by the Canadian Federal and Ontario provincial governments.

\subsubsection{Waste Shipments}

Impacts for both waste disposal options are shown in Table 4-20 (for the option of shipping the Hot Cell Facility wastes from SNL/NM to the NTS) and Table 4-21 (for the option of shipping the wastes from SNL/NM to Hanford). With the exception of the destination there would be no differences in the number and type of waste shipments for each option. The dose associated with these options would be experienced by the waste truck crews and the public living along and sharing the transportation route between SNUNM and NTS or Hanford. Worker dose estimates (for handlers of the waste packages at both SNLNM and the waste repositories) were not included in the transportation analysis. The handler doses at SNL/NM are discussed and accounted for in the waste management portion of this study, and handler doses at the repositories would be accounted for under the disposal sites' environmental documentation.

The incident-free impacts vary according to the distance over which the waste must be shipped and the potentially exposed population living along the waste transportation route modeled in the RADTRAN 4 risk assessment. Incident-free dose estimates for the Hanford option are about a factor of two higher than estimates for the NTS option. The distance covered in a representative highway route between SNL/NM and the NTS is estimated as $1423 \mathrm{~km}(882 \mathrm{mi})$, and between SNL/NM and Hanford as $2594 \mathrm{~km}$ (1608 mi). The potentially exposed population along the representative route from SNL/NM to the NTS modeled for the risk assessment is 126,000 , and for the route from SNL/NM to Hanford, the population estimate is 282,000 . The potentially exposed populations along these routes are estimated from the route distances and the appropriate population densities discussed in Appendix $L$. This information is derived using the HIGHWAY 5.0 (ORNL, 1992) code. These parameters are combined with the width of the transportation corridor in which incident-free consequences are modeled by RADTRAN 4 (Neuhauser, 1992). This width is $1610 \mathrm{~m}$ (1 mi). 
Table 4-20. Incident-Free Radiological Transportation Impacts Waste Shipments to NTS

\begin{tabular}{|c|c|c|c|c|c|c|}
\hline \multicolumn{7}{|c|}{ Annual Impacts } \\
\hline Market Share & \multicolumn{2}{|c|}{30 percent } & \multicolumn{2}{|c|}{100 percent } & \multicolumn{2}{|c|}{200 percent } \\
\hline Shipments/yr & \multicolumn{2}{|c|}{23} & \multicolumn{2}{|c|}{75} & \multicolumn{2}{|c|}{149} \\
\hline Impact & $\begin{array}{c}\text { Person- } \\
\text { Rem }\end{array}$ & LCF & $\begin{array}{c}\text { Person- } \\
\text { Rem }\end{array}$ & LCF & $\begin{array}{c}\text { Person- } \\
\text { Rem }\end{array}$ & LCF \\
\hline Crew & $3.9 e-02$ & $1.6 \mathrm{e}-05$ & $1.3 e-01$ & 5.1e-05 & $2.5 e-01$ & $1.0 \mathrm{e}-04$ \\
\hline Workers & 0.0 & 0.0 & 0.0 & 0.0 & 0.0 & 0.0 \\
\hline Public & $2.4 e-01$ & $1.2 e-04$ & $7.9 e-01$ & $4.0 e-04$ & $1.6 e+00$ & $7.9 e-04$ \\
\hline Total & $2.8 \mathrm{e}-01$ & $1.4 e-04$ & $9.2 e-01$ & $4.5 e-04$ & $1.8 \mathrm{e}+00$ & $8.9 e-04$ \\
\hline Maximum Individual (rem) & $4.1 e-07$ & $2.1 e-10$ & $1.4 e-06$ & $6.8 \mathrm{e}-10$ & $2.7 e-06$ & $1.3 e-09$ \\
\hline \multicolumn{7}{|c|}{ Total Life of Program Impacts (30 years) } \\
\hline Market Share & \multicolumn{2}{|c|}{30 percent } & \multicolumn{2}{|c|}{100 percent } & \multicolumn{2}{|c|}{200 percent } \\
\hline Impact & $\begin{array}{c}\text { Person- } \\
\text { Rem }\end{array}$ & LCF & $\begin{array}{c}\text { Person- } \\
\text { Rem }\end{array}$ & LCF & $\begin{array}{c}\text { Person- } \\
\text { Rem } \\
\end{array}$ & LCF \\
\hline Crew & $1.2 e+00$ & $4.7 e-04$ & $3.8 e+00$ & $1.5 e-03$ & $7.6 e+00$ & 3.0e-03 \\
\hline Workers & 0.0 & 0.0 & 0.0 & 0.0 & 0.0 & 0.0 \\
\hline Public & $7.3 \mathrm{e}+00$ & $3.7 e-03$ & $2.4 e+01$ & $1.2 \mathrm{e}-02$ & $4.7 e+01$ & $2.4 e-02$ \\
\hline Total & $8.5 \mathrm{e}+00$ & 4.1e-03 & $2.8 e+01$ & $1.3 \mathrm{e}-02$ & $5.5 \mathrm{e}+01$ & $2.7 e-02$ \\
\hline Maximum Individual (rem) & $1.2 e-05$ & $6.2 \mathrm{e}-09$ & 4.1e-05 & $2.0 \mathrm{e}-08$ & $8.0 e-05$ & 4.0e-08 \\
\hline
\end{tabular}

Table 4-21. Incident-Free Radiological Transportation Impacts Waste Shipments to Hanford

\begin{tabular}{|c|c|c|c|c|c|c|}
\hline \multicolumn{7}{|c|}{ Annual Impacts } \\
\hline Market Share & \multicolumn{2}{|c|}{30 percent } & \multicolumn{2}{|c|}{100 percent } & \multicolumn{2}{|c|}{200 percent } \\
\hline Shipments/yr & \multicolumn{2}{|c|}{23} & \multicolumn{2}{|c|}{75} & \multicolumn{2}{|c|}{149} \\
\hline Impact & $\begin{array}{l}\text { Person- } \\
\text { Rem }\end{array}$ & LCF & $\begin{array}{c}\text { Person- } \\
\text { Rem }\end{array}$ & LCF & $\begin{array}{c}\text { Person- } \\
\text { Rem }\end{array}$ & LCF \\
\hline Crew & $6.7 e-02$ & $2.7 e-05$ & $2.2 \mathrm{e}-01$ & $8.7 e-05$ & $4.3 e-01$ & $1.7 e-04$ \\
\hline Workers & 0.0 & 0.0 & 0.0 & 0.0 & 0.0 & 0.0 \\
\hline Public & $4.2 \mathrm{e}-01$ & $2.1 e-04$ & $1.4 e+00$ & $6.8 \mathrm{e}-04$ & $2.7 e+00$ & $1.4 \mathrm{e}-03$ \\
\hline Total & $4.9 \mathrm{e}-07$ & $2.4 e-04$ & $1.6 e+00$ & $7.7 \mathrm{e}-04$ & $3.2 e+00$ & $1.5 e-03$ \\
\hline Maximum Individual (rem) & $4.1 \mathrm{e}-07$ & $2.1 e-10$ & $1.4 \mathrm{e}-06$ & $6.8 \mathrm{e}-10$ & $2.7 \mathrm{e}-06$ & $1.3 e-09$ \\
\hline \multicolumn{7}{|c|}{ Total Life of Program Impacts ( 30 years) } \\
\hline Market Share & \multicolumn{2}{|c|}{30 percent } & \multicolumn{2}{|c|}{100 percent } & \multicolumn{2}{|c|}{200 percent } \\
\hline Impact & $\begin{array}{c}\text { Person- } \\
\text { Rem } \\
\end{array}$ & LCF & $\begin{array}{c}\text { Person- } \\
\text { Rem } \\
\end{array}$ & LCF & $\begin{array}{c}\text { Person- } \\
\text { Rem }\end{array}$ & LCF \\
\hline Crew & $2.0 \mathrm{e}+00$ & $8.0 e-04$ & $6.5 e+00$ & $2.6 e-03$ & $1.3 e+01$ & $5.2 e-03$ \\
\hline Workers & 0.0 & 0.0 & 0.0 & 0.0 & 0.0 & 0.0 \\
\hline Public & $1.3 e+01$ & $6.3 e-03$ & $4.1 \mathrm{e}+01$ & $2.1 \mathrm{e}-02$ & $8.2 e+01$ & $4.1 \mathrm{e}-02$ \\
\hline Total & $1.5 \mathrm{e}+01$ & $7.1 \mathrm{e}-03$ & $4.8 \mathrm{e}+01$ & $2.3 e-02$ & $9.5 e+01$ & $4.6 e-02$ \\
\hline Maximum Individual (rem) & $1.2 \mathrm{e}-05$ & $6.2 e-09$ & $4.1 e-05$ & $2.0 e-08$ & $8.0 e-05$ & $4.0 e-08$ \\
\hline
\end{tabular}


The largest single contributor to incident-free impacts is the exposure to members of the public sharing the transportation routes with the waste shipments, 1.6 person-rem/yr for NTS and 2.7 person-rem/yr for Hanford. The truck crews' dose would be approximately a factor of six lower, but would be distributed among a much smaller population group than the public dose.

\subsubsection{Total Radiological Impacts}

Total impacts for both options are shown in Table 4-22 (for the option of shipping the Hot Cell Facility wastes from SNL/NM to the NTS) and Table 4-23 (for the option of shipping the wastes from SNL/NM to Hanford). With the exception of the destination for the waste shipments, there are would be no differences in the shipping campaigns for each option. The estimates of impacts associated with the two options are essentially equivalent.

The incident-free impacts vary according to the distance over which the waste must be shipped and the potentially exposed population using and living along the waste transportation route modeled in the RADTRAN 4 risk assessment (see Appendix M). The dose differential associated with the option of shipping the waste to Hanford would be experienced by the waste truck crews and the public using and living along and sharing the transportation route between SNL/NM and Hanford. The impacts from the other shipments associated with the proposed production (targets and isotope products) would not be affected by the choice of a waste disposal site.

The largest single contributor to incident-free impacts is the exposure to the workers, principally due to loading and unloading isotope product packages during air shipment from Albuquerque to Boston, Chicago, and St. Louis. The next dominant impact categories are the truck and air crews. The public is the least impacted group. The dose estimates in Tables 4-22 and 4-23 represent total dose to all the persons within each risk group. Thus, for the NTS option, the annual dose estimate for the public is 5.4 person-rem distributed throughout the potentially exposed populations of 57,300 persons living along the truck route from LANL to SNLNM, 126,000 living along the waste shipment route between SNL/NM and NTS, and 23,600 living near the route for isotope product shipment between SNL/NM, TA-V, to the Albuquerque International Airport (AIA). The dominant contributor to public dose estimates is from expected doses to persons sharing the route between SNLNM, TA-V, and AIA. This annual dose is estimated at 3.3 person-rem and is largely attributable to the assumption that the traffic volume on Gibson Boulevard in Albuquerque is 2800 vehicles/ $\mathrm{hr}$ in each direction. Furthermore, each vehicle is assumed to carry two persons.

\subsubsection{Nonradiological Transportation Impacts}

The nonradiological health effects associated with transportation are estimated using the nonradiological impact modeling method discussed in Appendix $M$. The estimated number of LCFs due to diesel emissions are shown in Table 4-24.

\section{Mechanical Risk Impacts}

No mechanical risks or impacts are expected for incident-free operations. 
Table 4-22. Incident-Free Radiological Transportation Impacts (Target Shipments, Product Shipments, and All Waste Shipped to NTS)

\begin{tabular}{|c|c|c|c|c|c|c|}
\hline \multicolumn{7}{|c|}{ Annual Impacts } \\
\hline Market Share & \multicolumn{2}{|c|}{30 percent } & \multicolumn{2}{|c|}{100 percent } & \multicolumn{2}{|c|}{200 percent } \\
\hline Impact & $\begin{array}{c}\text { Person- } \\
\text { Rem }\end{array}$ & LCF & $\begin{array}{c}\text { Person- } \\
\text { Rem }\end{array}$ & LCF & $\begin{array}{c}\text { Person- } \\
\text { Rem } \\
\end{array}$ & LCF \\
\hline Crew & $1.9 e+00$ & $7.5 e-04$ & $6.3 e+00$ & $2.5 \mathrm{e}-03$ & $1.3 e+01$ & $5.0 \mathrm{e}-03$ \\
\hline Workers & $8.4 e+00$ & $3.4 e-03$ & $2.8 \mathrm{e}+01$ & $1.1 \mathrm{e}-02$ & $5.6 e+01$ & $2.2 \mathrm{e}-02$ \\
\hline Public & $8.2 \mathrm{e}-01$ & $4.1 e-04$ & $2.7 e+00$ & $1.4 \mathrm{e}-03$ & $5.4 e+00$ & $2.7 e-03$ \\
\hline Total & $1.1 \mathrm{e}+01$ & $4.5 e-03$ & $3.7 e+01$ & $1.5 e-02$ & $7.4 e+01$ & $3.0 \mathrm{e}-02$ \\
\hline Maximum Individual (rem) & $2.6 e-05$ & $1.3 e-08$ & $8.7 e-05$ & $4.4 \mathrm{e}-08$ & $1.7 \mathrm{e}-04$ & $8.7 e-08$ \\
\hline \multicolumn{7}{|c|}{ Total Life of Program Impacts (30 years) } \\
\hline Market Share & \multicolumn{2}{|c|}{30 percent } & \multicolumn{2}{|c|}{100 percent } & \multicolumn{2}{|c|}{200 percent } \\
\hline Impact & $\begin{array}{c}\text { Person- } \\
\text { Rem }\end{array}$ & LCF & $\begin{array}{c}\text { Person- } \\
\text { Rem }\end{array}$ & LCF & $\begin{array}{c}\text { Person- } \\
\text { Rem }\end{array}$ & LCF \\
\hline Crew & $5.7 e+01$ & $2.3 e-02$ & $1.9 e+02$ & $7.5 e-02$ & $3.8 \mathrm{e}+02$ & $1.5 \mathrm{e}-01$ \\
\hline Workers & $2.5 e+02$ & $1.0 \mathrm{e}-01$ & $8.4 e+02$ & $3.4 e-01$ & $1.7 e+03$ & $6.7 e-01$ \\
\hline Public & $2.5 e+01$ & $1.2 \mathrm{e}-02$ & $8.2 e+01$ & $4.1 \mathrm{e}-02$ & $1.6 e+02$ & $8.1 \mathrm{e}-02$ \\
\hline Total & $3.2 \mathrm{e}+02$ & $1.4 e-01$ & $1.1 \mathrm{e}+03$ & $4.5 e-01$ & $2.2 e+03$ & $9.0 e-01$ \\
\hline Maximum Individual (rem) & $7.9 e-04$ & $3.9 e-07$ & $2.6 \mathrm{e}-03$ & $1.3 e-06$ & $5.2 e-03$ & $2.6 e-06$ \\
\hline
\end{tabular}

Table 4-23. Incident-Free Radiological Transportation Impacts (Target Shipments, Product Shipments, and All Waste Shipped to Hanford)

\begin{tabular}{|c|c|c|c|c|c|c|}
\hline \multicolumn{7}{|c|}{ Annual Impacts } \\
\hline Market Share & \multicolumn{2}{|c|}{30 percent } & \multicolumn{2}{|c|}{100 percent } & \multicolumn{2}{|c|}{200 percent } \\
\hline Impact & $\begin{array}{c}\text { Person- } \\
\text { Rem }\end{array}$ & LCF & $\begin{array}{c}\text { Person- } \\
\text { Rem }\end{array}$ & LCF & $\begin{array}{c}\text { Person- } \\
\text { Rem } \\
\end{array}$ & LCF \\
\hline Crew & $1.9 e+00$ & $7.6 e-04$ & $6.4 \mathrm{e}+00$ & $2.5 e-03$ & $1.3 e+01$ & $5.1 e-03$ \\
\hline Workers & $8.4 e+00$ & $3.4 e-03$ & $2.8 e+01$ & $1.1 \mathrm{e}-02$ & $5.6 \mathrm{e}+01$ & $2.2 e-02$ \\
\hline Public & $1.0 e+00$ & $5.0 e-04$ & $3.3 e+00$ & $1.6 e-03$ & $6.6 e+00$ & $3.3 e-03$ \\
\hline Total & $1.1 \mathrm{e}+01$ & $4.6 e-03$ & $3.8 e+01$ & $1.5 \mathrm{e}-02$ & $7.5 e+01$ & $3.1 \mathrm{e}-02$ \\
\hline Maximum Individual (rem) & $2.6 e-05$ & $1.3 e-08$ & $8.7 e-05$ & $4.4 e-08$ & $1.7 \mathrm{e}-04$ & $8.7 e-08$ \\
\hline \multicolumn{7}{|c|}{ Total Life of Program Impacts ( 30 years) } \\
\hline Market Share & \multicolumn{2}{|c|}{30 percent } & \multicolumn{2}{|c|}{100 percent } & \multicolumn{2}{|c|}{200 percent } \\
\hline Impact & $\begin{array}{c}\text { Person- } \\
\text { Rem } \\
\end{array}$ & LCF & $\begin{array}{c}\text { Person- } \\
\text { Rem }\end{array}$ & LCF & $\begin{array}{c}\text { Person- } \\
\text { Rem } \\
\end{array}$ & LCF \\
\hline Crew & $5.7 e+01$ & $2.3 e-02$ & $1.9 e+02$ & $7.6 \mathrm{e}-02$ & $3.8 \mathrm{e}+02$ & $1.5 e-01$ \\
\hline Workers & $2.5 e+02$ & $1.0 \mathrm{e}-01$ & $8.4 e+02$ & $3.4 e-01$ & $1.7 e+03$ & $6.7 e-01$ \\
\hline Public & $3.0 e+01$ & $1.5 e-02$ & $9.9 e+01$ & $4.9 e-02$ & $2.0 e+02$ & $9.9 e-02$ \\
\hline Total & $3.4 e+02$ & $1.4 \mathrm{e}-01$ & $1.1 \mathrm{e}+03$ & $4.3 e-01$ & $2.3 e+03$ & $9.2 e-01$ \\
\hline Maximum Individual (rem) & $7.9 e-04$ & $3.9 \mathrm{e}-07$ & $2.6 e-03$ & $1.3 e-06$ & $5.2 e-03$ & $2.6 e-06$ \\
\hline
\end{tabular}


Table 4-24. Incident-Free Non-radiological Transportation Impacts (LCFs Due to Diesel Emissions)

\begin{tabular}{|l|c|c|c||c|}
\hline \multicolumn{1}{|c|}{ Shipments } & Market Share & 30 percent & 100 percent & 200 percent \\
\hline \hline \multirow{2}{*}{ Targets - SNLNM } & Annual & $2.1 \mathrm{e}-05$ & $7.0 \mathrm{e}-05$ & $1.4 \mathrm{e}-04$ \\
\cline { 2 - 5 } & Life of Program & $6.2 \mathrm{e}-04$ & $2.1 \mathrm{e}-03$ & $4.2 \mathrm{e}-03$ \\
\hline \multirow{2}{*}{ Targets - Ottawa } & Annual & $2.1 \mathrm{e}-05$ & $7.0 \mathrm{e}-05$ & $1.4 \mathrm{e}-04$ \\
\cline { 2 - 5 } & Life of Program & $6.2 \mathrm{e}-04$ & $2.1 \mathrm{e}-03$ & $4.2 \mathrm{e}-03$ \\
\hline \multirow{2}{*}{ Isotopes to Airport } & Annual & $9.1 \mathrm{e}-04$ & $3.0 \mathrm{e}-03$ & $6.1 \mathrm{e}-03$ \\
\cline { 2 - 5 } & Life of Program & $2.7 \mathrm{e}-02$ & $9.1 \mathrm{e}-02$ & 0.18 \\
\hline \hline Waste Shipments to NTS & Annual & $7.4 \mathrm{e}-05$ & $2.4 \mathrm{e}-04$ & $4.8 \mathrm{e}-04$ \\
\cline { 2 - 5 } & Life of Program & $2.2 \mathrm{e}-03$ & $7.2 \mathrm{e}-03$ & $1.4 \mathrm{e}-02$ \\
\hline \multirow{2}{*}{$\begin{array}{l}\text { Waste Shipments to } \\
\text { Hanford }\end{array}$} & Annual & $1.6 \mathrm{e}-04$ & $5.1 \mathrm{e}-04$ & $1.0 \mathrm{e}-03$ \\
\hline Total - NTS Waste & Life of Program & $4.7 \mathrm{e}-03$ & $1.5 \mathrm{e}-02$ & $3.0 \mathrm{e}-02$ \\
\hline Disposal Option & Annual & $1.0 \mathrm{e}-03$ & $3.4 \mathrm{e}-03$ & $6.8 \mathrm{e}-03$ \\
\hline $\begin{array}{l}\text { Total - Hanford Waste } \\
\text { Disposal Option }\end{array}$ & Life of Program & $3.1 \mathrm{e}-02$ & 0.10 & 0.20 \\
\hline
\end{tabular}

\subsection{Target Fabrication Site Options}

Target fabrication could occur at several altemative sites other than LANL, including SNL/NM, Oak Ridge National Laboratory, or commercial facilities such as Babcock and Wilcox located in Lynchburg, Virginia. Target fabrication at SNL/NM would reduce annual radiological exposures to the public by only 0.025 person-rem under normal operations for 200 percent production.

If targets were fabricated at sites other than LANL or SNL/NM, it is expected they would be shipped from that facility to an airport by truck followed by exclusive-use air freight transport to SNL/NM. In the U.S., the shipments from an alternative fabrication site would be bound by the transportation risks analyzed from the Babcock and Wilcox facility in Lynchburg, Virginia (See Table 4-17 and Table 4-18).

\subsection{Alternative Waste Facilities}

The incident-free impacts of shipping LLW to alternative waste disposal sites are primarily dependent on the distance over which the waste must be shipped and secondarily to the potentially exposed population living along the transportation route. The radiological risk analysis performed with the RADTRAN 4 transportation risk model indicates that the largest contributor to incident-free impact is exposure to the public during highway rest stops, followed by exposure to the truck crew. The number of stops and the crew dose is directly dependent on the number of miles for a shipment.

Transportation risk assessments have shown that greater than 90 percent of the transportation radiological risk is a function of distance (Massey et al, 1993; Massey and Litman, 1994). Since the distance from SNL/NM to the Hanford site is $2580 \mathrm{~km}(1600 \mathrm{mi})$ and to Savannah River Site (SRS) is $2660 \mathrm{~km}$ (1650 mi), the difference of $80 \mathrm{~km}$ (50 mi) would result in less than a 10 
percent increase in transportation radiological risk if SRS were selected as an alternative waste disposal site.

SRS is the most distant alternative disposal site reasonably available for disposal of LLW from a medical isotope production program at SNLNM, all other alternative sites, which are closer to SNLNM, would have lower risks than SRS or the Hanford site options. This includes transportation radiological risks, air quality impacts, and transportation nonradiological risks.

\subsection{Cumulative Impacts}

This section describes the cumulative impacts that would result from the production of medical isotopes and other past, present, and reasonable future activities at SNL/NM.

The following maximum annual doses are summed to calculate cumulative radiological impact:

- doses from the isotopic production;

- doses from other sources of radiation at the same facilities; and

- doses from other radioactive materials shipments occurring at the same facilities, along the same routes, and projected to occur concurrently during with the isotopic production.

This approach neglects the fact that dose fractionation (delivery of a total dose in a number of separate doses spread over time) may reduce the effect of the total cumulative dose (Ullich et al., 1987; Miller et al., 1989).

\subsubsection{Cumulative Production Impacts}

Cumulative impacts from isotopic production activities would be the combination of impacts from three types of operations; the ACRR, isotope production processes in the HCF, and impacts from spin-off industry activity within the Albuquerque area. Workers involved in each of these three types of operations would not experience cumulative impacts from the other operations. Worker exposures would only occur within the immediate zone of work activity for each type of operation. Thus, operational sources of exposure to workers at a particular facility would not impact workers involved in other operations.

Cumulative impacts to the public would be the result of operational environmental releases from each of the three types of operations. Summaries of releases and dose estimates to maximally exposed members of the public are discussed in Table 4-12 for ACRR and HCF operations. Public exposure estimates from potential local spin-off industries are discussed in Section 4.7. Public dose estimates from these three sources are dominated by HCF operations. The estimated annual individual public dose from HCF and ACRR operations is about $1 \mathrm{mrem}$ at $6000 \mathrm{~m}(3.7 \mathrm{mi})$. This is the approximate distance to the boundary between Kirtland AFB and the metropolitan area of Albuquerque. Expected releases from spin-off industries on the order of $50 \mathrm{mCi}$ would be small compared to expected releases from ACRR and HCF operations which are on the order of $50,000 \mathrm{Ci}$.

Thus, the cumulative public impact from the three operations, ACRR, HCF isotope production, and spin-off industries would be essentially equivalent to the estimates for impacts for the HCF isotope production operations. 


\subsubsection{Cumulative Waste Management Impacts}

The estimation of impacts from waste management related activities has been incorporated into the analysis of the HCF operations and the waste transportation activities. Any impacts from waste management are therefore incorporated into the assessments of Section 4.4.

\subsubsection{Cumulative Transportation Impacts}

The following discussion focuses, in two parts, on the cumulative radiological impacts on the workers and the general public who would be exposed as a result of isotopic production. The first section describes the results of the "Final Environmental Statement on the Transportation of Radioactive Material by Air and Other Modes," NUREG-0170 (NRC, 1977). The estimated doses associated with isotopic production are compared to natural background radiation and estimates from NUREG-0170. The second section summarizes the cumulative effect evaluation.

\subsubsection{NUREG-0170 and Other Studies on Population Exposures}

Transportation activities associated with the isotopic production concept are similar in many respects to other radioactive material transportation that is taking place in the same locations and along similar routes. The "Final Environmental Statement on the Transportation of Radioactive Material by Air and Other Modes, NUREG-0170" (NRC, 1977), considered the risk of transporting various types of packages of radioactive materials, including the shipment of spent nuclear fuel and other radioactive materials along transportation corridors similar to those that would be used for the proposed action. More recent studies of radioactive material shipments indicate that no substantial change in the number and characteristics of shipments has occurred that would invalidate the general result of NUREG-0170 (Weiner, et al., 1991).

For individuals residing near principal transportation routes, NUREG-0170 estimated that the average annual individual dose from radioactive material transportation activities is about 0.09 mrem. Recently, Weiner et al. (1991) estimated that a maximally exposed individual member of the public would not receive more than $0.14 \mathrm{mrem}$ if exposed to the in-transit passage of all of the approximately $1,600,000$ radioactive materials packages shipped in the United States in a single year. This is, of course, not a realistic scenario, but it does place an upper bound on the individual in-transit dose from other shipments.

Mills and Neuhauser (Mills, 1994) estimated the individual in-transit dose, for a person located 30 meters from an average route segment, as only $9 \mathrm{e}-05 \mathrm{mrem}$. However, the number of radioactive materials shipments occurring annually in the vicinity of the SNLNM as a result of a medical isotope production program at SNLNM could exceed the average radioactive materials traffic on the nation's roadways because of all of the unirradiated target, isotope product, and waste shipments that would travel through part of Albuquerque. NUREG-0170 used annual shipment levels for the United States as a whole to obtain maximum individual dose estimates. The two classes of shipments considered in NUREG-0170 that can be used to conservatively model traffic in the SNLNM and Albuquerque vicinity are spent fuel shipments (250 commercial reactor shipments) and secondary transport. NUREG-0170 estimated that the dose to an individual living $30 \mathrm{~m}$ (100 ft) from a roadway on which all 250 spent fuel shipments pass would be $0.009 \mathrm{mrem}$ and that no individual would receive more than an additional $0.009 \mathrm{mrem}$ from secondary transport, for a total of $0.018 \mathrm{mrem}$ from these sources. 


\subsubsection{Summary of Estimated Individual Radiological Doses}

\section{Public Doses}

The maximum individual dose estimates as presented in Tables 4-22 and 4-23 demonstrate the relatively low dose that a single individual might receive from incident-free transportation. The differences between the maximum individual dose estimates and the dose estimates for the various population groups demonstrate the effect of population groups on dose estimates. It should be noted that the maximum individual dose represents an estimate of the dose that would be received by the same individual if that individual were to be exposed to each shipment of fresh targets, isotope products, and waste shipments. Thus, as modeled in this analysis, for 200 percent of the market share, the maximum individual would be exposed to 174 fresh target shipments ( 87 from LANL to SNL/NM, 87 from LANL to Ottawa), 6448 isotope shipments, and 149 waste shipments annually.

\section{"Traffic Jam" Individual}

The dose to an individual who is situated next to a shipment of $820 \mathrm{Ci}$ of ${ }^{99} \mathrm{Mo}$ in a $20 \mathrm{WC}$ shipping cask was estimated to establish a perspective on possible "off-normal" non-accident impacts associated with the proposed action. The Mo shipments were used because the package dose rate for these shipments is estimated to be $10 \mathrm{mrem} / \mathrm{hr}$ at one meter. This would be the highest package dose rate for the transportation campaign associated with the proposed action. The dose estimate for an individual who remains next to an average shipment for 2

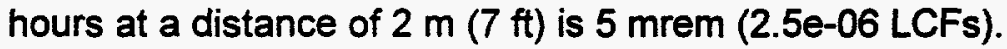

\section{Maximally Exposed Individual}

The maximum annual dose to an individual exposed to each shipment of targets, isotope products, and waste in the vicinity of Albuquerque was estimated at 1.7e-4 rem (Table 4-22). This estimate was based on the conservative model that the same individual would be exposed to every shipment associated with medical isotopic production at SNUNM. Therefore, a total annual individual dose estimate from both the NUREG-0170 shipment model (250 spent fuel shipments and secondary transport) and the model of this analysis (Section 4.1.4) would be $0.19 \mathrm{mrem}$. This dose estimate is small compared to estimates of expected exposures from background radiation. Along the transportation corridors that would be used in implementing the proposed action, the average annual effective dose equivalent for a member of the general population from all sources of radiation is expected to be approximately 360 mrem (NAS, 1990).

\section{Worker Doses}

Two different worker doses were estimated: 1) dose to handlers and 2) dose to conveyance crew members. The maximum exposure for a package handler involved in transporting radioactive material packages associated with isotopic production is predicted to occur with air cargo handlers. The dose would result from the loading, inter-flight transfer, and unloading of isotope product packages during air transport. The annual worker dose estimate of 56 personrem/yr (Table 4-22) would be largely attributable to the handling of the ${ }^{99}$ Mo packages during loading and unloading to and from aircraft and ground transportation. Of this total, 45 person$\mathrm{rem} / \mathrm{yr}$ is attributable to loading, unloading, and short-term storage of isotope product packages 
at air cargo terminals. The remaining 11 person-rems of the total worker dose estimate would be incurred predominantly by handlers at SNL/NM TA-V who would load the isotope packages onto trucks for shipment to Albuquerque International Airport.

The most conservative worker exposure estimate is derived by assuming that the same air cargo employee at Albuquerque International Airport would be present for the receipt of each isotope product package from SNL/NM and for the loading of each package onto an aircraft. This is a conservative model designed to achieve a conservative bound on potential maximum worker exposure. The air cargo handler exposure model also assumes that four handlers would be involved in the receipt and loading of the packages at Albuquerque International Airport, four handlers would be involved for the unloading and reloading of the packages at the central air cargo hub, 300 air cargo hub warehouse workers would be exposed during temporary storage of the packages, and four handlers would be involved in unloading the packages at each destination air terminal. Albuquerque International Airport cargo handlers would receive an estimated 16.4 person-rem/yr, other cargo handlers at both the air cargo hub and the destination terminals would receive 15.8 person-rem/yr, and air hub warehouse workers would receive 17.7 person-rem/yr. Based on this model where the same worker handles all shipments of medical radioisotopes, the maximum annual individual handler dose estimate would be $6.71 \mathrm{rem}(6710 \mathrm{mrem})$ to an air cargo handler at Albuquerque International Airport. As a result, air cargo handlers would have to be monitored and rotated to maintain doses within acceptable limits.

Conveyance crew members would receive an annual total dose of 13 person-rem. This would be distributed between air crew (7 person-rem) and ground transportation crew ( 6 person-rem). The annual truck crew dose estimates are dominated by the isotope product shipments from SNL/NM TA-V to Albuquerque International Airport (5.1 person-rem). Based on conveyance crew models of 3 crew members per flight and 2 per truck, the maximum annual individual crew doses would be 0.233 rem for air crew and 2.541 rem for truck crew.

\subsubsection{Estimated Individual Doses from Other Proposed Activities at SNLNM}

DOE has proposed to ship LLW generated at SNL/NM to NTS for disposal. The LLW in question here would not be connected to activities associated with a medical isotope production program. Potential impacts associated with these shipments of LLW have been estimated and are shown in Table 4-25. These shipments would involve the shipment to NTS of approximately $222 \mathrm{~m}^{3}$ of LLW generated at SNL/NM as a result of general research and development activities. The highest annual dose estimate to the public from the LLW offsite shipment activity was estimated as 0.5 person-rem. Maximum individual dose estimates from the LLW offsite shipment activity would be 1.1e-06 rem for a member of the public, and 0.08 person-rem to a member of the truck crew who participated in each LLW shipment.

\subsubsection{Summary of Cumulative Transportation Effect Evaluation}

Table 4-25 contains a summary of the potential cumulative maximum individual dose estimates for three potential sources; SNL/NM isotope production, the SNL/NM offsite shipments, and the NUREG-0170 risk assessment of transporting spent nuclear fuel and secondary transport along transportation corridors similar to those that would be used for an isotope production program. 
Table 4-25. Cumulative Individual Annual Radiation Dose for Maximally Exposed Individuals

\begin{tabular}{|l|c|c|c|c|}
\hline \multirow{2}{*}{$\begin{array}{l}\text { Maximum } \\
\text { Individual Impact } \\
\text { Group }\end{array}$} & \multicolumn{4}{|c|}{ Dose From Various Activities (mrem) } \\
\cline { 2 - 5 } & $\begin{array}{c}\text { Isotope } \\
\text { Production }\end{array}$ & $\begin{array}{c}\text { SNL/NM } \\
\text { Off-Site } \\
\text { Shipments }\end{array}$ & NUREG-0170 & $\begin{array}{c}\text { Total Annual } \\
\text { Dose }\end{array}$ \\
\hline Public & 0.17 & 0.0011 & 0.018 & 0.19 \\
\hline Truck Crew & 2541 & 720 & $870^{1}$ & 4131 \\
\hline Air Crew & 233 & N/A & N/A & 233 \\
\hline Air Cargo Handlers ${ }^{3}$ & 6710 & N/A & 500 & 7210 \\
\hline $\begin{array}{l}\text { Air Cargo } \\
\text { Warehouse Workers }\end{array}$ & 45 & N/A & 500 & 545 \\
\hline $\begin{array}{l}\text { 1 This value is the sum for truck and van maximum individual crew members from Table 4-8 in NUREG-0170. } \\
\text { 2 NA = Not Applicable. } \\
\text { 3. Estimated worker dose assumes same individual handles all shipments during a year. }\end{array}$ \\
\hline
\end{tabular}

\subsection{Environmental Justice}

On February 11, 1994, Order 12898, "Federal Actions to Address Environmental Justice in Minority Populations and Low-Income Populations" was published in the Federal Register (59 FR 7629).

The determination of environmental justice relative to the production of ${ }^{99} \mathrm{Mo}$ requires the consideration of potential pathways of radioactive and chemical exposures. These consist of dispersion of airborne contaminants, contaminants transported in waterways and solid or solidified wastes that go to landfills. All of the liquid wastes produced during the process would be neutralized and stabilized before transportation to the Nevada Test Site or to other waste disposal facilities. Exposure of the general public due to the transportation of these materials is addressed quantitatively in Section 4.1.4. There would be no disposal of any radioactive or hazardous liquids into waterways. The remaining pathway is then the airborne route. Exposures to any airborne contaminants depend upon proximity of the community to LANL and SNLNM and upon meteorological conditions.

Isleta Pueblo is immediately south of SNL/NM; the border is about $8 \mathrm{~km}(5 \mathrm{mi})$ from TA-V. The Pueblo acreage is about 81,000 ha $(200,000$ ac) in size, and the 4000 person population is clustered along the Rio Grande River. The closest Isleta population is about $13 \mathrm{~km}$ (8 mi) mostly southwest of TA-V. For comparison, the Four Hills area of Albuquerque, which is a higher-income district, is located $6.1 \mathrm{~km}(3.8 \mathrm{mi})$ northeast of TA-V and has a population of about 3500 people. The average prevailing wind is from the southeast direction at about 14.5 $\mathrm{km}$ per hr ( 9 mi per hour) (Restrepo, 1994). Thus, any contamination through the air route will not affect the Isleta Pueblo more than other surrounding populations. 
The communities of Los Alamos and White Rock lie closest to the CMR, while Albuquerque is closest to SNL/NM. None of these communities are identified in the 1990 U.S. census data as being a minority or low-income community. Pueblos of the four Accord Tribes are located near LANL, but are farther away than Los Alamos and White Rock.

\subsection{Spin-off Industries}

Potential spin-off industries that might be developed in the area due to the proximity of an isotope production facility include:

- nuclear medical imaging,

- nuclear pharmaceutical production, and

- research on radionuclide applications.

Potential activities would include:

- development of hardware and software to improve the clinical medical imaging process,

- relocation or expansion of a radio-pharmaceutical company in Albuquerque, and

- collaboration of local hospitals, universities and agencies to develop a regional nuclear medicine technology center.

The impact of these spin-off industries is estimated to be similar to radiopharmaceutical companies currently in production. For example, DuPont-Merck, a radiopharmaceutical company in Boston, was contacted to determine the air emissions and water effluent associated with ${ }^{99}$ Mo production (Romero, 1994). DuPont-Merck indicated that liquids are held on site to allow for decay prior to release and the total liquid effluent for 1993 was $50 \mathrm{mCi}$. For air emissions, stack monitors typically indicated effluent of less than $100 \mu \mathrm{Ci}$ per week. DuPontMerck estimates the total annual air release for 1993 to be $10 \mathrm{mCi}$.

\subsection{Summary of Radiological Impacts for A Medical Isotope Production Program}

In this section the radiological impacts associated with the isotope production concept and those of the alternatives are summarized and compared in Table 4-26. The comparison demonstrates that there is little difference between the risks associated with variations of the concept. 
Table 4-26. A Summary of Radiological Impacts for a Medical Isotope Production Program

\begin{tabular}{|c|c|c|c|c|c|c|c|c|c|c|c|c|}
\hline \multirow[t]{3}{*}{ Activity } & \multicolumn{4}{|c|}{$\begin{array}{l}\text { Proposed Action } \\
\text { (200\% Production) }\end{array}$} & \multicolumn{4}{|c|}{ Alternate Target Fabrication Sites } & \multicolumn{4}{|c|}{ Alternate Waste Disposal Sites } \\
\hline & \multicolumn{2}{|c|}{$\begin{array}{l}\text { Maximum } \\
\text { Individual* }\end{array}$} & \multicolumn{2}{|c|}{ Population } & \multicolumn{2}{|c|}{$\begin{array}{l}\text { Maximum } \\
\text { Individual* }\end{array}$} & \multicolumn{2}{|c|}{ Population } & \multicolumn{2}{|c|}{$\begin{array}{l}\text { Maximum } \\
\text { Individual* }\end{array}$} & \multicolumn{2}{|c|}{ Population } \\
\hline & $\begin{array}{c}\text { Dose } \\
\text { (mrem) }\end{array}$ & $\begin{array}{c}\text { Risk } \\
\text { (LCF)** }\end{array}$ & $\begin{array}{c}\text { Dose } \\
\text { (Person- } \\
\text { rem) }\end{array}$ & $\begin{array}{c}\text { Risk } \\
(\text { LCF) }\end{array}$ & $\begin{array}{l}\text { Dose } \\
\text { (mrem) }\end{array}$ & $\begin{array}{c}\text { Risk } \\
\text { (LCF) }\end{array}$ & $\begin{array}{c}\text { Dose } \\
\text { (Person } \\
\text { rem) }\end{array}$ & $\begin{array}{c}\text { Risk } \\
(\text { LCF)* }\end{array}$ & $\begin{array}{c}\text { Dose } \\
\text { (mrem) }\end{array}$ & $\begin{array}{c}\text { Risk } \\
(\text { LCF })^{\star}\end{array}$ & $\begin{array}{c}\text { Dose } \\
\text { (Person } \\
\text { rem) }\end{array}$ & $\begin{array}{l}\text { Risk } \\
\text { (LCF) }\end{array}$ \\
\hline $\begin{array}{l}\text { CMR } \\
\text { Target } \\
\text { Fab. }\end{array}$ & 0 & 0 & 0 & 0 & 0 & 0 & 0 & 0 & 0 & 0 & 0 & 0 \\
\hline ACRR & 0.6 & $3 e-7$ & 15.5 & $7.8 e-3$ & 0.6 & $3 e-7$ & 15.5 & $7.8 \mathrm{e}-3$ & 0.6 & $3 e-7$ & 15.5 & $7.8 e-3$ \\
\hline HCF & 3.7 & $1.8 e-6$ & 147 & 0.07 & 3.7 & $1.8 e-6$ & 147 & 0.07 & 3.7 & $1.8 e-6$ & 147 & 0.07 \\
\hline $\begin{array}{c}\text { Target } \\
\text { Transport }\end{array}$ & $2.1 \mathrm{e}-4$ & $1 e-10$ & $2.5 e-2$ & $1.2 e-5$ & $2.1 e-4$ & $1 e-10$ & $3.1 e-1$ & $1.5 e-4$ & $2.1 e-4$ & $1 e-10$ & $2.5 e-2$ & $1.2 e-5$ \\
\hline $\begin{array}{l}\text { Product } \\
\text { Transport }\end{array}$ & $1.7 e-1$ & $8.6 e-8$ & 72 & $2.9 e-2$ & $1.7 e-1$ & $8.6 e-8$ & 72 & $2.9 \mathrm{e}-2$ & $1.7 e-4$ & $8.6 e-8$ & 72 & $2.9 e-2$ \\
\hline $\begin{array}{c}\text { Waste } \\
\text { Transport }\end{array}$ & $2.7 e-3$ & $1.3 e-9$ & 3.2 & $1.5 \mathrm{e}-3$ & $2.7 e-3$ & $1.3 e-9$ & 3.2 & $1.5 e-3$ & $3 e-3$ & $1.4 e-9$ & 3.5 & $1.7 e-3$ \\
\hline
\end{tabular}

- Note: Maximum Individual Risks or Population Risks cannot be summed for any option since the potentially affected individuals and populations would be different.

* LCF = Latent Cancer Fatality

** For the alternate target fabrication and waste disposal sites, the impacts presented in this table are for bounding (maximum) scenarios. For target transport the impact is for target transport from Babcock and Wilcox in Lynchburg, VA and for waste transport the impact is for waste transport to Hanford, WA. 


\subsection{POTENTIAL ENVIRONMENTAL IMPACTS OF ACCIDENT SITUATIONS}

In this section the potential consequences of accidents which could occur are discussed.

\subsection{CMR Target Fabrication Accident Analysis}

\section{Radiological Impacts}

Target fabrication presents few opportunities for accidents that would cause radioactive material to be released. The only accidents identified within the CMR are an operator dropping a canister of ${ }^{235} \mathrm{U}_{3} \mathrm{O}_{8}$ and a solution spill. Solution containing ${ }^{235} \mathrm{U}$ in $\mathrm{HNO}_{3}$ could be spilled due to earthquake or to operator error. The consequences of this accident are presented below.

Other accidents were considered but were not analyzed because the required conditions would not exist. Limits on the quantity of ${ }^{235} \mathrm{U}$ in a glove box prevent criticality accidents. No flammable materials would be used and welding would be done in an inert atmosphere that would prevent fires. If a worker should drop an open-ended target, no release would be expected because the ${ }^{235} \mathrm{U}$ would be electrocoated onto the tube's inner wall.

\section{Canister Drop}

An operator could drop a canister of particulate ${ }^{235} \mathrm{U}_{3} \mathrm{O}_{8}$. No release would be expected because the ${ }^{235} \mathrm{U}_{3} \mathrm{O}_{8}$ is contained in a canister, which is in a sealed plastic bag, which is in an outer canister. The canisters have slip-on tops which are taped in place.

\section{Spill}

A spill would be unlikely to occur because solutions would be moved using vacuum lines. However, a major line rupture or an earthquake could a cause solution of ${ }^{235} \mathrm{U}$ in $\mathrm{HNO}_{3}$ to spill on the laboratory floor. Volume of the spill is assumed to be 5 liters.

In the event of a spill, an alarm for evacuation would be sounded by personnel monitors and/or CAMs. Personnel would immediately leave the area. The accident response team, equipped with protective clothing and supplied breathing air, would clean up the spill. Because ${ }^{235} U$ would be in solution, none would be resuspended or released in any other way to the environment. No doses to involved personnel, other personnel in CMR, or members of the public would be expected.

\section{Toxicological Impacts}

No accidents involving release of toxicological materials were identified. If solution were spilled, any acid fumes in the ventilation system would be neutralized by the $\mathrm{NaOH}$ scrubber before leaving the CMR.

\subsection{ACRR Accident Analysis}

The following sections present the radiological and mechanical consequences of three major categories of accidents that could occur during operation of the ACRR for ${ }^{99} \mathrm{Mo}$ target irradiation. Target irradiation would only utilize the steady state mode of reactor operation. The 
pulse modes, which are used for current missions, would be physically disabled and accidents associated with pulsing would not be possible. All potential steady-state mode accidents at the ACRR were evaluated and three representative accidents are presented in this section. Appendix I contains a description of the scope of the evaluated accidents. The three accidents presented in this section were selected on the basis of (a) type of event resulting in the accident; (b) probability of the event; and (c) the severity of the event capable of causing a release of radioactive materials. However, a maximum pulse accident, which serves as the pulsing bounding accident, is included in Appendix $F$.

The three accidents selected are a natural phenomena (earthquakes); an external event resulting in an accident (airplane crash); and an operational accident (fuel element rupture). These accidents bound the risks from all other accidents, such as tornadoes, loss of coolant, explosion, or fire, as discussed in Appendix I.

It is important to note that unless a target or fuel element were to rupture, none of the postulated accidents would result in a fission product release to the outside environment.

\section{Earthquake}

The reactor safety and emergency systems are designed to maintain operational capability in the event that an earthquake should occur; vibration and acceleration effects are not expected to result in damage to the reactor fuel elements or the regulating rod systems to the extent that the reactor could not be shut down. If the earthquake should result in loss of power to the facility, the reactor instrumentation and control system is designed to fail safe and reactor shutdown would occur. If such an earthquake were to occur, the reactor and safety systems would be inspected prior to the restart of the reactor.

As defined in the Uniform Building Code, ACRR facilities were designed and constructed in accordance with the requirements for Seismic Zone 2. The ACRR High Bay is rated as a Category II structure, which means that failure of the structure as a result of earthquake would neither release significant quantities of radioactive material nor prevent reactor shutdown. Facility structures have been undamaged by seismic activity up to 3.8 on the Richter scale, which available evidence indicates to be an upper limit on the most likely seismic event. Since the Uniform Building Code Acceleration (horizontal) for Zone 2 is $0.067 \mathrm{~g}$, and the Richter 3.8 acceleration is about $0.003-0.007 \mathrm{~g}$, there is ample conservatism in the construction for the maximum expected event. Analysis has shown that, even if a Richter M6 earthquake occurred, the bridge crane supports would not fail, and, except for the slight loss of building mechanical integrity in the concrete block walls, the reactor room would be expected to survive.

An earthquake could damage the high bay structure. This structure serves as confinement only and is not adequate for containment. Because ACRR fission product inventories are low, the site is isolated (the nearest population group is KUMSC at $1610 \mathrm{~m} \mathrm{[1} \mathrm{mi])} \mathrm{and} \mathrm{its} \mathrm{two} \mathrm{exhaust}$ systems are equipped with HEPA filters, there is no requirement for containment or other structural integrity features. The capability to shut down the reactor and maintain it in a safe shutdown condition is not a function of the confinement structure, but rather of the inherent failsafe design of the reactor itself.

Earthquakes associated with Zone 2 are not likely to result in structure collapse, but moderate damage might include failures severe enough to cause the 15-ton capacity overhead bridge 
crane to collapse into the reactor room. The crane can fall a total distance of about $8.2 \mathrm{~m}$ ( 27 $\mathrm{ft}$ ), at which point it would have a velocity of $12.7 \mathrm{~m} / \mathrm{sec}(42 \mathrm{ft} / \mathrm{sec}$ ) and a kinetic energy of 0.4 MJ.

It is expected that a direct hit by the falling bridge crane on the reactor would crush all of the reactor superstructure (components protruding above the reactor pool) to floor level. Since operating procedures specify that the bridge crane cannot be operated or stored over the reactor when the reactor is operating, a direct hit during reactor operation is extremely unlikely. The most critical items that would be crushed are the reactor control rod drives. These rods are designed to have a very small cross section $(22 \mathrm{~mm}[0.9 \mathrm{in}]$ diameter $\times 0.76 \mathrm{~mm}[0.03 \mathrm{in}]$ wall

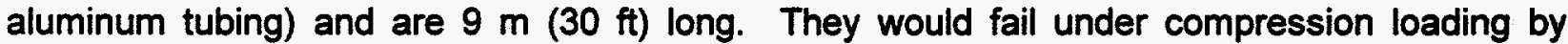
buckling rather than collapsing or crushing the air-filled bottom section of the rods or penetrating the safety plate and bottom of the tank. The control and safety rods would remain in the core region and the reactor would remain shut down. For the purpose of the analysis it is assumed that a bridge crane collapse could rupture up to four fuel elements or four targets.

Calculations for a fuel element rupture and the bridge crane collapse assume there is a credible probability that the fission products from as many as four fuel elements could be released into the reactor tank. The target rupture makes the same assumption. A fuel cask drop assumes three targets would be crushed in the GIF pool, releasing their contents.

As shown in Tables 5-1 and 5-2, the dose to the maximum public individual located $1610 \mathrm{~m}$ from the facility for an earthquake/bridge crane collapse accident would be 19 mrem. Considering the probability of the event occurrence, the annual latent cancer fatality risk to the maximum individual would be 9.5e-06. That is about a 1 in $1,000,000,000$ (one in a billion) chance per year that a person located $1,610 \mathrm{~m}(1 \mathrm{mi})$ from the ACRR would die of a cancer as a result of an earthquake/bridge crane collapse at the ACRR. For facility workers it is assumed that, except during maintenance or target loading/unloading, workers would not be present inside the ACRR high bay. Further, it is assumed that anyone in the high bay during an earthquake severe enough to cause a bridge crane collapse would either have already evacuated the high bay area or would be killed by the collapsing building and/or structures.

In summary, the principal hazard resulting from the occurrence of natural events would be the onset of structural damage. As a secondary effect, however, the bridge crane could fall onto the reactor and cause core damage. The consequences of natural events are within those evaluated for the collapse of the bridge crane. In terms of reactor safety, natural disasters are trivial events because of their low probability of occurrence, especially for magnitudes sufficient to cause damage.

\section{Airplane/Projectile Impact}

Landing and takeoff patterns for the various runways at the airport facilities do not affect reactor operations. The runway of most concern relative to reactor operations is the east-west runway. Aircraft using the east end of this runway for landing or takeoff could fly over the facilities if they were approaching or leaving the airport in a southerly direction. However, the east end of the runway is $7.0 \mathrm{~km}$ ( $4.3 \mathrm{mi}$ ) from TA-V, and aircraft that may fly over the area during takeoff should be fully airborne. The estimated probability of an aircraft crash into the ACRR facility is about 5e-05 per year, or one crash expected in 20,000 years. Other than fatalities as a result 
of the crash, consequences to the ACRR would not be expected to exceed those discussed for collapse of the bridge crane.

Missiles generated from an explosive source inside the facility or other actions outside the facility could conceivably penetrate the structure, but would not compromise safety. The only source in the reactor room for generating large, sustained positive pressure differentials that could rupture the reactor building is the steam system located on top of the GIF cells that is associated with the High Intensity Adjustable Cobalt Array (HIACA). This system has been deactivated and is no longer operational. Removal of the steam system hardware is dependent on scheduling an appropriate time period with the reactor shutdown.

Table 5-1. Estimated Dose Consequences for ACRR Accident Scenarios

\begin{tabular}{|c|c|c|c|c|c|c|}
\hline \multirow{3}{*}{$\begin{array}{l}\text { Event } \\
\text { Earthquake/ } \\
\text { Bridge Crane } \\
\text { Collapse, } 4 \text { fuel } \\
\text { elements rupture }\end{array}$} & \multirow{3}{*}{$\begin{array}{c}\text { Estimated } \\
\text { Probability of } \\
\text { Occurrence } / \mathbf{r} \\
<10^{-6}\end{array}$} & \multicolumn{5}{|c|}{ Maximum Individual Dose (mrem) } \\
\hline & & $300 \mathrm{~m}$ & $1610 \mathrm{~m}$ & $3000 \mathrm{~m}$ & $6000 \mathrm{~m}$ & $20,000 \mathrm{~m}$ \\
\hline & & 64 & 19 & 5.6 & 1.0 & 0.096 \\
\hline $\begin{array}{l}\text { Airplane } \\
\text { Crash }\end{array}$ & $5 \times 10^{-5}$ & 64 & 19 & 5.6 & 1.0 & 0.096 \\
\hline $\begin{array}{l}\text { Fuel Element } \\
\text { Rupture, } 4 \\
\text { elements }\end{array}$ & $10^{-4}-10^{-6}$ & 64 & 19 & 5.6 & 1.0 & 0.096 \\
\hline
\end{tabular}

Table 5-2. Estimated Risk Data for ACRR Accident Scenarios

\begin{tabular}{|l|c|c|c|c|}
\hline \multirow{2}{*}{ Event } & \multicolumn{2}{|c|}{ Maximum Public Individual at 1610 m } & \multicolumn{2}{c|}{ Total Population } \\
\cline { 2 - 5 } & $\begin{array}{c}\text { Dose Risk } \\
\text { (rem) }\end{array}$ & LCF & $\begin{array}{c}\text { Dose Risk } \\
\text { (person-rem) }\end{array}$ & LCF \\
\hline $\begin{array}{l}\text { Bridge Crane } \\
\text { Collapse, 4 fuel } \\
\text { elements rupture }\end{array}$ & $1.9 \mathrm{e}-08$ & $9.5 \mathrm{e}-12$ & $2.3 \mathrm{e}-05$ & $1.2 \mathrm{e}-08$ \\
\hline $\begin{array}{l}\text { Airplane } \\
\text { Crash }\end{array}$ & $9.5 \mathrm{e}-07$ & $4.8 \mathrm{e}-10$ & $1.1 \mathrm{e}-03$ & $5.8 \mathrm{e}-07$ \\
\hline $\begin{array}{l}\text { Fuel Element } \\
\text { Rupture, 4 } \\
\text { elements }\end{array}$ & $1.9 \mathrm{e}-06$ & $9.5 \mathrm{e}-10$ & $2.3 \mathrm{e}-03$ & $1.2 \mathrm{e}-06$ \\
\hline
\end{tabular}


Other than the HIACA, there are no pressurized systems; therefore, dynamic effects of such incidents as whipping pipes are an unlikely occurrence. Since most piping systems are confined below grade and operate at basically ambient pressure, they could not conceivably affect the reactor. The probability of a reactor incident occurring as a result of the dynamic effects of missiles is negligible.

If an airplane were to crash into the ACRR building there would be no release of materials unless targets or fuel elements were ruptured. In the interest of bounding the risks of an airplane crash, it is assumed that the crash results in the bridge crane falling into the reactor pool and rupturing four fuel elements. The impacts and risks of such an accident are shown in Tables 5-1 and 5-2. The average annual risk to a member of the general public is about a 1 in 800 billion chance of developing a cancer as a result of an airplane crash. For facility workers it is assumed that anyone in the facility during an airplane crash would be killed by the impact, building collapse, or subsequent fires.

The probability of an airplane crash which resulted in a large portion of the aircraft crashing directly into the $3.6 \mathrm{~m}$ (12 ft) diameter ACRR pool and then impacting the core $9.1 \mathrm{~m} \mathrm{(30} \mathrm{ft)}$ below water was evaluated but the probability was determined to be so low (about 1 in a billion per year) this crash was not analyzed.

\section{Waterlogged Fuel Element Rupture}

If a pinhole leak develops in the cladding, water can be drawn into the fuel element by the pumping action from repeated thermal cycling due to periodic reactor operation. During the first heating after a pinhole has developed, some of the fill gas will be forced out through the pinhole. After cool down, the decreased pressure within the element will cause some water to be drawn in. Provided the heating rate is slow, water will continue to be drawn in during subsequent thermal cycling. Since the helium fill gas can be gradually displaced by water and water vapor, there is a tendency for pumping efficiency to increase with each cycle, and a significant fraction of the fuel element void space can be filled with water.

In pulse operation, the steam generation rate within a waterlogged fuel element can exceed the venting capacity of the hole, and if the resulting internal pressure exceeds the bursting strength of the cladding, it will rupture. While waterlogged fuel element failures have occurred (Potenza, 1966; Nuclear Safety, 1972), there have been no failures of elements used in the ACRR. All recorded failures have occurred during pulsed operation. Since the ACRR would only be operated in the steady-state mode for isotope production, this type of fuel element failure is even more unlikely to occur during ${ }^{99}$ Mo production and is assumed to have a probability of occurrence of less than 1e-6/yr. If a rupture were to occur, it would be detected through the increase in coolant radioactivity and changes in core reactivity.

For the target rupture, MACCS was used to perform the downwind dose estimates assuming that rupture occurs after a 21-kW, 7-day irradiation, and that all of the noble gases and 1 percent of the halogens are immediately released from the pool. All of the noble gases and 10 percent of the remaining halogens were assumed to be released from the stack (Restrepo, 1992). These assumptions are conservative; pool releases on the order of 37 percent of the krypton, 23 percent of the xenon, and 1.3e-04 percent of the iodine are plausible (Powers, 1991). 
The fuel element rupture is assumed to occur at a time when all of the noble gases and halogens have reached equilibrium activity conditions.

If a worker were in the ACRR high-bay when a fuel element ruptured, the worker would be immediately notified of the rupture by various alarms and detectors in the reactor and reactor area. The worker would then immediately evacuate the area and not return until safe conditions were established or protective equipment used. If the worked did remain in the highbay for 5 minutes to perform a safety task, and the worker was assumed to be exposed to $10 \%$ of the total nobles and halogens assumed to be immediately released into the high-bay atmosphere and $1 \%$ of the total halogens and fission products were respirable, the worker would receive an estimated dose of $80 \mathrm{rem}$. The latent cancer fatality risk to the worker, taking into account the probability of a target rupture, is less than $3.2 e-8$ or 1 chance in $30,000,000$ of developing a fatal cancer.

\subsection{Target Transfer Accident Analysis}

The bounding impact for all target transfer operations would be represented by the rupture of a single target as the result of a manned transport accident while in transit between the ACRR and the HCF. Although highly improbable (estimated probability is less than 1e-06 per year), this accident scenario assumes the loss of all noble gas radionuclides directly to the atmosphere. Downwind dose estimates for a cask transport accident between the ACRR and the HCF are presented in Table 5-3. MACCS was used to perform the downwind dose estimates assuming that rupture occurs after a $21-\mathrm{kW}, 7$-day irradiation, and that all of the noble gases and 1 percent of the halogens are immediately released from one target into the atmosphere. The dose to an off-site individual located $1610 \mathrm{~m}(1 \mathrm{mi})$ away would be $3.8 \mathrm{mrem}$. Risk data for the transport accidents are shown in Table 5-4. The maximum public individual dose risk from a target transfer accident would be 3.8e-09 rem for an individual located $1610 \mathrm{~m}$ (1 mi) from TA-V. The total population risk would be 3.6e-09 LCFs. This translates into an average annual accident risk of $7.5 \mathrm{e}-13$ or that the chance of any one individual dying of a cancer from a target transport accident is about 1 in a trillion per year.

Due to the extremely high speeds and the impact severity necessary to breach the transportation cask, it is assumed that the worker that would be driving the transport vehicle would likely be killed by the impact of the mobile transport accident.

If a mobile transport accident were to occur with the same consequences in Zone $2 \mathrm{~A}$, only the noble gases would be released; the halogens would be trapped in the building ventilation system charcoal filters, which could then be isolated and changed out. As a result, the doses and risks would be less than those shown in Tables 5-3 and 5-4.

\subsection{HCF Accident Analysis}

In this section, impacts of potentially credible accidents in the HCF are presented. All potential accidents at the HCF were evaluated and three representative accidents are presented in this section. Appendix I contains a description of all evaluated accidents as well as the methodology used to screen the accidents. The accidents were selected on the basis of: (a) type of event leading to the accidents; (b) probability of the event; and (c) severity of the event capable of causing a release of radioactive materials. The three accidents presented are airplane crash, fire, and target process spill. 
Table 5-3. Downwind Dose Estimates for a Target Rupture During Transport to the HCF

\begin{tabular}{|l|c|c|c|c|c|}
\hline \multirow{2}{*}{ Accident } & \multicolumn{5}{|c|}{ Maximum Individual Dose at Distance from HCF (mrem) } \\
\cline { 2 - 6 } & $300 \mathrm{~m}$ & $1610 \mathrm{~m}$ & $\mathbf{3 0 0 0} \mathrm{m}$ & $\mathbf{6 0 0 0} \mathrm{m}$ & $20,000 \mathrm{~m}$ \\
\hline $\begin{array}{l}1 \text { Target ruptures } 6 \\
\text { hrs after irradiation; } \\
\begin{array}{l}100 \% \text { nobles and } \\
1 \% \text { halogens } \\
\text { released }\end{array}\end{array}$ & 30.5 & 3.8 & 0.94 & 0.17 & 0.020 \\
\hline
\end{tabular}

Table 5-4. Estimated Risk Data for Target Rupture During Transport to the HCF

\begin{tabular}{|l|c|c|c|c|}
\hline \multirow{2}{*}{ Event } & \multicolumn{2}{|c|}{$\begin{array}{c}\text { Maximum Off Site Individual } \\
\mathbf{1 6 1 0} \mathbf{m}\end{array}$} & \multicolumn{2}{c|}{ Total Population } \\
\cline { 2 - 5 } & $\begin{array}{c}\text { Dose Risk } \\
\text { (rem) }\end{array}$ & LCF & $\begin{array}{c}\text { Dose Risk } \\
\text { (person-rem) }\end{array}$ & LCF \\
\hline $\begin{array}{l}1 \text { Target ruptures 6 } \\
\text { hrs after irradiation; } \\
100 \% \text { nobles and } \\
\begin{array}{l}1 \% \text { halogens } \\
\text { released }\end{array}\end{array}$ & $3.8 \mathrm{e}-09$ & $1.9 \mathrm{e}-12$ & $7.1 \mathrm{e}-06$ & $3.6 \mathrm{e}-09$ \\
\hline
\end{tabular}

The main safety system in the HCF, its passive shield walls, would remain effective during accidents or abnormal conditions with no additional action required by an operator or an automated system. Therefore, in the event of a shutdown, radioactive material would be secured (i.e., returned to shielded containers) only if this could be easily and safely accomplished. Other operations would be conducted during accident conditions only after review by appropriate safety review and/or emergency response groups. The TA-V Emergency Plan describes the plans and equipment for responding to and handling emergency conditions and events in the HCF and the rest of TA-V.

\section{Airplane Crash}

As discussed in Section 5.2, the probability of an aircraft hitting either the ACRR or the HCF is about 5e-05/yr. Small airplanes that crash into the facility would not be expected to cause severe damage to Building 6580 , especially to the HCF which is located in the basement of Building 6580 and is constructed of steel reinforced concrete approximately $1.37 \mathrm{~m} \mathrm{(4.5 \textrm {ft } )}$ thick. Only large aircraft would have the potential to cause major building damage; however, this would probably not impact the HCF. While the airplane crash itself would probably not affect the radioactive material within the HCF, the crash and probable fire would damage the ventilation system. In this case all materials in the cold trap and charcoal filters are assumed to be released to the environment. Workers in the below-ground portion of the HCF would be protected from an airplane crash by the HCF structure. There would be no expected worker impact from radioactive materials in the SCBs in the HCF because of facility design features. 
The dose to the maximally exposed individual at $1610 \mathrm{~m}(1 \mathrm{mi})$ would be approximately 0.15 mrem. The annual cancer risk to this individual is approximately 1 in a billion. Table 5-5 shows the risks from the airplane accident. These impacts do not include the fatalities expected for aircraft crew, passengers, and facility personnel.

Table 5-5. Estimated Maximum Individual and Population Risks for Aircraft Crash into HCF

\begin{tabular}{|c|c|c|c|}
\hline $\begin{array}{c}\text { Maximum Public } \\
\text { Individual Dose } \\
\text { Risk }\end{array}$ & $\begin{array}{c}\text { Individual } \\
\text { LCF Risk }\end{array}$ & $\begin{array}{c}\text { Population } \\
\text { Dose Risk }\end{array}$ & $\begin{array}{c}\text { Population } \\
\text { LCF Risk }\end{array}$ \\
\hline $8 \mathrm{e}-9$ rem & $4 \mathrm{e}-12$ & $3.6 \mathrm{e}-4$ & $1.8 \mathrm{e}-7$ \\
\hline
\end{tabular}

"Individual assumed to be located $1610 \mathrm{~m}$ from HCF.

\section{Fire}

Buildings 6580 and 6581 are provided with automatic sprinkler systems everywhere except HCF Zones 1 and $2 A$ where, due to the possible presence of reactive metals such as sodium, a nitrogen fire suppression system is used. This system is on the emergency power system, and the nitrogen valves are designed so that once open, they will not fail in the event of a power failure. If the power to the exhaust blower should fail, a natural draft would be established from Zone 1 through the TA-V stack to minimize possible pressurization of the SCBs under the highly unlikely condition that both normal and emergency power fail at the same time a fire occurs. Water spray heads, scrubbers and de-misters are incorporated into the Zones 1 and $2 \mathrm{~A}$ exhaust lines to keep air temperatures at the HEPA filters below $148^{\circ} \mathrm{C}\left(298^{\circ} \mathrm{F}\right)$. HEPA filters are designed to operate up to $200^{\circ} \mathrm{C}\left(392^{\circ} \mathrm{F}\right)$. This system would be activated when the air duct temperature exceeded $87^{\circ} \mathrm{C}\left(189^{\circ} \mathrm{F}\right)$. Zones 1 and $2 \mathrm{~A}$ are separated from the Zone 2 support area by concrete walls fire-rated for at least 4 hours and by viewing windows fire-rated for at least 2 hours. Room 108 is separated from other adjacent areas by concrete walls and a sliding concrete door fire-rated for at least 4 hours. The building has a fully supervised alarm and evacuation system, connected to both Sandia Security and the KAFB East Fire Department, that is automatically activated by any sprinkler water flow. The HCF is equipped with an independent fire alarm control panel, located in Room 107, that monitors all areas of the HCF and is the control panel for the nitrogen fire suppression system. Portable fire extinguishers are also located throughout the facility at strategic locations.

Since there has never been a fire in the HCF, it is difficult to define a particular initiating event, and therefore, for purposes of analysis, it is assumed that the fire is of unspecified origin, and could be the result of an electrical short or spark or maintenance activities (e.g., welding). In the last five years, about 16 fires have been recorded at the 500 SNL/NM Albuquerque facilities, leading to an annual probability of occurrence of $6.4 \mathrm{e}-03 /$ facility.

Due to the exhaust system HEPA filters, doses to the maximum-exposed off-site individual, onsite collocated personnel, and the general public are small for all fire accident scenarios and all areas. The worst fire scenario, a Beyond Evaluation Basis Fire in Room 108 (probability of occurrence $=2 e-07$ ), would result in a calculated dose of 0.22 mrem to on-site personnel and 0.43 mrem to the maximum exposed individual located at 1610 (1 mi). These numbers are 10,000 times smaller than the allowable limits, as defined by Secretary of Energy Notice SEN- 
35-91, for an abnormal event with a probability of occurrence of 1 in 10,000 to 1 in $1,000,000$ (DOE, 1991).

Consequences to workers in the immediate area from fire scenarios would be dominated by exposure to airborne radioactive material either due to inhalation and/or immersion. Previous calculations have shown that for various amounts of radioactive materials in Zone $2 \mathrm{~A}$ of the HCF, including amounts equal to established radioactive material limits, the maximum calculated worker exposure for a credible accident scenario is about 21 rem (Restrepo, 1994).

\section{Target Process Spill}

HCF workers would receive no dose from a target process spill because the released materials would be trapped either in the SCBs or the ventilation system filters (particulates and halogens such as bromine and iodine) or released to the HCF stack (noble gases such as krypton and xenon). Table 5-6 summarizes the estimated potential doses to on-site personnel, and the public for process spills where, due to operator error or mechanical failure, the ventilation system filter is not isolated, causing a release of secondary xenon and krypton from the decay of bromine and iodine. For the target and process solution spills, it was assumed that released halogens would not be cleaned up until two hours after the spill, a conservative estimate. In the case of a release of the nobles and halogens from the cold trap, it was assumed that the maximum amount was present; i.e., 95 percent of the total from two targets. It was further assumed that processing of the second target was completed and the cold trap was not changed out until the next day, giving the halogens 24 hours in which to decay. This would be the worst-case scenario for this event.

Table 5-6. Estimated Individual Doses for HCF ${ }^{99}$ Mo Spills, SCB Ventilation Filter Not Isolated, Processing Starts 6 Hours After Irradiation

\begin{tabular}{|l|c|c|c|c|c|}
\hline Accident & \multicolumn{5}{|c|}{ Dose (mrem) } \\
\cline { 2 - 6 } & $300 \mathrm{~m}$ & $1610 \mathrm{~m}$ & $3000 \mathrm{~m}$ & $6000 \mathrm{~m}$ & $20,000 \mathrm{~m}$ \\
\hline $\begin{array}{l}\text { Target spill, all nobles } \\
\text { released, halogens } \\
\text { decay for 6 hrs }\end{array}$ & 0.15 & 0.052 & 0.034 & 0.015 & 0.0024 \\
\hline $\begin{array}{l}\text { Cold trap release of } \\
\text { nobles from 2 targets, } \\
\text { halogens decay for } \\
6 \text { hrs }\end{array}$ & 0.28 & 0.099 & 0.064 & 0.028 & 0.0046 \\
\hline $\begin{array}{l}\text { Process solution spill, } \\
\begin{array}{l}10 \% \text { of nobles } \\
\text { released, halogens } \\
\text { decay for 6 hrs }\end{array}\end{array}$ & 0.0074 & 0.0026 & 0.00088 & 0.00075 & 0.00012 \\
\hline
\end{tabular}




\subsection{Transportation Accident Analysis}

\subsubsection{Introduction}

The potential risks associated with transporting radioactive materials related to isotope production are estimated for the same types of shipments shown in Table 4-14. Accident risks are estimated for two time regimes, 1) annually, and 2) life of program (assumed to be 30 years). Appendix A, Section A.7 describes the shipping campaigns used in the analysis for this section.

\subsubsection{Pre-operational Waste Transportation}

A bounding estimate for risks associated with the transportation of the pre-operations waste was derived by assuming that the entire inventory of the pre-operations waste would have the same specific activity as the operations Hot Cell Facility wastes (see Section 5.5.5) and would be shipped in the same container. The Hot Cell Facility waste inventory model was based on the inventory of a $21 \mathrm{~kW}, 7$-day irradiated target 180 days out of the reactor. The waste capacity of the B-3 is essentially equivalent to that of a 55 gallon drum, $0.212 \mathrm{~m}^{3}\left(7.5 \mathrm{ft}^{3}\right)$. Repository waste acceptance criteria would limit the amount of ${ }^{235} \mathrm{U}$ per waste package to a quantity equivalent to the ${ }^{235} \mathrm{U}$ in fourteen such targets. This inventory is documented in Appendix $L$. Thus, the preoperations waste transportation campaign was modeled as 1000 B-3 cask shipments. The estimates of accident dose risk are summarized in Table 5-7. The accident dose risk estimates from the pre-operations waste shipments (3.1e-11 person-rems for the NTS waste disposal option, and $8.9 \mathrm{e}-11$ person-rem for the Hanford option) would be about half of the estimated dose risk to the public from the production Hot Cell Waste shipments (see Section 5.5.5).

Table 5-7. Pre-Operational Hot Cell Cleanup Waste Shipment Accident Risks

\begin{tabular}{||l|l|l|l|l|}
\hline Waste Repository Location & NTS & Hanford & \\
\hline Shipments/yr & 1000 & 1000 & \\
\hline Accident Risks & Person-Rem & LCF & Person-Rem & LCF \\
\hline Public & $3.1 \mathrm{e}-11$ & $1.6 \mathrm{e}-14$ & $8.9 \mathrm{e}-11$ & $4.5 \mathrm{e}-14$ \\
\hline Maximum Individual & $2.9 \mathrm{e}-03$ & $1.5 \mathrm{e}-06$ & $2.9 \mathrm{e}-03$ & $1.5 \mathrm{e}-06$ \\
\hline
\end{tabular}

\subsubsection{Unirradiated Target Shipments}

Transportation impacts associated with shipments of unirradiated targets were estimated for two sets of target shipments. The first is the set of target shipments from LANL to SNL/NM to support the production of radioisotopes at SNLNM's TA-V. The second is the set of target shipments from LANL to Ontario, Canada, to support the production of radioisotopes at Nordion in Chalk River. Shipments of unirradiated targets to SNLNM were modeled as exclusive-use truck shipments where only a single package of 24 targets would be shipped per truck. Shipments to Nordion in Chalk River, Ontario were modeled as two-stage shipments - exclusive-use shipments from LANL to AIA, and then exclusive-use air cargo from AIA to Ottawa, Ontario. An intermediate refueling stop was included in the air cargo model to establish an upper bound on the risk associated with takeoff and landing operations. Dose risk estimates for the target shipments are shown in Table 5-8. 
Table 5-8 Total Accident Radiological Transportation Dose-Risks for Shipping: Unirradiated Targets Fabricated at LANL

\begin{tabular}{|c|c|c|c|c|c|c|c|}
\hline \multicolumn{2}{|c|}{ Market Share } & \multicolumn{2}{|c|}{30 percent } & \multicolumn{2}{|c|}{100 percent } & \multicolumn{2}{|c|}{200 percent } \\
\hline \multicolumn{2}{|c|}{ Shipments/yr } & \multicolumn{2}{|c|}{13} & \multicolumn{2}{|c|}{44} & \multicolumn{2}{|l|}{87} \\
\hline Destination & Risk & $\begin{array}{l}\text { Person- } \\
\text { Rem }\end{array}$ & LCF & $\begin{array}{l}\text { Person- } \\
\text { Rem }\end{array}$ & $\overline{L C F}$ & $\begin{array}{l}\text { Person- } \\
\text { Rem }\end{array}$ & LCF \\
\hline \multirow[t]{2}{*}{ SNLINM } & $\begin{array}{l}\text { Annual } \\
\text { Total }\end{array}$ & $2.3 e-04$ & $1.2 \mathrm{e}-07$ & $7.9 e-04$ & $4.0 \mathrm{e}-07$ & $1.6 \mathrm{e}-03$ & $7.8 e-07$ \\
\hline & $\begin{array}{l}\text { Life Of } \\
\text { Program }\end{array}$ & $7.0 \mathrm{e}-03$ & $3.5 \mathrm{e}-06$ & $2.4 \mathrm{e}-02$ & $1.2 \mathrm{e}-05$ & $4.7 e-02$ & $2.3 e-05$ \\
\hline \multirow[t]{2}{*}{ Ottawa } & $\begin{array}{l}\text { Annual } \\
\text { Total }\end{array}$ & $4.9 e-04$ & $2.4 e-07$ & $1.7 e-03$ & $8.3 e-07$ & $3.3 e-03$ & $1.8 e-06$ \\
\hline & $\begin{array}{l}\text { Life Of } \\
\text { Program }\end{array}$ & $1.5 e-02$ & $7.3 e-06$ & $5.0 \mathrm{e}-02$ & $2.5 \mathrm{e}-05$ & $9.8 \mathrm{e}-02$ & $4.9 e-05$ \\
\hline
\end{tabular}

An alternative to fabricating the targets at LANL would be to fabricate the targets at a commercial facility such as Babcock and Wilcox in Lynchburg, Virginia. The targets would be transported directly from Lynchburg to Albuquerque via exclusive-use air cargo truck and then transported by truck from AIA to SNL/NM TA-V. A refueling stop between Lynchburg, Va. and Albuquerque was incorporated into the model to establish an upper bound estimate of risks associated with takeoff and landing operations. However, exclusive-use truck could also be used to ship the targets to SNL/NM. The transportation risks associated with this alternative are shown in Table 5-9.

Table 5-9 Total Accident Radiological Transportation Dose-Risks: Unirradiated Target Shipments From Babcock and Wilcox, Lynchburg, Virginia, To SNL/NM

\begin{tabular}{|c|c|c|c|c|c|c|c|}
\hline \multicolumn{2}{|c|}{ Market Share } & \multicolumn{2}{|c|}{30 percent } & \multicolumn{2}{|c|}{100 percent } & \multicolumn{2}{|c|}{200 percent } \\
\hline \multicolumn{2}{|c|}{ Shipments/yr } & \multicolumn{2}{|l|}{13} & \multicolumn{2}{|l|}{44} & \multicolumn{2}{|l|}{$\overline{87}$} \\
\hline $\begin{array}{l}\text { Mode Of } \\
\text { Shipment }\end{array}$ & Risks & $\begin{array}{l}\text { Person- } \\
\text { Rem }\end{array}$ & LCF & $\begin{array}{l}\text { Person- } \\
\text { Rem }\end{array}$ & LCF & $\begin{array}{l}\text { Person- } \\
\text { Rem }\end{array}$ & LCF \\
\hline \multirow[t]{2}{*}{ Air Cargo } & $\begin{array}{l}\text { Annual } \\
\text { Total }\end{array}$ & $6.0 \mathrm{e}-04$ & $2.6 e-06$ & $2.0 e-03$ & $1.0 e-06$ & $4.0 e-03$ & $2.0 e-06$ \\
\hline & $\begin{array}{l}\text { Life Of } \\
\text { Program }\end{array}$ & $1.8 \mathrm{e}-02$ & $9.0 \mathrm{e}-06$ & $6.1 \mathrm{e}-02$ & $3.1 \mathrm{e}-05$ & $1.2 \mathrm{e}-01$ & $6.0 e-05$ \\
\hline \multirow[t]{2}{*}{ Truck } & $\begin{array}{l}\text { Annual } \\
\text { Total }\end{array}$ & $5.6 e-04$ & $2.8 \mathrm{e}-07$ & $1.9 e-03$ & $9.5 e-07$ & $3.8 \mathrm{e}-03$ & $1.9 e-06$ \\
\hline & $\begin{array}{l}\text { Life Of } \\
\text { Program }\end{array}$ & $1.7 e-02$ & $8.4 e-06$ & $5.7 e-02$ & $2.9 e-05$ & $1.1 \mathrm{e}-01$ & $5.6 e-05$ \\
\hline
\end{tabular}




\subsubsection{Isotope Product Shipments}

\subsubsection{Isotope Product Shipments Associated With Full Purification Of Isotopes At SNLNM}

In Table 5-10 the transportation accident risk estimates of shipping the fully purified isotope products from SNL/NM to three locations (Boston, Chicago, and Saint Louis) are shown. In the transportation model it was assumed that each package of ${ }^{99} \mathrm{Mo},{ }^{133} \mathrm{Xe},{ }^{131} \mathrm{I}$, and ${ }^{125} \mathrm{I}$ was shipped individually. This bounds the potential frequency risk from accidents by maximizing the number of shipments modeled. Approximately 40 percent of the accident risk is associated with shipping ${ }^{99}$ Mo and a similar contribution from the ${ }^{131} 1$ shipments. The risk associated with the ${ }^{133} \mathrm{Xe}$ shipments is approximately 10 percent of the total. This is primarily due to the risk associated with shipping the ${ }^{133} \mathrm{Xe}$ from SNLNM TA-V to Albuquerque International Airport. ${ }^{133} \mathrm{Xe}$ would be shipped in Type A packages that could fail in relatively minor accident environments. The risk associated with the shipments of ${ }^{99} \mathrm{Mo}$ and ${ }^{131} \mathrm{I}$ would be dominated by air-cargo accidents. This is because ${ }^{99} \mathrm{Mo}$ and ${ }^{131} \mathrm{I}$ would be shipped in Type B containers designed to withstand most accident conditions that might be encountered while being shipped from SNLNM TA-V to Albuquerque International Airport.

Table 5-10. Accident Radiological Transportation Risk: Purified Isotope Product Shipment

\begin{tabular}{|c|c|c|c|c|c|c|}
\hline Market Share & \multicolumn{2}{|c|}{30 percent } & \multicolumn{2}{c|}{100 percent } & \multicolumn{2}{c|}{200 percent } \\
\hline Shipments/yr & \multicolumn{2}{|c|}{967} & \multicolumn{2}{c|}{3224} & \multicolumn{2}{c|}{6448} \\
\hline Dose Risk & Person-rem & LCF & Person-rem & LCF & Person-rem & LCF \\
\hline Annual Total & $3.1 \mathrm{e}-02$ & $1.5 \mathrm{e}-05$ & $1.0 \mathrm{e}-01$ & $5.1 \mathrm{e}-05$ & $2.0 \mathrm{e}-01$ & $1.0 \mathrm{e}-04$ \\
\hline $\begin{array}{c}\text { Life of Program } \\
\text { (30 years) }\end{array}$ & $9.2 \mathrm{e}-01$ & $4.6 \mathrm{e}-04$ & $3.1 \mathrm{e}+00$ & $1.5 \mathrm{e}-03$ & $6.1 \mathrm{e}+00$ & $3.1 \mathrm{e}-03$ \\
\hline
\end{tabular}

\subsubsection{Shipment of Unpurified ${ }^{99}$ Mo between SNL/NM and Ottawa, Canada}

As discussed in Section 4.1.4.3.2, the shipping campaign that would result from the option of shipping unpurified ${ }^{99}$ Mo from SNL/NM to Ottawa would be very similar to the shipping campaign for shipping purified isotope products. Thus, the risks associated with shipping unpurified ${ }^{99}$ Mo from SNL/NM to Ottawa instead of shipping purified ${ }^{99}$ Mo from SNL/NM to Boston, Chicago, and St. Louis would be essentially the same.

\subsubsection{Waste Shipments}

Transportation risks associated with both waste disposal options are shown in Table 5-11. With the exception of the destination repository there are would be no differences in the number and types of waste shipments for each option. The dose risk that would be associated with these options would vary according to the distance over which the waste must be shipped and the potentially exposed population living along the waste transportation route modeled in the RADTRAN 4 risk assessment. Accident dose risk estimates for the Hanford option are about a factor of two higher than estimates for the NTS option. The distance covered in a representative highway route between SNL/NM and the NTS is estimated as $1423 \mathrm{~km}$ ( $882 \mathrm{mi}$ ), and between SNL/NM and Hanford as $2594 \mathrm{~km}(1608 \mathrm{mi})$. The potentially exposed population along the 
representative route from SNL/NM to the NTS modeled for the risk assessment is 126,000 , and for the route from SNL/NM to Hanford, the population estimate is 282,000 .

Table 5-11. Accident Radiological Transportation Risk: Waste Shipments

\begin{tabular}{|c|c|c|c|c|c|c|c|}
\hline \multicolumn{2}{|c|}{ Market Share } & \multicolumn{2}{|c|}{30 percent } & \multicolumn{2}{|c|}{100 percent } & \multicolumn{2}{|c|}{200 percent } \\
\hline \multicolumn{2}{|c|}{ Shipments/yr } & \multicolumn{2}{|c|}{23} & \multicolumn{2}{|c|}{75} & \multicolumn{2}{|c|}{149} \\
\hline $\begin{array}{c}\text { Waste site } \\
\text { Option } \\
\end{array}$ & & $\begin{array}{c}\text { Dose Risk } \\
\text { (Person-rem) }\end{array}$ & LCF & $\begin{array}{c}\text { Dose Risk } \\
\text { (Person-rem) }\end{array}$ & LCF & $\begin{array}{c}\text { Dose Risk } \\
\text { (Person-rem) }\end{array}$ & LCF \\
\hline \multirow[t]{2}{*}{ NTS } & Annual Total & $7.1 e-13$ & $3.6 e-16$ & $2.3 e-12$ & $1.2 e-15$ & $4.6 e-12$ & $2.3 e-15$ \\
\hline & $\begin{array}{l}\text { Life of } \\
\text { Program }\end{array}$ & $2.1 e-11$ & $1.1 \mathrm{e}-14$ & $7.0 e-11$ & $3.5 e-14$ & $1.4 e-10$ & $6.9 e-14$ \\
\hline \multirow[t]{2}{*}{ Hanford } & Annual Total & $2.0 e-12$ & $1.0 \mathrm{e}-15$ & $6.7 e-12$ & $3.3 e-15$ & $1.3 e-11$ & $6.6 e-15$ \\
\hline & $\begin{array}{l}\text { Life of } \\
\text { Program }\end{array}$ & $6.1 e-11$ & $3.1 e-14$ & $2.0 e-10$ & $1.0 e-13$ & $4.0 e-10$ & $2.0 e-13$ \\
\hline
\end{tabular}

\subsubsection{Nonradiological Impacts}

Mechanical or non-radiological risks associated with the transportation activities are illustrated in Tables 5-12 and 5-13. These risks are dominated by highway traffic accident risk. Theses risk estimates are most sensitive to increases in distance traveled. Thus, the risk associated with shipping the waste to Hanford would be higher than the risk associated with shipping the waste to NTS. In comparing the results of Tables 5-12 and 5-13 with Table 5-14, it is interesting to note that nonradiological risks (deaths from traffic accidents) are much greater than those from radioactive material accidents risks. For example, if Hanford were the disposal site, the total nonradiological annual transportation accident risk is 0.019 deaths at 100 percent production while the radiological annual accident risk is 0.00005 deaths or about 400 times less. What this means is that a member of the public is 400 times more likely to die from an accident simply involving the truck than from a release of radioactive materials from the truck.

No toxicological impacts would be expected from any accidental release of the materials to be shipped.

\subsubsection{Total Radiological Impacts}

As can be seen from the risk estimates in Table 5-14, the total transportation risk estimates associated with either waste repository option are equivalent. The transportation accident risk is dominated by the risk associated with the shipment of isotope products from SNL/NM to Boston, Chicago, and St. Louis. Thus, even though the increased distance and potentially exposed population associated with shipping the waste to Hanford are approximately a factor of two higher than for the NTS option, the contribution of waste shipments to total risk would be insignificant. As stated in Section 5.5.5, the only shipment characteristic that would differ between the two options would be the waste repository destinations. 
Table 5-12. Accident Non-radiological Transportation Fatality Risk - Annual Risk

\begin{tabular}{|c|c|c|c|c|}
\hline Shipment & Market Share & 30 percent & 100 percent & 200 percent \\
\hline \multirow{2}{*}{ Targets - SNLINM } & Workers & $5.5 \mathrm{e}-05$ & $1.8 \mathrm{e}-04$ & $3.7 \mathrm{e}-04$ \\
\cline { 2 - 5 } & Public & $2.0 \mathrm{e}-04$ & $6.6 \mathrm{e}-04$ & $1.3 \mathrm{e}-03$ \\
\hline \hline \multirow{2}{*}{ Targets - Ottawa } & Workers & $5.5 \mathrm{e}-05$ & $1.8 \mathrm{e}-04$ & $3.7 \mathrm{e}-04$ \\
\cline { 2 - 5 } & Public & $2.0 \mathrm{e}-04$ & $6.6 \mathrm{e}-04$ & $1.3 \mathrm{e}-03$ \\
\hline \hline \multirow{2}{*}{ Isotopes to Airport } & Workers & $4.1 \mathrm{e}-04$ & $1.4 \mathrm{e}-03$ & $2.7 \mathrm{e}-03$ \\
\cline { 2 - 5 } & Public & $1.5 \mathrm{e}-03$ & $4.8 \mathrm{e}-03$ & $9.7 \mathrm{e}-03$ \\
\hline \multirow{2}{*}{$\begin{array}{c}\text { Waste Shipments } \\
\text { to NTS }\end{array}$} & Workers & $9.7 \mathrm{e}-04$ & $3.2 \mathrm{e}-03$ & $6.3 \mathrm{e}-03$ \\
\cline { 2 - 5 } & Public & $3.5 \mathrm{e}-03$ & $1.1 \mathrm{e}-02$ & $2.2 \mathrm{e}-02$ \\
\hline \multirow{2}{*}{$\begin{array}{c}\text { Waste Shipments } \\
\text { to Hanford }\end{array}$} & Workers & $1.7 \mathrm{e}-03$ & $5.4 \mathrm{e}-03$ & $1.1 \mathrm{e}-02$ \\
\cline { 2 - 5 } & Public & $5.8 \mathrm{e}-03$ & $1.9 \mathrm{e}-02$ & $3.7 \mathrm{e}-02$ \\
\hline Total - NTS Waste & Workers & $1.5 \mathrm{e}-03$ & $4.9 \mathrm{e}-03$ & $9.7 \mathrm{e}-03$ \\
\cline { 2 - 5 } Disposal Option & Public & $5.3 \mathrm{e}-03$ & $1.7 \mathrm{e}-02$ & $3.5 \mathrm{e}-02$ \\
\hline \hline Total - Hanford Waste & Workers & $2.2 \mathrm{e}-03$ & $7.1 \mathrm{e}-03$ & $1.4 \mathrm{e}-02$ \\
\cline { 2 - 5 } Disposal Option & Public & $7.6 \mathrm{e}-03$ & $2.5 \mathrm{e}-02$ & $5.0 \mathrm{e}-02$ \\
\hline
\end{tabular}

Table 5-13. Accident Non-radiological Transportation Fatality Risk - Life of Program

\begin{tabular}{|c|c|c|c||c|}
\hline Shipment & Market Share & 30 percent & 100 percent & 200 percent \\
\hline \multirow{2}{*}{ Targets - SNL/NM } & Workers & $1.6 \mathrm{e}-03$ & $5.5 \mathrm{e}-03$ & $1.1 \mathrm{e}-02$ \\
\cline { 2 - 5 } & Public & $5.9 \mathrm{e}-03$ & $2.0 \mathrm{e}-02$ & $3.9 \mathrm{e}-02$ \\
\hline \multirow{2}{*}{ Targets - Ottawa } & Workers & $1.6 \mathrm{e}-03$ & $5.5 \mathrm{e}-03$ & $1.1 \mathrm{e}-02$ \\
\cline { 2 - 5 } & Public & $5.9 \mathrm{e}-03$ & $2.0 \mathrm{e}-02$ & $3.9 \mathrm{e}-02$ \\
\hline \hline \multirow{2}{*}{ Isotopes to Airport } & Workers & $1.2 \mathrm{e}-02$ & $4.1 \mathrm{e}-02$ & $8.1 \mathrm{e}-02$ \\
\cline { 2 - 5 } & Public & $4.4 \mathrm{e}-02$ & $1.5 \mathrm{e}-01$ & $2.9 \mathrm{e}-01$ \\
\hline \hline \multirow{2}{*}{$\begin{array}{c}\text { Waste Shipments } \\
\text { to NTS }\end{array}$} & Workers & $2.9 \mathrm{e}-02$ & $9.5 \mathrm{e}-02$ & $1.9 \mathrm{e}-01$ \\
\cline { 2 - 5 } & Public & $1.0 \mathrm{e}-01$ & $3.4 \mathrm{e}-01$ & $6.7 \mathrm{e}-01$ \\
\hline \hline \multirow{2}{*}{$\begin{array}{c}\text { Waste Shipments } \\
\text { to Hanford }\end{array}$} & Workers & $5.0 \mathrm{e}-02$ & $1.6 \mathrm{e}-01$ & $3.2 \mathrm{e}-01$ \\
\cline { 2 - 5 } & Public & $1.7 \mathrm{e}-01$ & $5.6 \mathrm{e}-01$ & $1.1 \mathrm{e}+00$ \\
\hline \hline Total - NTS Waste \\
Disposal Option & Workers & $4.4 \mathrm{e}-02$ & $1.5 \mathrm{e}-01$ & $2.9 \mathrm{e}-01$ \\
\cline { 2 - 5 } & Public & $1.6 \mathrm{e}-01$ & $5.2 \mathrm{e}-01$ & $1.0 \mathrm{e}+00$ \\
\hline \hline Total - Hanford Waste \\
Disposal Option & Workers & $6.5 \mathrm{e}-02$ & $2.1 \mathrm{e}-01$ & $4.3 \mathrm{e}-01$ \\
\cline { 2 - 5 } & Public & $2.3 \mathrm{e}-01$ & $7.5 \mathrm{e}-01$ & $1.5 \mathrm{e}+00$ \\
\hline
\end{tabular}

Table 5-14. Total Accident Radiological Transportation Risk (Target, Waste, and Product Transportation)

\begin{tabular}{|c|c|c|c|c|c|c|c|}
\hline \multicolumn{2}{|c|}{ Market Share } & \multicolumn{2}{|c|}{30 percent } & \multicolumn{2}{|c|}{100 percent } & \multicolumn{2}{|c|}{200 percent } \\
\hline $\begin{array}{c}\text { Waste site } \\
\text { Option }\end{array}$ & & $\begin{array}{c}\text { Dose Risk } \\
\text { (Person-rem) }\end{array}$ & LCF & $\begin{array}{c}\text { Dose Risk } \\
\text { (Person-rem) }\end{array}$ & LCF & $\begin{array}{c}\text { Dose Risk } \\
\text { (Person-rem) }\end{array}$ & LCF \\
\hline \multirow[t]{2}{*}{ NTS } & Annual Total & $3.1 e-02$ & $1.6 \mathrm{e}-05$ & $1.0 e-01$ & $5.2 e-05$ & $2.1 e-01$ & $1.0 e-04$ \\
\hline & $\begin{array}{l}\text { Life of } \\
\text { Program }\end{array}$ & $9.3 e-01$ & $4.7 e-04$ & $3.1 e+00$ & $1.6 e-03$ & $6.2 e+00$ & $3.1 e-03$ \\
\hline \multirow[t]{2}{*}{ Hanford } & Annual Total & $3.1 \mathrm{e}-02$ & $1.6 e-05$ & $1.0 e-01$ & $5.2 e-05$ & $2.1 \mathrm{e}-01$ & $1.0 \mathrm{e}-04$ \\
\hline & $\begin{array}{l}\text { Life of } \\
\text { Program }\end{array}$ & $9.3 e-01$ & $4.7 e-04$ & $2.7 e+00$ & $1.3 e-03$ & $6.2 e+00$ & $3.1 \mathrm{e}-03$ \\
\hline
\end{tabular}




\section{Maximally Exposed Individual}

The calculation of the maximally exposed individual was estimated using the TICLD code (Weiner, 1993). The most severe foreseeable accident environment model involved major mechanical damage, fire, and oxidation of all of the radioactive material released during such an accident (severity category 6 , see Appendix $L$ ). The dose to a maximally exposed individual located 34 meters (112 feet) from the package and exposed to the entire plume passage and the next 24 hours of exposure to resultant fallout would be:

- 4.2 rem (0.0021 LCFs) for a failed package of ${ }^{99} \mathrm{Mo}$,

- 0.9 rem (0.00045 LCFs) for a failed package of ${ }^{131} \mathrm{I}$,

- 0.02 rem (0.00001 LCFs) for a failed package of ${ }^{133} \mathrm{Xe}$,

- 0.003 rem (0.0000015 LCFs) for a failed package of ${ }^{125} \mathrm{I}$,

- 0.4 rem (0.0002 LCFs) for a failed package of unirradiated targets, and

- 0.0000029 rem (0.0000000015 LCFs) for a failed waste package.

A distance of $34 \mathrm{~m}$ (112 ft) is the maximum distance away from the accident site of the highest downwind concentration used in the risk calculations because the plume would rise for a short downwind distance before starting to fall. The waste would be stabilized, which would greatly retard the release of material even in an extreme accident environment. The isotope products would be shipped in highly dispensable forms.

At such a close distance as $34 \mathrm{~m}(112 \mathrm{ft})$, it is highly probable that the individual, if not evacuated, would be harmed more by the explosion and fire engulfing the cask than by the radiation dose. A dose as low as $4.2 \mathrm{rem}$ in a 24-hour or shorter period would cause no observable clinical effects. An acute dose of around 600 rem results in death of 50 percent of the exposed population within 30 days.

\subsection{Simultaneous Accidents}

The only plausible scenario for simultaneous accidents is one where, due to their proximity an accident at either the ACRR or the HCF could affect the other facility. The structural design and integrity of the HCF and ACRR and the below-ground location of the HCF must be considered for accidents affecting both facilities. The only accident likely to impact both facilities would be an airplane crash resulting in a collapse of the bridge crane in the ACRR while simultaneously causing a fire which damaged the ventilation filters for the HCF. The probability of this event is less than 1 in a million per year making the event not credible. The risks associated with this event on shown in Table 5-15. The average individual in the Albuquerque area would have an annual chance of dying from cancer as a result of a large airplane crashing into the ACRR and HCF of about 1 in $600,000,000,000$.

The risks reported in Table 5-15 do not include the fatalities which would be expected for the crew and passengers of the aircraft or of the SNL/NM personnel working in the facilities impacted by the crash. 
Table 5-15. Simultaneous Accident Risks: Airplane Crash into ACRR and HCF

\begin{tabular}{|c|c|c|c|c|}
\hline $\begin{array}{c}\text { Facility Affected } \\
\text { by Airplane } \\
\text { Crash }\end{array}$ & \multicolumn{2}{|c|}{$1610 \mathrm{~m}$} & \multicolumn{2}{c|}{ Total Population } \\
\cline { 2 - 5 } & $\begin{array}{c}\text { Maximum Public Individual at } \\
\text { Dose Risk } \\
\text { (Person-rem) }\end{array}$ & LCF & $\begin{array}{c}\text { Dose Risk } \\
\text { (Person -rem) }\end{array}$ & LCF \\
\hline ACRR & $9.5 \mathrm{e}-7$ & $4.8 \mathrm{e}-10$ & $1.1 \mathrm{e}-3$ & $5.8 \mathrm{e}-7$ \\
\hline HCF & $8 \mathrm{e}-9$ & $4 \mathrm{e}-12$ & $3.6 \mathrm{e}-4$ & $1.8 \mathrm{e}-7$ \\
\hline Total & $9.6 \mathrm{e}-7$ & $4.8 \mathrm{e}-10$ & $1.46 \mathrm{e}-3$ & $7.6 \mathrm{e}-7$ \\
\hline
\end{tabular}




\subsection{GLOSSARY}

Accelerator: A device for imparting kinetic energy to charged particles, such as electrons, protons, deuterons, and helium ions. Common types of accelerators are the cyclotron, synchrotron, synchrocyclotron, betatron, linear accelerator and Van de Graff electrostatic generator.

Acute Exposure: Term used to denote radiation exposure of short duration.

Air lock: An intermediate chamber between the outer air and a working chamber, generally for the purpose of accommodating transfer of materials while maintaining chamber isolation.

As Low As Reasonably Achievable (ALARA): An approach to radiological control to manage and control doses (individual and collective) received by the work force and to the general public at levels as low as is reasonable, taking into account social, technical, economic, practical and public considerations. As normally used in this document, ALARA is not a dose limit but a process that has the objective of attaining doses as far below the applicable controlling limits as is reasonably achievable.

Background Radiation: Radiation arising from radioactive material naturally occurring in the environment and from cosmic rays.

Charcoal filter: Charcoal filters are used to trap fission product gases from nuclear reactors and radiochemical operations. These filters, also known as activated-carbon absorbers, are made of tightly packed beds of absorbent carbon granules.

Confinement/Containments: Boundaries which prevent and/or control the release of an enclosed substance. A confinement boundary may contain leakage paths; however, release is prevented by negative pressure differentials or other means. A containment boundary is a full enclosure which is sealed to a specified leak rate.

Control rod: Any rod used to control the reaction rate in a nuclear reactor, typically by absorption or reflection of neutrons.

Core: In a nuclear reactor, the region containing the fissionable material. The body of fuel or moderator and fuel in a nuclear reactor.

Critical Assembly: Is an assembly of fissionable materials, moderators and reflectors which have attained or exceeded the critical mass.

Critical Mass: Is the smallest mass of fissionable material that will support a self-sustaining chain reaction under specified conditions.

Decay: Disintegration of the nucleus of an unstable nuclide by the spontaneous emission of charged particles and/or photons.

Decontamination: Process of removing radioactive contamination and materials from personnel, equipment or areas. 
Dose: The amount of energy deposited in body tissue due to exposure to ionizing radiation. Various technical terms, such as dose equivalent, effective dose equivalent and collective dose, are used to evaluate the amount of radiation an exposed worker receives. These terms are used to describe the differing interactions of radiation with tissue as well as to assist in the management of personnel exposure to radiation.

Absorbed dose: Energy imparted to matter by ionizing radiation per unit mass of irradiated material at the place of interest in that material. The units of absorbed doses are the rad and the gray (Gy).

Dose equivalent: Some types of radiation, such as neutron and alpha, deposit their energy more densely in affected tissue than gamma radiation and, thereby, cause more damage to tissue. The term dose equivalent, measured in units of rem, is used to take into account this difference in tissue damage. The product of the absorbed dose in tissue, a quality factor, and all other necessary modifying factors at the location of interest. The units of dose equivalent are the rem and sievert (Sv).

Effective dose equivalent (EDE): The sum of the products of the dose equivalent to the organ or tissue and the weighting factors applicable to each of the body organs or tissues that are irradiated.

Committed dose equivalent (CDE): The dose equivalent to organs or tissues of reference that will be received from an intake of radioactive material by a person during the 50-year period following the intake.

Committed effective dose equivalent (CEDE): The sum of the products of the weighting factors applicable to each of the body organs or tissues that are irradiated and the committed dose equivalent to these organs or tissues.

Quality Factor: Dimensionless weighting number used to take into account the differences in tissue damage due to radiation.

\section{UNITS FOR DOSE:}

RAD (Radiation Absorbed Dose): The unit of absorbed dose, which is 100 ergs/gram in any medium.

REM (Roentgen Equivalent Man): The dose in rems is equal to the absorbed dose in rads times a quality factor for the type of radiation being absorbed.

Sievert (Sv): SI unit of any of the quantities expressed as dose equivalent. The dose equivalent in sieverts is equal to the absorbed dose in grays multiplied by the quality factor ( $1 \mathrm{~Sv}=100 \mathrm{rems})$.

Dosimeter: Instrument used to detect and measure an accumulated dosage of radiation.

Enriched: Material (e.g. Uranium) in which the relative amount of one or more isotopes of a constituent has been increased, e.g., uranium in which the abundance of the U235 isotope is increased above the naturally occurring amount of 0.71 percent. 
Exclusion zone: Defined in 10 CFR 100 as "that area surrounding the reactor in which the reactor licensee has the authority to determine all activities, including exclusion or removal of personnel and property from the area. This area may be transversed by a highway, railroad, or waterway, provided that these are not so close to the facility as to interfere with normal operation of the facility and provided appropriate and effective arrangements are made to control traffic on the highway, railroad, or waterway, in case of emergency, to protect the public health and safety. Residence within the exclusion zone will normally be prohibited."

Extraction: For the purpose of the production of molybdenum-99, extraction refers to the first step performed in the chemical separation of the molybdenum-99 from the other fission products which are produced during the irradiation of uranium-235. Additional chemical separations are then performed to purify the molybdenum-99 product.

Fissile Classification: Classification of a package or shipment of fissile materials according to the controls needed to provide nuclear criticality safety during transportation as follows:

Fissile Class I: Packages that may be transported in unlimited numbers and in any arrangement and that require no nuclear criticality safety controls during transportation. For purposes of nuclear criticality safety control, a transport index is not assigned to Fissile Class I packages. However, the external radiation levels may require a transport index number.

Fissile Class II: Packages that may be transported in any arrangement but in numbers that do not exceed a transport index of 50 . For purposes of nuclear criticality safety control, individual packages may have a transport index of not less than 0.1 and not more than 10. However, the external radiation levels may require a high transport index number but not to exceed 10 . Such shipments require no nuclear criticality safety control by the shipper during transportation.

Fissile Class III: Shipments of packages that do not meet the requirements of Fissile Class I and II and that are controlled in transportation by special arrangements between the shipper and the carrier to provide nuclear criticality safety.

Fission: The splitting of an atomic nucleus, resulting in the release of fission products, neutrons, and energy.

Fission Products: Elements or compounds which result from the fission process.

Gamma radiation: Short wavelength electromagnetic radiation of nuclear origin with a range of wave lengths from about $10^{-8}$ to $10^{-11} \mathrm{~cm}$, emitted from the nucleus of an atom.

High Efficiency Particulate Air (HEPA) filter: Throw-away, extended pleated medium drytype filter with 1) a rigid casing enclosing the full depth of the pleats, 2) a minimum particle removal efficiency of 99.97 percent for thermally generated monodisperse smoke particles with a diameter of 0.3 micrometer, and 3) a maximum pressure drop of 1.0 inch w.g. when clean and operated at its rated airflow capacity. 
lonizing radiation: Any electromagnetic or particulate radiation capable of producing ions, directly or indirectly, in its passage through matter.

Irradiation: Exposure to radiation; typically exposure to neutron radiation which might be present near or within the core of a nuclear reactor.

Isotope: One of several nuclides having the same number of protons in their nuclei, and hence having the same atomic number, but differing in the number of neutrons, and therefore in the mass number(e.g. U235, U238). Almost identical chemical properties exist between isotopes of a particular element.

Latent cancer fatality: The term Latent Cancer Fatality (LCF) refers to cancer that is induced by the exposure to, or intake of, chemical or radioactive materials, but does not become evident for many years after the exposure or intake has occurred.

Long-lived radionuclide: In reference to the production of molybdenum- 99 , which has a halflife of about 67 hours, the term long-lived radionuclide refers to radionuclides with half-lives that are greater than a few months.

Low-level waste: Low-level waste is defined as waste that contains radioactivity and is not classified as high-level waste, transuranic waste, spent nuclear fuel, or material defined as $11 \mathrm{e}(2)$ by-product material under the Atomic Energy Act.

Maximum exposed individual: A theoretical individual defined to allow dose or dosage comparison with numerical criteria for the public. This individual is located at the point either on or off the DOE site nearest to the facility in question.

Medical Isotope: The term medical isotope refers to radioactive isotopes that are used for the purpose of medical treatment or diagnosis. These include technetium-99m, iodine-125, iodine131 , xenon-133, and cobalt-60. These isotopes can be prepared in a variety of chemical forms, depending on the specific medical need.

Mixed waste: Mixed waste consists of waste that contains both a radioactive component regulated under the Atomic Energy Act and a hazardous component regulated by the EPA Resource Conservation and Recovery Act.

Neutralize: To make chemically neutral, or to adjust the pH to approximately 7.

North American demand: Term used to define the total demand for medical radioisotopes for the North American Continent (including the United States, Canada, and Mexico). As usually used, this term defines the production requirement (approximately 16,400 curies from the reactor) to satisfy 100 percent of the North American ${ }^{99}$ MO demand in 1994.

Radiation: The emission and propagation of energy through space or through a material in the form of waves; for instance the emission and propagation of electromagnetic waves.

Radioactive air emissions: Air effluent which contains a radioactive component.

Radioisotope: A radioactive isotope. 
Radiological impact: The term radiological impact refers to impacts on human health due to exposure to, or intake of, radioactive materials. These impacts are typically described as damage to organs or the induction of cancer.

Radiopharmaceuticals: The term radiopharmaceuticals is used to describe products that include radioactive materials that are prepared, produced, or packaged by the pharmaceutical industry for use in nuclear medicine. Typically, radiopharmaceuticals include one or more of the medical isotopes as the radioactive material.

Reactor: An apparatus in which nuclear fission may be sustained in a self-supporting chain reaction. It includes fissionable material, such as uranium, and moderating material, such as graphite or water, provision for heat removal, and control elements.

Shielding: Material used to prevent or reduce the passage of particles or radiation. It may be required for the safety of personnel or to reduce radiation sufficiently to allow use of counting instruments.

Short-lived radionuclide: In reference to the production of molybdenum-99, which has a halflife of about 67 hours, the term short lived radionuclide refers to radionuclides with half-lives that are less than a few days.

Special Nuclear Materials (SNM): Plutonium, uranium-233, uranium enriched in uranium-233 or uranium-235, or any material artificially enriched in any of the foregoing (but does not include source material) and any other material that, pursuant to the provisions of Section 51 of the Atomic Energy Act of 1954, as amended, has been determined to be special nuclear material.

Spent nuclear fuel: fuel that has been withdrawn from a nuclear power reactor following irradiation, the constituent elements of which have not been separated by reprocessing.

Steel confinement box (SCB): For the purpose of molybdenum-99 production, a steel confinement box (SCB) is a box consisting of shielding used to protect personnel outside the box from exposure to radioactivity, manipulators for working inside the box remotely (without handling the materials directly), and a ventilation system that filters all air exhausted from the box. SCBs are located in the Hot Cell Facility.

Target: Cylindrical sealed elements irradiated in the ACRR core for the purpose of generating radioisotopes either from fission or absorption. Fission targets contain enriched uranium plated on the inner cylinder wall for the purpose of generating numerous radioisotopes from fission of ${ }^{235} \mathrm{U}$ (e.g., ${ }^{99} \mathrm{Mo},{ }^{131} \mathrm{l},{ }^{133} \mathrm{Xe}$ ). Absorption targets contain isotopes that produce the desired radioisotope (e.g., ${ }^{125} \mathrm{I}$ ) by neutron absorption. 
Transport index (TI): means the dimensionless number (rounded up to the first decimal place) placed on the label of a package to designate the degree of control to be exercised by the carrier during transportation. The transport index is determined as follows: (1) The number expressing the maximum radiation level in millirem per hour at one meter ( 3.3 feet) from the external surface of the package; or (2) for Fissile Class II packages or packages in a Fissile Class III shipment, the number expressing the maximum radiation level at one meter ( $3.3 \mathrm{feet}$ ) from the external surface of the package, or the number obtained by dividing 50 by the allowable number of packages which may be transported together, whichever is larger.

Toxicological impact: The term toxicological impact refers to impacts on human health due to exposure to, or intake of, chemical materials. These impacts are typically described in terms of the damage to organs or the induction of cancer.

Uranium, U235: U235 is an isotope of uranium with an atomic weight of 235 . This atomic weight includes 92 protons and 143 neutrons.

${ }^{99}$ Mo: Molybdenum 99 , the isotope of molybdenum with mass number 99 , which contains 42 protons and 57 neutrons.

1251: lodine 125 , the isotope of iodine with mass number 125 , which contains 53 protons and 72 neutrons.

${ }^{131}$ I: lodine 131 , the isotope of iodine with mass number 131 , which contains 53 protons and 78 neutrons.

${ }^{133}$ Xe: Xenon 133, the isotope of Xenon with a mass number 133 , which contains 54 protons and 79 neutrons. 


\subsection{REFERENCES}

Bowen, B. M., 1990, Los Alamos Climatology, Los Alamos National Laboratory report LA11735-MS.

CEQ, see Council on Environmental Quality.

Chanin, D.I. et al., 1990, MELCOR Accident Consequence Code System (MACCS), NUREG/CR-4691, U.S. Nuclear Regulatory Commission.

Coats, D. W., and Murray, R. C., 1984, Natural Phenomena Hazards Modeling Project: Extreme Wind/Tornado Hazard Models for Department of Energy Sites, UCRL53526, Rev. 1, Lawrence Livermore National Laboratory, Livermore, California.

Committee on Government Operations, 1992, One Hundred Second Congress, August 12, 1992.

Council on Environmental Quality (CEQ), 1978, Regulations on Implementing NEPA Procedures, Part 1500-1508, 43 FR 5-5990, Washington D.C.

Croff, A. G., 1991, ORIGEN2.1 Isotope Generation and Depletion Code, CCC-371, Oak Ridge National Laboratory, Oak Ridge, Tennessee.

Culp, T., et. al., 1992, SNLNM Annual Environmental Monitoring Report, SAND 920939:UC-630, Sandia National Laboratories, Albuquerque, New Mexico.

Culp, T., et. al., 1993a, SNLNM Annual Environmental Monitoring Report, SAND931448:UC-630, Sandia National Laboratories, Albuquerque, New Mexico.

Culp, T., et. al., 1993b, 1993 Site Environmental Report Sandia National Laboratories, Albuquerque, New Mexico. SAND94-1293:UC-630, Sandia National Laboratories, Albuquerque, New Mexico.

DOE see U.S. Department of Energy.

FR see U.S. Federal Register.

Key, C. 1995, Conversation between Dr. Charles Key and Dr. Susan Carson, New Mexico Tumor Registry, University of New Mexico School of Medicine, January 13, 1995.

LANL see Los Alamos National Laboratory.

LATA see Los Alamos Technical Associates.

Los Alamos National Laboratory (LANL), 1991, Waste Management at Los Alamos: Protecting Our Environment, LALP-90-30, Los Alamos National Laboratory, Los Alamos, NM, June 1991. 
Los Alamos National Laboratory (LANL), 1993, Environmental Protection Group, Environmental Surveillance at Los Alamos During 1991, LA-12572-ENV, Los Alamos National Laboratory, Los Alamos, NM.

Los Alamos National Laboratory (LANL), 1994, Environmental Protection Group, Environmental Surveillance at Los Alamos During 1992, LA-12764-ENV, Los Alamos National Laboratory, Los Alamos, NM.

Los Alamos Technical Associates (LATA), 1991, AIRDOS-EPA Data Upgrade and Dose Calculations for Sandia National Laboratories Facilities at Sandia, and Sandia, Tonopah Test Range, prepared for Sandia National Laboratories, Albuquerque, NM.

Malenfant, R.E., Forehand, H. M., Koelling, J. J., 1980, SHEBA: A Solution Critical Assembly, Transactions of the American Nuclear Society, 35:279-280.

Massey, C. D., T. A. Wheeler, and H. R. Yoshimura, 1993, Comparison of Differences Between Ports for Radioactive Material Transport, Sandia National Laboratories, Albuquerque, New Mexico for U.S. Department of Energy contract DE-AC0494AL58000.

Massey, C. D., and A. P. Litman, 1994, Radiological Analyses for Importation of Russian Uranium, WAM-B2, Sandia National Laboratories, Albuquerque, New Mexico.

Miller, A. B., Howe, G. R. et al., 1989, Mortality From Breast Cancer After Irradiation During Fluoroscopic Examinations in Patients Being Treated for Tuberculosis, New England Journal, Med 321 (1285-1289).

Mills, G. S., and K. S. Neuhauser, 1994, Cumulative Dose to Members of the Public from Routine Highway Transportation of RAM, Waste Management '94, University of Arizona, Tucson, Arizona.

NAS see National Academy of Sciences, Committee on Effects of lonizing Radiation.

National Academy of Sciences Committee on the Effects of lonizing Radiation (NAS), 1990 Health Effects of Exposure to Low Levels of lonizing Radiation (BEIR V), National Academy of Sciences, Washington, D.C.

Neuhauser, K. S. And F. L. Kanipe, 1992, RADTRAN 4 - Volume III: User Guide, SAND892370, Sandia National Laboratories, Albuquerque, NM, January 1992.

NRC see U.S. Nuclear Regulatory Commission.

Nuclear Safety, Vol. 13, No. 1, January-February 1972, pp. 57-58.

ORNL (Oak Ridge National Laboratory), 1992, P. Johanson, Highway 5.0 - An Expanded Highway Routing Model: Program Description, Methodology and Revised User's Manual, ORNL/TM-12124, Oak Ridge National Laboratory, Oak Ridge, TN, 1992. 
Parks, B. S. 1992, User's Guide for CAP88-PC, 402-B-92-001, U.S. Environmental Protection Agency, Las Vegas, NV.

Potenza, R. M. (ed), 1966, Quarterly Technical Report - Spert Project (January, February, March 1966), IDO-17206, Phillips Co.

Powers, D. A., 1991, An Analysis of Radionuclide Behavior in Water Pools During Accidents at the Annular Core Research Reactor, SAND91-1222, Sandia National Laboratories, Albuquerque, NM.

Restrepo, L. F, 1992, The Annular Core Research Reactor (ACRR) Postulated Limiting Event, Initial and Building Source Terms, SAND91-0571, Sandia National Laboratories, Albuquerque, NM.

Restrepo, L. F., 1994, Hot Cell Facility (HCF) Safety Analysis Report, SAND94-2650 Unlimited Release, Sandia National Laboratories, Albuquerque, New Mexico.

Reuscher, J. A., Schmidt, T. R. and Pickard, P. S., 1982, Experimental Capabilities of the Annular Core Research Reactor, SAND81-2139C, Sandia National Laboratories, Albuquerque, NM.

Romero, V.D., 1994, Telephone Conversation with the Health Physics Department of DuPont Merck, Boston, MA, December 1994.

Savoie, R. A., Singh, B. P., 1994, Independent Assessment of the DOE Plan to Establish a United States Production Source for Molybdenum-99, Jupiter, Corp., Washington, D.C.

Seylar, R., 1994. Memorandum dated November 16, 1994, from R. Seylar, SNL, to D. L. Miller, SNL subject: Approval to Dispose of Non-Defense Low-Level at the Nevada Test Site.

Ullrich, R. L., and Jernigan, M. C., et al., 1987 Radiation Carcinogenesis: Time Dose Relationships, Radiat. Res. 111 (179-184).

U.S. Council for Energy Awareness, 1993 What do You Know about Low-Level Radioactive Waste?; Washington, D.C., October 1993.

U.S. Department of Energy (DOE), 1979, Final Environmental Impact Statement: Los Alamos Scientific Laboratory Site, Los Alamos, New Mexico," U. S. Department of Energy report DOE/EIS-0018, December 1979.

U.S. Department of Energy (DOE), 1988, Radioactive Waste Management, DOE Order 5820.2A, US Department of Energy, Washington, D.C.

U.S. Department of Energy (DOE), 1991, Nuclear Safety Policy, Secretary of Energy Notice SEN-35-91, U.S. Department of Energy, Washington, D.C. 
U.S. Department of Energy (DOE), 1994, Transfer of the Annular Core Research Reactor and Associated Hot Cell Facilities from the Office of Defense Programs to the Office of Nuclear Energy for conversion to the production of molybdenum-99, Memorandum from Daniel A. Dreyfus, Acting Director, Office of Nuclear Energy, Washington, D.C.

U.S. Federal Register (FR), 1994, Advance Notice of Intent to Prepare a Site-Wide Environmental Impact Statement for Los Alamos National Laboratory, 59 FR 40889, August 10, 1994.

U.S. Nuclear Regulatory Commission (NRC), 1977 Final Environmental Statement on the Transportation of Radioactive Material by Air and Other Modes, NUREG-0710, Vols. I and II, Office of Standards Development, USNRC, Washington, D.C.

U.S. Nuclear Regulatory Commission (NRC), 1991, Preamble to Standards for Protection Against Radiation, 56 Federal Register 23363, May 21, 1991.

Weiner, R. S., La Plante, P. A., and Hageman, J. P., 1991, Risks of Incident Free Transportation of Radioactive Materials by Highway, Risk Analysis, Vol. II, pp. 660666, December, 1991.

Weiner, R. F., Neuhauser, K. S. and Kanipe, F. L., 1993, Maximum Individual Risks From Transported Spent Nuclear Fuel, TTC-1230, presented at The 4th Annual International High-Level Radioactive Waste Management Conference \& Exposition, April 1993, Las Vegas, Nevada. 


\section{APPENDICES}

A 



\section{APPENDIX A \\ DESCRIPTION OF MEDICAL \\ ISOTOPE PRODUCTION PROCESS}




\section{APPENDIX A \\ DESCRIPTION OF MEDICAL \\ ISOTOPE PRODUCTION AND DISTRIBUTION PROCESSES}

The following section provides a detailed description of the isotope production process discussed in the study. The descriptions in this section are based on the production and extraction process used by Cintichem to produce ${ }^{99} \mathrm{Mo}$ in the late $1980 \mathrm{~s}$, and the distribution process currently used by Nordion to provide the North American supply of ${ }^{99} \mathrm{Mo}$.

\section{A.1 Target Fabrication}

In full production mode, up to 40 targets, each containing a maximum of $25 \mathrm{~g}{ }^{235} \mathrm{U}$, would be produced each week, 50 weeks per year. Maximum expected annual needs would be 2,080 targets containing up to $50 \mathrm{~kg}(116 \mathrm{lb}){ }^{235} \mathrm{U}$. This activity would continue for the foreseeable future.

Powdered $\mathrm{U}_{3} \mathrm{O}_{8}$, obtained from Los Alamos National Laboratory (LANL) inventories and enriched to 93 percent ${ }^{235} \mathrm{U}$, is regularly stored in double sealed canisters in CMR vault. $A$ canister would be carried into the target fabrication area and introduced into the glove box containing the dissolution tank. ${ }^{235} \mathrm{U}_{3} \mathrm{O}_{8}$ would be dissolved in concentrated nitric acid (about $250 \mathrm{~g}$ in 50 liters concentrated $\mathrm{HNO}_{3}$ ). The solution would be neutralized by adding ammonium oxalate and formic acid. The solution would be transferred by the wet vacuum system to the electrocoating tanks.

A target tube would be connected to a direct current source as the cathode. A graphite rod, centered inside the tube, would act as the anode. The tube would be placed in the ${ }^{235} \mathrm{U}$ solution which would be pumped through the tube. The current would be about 12 amps at low direct current (DC) voltage. The electrocoating apparatus would operate at $91^{\circ} \mathrm{C}\left(196^{\circ} \mathrm{F}\right)$, regulated by hot water flowing through the external jackets on the outsides of the tubes. The electrocoating process would continue for 12 to 15 hours, to deposit up to $25 \mathrm{~g}$ of ${ }^{235} \mathrm{U}$ oxide inside each target. Some tubes may be electrocoated with less than $25 \mathrm{~g}^{235} \mathrm{U}$.

In an exhaustive quality assurance/quality control program, targets would be checked for quantity, integrity, and uniformity of plating. Each tube would be tested for ability to withstand thermal stresses of a reactor by heating it to about $500^{\circ} \mathrm{C}\left(930^{\circ} \mathrm{F}\right)$. In the pyrolyzing and welding glove box, the top and bottom caps would be welded in place. The welds would be checked visually and then leak tested in a hypobaric chamber. Any tube with a detectable leak would be rejected.

Tubes would be moved to the assay and quality assurance station for final verification of uranium weight, tube dimensions, identification, etc. Again, any tube which did not meet specifications would be rejected. Tubes that met specifications would be placed in the CMR vault pending shipment. Up to 1,000 targets for each reactor could be accumulated at any time, in order to provide for fluctuations in demand and transportation schedules. At any time the vault might contain $53 \mathrm{~kg}$ (116 lb) of ${ }^{235} \mathrm{U}$ electrocoated in targets. 


\section{A.1.1 Waste Management}

The target fabrication activities would not require expansion of existing waste management or disposal facilities at LANL, nor construction of new facilities.

The spent electrocoating solution would be passed through an ion exchange column to remove remaining uranium, after which it would contain trace quantities of ${ }^{235} \mathrm{U}$, below the economic discard limit. The neutralized solution would be put into the radioactive liquid waste line which connects to the Radioactive Liquid Waste Treatment Facility (RLWTF) at TA-50. Alternatively, the solution could be pumped to interim liquid waste storage tanks behind CMR and rerouted to RLWTF later. Wastewater volume would not exceed 100,000 liters (26,000 gallons) annually.

The ion exchange resin and rejected tubes would be sent to the Uranium Processing Group in Wing 4 of CMR where residual uranium could be reclaimed for reuse in the target fabrication process. This reclamation process is an ongoing operation; no change would be expected.

During normal operations, target fabrication processes would produce no radioactive air emissions. The only emissions would be inert gases from the glove boxes, a small volume of hydrogen from chemical reactions, and small volumes of welding gases which are not regulated by the New Mexico Environment Division (NMED) (NMEIB, 1988). The hydrogen would be diluted in the glove box air stream to below the lower explosive limit.

Some solid LLW, mainly gloves and laboratory apparatus, would be produced annually, estimated at about $5 \mathrm{~m}^{3}\left(175 \mathrm{ft}^{3}\right)$.

No hazardous waste and no mixed waste would be produced.

\section{A.1.2 Staging Tubes for Transportation}

Finished tubes would be accumulated in the CMR vault pending shipment. Up to 1,000 targets for each reactor could be held before shipment. The shipment schedule would be developed later. The vault inventory of ${ }^{235} \mathrm{U}$ would be about constant as uranium would be stored in the vault as ${ }^{235} \mathrm{U}_{3} \mathrm{O}_{8}$, then plated in targets, and returned to the vault pending shipment.

\section{A.1.3 Waste Minimization}

Waste minimization would be implemented to the extent consistent with good and safe laboratory practices. Uranium from the ion exchange resin and rejected targets would be reclaimed for reuse as stated.

Uncontaminated wastes from construction and other activities would be collected by Johnson Controls World Services $(\mathrm{JCl})$, the contractor who manages LANL's uncontaminated waste. The LANL/JCl team has such a strong waste minimization program that in $1993 \mathrm{JCl}$ received DOE's award for redirecting waste to salvage and reuse.

\section{A.1.4 Criticality Safety and Hazard Category}

No more than $800 \mathrm{~g}(1.8 \mathrm{lb})$ of ${ }^{235} \mathrm{U}$ would be placed in any glove box at a time for reasons of criticality safety. A maximum of $6 \mathrm{~kg}(2.7 \mathrm{lb}){ }^{235} \mathrm{U}$ would be permitted in the target fabrication area, consistent with Category III limits. 


\section{A.2 ACRR Operations}

Calculations indicate that for a 129 fuel element core configuration, 19 to 37 targets irradiated in the central region of the core with the cavity liner removed would provide the North American demand for ${ }^{99} \mathrm{Mo}$. This is a relatively minor modification to the core configuration. With the 19 target configuration as the baseline, the average target power would be $21.1 \mathrm{~kW}$ and the core power 1.92 MW. A sufficient amount of margin and flexibility exists in the core to allow for a high degree of confidence that the North American demand can be met. The actual target fuel configuration to be employed depends on the production goal (fraction of North American demand) at any given time. However, the target/core configurations chosen are robust enough to cover the possibilities for $20 \%$ to $100 \%$ and greater shares of the North American market.

Since the ACRR is an open pool reactor, targets as well as fuel elements are readily accessible. They can be transferred underwater with minimum down time and transfer time (a few minutes per target or fuel element) to the GIF pool for loading to a transfer cask for on-site movement to the HCF. After removal of an irradiated target from the core, it would be transferred via the pass-through ports to a rack in the GIF pool, or into the cask. The cask would be removed from the pool, surveyed for exposure and contamination, and would be moved using a transfer vehicle.

The activity of a target following a $7-$ day, $21-\mathrm{kW}$ irradiation would be $20,000 \mathrm{Ci}$. Although this is very high activity, the isotopes are mostly short-lived. Three meters ( 10 feet) of water reduces the radiation level from a target to $\sim 20 \mathrm{millirem} /$ hour $(\mathrm{mrem} / \mathrm{hr})$ at the surface. The dose rate one meter ( 3 feet) from the centerline of a cask with $20 \mathrm{~cm}$ ( 7.87 inches) of depleted uranium as the shield is $\sim 0.2 \mathrm{mrem} / \mathrm{hr}$.

\section{A.3 Transfer to the HCF}

This section describes the transfer of the target from the reactor facility to the hot cell facility. Operational requirements are based upon operation of the target elements at $21 \mathrm{~kW}$ for 7 days prior to their removal from the core. Since the targets must be processed soon after removal from the ACRR, they are very active and must be shielded from operational personnel during target movement. That shielding is provided by the pool water initially, then by the transfer cask, and finally by the shielding walls of Zone $2 A$ within the HCF.

\section{Transportation Specifics}

The targets, having been irradiated within the reactor at a power level of about $21 \mathrm{~kW}$ for one week, would be removed only upon shutdown of the reactor. The total time between reactor shutdown for target extraction and shipment of the pharmaceutical product is anticipated to be between 6 and 12 hours, which accounts for both processing time and any target decay necessary before processing is initiated.

After shutdown, a transport cask would be lowered into the GIF pool, opened, and readied for receipt of the target. It is anticipated that the operational time to place and prepare the cask within the GIF pool would be approximately 30 minutes. At that time, the fission product activity would result in 100 watts beta activity and 90 watts gamma activity, sufficiently low to prevent heat-generated optical distortion within the pool. The targets would then be moved from the reactor, transferred to the GIF pool through the fuel handling ports, and placed immediately within the transport cask. For each target removed, a new target would be inserted in the reactor. 
After loading the transport cask with the required number of targets, the cask would be closed and removed from the GIF pool. A drain hose would be attached to the cask and the system purged of the majority of GIF pool water, and the system would be checked for leaks.

The hot cell crew would move the cask to the hot cell utilizing a manned transporter. The transporter would exit the reactor facility through an air lock, which would permit the continued operation of the reactor, and proceed down the ramp of the HCF. The transporter would enter the HCF through the rollup door at the west end of the HCF, then proceed to the HCF transporter airlock. Once through the airlock, the manned transporter would move the transport cask to the shielded region of Zone $2 \mathrm{~A}$.

The cask would then be opened and one or more targets transferred to dedicated processing boxes designed to conduct the initial isotope extraction from the bulk fission products. If parallel processing lines are operated, targets are moved from the cask to an additional processing box. Once emptied of the targets, the transfer cask is removed from Zone 2A, inserted into its overpack, and returned to the reactor facility to await the next movement of targets.

\section{Manned Transporter Specifications}

The targets would be moved between the Reactor Facility and Hot Cell Facility within Technical Area $V$ by utilizing either the HCF forklift, the Reactor Facility forklift or a modified forklift transporter. These forklifts are similar in design and have a lifting capacity of $10000 \mathrm{lb}$. Either of these forklifts would be adequate for the job, and designation of primary and secondary units would be completed before routine production is undertaken.

The movement of targets from the Reactor Facility to the HCF is anticipated to be conducted up to three times per day, five days of the week, 52 weeks of the year. The number of targets transported would depend upon the DOE requested production rate, but should be bounded between one and eight targets.

\section{A.4 Isotope Extraction at HCF}

The extraction process for $99 \mathrm{Mo}$ is a combined chemical/distillation process in which the noble gases and iodine are condensed from the target fill gas; the fuel and fission products are dissolved from the inside of the target; chemicals are added to maintain specific fission products in solution; the molybdenum is precipitated, filtered, and purified and finally the precipitated molybdenum is re-dissolved for shipment to the necessary pharmaceutical companies. The extraction process is anticipated to provide necessary radioisotopes of xenon, iodine, and molybdenum.

Each target would yield approximately 600 curies of ${ }^{99} \mathrm{Mo}, 200$ curies of ${ }^{131} \mathrm{I}$ and 600 curies of ${ }^{133} \mathrm{Xe}$ one day after discharge from the reactor. One-half liter of process liquid is generated per target. This liquid is neutralized, stabilized, allowed to decay, and then shipped to an approved low-level waste site. Although shipments to the disposal site could be made as soon as six months after generation, sufficient storage exists within the HCF to allow up to one year's storage at the $200 \%$ North American demand level before waste disposal must be initiated. 
The chemical recovery of $99 \mathrm{Mo}$ from the targets proceeds only after a decay period of one to six hours after removal from the reactor. The processing takes place in sealed hot cells which have fixtures to facilitate remote handling. After the decay period, the gaseous fission products are removed by condensation into a trap. Next, an acid cocktail $\left(\mathrm{H}_{2} \mathrm{SO}_{4}\right.$ and $\left.\mathrm{HNO}_{3}\right)$ is used to dissolve the uranium target and fission products (see Figures A-1 through A-5). The dissolution is aided by heating. Gases that are evolved during the dissolution are removed by a second trap/condensation step. The targets are then drained and rinsed of the uranium/fission product solution. Several small additions ( $\mathrm{Nal}, \mathrm{AgNO}_{3}$, and $\mathrm{HCl}$ ) are then made to the raw fission products to precipitate iodine. Following the iodine precipitation, a molybdenum carrier solution is added to the uranium fission product solution. This is followed by the addition of an oxidizing agent $\left(\mathrm{KMnO}_{4}\right)$. After the desired oxidation states of the species in solution are reached, carriers are added for rhodium and ruthenium and the molybdenum is selectively precipitated by the addition of benzoin- $\alpha$-oxime. The precipitate is then separated from the solution by filtration. Multiple acid rinse steps and filtrations are used to insure maximum molybdenum recovery. At this point in the process, the filtrate is set aside for neutralization and then is processed as waste.

The recovered molybdenum is then subjected to several purification steps. First the filtercake is repeatedly washed with an acid solution $\left(\mathrm{H}_{2} \mathrm{SO}_{4}\right)$. The precipitated iodine is still present at this point of the process. The molybdenum precipitate is then dissolved by adding a base solution $(\mathrm{NaOH})$ containing an oxidizing agent $\left(\mathrm{H}_{2} \mathrm{O}_{2}\right)$ and heating. This process also returns the iodine to solution. The dissolution step is repeated twice and the resulting solutions are collected in a single vessel along with a rinse solution. The activity of the collected solution is measured at this point to verify that the molybdenum is present. The solution is then purified by passing it through a column (silver supported on charcoal) to adsorb impurities. This step removes iodine and other impurities which color the solution. After rinsing the column, the resulting clear, colorless solution is monitored for activity to verify that the molybdenum was not retained on the column. Next, another iodine precipitation is performed on the solution. The solution is then filtered through a second column containing three separate purifying agents (silver on charcoal, hydrated zirconium oxide, and activated carbon). The resulting final product solution is passed through a 0.2 micron $(\mu \mathrm{m})\left(\sim 8 \times 10^{-6}\right.$ inch) filter into the final product bottle. The activity of the product is measured and samples are submitted for assay and quality control. Quality control tests that are performed include ${ }^{99} \mathrm{Mo}$ concentration, $\alpha$-contamination, and radionuclidic purity. Batches that fail to meet purity specifications may be reprocessed/purified as necessary. 
Figure A-1. Cintichem Process Stage 1: Fission Product Dissolution

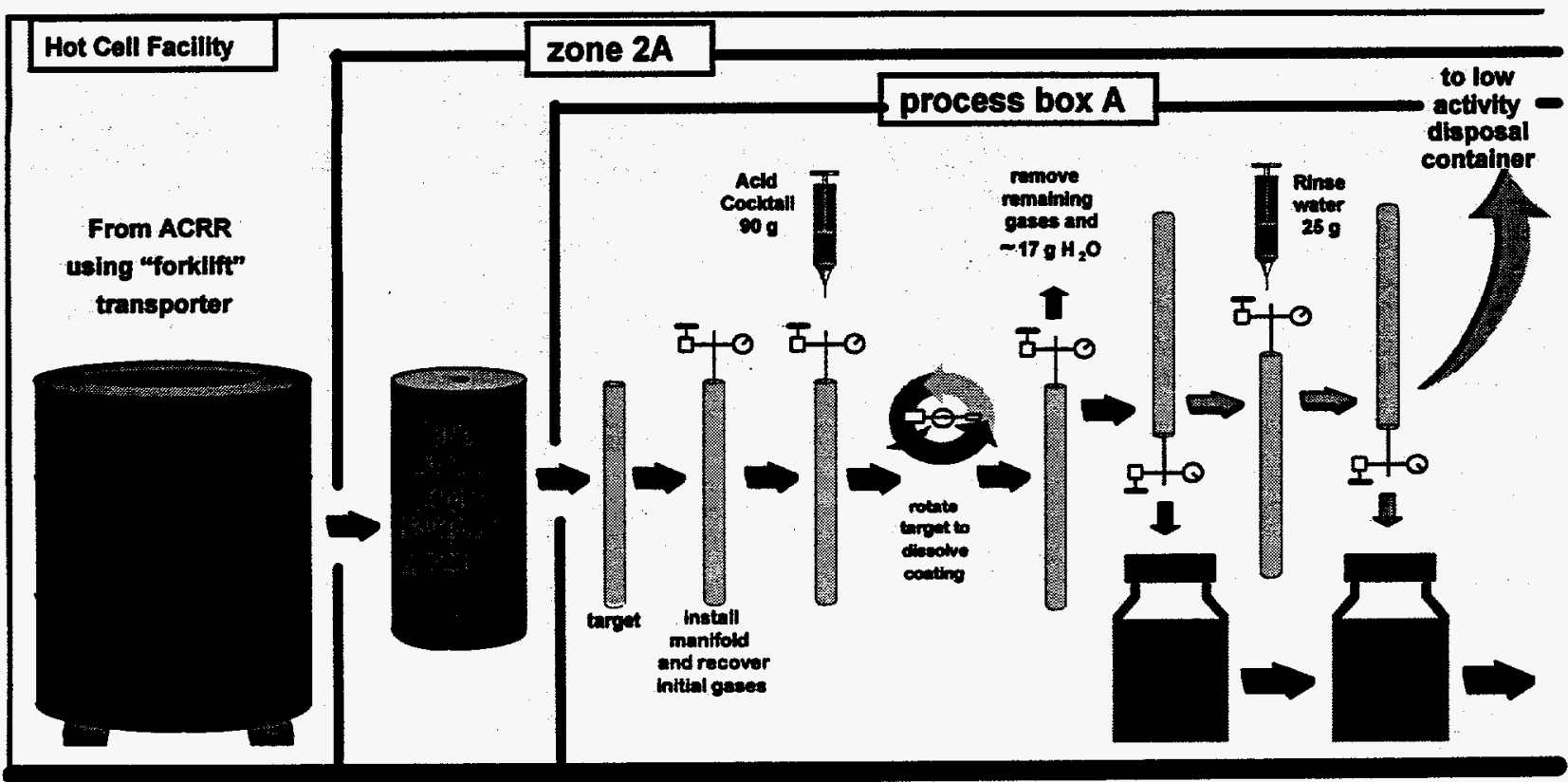

Figure A-2. Cintichem Process Stage 2: Precipitation Preparation

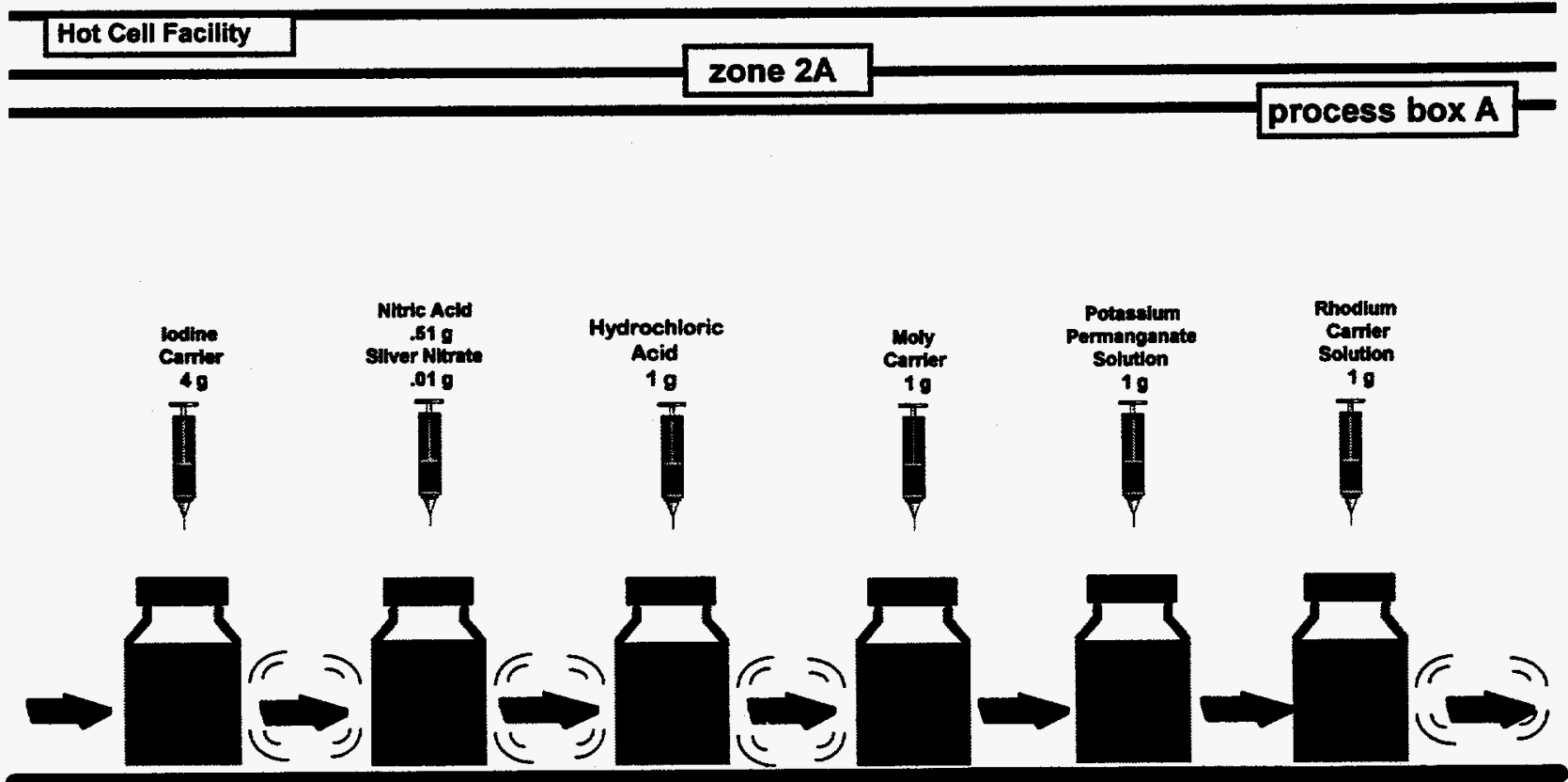


Figure A-3. Cintichem Process Stage 3: Moly Precipitation

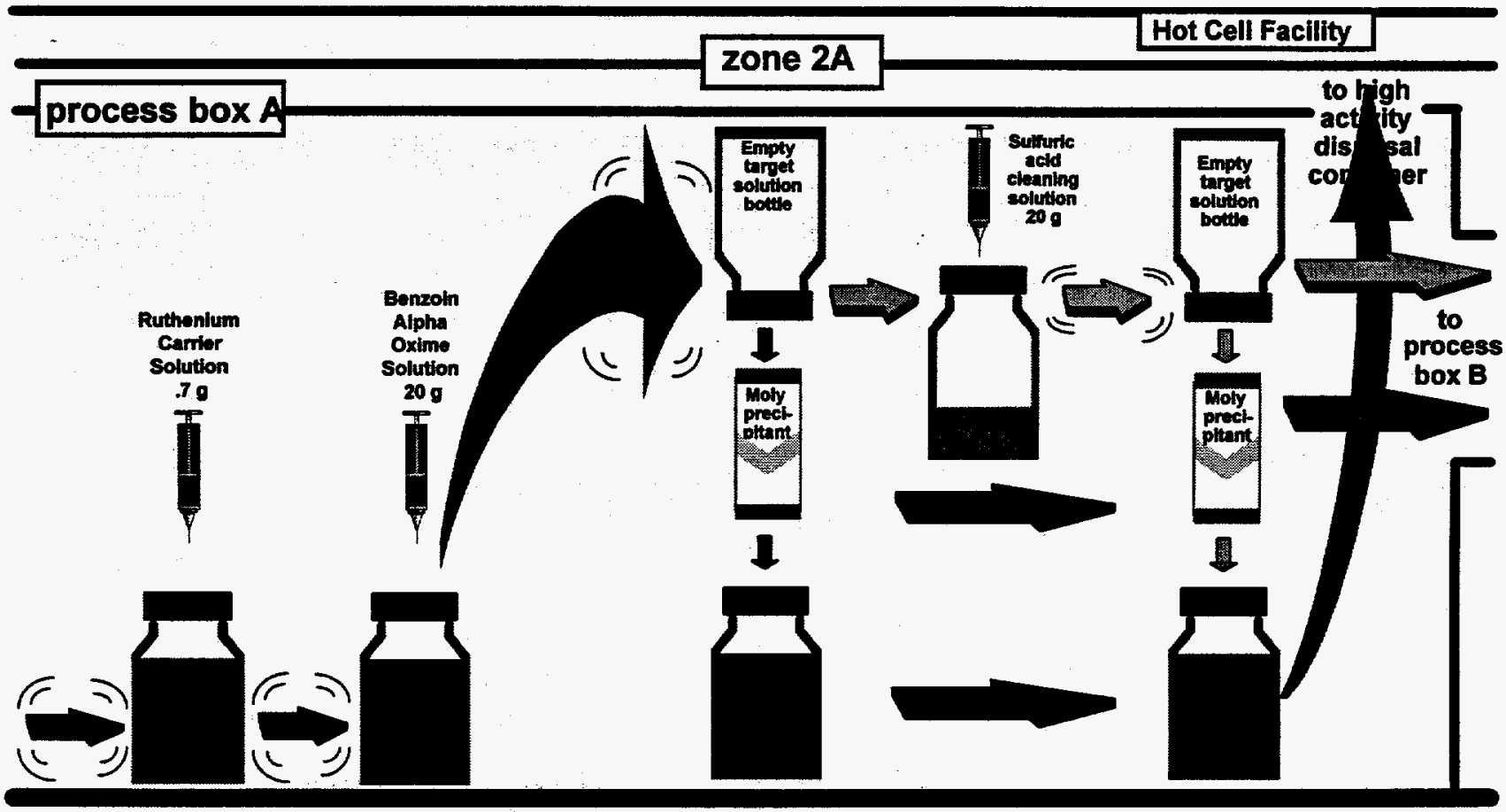

Figure A-4. Cintichem Process Stage 4: Moly Cleanup

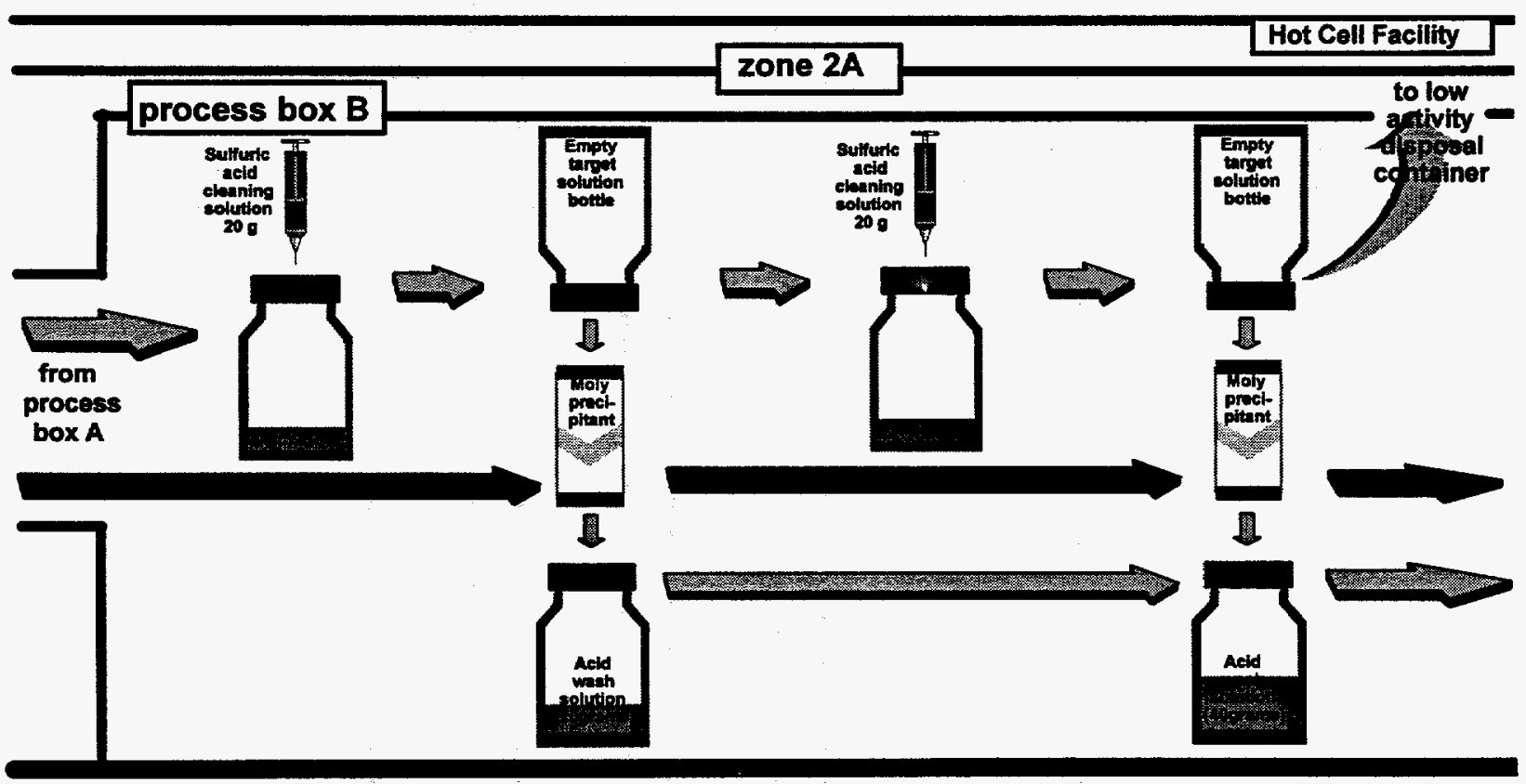


Figure A-5. Cintichem Process Stage 5: Moly Preparation for Shipment

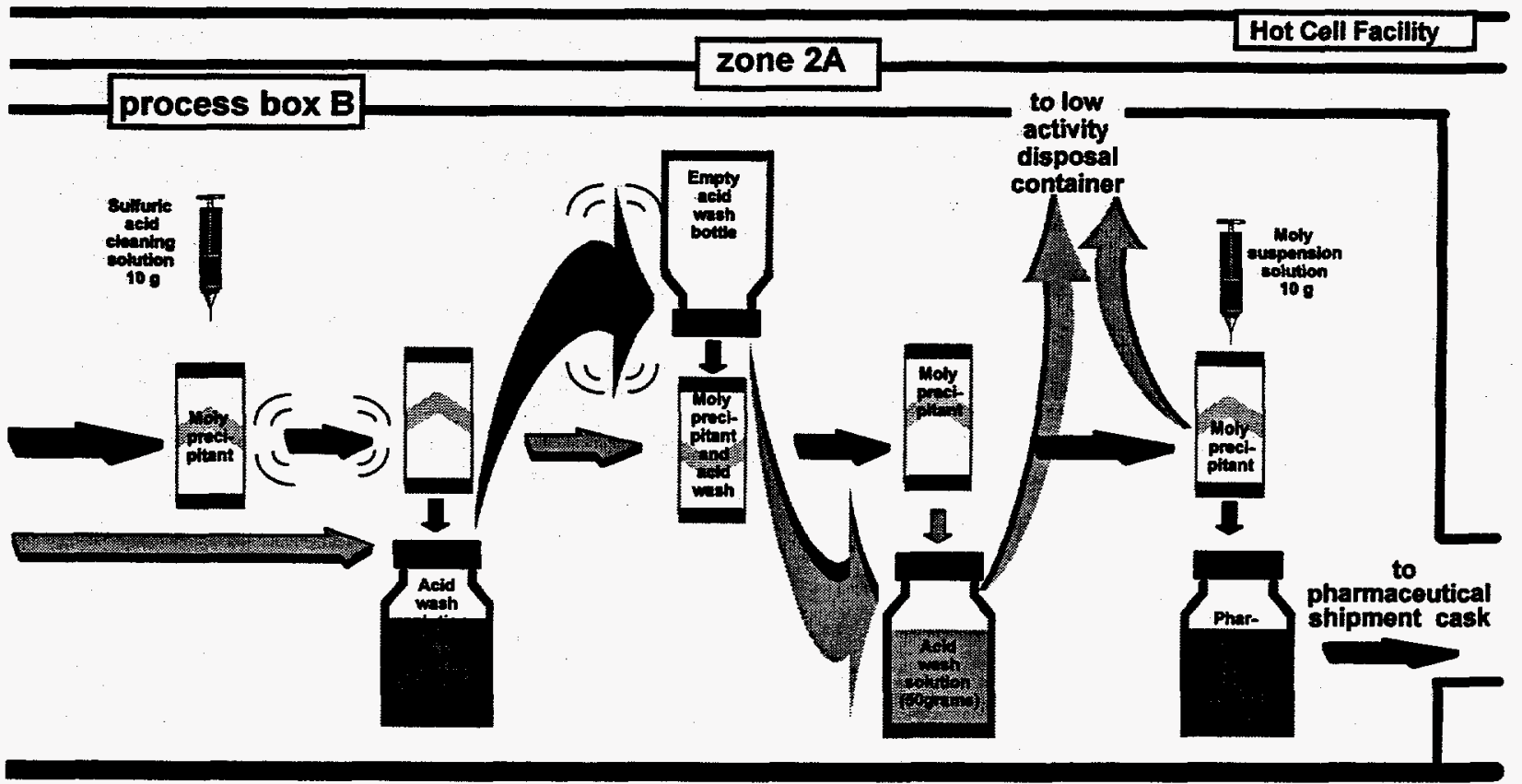

\section{Product QC}

Product quality control (QC) would be performed within RM 112 of the HCF. This room is within Zone 2 of the HCF, and its use would prevent having to take high activity molybdenum from the HCF. The QC process involves the extraction of a $1-2$ microliter sample from the $10 \mathrm{cubic} c \mathrm{~cm}$ (cc) vial of product. This sample would contain approximately 100 millicuries of 99 Mo that would be further diluted to prevent excessive dead-time within the gamma spectroscopy equipment. By examining the gamma signatures of the sample, the isotopic content of the original vial can be determined, permitting the generation of a material survey sheet that would go along with the shipment to the respective pharmaceutical company.

\section{Detailed Product Preparation For Shipping Procedures}

The molybdenum is subdivided or accumulated into quantities that are permissible to be shipped within the 20WC containers. These shipments would then be put into a $10 \mathrm{cc}$ vial, which would be overpacked by an impact mitigator, then packed within a $6 R$ container that is the innermost container identified in the 20WC shipping package. The $6 R$ container would be leak-tested to certify its leak-rate, and when found acceptable, the container would be further packaged within the depleted uranium shield cask and then the 20 gallon overpack for shipment from the facility. All leak testing and packaging would be conducted within Zone 2 of the HCF. 
lodine-125 would be produced by one of two alternate methods. In either method a sealed container is filled with several grams of xenon gas, enriched in xenon-124, and is placed in a reactor irradiation location where it is irradiated for several hours producing xenon-125 (17.5 hour half-life). Following irradiation, the gas is removed from the reactor core region and the activation products are allowed to decay for up to 6 days. Following the decay period, the gas is placed in a shielded glove box where the iodine, rich in iodine-125, is extracted from the target gas. The xenon gas is retained in a storage vessel for subsequent transfer to the irradiation container for further irradiation. It is anticipated that approximately 100 such production runs would be made each year, resulting in the production of approximately 750 curies of iodine-125 per year.

The two methods differ only in the manner in which the gas is transferred to the reactor irradiation location. In the "batch" or "drop-in" method, the irradiation container is filled external to the reactor and remotely placed in the reactor irradiation location. After irradiation, the irradiation container is remotely moved from the irradiation location to the GIF pool for decay. After the appropriate decay period, the irradiation container is moved to a Hot Cell Facility, a controlled ventilated and filtered glove box where the iodine is extracted and the target gas is stored or returned to the irradiation container for subsequent irradiation.

The "in-pile loop (IPL) method," similar to the method used by Cintichem, employs an irradiation container which is semi-permanently installed in a reactor irradiation location. The irradiation container is filled by cryogenically pumping the target gas from a filtered and ventilated glove box in the reactor room to the container through connecting tubing. After irradiation, the target gas is cryogenically pumped from the irradiation to a decay storage container in the reactor room glove box where it is allowed to decay and is subsequently processed as described above. Eventually, the target gas is pumped back to the irradiation container for further irradiation.

The iodine is separated from the xenon by passing the target gas through an iodine trap such as an alumina chromatography column. The iodine is either 1 ) eluted from the column with ammonium hydroxide with ammonium iodide in a weak solution of ammonium hydroxide as the product or 2) collected by heating the column and passing the out-gas through a sodium hydroxide wetted glass bed, giving sodium iodide in a weak solution of sodium hydroxide as a product.

\section{A.5 Product Shipment}

${ }^{99}$ Mo decays $\sim 1 \%$ per hour after its removal from the reactor. Therefore, shipping the product must be expedited to prevent needless product loss by decay. It is presumed that the shipping and delivery times would be equal or greater than the processing time to prepare the product. Nordion, which is the only company presently shipping bulk ${ }^{99} \mathrm{Mo}$, performs this task by a combination of commercial and chartered air flights using Syracuse, NY as the U.S. hub. The following SNL product shipment plans assume commercial and chartered air flights originating at Albuquerque International Airport and distributing product to all of the major U.S. radiopharmaceutical companies. Every attempt would be made to assure that fresh product is at the customer's receiving stations when they are ready to perform their final processing procedures. This is assumed to be overnight shipment and morning delivery to mesh with most of the customer schedules. 


\section{Transportation Specifics}

99Mo is expected to be shipped on a daily basis to one of five different locations. The locations would be at the four corners of the country: NE, SE, NW, and SW, and to the mid-west. This shipping regime would comprise five to six shipments per week, dependent on whether product shipment is made to two NE locations. The initial specific locations corresponding with the radiopharmaceutical companies are as follows:

- Dupont-Merck (Boston, MA)

- Amersham Mediphysics (Chicago, IL)

- Mallinckrodt (St. Louis, MO)

The ${ }^{99}$ Mo would be packaged in accident-resistant Type B packaging. Air express of shipments are envisioned with direct routing, if possible, to the customer city. Passenger aircraft could not be used, since the transport index of the ${ }^{99} \mathrm{Mo}$ exceeds that allowed on passenger aircraft. If a stop is required, the shortest time of routing from Albuquerque to the customer city is preferable. Product movement from Technical Area $V$ to the airport is still under study. The preferred routing is directly from the Technical Area $V$ to the airport transfer point using Kirtland Air Force Base access roads and avoiding off-base routing.

\section{Sample Transport to Customer}

Medical house customers would typically require sample quantities of isotope products to judge quality and other factors prior to commitment to purchase the product. Since potential customers have not been queried on their requirements, the sample could be some small fraction of a production lot to a quantity equivalent to a lot. The Cl-20WC-2 package could be used to transport material in the latter case. For the former case it may be appropriate to select a sample container to transport small quantities of product for customer testing. Since customer sample requirements are not yet known, selection and availability of specific sample packages have not been determined.

\section{A.6 Waste Management}

A Medical Isotope Production Program at SNL/NM would produce trash, chemical waste, wastewater, and radioactive wastes. The anticipated waste streams are:

- Trash, Chemical Waste, and Wastewater

Office and laboratory trash

Chemical waste

Wastewater

- Low-Level Radioactive Wastes

Personal protective equipment (PPE) and contaminated equipment

${ }^{99}$ Mo extraction process wastes

lon-exchange resins

Wastewater

- Spent Nuclear Fuel

Spent ACRR fuel elements

- Mixed Waste 
These waste streams and the processes that would be used to manage and dispose of these waste streams are discussed in the subsections that follow.

\section{A.6.1 Trash, Chemical Waste, and Wastewater}

Office trash, lab trash, and some chemical waste from research and development activities or from expired, contaminated, or otherwise unusable chemicals would be generated. These trash and chemical wastes would be handled through the established waste management processes at SNL/NM.

The total yearly consumption and disposal of chemicals is anticipated to be about 300 liters of chemical liquids and about $5 \mathrm{Kg}$ of chemical solids. Table A-1 provides a breakdown of the estimated amount of chemicals that would be used each year assuming that SNL/NM produces 200 percent of the current North American demand for ${ }^{99}$ Mo. However, it is anticipated that Sandia would initially produce 20 percent to 30 percent of the North American level of demand for ${ }^{99}$ Mo. SNL/NM would increase production only in response to events such as a loss of ${ }^{99}$ Mo supply from the current producer or a significant increase in demand for ${ }^{99} \mathrm{Mo}$ or other radioisotopes.

The chemicals listed in Table A-1 would be constituents in the low-level radioactive waste stream when used in the process to extract ${ }^{99} \mathrm{Mo}$; otherwise, any batches of these chemicals that are declared to be waste for reasons such as contamination or expiration and are not contaminated with radioactive material would be disposed of as chemical waste.

Wastewater would be generated as a result of the isotope production program. Office, lavatory, other existing facilities, and new facility modifications that would not discharge radioactive water under normal circumstances connect directly to the local sewer system, which connects to the City of Albuquerque sewer system.

Water systems and drains that could receive water contaminated with radioactive materials are connected to a recently installed system of monitored hold-up tanks. This system is called the Liquid Effluent Control System (LECS). This system consists of three tanks with a capacity of 5,000 gallons each. Any water that drains into the LECS must be monitored to ensure that radioactive materials in the water, if any, are below the levels allowed by State, local, DOE, and other applicable laws and regulations. If the water is found to exceed these limits, a cleanup system is provided to remove the contamination prior to release to the sewer system.

\section{A.6.2 Low-Level Radioactive Waste}

The low-level radioactive wastes that could be generated include: 1) personal protective equipment (PPE), e.g., respirators, gloves, shoe covers, overalls, etc.; 2) wastes resulting from the extraction of radioisotopes; 3 ) expendable or unserviceable contaminated equipment, e.g., wipes, cloths, charcoal filters, HEPA filters, broken equipment, etc., 4) expended ion-exchange resins; and 4) radioactive wastewater. These low-level radioactive waste streams and the processes that would be used to manage and dispose of these waste streams are discussed in the subsections that follow.

SNL/NM generates approximately 2500 cubic feet of uncompacted LLW each year. Currently, the SNL ACRR and HCF generate about 35 percent ( 860 cubic feet, uncompacted) of this 
Table A-1. Approximate Yearly Process Chemical Usage

\begin{tabular}{|c|c|}
\hline Chemical Identification & Yearly Consumption \\
\hline Sulfuric acid, $2 \mathrm{~N}$ & 240 liters \\
\hline Sulfuric acid, $0.1 \mathrm{~N}$ & 72 liters \\
\hline Hydrochloric acid, reagent grade & 2.4 liters \\
\hline Nitric acid, reagent grade & 12 liters \\
\hline Sodium hydroxide, $0.2 \mathrm{~N}$ & 48 liters \\
\hline Sodium iodide & 240 grams \\
\hline Silver Nitrate & 1200 grams \\
\hline Bezoin- $\alpha$-oxime & 4800 grams \\
\hline Molybdenum trioxide & 48 grams \\
\hline Potassium permanganate & 200 grams \\
\hline Rhodium trichloride & 48 grams \\
\hline Potassium hexachlororuthenate & 48 grams \\
\hline Hydrogen peroxide & 4.8 liters \\
\hline Calcium oxide & 24 liters \\
\hline Calcium sulfate "drierite" & 72 liters \\
\hline Molecular sieve type 13X & 72 liters \\
\hline
\end{tabular}

LLW. (Seylar, 1994) When compacted, this waste would fill about thirty-nine 55-gallon drums. Much of this LLW is PPE and wipes with the remainder consisting of discarded items that are contaminated with radioactive materials. This waste is packaged in a form acceptable for disposal at a designated LLW disposal site.

Currently, LLW from SNL/NM is designated for disposal at the Nevada Test Site (NTS). An application has been submitted to dispose of current SNL/NM LLW at NTS. The LLW from isotope production is not included on the current application. The current application is still in the approval process; hence, to date no LLW from existing SNL/NM activities has been shipped to NTS. The NTS application would be amended to include the isotope production LLW stream. If another disposal site were designated for the LLW from the program then an application would be submitted to the selected disposal site. The other sites that are considered to be viable alternatives include the DOE Hanford site near Richland, Washington and a commercial facility operated by US Ecology which is also located on the Hanford site.

\section{A.6.2.1 PPE and Contaminated Equipment}

The PPE wastes would be generated continuously as a part of daily operations. PPE, such as respirators, gloves, shoe covers and overalls, is worn by facility personnel to protect against hazards and to minimize the spread of radioactive contamination from a contaminated area to a non-contaminated area.

Contaminated equipment such as charcoal filters and HEPA filters would be changed out as a part of a regular maintenance program. Some of this equipment would become contaminated with radioactive particles or substances and would be disposed of as low-level radioactive waste. Also, any malfunctioning facility equipment that is contaminated and cannot be repaired or sufficiently cleaned would be appropriately packaged and disposed of as low-level waste. 
The production rate of PPE and contaminated equipment for the isotope production program is estimated to be less than 2500 cubic feet of uncompacted LLW per year. Waste minimization efforts, such as using laundered PPE rather than disposable PPE, would be evaluated as options to reduce the amount of waste generated.

\section{A.6.2.2 ${ }^{99}$ Mo Extraction Process Wastes}

The wastes that would be generated in the isotope extraction process would account for the majority of the low-level radioactive waste volume generated by the isotope production program. The extraction of isotopes from irradiated targets involves a number of wet chemical processes. These production activity chemical processes are "bench-top" type processes that are conducted using small (<500 ml) laboratory equipment of various forms, typically glassware. The extraction process that would be used by Sandia was developed by a U.S. company and is closely regulated by the U.S. Food and Drug Administration (FDA). Since the isotopes that would be produced are used as radiopharmaceuticals for eventual human use, the extraction process is closely controlled and monitored for contamination by chemical remnants and unwanted radioisotopes. Hence, all equipment such as glass flasks, tubing, etc. would be replaced after a single use to prevent possible contamination of future batches. This equipment would be placed in small containers about the size of a one gallon paint can which, when full, would be placed in a waste container that has a volume of about 7.4 cubic feet ( 55 gallons).

The acidic liquid process solutions that remain after the radioisotopes are extracted contain uranium and radioactive elements called fission products. These liquid solutions would be neutralized to make the solution essentially non-acidic and then stabilized with an agent such as portland cement and placed in a waste container. The uranium would not be recovered from the solution nor from the solidified waste because it is not economical nor is it feasible to recover it at other DOE recovery facilities.

Since the waste container that would be used during storage and eventual disposal for this solidified process waste would have a volume of about 7.4 cubic feet (55 gallons). The radioactive process equipment discussed above and the solidified process waste may be placed together in the same container or may be placed in separate containers based on operational and disposal considerations. Once full, the waste containers would be stored in a shielded area(s). The solidified process waste would be stored on site for approximately 6 to 12 months at which time the radioactivity of the waste would have been reduced significantly as shown in Figure A-6. It is anticipated that the process hardware waste would have a lower level of radioactivity and could be transported to the selected waste disposal site at any time after final packaging.

An isotope production program would generate between 24 and 160 containers (similar in size to a standard 55 gallon drum) of low-level waste from the isotope extraction processes each year. This estimate includes both the process hardware and solidified process waste. At the earliest time that these waste containers would be shipped to the disposal site (about 6 months) they would contain about 1500 curies of radioactive waste. Fission products would be responsible for $95 \%$ of the activity level. The remaining activity is mostly from the activation of the stainless steel target shell. 
Figure A-6. Estimated Extraction Process Waste Container Activity Level

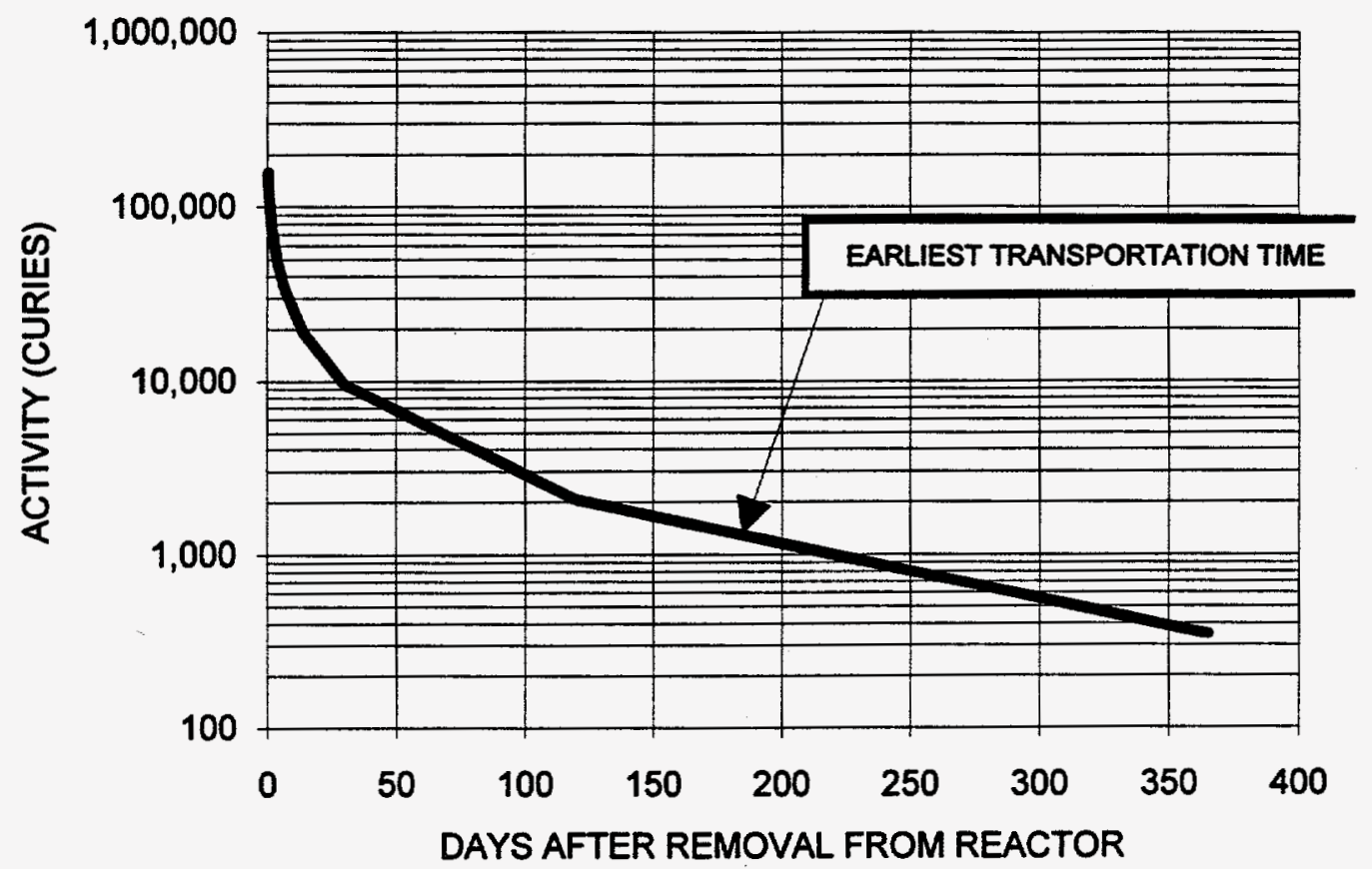

Table A-2 identifies most of the waste materials and quantities that are known to be included in the extraction process waste stream. After storage, the extraction process waste would be transported to the designated DOE low-level waste disposal site.

Table A-2. Isotope Extraction Process Waste Estimates

\begin{tabular}{|c|c|c|}
\hline Waste Constituent & Mass/Target (Ib) & Mass/Container (Ib) \\
\hline Copper & 3.15 & 44.10 \\
\hline Stainless Steel & 3.05 & 42.70 \\
\hline Brass & 0.04 & 0.56 \\
\hline Tin & 0.64 & 8.96 \\
\hline Aluminum & Trace & Trace \\
\hline Uranium & 0.06 & 0.84 \\
\hline Glass & 6.12 & 85.68 \\
\hline Plastic & 0.85 & 11.90 \\
\hline Dry Chemicals & 0.95 & 13.30 \\
\hline Liquid Chemicals and Water & 0.82 & 11.48 \\
\hline \hline Stabilization Agent & 5.35 & 74.90 \\
\hline \hline Total Mass & 21.03 & 294.42 \\
\hline Total Curies (@ 6 months) & 104 & 1456 \\
\hline
\end{tabular}

Past assessments indicate that once neutralized, the wastes produced in the extraction process would be "radioactive mixed wastes" which means that the radioactive waste would not contain nor be mixed with waste that is considered hazardous according to the Resource Conservation and Recovery Act (RCRA). 


\section{A.6.2.3 Ion Exchange Resins}

Ion exchange systems provide an effective method of removing impurities and many radioactive contaminants from water systems. Currently the ACRR pool, the GIF pool, and the LECS system have water cleanup systems that use ion exchange resins to remove and control impurities in the waters contained within these systems. In the ACRR and GIF pools the ion exchange systems are used to continuously remove impurities as water is circulated through the cleanup system. The LECS cleanup system would be used only as necessary to reduce wastewater radioactivity to applicable limits. To date the LECS system has not been needed as no water in the LECS tanks has approached applicable regulatory limits. Hence, the resins in the LECS ion exchange system have never been replaced.

As a part of routine maintenance, ACRR and GIF resins are changed when the capacity of the resins to remove impurities has diminished. The replacement rate for these resins depends primarily upon the total number of ions exchanged. After use, these resins must be disposed of as low-level radioactive waste.

The ACRR ion exchange resins are currently replaced about once per year. Each replacement cycle generates about 10 cubic feet of used resins. It is anticipated that isotope production may result in the need to replace the resins more often, the total volume of waste resins from the ACRR cleanup system is not expected to exceed 20 cubic feet per year.

The GIF ion exchange resins are replaced about 6 to 8 times each year. Each replacement cycle generates about 2.5 cubic feet of used resins. Isotope production would increase the amount of resins used by the GIF cleanup system. The total volume of waste resins from the GIF cleanup system is not expected to exceed 40 cubic feet per year.

The LECS ion exchange resins have not been used to date; hence, the resins have never been replaced. Each replacement cycle would generate about 14 cubic feet of used resins. The replacement rate for the LECS has no baseline established from past operations; however, isotope production should not increase the replacement rate experienced from operational history.

It may be necessary to install a small decontamination station inside the Hot Cell Facility to remove surface decontamination from facility equipment and waste containers prior to reuse or disposal. If this system uses water solutions to decontaminate the equipment, then a water cleanup system using ion exchange resins could be provided for this system. This system would likely be smaller than the existing systems.

\section{A.6.2.4 Wastewater}

Radioactive wastewater could come from sources such as water contained in the spent ion exchange resins when they are removed from service and potentially from the storage pools and the decontamination station. This wastewater would not be discharged to the City of Albuquerque sewer system unless it was within the established regulatory limits. When possible any wastewater would be decontaminated and reused. If wastewater is not reused it would be decontaminated and discharged or solidified and disposed as low-level waste. 


\section{A.6.3 Spent Nuclear Fuel}

The ACRR fissions or "burns" uranium which is enriched to contain a higher concentration of ${ }^{235} \mathrm{U}$ than that which occurs naturally. The uranium fuel is contained within cylindrical shaped assemblies called fuel elements. These assemblies are approximately 29 inches long and 1.5 inches in diameter. Reactor fuel elements have a limited amount of energy that can be extracted before they must be replaced. The fuel elements that are removed because they need to be replaced or are no longer needed are typically called "spent nuclear fuel."

The current ACRR core has 236 fuel elements that are of a specialized design that can be used for both steady-state and pulsed operation. An isotope production program does not need the pulsed-mode operational capability; therefore, a replacement fuel element design suitable for steady-state operation would be used. Current plans call for the removal and storage of the current fuel elements so that they would still be usable for pulsed-mode operation. Maintenance of the pulsed-mode testing capability is part of the change-of-mission agreement that allows the ACRR to be used for the production of medical isotopes. It is estimated that the current core of fuel elements could be used for one to five years and still be useable for pulsedmode operation; the fuel element lifetime depends primarily on the amount of ${ }^{99}$ Mo that would be required to be produced by the reactor.

The ACRR is designed so that it can be operated with a number of different fuel configurations and various numbers of fuel elements. For the isotope production program the ACRR core would have between 130 and 180 fuel elements. Current estimates indicate that the current core would be replaced somewhere between the years 1997 and 2001 . The replacement core would be expected to be usable for at least six years while producing 200 percent of the current North American demand for ${ }^{99}$ Mo and possibly as long as 24 years if the ${ }^{99}$ Mo production does not exceed $30 \%$ of the current demand. Hence, for a total production life of 30 years, an isotope production program would use between two and five complete core loadings consisting of 150 to 200 fuel elements.

When removed from service, the spent nuclear fuel would be moved to the GIF pool for storage. The spent fuel would be kept in the GIF pool until it is either disposed of or placed in dry storage.

If dry storage is necessary, the spent fuel would be removed from the pool and placed in specially designed containers called "storage casks" or "dry storage casks." These casks would reside in a storage facility, likely in Area $\mathrm{V}$, and would be monitored to verify the integrity of the spent fuel and the casks. The fuel would be kept in the dry storage casks until it could be transported to a disposal site. At this time all potential DOE disposal facilities are in the design or evaluation stage and are not yet open for shipments of spent nuclear fuel.

SNL/NM does not currently have a dry storage facility for spent nuclear fuel. A dry storage facility would be developed for an isotope production program. This facility development could involve the modification of existing buildings or the construction of a new building or facility. The dry storage facility would be relatively small since it is anticipated that less than 900 additional spent fuel elements would be generated and stored on site during the duration of the isotope production program. The first new core of spent nuclear fuel is not expected to be generated until the year 2003. In addition, since spent fuel would probably not be placed in dry storage until the replacement of the second new core, a dry fuel storage capability may not be necessary until at least the year 2009 and possibly as late as 2027. 


\section{A.6.4 Mixed Waste}

Mixed waste is waste that contains a mixture of both radioactive and hazardous wastes. This waste must be treated prior to disposal to reduce the hazardous portion of the waste consistent with the Resource Conservation and Recovery Act (RCRA). For the isotope production program, the treated mixed waste would eventually be disposed of at a mixed waste disposal facility along with the mixed waste from other DOE programs in accordance with ongoing mixed waste disposal site assessment and development activities.

Mixed wastes that may be generated as a result of the operation of the ACRR and Hot Cell Facility operations include hazardous wastes such as absorbent wipes, batteries, spent solvents, solvent rags, vacuum pumps, electronics containing heavy metals, lubricants, etc. that become contaminated with radioactive materials.

Mixed wastes generated at SNL/NM are subject to RCRA including the amendments implemented by the Federal Facility Compliance Act (FFCA) of 1992. Under these regulations the DOE is required to develop site treatment plans (STPS) that describe the development of treatment capacities and technologies for mixed waste such that the waste meets the Land Disposal Restrictions (LDRs) of RCRA. DOE and SNL/NM are currently working with the New Mexico Environment Department (NMED) and the US Environmental Protection Agency (EPA) to develop approved STPs for SNL/NM mixed wastes. The most recent STP is the draft "Proposed Site Treatment Plan for Mixed Waste, Sandia National Laboratories/New Mexico," dated December 6, 1994. This STP is the third and final plan required for the implementation phase in accordance with the "Schedule for Submitting Plans for the Treatment of Mixed Waste Generated or Stored at Each Site" as published on April 6, 1993 in the Federal Register at 58 FR 17875.

The current STPS cover only mixed wastes that were generated or stored on site prior to October 1994. Mixed wastes that are generated after October 1994 are to be addressed in annual updates to the STPs. Any mixed waste that is generated by isotope production would be included in future STP updates as required by the RCRA regulations. The total mixed waste production rate from isotope production is estimated to be less than $12 \mathrm{~m}^{3}\left(400 \mathrm{ft}^{3}\right)$ per year. Since 1989, the mixed waste volume generated annually at the SNL/NM nuclear facilities in Area $V$ has varied from a low of $0.5 \mathrm{~m}^{3}\left(18 \mathrm{ft}^{2}\right)$ in 1993 to a high of $5.6 \mathrm{~m}^{3}\left(200 \mathrm{ft}^{3}\right)$ in 1992. These volumes include the wastes that were generated from experiments or processes that would not be conducted during the production of medical isotopes and also includes waste from other Area $V$ facilities.

The categories of mixed wastes that would be generated by isotope production are anticipated to fit within the fifteen treatability groups identified in the Draft Proposed Site Treatment Plan for Mixed Waste. These treatability groups are listed in Table A-3. Each of these treatability groups has an identified preferred treatment option. Additional preferred treatment options would be developed if any mixed waste generated by the isotope production program could not be treated under one of the existing treatability groups. 
Table A-3. Summary of SNLNM Mixed Waste Treatability Groups

\begin{tabular}{|c|c|}
\hline Treatability Group (TG) & TG Description \\
\hline TG1 & Inorganic Debris w/Explosive \\
\hline TG2 & Inorganic Debris w/Water Reactive \\
\hline TG3 & Reactive Metals \\
\hline TG4 & Elemental Lead \\
\hline TG5 & Aqueous Liquids (Corrosives) \\
\hline TG6 & Elemental Mercury \\
\hline TG7 & Organic Liquids I \\
\hline TG8 & Organic Debris w/Organic Contaminants \\
\hline TG9 & Inorganic Debris w/TCLP Metals \\
\hline TG10 & Heterogeneous Debris \\
\hline TG11 & Organic Liquids II \\
\hline TG12 & Organic Debris w/TCLP Metals \\
\hline TG13 & Oxidizers \\
\hline TG14 & Aqueous Liquids w/Organic Compounds \\
\hline TG15 & Soils <50\% Debris \\
\hline
\end{tabular}

\section{A.6.5 Waste Management at LANL}

Anticipated additions from target fabrication to the LANL waste streams are summarized in Table A-4 below.

Table A-4. Annual Waste Steam Increases Due to Target Fabrication at LANL

\begin{tabular}{|c|c|c|c|}
\hline Waste Stream & $\begin{array}{l}\text { LANL Normal } \\
\text { Operations }\end{array}$ & Target Fabrication & $\begin{array}{l}\text { Percent } \\
\text { Increase }\end{array}$ \\
\hline Uranium air emissions & $0.022 \mathrm{mCi}$ & none expected & 0 \\
\hline $\begin{array}{c}\text { Radioactive Liquid Waste } \\
\text { Effluents (treated) } \\
{ }^{235} \mathrm{U} \text { in Effluent }\end{array}$ & $\begin{array}{c}20 \text { million liters } \\
0\end{array}$ & $\begin{array}{l}100,000 \text { liters } \\
\text { none expected }\end{array}$ & $\begin{array}{c}<1 \\
0\end{array}$ \\
\hline $\begin{array}{l}\text { Uncontaminated Solid } \\
\text { Waste }\end{array}$ & 11,121 metric tons & $\begin{array}{c}5 \mathrm{~m}^{3} \\
\text { (<10 metric ton) }\end{array}$ & $\ll 1$ \\
\hline LLW & $4,500 \mathrm{~m}^{3}$ & $\begin{array}{c}\text { Preoperational: } \\
5 \mathrm{~m}^{3} \\
\text { Operational: } \\
5 \mathrm{~m}^{3}\end{array}$ & $\begin{array}{l}<1 \\
<1\end{array}$ \\
\hline
\end{tabular}

\section{A.7 Transportation Shipping Campaign}

A medical isotope program would create the need for a series of routine transportation shipments. These would be shipments of: 1) unirradiated targets from LANL to SNL/NM and, if necessary to Ottawa, Canada; 2) isotopic products from SNLNM to the three manufacturers of radiopharmaceutical generators; Dupont-Merck in Boston, Amersham Mediphysics in Chicago, and Mallinckrodt in St. Louis; and 3) production wastes from SNL/NM to NTS or to the Hanford 
Reservation in Washington State. The transportation shipping campaign for each of these three types of shipments would ultimately be defined by the level of isotopic production. It is expected that to meet $100 \%$ of the ${ }^{99}$ Mo market SNL/NM would have to produce about 16,700 $\mathrm{Ci}$ of ${ }^{99} \mathrm{Mo}$ in the reactor each week. Approximately 20 targets would be processed each week to achieve this, or 1040 each year based on a 52-week annual production schedule. This level of target processing would define the transportation shipping needs. Table A-5 illustrates the number of target, product, and waste packages that would have to be shipped annually to meet this level of production as well as two other production levels - $30 \%$ and $200 \%$ of market share.

\section{Unirradiated Targets}

Unirradiated targets would be shipped from LANL to SNLNM or from LANL to Ottawa, Canada to supply Nordion. Approximately 44 Type A package shipment carrying 24 targets each would be required to supply the demand of the SNL/NM production estimates and Nordion's needs. Each package was assumed to be shipped individually from LANL to SNL/NM and to Canada. The mode of shipment for the shipments to SNL/NM was modeled as truck. For the Ottawa shipments the mode was truck to Albuquerque International Airport and then air cargo to Ottawa. Thus, for the $100 \%$ market share model 88 truck shipments annually between LANL and Albuquerque were modeled and 88 total air shipments were modeled for the Ottawa shipments ( 44 between Albuquerque and a central air cargo hub, and 44 from the hub to Ottawa). This model doubles the number of shipments required for the purpose of establishing a conservative assessment. In actuality, the 44 package shipment from LANL would be split between the destination of SNL/NM and Ottawa according to the percent of the market share that each production site was responsible for meeting. However, because it is not known how market production might be split between the two sites, the transportation campaign was defined so as to establish a bounding estimate on impacts and risk

It would be possible to package the unirradiated targets in Type B containers that could carry 12 targets per package. Up to five Type B containers could be loaded per truck shipment. This would define a transportation campaign of 88 packages shipped on 18 truck shipments annually for $100 \%$ of the market share. However, the risk assessment was based on the transportation of 44 Type A package shipments annually wherein each package contained $500 \mathrm{gm}$ of ${ }^{235} \mathrm{U}$. This approach yields a bounding risk estimate that encompasses the potential risk associated with shipping the targets in Type B containers. Two factors establish this: 1) the model used in the risk assessment maximizes the likelihood of an accident by modeling a higher number of shipments (44 vs. 18 annually), and 2) Type A packages offer far less protection to the material from severe accident environments. 
Table A-5. Transportation Risk Assessment Shipping Campaign

\begin{tabular}{|c|c|c|c|c|c|c|c|c|}
\hline \multicolumn{9}{|c|}{ Transportation Risk Assessment Shipping Campaign } \\
\hline \multirow[t]{2}{*}{ shipment Type } & \multirow[t]{2}{*}{$\begin{array}{l}\text { Package } \\
\text { Type }\end{array}$} & \multirow[t]{2}{*}{$\begin{array}{l}\text { Contents/ } \\
\text { Package }\end{array}$} & \multirow[t]{2}{*}{ Mode } & \multirow[t]{2}{*}{ Origin } & \multirow[t]{2}{*}{ Dest. } & \multicolumn{3}{|c|}{$\begin{array}{l}\text { Annual Package Shipment } \\
\text { Rate By Market Share }\end{array}$} \\
\hline & & & & & & $30 \%$ & $200 \%$ & $100 \%$ \\
\hline Fresh Targets* & Type A & $500 \mathrm{~g} 235 \mathrm{U}$ & Truck/Air & LANL & SNUOttawa & 13 & 87 & 44 \\
\hline \multirow[t]{3}{*}{$9_{\mathrm{Mo}}$} & \multirow[t]{3}{*}{$20 \mathrm{WC}$} & \multirow[t]{3}{*}{$820 \mathrm{Ci}$} & \multirow[t]{3}{*}{ Air } & SNL & Boston & 104 & 691 & 346 \\
\hline & & & & SNL & Chicago & 104 & 693 & 347 \\
\hline & & & & SNL & St. Louis & 104 & 693 & 347 \\
\hline \multirow[t]{3}{*}{ 131, } & \multirow[t]{3}{*}{ 20WC } & \multirow[t]{3}{*}{$220 \mathrm{Ci}$} & \multirow[t]{3}{*}{ Air } & SNL & Boston & 104 & 691 & 346 \\
\hline & & & & SNL & Chicago & 104 & 693 & 347 \\
\hline & & & & SNL & St. Louis & 104 & 693 & 347 \\
\hline \multirow[t]{3}{*}{${ }^{133} \mathrm{xe}$} & \multirow{3}{*}{$\begin{array}{l}\text { SPEC } \\
7 A\end{array}$} & \multirow[t]{3}{*}{$620 \mathrm{Ci}$} & \multirow[t]{3}{*}{ Air } & SNL & Boston & 104 & 691 & 346 \\
\hline & & & & SNL & Chicago & 104 & 693 & 347 \\
\hline & & & & SNL & St. Louis & 104 & 693 & 33347 \\
\hline \multirow[t]{3}{*}{125} & \multirow{3}{*}{$\begin{array}{l}\text { SPEC } \\
7 A\end{array}$} & \multirow[t]{3}{*}{$7 \mathrm{Ci}$} & \multirow[t]{3}{*}{ Air } & SNL & Boston & 11 & 68 & 34 \\
\hline & & & & SNL & Chicago & 11 & 70 & 35 \\
\hline & & & & SNL & St. Louis & 11 & 70 & 35 \\
\hline \multicolumn{6}{|c|}{ Total Annual Isotope Product Package Shipments } & 969 & 6448 & 3224 \\
\hline $\begin{array}{l}\text { Process } \\
\text { Wastes }\end{array}$ & $\begin{array}{l}\text { B-3 } \\
\text { Cask }\end{array}$ & $\begin{array}{l}\text { Inventory of } 14 \\
\text { Irradiated } \\
\text { Targets - } 180 \\
\text { Days Out of } \\
\text { Reactor }\end{array}$ & Truck & SNL & $\begin{array}{l}\text { NTS or } \\
\text { Hanford }\end{array}$ & 23 & 149 & 75 \\
\hline
\end{tabular}

*If isotope production were split between SNL/NM and Nordion in Canada, then the target Shipments required to meet production would be split between SNL/NM and Ottawa accordingly. Furthermore, all isotope production and process waste shipment estimates out of SNL/NM would be reduced.

\section{Isotope Product Shipment Model}

The number of packages that would be shipped in each isotope product shipment was defined by assuming that for each $21 \mathrm{~kW}, 7$-day target irradiated, the entire quantity of each isotope produced by the processing of a single target would be individually packaged and shipped to market. Thus, for each target irradiated one package each of $820 \mathrm{Ci}$ of $99 \mathrm{Mo}, 220 \mathrm{Ci}$ of $131 \mathrm{I}$, and $620 \mathrm{Ci}{ }^{133} \mathrm{Xe}$ would be shipped. The curie values are for zero minutes out of the reactor. The actual number of curies packaged would be less due to the decay of product during the time for processing, inspecting, and packaging. The one exception is for $125 \mathrm{I}$, for which it is assumed that only $14 \mathrm{Ci} /$ week would be required, and this would be packaged into two $7 \mathrm{Ci}$ shipments each week.

The current market for 131 / and $133 \mathrm{Xe}$ is not as large as that defined by this model; however, this approach creates a conservative model for estimating transportation impacts and risks that would bound the actual impacts and risks in the event that the market for 131 I and $133 \times \mathrm{Xe}$ should increase. 
It is expected that the actual isotope products would be shipped out from SNLNM on a five day per week schedule to facilitate the use of commercial air cargo service between Albuquerque, New Mexico and Boston, Chicago, and St. Louis. This would require that multiple packages of products be placed on the same air cargo flight from Albuquerque to an air cargo hub, and from there the product shipments would be segregated into three separate air shipments, one to Boston, one to Chicago, and one to St. Louis. Thus, as many as 62 packages of products would be shipped each week (20 each for $99 \mathrm{Mo}, 131 \mathrm{I}$, and $133 \mathrm{Xe}$, and two for $125 \mathrm{I}$ ). If it is assumed that a particular air cargo carrier has five flights per week from Albuquerque to a distribution hub, then approximately 12 packages of products would be shipped out of Albuquerque on each flight. Such quantities of isotopes could be shipped in a single flight as long as the total package dose rates for all packages on a single flight remained below DOT quantity limitation requirements defined in 49 CFR 175.75. These limits are achievable based on the packages to be used and the quantities of isotopes that would be packaged.

Since the isotope shipments would typically be packaged on a "one target - one package" basis for each isotope (with the exception of 125 ) it was assumed that one third of all packages for each isotope product would go to each fabrication site. However, it is difficult to define exactly a specific isotope shipment inventory since the actual configuration of isotopic products available for shipment could vary somewhat from day to day. In order to establish a bounding estimate on transportation impacts and risks, the isotope product shipment campaign was conservatively modeled by assuming that each package of isotopes would be shipped separately. Thus, all 3224 packages of isotope products that would be required annually to package all of the $99 \mathrm{Mo}, 131_{\mathrm{I}}$, and $133 \mathrm{Xe}$ produced were modeled as being shipped on 3224 separated flights to a central distribution hub, and then 1075 were modeled as shipped to each fabrication center. In actuality, 6448 total flights are modeled since each package was modeled as being shipped on two flights, first to a central air cargo hub and then to its final destination. This method greatly overstates the number of flights required to ship the isotope products and consequently overestimates the accident risk from transporting the product. By maximizing the number of flights required, the probability of an accidental release is maximized in the transportation impact and risk analysis. For example, if 12 packages were loaded at a time onto an air cargo flight out of Albuquerque five times per week, then the actual number of flights needed annually to ship the products to market would be $1040 ; 260$ from Albuquerque to a central hub and then another 780 flights from the hub to the three fabrication sites. Thus, the isotope shipping model increases the likelihood of a transportation accident by more than a factor of six over what is actually expected based on the frequency of flights required.

Incident-free impacts would not be significantly overestimated by this approach. Since the public and workers would be exposed to radiation from each package that would be shipped, it is reasonable that the incident-free dose estimates derived by modeling each package shipment individually would be similar to dose estimates derived by modeling multiple package shipments.

\section{Process Wastes}

The shipments of low-level process wastes are defined by the limitation of the amount of $235 \mathrm{U}$ that would be accepted at the NTS or Hanford repositories. Thus, the amount of wastes that could be packaged into a single B-3 cask would be equivalent to the inventory generated by fourteen $21 \mathrm{~kW}, 7$-day irradiated targets. Furthermore, only one B-3 cask is planned for each truck shipment. This would define a waste shipment campaign of up to 149 B-3 cask shipments annually. 


\section{References}

1. NMEIB (New Mexico Environmental Improvement Board), 1988, Health and Environment Department, Environmental Improvement Division, Santa Fe, New Mexico.

2. Seylar, R., 1994. Memorandum dated November 16, 1994, from R. Seylar, SNL, to D. L. Miller, SNL subject: Approval to Dispose of Non-Defense Low-Level at the Nevada Test Site. 


\section{APPENDIX B \\ DESCRIPTION OF CONTAINERS USED FOR \\ TRANSPORTING TARGETS, PRODUCTS, AND WASTES}




\section{APPENDIX B \\ DESCRIPTION OF CONTAINERS USED FOR TRANSPORTING TARGETS, PRODUCTS, AND WASTES}

\section{B.1 Pre-Production Activity}

\section{Target Packaging}

Targets would be fabricated, tested, and packaged for shipment at LANL. Twenty grams of uranium enriched to $93 \%$ is the planned loading for each target. The number of targets to be shipped at one time would be a maximum of 24 packaged in a Type A container. Part 71.22 of 10 Code of Federal Regulations (CFR), General License: Type A package, Fissile Class III shipment states in part "if material is shipped as a Fissile Class III shipment...(c), This general license applies only when the fissile radionuclides in the Fissile Class III exceeds none of the following: (1) 500 grams of uranium-235. ..." If the gram loading of uranium is increased per target then a lesser number of targets may be shipped to stay under the 500 gram limit. LANL is investigating the possibility of making Fissile Class I shipments using Type B packaging.

DOE Order 5632.2A specifies a physical protection classification of Category IV for ${ }^{235} \mathrm{U}$ if the amount is less than $2 \mathrm{~kg}$. The regulation further states, "Baseline requirements for protection of Category IV quantities of SNM in transit are as follows:...(2) Shipments of all category IV quantities of SNM not transported by the Transportation Surety Department (TSD) may be made by one of the following methods: truck, rail, air, or water in commercial, for-hire vehicles."

Target shipments would be a small increase in road traffic volume and the shipments would be under exclusive use rules of the Department of Transportation, 49 CFR Part 173, if Type A packaging were used.

\section{Target Transfer Cask}

The concept for a target transfer container is under development. An internal cylinder $10 \mathrm{~cm}$ in diameter and $76 \mathrm{~cm}$ deep would hold up to four targets. This entire volume would be surrounded by $16 \mathrm{~cm}$ thick stainless steel clad depleted uranium to provide for sufficient shielding. The cask would be designed to work easily in the HCF. It would contain between one and four targets, and be transported from the reactor area to the HCF around a driveway adjacent to the reactor building. This operation is a part of the reactor functions and is not considered transport since it is adjacent to a building inside the TA-V security and fenced boundary. The cask does not require certification, as it would not be in transportation. However, it must be developed with an appropriate quality control program and have a safety analysis performed, which then must be approved by DOE per DOE Order 5480.3 .

\section{B.2 Product Transportation to Customer}

The Type B cask designated for use in transporting ${ }^{99} \mathrm{Mo}$ is the $\mathrm{Cl}-20 \mathrm{WC}-2$ (or $\mathrm{Cl}-20 \mathrm{WC}-2 \mathrm{~A}$ which differs slightly) model that is described as follows: steel encased, wooden outer protective jackets with a uranium shielded cask and inner steel containment vessel. The protective jackets are constructed of disks and rings of plywood, which are glued together and reinforced with steel rods. The protective jackets are contained in an 18 gauge steel drum. The shielded casks have depleted uranium shields encapsulated in steel with a gasketed and bolted flange closure with six, $3 / 8$ in -16UNC-2A $\times 3 / 4$ in long bolts. The inner containment 
vessel is a 2.73 in OD X 5.56 in long 416 stainless steel, gasketed and threaded container. The gross weight of the package is about $400 \mathrm{lbs}$. The protective jacket's overall dimensions are 24-1/4 $\times 22 \times 28-3 / 4$ in, the depleted uranium thickness is 2 in, and the cylindrical cavity is 3.1 $X 6$ in.

The contents type and form of material for which the cask is certified are: ${ }^{99} \mathrm{Mo} /{ }^{99} \mathrm{Tc}$ in normal form as solids or liquids, with a maximum quantity of material per package of $1,000 \mathrm{Ci}$, and ${ }^{131}$ I in normal form, or liquids with a maximum quantity of material per package of $200 \mathrm{Ci}$.

Medical house customers would typically require sample quantities of isotope products to judge quality and other factors before committing to purchase the product. Since potential customers have not been queried on the requirements, the sample could be some small fraction of a production lot to a quantity equivalent to a lot. The $\mathrm{Cl}-20 \mathrm{WC}-2$ or $\mathrm{Cl}-20 \mathrm{WC}-2 \mathrm{~A}$ package could be used to transport material in the latter case. For the former case it might be appropriate to select a sample container to transport small quantities of product for customer testing. Since customer sample requirements are not yet known, selection and availability of specific sample packages have not been determined.

\section{B.3 Waste Transportation and B-3 Package Status/Plans}

The package for transporting product waste would be the B-3 Type B packaging. The packaging consists of a lead shielded steel weldment in the shape of a right hollow cylinder with a bottom containing a drain assembly and a recessed, plug type gasketed and bolted lid. The packaging provides a minimum of 6 in of lead shielding. Packaging features include lifting and tie down devices and a drain to the central cavity. The maximum weight of the loaded package is $30,000 \mathrm{lbs}$.

Because of the weight of the B-3 package, it is most likely that one truck would carry one B-3 package per shipment. Two packages per truck may be possible; however, depending on the exact payload weight, two packages would likely exceed the maximum gross weight allowed for one truck. The shipments would go directly from the ACRR building to either the primary site along $1-40$, or to either alternative site along the most direct route selected by the motor transport company using appropriate guidance. Transporting this waste would increase traffic volume, since it is expected that approximately 85 shipments per year would be required. The dose criteria are the same as stated above for the product transport package, as this package is Type $B$ and must meet the same listed constraints. The calculated dose rate at one-meter from the surface of the package is $1.6 \mathrm{mR} / \mathrm{hr}$, or $\mathrm{TI}=1.6$ at four months after storage (personal communication from E. Parma to A. Trennel, November 3, 1994).

Two B-3 packages are located at Cintichem Co., and two are located at the National Institute of Science and Technology (NIST). The casks have been tested within the last two years, although not all casks are current in this regard. Casks would be inspected and tested prior to use in accordance with their Certificate of Compliance (U.S. NRC, 1980) instructions. 


\section{References}

1. U.S. Nuclear Regulatory Commission (NRC), 1990, Approval Record, Model No.: B-3 Packaging, Certificate of Compliance No. 6058, Revision No. 10., dated December 6, 1990. 


\section{APPENDIX C \\ REACTOR NEUTRONICS}




\section{APPENDIX C \\ REACTOR NEUTRONICS}

This appendix presents the results of calculations and analyses on the use of the ACRR for production of molybdenum-99 $\left({ }^{99} \mathrm{Mo}\right)$. Targets containing uranium (U) will be irradiated by neutrons in the ACRR to produce ${ }^{99} \mathrm{Mo}$ and other isotopes by the fission reaction in the uranium. The rate of the fission reaction and ${ }^{99}$ Mo production is indicated by the fission heat or power produced in the targets. The total energy developed in the target cylinders must be high enough to produce the needed amount of ${ }^{99}$ Mo during the period of target irradiation. Of course ${ }^{99} \mathrm{Mo}$ is lost during extended irradiations due to radioactive decay. Therefore, the instantaneous power level must be high enough to optimize production of the required amount of ${ }^{99} \mathrm{Mo}$ in a practical irradiation period.

Targets used in actual production of ${ }^{99} \mathrm{Mo}$ must be irradiated at 400 kilowatts (kW ) of total target power for 7 days, 24 hours per day, in order to meet the North American demand for one week. Every day sufficient targets to provide the daily demand would be withdrawn from the ACRR for ${ }^{99}$ Mo processing and new targets installed. To accomplish the ${ }^{99}$ Mo production, the reactor must be capable of providing a neutron flux sufficient to produce the required fission power. In addition, adequate cooling of the targets must be provided to remove the fission heat. This appendix will present both the neutronic and thermodynamic analyses performed to date for the Cintichem target/ACRR combination, The results will show that the ACRR has enough flexibility to produce all of the North American demand for ${ }^{99} \mathrm{Mo}$ without significant reactor modifications.

\section{C.1 Reference Target Design}

Although not necessarily optimum for the ACRR neutronic characteristics, the target design for the FDA-approved Cintichem process must be used for the production of ${ }^{99} \mathrm{Mo}$. The Cintichem target is shown in Figure C-1. For the calculations and analyses, the target can be represented as a hollow, closed-end, stainless-steel pipe with a thin layer of uranium oxide $\left(\mathrm{U}_{3} \mathrm{O}_{8}\right)$ on the inside surface. Wall thickness of the pipe is $0.076 \mathrm{~cm}(.030$ in). The target length is $50 \mathrm{~cm}$ (19.7 in) and the outer diameter is $3.175 \mathrm{~cm}\left(1.25\right.$ inches). The $\mathrm{U}_{3} \mathrm{O}_{8}$ in the target cylinder would use uranium enriched in the uranium-235 $\left.{ }^{235} \mathrm{U}\right)$ isotope to $93 \%$ of total content. The ${ }^{235} \mathrm{U}$ loading in the target cylinders can vary but was assumed for this study to be $20 \mathrm{~g}$ per target. Loadings as high as $\mathbf{2 5} \mathrm{g}$ have been demonstrated using the current plating process.

The diameter and length of the target are very similar to the ACRR fuel element design. Although this does not necessarily suggest that the targets will be optimally coupled, neutronically, to the reactor core, it does allow for the application of existing ACRR heat transfer analyses and test data. The heat transfer and critical heat flux conditions presented later can be analyzed with more certainty and confidence because of the similar design of the targets and ACRR fuel elements.

\section{C.2 Neutronic Analysis Techniques}

Neutronic calculations and analyses were performed using the Monte Carlo computer code MCNP with ENDF B-V cross sections (Briesmeister, 1986). Hundreds of MCNP calculations have been run in an attempt to optimize the target/core configuration. The objective was to meet the North American demand for ${ }^{99}$ Mo using the Cintichem targets while achieving the 
Figure C-1. Target Design

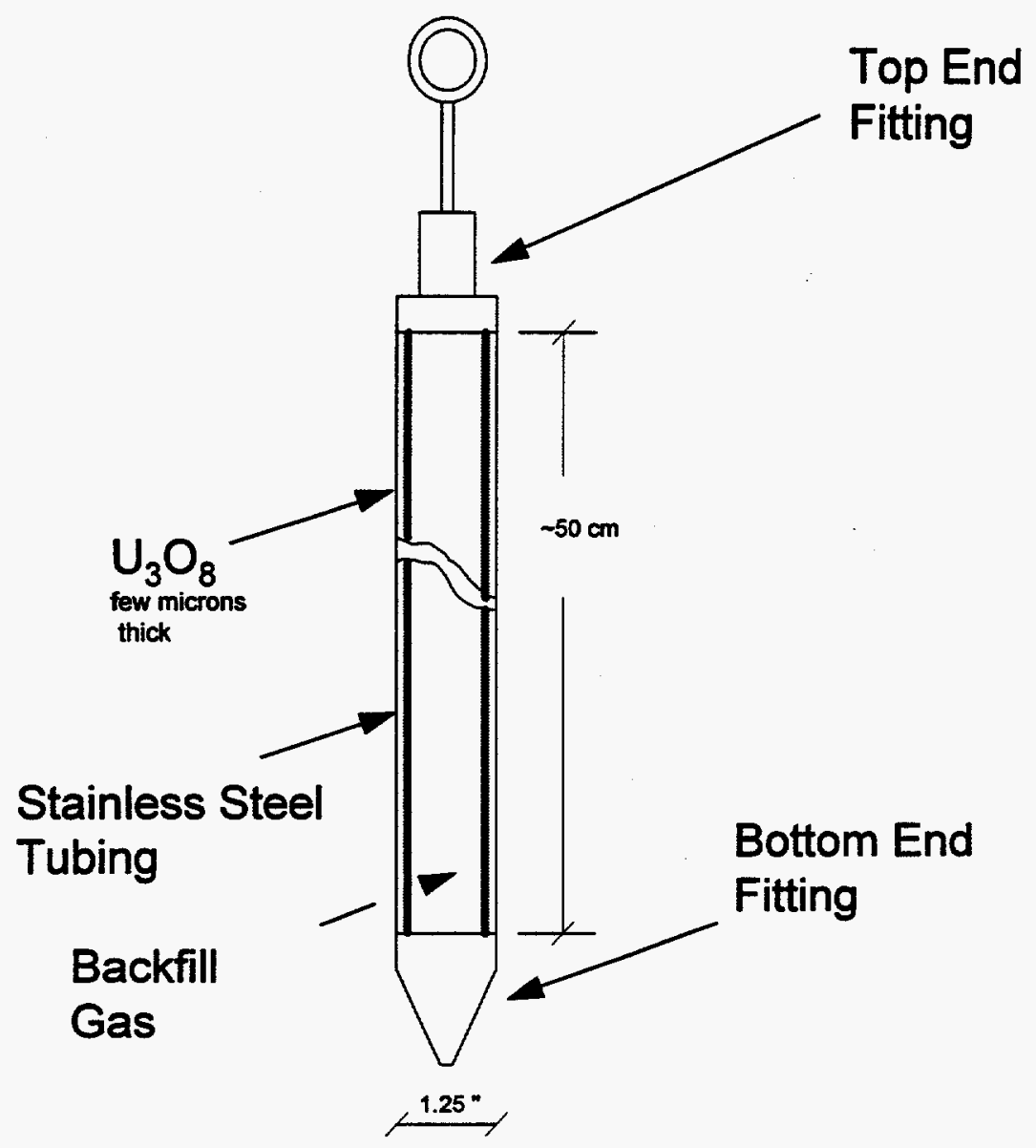

most efficient operating conditions. In the study, the number and location of the targets and the number and location of the ACRR fuel elements were varied to determine the most appropriate configurations. As the study progressed, two configurations became evident as the most appropriate to pursue since they were the most economical and simple to implement. These configurations are presented in the analyses below. Preliminary scoping calculations and calculations to develop optimal core/target configurations are reported in the following sections.

\section{C.2.1 Preliminary Neutronic Results}

Preliminary calculations using MCNP focused on the location and number of targets in an attempt to show that the ACRR could meet the North American demand for ${ }^{99}$ Mo (Coats, 1994). The targets were placed in the center of the reactor to take advantage of the concentration or trapping of neutron flux in an annular core design. General results are presented first to illustrate the flux profile and target fission density possible in the ACRR. Three case studies of possible preliminary configurations are also presented.

Figure C-2 shows a schematic side view of the existing ACRR at the bottom of its $9 \mathrm{~m}$ (30 ft) deep pool. A dry central irradiation cavity with stainless steel liner, $23 \mathrm{~cm}$ ( 9 in) in diameter, extends from the bottom of the reactor core to the water surface to allow experiment 
Figure C-2. ACRR Reactor Tank and Pool Cooling

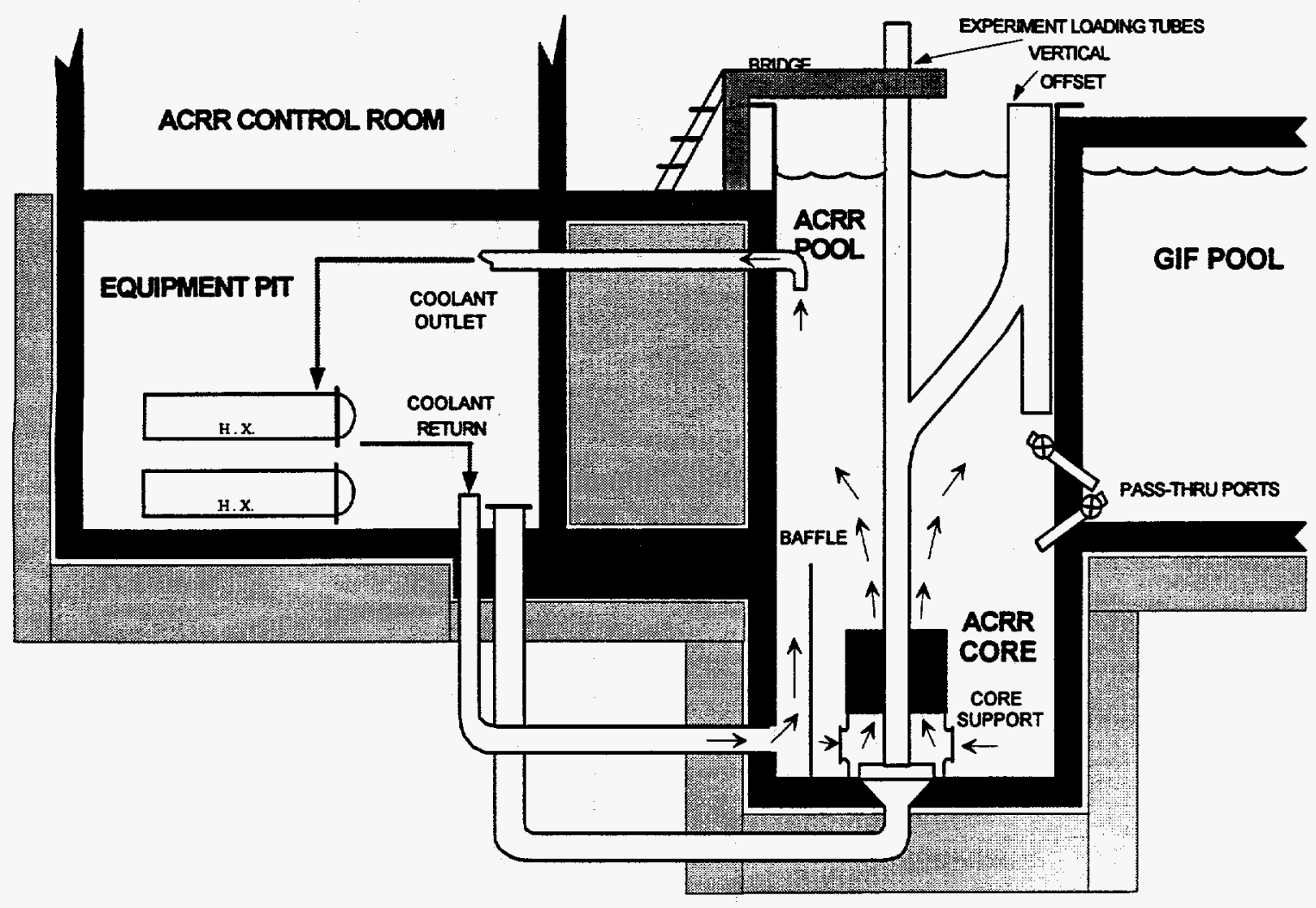

placement. Placement was through vertical and offset loading tubes with experiment storage available in the water as shown in Figure C-2. The ACRR also included other experiment mounting hardware not shown in Figure C-2. This other hardware may be removed for ${ }^{99} \mathrm{Mo}$ production. Placement from above was necessary for the ACRR's previous role as a defense programs research reactor. The stainless steel central cavity liner and associated loading tubes may not be needed for ${ }^{99}$ Mo production.

The ACRR is cooled by natural convection using the water in the pool. The water is also circulated through the first stage of a two-stage heat exchanger arrangement to maintain the temperature of the pool. The reactor cooling first stage is shown schematically in Figure C-2.

Independent calculations were made with two geometric modeling methods for comparison and verification of results. The two modeling methods were: discrete geometric representations of the targets and core; and averaged fuel element and target properties in a smoothed or homogenized geometry. The discrete representation of the ACRR standard core is shown in Figure C-3 with the central cavity liner and no targets. Note the nickel (Ni) plate and rods around the fuel elements to reflect escaping neutrons back into the reactor core. Also note the location of control rods, transient rods, and safety rods which absorb neutrons to remove them from the fission reaction process for reactor control.

The calculation results from the discrete representation model generally gave target fission powers a few percent less than those obtained using the homogenized region representation. 

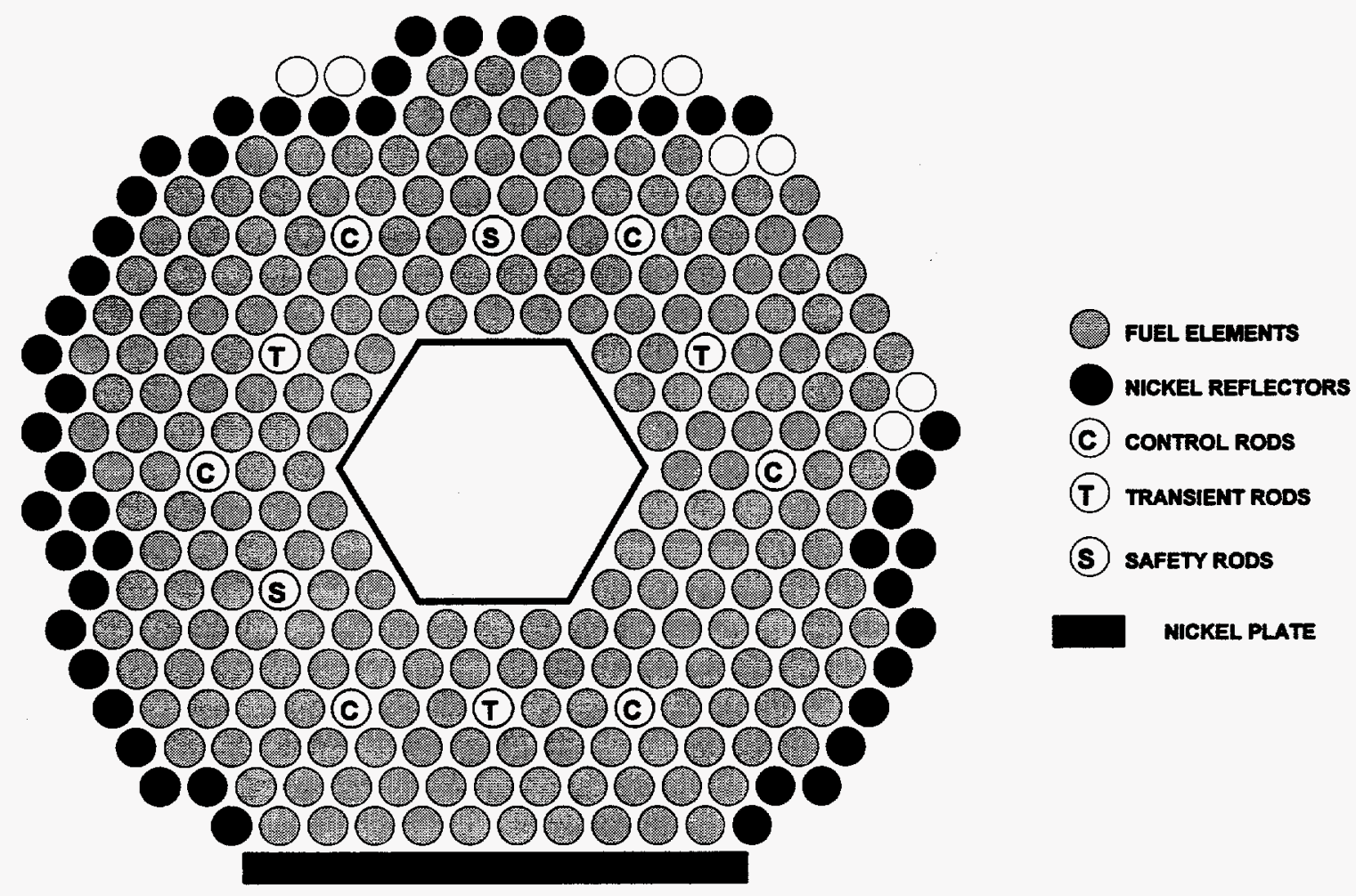

The discrete representation calculations more accurately represented local neutron flux reduction due to neutron absorption in the targets.

The effects of flux trapping in the ACRR can be seen in Figures $\mathrm{C}-4$ and $\mathrm{C}-5$, which show the neutron flux and small-sample fission density profiles in continuous operation. The neutron flux and small-sample fission density profiles are calculated for a few plausible configurations without targets. The configurations are: 1) the standard ACRR core with the dry central cavity and its stainless steel central cavity liner in place; 2) the same as 1) with the cavity flooded; and 3) the same as 2) with the stainless steel liner removed.

Figure $\mathrm{C}-4$ shows neutron flux versus radial distance from the center line of the ACRR core. The ${ }^{235} \mathrm{U}$ fuel elements, the source of fission neutrons, are located between 14 and $36 \mathrm{~cm}$ (5.5 and 14.2 in) from the center line. Values for two types of neutron flux are graphed for each of the three configurations. The total flux $(\Phi)$ includes neutrons traveling with all velocities or energies. The neutron energy varies from several million electron volts (MeV), for neutrons just produced in the fission reaction in ${ }^{235} \mathrm{U}$, to 0.025 electron volts $(\mathrm{eV})$ for neutrons whose average energy is in thermal equilibrium with the room temperature water in the core. Fission neutrons lose energy and slow down as they undergo multiple collisions with the water molecules. The neutrons continue to slow down until they reach an average energy characteristic of the temperature of the moderating water.

The second type of neutron flux shown in Figure $\mathrm{C}-4$ is for neutrons with energy less than 1.0 $\mathrm{eV}$. These epithermal neutrons produce the bulk of the ${ }^{235} \mathrm{U}$ fission reactions in the ACRR because the probability of causing a fission reaction is much higher for low energy collisions 
Figure C-4. ACRR Radial Neutron Flux For Dry Cavity, Flooded Liner, and No Liner

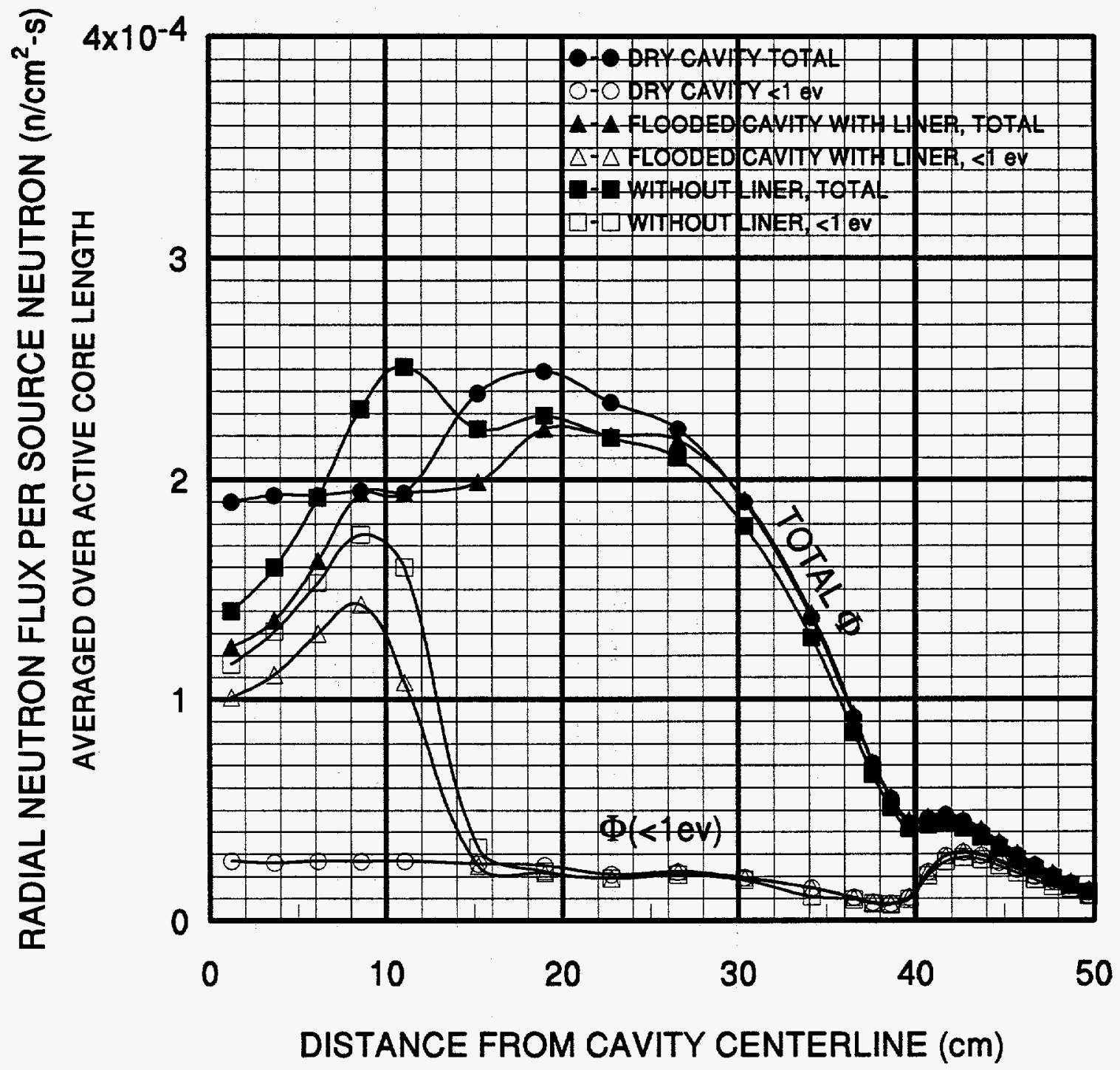

between neutrons and ${ }^{235} \mathrm{U}$ nuclei. The ACRR was designed with limited space between the fuel elements for its previous role in defense system testing. The limited water between the fuel elements limits moderation of the neutrons so the ACRR does not operate on the lowest energy neutrons.

In Figure $\mathrm{C}-4$ the dry central cavity liner configuration shows a constant neutron flux in the central cavity for both total and epithermal neutrons. When water is introduced in the central cavity, with or without the liner, the total neutron flux decreases toward the center compared with the dry configuration. The epithermal neutron flux, however, increases well above the dry configuration with water in the central cavity. The increased epithermal flux shows the effect of increased water moderation. It should also be noted that the flooded central cavity configuration with the liner had lower neutron flux than without the liner. 
Figure C-5. ACRR Fission Density For Dry Cavity, Flooded Liner, and No Liner

\section{MW OPERATION WITHOUT TARGETS}

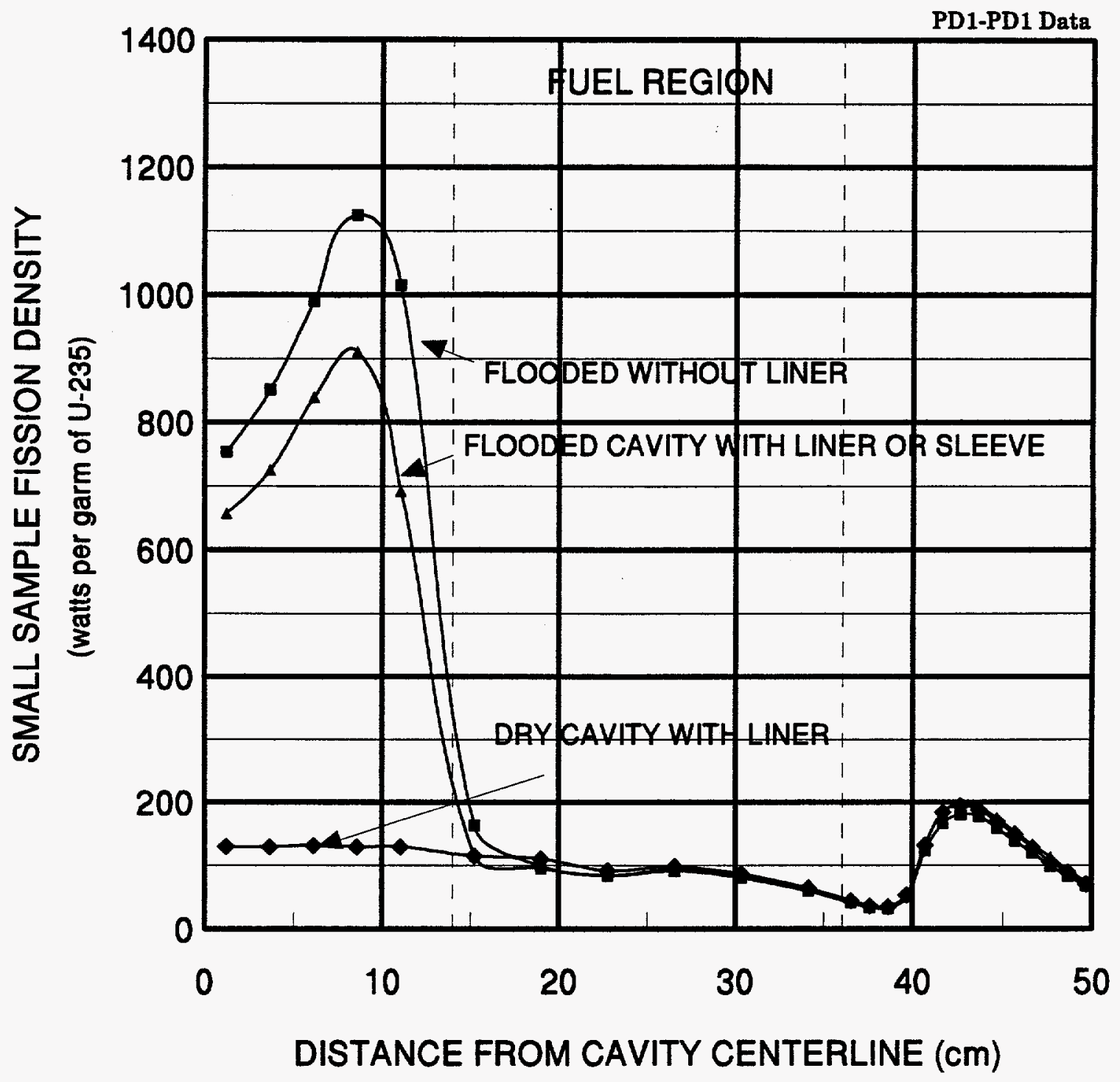

Figure C-5 shows the fission density in the ACRR without targets versus radial distance from the core center line for the same three configurations as Figure $\mathrm{C}-4$. The increase in fission density is quite evident with water in the central core cavity to moderate the neutrons. Peak fission density with water is about ten times the dry cavity value. The increased fission density should increase ${ }^{99}$ Mo production.

In Figure C-6, the calculated fission density is shown for targets placed in the standard ACRR. The peak fission density occurs for 19 targets in the central core with no liner. Figure C-7 shows the fission density for various configurations of targets and increased water moderation, without the nickel reflector plate and rods. 
Figure C-6. ACRR Fission Flux Density For Targets In Various Locations

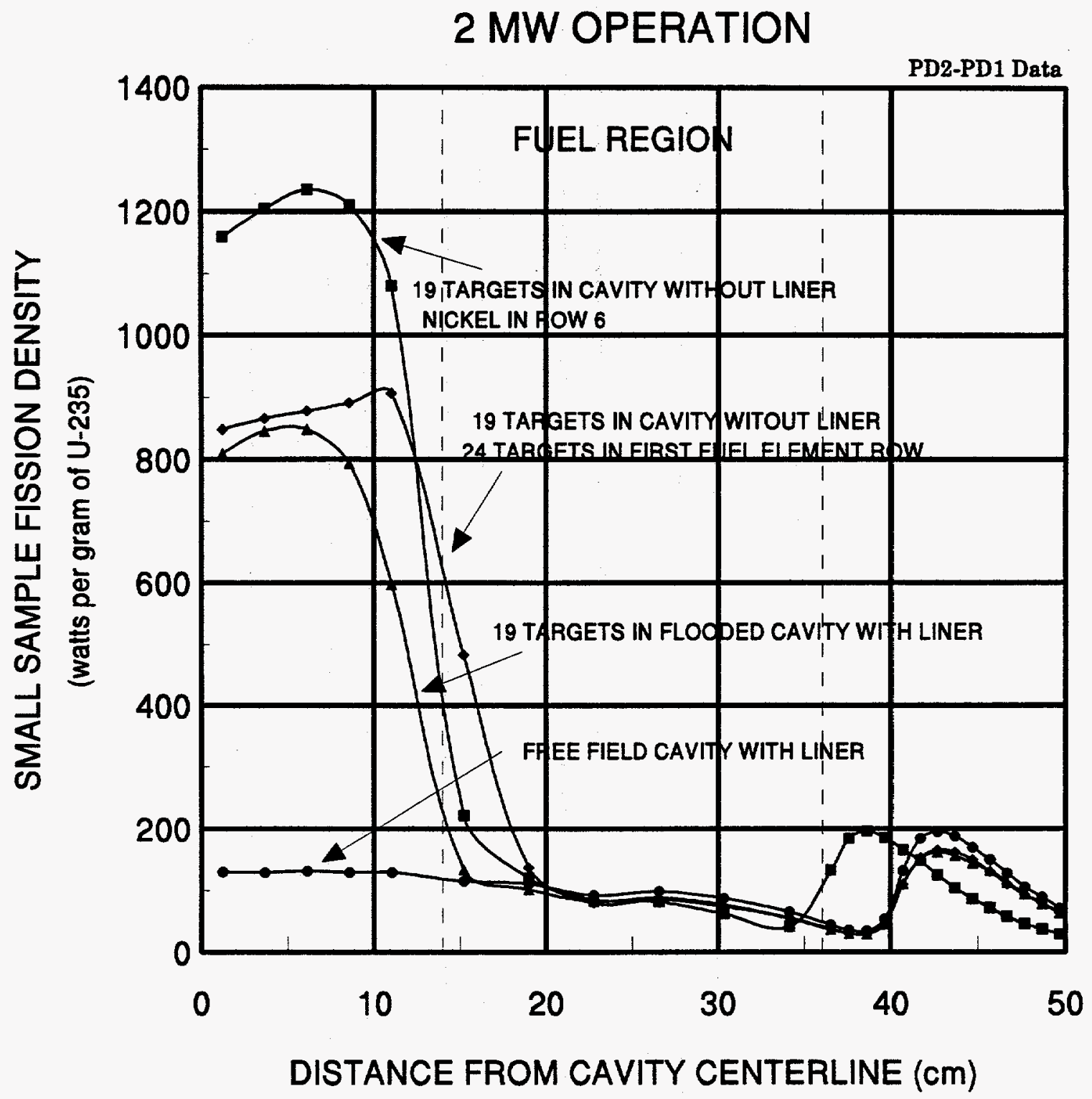

The figures show the potential for increases in epithermal flux and target fission density by locally increasing the water moderator-to-fuel ratio. The increase is obtained by placing targets in the water instead of air. Therefore, all of the following case studies of target power use targets moderated in the water. The results of the target power case studies for three possible preliminary target/core configurations are presented. For Case 1, targets are simply placed in ACRR fuel element locations; in Case 2, targets are placed in the central cavity of the ACRR inside the stainless steel liner with the cavity flooded; and for Case 3, the targets are in the flooded central cavity with the stainless steel liner removed. 
Figure C-7. ACRR Fission Flux Density For Targets With Various Locations And Moderation

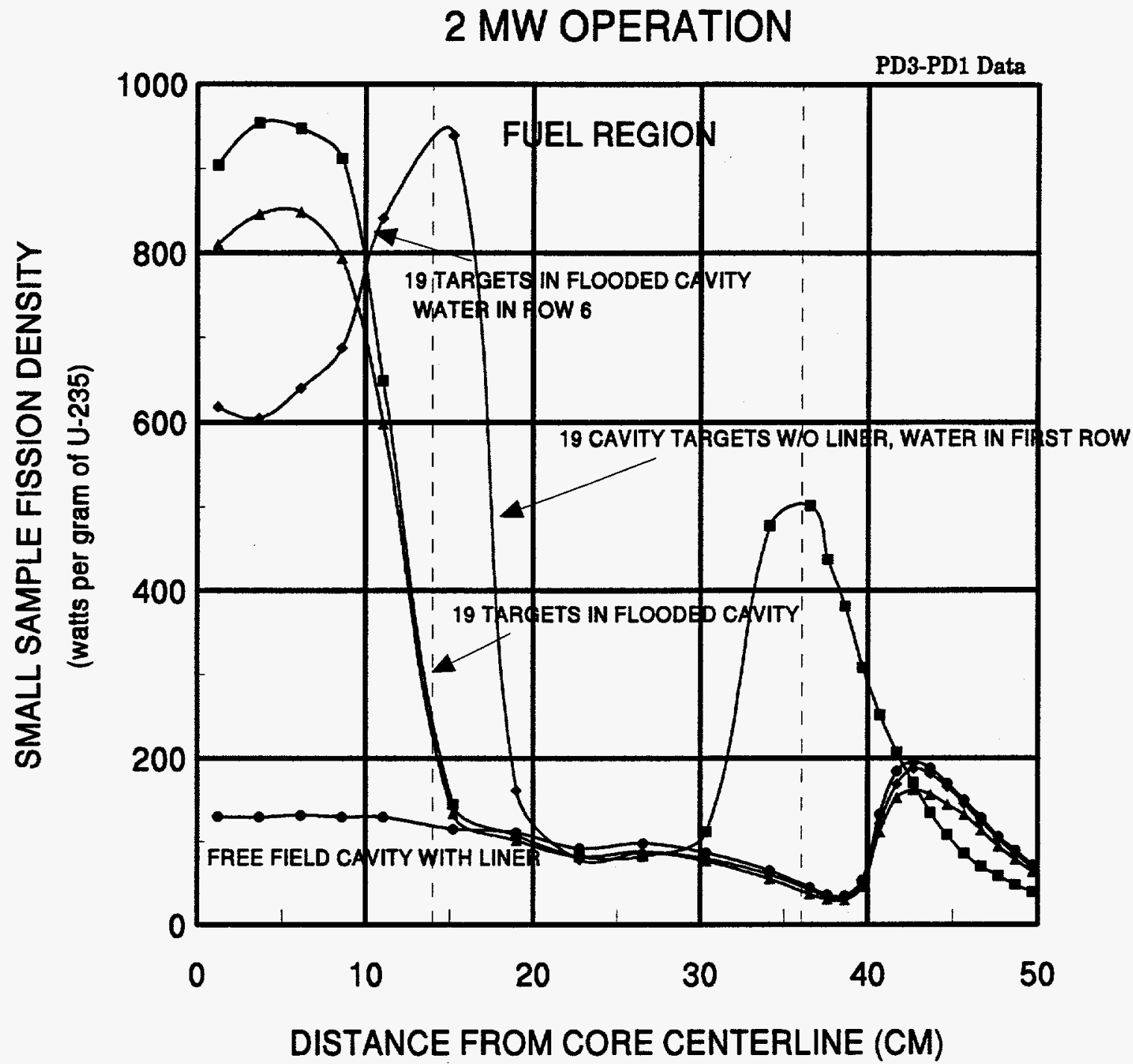

\section{Case 1- Targets In ACRR Fuel Element Locations}

These calculations examined targets simply placed in locations of the ACRR fuel element grid without any attempt to further optimize moderator or moderator-to-fuel ratios. The results showed target powers ranging from 4 to $8 \mathrm{~kW}$ per target could be achieved with 2 megawatt (MW) ACRR power continuous operation. The lower value corresponds to the outermost grid locations while the higher value corresponds to inner grid rows. Higher target powers could also be achieved by removing some fuel elements in the vicinity of the targets to locally increase the moderator-to-fuel ratio. The additional water moderation of the reactor neutrons would increase the local flux of the low energy neutrons which produce the fission reaction. Although plausible, this configuration would be expensive, requiring about 50 targets to be processed per week in order to meet the North American demand. 


\section{Case 2- Targets In Flooded Stainless Steel Liner In Reactor Central Cavity}

These calculations examined targets placed in the flooded central cavity with the stainless steel liner in place. Target powers of $10.5 \mathrm{~kW}$ each were found with this configuration for $2 \mathrm{MW}$ ACRR continuous operation. Up to 25 targets can be closely placed in this configuration, resulting in about $260 \mathrm{~kW}$ total power to provide $65 \%$ of the North American demand. A side view of this configuration is shown in Figure $\mathrm{C}-8$.

Figure C-8. Targets In Flooded ACRR Central Cavity With Liner

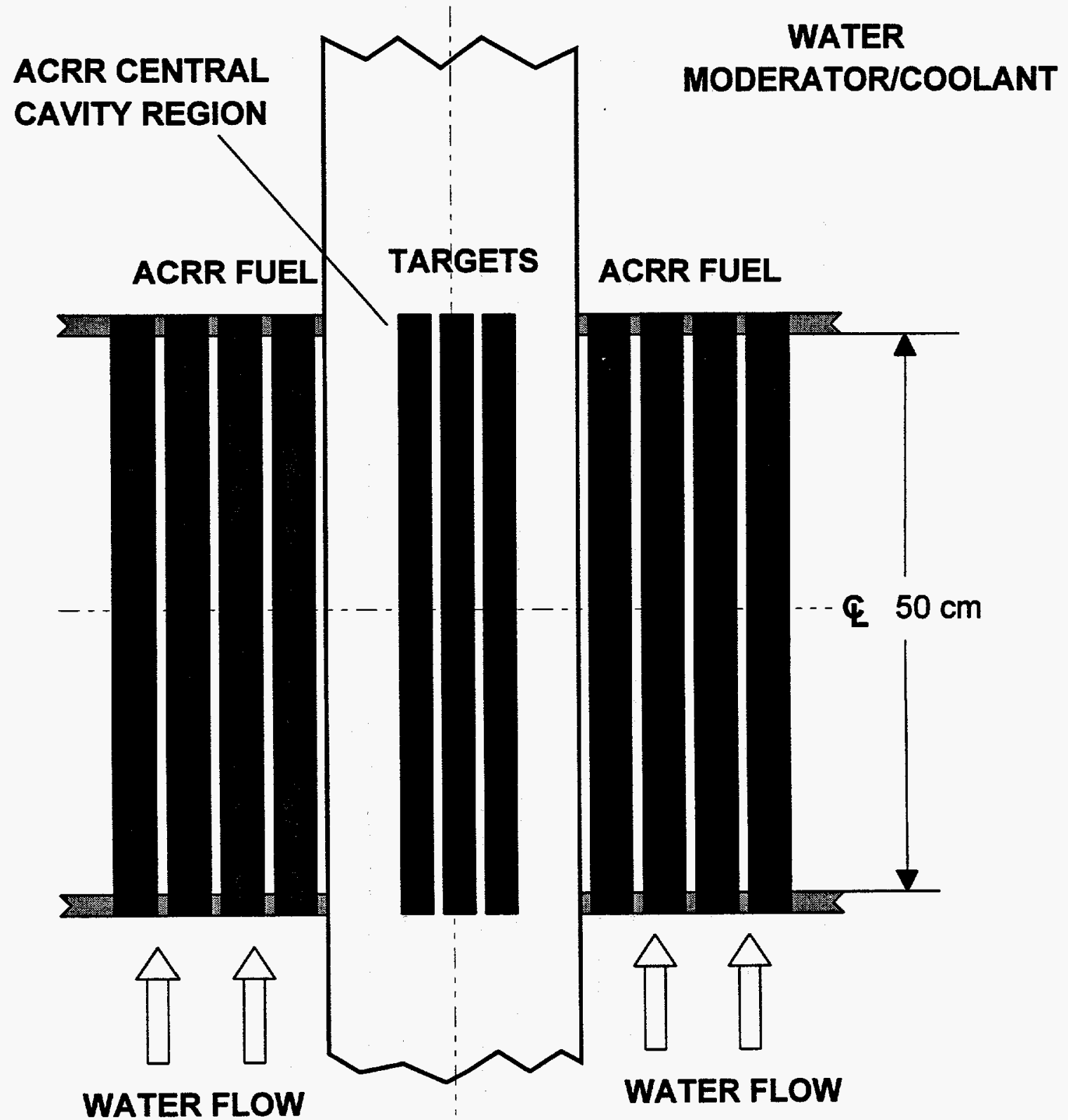


Since the liner in the central cavity is normally dry, water in the liner would be isolated from the pool water. To ensure adequate target cooling, a cooling system would have to be engineered. The amount of cooling that could be obtained by convective flow around the liner in the central cavity has been estimated to be greater than $200 \mathrm{~kW}$. Forced flow would provide greater cooling capacity. Target transfer from the central cavity up the liner tube and into a shielded cask at the pool surface would present some difficulties. This configuration takes advantage of the flux trapping capabilities of the ACRR but ${ }^{99}$ Mo production is limited due to the size of the liner in the central cavity.

\section{Case 3- Targets In Flooded Reactor Central Cavity Without Stainless Steel Liner}

The configuration for this case is shown in Figure C-9. With the central cavity liner removed and replaced by a grid structure for target mounting, target cooling and transfer are facilitated. More importantly, local target fission power is increased by the increased neutron moderation. Removal of the neutron absorbing stainless steel liner between the ACRR core and the targets also increases target fission power. This configuration provides the greatest coupling between target power and core power.

The calculations show $13 \mathrm{~kW}$ of fission power can be generated in each of 19 targets mounted in the central region grid structure for 2 MW ACRR continuous operation. This would result in about $250 \mathrm{~kW}$ total target power to provide about $60 \%$ of the North American demand. This mounting grid configuration also allows up to 37 targets to be placed in the central core region, adding flexibility.

The results presented so far focused on $2 \mathrm{MW}$ continuous operations but this is not the limit for the ACRR core. ACRR power levels of up to $4.75 \mathrm{MW}$ have been achieved. If the ACRR power were increased to $3 \mathrm{MW}$, the 19 targets in the Case 3 configuration could supply the entire North American demand for ${ }^{99} \mathrm{Mo}$. The calculations show an average target power of 21 kW for the 19 targets in 3 MW ACRR continuous operation. The thermodynamic calculations presented later will show target cooling for this power level should be achievable.

\section{C.2.2 Optimal Core/Target Configuration Results}

The results of preliminary calculations indicated that the best coupling between target power and core power was achieved with targets in the central core region and the cavity liner removed. Further investigation of this scenario has led to two configurations of the ACRR that are now referred to as the baseline conditions. One is a 19 target configuration, the other a 37 target configuration; either configuration could be used to meet the North American demand for ${ }^{99}$ Mo.

Figure C-10 shows the 19 target configuration in a standard ACRR core of 236 fuel elements. The central cavity liner has been removed and replaced with a grid structure to hold the targets. The optimum pitch or separation for this configuration was found to be $5.3 \mathrm{~cm}$ (2.1 inches). As presented in Table $\mathrm{C}-1$, the North American demand for ${ }^{99} \mathrm{Mo}$ can be met by running the core power at 3.06 MW with an average target power of $21.1 \mathrm{~kW}$ (SNL, 1994). For this configuration, the peak ACRR fuel element power would be $26.6 \mathrm{~kW}$ in the first row of elements. The ACRR has been tested to this power level per element in previous experiments.

An important issue for reactor operations is core reactivity or ability to increase the neutron flux that sustains the fission chain reaction in the ${ }^{235} \mathrm{U}$. The unit of measurement for reactivity in reactors like the ACRR is the dollar (\$). Positive values of reactivity indicate the capability to 
Figure C-9. Targets In Flooded ACRR Central Cavity Without Liner

\section{ACRR CORE GRID MODERATOR/COOLANT} PLATE EXTENSION WATER

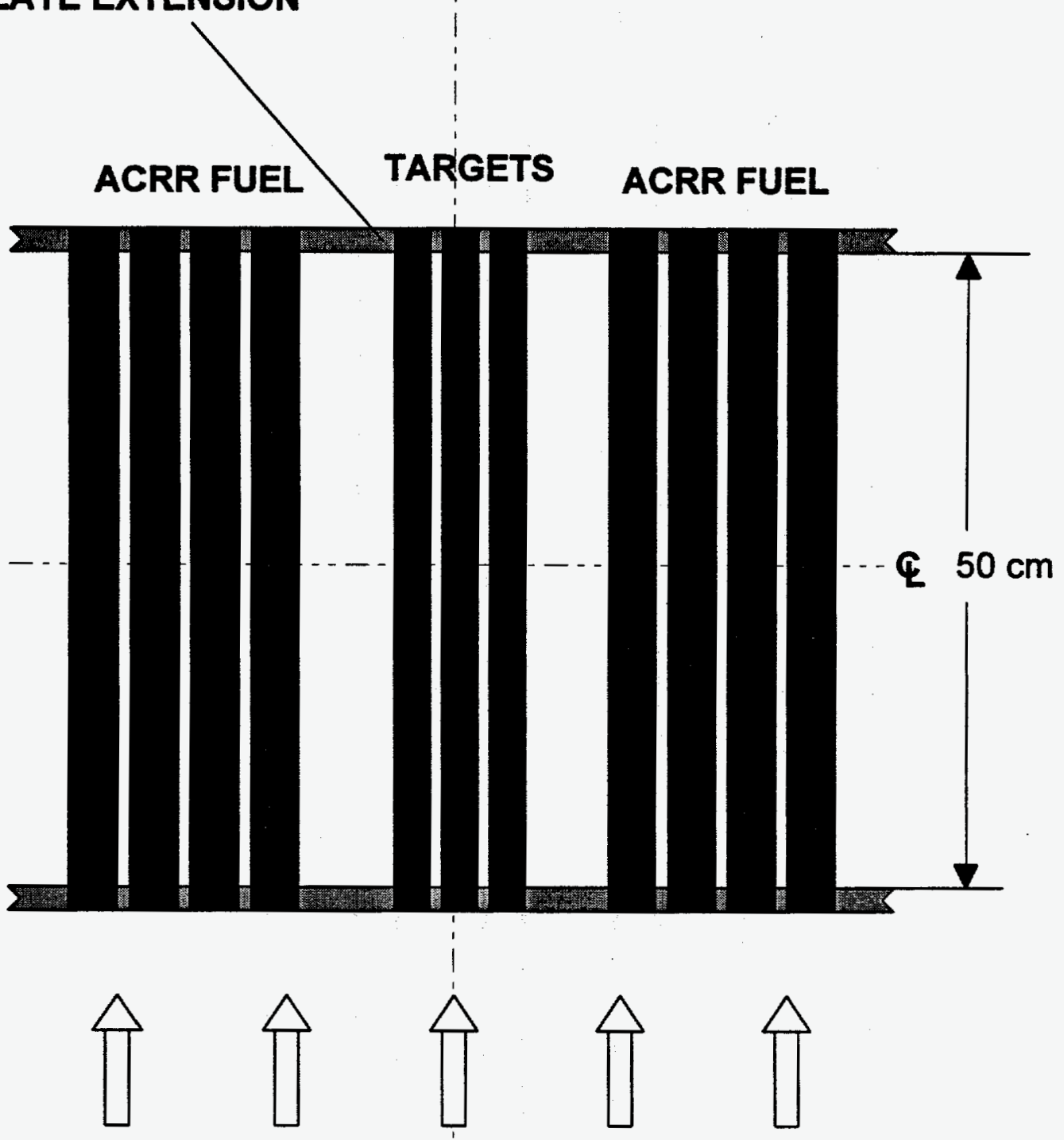

WATER FLOW

multiply or increase neutron flux and increase the power of the reactor. Note from Table C-1 excess reactivity is a positive $\$ 16.80$ for the standard 236 fuel rod ACRR with the central cavity removed and 19 targets installed. The control rods in the ACRR can maintain about $\$ 10.00$ worth of negative reactivity; which suggests that the core size must be reduced (i.e. removal of fuel elements) to reduce the excess reactivity to a few dollars.

Figures $\mathrm{C}-11$ and $\mathrm{C}-12$ present smaller core configurations for 19 and 37 targets placed in the central core region, respectively. The core now has 129 fuel elements surrounded by nickel elements to reflect neutrons. While the nickel elements are not necessarily required, they provide a slight peaking of the flux toward the center of the core and a slightly higher coupling factor. Removing the nickel elements adds about $\$ 3.00$ of reactivity; hence these elements can be used for adjustment of reactivity as necessary. 
Figure C-10. 19 Targets In Flooded ACRR Central Cavity With No Liner And 236 Fuel Elements

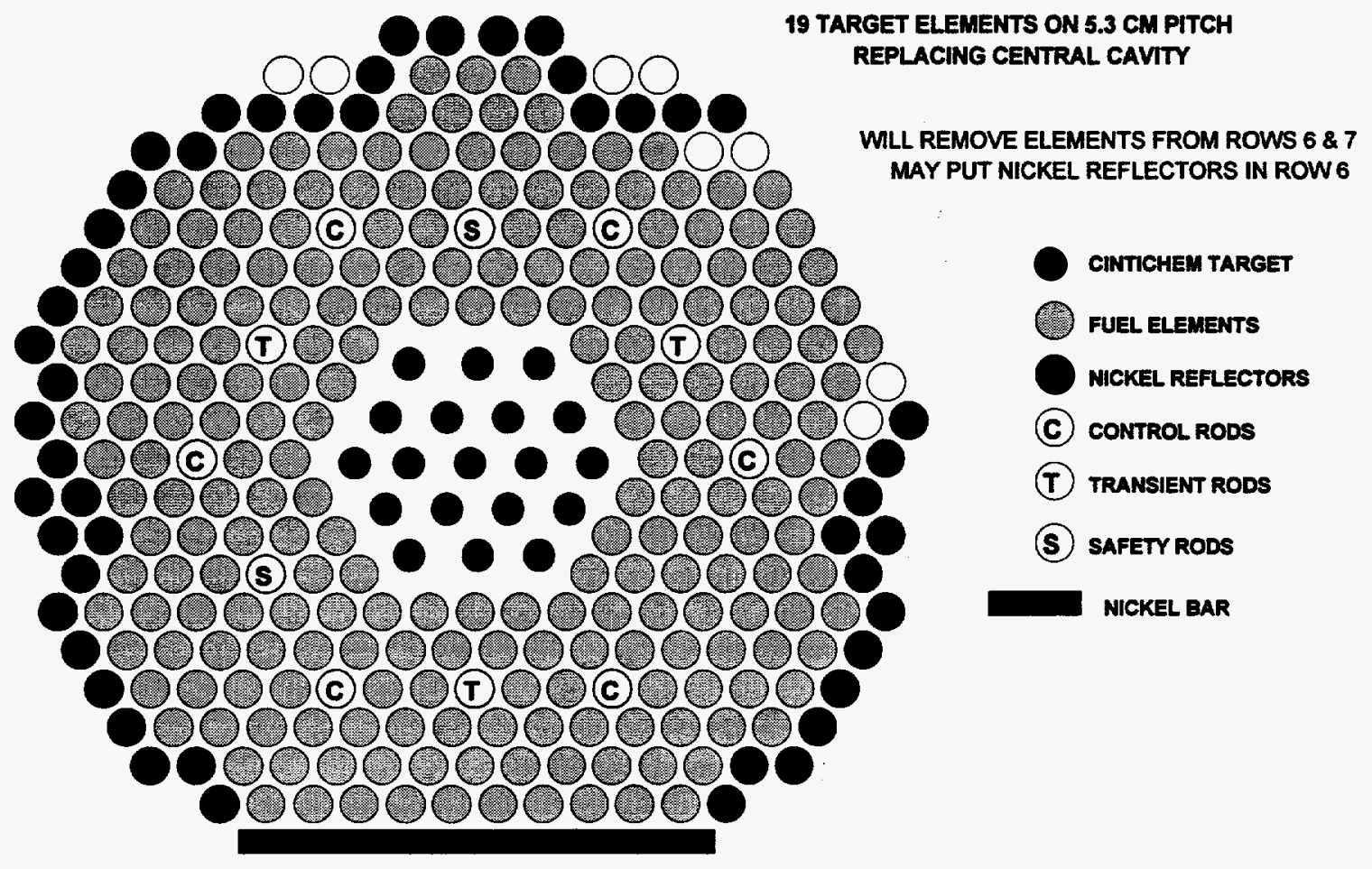

Table C-1. MCNP Results for the Baseline Core Configurations

MCNP Results, 3-D Discrete Core

Cintichem Targets with $20 \mathrm{~g}^{235} \mathrm{U}$ each

\begin{tabular}{|c|c|c|c|c|c|c|}
\hline Configuration & $\begin{array}{l}\text { Total } \\
\text { Target } \\
\text { Pwr (kW) }\end{array}$ & $\begin{array}{l}\text { Average } \\
\text { Target } \\
\text { Pwr (kW) }\end{array}$ & $\begin{array}{l}\text { Total } \\
\text { Core } \\
\text { Pwr } \\
\text { (MW) }\end{array}$ & $\begin{array}{l}\text { Average } \\
\text { Fuel } \\
\text { Element } \\
\text { Pwr (kW) }\end{array}$ & $\begin{array}{l}\text { Peak } \\
\text { Fuel } \\
\text { Element } \\
\text { Pwr (kW) }\end{array}$ & $\begin{array}{c}\text { Excess } \\
\text { Reactivity } \\
\text { (\$) }\end{array}$ \\
\hline $\begin{array}{l}236 \text { Element } \\
\text { ACRR (w/o central } \\
\text { cavity liner) } 19 \\
\text { Targets - Pitch } 5.3 \\
\text { cm }\end{array}$ & 400 & 21.1 & 3.06 & 13.0 & 26.6 & +16.80 \\
\hline $\begin{array}{l}129 \text { Element Core } \\
4 \text { th row fuel, } 5 \text { th } \\
\text { row } \mathrm{Ni}^{*}(\mathrm{w} / \mathrm{o} \\
\text { central cavity } \\
\text { liner) } 19 \text { Targets - } \\
\text { Pitch } 5.3 \mathrm{~cm}\end{array}$ & 400 & 21.1 & 1.92 & 14.9 & 26.4 & +1.00 \\
\hline $\begin{array}{l}129 \text { Element Core } \\
\text { 4th row fuel, } 5 \text { th } \\
\text { row Ni* (w/o } \\
\text { central cavity } \\
\text { liner) } 37 \text { Targets - } \\
\text { Pitch } 4.0 \mathrm{~cm}\end{array}$ & 400 & 10.8 & 1.50 & 11.6 & 19.3 & +6.40 \\
\hline
\end{tabular}

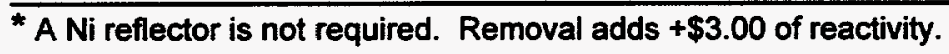


Figure C-11. 19 Targets In Flooded ACRR Central Cavity With No Liner And 129 Fuel Elements

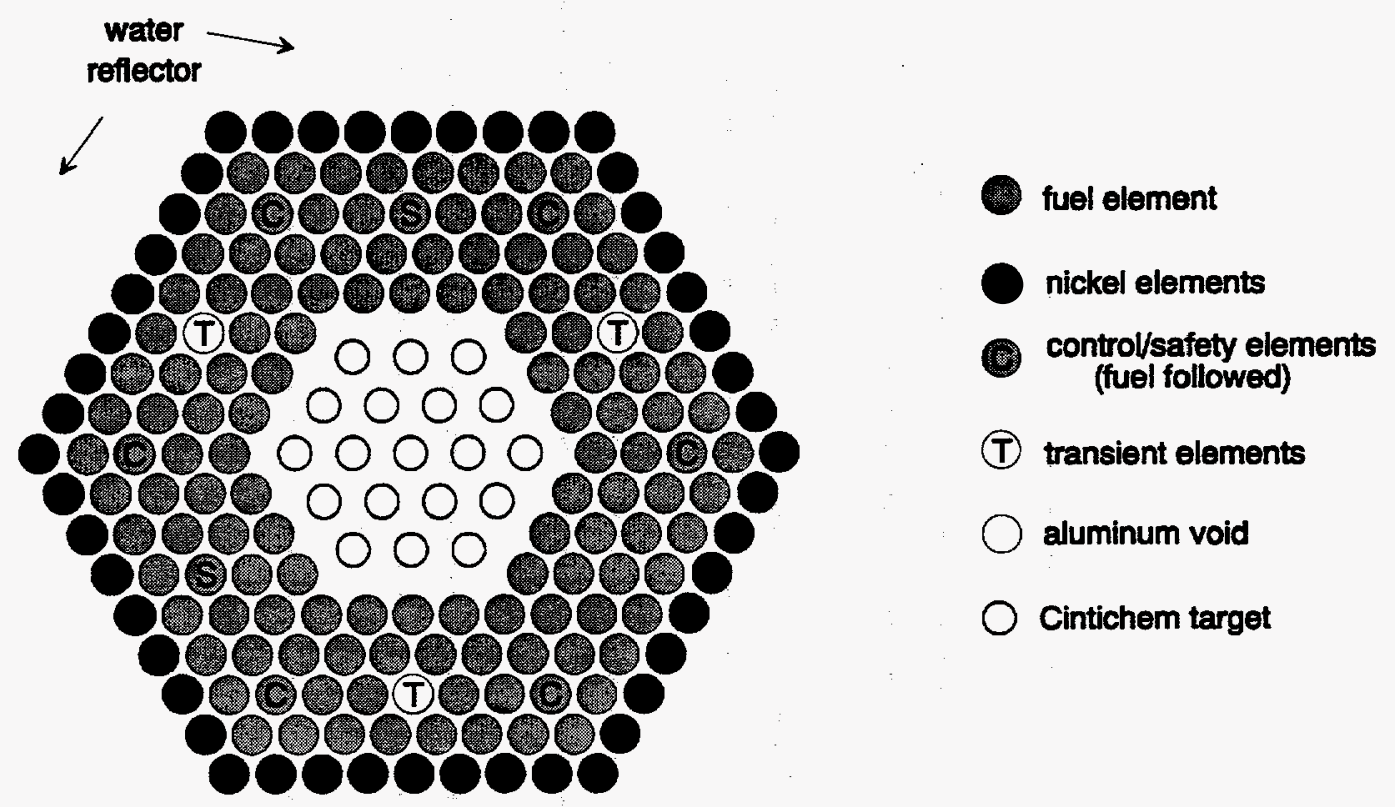

Figure C-12. 37 Targets In Flooded ACRR Central Cavity With No Liner And 129 Fuel Elements

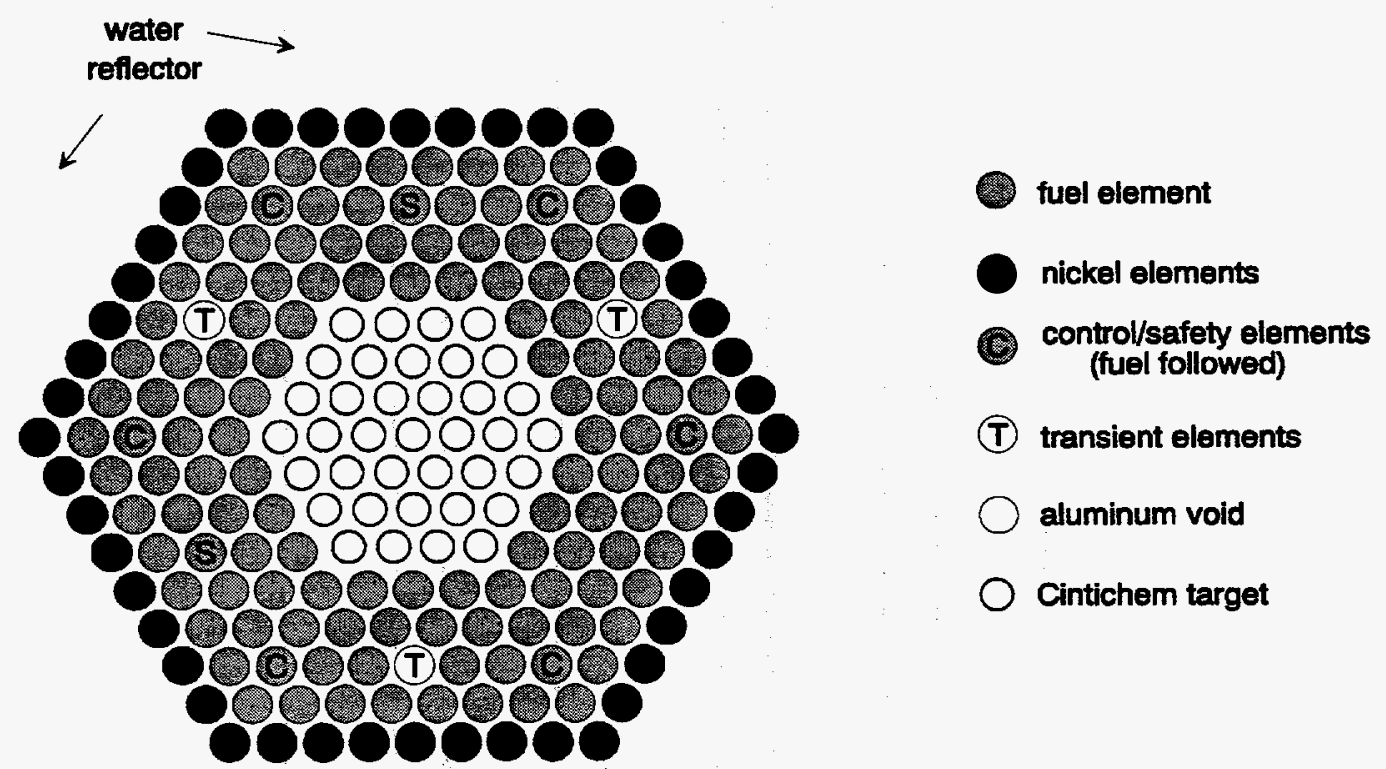

The 19 target configuration is the one of choice since it would require fewer targets to be processed each week. The average target and peak fuel element power for the 19 target 
configuration would be $21.1 \mathrm{~kW}$ and $26.4 \mathrm{~kW}$, respectively. This is very close to the result of the standard core case. The major advantages of the small core over the standard core are 1) less excess reactivity ( $\$ 1.00$ compared to $\$ 16.80)$ and 2$)$ less core power (1.92 MW versus $3.06 \mathrm{MW}$ ). The 37 target configuration allows for lower power levels in the target and peak fuel elements if for some unknown reason, $21.1 \mathrm{~kW}$ cannot be achieved in the targets. If $21.1 \mathrm{~kW}$ is achievable in the targets, the 37 target configuration will allow for an excess capacity of between 40 and $100 \%$, depending on the fuel element power limits ( $27 \mathrm{~kW}$ versus $40 \mathrm{~kW}$, respectively).

Periodic replacement of the current fuel will be required for continued ${ }^{99}$ Mo production. The effective neutronic core life of the ACRR has been estimated to be approximately 12 megawatt years (MW-y). This life can be attributed to the high ${ }^{235} \mathrm{U}$ loading in the BeO fuel. Thus, the 129 element baseline core could be operated for 6 years in the 19 target configuration at 2 MW power, 24 hours per day, 7 days per week. At that time the original 236 fuel element core configuration could be re-established. This re-established configuration of used and stored fuel elements would still maintain greater than $\$ 4.00$ of excess reactivity. This implies that, although the fuel will be required to be replaced with another type in order to save the specially designed BeO fuel, quick replacement is not urgent.

\section{C.3 Critical Heat Flux Analyses}

Calculations and experiments performed by the University of New Mexico (UNM) investigated the heat transfer and critical heat flux (CHF) conditions for ACRR type reactors under natural convection coolant flow (Rao, 1992). Correlations to the basic calculations were developed to determine the CHF power level in an element as a function of the mass flow rate (which is also dependent on the power under natural convective conditions), the inlet temperature conditions, and the geometry of the elements. A series of experiments performed in the ACRR was used as the benchmark for the correlations.

The CHF out of the element represents the ultimate limit to fuel element or target cooling. For heat fluxes greater than the CHF, the coolant on the surface of the fuel element turns to steam, and heat transfer into the water is greatly reduced. The trapped heat in the fuel elements can cause extensive damage. The ACRR was never brought to a condition in the UNM experiments where the CHF was attained, which would result in fuel failure. However, nucleate boiling conditions of the bulk coolant at a lower heat flux were investigated. The experimental results give confidence that the correlations developed can be used to conservatively predict the CHF condition for fuel elements and targets in ${ }^{99}$ Mo production.

The CHF correlations were applied to the ACRR fuel elements to predict the minimum CHF ratio (MCHFR). MCHFR is the ratio of CHF to the highest heat flux predicted under the conditions of reactor operation. A MCHFR value of one indicates that CHF has been reached, A value greater than one indicates the predicted fuel element heat flux is less than CHF. For a fuel element power of $27 \mathrm{~kW}$, MCHFR varies linearly from 2.0 to 1.3 as the inlet temperature varies from 20 to $50^{\circ} \mathrm{C}$. Thus, the predicted heat flux is below the CHF damage limit. $27 \mathrm{~kW}$ is the maximum fuel element power in the 19 target baseline configuration.

The geometry of the Cintichem targets is very similar to both the fuel elements and the tests performed by UNM. The UNM CHF correlations were also used to determine expected target 
heat flux and the maximum target power level that could be cooled. For the expected target power of $21.1 \mathrm{~kW}$, the MCHFR varies linearly from 9.5 to 6.0 as the inlet temperature varies from 20 to $50^{\circ} \mathrm{C}$. Thus, target heat flux for the 19 target baseline is predicted to be below CHF by a very large margin. This large margin gives high confidence in the coolability of the targets.

Initial testing will be performed in the ACRR with the targets in place to ensure that cooling at the power levels indicated can be achieved. The CHF analysis indicates that the proposed power level requirements can be easily met. However, the fuel coating in the targets must also be subjected to these power levels on an experimental basis to ensure its robustness to remain attached to the inside of the targets.

\section{C.4 ACRR Capability Summary}

The results presented indicate that for the 129 element core configuration, target loadings of 19 to 37 in the central region of the core with the cavity liner removed will allow for the North American demand for ${ }^{99}$ Mo to be met with relatively minor modifications to the ACRR core configuration. With the 19 Target configuration as the baseline, the average target power will be $21.1 \mathrm{~kW}$ and the core power $1.92 \mathrm{MW}$. A sufficient amount of margin and flexibility exists in the core to allow for a high degree of confidence that the North American demand can be met. The actual target fuel configuration to be employed depends on the production goal (fraction of North American demand) at any given time. However, the target/core configuration candidates chosen are robust enough to cover the possibilities for $20 \%$ to $100 \%$ and greater shares of the North American market. 
References

1. Briesmeister, J. F., Editor, 1986, MCNP - A General Purpose Monte Carlo Code for Neutron and Photon Transport, LA-7396-M. Rev 2, Los Alamo National Laboratory, Los Alamos, NM.

2. Coats, R. L. and Edward J. Parma, 1994, Medical Isotope Production: A New Research Initiative for the Annular Core Research Reactor, Isotope Production Program Office (6500), Sandia National Laboratory, Albuquerque, NM.

3. Roo, D. V. and Mohammed S. El-genk, Critical Heat Flux Predictions For Sandia's Annular Core Research Reactor, Report \# ISNPS-312631-1-90, Institute for Space Nuclear Power Systems, Department of Chemical and Nuclear Engineering, University of New Mexico, Albuquerque, NM.

4. Candia National Laboratory (SNL), $1994,{ }^{99}$ Mo Production at the SNL-Area V Annular Core Research Reactor Facility, Slide Presentation, Reactor Engineering Technology Center (6500), Sandia National Laboratory, Albuquerque, NM.

C-17 

APPENDIX D

ENVIRONMENTAL DATA

D-1 
Table D-1. Meteorological Data for Albuquerque, 1991 (Restrepo, 1994)

Latitude: $35^{\circ} 03^{\prime} \mathrm{N} \quad$ Longitude: $106^{\circ} 37 \mathrm{~W}$ Elevation: $5311 \mathrm{ft} . \mathrm{ms}$ Time Zone: Mountain

\begin{tabular}{|c|c|c|c|c|c|c|c|c|c|c|c|c|c|}
\hline & 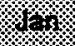 & 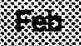 & 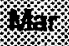 & 然列 & wax & 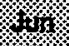 & 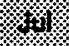 & 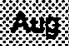 & s. & 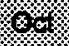 & \% & 83. & 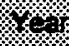 \\
\hline $\begin{array}{l}\text { TEMPERATURE, F } \\
\text { Averages } \\
\text { - Daiily Maximum } \\
\text {-Daihy Minimum } \\
\text {-Monthly } \\
\text {-Monthly Dewpoint } \\
\text { Extremes } \\
\text { - Highest } \\
\text {-Date } \\
\text { - Lowest } \\
\text {-Date }\end{array}$ & $\begin{array}{r}46.0 \\
25.3 \\
35.7 \\
19.4 \\
\\
54 \\
5 \\
18 \\
31\end{array}$ & $\begin{array}{r}58.7 \\
30.4 \\
44.6 \\
19.6 \\
66 \\
22 \\
19 \\
1\end{array}$ & $\begin{array}{r}59.9 \\
32.2 \\
46.1 \\
18.1 \\
72 \\
24 \\
20 \\
8\end{array}$ & $\begin{array}{l}71.8 \\
40.1 \\
56.0 \\
14.5 \\
\\
83 \\
6 \\
26 \\
13\end{array}$ & $\begin{array}{r}81.7 \\
49.3 \\
65.5 \\
22.1 \\
91 \\
19 \\
37 \\
5\end{array}$ & $\begin{array}{r}88.4 \\
58.3 \\
73.4 \\
39.4 \\
\\
101 \\
25 \\
46 \\
3\end{array}$ & $\begin{array}{l}89.9 \\
63.8 \\
76.9 \\
50.5 \\
99 \\
99 \\
7 \\
58 \\
27\end{array}$ & $\begin{array}{l}80.0 \\
62.9 \\
75.5 \\
53.6 \\
\\
95 \\
22 \\
59 \\
18\end{array}$ & $\begin{array}{r}80.5 \\
55.6 \\
68.1 \\
46.1 \\
93 \\
3 \\
49 \\
21\end{array}$ & $\begin{array}{r}74.6 \\
44.5 \\
59.6 \\
29.4 \\
\\
86 \\
3 \\
19 \\
31\end{array}$ & $\begin{array}{r}54.9 \\
31.8 \\
43.4 \\
25.7 \\
\\
70 \\
7 \\
19 \\
3\end{array}$ & $\begin{array}{r}47.0 \\
27.6 \\
37.3 \\
24.6 \\
\\
58 \\
8 \\
18 \\
3\end{array}$ & $\begin{array}{r}70.1 \\
43.5 \\
56.8 \\
30.3 \\
\\
101 \\
625 \\
18 \\
12 / 3\end{array}$ \\
\hline $\begin{array}{l}\text { DEGREE DAYS, BASE 65\%F } \\
\text { Heating } \\
\text { Cooling }\end{array}$ & $\begin{array}{c}903 \\
0\end{array}$ & $\begin{array}{r}563 \\
0\end{array}$ & $\begin{array}{r}581 \\
0\end{array}$ & $\begin{array}{r}263 \\
0\end{array}$ & $\begin{array}{l}60 \\
87\end{array}$ & $\begin{array}{r}12 \\
269\end{array}$ & $\begin{array}{r}0 \\
375\end{array}$ & $\begin{array}{r}0 \\
331\end{array}$ & $\begin{array}{r}21 \\
120\end{array}$ & $\begin{array}{r}188 \\
25\end{array}$ & $\begin{array}{r}645 \\
0\end{array}$ & $\begin{array}{r}851 \\
0\end{array}$ & $\begin{array}{l}4087 \\
1207\end{array}$ \\
\hline $\begin{array}{l}\text { \% POSSIBLE SUNSHINE } \\
\text { MEAN SKY COVER (tenths) } \\
\text { Sumise - Sunset } \\
\text { Midnight - Midnight }\end{array}$ & $\begin{array}{l}62 \\
4.5 \\
4.3\end{array}$ & $\begin{array}{l}79 \\
5.5 \\
4.6\end{array}$ & $\begin{array}{l}73 \\
5.5 \\
5.0\end{array}$ & $\begin{array}{l}88 \\
3.0 \\
2.7\end{array}$ & $\begin{array}{l}88 \\
3.1 \\
2.7\end{array}$ & $\begin{array}{l}84 \\
\vdots \\
4.6 \\
4.3\end{array}$ & $\begin{array}{l}74 \\
5.1 \\
5.3\end{array}$ & $\begin{array}{l}69 \\
5.1 \\
5.2\end{array}$ & $\begin{array}{l}68 \\
5.0 \\
4.7\end{array}$ & $\begin{array}{l}84 \\
3.2 \\
2.8\end{array}$ & $\begin{array}{l}69 \\
4.4 \\
4.2\end{array}$ & $\begin{array}{l}56 \\
5.8 \\
5.3\end{array}$ & $\begin{array}{l}75 \\
4.6 \\
4.6\end{array}$ \\
\hline $\begin{array}{l}\text { NUMBER OF DAYS } \\
\text { Sunnise - Sunset } \\
\text { - Clear } \\
\text { - Partly Cloudy } \\
\text { - Cloudy } \\
\text { Precipitation } \\
\text { - } 0.01 \text { inch or more } \\
\text { Snow, kee, Pellets, Hail } \\
-1.0^{\circ} \text { inch or more } \\
\text { Thunderstorms } \\
\text { Heary Fog (visibility } \% \text { mile } \\
\text { or less) } \\
\text { Temperature, "F } \\
\text { - Maximum } \\
90^{\circ} F \text { and above } \\
32^{\circ} \mathrm{F} \text { and below } \\
- \text { Minimum } \\
32^{\circ} \mathrm{F} \text { and below } \\
0^{\circ} \mathrm{F} \text { and below }\end{array}$ & $\begin{array}{r}16 \\
5 \\
10 \\
6 \\
0 \\
0 \\
0 \\
\\
0 \\
1 \\
27 \\
0\end{array}$ & $\begin{array}{c}8 \\
8 \\
12 \\
1 \\
0 \\
1 \\
0 \\
0 \\
0 \\
20 \\
0\end{array}$ & $\begin{array}{r}8 \\
11 \\
12 \\
5 \\
0 \\
0 \\
0 \\
0 \\
\\
0 \\
0 \\
18 \\
0\end{array}$ & $\begin{array}{l}20 \\
7 \\
3 \\
0 \\
0 \\
0 \\
0 \\
0 \\
0 \\
5 \\
0\end{array}$ & $\begin{array}{l}18 \\
8 \\
5 \\
3 \\
0 \\
4 \\
0 \\
2 \\
0 \\
0 \\
0\end{array}$ & $\begin{array}{c}14 \\
8 \\
8 \\
6 \\
0 \\
6 \\
0 \\
0 \\
\\
16 \\
0 \\
0 \\
0\end{array}$ & $\begin{array}{r}9 \\
15 \\
7 \\
11 \\
0 \\
0 \\
12 \\
0 \\
\\
17 \\
0 \\
0 \\
0\end{array}$ & $\begin{array}{c}10 \\
16 \\
5 \\
9 \\
0 \\
6 \\
0 \\
\\
15 \\
0 \\
0 \\
0\end{array}$ & $\begin{array}{r}14 \\
5 \\
11 \\
5 \\
0 \\
6 \\
0 \\
\\
2 \\
0 \\
0 \\
0\end{array}$ & $\begin{array}{c}16 \\
11 \\
4 \\
2 \\
1 \\
0 \\
0 \\
0 \\
0 \\
4 \\
0\end{array}$ & $\begin{array}{r}14 \\
9 \\
7 \\
5 \\
1 \\
1 \\
0 \\
0 \\
0 \\
19 \\
0\end{array}$ & $\begin{array}{r}11 \\
3 \\
17 \\
10 \\
1 \\
0 \\
4 \\
\\
0 \\
1 \\
26 \\
0\end{array}$ & $\begin{array}{r}158 \\
106 \\
101 \\
63 \\
3 \\
3 \\
36 \\
4 \\
\\
52 \\
2 \\
119 \\
0\end{array}$ \\
\hline AVG. STA. PRESSURE, mb & 838.8 & 839.8 & 833.7 & 834.1 & 834.9 & 837.6 & 840.8 & 842.2 & 841.5 & 838.8 & 839.1 & 840.3 & 838.5 \\
\hline $\begin{array}{l}\text { RELATINE HUMIDITY, \% } \\
\text { Hour 05 (local time) } \\
\text { Hour } 11 \\
\text { Hour } 17 \\
\text { Hour } 23\end{array}$ & $\begin{array}{l}70 \\
50 \\
44 \\
62\end{array}$ & $\begin{array}{l}57 \\
35 \\
24 \\
44\end{array}$ & $\begin{array}{l}53 \\
32 \\
26 \\
40\end{array}$ & $\begin{array}{l}34 \\
19 \\
11 \\
21\end{array}$ & $\begin{array}{l}36 \\
19 \\
14 \\
23\end{array}$ & $\begin{array}{l}55 \\
28 \\
23 \\
39\end{array}$ & $\begin{array}{l}64 \\
37 \\
30 \\
51\end{array}$ & $\begin{array}{l}72 \\
43 \\
33 \\
61\end{array}$ & $\begin{array}{l}68 \\
44 \\
32 \\
57\end{array}$ & $\begin{array}{l}53 \\
31 \\
22 \\
42\end{array}$ & $\begin{array}{l}68 \\
45 \\
41 \\
62\end{array}$ & $\begin{array}{l}76 \\
57 \\
54 \\
71\end{array}$ & $\begin{array}{l}59 \\
37 \\
30 \\
48\end{array}$ \\
\hline $\begin{array}{l}\text { PRECIPITATION, inches } \\
\text { Water Equivalent } \\
\text { - Total } \\
\text { - Greatest (24 h) } \\
\text { - Date } \\
\text { Snow, Pellets, lce. Hail } \\
\text { - Total } \\
\text { - Greatest (24 h) } \\
\text { - Date }\end{array}$ & $\begin{array}{c}0.60 \\
0.22 \\
6 \\
0.9 \\
0.9 \\
21\end{array}$ & $\begin{array}{c}0.06 \\
0.06 \\
28 \\
T \\
T \\
18\end{array}$ & $\begin{array}{c}0.14 \\
0.07 \\
P M-1 \\
0.8 \\
0.7 \\
30\end{array}$ & $\begin{array}{c}T \\
T \\
26 \\
T \\
T \\
T \\
26\end{array}$ & $\begin{array}{l}1.14 \\
1.02 \\
2011 \\
0.0 \\
0.0\end{array}$ & $\begin{array}{l}0.65 \\
0.31 \\
10 / 1 \\
\\
0.0 \\
0.0\end{array}$ & $\begin{array}{l}2.63 \\
1.23 \\
24 \\
\\
0.0 \\
0.0\end{array}$ & $\begin{array}{l}1.26 \\
0.54 \\
2 \sqrt{3} \\
0.0 \\
0.0\end{array}$ & $\begin{array}{c}1.43 \\
0.76 \\
5.6 \\
0.0 \\
0.0\end{array}$ & $\begin{array}{c}0.26 \\
0.26 \\
30 / 1 \\
\\
2.5 \\
2.5 \\
30 / 1\end{array}$ & $\begin{array}{l}1.93 \\
1.67 \\
15 / 6 \\
\\
1.5 \\
1.1 \\
16\end{array}$ & $\begin{array}{c}1.49 \\
0.56 \\
11 \\
\\
2.1 \\
1.3 \\
30 / 4\end{array}$ & $\begin{array}{r}11.59 \\
1.67 \\
\text { Nov } \\
\\
7.8 \\
2.5 \\
\text { Oct }\end{array}$ \\
\hline $\begin{array}{l}\text { WWND, minh } \\
\text { Resultant } \\
\text { - Direction } \\
\text { - Speed } \\
\text { Average Speed } \\
\text { Fastest Observed in } 1 \text { min } \\
\text { - Direction } \\
\text { - Speed } \\
\text { - Datte } \\
\text { Peak Gust } \\
\text { - Direction } \\
\text { - Speed } \\
\text { - Date }\end{array}$ & $\begin{array}{l}001 \\
4.9 \\
8.7 \\
09 \\
29 \\
20 \\
\text { E } \\
39 \\
20\end{array}$ & $\begin{array}{l}005 \\
2.5 \\
9.2 \\
08 \\
29 \\
24 \\
\\
E \\
41 \\
24\end{array}$ & $\begin{array}{r}245 \\
4.3 \\
11.2 \\
19 \\
49 \\
26 \\
\text { SW } \\
77 \\
26\end{array}$ & $\begin{array}{r}267 \\
5.0 \\
11.2 \\
23 \\
40 \\
11 \\
5 W \\
61 \\
11\end{array}$ & $\begin{array}{l}198 \\
4.6 \\
12.1 \\
18 \\
37 \\
11 \\
\text { sw } \\
70 \\
14\end{array}$ & $\begin{array}{c}176 \\
1.7 \\
9.5 \\
16 \\
40 \\
5 \\
5 \\
5 \\
52 \\
5\end{array}$ & $\begin{array}{c}113 \\
2.9 \\
8.3 \\
\\
09 \\
38 \\
3 \\
E \\
56 \\
3\end{array}$ & $\begin{array}{l}129 \\
1.3 \\
6.3 \\
09 \\
26 \\
13 \\
\\
E \\
43 \\
13\end{array}$ & $\begin{array}{c}113 \\
3.0 \\
7.4 \\
10 \\
32 \\
18 \\
\\
E \\
41 \\
30\end{array}$ & $\begin{array}{l}144 \\
1.4 \\
8.5 \\
10 \\
38 \\
30 \\
E \\
49 \\
30\end{array}$ & $\begin{array}{l}074 \\
0.8 \\
9.3 \\
09 \\
40 \\
30 \\
\\
E \\
58 \\
30\end{array}$ & $\begin{array}{l}024 \\
2.3 \\
6.9 \\
\\
09 \\
30 \\
20 \\
E \\
46 \\
20\end{array}$ & $\begin{array}{l}198 \\
0.2 \\
9.1 \\
\\
19 \\
49 \\
3 / 26 \\
5 w \\
57 \\
7 / 26\end{array}$ \\
\hline
\end{tabular}


Table D-2. Meteorological Data for Albuquerque, 1940-1991 (Normals, Means, and Extremes) (Restrepo, 1994)

\begin{tabular}{|c|c|c|c|c|c|c|c|c|c|c|c|c|c|}
\hline & 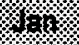 & 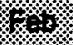 & m & 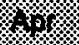 & Y, & 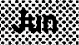 & Kx & 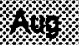 & (10.1. & \% & 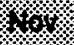 & 86 & 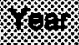 \\
\hline $\begin{array}{l}\text { TEMPERATURE. 'F } \\
\text { Mormals } \\
\text { - Daily Maximum } \\
\text { - Daily Minimum } \\
\text { - Monthly } \\
\text { Extremes } \\
\text { - Record Highest } \\
\text { - YYer } \\
\text { - Record Lowest } \\
\text { - Year }\end{array}$ & $\begin{array}{r}47.2 \\
22.3 \\
34.8 \\
69 \\
6971 \\
1971 \\
-17 \\
1971\end{array}$ & $\begin{array}{c}52.9 \\
25.9 \\
39.4 \\
76 \\
7686 \\
1966 \\
5 \\
1951\end{array}$ & $\begin{array}{c}60.7 \\
31.7 \\
46.2 \\
85 \\
85 \\
1971 \\
8 \\
1948\end{array}$ & $\begin{array}{c}70.6 \\
39.5 \\
55.1 \\
89 \\
1999 \\
19 \\
1980\end{array}$ & $\begin{array}{c}79.9 \\
48.6 \\
64.3 \\
98 \\
98 \\
1951 \\
28 \\
1975\end{array}$ & $\begin{array}{c}80.6 \\
58.4 \\
74.5 \\
105 \\
1980 \\
40 \\
1980\end{array}$ & $\begin{array}{c}92.8 \\
64.7 \\
78.8 \\
105 \\
1980 \\
52 \\
52 \\
1985\end{array}$ & $\begin{array}{c}69.4 \\
54.9 \\
69.0 \\
\\
101 \\
1979 \\
52 \\
1968\end{array}$ & $\begin{array}{c}83.0 \\
54.9 \\
69.0 \\
100 \\
1979 \\
37 \\
1971\end{array}$ & $\begin{array}{c}71.7 \\
43.1 \\
57.4 \\
\\
91 \\
1979 \\
21 \\
1991\end{array}$ & $\begin{array}{c}57.2 \\
30.7 \\
44.0 \\
77 \\
7975 \\
197 \\
-7 \\
1976\end{array}$ & $\begin{array}{c}48.0 \\
421 \\
56.2 \\
72 \\
7958 \\
-7 \\
7990\end{array}$ & $\begin{array}{l}70.3 \\
42.1 \\
56.2 \\
105 \\
6 / 80 \\
-17 \\
1 / 71\end{array}$ \\
\hline $\begin{array}{l}\text { DEGREE DAYS, BASE 65\% } \\
\text { Heating } \\
\text { Cooling }\end{array}$ & $\begin{array}{r}936 \\
0\end{array}$ & $\begin{array}{r}717 \\
0\end{array}$ & $\begin{array}{r}583 \\
0\end{array}$ & $\begin{array}{r}302 \\
0\end{array}$ & $\begin{array}{l}81 \\
59\end{array}$ & $\begin{array}{r}0 \\
285\end{array}$ & $\begin{array}{r}0 \\
428\end{array}$ & $\begin{array}{r}0 \\
344\end{array}$ & $\begin{array}{r}12 \\
132\end{array}$ & $\begin{array}{r}242 \\
6\end{array}$ & $\begin{array}{r}630 \\
0\end{array}$ & $\begin{array}{r}911 \\
0\end{array}$ & $\begin{array}{l}4414 \\
1254\end{array}$ \\
\hline $\begin{array}{l}\text { * POSSIBLE SUNSHINE } \\
\text { MEAN SKY COVER (lenths) } \\
\text { Sunrise - Sunset }\end{array}$ & $\begin{array}{l}72 \\
4.8\end{array}$ & $\begin{array}{l}73 \\
5.0\end{array}$ & $\begin{array}{l}73 \\
5.1\end{array}$ & $\begin{array}{l}77 \\
4.6\end{array}$ & $\begin{array}{l}80 \\
4.2\end{array}$ & $\begin{array}{l}83 \\
3.4\end{array}$ & $\begin{array}{l}76 \\
4.5\end{array}$ & $\begin{array}{l}75 \\
4.4\end{array}$ & $\begin{array}{l}79 \\
3.6\end{array}$ & $\begin{array}{l}79 \\
3.5\end{array}$ & $\begin{array}{l}77 \\
4.0\end{array}$ & $\begin{array}{l}72 \\
4.6\end{array}$ & $\begin{array}{l}76 \\
4.3\end{array}$ \\
\hline 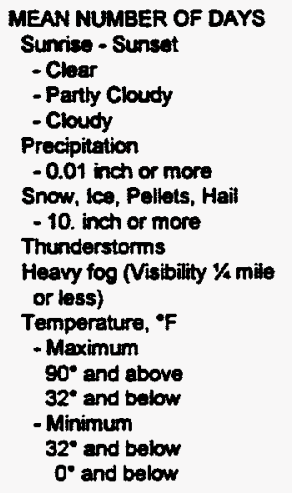 & $\begin{array}{r}13.1 \\
7.7 \\
10.3 \\
4.0 \\
1.0 \\
0.1 \\
1.1 \\
\\
0.0 \\
2.3 \\
28.9 \\
0.4\end{array}$ & $\begin{array}{r}11.1 \\
7.7 \\
9.5 \\
4.0 \\
0.9 \\
0.3 \\
0.9\end{array}$ & $\begin{array}{r}11.4 \\
9.8 \\
9.8 \\
4.6 \\
0.7 \\
0.9 \\
0.6\end{array}$ & $\begin{array}{r}12.7 \\
9.4 \\
7.9 \\
\\
3.4 \\
0.2 \\
1.6 \\
0.2\end{array}$ & $\begin{array}{r}14.5 \\
10.3 \\
6.2 \\
4.3 \\
0.0 \\
3.9 \\
0.0\end{array}$ & $\begin{array}{r}17.5 \\
8.6 \\
3.9 \\
\\
3.9 \\
0.0 \\
5.1 \\
0.0 \\
\\
17.1 \\
0.0 \\
0.0 \\
0.0\end{array}$ & $\begin{array}{r}12.0 \\
14.3 \\
4.8 \\
8.8 \\
0.0 \\
11.1 \\
0.1 \\
\\
23.0 \\
0.0 \\
0.0 \\
0.0\end{array}$ & $\begin{array}{r}13.4 \\
12.5 \\
5.1 \\
9.5 \\
0.0 \\
10.8 \\
0.0 \\
\\
\\
15.9 \\
0.0 \\
0.0 \\
0.0\end{array}$ & $\begin{array}{r}16.6 \\
7.8 \\
5.6 \\
5.7 \\
0.0 \\
4.7 \\
0.1\end{array}$ & $\begin{array}{r}17.3 \\
7.8 \\
5.9 \\
4.8 \\
0.0 \\
0.3 \\
2.3 \\
0.3\end{array}$ & $\begin{array}{r}15.1 \\
7.7 \\
7.2 \\
3.4 \\
0.4 \\
0.6 \\
0.6\end{array}$ & $\begin{array}{r}13.9 \\
7.4 \\
9.7 \\
4.3 \\
0.9 \\
0.2 \\
1.5 \\
\\
0.0 \\
1.8 \\
28.5 \\
0.1\end{array}$ & $\begin{array}{r}168.6 \\
110.8 \\
85.8 \\
60.7 \\
4.2 \\
41.3 \\
\\
5.6 \\
\\
62.6 \\
5.1 \\
118.9 \\
0.6\end{array}$ \\
\hline AVG. STA PRESSURE, mb & 838.9 & 837.9 & 835.0 & 835.7 & 835.8 & 838.1 & 840.4 & 840.7 & 840.2 & 840.0 & 838.8 & 839.2 & 838.5 \\
\hline $\begin{array}{l}\text { RELATIVE HUMIOITY, \% } \\
\text { Hour 05 (local time) } \\
\text { Hour } 11 \\
\text { Hour } 17 \\
\text { Hour } 23\end{array}$ & $\begin{array}{l}70 \\
50 \\
40 \\
61\end{array}$ & $\begin{array}{l}65 \\
44 \\
32 \\
53\end{array}$ & $\begin{array}{l}56 \\
34 \\
24 \\
43\end{array}$ & $\begin{array}{l}49 \\
26 \\
19 \\
35\end{array}$ & $\begin{array}{l}47 \\
25 \\
18 \\
34\end{array}$ & $\begin{array}{l}46 \\
24 \\
18 \\
33\end{array}$ & $\begin{array}{l}60 \\
34 \\
27 \\
48\end{array}$ & $\begin{array}{l}66 \\
40 \\
30 \\
53\end{array}$ & $\begin{array}{l}62 \\
40 \\
31 \\
52\end{array}$ & $\begin{array}{l}62 \\
38 \\
29 \\
49\end{array}$ & $\begin{array}{l}65 \\
42 \\
36 \\
55\end{array}$ & $\begin{array}{l}70 \\
50 \\
43 \\
61\end{array}$ & $\begin{array}{l}60 \\
37 \\
29 \\
48\end{array}$ \\
\hline $\begin{array}{l}\text { PRECIPITATION, inches } \\
\text { Water Equivalent } \\
\text { - Normal } \\
\text { - Maximum Monthly } \\
\text { - Year } \\
\text { - Minimum Monthly } \\
\text { - Year } \\
\text { - Maximum in } 24 \text { hours } \\
\text { - Year } \\
\text { Snow, Ice, Pollots, Hail } \\
\text { - Maximum Monthly } \\
\text { - Year } \\
\text { - Maximum in } 24 \text { hours } \\
\text { - Year }\end{array}$ & $\begin{array}{c}0.41 \\
1.32 \\
1978 \\
T \\
1970 \\
0.87 \\
1962 \\
\\
9.5 \\
1973 \\
5.1 \\
1973\end{array}$ & $\begin{array}{c}0.40 \\
1.42 \\
1948 \\
T \\
1984 \\
0.51 \\
1981 \\
\\
10.3 \\
1986 \\
6.0 \\
1986\end{array}$ & $\begin{array}{c}0.52 \\
2.18 \\
1973 \\
T \\
1966 \\
1.11 \\
1973 \\
\\
13.9 \\
1973 \\
10.7 \\
1973\end{array}$ & $\begin{array}{c}0.40 \\
1.97 \\
1942 \\
T \\
1991 \\
1.66 \\
1969 \\
\\
8.1 \\
1973 \\
10.9 \\
1988\end{array}$ & $\begin{array}{c}0.46 \\
3.07 \\
1949 \\
T \\
1945 \\
1.14 \\
1969 \\
1.0 \\
1.079 \\
1979 \\
1.079\end{array}$ & $\begin{array}{c}0.51 \\
2.57 \\
1996 \\
T \\
1975 \\
1.64 \\
1952 \\
T \\
T \\
1990 \\
T \\
1990\end{array}$ & $\begin{array}{c}1.30 \\
3.33 \\
1968 \\
0.08 \\
1980 \\
1.77 \\
1961 \\
T \\
T \\
1990 \\
T \\
1999\end{array}$ & $\begin{array}{c}1.51 \\
3.30 \\
1967 \\
T \\
1962 \\
1.75 \\
1980 \\
\\
0.0 \\
0.0\end{array}$ & $\begin{array}{c}0.85 \\
2.63 \\
1988 \\
T \\
1957 \\
1.92 \\
1955 \\
T \\
T \\
1971 \\
T \\
1971\end{array}$ & $\begin{array}{c}0.86 \\
3.08 \\
1972 \\
0.00 \\
1952 \\
1.80 \\
1969 \\
\\
3.2 \\
1986 \\
3.2 \\
1986\end{array}$ & $\begin{array}{c}0.38 \\
1.93 \\
1991 \\
0.00 \\
1949 \\
1.67 \\
1991 \\
\\
8.3 \\
1940 \\
5.5 \\
1946\end{array}$ & $\begin{array}{r}0.52 \\
1.85 \\
1959 \\
0.00 \\
1981 \\
1.35 \\
1958 \\
\\
14.7 \\
1959 \\
14.2 \\
1958\end{array}$ & $\begin{array}{c}8.12 \\
3.33 \\
4.68 \\
0.00 \\
12 / 81 \\
1.92 \\
9155 \\
14.7 \\
12159 \\
14.2 \\
12 / 58\end{array}$ \\
\hline $\begin{array}{l}\text { WIND, min } \\
\text { Mean Speed } \\
\text { Prevailing Direction } \\
\text { Fastest Observed in } 1 \text { min } \\
\text { - Direction } \\
\text { - Speed } \\
\text { - Year } \\
\text { Peak Gust } \\
\text { - Direction } \\
\text { - Speed } \\
\text { - Year }\end{array}$ & $\begin{array}{c}8.1 \\
N \\
09 \\
52 \\
1990 \\
E \\
70 \\
1990\end{array}$ & $\begin{array}{c}8.9 \\
N \\
09 \\
40 \\
1989 \\
W \\
63 \\
1984\end{array}$ & $\begin{array}{c}10.1 \\
\text { SE } \\
19 \\
49 \\
1991 \\
\\
\text { SW } \\
77 \\
1991\end{array}$ & $\begin{array}{c}11.0 \\
5 \\
17 \\
46 \\
1985 \\
E \\
64 \\
1990\end{array}$ & $\begin{array}{c}10.6 \\
S \\
28 \\
46 \\
1986 \\
\\
\text { Sw } \\
70 \\
1991\end{array}$ & $\begin{array}{c}10.0 \\
S \\
16 \\
40 \\
1991 \\
E \\
67 \\
1986\end{array}$ & $\begin{array}{c}9.1 \\
\text { SE } \\
\\
36 \\
52 \\
1990 \\
\\
N \\
72 \\
1990\end{array}$ & $\begin{array}{c}8.2 \\
\text { SE } \\
27 \\
41 \\
1990 \\
E \\
63 \\
1989\end{array}$ & $\begin{array}{c}8.6 \\
\text { SE } \\
25 \\
40 \\
1985 \\
\\
W \\
61 \\
1985\end{array}$ & $\begin{array}{c}8.3 \\
\text { SE } \\
10 \\
38 \\
1991 \\
\\
\mathrm{NW} \\
51 \\
1986\end{array}$ & $\begin{array}{c}8.0 \\
N \\
27 \\
48 \\
1988 \\
W \\
W \\
63 \\
1988\end{array}$ & $\begin{array}{c}7.7 \\
N \\
0.9 \\
47 \\
1987 \\
E \\
71 \\
2987\end{array}$ & $\begin{array}{c}09 \\
52 \\
1990 \\
\\
5 w \\
77 \\
3991\end{array}$ \\
\hline
\end{tabular}


Table D-3. Precipitation, 1960-1991 (inches) (Restrepo, 1994)

\begin{tabular}{|c|c|c|c|c|c|c|c|c|c|c|c|c|c|}
\hline K & א⿱ & F. & 1. & $\%$ & Kot & sin & m & \% & 58 & 9 & \% & \% & $4 \% 11$ \\
\hline 1960 & 0.34 & 0.38 & 0.44 & 0.19 & 0.71 & 0.91 & 0.47 & 0.78 & 0.56 & 2.88 & 0.07 & 0.39 & 8.12 \\
\hline 1961 & 0.23 & 0.10 & 0.61 & 0.73 & 0.01 & 0.11 & 2.70 & 1.69 & 1.09 & 0.47 & 0.48 & 0.65 & 8.87 \\
\hline 1962 & 1.01 & 0.11 & 0.18 & 0.07 & 0.01 & 0.19 & 1.24 & $T$ & 0.71 & 0.75 & 0.61 & 0.51 & 5.39 \\
\hline 1963 & 0.29 & 0.24 & 0.55 & 0.14 & 0.03 & 0.11 & 1.43 & 3.00 & 0.63 & 0.76 & 0.29 & $T$ & 7.47 \\
\hline 1964 & 0.07 & 1.12 & 0.13 & 0.61 & 0.35 & $T$ & 1.87 & 0.98 & 1.57 & 0.04 & 0.21 & 0.49 & 7.44 \\
\hline 1965 & 0.47 & 0.60 & 0.49 & 0.49 & 0.19 & 0.99 & 1.65 & 0.61 & 1.18 & 0.89 & 0.33 & 1.42 & 9.31 \\
\hline 1966 & 0.42 & 0.30 & $T$ & 0.04 & 0.02 & 1.66 & 0.61 & 1.06 & 1.04 & 0.54 & 0.09 & 0.01 & 6.81 \\
\hline 1967 & 0.01 & 0.44 & 0.25 & $T$ & 0.04 & 1.71 & 3.33 & 3.30 & 0.79 & 0.18 & 0.15 & 0.56 & 8.04 \\
\hline 1968 & 0.01 & 0.98 & 1.48 & 0.51 & 0.99 & 0.05 & 0.94 & $1 / 49$ & 0.30 & 0.12 & 0.59 & 0.82 & 10.67 \\
\hline 1969 & 0.08 & 0.34 & 0.41 & 1.76 & 1.31 & 0.59 & 1.22 & 0.95 & 1.08 & 2.37 & 0.01 & 0.72 & 10.56 \\
\hline 1970 & $T$ & 0.27 & 0.42 & 0.05 & 0.33 & 0.40 & 1.05 & 2.24 & 0.79 & 0.25 & 0.08 & 0.23 & 6.28 \\
\hline 1971 & 0.27 & 0.21 & 0.03 & 0.78 & 0.16 & 0.02 & 1.00 & 0.87 & 1.44 & 1.15 & 0.67 & 1.40 & 8.50 \\
\hline 1972 & 0.12 & 0.12 & 0.08 & $\boldsymbol{T}$ & 0.18 & 0.55 & 1.80 & 2.93 & 1.00 & 3.08 & 0.69 & 0.36 & 10.11 \\
\hline 1973 & 0.85 & 0.33 & 2.18 & 0.91 & 0.66 & 1.37 & 2.40 & 1.19 & 1.13 & 0.35 & 0.08 & $0 .-3$ & 10.88 \\
\hline 1974 & 0.88 & 0.11 & 0.85 & 0.14 & 0.01 & 0.22 & 1.43 & 0.79 & 1.58 & 1.96 & 0.38 & 0.51 & 9.83 \\
\hline 1975 & 0.26 & 0.99 & 0.95 & 0.10 & 0.66 & $T$ & 1.32 & 1.40 & 1.66 & $T$ & 0.28 & 0.28 & 8.01 \\
\hline 1976 & 0.00 & 0.40 & 0.09 & 0.31 & 0.82 & 0.60 & 0.69 & 0.73 & 0.45 & 0.03 & 0.24 & 0.20 & 5.19 \\
\hline 1977 & 0.88 & 0.23 & 0.63 & 1.07 & 0.10 & 0.04 & 0.24 & 2.28 & 0.78 & 0.76 & 0.42 & 0.13 & 7.91 \\
\hline 1978 & 1.32 & 1.02 & 0.54 & 0.05 & 0.69 & 1.05 & 0.80 & 2.49 & 0.59 & 1.22 & 1.00 & 0.76 & 10.97 \\
\hline 1979 & 1.07 & 0.62 & 0.14 & 0.24 & 2.48 & 1.02 & 0.08 & 1.53 & 0.40 & 0.27 & 0.91 & 0.87 & 10.35 \\
\hline 1980 & 0.87 & 0.58 & 0.60 & 0.60 & 0.56 & 0.01 & 1.07 & 2.61 & 1.83 & 0.09 & 0.30 & 0.74 & 8.87 \\
\hline 1981 & 0.05 & 0.67 & 0.80 & 0.30 & 0.53 & 0.35 & 1.32 & 2.68 & 0.41 & 1.43 & 0.37 & 0.00 & 7.66 \\
\hline 1982 & 0.32 & 0.20 & 0.84 & 0.05 & 0.52 & 0.09 & 0.55 & 1.09 & 1.34 & 0.26 & 0.60 & 0.78 & 7.41 \\
\hline 1983 & 1.10 & 0.71 & 0.61 & 0.02 & 0.32 & 1.21 & 1.13 & 0.27 & 0.91 & 1.20 & 0.44 & 0.42 & 7.76 \\
\hline 1984 & 0.33 & $T$ & 0.62 & 0.50 & 0.16 & 0.48 & 1.16 & 2.70 & 1.13 & 3.04 & 0.63 & 1.36 & 12.08 \\
\hline 1985 & 0.49 & 0.54 & 0.70 & 1.69 & 1.12 & 0.53 & 1.51 & 0.49 & 1.51 & 2.15 & 0.19 & 0.16 & 10.75 \\
\hline 1986 & 0.22 & 1.01 & 0.17 & 0.33 & 1.11 & 2.57 & 0.91 & 2.26 & 0.53 & 1.54 & 1.29 & 0.44 & 12.98 \\
\hline 1987 & 0.66 & 0.61 & 0.07 & 1.00 & 0.58 & 0.13 & 2.26 & 2.98 & 0.20 & 0.44 & 0.42 & 0.34 & 8.34 \\
\hline 1988 & 0.15 & 0.07 & 0.85 & 1.42 & 0.62 & 1.25 & 1.51 & 3.29 & 2.63 & 0.32 & 0.22 & 0.03 & 13.11 \\
\hline 1989 & 0.57 & 0.35 & 0.48 & $T$ & 0.01 & 0.02 & 2.33 & 0.48 & 0.31 & 0.97 & $\mathbf{T}$ & 0.28 & 4.99 \\
\hline 1990 & 0.21 & 0.49 & 0.41 & 1.71 & 0.45 & 0.27 & 2.36 & 1.79 & 0.96 & 0.15 & 0.86 & 0.59 & 10.25 \\
\hline 1991 & 0.60 & 0.06 & 0.14 & $\mathbf{T}$ & 1.14 & 0.65 & 2.63 & 1.26 & 1.43 & 0.26 & 1.93 & 1.49 & 11.59 \\
\hline Mean & 0.40 & 0.38 & 0.45 & 0.55 & 0.63 & 0.60 & 1.39 & 1.39 & 0.93 & 0.85 & 0.41 & 0.45 & 8.43 \\
\hline
\end{tabular}


Table D-4. Snowfall, 1960-1991 (inches) (Restrepo, 1994)

\begin{tabular}{|c|c|c|c|c|c|c|c|c|c|c|c|c|c|}
\hline 50140 & 兹兹 & \% & \% & \% & 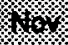 & axt & 梦 & 桑动 & 14 & xy & (k & 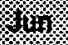 & 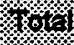 \\
\hline $1960-61$ & 0.0 & 0.0 & 0.0 & 0.0 & 0.0 & 2.5 & 0.6 & 0.4 & 3.0 & $\mathbf{T}$ & 0.0 & 0.0 & 6.5 \\
\hline $1961-62$ & 0.0 & 0.0 & 0.0 & $\mathbf{T}$ & 3.4 & 2.4 & 4.0 & $T$ & 0.2 & 0.0 & 0.0 & 0.0 & 10.0 \\
\hline $1962-63$ & 0.0 & 0.0 & 0.0 & 0.0 & $T$ & 1.0 & 2.5 & 0.8 & 2.5 & 0.0 & 0.0 & 0.0 & 6.8 \\
\hline $1963-64$ & 0.0 & 0.0 & 0.0 & 0.0 & $T$ & $\mathbf{T}$ & 0.5 & 8.2 & 1.3 & $T$ & 0.0 & 0.0 & 10.0 \\
\hline $1964-65$ & 0.0 & 0.0 & 0.0 & 0.0 & $T$ & 0.3 & 1.4 & 3.6 & $T$ & $T$ & 0.0 & 0.0 & 5.3 \\
\hline $1965-66$ & 0.0 & 0.0 & 0.0 & 0.0 & $T$ & 3.0 & 5.4 & 1.0 & 0.0 & $\mathbf{T}$ & 0.0 & 0.0 & 9.4 \\
\hline $1966-67$ & 0.0 & 0.0 & 0.0 & 0.0 & $T$ & $T$ & $\mathbf{T}$ & 1.0 & 1.1 & $T$ & 0.0 & 0.0 & 2.1 \\
\hline $1967-68$ & 0.0 & 0.0 & 0.0 & 0.2 & 1.0 & 2.8 & $\mathbf{T}$ & 2.0 & 1.4 & $T$ & 0.0 & 0.0 & 7.4 \\
\hline $1968-69$ & 0.0 & 0.0 & 0.0 & 0.0 & $T$ & 7.4 & $\mathbf{T}$ & 1.8 & 5.5 & $T$ & 0.0 & 0.0 & 14.7 \\
\hline $1969-70$ & 0.0 & 0.0 & 0.0 & 0.0 & $T$ & 1.1 & $\mathbf{T}$ & 2.7 & 3.3 & 0.0 & 0.0 & 0.0 & 7.1 \\
\hline $1970-71$ & 0.0 & 0.0 & 0.0 & 0.5 & $T$ & 0.5 & 3.0 & 2.3 & 0.5 & $T$ & 0.0 & 0.0 & 6.8 \\
\hline $1971-72$ & 0.0 & 0.0 & $T$ & $T$ & $T$ & 6.8 & 1.2 & 1.1 & 0.0 & $T$ & 0.0 & 0.0 & 9.1 \\
\hline $1972-73$ & 0.0 & 0.0 & 0.0 & $T$ & 2.9 & 1.2 & 9.5 & 1.8 & 13.9 & 8.1 & 0.0 & 0.0 & 37.4 \\
\hline $1973-74$ & 0.0 & 0.0 & 0.0 & 0.3 & 0.6 & 0.1 & 9.3 & 0.6 & 2.0 & 0.0 & 0.0 & 0.0 & 12.9 \\
\hline $1974-75$ & 0.0 & 0.0 & 0.0 & 0.0 & $T$ & 4.9 & 0.9 & 6.7 & 3.8 & 0.2 & 0.0 & 0.0 & 16.5 \\
\hline $1975-76$ & 0.0 & 0.0 & 0.0 & 0.0 & 0.2 & 2.9 & 0.0 & $\mathbf{T}$ & 0.5 & 0.2 & 0.0 & 0.0 & 3.8 \\
\hline $1976-77$ & 0.0 & 0.0 & 0.0 & $\mathbf{T}$ & 2.4 & 1.2 & 8.4 & 1.4 & 2.3 & 2.6 & 0.0 & 0.0 & 18.3 \\
\hline $1977-78$ & 0.0 & 0.0 & 0.0 & 0.0 & 0.0 & $T$ & 6.0 & 3.4 & 2.0 & 0.0 & 0.1 & 0.0 & 11.5 \\
\hline $1978-79$ & 0.0 & 0.0 & 0.0 & 0.0 & $T$ & 1.0 & 2.6 & 6.0 & $T$ & 0.5 & 1.0 & 0.0 & 11.1 \\
\hline $1979-80$ & 0.0 & 0.0 & 0.0 & 0.9 & 0.8 & 2.7 & $\mathbf{T}$ & 0.9 & 3.1 & $\mathbf{T}$ & $\mathbf{T}$ & 0.0 & 8.4 \\
\hline $1980-81$ & 0.0 & 0.0 & 0.0 & $T$ & 2.8 & 7.4 & 0.5 & 2.6 & 0.9 & $T$ & 0.0 & 0.0 & 14.2 \\
\hline $1981-82$ & 0.0 & 0.0 & 0.0 & 0.0 & 0.0 & 0.0 & 3.6 & 1.2 & 0.7 & $T$ & 0.0 & 0.0 & 5.5 \\
\hline $1982-83$ & 0.0 & 0.0 & 0.0 & 0.0 & 0.9 & 3.3 & 7.3 & 4.2 & 1.0 & $T$ & $\mathbf{T}$ & 0.0 & 16.7 \\
\hline $1983-84$ & 0.0 & 0.0 & 0.0 & 0.0 & 0.8 & 0.8 & 4.1 & $T$ & 0.1 & 3.0 & 0.0 & 0.0 & 8.8 \\
\hline $1984-85$ & 0.0 & 0.0 & 0.0 & $T$ & $T$ & 3.4 & 2.0 & 2.9 & 0.6 & 0.0 & 0.0 & 0.0 & 8.9 \\
\hline $1985-86$ & 0.0 & 0.0 & 0.0 & 0.0 & 0.7 & 0.9 & 2.9 & 10.3 & 0.3 & 0.0 & $\mathbf{T}$ & 0.0 & 15.1 \\
\hline 1986-87 & 0.0 & 0.0 & 0.0 & 3.2 & 0.6 & 0.2 & 4.9 & 4.9 & 0.2 & 2.2 & 0.0 & 0.0 & 16.2 \\
\hline $1987-88$ & 0.0 & 0.0 & 0.0 & 0.0 & 1.1 & 1.7 & 1.2 & $\mathbf{T}$ & 7.9 & 4.2 & 0.0 & 0.0 & 16.1 \\
\hline $1988-89$ & 0.0 & 0.0 & 0.0 & 0.0 & 1.7 & 0.3 & 3.4 & 3.2 & 3.1 & 0.0 & 0.0 & 0.0 & 11.7 \\
\hline $1989-90$ & 0.0 & 0.0 & 0.0 & 0.0 & $T$ & 2.5 & 1.8 & 4.8 & $T$ & 0.3 & 0.0 & $T$ & 9.4 \\
\hline $1990-91$ & $T$ & 0.0 & 0.0 & 0.0 & 2.2 & 6.3 & 0.9 & $\mathbf{T}$ & 0.8 & $T$ & 0.0 & 0.0 & 10.2 \\
\hline 1991- & 0.0 & 0.0 & 0.0 & 2.5 & 1.5 & 2.1 & & & & & & & \\
\hline Mean & 0.0 & 0.0 & $T$ & 0.1 & 1.1 & 2.5 & 2.5 & 2.2 & 1.9 & 0.8 & $T$ & 0.0 & 11.1 \\
\hline
\end{tabular}


Table D-5. Average Temperatures, 1960-1989 ( $\left.{ }^{\circ} \mathrm{F}\right)$ (Restrepo, 1994)

\begin{tabular}{|c|c|c|c|c|c|c|c|c|c|c|c|c|c|}
\hline \% & 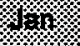 & 标 & 学 & \% & Wh & 森 & 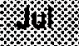 & 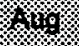 & 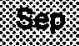 & $\%$ & $y$ & 80 & $\%$ \\
\hline 1960 & 33.0 & 36.5 & 49.9 & 57.9 & 64.7 & 76.6 & 78.7 & 78.4 & 71.8 & 56.5 & 46.5 & 33.9 & 57.1 \\
\hline 1961 & 33.9 & 40.6 & 47.0 & 54.5 & 65.9 & 75.8 & 76.7 & 75.2 & 65.6 & 56.8 & 40.3 & 34.1 & 55.5 \\
\hline 1962 & 31.6 & 42.3 & 41.2 & 58.1 & 64.1 & 72.7 & 76.3 & 77.6 & 69.4 & 58.1 & 46.9 & 36.9 & 56.3 \\
\hline 1963 & 29.4 & 40.5 & 45.2 & 57.7 & 68.0 & 74.6 & 81.4 & 75.9 & 72.5 & 61.5 & 45.7 & 34.8 & 57.3 \\
\hline 1964 & 30.0 & 29.1 & 41.5 & 51.7 & 65.8 & 73.6 & 78.2 & 76.8 & 69.3 & 59.4 & 43.7 & 35.5 & 54.5 \\
\hline 1965 & 38.8 & 39.4 & 44.6 & 54.8 & 61.7 & 69.4 & 77.9 & 75.4 & 66.6 & 58.0 & 48.4 & 35.8 & 55.9 \\
\hline 1966 & 30.1 & 33.2 & 45.6 & 54.6 & 67.2 & 72.8 & 79.8 & 75.7 & 68.4 & 56.8 & 46.7 & 34.3 & 55.4 \\
\hline 1967 & 33.2 & 40.5 & 52.0 & 57.8 & 63.8 & 71.5 & 79.2 & 74.5 & 68.4 & 58.2 & 46.1 & 32.4 & 56.5 \\
\hline 1968 & 36.8 & 43.3 & 46.7 & 53.4 & 62.7 & 75.2 & 76.1 & 72.4 & 68.0 & 58.3 & 42.8 & 30.0 & 55.5 \\
\hline 1969 & 38.0 & 38.5 & 41.1 & 57.4 & 66.2 & 73.6 & 80.2 & 79.0 & 70.0 & 53.8 & 41.4 & 39.1 & 56.6 \\
\hline 1970 & 34.5 & 42.8 & 44.1 & 52.5 & 66.2 & 72.7 & 79.6 & 77.8 & 67.5 & 52.6 & 44.5 & 36.4 & 56.0 \\
\hline 1971 & 33.6 & 38.9 & 47.7 & 53.3 & 61.7 & 73.8 & 78.1 & 73.9 & 66.4 & 53.8 & 45.2 & 31.9 & 54.8 \\
\hline 1972 & 36.1 & 42.5 & 53.6 & 56.9 & 64.0 & 73.7 & 78.6 & 74.1 & 68.1 & 57.6 & 40.1 & 35.0 & 56.7 \\
\hline 1973 & 31.8 & 35.9 & 45.1 & 50.2 & 62.7 & 73.5 & 78.4 & 78.0 & 67.5 & 56.4 & 44.6 & 34.0 & 54.8 \\
\hline 1974 & 33.6 & 37.9 & 52.8 & 56.4 & 68.5 & 80.1 & 77.0 & 72.7 & 66.1 & 58.1 & 45.0 & 32.0 & 56.7 \\
\hline 1975 & 30.8 & 38.0 & 45.0 & 49.9 & 61.0 & 73.0 & 76.8 & 76.1 & 66.3 & 56.5 & 42.6 & 35.6 & 54.3 \\
\hline 1976 & 33.2 & 43.3 & 44.3 & 54.6 & 62.8 & 73.4 & 77.0 & 75.0 & 68.0 & 53.1 & 40.6 & 33.0 & 54.9 \\
\hline 1977 & 29.8 & 40.7 & 43.2 & 56.5 & 64.2 & 75.5 & 78.6 & 77.4 & 69.4 & 58.9 & 46.4 & 34.4 & 56.8 \\
\hline 1978 & 36.8 & 39.3 & 50.2 & 57.7 & 60.5 & 75.5 & 81.6 & 75.5 & 69.1 & 60.3 & 47.5 & 34.3 & 57.4 \\
\hline 1979 & $32 . .9$ & 41.1 & 48.4 & 56.9 & 63.7 & 73.3 & 80.6 & 77.1 & 72.3 & 61.5 & 41.0 & 37.7 & 57.2 \\
\hline 1980 & 40.2 & 44.2 & 46.1 & 52.1 & 61.1 & 77.2 & 82.7 & 77.4 & 69.9 & 54.5 & 43.5 & 40.5 & 57.4 \\
\hline 1981 & 38.0 & 42.9 & 46.2 & 59.0 & 64.5 & 77.0 & 79.8 & 76.4 & 69.7 & 55.7 & 47.0 & 40.5 & 58.0 \\
\hline 1982 & 35.9 & 39.4 & 47.4 & 56.1 & 63.0 & 74.8 & 79.1 & 77.4 & 69.5 & 54.8 & 42.9 & 34.4 & 56.2 \\
\hline 1983 & 35.0 & 39.7 & 46.9 & 50.2 & 63.0 & 73.4 & 80.2 & 79.4 & 73.4 & 58.3 & 45.1 & 36.7 & 56.8 \\
\hline 1984 & 34.1 & 40.1 & 46.8 & 52.8 & 69.9 & 73.6 & 78.9 & 75.7 & 68.8 & 51.6 & 43.7 & 35.6 & 56.0 \\
\hline 1985 & 33.8 & 38.3 & 46.5 & 57.4 & 64.0 & 74.1 & 77.1 & 76.6 & 65.9 & 57.5 & 45.4 & 37.6 & 56.3 \\
\hline 1986 & 41.3 & 43.0 & 50.9 & 56.5 & 63.7 & 72.7 & 74.7 & 76.0 & 66.5 & 54.6 & 42.0 & 36.3 & 56.5 \\
\hline 1987 & 32.3 & 39.2 & 43.7 & 54.8 & 62.8 & 73.0 & 77.8 & 74.7 & 68.8 & 61.3 & 45.2 & 35.3 & 55.7 \\
\hline 1988 & 34.6 & 43.9 & 47.0 & 55.1 & 64.3 & 74.4 & 78.1 & 75.0 & 66.3 & 61.1 & 45.4 & 33.9 & 56.6 \\
\hline 1989 & 35.5 & 41.9 & 52.8 & 61.4 & 68.8 & 75.6 & 78.6 & 74.3 & 69.4 & 56.7 & 46.4 & 35.1 & 58.0 \\
\hline Mean & 34.6 & 39.7 & 46.5 & 54.9 & 63.8 & 73.5 & 77.4 & 75.3 & 68.4 & 56.8 & 44.0 & 35.3 & 55.9 \\
\hline Max & 47.1 & 53.0 & 60.9 & 70.0 & 79.0 & 89.0 & 91.3 & 88.8 & 82.2 & 71.0 & 57.5 & 47.6 & 69.8 \\
\hline Min & 22.1 & 26.4 & 32.1 & 39.8 & 48.6 & 56.0 & 63.5 & 81.8 & 54.6 & 42.6 & 30.4 & 23.0 & 41.9 \\
\hline
\end{tabular}




\section{D.1 Methods for Determining Meteorological Dispersion Parameters}

A modified Gaussian bivarian dispersion model like the one used for the Reactor Safety Study was used to hand calculate the dispersion factor $(\chi / Q)$ or air concentration $(\chi)$, as indicated by the use of Equation 1 (Strenge, 1980).

$$
\chi / Q=2 /\left[3 s_{y}(2 p)^{1 / 2} s_{z} v E_{t}\right]^{*} \operatorname{Exp}\left(-h_{e}{ }^{2} / 2 s_{z}^{2}\right)
$$

Where $\quad \chi / Q$ is the dispersion factor $\left(\mathrm{s} / \mathrm{m}^{3}\right)$

$v \quad$ is the average wind speed at the release elevation $(\mathrm{m} / \mathrm{s})$

$E_{t} \quad$ is the expansion factor to correct for prolonged release times (unitless).

$E_{t}=\left(2 T_{r}\right)^{1 / 2}$, where $T_{r}$ is the release duration for airborne releases $(h r)$.

$h_{e} \quad$ is the effective height of the plume centerline at down-wind location (m)

$S_{y} \quad$ is the crosswind horizontal standard deviation of the plume concentration at the downwind distance $(\mathrm{m})$

$s_{z} \quad$ is the crosswind vertical standard deviation of the plume concentration at the downwind distance $(\mathrm{m})$

The horizontal and vertical dispersion coefficients, $s_{y}$ and $s_{z}$ respectively, are evaluated by empirical expressions. These expressions are $s_{y}=a X^{b}$ and $s_{z}=c X^{d}+e$, where the values for the empirical constants $a, b, c, d$, and $e$ are given in Table $D-6$, and $X$ is the down-wind distance from the release point.

Table D-6. Values of Empirical Constants (Strenge, 1980)

\begin{tabular}{|c|c|c|c|c|c|c|c|c|}
\hline \multirow{2}{*}{ Stabiass } & \multicolumn{2}{|c|}{ 8. } & \multicolumn{3}{|c|}{$3 / 14$} & \multicolumn{3}{|c|}{$5.1(101000 \%)$} \\
\hline & \% & 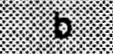 & \% & \% & e. & 6 & \% & \% \\
\hline A & 0.3658 & 0.9031 & 0.0015 & 1.941 & 9.27 & 0.00024 & 2.094 & -9.6 \\
\hline B & 0.2751 & 0.9031 & 0.028 & 1.149 & 3.3 & 0.055 & 1.098 & 2.0 \\
\hline C & 0.2089 & 0.9031 & 0.113 & 0.911 & 0.0 & 0.113 & 0.911 & 0.0 \\
\hline$D$ & 0.1471 & 0.9031 & 0.222 & 0.725 & -1.7 & 1.26 & 0.516 & -13.0 \\
\hline$E$ & 0.1046 & 0.9031 & 0.211 & 0.678 & -1.3 & 6.73 & 0.305 & -34.0 \\
\hline $\mathbf{F}$ & 0.0722 & 0.9031 & 0.086 & 0.74 & -0.35 & 18.05 & 0.18 & -48.6 \\
\hline
\end{tabular}


Table D-7 gives values of dispersion coefficients, $s_{y}$ and $s_{z}$, for various distances from the HCF, by stability class, for an inversion layer of $3000 \mathrm{~m}$ (9800 ft). These values were used to hand calculate the dispersion factors $(\chi / Q)$ for those listed distances.

Table D-7. Dispersion Parameters and Coefficients (Restrepo, 1994)

\begin{tabular}{|c|c|c|c|c|c|c|c|c|}
\hline \multirow{2}{*}{ Shaving } & \multicolumn{4}{|c|}{ 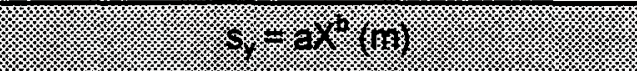 } & \multicolumn{3}{|c|}{ 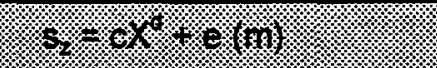 } & \\
\hline & $10_{36}$ & $301 \%$ & 50013 & 6083013 & 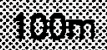 & $6018 \%$ & 5000381 & $800 \%$ \\
\hline A & 23.4 & 63.1 & 100.2 & 944.7 & 20.7 & 105.7 & 269.2 & 3000.0 \\
\hline B & 17.6 & 47.5 & 75.3 & 710.5 & 8.9 & 23.0 & 142.6 & 776.1 \\
\hline C & 13.4 & 36.1 & 57.2 & 539.5 & 7.5 & 20.4 & 32.5 & 312.6 \\
\hline D & 9.4 & 18.1 & 40.3 & 379.9 & 4.6 & 12.2 & 18.4 & 99.2 \\
\hline$E$ & 6.7 & 18.1 & 28.6 & 270.1 & 3.5 & 8.8 & 13.0 & 61.6 \\
\hline$F$ & 4.6 & 12.5 & 19.8 & 124.2 & 2.2 & 5.5 & 8.2 & 37.8 \\
\hline
\end{tabular}

Table D-8 gives the results of hand calculations of the dispersion factors $(\chi / Q)$ as a function of distance from the HCF stack, for a wind speed of $1 \mathrm{~m} / \mathrm{s}(2.2 \mathrm{mi} / \mathrm{h})$ and the yearly average wind speed in the Albuquerque area of $4 \mathrm{~m} / \mathrm{s}(9 \mathrm{mph})$ from Table D-1; the actual stack height of 38.1 $\mathrm{m}$ (125 ft) was used, and $E_{t}=1$ (to ignore meandering of plume). The $6000 \mathrm{~m}$ (3.7 mi) represents the approximate distance from TA-V to the closest population areas. These values may be used to calculate directly the consequences from normal (long-term) or accident (shortterm or instantaneous) release conditions, or they may be used to benchmark the results of the various atmospheric and transport models to be used in the assessment of releases from normal or accident conditions. (The results presented in Table D-8 tend to err on the conservative side; that is, they would result in over-estimates of doses.)

Table D-8. Dispersion Factors $(\chi / Q)$ as a Function of Distance from the HCF (Restrepo, 1994)

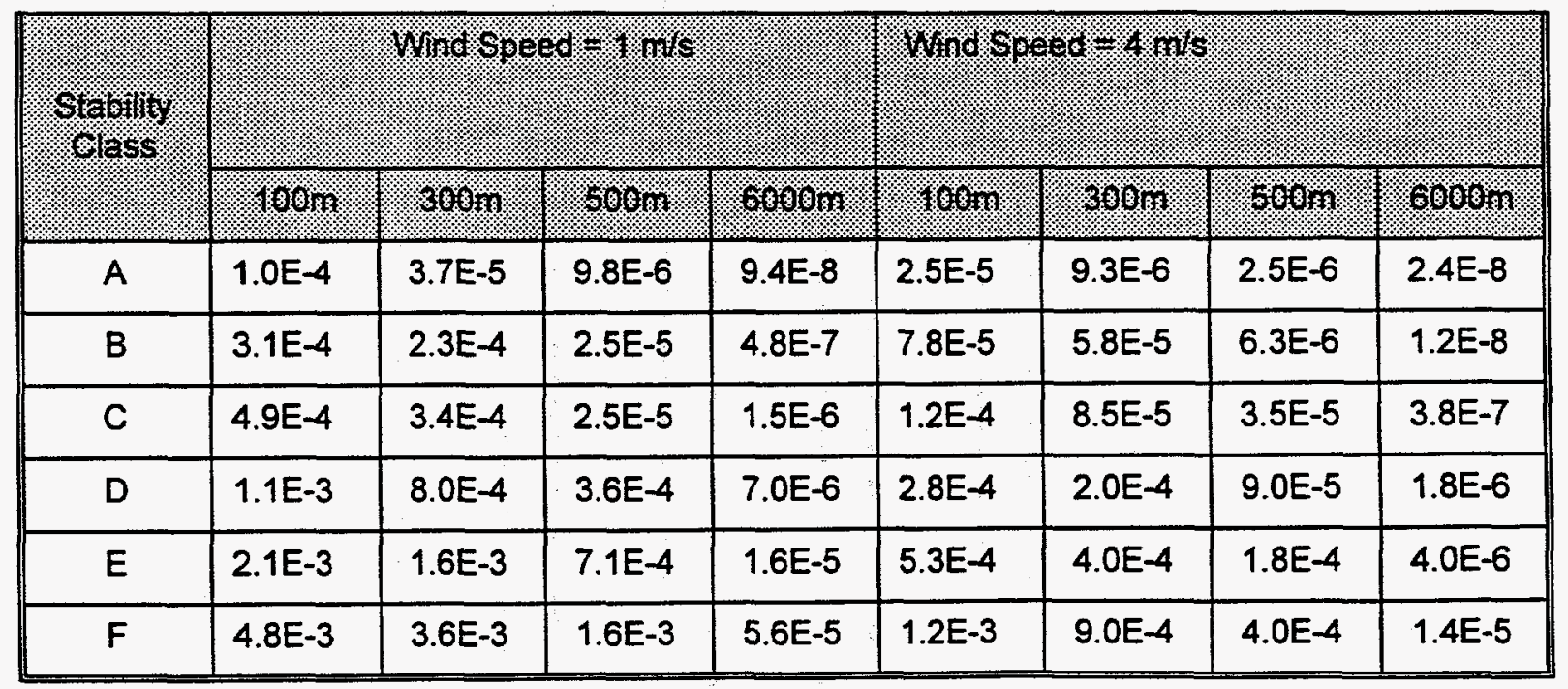




\section{D.2 Site Geology}

\section{Field Explorations}

Field explorations have been made at TA-V to evaluate the geologic and foundation characteristics of the site. Specifically, samples have been taken which represent the different types of material and characteristics.

\section{Site Geology}

The site is underlain by formations of the Santa Fe group of Quaternary and Tertiary age as shown in Figures D-1 and D-2. The Santa Fe group is in turn underlain by formations of Permian, Pennsylvanian, and Pre-Cambrian age as shown in Table D-9. These older rocks crop out in the horst about $800 \mathrm{~m}(0.5 \mathrm{mi})$ east of the site and also in the mountains farther east. Thin deposits of alluvium of recent age occur in the arroyos in the area.

The alluvium [4.5 to $6 \mathrm{~m}$ (15 to $20 \mathrm{ft}$ ) maximum thickness] consists of unconsolidated sand, gravel, and silt. This material is largely derived from the granite and metamorphosed rocks of Precambrian age which are exposed to the east. Generally, the porosity and permeability of this alluvial material are high, allowing relatively free movement of water. The Santa Fe group contains material similar to the alluvium, but much of the material has come into the area from the north, and there is a slightly greater degree of consolidation of some of the beds.

The Santa Fe group was deposited by streams and, consequently, there are rapid lateral and vertical changes in the character of the sediments. Individual beds are generally lenticular, but some extend for considerable distances as channel deposits. These long, narrow channel deposits are generally oriented in a northeast-southwest direction. The thickness of the Santa Fe group beneath the site is not known but is probably more than $150 \mathrm{~m}(500 \mathrm{ft})$, as indicated by the log of the well that was drilled for the Sandia Engineering Reactor about $460 \mathrm{~m}$ (1500 ft) west of the reactor building (Table D-9). The porosity and permeability of the Santa Fe group as a unit in this general area are generally high; however, the permeability of individual beds or lenses of silt or clay is quite low.

Tables D-10, D-11, and D-12 summarize the mechanical, mineralogical, and ion-exchange characteristics of material of the Santa Fe group. The samples were chosen to represent the different types of material present, but not the relative quantities of each type. Samples ranged from a sandy gravel to an argillaceous silt. These samples are similar to, but not identical with, material at the reactor site.

The pre-Tertiary rocks that underlie the Santa Fe group consist of sandstones, siltstones, limestones, and metamorphosed sediments lying on top of granite. These rocks are well consolidated and less porous and permeable than the rocks of the Santa Fe group. The thickness of these rocks is not known, but it appears to be at least $6700 \mathrm{~m}(22,000 \mathrm{ft})$. 


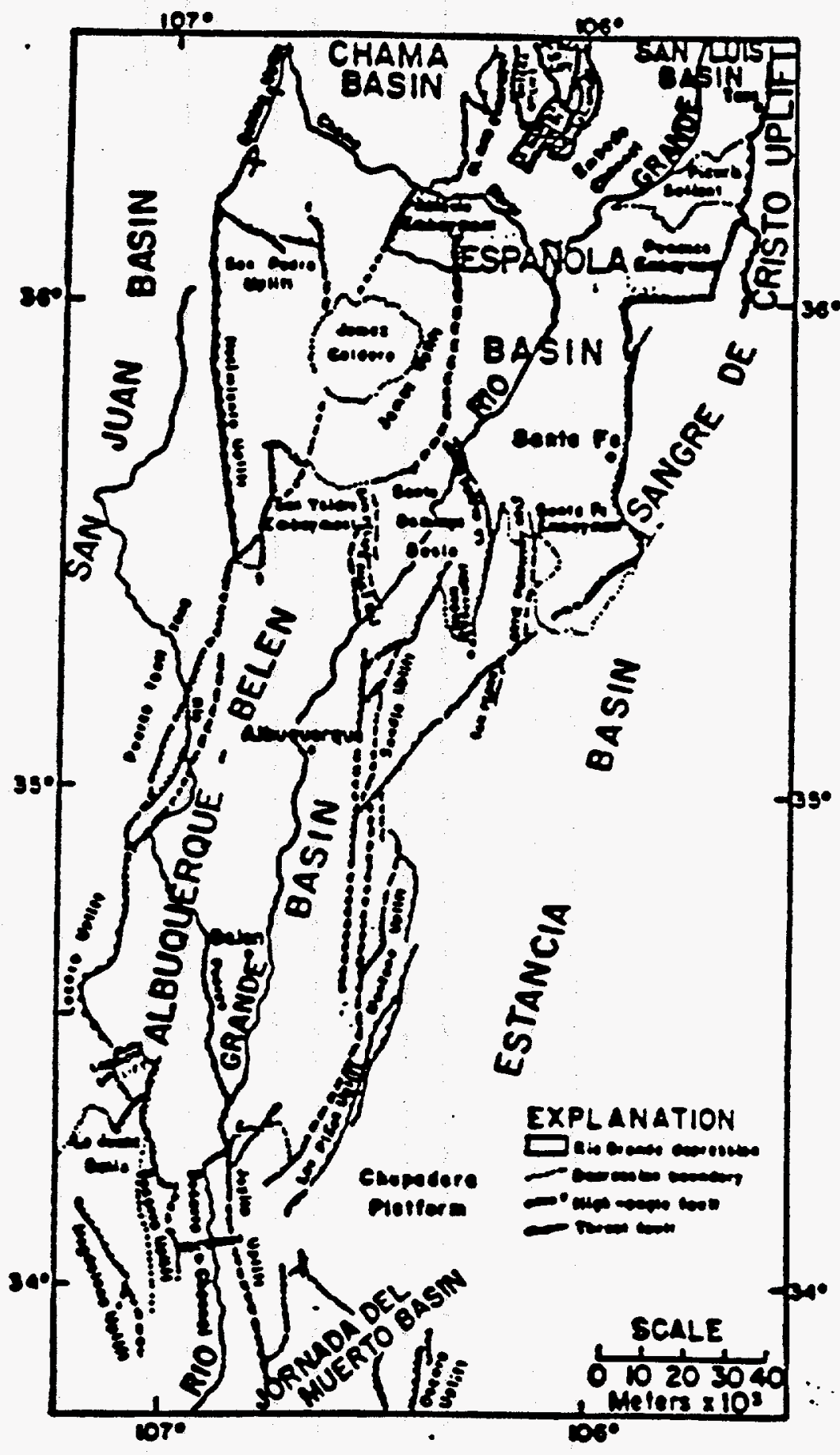

Figure D-1. Tectonic map of the Middle Rio Grande Depression (Modified from U.S. Geological Survey Map OM-157 Albuquerque, by V. C. Kelly) 


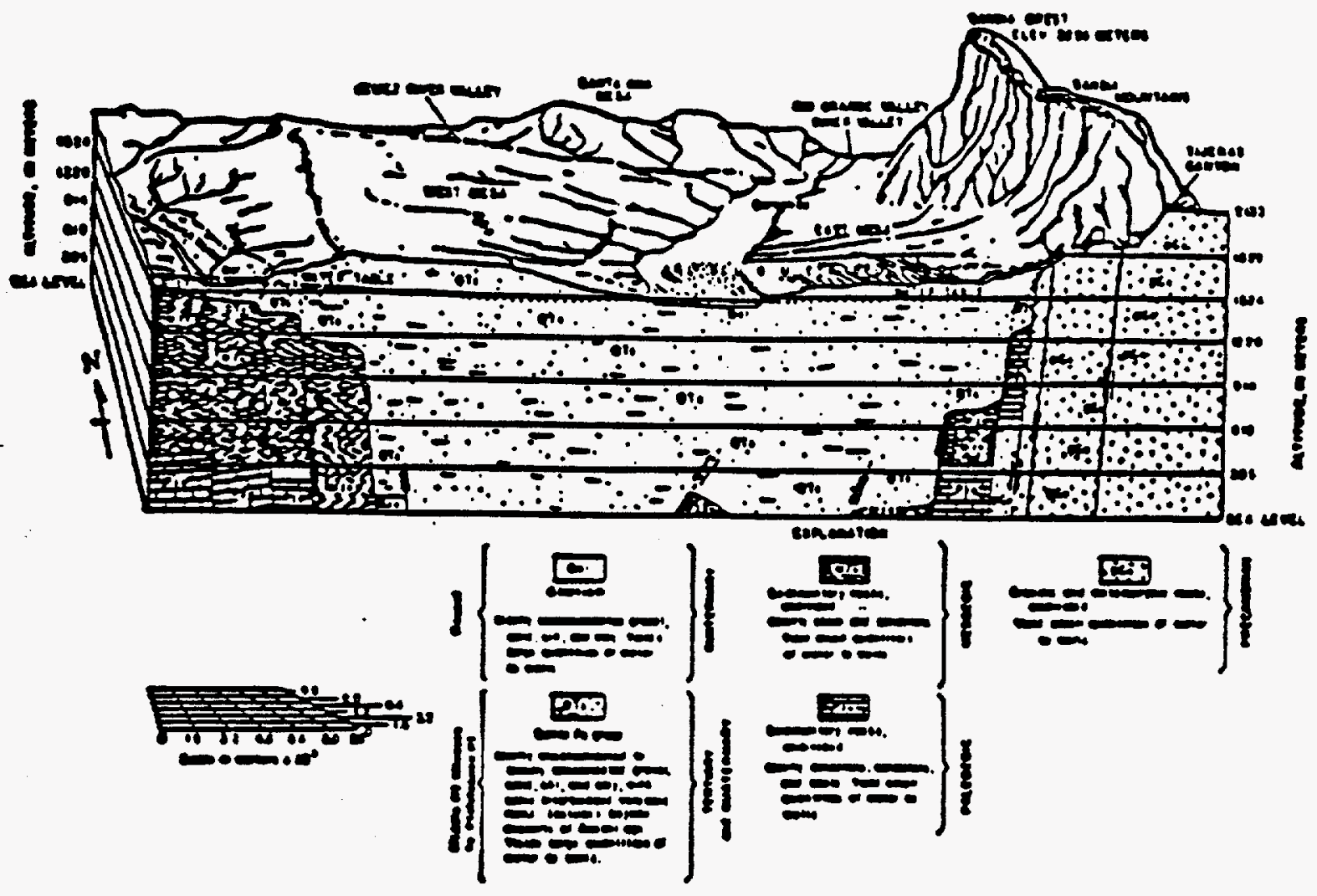

Figure D-2. Block Diagram of an area near Albuquerque, New Mexico. The map covers approximately $85.5 \times 10^{6} \mathrm{~m}^{2}$ and shows topography, generalized geology and the water table in the alluvium and the Santa Fe Formation 
Table D-9. Formations Present in the Area Near TV-V (Restrepo, 1994)

\begin{tabular}{|c|c|c|c|c|}
\hline (xistix & 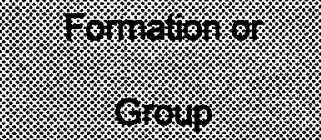 & 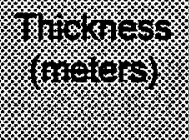 & 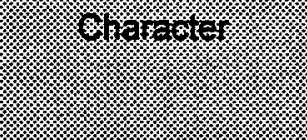 & 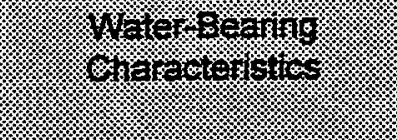 \\
\hline Recent & Alluvium & 4 to 6 & Sand and gravel & $\begin{array}{l}\text { Unsaturated, but gen- } \\
\text { erally highly porous and } \\
\text { permeable }\end{array}$ \\
\hline $\begin{array}{l}\text { Quaternary } \\
\text { and Tertiary }\end{array}$ & Santa Fe Group & 0 to 3000 & $\begin{array}{l}\text { Sand, gravel, and } \\
\text { silt; generally } \\
\text { unconsolidated }\end{array}$ & $\begin{array}{l}\text { Permeable and porous; } \\
\text { the only important aqui- } \\
\text { fer in the area }\end{array}$ \\
\hline Permian & $\begin{array}{l}\text { San Andres For- } \\
\text { mation, Glorieta } \\
\text { Sandstone, Yeso } \\
\text { Formation, Abo } \\
\text { Formation }\end{array}$ & 850 & $\begin{array}{l}\text { Sandstone, silt- } \\
\text { stone, and lime- } \\
\text { stone }\end{array}$ & $\begin{array}{l}\text { Low permeability and } \\
\text { porosity, but some } \\
\text { water occurs in Glorieta } \\
\text { sandstone; most water } \\
\text { in these formations } \\
\text { occurs in cracks and } \\
\text { joints }\end{array}$ \\
\hline Pennsylvanian & Magdalena Group & 240 to 270 & $\begin{array}{l}\text { Siltstone, lime- } \\
\text { stone, } \\
\text { sandstone }\end{array}$ & $\begin{array}{l}\text { Low permeability and } \\
\text { porosity; most, if not all, } \\
\text { water occurs in cracks } \\
\text { and joints }\end{array}$ \\
\hline Precambrian & $\begin{array}{l}\text { Seviletta Forma- } \\
\text { tion, Upper Meta- } \\
\text { clastic Series, } \\
\text { Lower Metaclastic } \\
\text { Series, Green- } \\
\text { stone complex in- } \\
\text { trusives }\end{array}$ & $5500+$ & $\begin{array}{l}\text { Metamorphosed } \\
\text { sedimentary and } \\
\text { pyroclastic rock } \\
\text { and intrusives, } \\
\text { and granites and } \\
\text { pegmatites }\end{array}$ & $\begin{array}{l}\text { Low permeability, very } \\
\text { low porosity; all water in } \\
\text { these formations occurs } \\
\text { in cracks and joints }\end{array}$ \\
\hline
\end{tabular}


Table D-10. Log of Well (Restrepo, 1994)

\begin{tabular}{|c|c|c|c|c|c|}
\hline $\begin{array}{l}\text { Depth } \\
(\mathrm{ft})\end{array}$ & Driling & Formation & Depth & $\begin{array}{l}\text { Drilling } \\
\text { Time } \\
\text { (min) }\end{array}$ & Formation \\
\hline \multicolumn{6}{|c|}{ Hughes tri-cone bil } \\
\hline $\begin{array}{c}0-5 \\
5-10 \\
10-15 \\
15-20 \\
20-25 \\
25-30 \\
30-35 \\
35-40 \\
40-45 \\
45-50 \\
50-55 \\
55-60 \\
60-65 \\
65-70 \\
70-75 \\
75-80 \\
80-85 \\
85-90 \\
90-95 \\
95-100 \\
100-105 \\
105-110 \\
110-115 \\
115-120 \\
120-125 \\
125-130 \\
130-135 \\
135-140\end{array}$ & $\begin{array}{c}25 \\
70 \\
25 \\
20 \\
40 \\
20 \\
25 \\
40 \\
20 \\
35 \\
35 \\
25 \\
10 \\
10 \\
8 \\
8 \\
8 \\
7 \\
7 \\
12 \\
10 \\
7 \\
10 \\
14 \\
4 \\
8 \\
20 \\
15\end{array}$ & $\begin{array}{l}\text { Gravel } \\
\text { Coarse sand } \\
\text { Coarse sand } \\
\text { Coarse sand } \\
\text { Coarse sand } \\
\text { Coarse sand } \\
\text { Sand } \\
\text { Hard sand } \\
\text { Sand } \\
\text { Sand } \\
\text { Clay and sand } \\
\text { Clay and sand } \\
\text { Coarse sand } \\
\text { Coarse sand } \\
\text { Coarse sand } \\
\text { Coarse sand } \\
\text { Coarse sand } \\
\text { Coarse sand } \\
\text { Coarse sand } \\
\text { Coarse sand } \\
\text { Coarse sand } \\
\text { Coarse sand } \\
\text { Coarse sand } \\
\text { Coarse sand } \\
\text { Coarse sand } \\
\text { Coarse sand } \\
\text { Sand } \\
\text { Sand }\end{array}$ & $\begin{array}{l}140-145 \\
145-150 \\
150-155 \\
155-160 \\
160-165 \\
165-170 \\
170-175 \\
175-180 \\
180-185 \\
185-190 \\
190-195 \\
195-200 \\
200-205 \\
205-210 \\
210-215 \\
215-220 \\
220-225 \\
225-230 \\
230-235 \\
235-240 \\
240-245 \\
245-250\end{array}$ & $\begin{array}{l}12 \\
13 \\
15 \\
15 \\
13 \\
15 \\
10 \\
15 \\
15 \\
13 \\
15 \\
15 \\
20 \\
15 \\
15 \\
15 \\
5 \\
23 \\
41 \\
54 \\
75 \\
64 \\
\\
15 \\
43 \\
32 \\
45 \\
9\end{array}$ & $\begin{array}{l}\text { Sand } \\
\text { Sand } \\
\text { Sand } \\
\text { Sand } \\
\text { Sand } \\
\text { Clay and sand } \\
\text { Fine sand } \\
\text { Clay and sand } \\
\text { Clay and Sand } \\
\text { Clay and sand } \\
\text { Limestone/hard sand } \\
\text { Limestone } \\
\text { Sand } \\
\text { Sand } \\
\text { Sand and limestone } \\
\text { Sand } \\
\text { Sand } \\
\text { Limestone and gravel } \\
\text { Sandy rock and gravel } \\
\text { Gravel and rock } \\
\text { White sandstone/gravel } \\
\text { Black limestone and } \\
\text { white sandstone } \\
\text { Coarse sand } \\
\text { Boulders/sandstone } \\
\text { Clay } \\
\text { Clay } \\
\text { Clay }\end{array}$ \\
\hline
\end{tabular}


Table D-10. Log of Well (Continued)

\begin{tabular}{|c|c|c|c|c|c|}
\hline \multicolumn{6}{|c|}{ H. C. smith 4 -cone bit } \\
\hline $\begin{array}{l}275-280 \\
280-285 \\
285-290 \\
290-295 \\
295-300 \\
300-305 \\
305-310 \\
310-315 \\
315-320 \\
320-325 \\
325-330 \\
330-335 \\
335-340 \\
340-345\end{array}$ & $\begin{array}{c}10 \\
13 \\
3 \\
12 \\
10 \\
11 \\
11 \\
11 \\
12 \\
13 \\
12 \\
13 \\
15 \\
10\end{array}$ & $\begin{array}{l}\text { Clay } \\
\text { Clay } \\
\text { Clay } \\
\text { Clay } \\
\text { Gravel } \\
\text { Gravel } \\
\text { Clay } \\
\text { Clay } \\
\text { Clay } \\
\text { Clay } \\
\text { Clay and gravel } \\
\text { Clay } \\
\text { Clay } \\
\text { Clay }\end{array}$ & $\begin{array}{l}345-350 \\
350-355 \\
355-360 \\
360-365 \\
365-370 \\
370-375 \\
375-380 \\
380-385 \\
385-390 \\
390-395 \\
395-400 \\
400-405 \\
405-410 \\
410-415\end{array}$ & $\begin{array}{c}9 \\
15 \\
15 \\
10 \\
11 \\
12 \\
9 \\
12 \\
9 \\
14 \\
15 \\
13 \\
15 \\
15\end{array}$ & $\begin{array}{l}\text { Clay } \\
\text { Limestone } \\
\text { Limestone and clay } \\
\text { Clay } \\
\text { Sand and clay } \\
\text { Clay } \\
\text { Clay } \\
\text { Clay } \\
\text { Sand and clay } \\
\text { Clay } \\
\text { Clay } \\
\text { Clay } \\
\text { Clay } \\
\text { Clay }\end{array}$ \\
\hline Depth & $\begin{array}{l}\text { Drilling } \\
\text { Time } \\
\text { (min) }\end{array}$ & Formation & $\begin{array}{l}\text { Depth } \\
\text { (ft) }\end{array}$ & $\begin{array}{l}\text { Drilling } \\
\text { Timin }\end{array}$ & Formation \\
\hline \multicolumn{6}{|c|}{ H. C. Smith 4-cone bit } \\
\hline $\begin{array}{l}415-420 \\
420-425 \\
425-430 \\
430-435 \\
435-440 \\
440-445 \\
445-450 \\
450-455 \\
455-460 \\
460-465 \\
465-470 \\
470-475 \\
475-480 \\
480-485 \\
485-490 \\
490-495 \\
495-500 \\
500-505 \\
505-510\end{array}$ & $\begin{array}{c}15 \\
15 \\
20 \\
22 \\
17 \\
13 \\
24 \\
15 \\
15 \\
9 \\
9 \\
9 \\
9 \\
10 \\
10 \\
20 \\
7 \\
13 \\
23\end{array}$ & $\begin{array}{l}\text { Clay } \\
\text { Clay } \\
\text { Clay } \\
\text { Clay } \\
\text { Clay } \\
\text { Clay } \\
\text { Clay } \\
\text { Clay/Rock Ledges } \\
\text { Sandy clay/rock ledges } \\
\text { Sandy clay/rocks } \\
\text { Sandy clay } \\
\text { Sandy clay } \\
\text { Sandy Clay } \\
\text { Sandy clay } \\
\text { Sandy clay } \\
\text { Clay } \\
\text { Clay } \\
\text { Clay } \\
\text { Clay }\end{array}$ & $\begin{array}{l}510-515 \\
515-520 \\
520-525 \\
525-530 \\
530-535 \\
535-540 \\
540-545 \\
545-550 \\
550-555 \\
555-560 \\
560-565 \\
565-570 \\
570-575 \\
575-580 \\
580-585 \\
585-590 \\
590-595 \\
595-600 \\
600-605\end{array}$ & $\begin{array}{l}10 \\
11 \\
17 \\
11 \\
17 \\
22 \\
19 \\
17 \\
21 \\
52 \\
20 \\
25 \\
15 \\
13 \\
15 \\
11 \\
12 \\
14 \\
13\end{array}$ & $\begin{array}{l}\text { Clay } \\
\text { Clay } \\
\text { Sand and clay } \\
\text { Coarse sand/clay } \\
\text { Coarse sand/clay } \\
\text { Coarse sand/clay } \\
\text { Coarse sand/clay } \\
\text { Coarse sand/clay } \\
\text { Coarse sand/clay } \\
\text { Hard sandstone } \\
\text { Boulders/coarse sand } \\
\text { Coarse sand/clay } \\
\text { Clay } \\
\text { Clay } \\
\text { Clay } \\
\text { Clay } \\
\text { Clay } \\
\text { Clay } \\
\text { Sand and clay }\end{array}$ \\
\hline
\end{tabular}


Table D-10. Log of Well (Continued)

\begin{tabular}{|c|c|c|c|c|c|}
\hline \multicolumn{6}{|c|}{ (1. } \\
\hline $\begin{array}{l}605-610 \\
610-615 \\
615-620 \\
620-625 \\
625-630 \\
630-635 \\
635-640 \\
640-645 \\
645-650 \\
650-655 \\
655-660 \\
660-665 \\
665-670\end{array}$ & $\begin{array}{c}10 \\
8 \\
6 \\
11 \\
10 \\
7 \\
17 \\
8 \\
11 \\
31 \\
9 \\
15 \\
7\end{array}$ & $\begin{array}{l}\text { Sand and clay } \\
\text { Sand and clay } \\
\text { Sand } \\
\text { Sand and clay } \\
\text { Sand and clay } \\
\text { Sand } \\
\text { Sand } \\
\text { Sand } \\
\text { Sand } \\
\text { Sand and clay } \\
\text { Sandy clay } \\
\text { Sandy clay } \\
\text { Sandy clay }\end{array}$ & $\begin{array}{l}670-675 \\
675-680 \\
680-685 \\
685-690 \\
690-695 \\
695-700 \\
700-705 \\
705-710 \\
710-715 \\
715-720 \\
720-725 \\
725-730 \\
730-735\end{array}$ & $\begin{array}{c}9 \\
30 \\
13 \\
15 \\
4 \\
22 \\
22 \\
19 \\
24 \\
60 \\
60 \\
39 \\
13\end{array}$ & $\begin{array}{l}\text { Sandy clay } \\
\text { Clay and rock } \\
\text { Sandy clay/hard rock } \\
\text { Clay and rock } \\
\text { Clay } \\
\text { Clay } \\
\text { Sandy clay } \\
\text { Sandy clay } \\
\text { Sandy clay } \\
\text { Clay } \\
\text { Clay } \\
\text { Clay } \\
\text { Sand and clay }\end{array}$ \\
\hline $\begin{array}{l}\text { Depth } \\
\text { (f) }\end{array}$ & $\begin{array}{l}\text { Drilling } \\
\text { Time } \\
\text { (min) }\end{array}$ & Formation & $\begin{array}{l}\text { Depth } \\
\text { (fi) }\end{array}$ & $\begin{array}{l}\text { Drilling } \\
\text { Time } \\
\text { (min) }\end{array}$ & Formation \\
\hline \multicolumn{6}{|c|}{$12^{3 / 4}$-in H. C. Smith 4 -cone bit } \\
\hline $\begin{array}{l}735-740 \\
740-745 \\
745-750 \\
750-755 \\
755-760 \\
760-765 \\
765-770 \\
770-775 \\
775-780\end{array}$ & $\begin{array}{l}11 \\
7 \\
4 \\
3 \\
6 \\
4 \\
4 \\
9 \\
6\end{array}$ & $\begin{array}{l}\text { Sand } \\
\text { Sand and gravel } \\
\text { Sand and gravel } \\
\text { Sand and gravel } \\
\text { Sand and gravel } \\
\text { Sand and gravel } \\
\text { Sand and clay } \\
\text { Clay and gravel } \\
\text { Gravel }\end{array}$ & $\begin{array}{l}780-785 \\
785-790 \\
790-795 \\
795-800 \\
800-805 \\
805-810 \\
810-815 \\
815-820\end{array}$ & $\begin{array}{l}6 \\
6 \\
3 \\
5 \\
15 \\
12 \\
10 \\
10\end{array}$ & $\begin{array}{l}\text { Clay and gravel } \\
\text { Sand and gravel } \\
\text { Sand } \\
\text { Sand } \\
\text { Clay/sand/gravel } \\
\text { Clay/sand/gravel } \\
\text { Clay/sand/gravel } \\
\text { Clay/sand/gravel }\end{array}$ \\
\hline
\end{tabular}


Table D-10. Log of Well (Continued)

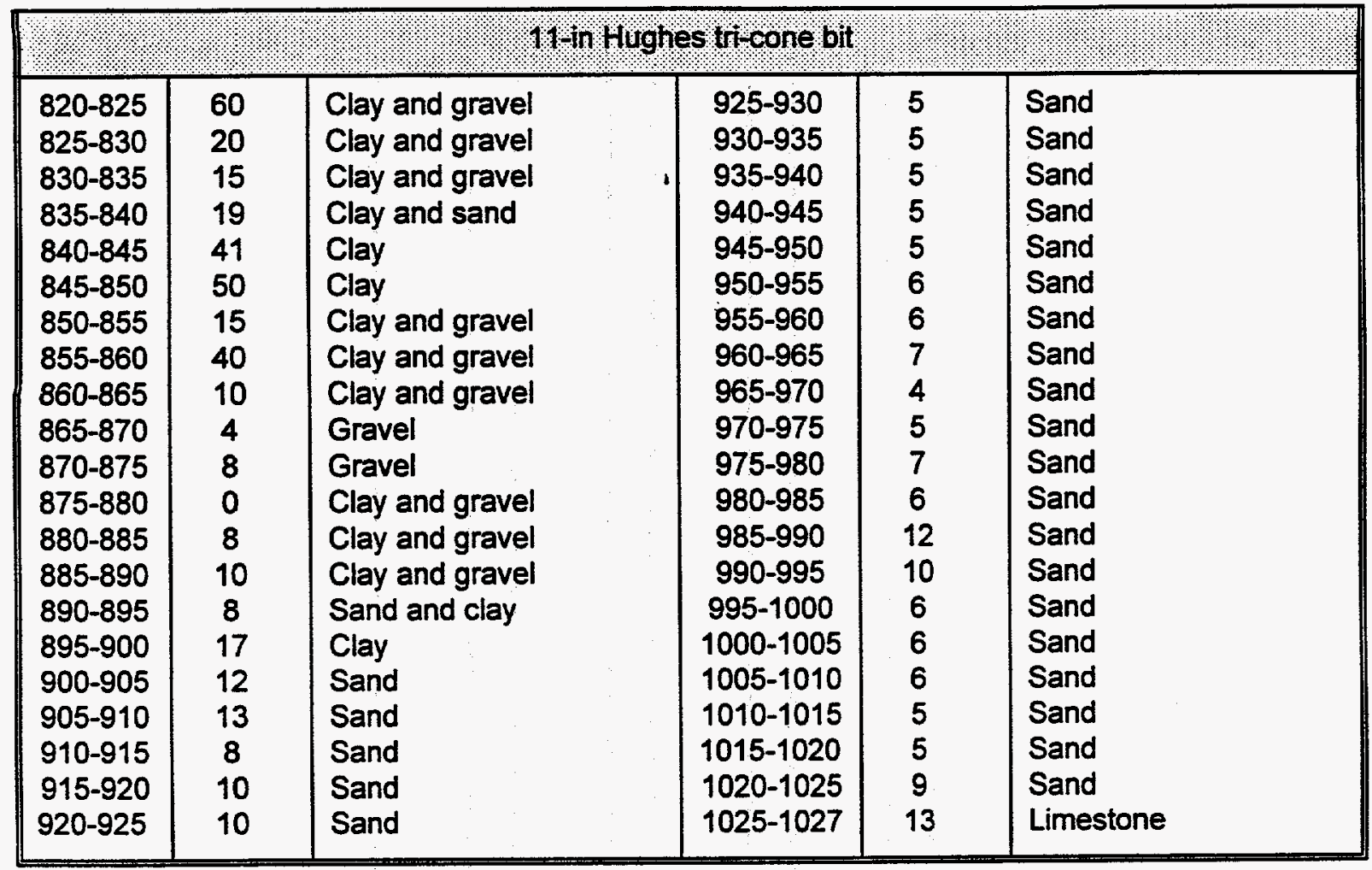


Table D-11. Mechanical Composition and lon-Exchange Capacity. The Five Samples of Tertiary and Recent Sands and Gravels from near TA-V (Restrepo, 1994)

\begin{tabular}{|c|c|c|c|c|c|c|}
\hline \multirow{2}{*}{ 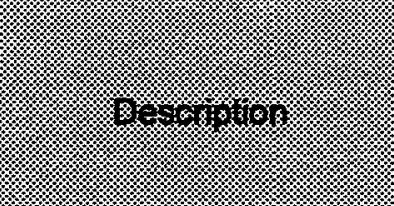 } & \multirow{2}{*}{ 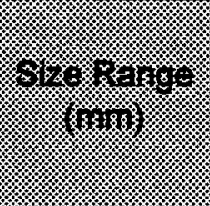 } & \multicolumn{5}{|c|}{ (4) } \\
\hline & & 18 & 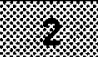 & 13. & 8 & 8 \\
\hline $\begin{array}{l}\text { Pebble gravel and larger } \\
\text { Pebble gravel } \\
\text { Pebble gravel } \\
\text { Granule gravel } \\
\text { Very coarse sand } \\
\text { Coarse sand } \\
\text { Medium sand } \\
\text { Fine sand } \\
\text { Very fine sand } \\
\text { Silt } \\
\text { Clay }\end{array}$ & $\begin{array}{c}>9.52 \\
5.66-9.52 \\
4.0-5.66 \\
2.0-4.0 \\
1.0-2.0 \\
0.5-1.0 \\
0.25-0.5 \\
0.125-0.25 \\
0.062-0.125 \\
0.002-0.062 \\
<0.002\end{array}$ & $\begin{array}{r}33.3 \\
6.8 \\
9.4 \\
14.9 \\
14.5 \\
11.0 \\
5.1 \\
2.2 \\
1.5 \\
1.2 \\
0.1\end{array}$ & $\begin{array}{r}- \\
- \\
- \\
2.7 \\
4.3 \\
4.9 \\
5.8 \\
8.4 \\
17.0 \\
38.0 \\
20.0\end{array}$ & $\begin{array}{r}5.8 \\
1.3 \\
5.4 \\
23.7 \\
37.0 \\
22.2 \\
3.6 \\
0.4 \\
0.2 \\
0.3 \\
0.1\end{array}$ & $\begin{array}{r}21.8 \\
10.4 \\
14.0 \\
20.7 \\
13.3 \\
5.5 \\
2.9 \\
4.3 \\
4.5 \\
1.9 \\
0.7\end{array}$ & $\begin{array}{c}- \\
- \\
- \\
\text { nil } \\
\text { nil } \\
0.2 \\
0.4 \\
17.7 \\
41.2 \\
27.2 \\
13.4\end{array}$ \\
\hline \multicolumn{2}{|c|}{$\begin{array}{l}\text { lon-exchange capacity of }<2 \mathrm{~mm} \text { material } \\
\text { [me/100 g] (Note } 3 \text { ) }\end{array}$} & 3.0 & 19.0 & 2.5 & 3.1 & 7.5 \\
\hline \multicolumn{2}{|c|}{$\begin{array}{l}\text { lon-exchange capacity recalculated for } \\
\text { whole material [me } / 100 \mathrm{~g} \text { ] (Note } 3 \text { ) }\end{array}$} & 1.0 & 19.0 & 1.6 & 1.0 & 7.5 \\
\hline
\end{tabular}

\section{Notes:}

1. Description and location:

Sample 1. Recent or Tertiary gravel from bank of Coyote Arroyo in SE 1/4 NW 1/4, Sec. 16, T.9N., R.4E.

Sample 2. Recent or Tertiary silt from bank of Coyote Arroyo about 100 feet downstream from old diversion structure in NE 1/4 NE 1/4, Sec. 17, T.9N., R.4E.

Sample 3. Tertiary sand from bank of Coyote Arroyo about 200 feet downstream from old diversion structure in NE $1 / 4$ NE 1/4, Sec. 17, T.9N., R.4E.

Sample 4. Tertiary sandy gravel from road cut on west side of access road about 0.1 mile north of bridge over Tijeras Arroyo in SW 1/4 SE 1/4 SW 1/4, Sec. 5, T.9N., R.4E.

Sample 5. Tertiary sand from road cut on east side of access road about 0.1 mile north of bridge over Tijeras Arroyo in SW 1/4 SE 1/4 SW 1/4, Sec. 5, T.9N., R.4E.

2. Mechanical composition: In order to obtain sufficient clay and silt for mineral analyses of samples 1, 3, and 4, all of these samples (excluding a portion for ion-exchange) were used in the mechanical analysis.

All material greater than $2-\mathrm{mm}$ median diameter was removed and fractionated as shown below. The remaining portion $(<2 \mathrm{~mm})$ was treated in the standard manner for mechanical analyses. Samples 2 and 5 were also treated in the standard manner as follows:

Each sample was wet sieved through a U.S. Standard Sieve Series sieve No. 230. The sand fraction was dried and fractionated according to the Wentworth scale. The percentages of clay and silt were determined by a standard pipette method.

3. Ion-exchange capacity: As all the samples except Numbers 2 and 5 contained large pebbles and gravel on which it is not practicable to make ion-exchange capacity determinations, the fraction passing a 2-mm sieve was used and the results recalculated for the entire material assuming that the pebbles and gravel do not contribute to the exchange capacity. 
Table D-12. Mineralogy of Silt and Clay Fractions

(same samples as described in Table D-11) (Restrepo, 1994)

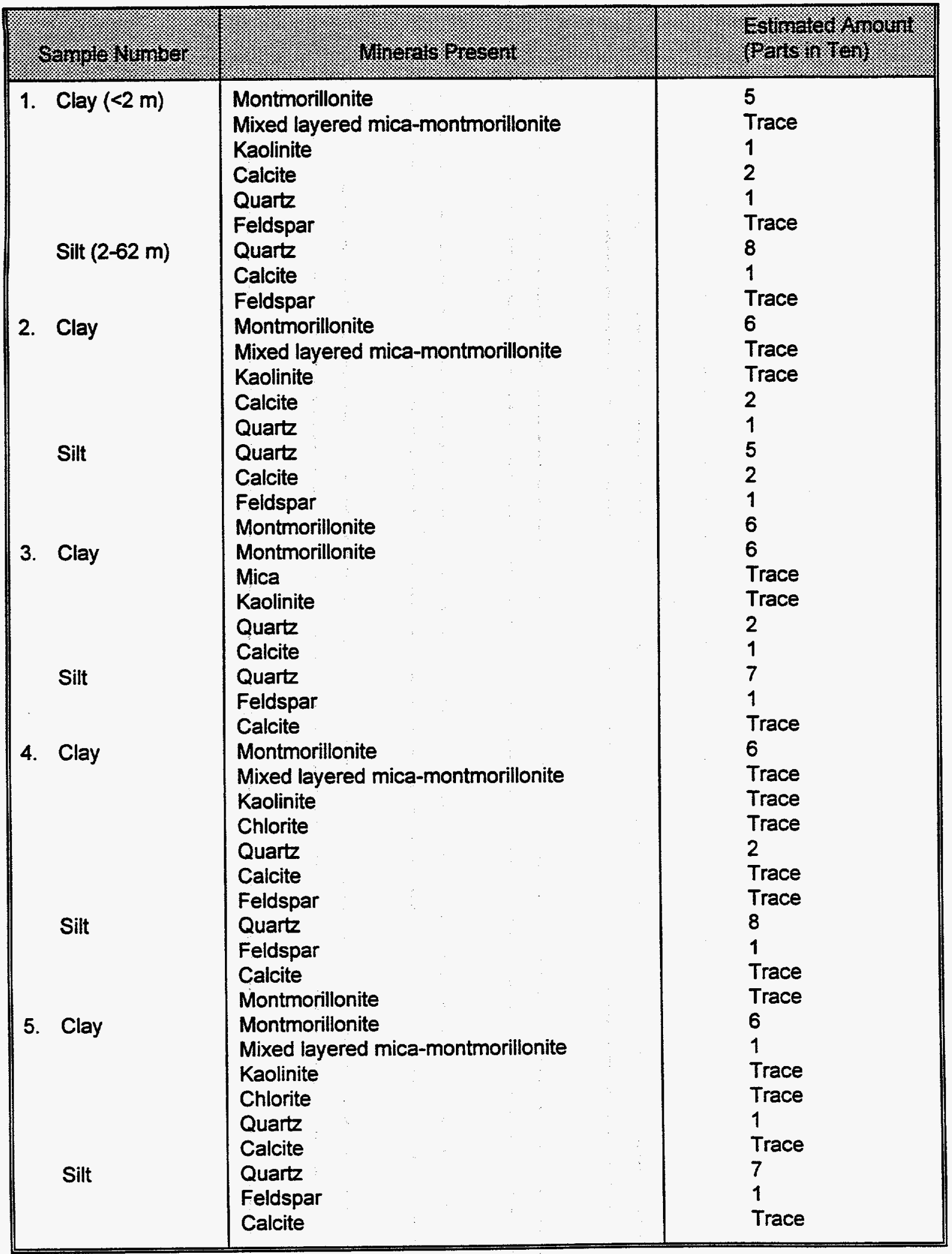




\section{D.3 Site Seismic Considerations}

The basin in which TA-V is situated is bounded on the east and west by complex fault zones which generally underlie the surface but are exposed along the edges of the mountains. Based on available information, most earthquakes recorded in New Mexico have occurred along the Rio Grande trough, with the region between Albuquerque and Socorro exhibiting the highest concentration (Figure D-3), accounting for about $90 \%$ of the recorded earthquakes between 1890 and 1960. Instrumented seismic records for New Mexico beginning in 1960 indicate that the pattern of seismic activity for earthquakes of Richter magnitude 2.7 or greater has shifted such that the center of activity is in the northeast quadrant of the state. No geological evidence indicates the occurrence of intensive earthquakes in the Albuquerque area within recent geologic history, although several earthquakes centered near Albuquerque during the last $\mathbf{2 0}$ years have recorded Richter magnitudes of 2.7 or greater as shown in Figure D-3 and Tables $\mathrm{D}-13$ and $\mathrm{D}-14$.

Based on the information in the tables above, the largest earthquake which is likely to occur would be of about magnitude 3.5. This value represents an "upper average" of the data shown for 1960 to 1986 . Quantitative probability studies of the occurrence of earthquakes in California have produced an expression for the Expected Number, EN, of earthquakes for a given period of time in years, $Y$, and Richter magnitude, $M$. This expression is written as:

$$
\begin{aligned}
& E N=\frac{Y}{370}\left(8 x^{2}-4.69 x^{3}+7.52 x^{4}\right) \\
& \text { where: } x=8.7-M
\end{aligned}
$$

If the period of observation is selected as 25 years, and the earthquake selected for review is of Richter Magnitude 3.5, the Expected Number of earthquakes is:

$$
\left.\mathrm{EN}=\frac{25}{370} 8(5.2)^{2}-4.69(5.2)^{3}+7.52(5.2)^{4}\right]=342
$$

The Albuquerque area of interest (that is, the total area from which TA-V would be affected by the earthquake) is selected as $4.8 \times 10^{9} \mathrm{~m}^{2}\left(1850 \mathrm{mi}^{2}\right)$, which corresponds to the geological region known as the Albuquerque-Belen Basin. Further, if it is assumed that there is an equal probability of occurrence throughout the state [area $=3.16 \times 10^{11} \mathrm{~m}^{2}\left(122,000 \mathrm{mi}^{2}\right)$ ], then the number of times that an earthquake would be expected in the Albuquerque area is:

$$
E N=\frac{342 \times 4.8 \times 10^{9}}{3.16 \times 10^{11}}=5.19
$$

or approximately 1 earthquake of Richter Magnitude 3.5 every 5 years. Table D-14 shows that this value is in good agreement with the recorded seismic history, and that the equation can be used to predict local events. 


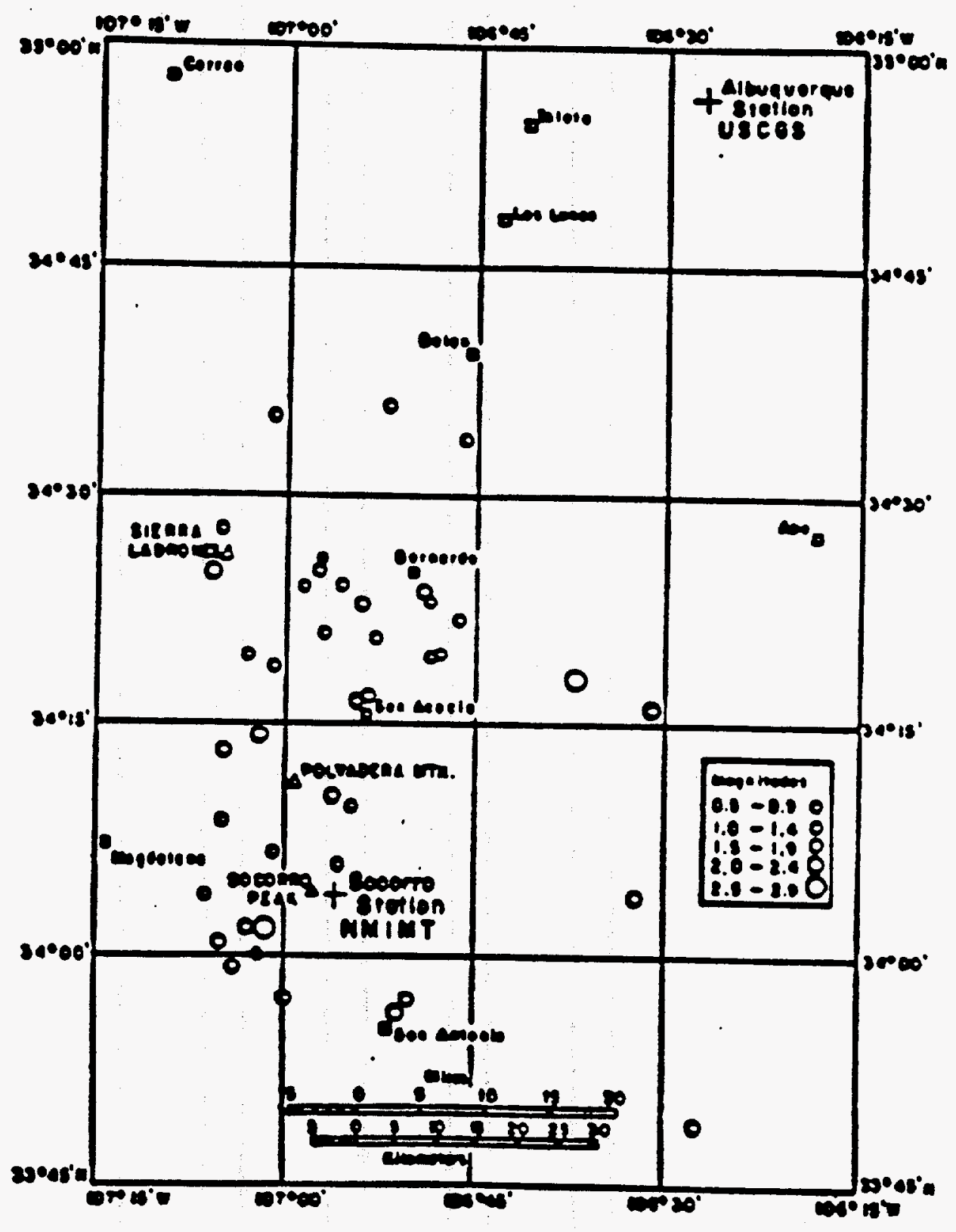

Figure D-3. Map of West-Central New Mexico Showing Locations of Earthquakes. These were detected by seismographs from January 1, 1962 to June 30, 1964 (Sanford, 1965) 
Table D-13. Noninstrumentally Located Earthquakes in New Mexico, 1868-1959 (Restrepo, 1994)

\begin{tabular}{|c|c|c|c|c|c|}
\hline & (x) & olate & 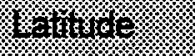 & (3) & (6) \\
\hline $\begin{array}{r}1868 \\
1869 \\
1879 \\
1886 \\
1893 \\
\\
1895 \\
1897 \\
1904 \\
\text { to } \\
1906\end{array}$ & $\begin{array}{lc}\text { Apr } & 28 \\
\text { Apr } & 18 \\
\text { Unknown } \\
\text { Jul } & 6 \\
\text { Apr } & 8 \\
\text { Jul } & 12 \\
\text { Sep } & 7 \\
\text { Oct } & 7 \\
\text { Oct } & 31 \\
\text { Unknown } \\
\text { Jan } & 19 \\
\text { Sep } & 10 \\
\text { Jul } & 12 \\
\text { Jul } & 16 \\
\text { Nov } & 15 \\
& \\
\text { Jul } & 18 \\
\text { Dec } & 5 \\
\text { May } & \\
\text { Jan } & 31 \\
\text { Feb } & 1 \\
\text { Aug } & 12 \\
\text { Mar } & 23 \\
\text { Dec } & 3 \\
\text { Dec } & 4 \\
\text { Jan } & 27 \\
\text { Feb } & 3 \\
\text { Feb } & \\
\text { Apr } & 7 \\
\text { Jan } & 7 \\
\text { May } & 6 \\
\text { Jan } & 17 \\
\text { Feb } & 20 \\
\text { Dec } & 12 \text { toDec } \\
20 & \\
\text { Sep } & 9 \\
\text { Sep } & 11 \\
\text { Apr } & 15 \\
\text { Apr } & 16 \\
\text { Sep } & 17 \\
\text { Sep } & 19 \\
\text { Sep } & 29 \\
\text { Oct } & 31 \\
\text { Nov } & 2 \\
\text { Aug } & 4 \\
\text { Nov } & 6\end{array}$ & 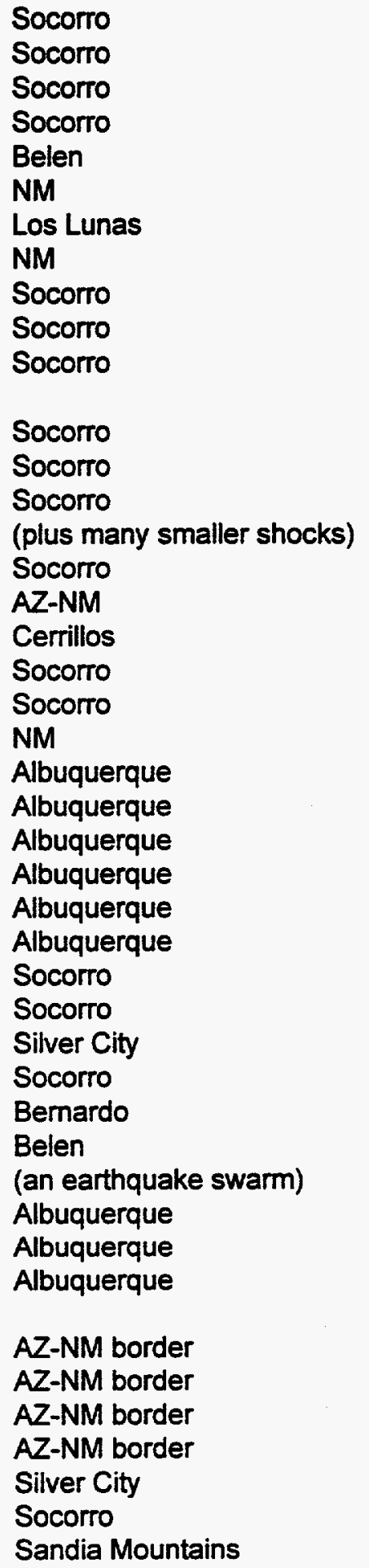 & $\begin{array}{l}34 \\
34 \\
34 \\
34 \\
34.8 \\
35 \\
34 \\
35.7 \\
34 \\
34 \\
34 \\
34 \\
34 \\
34 \\
34 \\
34 \\
7 \\
34 \\
34 \\
35 \\
34 \\
34 \\
34 \\
36 \\
0 \\
3\end{array}$ & $\begin{array}{l}107 \\
107 \\
107 \\
107 \\
106.8 \\
106.4 \\
106.6 \\
106.7 \\
107 \\
107 \\
107 \\
107 \\
107 \\
107 \\
107 \\
106.8 \\
106.6 \\
107 \\
107 \\
104.5 \\
106\end{array}$ & $\begin{array}{l}\text { VII } \\
\text { IV-V } \\
\text { V } \\
\text { V } \\
\text { slight } \\
\text { V-VI } \\
\text { slight } \\
\text { III } \\
\text { V } \\
\text { VI-VII } \\
\text { slight } \\
\text { V } \\
\text { V } \\
\\
\text { VI } \\
\text { V-VI } \\
\text { IV-V } \\
\text { III } \\
\text { slight } \\
\text { slight } \\
\text { VI } \\
\text { V } \\
\text { V } \\
\text { V-VI }\end{array}$ \\
\hline
\end{tabular}


Table D-13. Noninstrumentally Located New Mexico Earthquakes, 1868-1959 (Concluded)

\begin{tabular}{|c|c|c|c|c|c|c|}
\hline \multicolumn{3}{|c|}{ 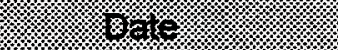 } & 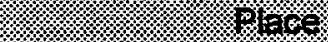 & 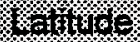 & 1 & Shtersivis \\
\hline $\begin{array}{l}1949 \\
1952 \\
\\
1955 \\
1956\end{array}$ & $\begin{array}{l}\text { May } \\
\text { Aug } \\
\text { Aug } \\
\text { Aug } \\
\text { Apr }\end{array}$ & $\begin{array}{l}23 \\
3 \\
17 \\
12 \\
25\end{array}$ & $\begin{array}{l}\text { East Vaughn } \\
\text { Cimarron } \\
\text { Los Alamos } \\
\text { Santa Fe } \\
\text { Sandia Mountains }\end{array}$ & $\begin{array}{l}34.6 \\
36.5 \\
35.5 \\
30.2\end{array}$ & $\begin{array}{c}105.2 \\
105.0 \\
106.2 \\
104.6\end{array}$ & $\begin{array}{l}\text { V } \\
\text { IV } \\
\text { V } \\
\text { V } \\
\text { slight }\end{array}$ \\
\hline
\end{tabular}

Table D-14. Instrumentally Located New Mexico Earthquakes, 1960-1986 (Richter Magnitude 2.7 or Greater) (Restrepo, 1994)

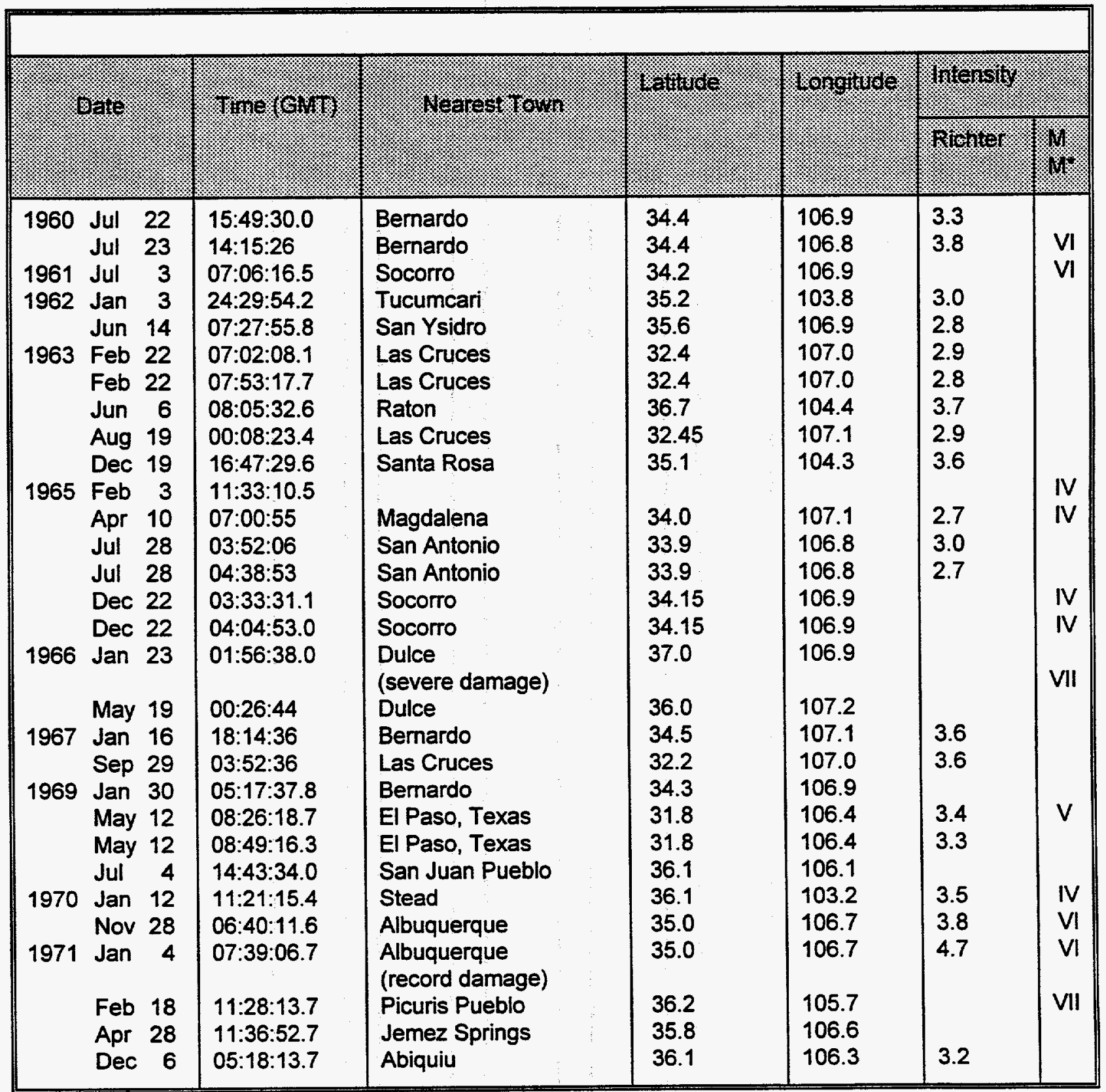


Table D-14. Instrumentally Located New Mexico Earthquakes, 1960-1986 (Richter Magnitude 2.7 Greater)(Concluded)

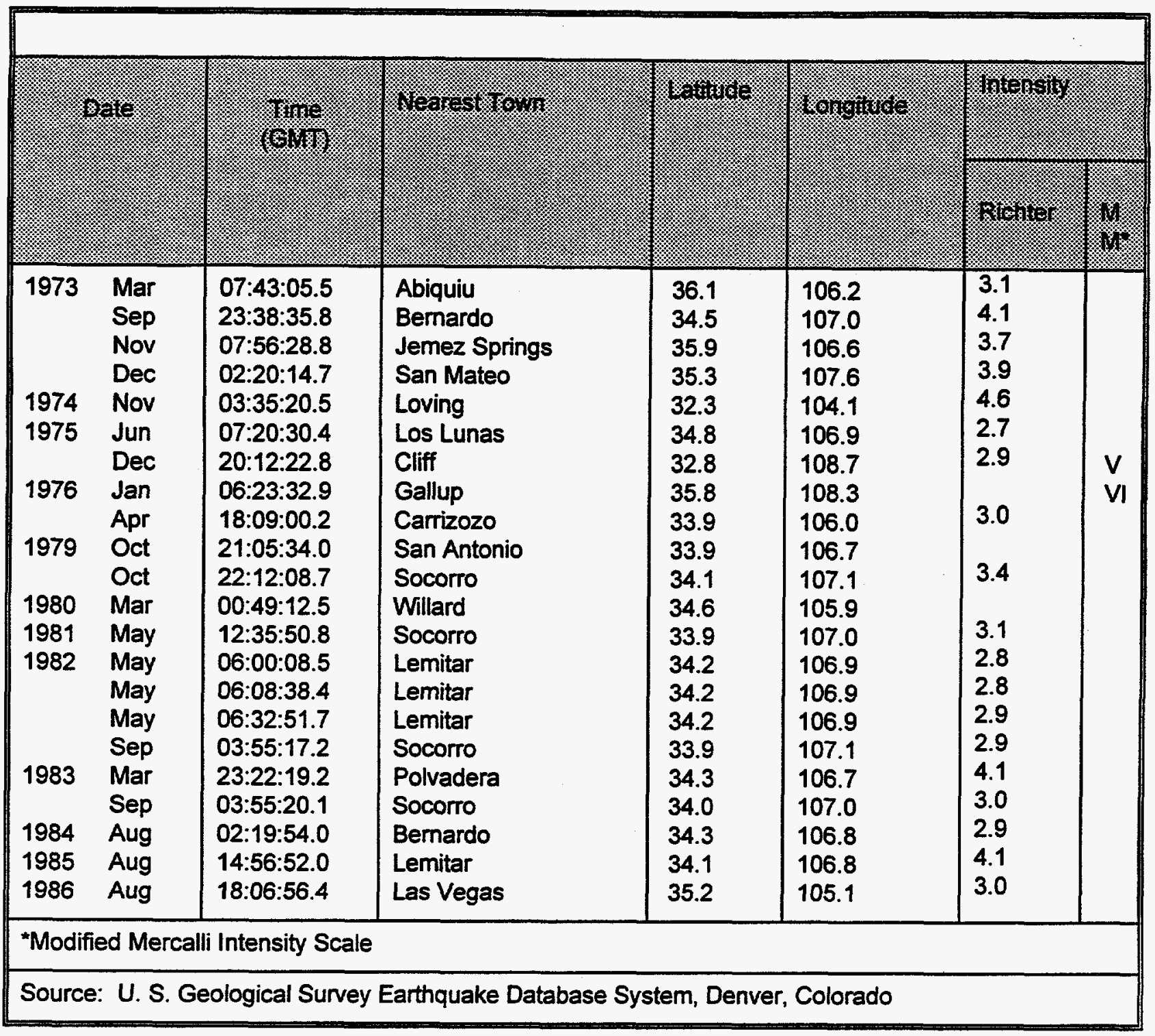




\section{References}

1. Restrepo, L. F., 1994, Hot Cell Facility (HCF) Safety Analysis Report, SAND94-2650: UC-700, Sandia National Laboratories, Albuquerque, New Mexico

2. Sanford, A. R., 1965, An Instrumental Study of New Mexico Earthquakes, Circular 78, NMIMT, Socorro, New Mexico

3. Strenge, D. L., 1980, Models Selected for Calculations of Doses, Health Effects, and Economic Costs due to Accidental Radionuclide Releases from Nuclear Power Plants, Battelle Pacific Northwest Laboratories, Richland, Washington. 


\section{APPENDIX E \\ LEAKING TARGETS AND FUEL ELEMENTS - \\ OFFSITE ACTIVITY RELEASES}




\section{APPENDIXE \\ LEAKING TARGETS AND FUEL ELEMENTS - OFFSITE DOSE ESTIMATES}

Downwind dose estimates were calculated by assuming all of the noble gases and halogens for a target or fuel element were immediately released into the pool. This is a very conservative assumption since the availability of these elements to be released requires them to diffuse out of the fuel matrix and into the void regions of the target or fuel, and the type of leak under consideration is a pin-hole type leak that would allow only minute but detectable quantities to be released. The leak was assumed to occur following a $21 \mathrm{~kW}, 7$-day target irradiation, and a $25 \mathrm{~kW}, 5$-year fuel irradiation. Since, as shown in Table E-1, both noble gases and halogens would be completely dissolved, the calculations assume that these gases are dissolved in the water and are released to the high bay through pool water evaporation. Also assumed in the calculations is that halogens can be removed from the pool using a cleanup system. For the ACRR pool and piping volume of approximately 56,000 liters, the solubility of these elements are 1,000 to 10,000 times greater than the amount produced in a fuel element or target under the assumed irradiation conditions.

Using these assumptions, the total activity release to the atmosphere outside the high bay for these elements can be calculated as:

$$
R_{i}=S_{i} \frac{m_{p}}{V_{p}}\left(\frac{1}{\lambda_{i+}\left(m_{p}+\gamma m_{c}\right) / V_{p}}\right) \frac{m_{s}}{V_{s}}\left(\frac{1}{\lambda_{i}+m_{s} / V_{s}}\right)
$$

where $R_{i}$ is the total activity released from the stack of isotope $i, S_{i}$ is the activity of isotope $i$ initially released from the target or element into the pool, $m_{p}$ is the evaporation rate from the pool, $m_{c}$ is the cleanup rate with efficiency $\gamma, m_{s}$ is the stack release rate, $V_{p}$ is the pool and piping volume, $V_{s}$ is the high bay room volume, and $\lambda_{i}$ is the decay constant for isotope $i$.

\begin{tabular}{|c|c|c|}
\hline \multirow[b]{2}{*}{ Element } & \multicolumn{2}{|c|}{ Solubility, g/ml $\mathrm{H}_{2} \mathrm{O}$} \\
\hline & Cold & Hot \\
\hline Bromine & 0.0417 & 0.0352 \\
\hline lodine & 0.00029 & 0.00078 \\
\hline Krypton & 0.0014 & 0.00050 \\
\hline Xenon & 0.00042 & 0.00018 \\
\hline
\end{tabular}

Data taken from the CRC Handbook of Chemistry and Physics, 53rd edition, 1973.

Using an evaporation rate of 9.31 liters per hour from the pool, a pool cleanup rate of 6,800 liters per hour with an efficiency for removing the halogens of 0.95 and an efficiency for removing noble gases of zero, a pool volume of 56,000 liters, a stack release rate of $4,600 \mathrm{l} / \mathrm{s}$, and a high bay room volume of 2,330,000 liters, the total activity released from the ACRR high bay stack was calculated for each of the noble gas and halogen elements produced. 
Tables E-2 and E-3 show the ACRR high bay release rates for these isotopes for a leaking target and fuel element, respectively. The total atmospheric release can be calculated with the data of Tables E-2 and E-3 to develop the dose at a downwind location. Tables E-4 and E-5 show the downwind dose for a leaking target and fuel element, respectively.

Table E-2 ACRR High Bay Release Rates for a Leaking Target Following a 21kW, 7-Day Irradiation

\begin{tabular}{|c|c|c|c|c|}
\hline Isotope & Half Life & $\begin{array}{c}\text { Activity Released } \\
\text { to Pool (Ci) }\end{array}$ & $\begin{array}{c}\text { Release Fraction } \\
\left(R_{1} / S_{i}\right)\end{array}$ & Stack Release (Ci) \\
\hline $\mathrm{Br}-82$ & $1.47 \mathrm{~d}$ & 0.297 & 0.00123 & 0.0004 \\
\hline $\mathrm{Br}-83$ & $2.40 \mathrm{~h}$ & 99.5 & 0.000411 & 0.0409 \\
\hline $\mathrm{Kr}-83 \mathrm{~m}$ & $1.86 \mathrm{~h}$ & 222.0 & 0.000446 & 0.099 \\
\hline $\mathrm{Br}-84$ & $30.80 \mathrm{~m}$ & 194.0 & 0.000117 & 0.0227 \\
\hline $\mathrm{Kr}-85 \mathrm{~m}$ & $4.48 \mathrm{~h}$ & 225.0 & 0.00107 & 0.2408 \\
\hline $\mathrm{Kr}-85$ & $10.73 y$ & 0.0568 & 0.958 & 0.0544 \\
\hline $\mathrm{Kr}-87$ & $1.27 \mathrm{~h}$ & 456.0 & 0.000304 & 0.1386 \\
\hline $\mathrm{Kr}-88$ & $2.84 \mathrm{~h}$ & 636.0 & 0.000680 & 0.4325 \\
\hline $1-130$ & $12.36 \mathrm{~h}$ & 0.193 & 0.000967 & 0.0002 \\
\hline $\mid-131$ & $8.04 d$ & 231.0 & 0.00139 & 0.3211 \\
\hline $\mathrm{Xe-131m}$ & $11.90 \mathrm{~d}$ & 155.0 & 0.0641 & 9.9355 \\
\hline $\mid-132$ & $2.28 \mathrm{~h}$ & 20300.0 & 0.000396 & 8.0388 \\
\hline $\mid-133$ & $20.80 h$ & 1200.0 & 0.00111 & 1.332 \\
\hline $\mathrm{Xe}-133 \mathrm{~m}$ & $2.19 \mathrm{~d}$ & 41.5 & 0.0124 & 0.5146 \\
\hline Xe-133 & $5.24 d$ & 822.0 & 0.0293 & 24.0846 \\
\hline $\mid-134$ & $52.60 \mathrm{~m}$ & 2280.0 & 0.000183 & 0.4172 \\
\hline $\mid-135$ & $6.57 h$ & 1100.0 & 0.000751 & 0.8261 \\
\hline $\mathrm{Xe}-135$ & $9.10 \mathrm{~h}$ & 911.0 & 0.00218 & 1.986 \\
\hline $\begin{array}{l}\text { TOTAL } \\
\text { (Rounded) }\end{array}$ & & 28873.5 & & 48.48 \\
\hline
\end{tabular}


Table E-3. ACRR High Bay Release Rates for a Leaking Fuel Element Following a 25kW, 5-Yr Irradiation

\begin{tabular}{|c|c|c|c|c|}
\hline Isotope & Half Life & $\begin{array}{c}\text { Activity Released } \\
\text { to Pool (Ci) }\end{array}$ & $\begin{array}{c}\text { Release Fraction } \\
\qquad\left(R / S_{i}\right)\end{array}$ & Stack Release (Ci) \\
\hline $\mathrm{Br}-82$ & $1.47 \mathrm{~d}$ & 0.863 & 0.00123 & 0.0011 \\
\hline $\mathrm{Br}-83$ & $2.40 \mathrm{~h}$ & 76.1 & 0.000411 & 0.0313 \\
\hline $\mathrm{Kr}-83 \mathrm{~m}$ & $1.86 h$ & 170.0 & 0.000446 & 0.0758 \\
\hline $\mathrm{Br}-84$ & $30.80 \mathrm{~m}$ & 148.0 & 0.000117 & 0.0173 \\
\hline $\mathrm{Kr}-85 \mathrm{~m}$ & $4.48 h$ & 171.0 & 0.00107 & 0.183 \\
\hline $\mathrm{Kr}-85$ & $10.73 y$ & 14.4 & 0.958 & 13.7952 \\
\hline $\mathrm{Kr}-87$ & $1.27 \mathrm{~h}$ & 347.0 & 0.000304 & 0.1055 \\
\hline $\mathrm{Kr}-88$ & $2.84 \mathrm{~h}$ & 483.0 & 0.000680 & 0.3284 \\
\hline $\mid-130$ & $12.36 \mathrm{~h}$ & 12.7 & 0.000967 & 0.0123 \\
\hline $\mid-131$ & $8.04 d$ & 398.0 & 0.00139 & 0.5532 \\
\hline $\mathrm{Xe-131m}$ & $11.90 \mathrm{~d}$ & 272.0 & 0.0641 & 17.4352 \\
\hline $\mid-132$ & $2.28 \mathrm{~h}$ & 20300.0 & 0.000396 & 8.0388 \\
\hline $1-133$ & $20.80 \mathrm{~h}$ & 937.0 & 0.00111 & 1.0401 \\
\hline $\mathrm{Xe}-133 \mathrm{~m}$ & $2.19 d$ & 37.1 & 0.0124 & 0.46 \\
\hline$X e-133$ & $5.24 d$ & 1080.0 & 0.0293 & 31.644 \\
\hline $1-134$ & $52.60 \mathrm{~m}$ & 1760.0 & 0.000183 & 0.3221 \\
\hline $\mid-135$ & $6.57 \mathrm{~h}$ & 853.0 & 0.000751 & 0.6406 \\
\hline$X e-135$ & $9.10 \mathrm{~h}$ & 894.0 & 0.00218 & 1.9489 \\
\hline $\begin{array}{l}\text { TOTAL } \\
\text { (Rounded) }\end{array}$ & & 27954.1 & & 76.63 \\
\hline
\end{tabular}


Table E-4. Downwind Dose Estimates for a Leaking Target

\begin{tabular}{|c|c|c|c|c|c|c|}
\hline \multirow[b]{2}{*}{ Isotope } & \multirow[b]{2}{*}{ Stack Release (Ci) } & \multicolumn{5}{|c|}{ Dose Rate (mrem) } \\
\hline & & $300 \mathrm{~m}$ & $1610 \mathrm{~m}$ & $3000 \mathrm{~m}$ & $6000 \mathrm{~m}$ & $20000 \mathrm{~m}$ \\
\hline Br-82 & 0.0004 & 3.49E-7 & $1.24 \mathrm{E}-7$ & $5.46 \mathrm{E}-8$ & 2.15E-8 & 4.00E-9 \\
\hline $\mathrm{Br}-83$ & 0.0409 & $2.53 \mathrm{E}-7$ & 8.58E-8 & $3.56 \mathrm{E}-8$ & 1.19E-8 & 1.10E-9 \\
\hline $\mathrm{Kr}-83 \mathrm{~m}$ & 0.099 & $1.48 \mathrm{E}-8$ & $5.15 E-9$ & 2.18E-9 & $7.42 E-10$ & 7.42E-11 \\
\hline $\mathrm{Br}-84$ & 0.0227 & $3.18 E-5$ & 8.17E-6 & 2.72E-6 & $5.67 E-7$ & 2.13E-8 \\
\hline $\mathrm{Kr}-85 \mathrm{~m}$ & 0.2408 & $2.66 \mathrm{E}-5$ & $9.42 E-6$ & 4.35E-6 & $1.62 E-6$ & 2.66E-7 \\
\hline $\mathrm{Kr}-85$ & 0.0544 & $1.20 \mathrm{E}-7$ & $4.57 E-8$ & $2.17 E-8$ & $9.24 E-9$ & 2.17E-9 \\
\hline Kr-87 & 0.1386 & $8.19 \mathrm{E}-5$ & $2.64 \mathrm{E}-5$ & $1.08 \mathrm{E}-5$ & $3.33 E-6$ & $2.64 \mathrm{E}-7$ \\
\hline $\mathrm{Kr}-88$ & 0.4325 & $6.49 \mathrm{E}-4$ & $2.34 \mathrm{E}-4$ & $1.04 \mathrm{E}-4$ & $3.72 \mathrm{E}-5$ & $4.76 \mathrm{E}-6$ \\
\hline $1-130$ & 0.0002 & $6.35 E-6$ & $1.49 \mathrm{E}-6$ & $3.36 \mathrm{E}-7$ & $4.30 E-8$ & $1.83 E-9$ \\
\hline $\mid-131$ & 0.3211 & $3.86 \mathrm{E}-2$ & $9.33 \mathrm{E}-3$ & $2.12 \mathrm{E}-3$ & $2.70 E-4$ & $1.22 \mathrm{E}-5$ \\
\hline$X e-131 m$ & 9.9355 & 6.37E-5 & $2.39 E-5$ & $1.10 E-5$ & $4.78 \mathrm{E}-6$ & $1.10 \mathrm{E}-6$ \\
\hline $1-132$ & 8.0388 & $6.20 \mathrm{E}-2$ & $1.37 \mathrm{E}-2$ & $2.90 \mathrm{E}-3$ & $3.38 \mathrm{E}-4$ & $1.13 E-5$ \\
\hline $1-133$ & 1.332 & $2.82 \mathrm{E}-2$ & $6.58 \mathrm{E}-3$ & $1.48 \mathrm{E}-3$ & $1.88 \mathrm{E}-4$ & $8.32 \mathrm{E}-6$ \\
\hline$X e-133 m$ & 0.5146 & $1.09 E-5$ & $4.03 E-6$ & $1.86 \mathrm{E}-6$ & $7.75 E-7$ & $1.81 \mathrm{E}-7$ \\
\hline$X e-133$ & 24.0846 & $5.78 E-4$ & $2.14 \mathrm{E}-4$ & $1.01 \mathrm{E}-1$ & 4.33E-5 & 9.87E-6 \\
\hline I-134 & 0.4172 & $1.80 \mathrm{E}-3$ & $3.48 \mathrm{E}-4$ & $6.7-E-5$ & $7.12 \mathrm{E}-6$ & 1.67E-7 \\
\hline $1-135$ & 0.8261 & $1.08 \mathrm{E}-2$ & $2.49 E-3$ & $5.72 E-4$ & $6.96 \mathrm{E}-5$ & $2.82 E-6$ \\
\hline $\mathrm{Xe}-135$ & 1.986 & $3.37 E-4$ & $1.23 E-4$ & $\underline{5.55 \mathrm{E}-5}$ & $2.18 \mathrm{E}-5$ & 4.36E-6 \\
\hline $\begin{array}{l}\text { TOTAL } \\
\text { (Rounded) }\end{array}$ & 48.48 & $1.43 E-1$ & 3.31E-2 & 7.43E-3 & $9.86 \mathrm{E}-4$ & $5.56 \mathrm{E}-5$ \\
\hline
\end{tabular}


Table E-5. Downwind Dose Estimates for a Leaking Fuel Element

Dose Rate (mrem)

$\begin{array}{lcccccc}\text { Isotepe } & \text { Stack Release (Ci) } & \underline{300 \mathrm{~m}} & 1610 \mathrm{~m} & \mathbf{3 0 0 0 \mathrm { m }} & 6000 \mathrm{~m} & 20000 \mathrm{~m} \\ \mathrm{Br}-82 & 0.0011 & 1.02 \mathrm{E}-5 & 3.60 \mathrm{E}-6 & 1.59 \mathrm{E}-6 & 6.25 \mathrm{E}-7 & 1.17 \mathrm{E}-7 \\ \mathrm{Br}-83 & 0.0313 & 1.94 \mathrm{E}-7 & 6.56 \mathrm{E}-8 & 2.72 \mathrm{E}-8 & 9.06 \mathrm{E}-9 & 8.44 \mathrm{E}-10 \\ \mathrm{Kr}-83 \mathrm{~m} & 0.0758 & 1.13 \mathrm{E}-8 & 3.93 \mathrm{E}-9 & 1.66 \mathrm{E}-9 & 5.67 \mathrm{E}-10 & 5.67 \mathrm{E}-11 \\ \mathrm{Br}-84 & 0.0173 & 2.42 \mathrm{E}-5 & 6.22 \mathrm{E}-6 & 2.07 \mathrm{E}-6 & 4.32 \mathrm{E}-7 & 1.62 \mathrm{E}-8 \\ \mathrm{Kr}-85 \mathrm{~m} & 0.183 & 2.02 \mathrm{E}-5 & 7.18 \mathrm{E}-6 & 3.31 \mathrm{E}-6 & 1.23 \mathrm{E}-6 & 2.02 \mathrm{E}-7 \\ \mathrm{Kr}-85 & 13.7952 & 3.03 \mathrm{E}-5 & 1.16 \mathrm{E}-5 & 5.51 \mathrm{E}-6 & 2.34 \mathrm{E}-6 & 5.51 \mathrm{E}-7 \\ \mathrm{Kr}-87 & 0.1055 & 6.22 \mathrm{E}-5 & 2.00 \mathrm{E}-5 & 8.23 \mathrm{E}-6 & 2.53 \mathrm{E}-6 & 2.00 \mathrm{E}-7 \\ \mathrm{Kr}-88 & 0.3284 & 4.93 \mathrm{E}-4 & 1.78 \mathrm{E}-4 & 7.89 \mathrm{E}-5 & 2.83 \mathrm{E}-5 & 3.62 \mathrm{E}-6 \\ \mathrm{I}-130 & 0.0123 & 4.16 \mathrm{E}-4 & 9.80 \mathrm{E}-5 & 2.20 \mathrm{E}-5 & 2.82 \mathrm{E}-6 & 1.20 \mathrm{E}-7 \\ \mathrm{I}-131 & 0.5532 & 6.66 \mathrm{E}-2 & 1.61 \mathrm{E}-2 & 3.66 \mathrm{E}-3 & 4.66 \mathrm{E}-4 & 2.11 \mathrm{E}-5 \\ \mathrm{Xe}-131 \mathrm{~m} & 17.4352 & 1.11 \mathrm{E}-4 & 4.18 \mathrm{E}-5 & 1.91 \mathrm{E}-5 & 8.35 \mathrm{E}-6 & 1.91 \mathrm{E}-6 \\ \mathrm{I}-132 & 8.0388 & 6.20 \mathrm{E}-2 & 1.37 \mathrm{E}-2 & 2.90 \mathrm{E}-3 & 3.38 \mathrm{E}-4 & 1.13 \mathrm{E}-5 \\ \mathrm{I}-133 & 1.0401 & 2.19 \mathrm{E}-2 & 5.12 \mathrm{E}-3 & 1.15 \mathrm{E}-3 & 1.46 \mathrm{E}-4 & 6.48 \mathrm{E}-6 \\ \mathrm{Xe}-133 \mathrm{~m} & 0.46 & 9.69 \mathrm{E}-6 & 3.60 \mathrm{E}-6 & 1.66 \mathrm{E}-6 & 6.92 \mathrm{E}-7 & 1.61 \mathrm{E}-7 \\ \mathrm{Xe}-133 & 31.644 & 7.58 \mathrm{E}-4 & 2.81 \mathrm{E}-4 & 1.33 \mathrm{E}-4 & 5.68 \mathrm{E}-5 & 1.29 \mathrm{E}-5 \\ \mathrm{I}-134 & 0.3221 & 1.39 \mathrm{E}-3 & 2.67 \mathrm{E}-4 & 5.15 \mathrm{E}-5 & 5.48 \mathrm{E}-6 & 1.29 \mathrm{E}-7 \\ \mathrm{I}-135 & 0.6406 & 8.33 \mathrm{E}-3 & 1.92 \mathrm{E}-3 & 4.42 \mathrm{E}-4 & 5.38 \mathrm{E}-5 & 2.18 \mathrm{E}-6 \\ \mathrm{Xe}-135 & 1.9489 & 3.31 \mathrm{E}-4 & 1.21 \mathrm{E}-4 & 5.45 \mathrm{E}-5 & 2.14 \mathrm{E}-5 & 4.28 \mathrm{E}-6 \\ \mathrm{TOTAL} & 76.63 & 1.63 \mathrm{E}-1 & 3.79 \mathrm{E}-2 & 8.53 \mathrm{E}-3 & 1.14 \mathrm{E}-3 & 6.53 \mathrm{E}-5\end{array}$

(Rounded) 


\section{APPENDIX F}

ANALYSIS AND CONSEQUENCES, ACRR DESIGN BASIS ACCIDENT 


\section{APPENDIX F \\ ANALYSIS AND CONSEQUENCES, ACRR DESIGN BASIS ACCIDENT}

Appendix F presents an evaluation of the Limiting Event (most severe accident) for the ACRR. It should be noted that physical modifications of the reactor to convert it to ${ }^{99} \mathrm{Mo}$ production eliminate both sources of reactivity required to initiate such an event. First, the central cavity will be removed and replaced with a target grid; this eliminates the large negative worth experiment scenario. Second, the transient rods will be removed or their transient drive mechanism removed or disabled; this eliminates the possibility of large, very rapid additions of reactivity.

\section{F.1 Limiting Event}

\section{F.1.1 Overview and Assumptions}

The accident mode analyzed in this section is a reactivity driven event wherein $\$ 10.25$ of reactivity is inserted over a time frame of 80 milliseconds. This accident is defined as the Limiting Event (most severe accident).

This initiating event represents a bounding case for postulated credible accidents, and since it requires the addition of reactivity by the transient rods coupled to an unplanned removal of a large negative worth experiment in the same time frame, this accident can be considered as the Design Basis Accident. An adiabatic analysis is used to calculate the energy deposition and temperature of the fuel material as a function of reactivity insertion. The downwind dose consequences are evaluated using the fission products in the fuel material as the source term. It is further assumed the fission products in the portion of the fuel material exceeding the melt temperature are available for release from the fuel matrix.

\section{F.1.2 Results}

The Limiting Event for the reactor is based on a reactivity insertion of $\$ 10.25$ over a time frame of 80 milliseconds. The scenario of events leading to the insertion of reactivity is not based on the failure of a reactivity control system or violation of prescribed procedures. The accident is assumed to occur without regard to some initial trigger event.

Total reactivity is a combination of reactivity inserted by withdrawal of the transient rod bank and supplemented by the removal of a negative worth experiment. The absolute reactivity value of each component is not defined for purposes of the calculation; however, the typical reactivity worth value for the transient rod bank is $\$ 6$ or less, which in turn restricts the value of the experiment. The results for the insertion of $\$ 10.25$ are shown in Table F-1.

These results are based on a PK1D code (Pickard, 1978) modified to include reactivity feedback and verified against reactor experimental data for measured insertion time, maximum measured fuel temperature, and reactor power. The dose consequences shown are for selected locations representing on-site and off-site. A summary of dose consequences, which shows dose reduction factors, is provided at the end of this appendix.

Table F-1 shows that the Whole Body dose to off-site personnel from this source (accident) is $3.74 \times 10^{-5}$ Sieverts, or $3.74 \times 10^{-3}$ rem $\sim 4$ mrem; refer to Tables F-2 through F-5 for additional data. This is orders of magnitude below the 25 Rem limit for accident siting criteria, e.g., in 10 CFR 100. That being the case, SNLINM's operating envelope for this study is any operation (and associated "beyond design basis accident" scenario/source) whose dose consequence, as evaluated by these or similar techniques, is $<40 \mathrm{mrem}$ (whole body) above background to an individual at the exclusion area boundary. 
This allows latitude for SNLNM to (1) evaluate other operational/accident scenarios, such as continuous operation for 30 days followed by a pulse of $850 \mathrm{MJ}$ (or less), and (2) demonstrate to the Sandia Independent Review and Appraisal System (SIRAS) that such operations (and associated accident scenarios) are within the approved operating envelope and do not result in an "unreviewed safety question" (USQ). All USQ determinations are reviewed by the SIRAS.

The primary reason that the consequence of this limiting event accident is significantly less than the criteria is the fact that the ACRR fission product inventory is relatively low compared to power reactors, even assuming an extremely busy operating history. Other assumptions used in analyzing this accident sequence are equally conservative based on technical data, engineering judgment, and/or actual performance data. Assumed release fractions may be uncertain due to an inadequate data base for transient overpower (TOP) conditions; however, conservative values are assumed in the analysis. The overall influence of these uncertainties on the net result is insignificant because the calculated consequences are orders of magnitude less than the accident siting criteria.

\section{F-2 DCELE}

The results of dose consequences shown in this section are based on the statistical operating history coupled with dose consequence calculations (Restrepo, 1992).

\section{F.2.1. Source Term}

These operational assumptions represent a base line for determining the fission product inventory in the core and are based on the actual operating history of the reactor for the longterm irradiation and on conservative estimates for the short-term (i.e., 8 days at $2 \mathrm{MW}$ ) and the single pulse of $850 \mathrm{MJ}$. The $850 \mathrm{MJ}$ pulse (i.e., $\$ 10.25$ ) is not possible under present conditions but is postulated to be the most limiting operating event for purposes of accident evaluation.

The ORIGEN2 PC (Bennett, 1979) and the FISSP (Bonzon, 1970) computer codes are used to estimate the radionuclide inventory in the fuel. The ORIGEN2 PC code is unable to model pulses; therefore, the FISSP code is used to extrapolate the results of ORIGEN to pulses based on the results of a benchmark case which evaluates these two codes using similar input data. Input to ORIGEN2 PC includes the following:

1. The operational history is as follows:

a. Continuous operation of the reactor for an operational life expectancy of 30 years at an average of 363,892 MJ per operational year (260 days/year at 8 hours/day). The $363,892 \mathrm{MJ}$ represents the average operational annual energy released beginning from 1979 (the year the ACRR started operations) to 1989.

b. Followed by a continuous operation for eight days at maximum full power operation of $2 \mathrm{MW}$. The historical maximum energy released during an eightoperational period is $76,948 \mathrm{MJ}$, from 12 October 1983 to 23 October 1983 . The nature of the experiments performed in the ACRR indicate that operations lasting one hour are routine, with the longest irradiation time on record being about 57 hours at less than full power

c. Followed by a single $850 \mathrm{MJ}$ pulse. 
TABLE F-1

CALCULATED RESULTS FOR \$10.25 REACTIVITY INSERTION

\begin{tabular}{|c|c|}
\hline $\begin{array}{l}\text { Reactor Power and Yield } \\
\text { Peak Power } \\
\text { Yield }\end{array}$ & $\begin{array}{l}3.05 \times 10^{5} \mathrm{MW} \\
860 \mathrm{MJ}\end{array}$ \\
\hline $\begin{array}{l}\text { Core Energy Deposition } \\
\qquad \text { Average } \\
\text { Peak }\end{array}$ & $\begin{array}{l}2390 \mathrm{~J} / \mathrm{G} \\
4254 \mathrm{~J} / \mathrm{G}\end{array}$ \\
\hline $\begin{array}{l}\text { Estimated Liquid Fuel Material/Clad } \\
\text { Fuel Material } \\
\text { Fuel Cladding }\end{array}$ & $\begin{array}{r}6.4 \mathrm{~kg} \\
23.8 \mathrm{~kg}\end{array}$ \\
\hline $\begin{array}{l}\text { Dose to On-site Personnel@ }<0.1 \mathrm{~km} \\
\text { Lungs } \\
\text { Thyroid } \\
\text { Whole Body }\end{array}$ & $\begin{array}{l}2.03 \times 10^{-4} \mathrm{~Sv} \\
2.51 \times 10^{-4} \mathrm{~Sv} \\
2.02 \times 10^{-4} \mathrm{~Sv}\end{array}$ \\
\hline $\begin{array}{l}\text { Dose to On-site Personnel@ } 3.1 \mathrm{~km} \\
\text { Lungs } \\
\text { Thyroid } \\
\text { Whole Body }\end{array}$ & $\begin{array}{l}3.08 \times 10^{-5} \mathrm{~Sv} \\
5.57 \times 10^{-5} \mathrm{~Sv} \\
3.74 \times 10^{-5} \mathrm{~Sv}\end{array}$ \\
\hline $\begin{array}{l}\text { Dose to Off-site Personnel @ 6.0 km } \\
\text { Lungs } \\
\text { Thyroid } \\
\text { Whole Body }\end{array}$ & $\begin{array}{l}1.20 \times 10^{-5} \mathrm{~Sv} \\
1.54 \times 10^{-5} \mathrm{~Sv} \\
1.11 \times 10^{-5} \mathrm{~Sv}\end{array}$ \\
\hline
\end{tabular}

Note: To convert Sieverts to Rems multiply by 100 
The continuous operation values (a. and b.) are based on the 12 years of actual operating history of the reactor. The $850 \mathrm{MJ}$ pulse, which requires a reactivity input of $\$ 10.25$, is assumed to be the maximum yield possible for a single pulse. Thus, for purposes of analysis this represents the limiting operational pulse for this facility. Fission product inventories for other types of accident scenarios can be determined in the same way in which the fission product inventory for this limiting event is evaluated. As an alternative, the inventory for other events can be scaled to this inventory.

2. The initial nuclide inventory is based on the original analytical data from the manufacturer on the isotopic and spectographic analysis (composition) of uranium isotopes and impurities in the fuel (Bowen, 1976). The core is assumed to consist of 236 fuel elements, which includes the fuel followed control and safety rods. The average weight of fuel material per fuel element is $1525 \mathrm{~g}$. The total mass of fuel material in the core is 359.9 $\mathrm{kg}$, which includes $23.865 \mathrm{~kg}$ of $235 \mathrm{U}, 164 \mathrm{~g}^{234 \mathrm{U}}, 157 \mathrm{~g}$ of $236 \mathrm{U}$, and $44.019 \mathrm{~g}$ of $238 \mathrm{U}$.

3. A fuel volume of $1.03 \times 10^{5} \mathrm{~cm}^{3}$.

4. A macroscopic fission cross section of $0.368 \mathrm{~cm}^{-1}$. Density of the $\mathrm{BeO}-\mathrm{UO}_{2}$ fuel is 3.55 $\mathrm{g} / \mathrm{cm}^{3}$.

5. Epithermal cross sections.

6. Decay and ingrowth intervals of 10 seconds, 15 minutes, 30 minutes, and 1 hour after shutdown.

\section{F.2.2 Dose Consequence}

The computer code (Restrepo, 1992) used to evaluate dose consequences is based on the following values and conditions as inputs:

1. The core inventory available for release is that at 10 seconds after the accident to simulate the averaged transit time of gases from the core to the pool surface.

2. Damage or melt fractions representing the fraction of the inventory of particulates and noble gases/halogens available for release are $3 \%$ and $48 \%$, respectively.

3. A hypothetical volume of $256 \mathrm{~m}^{3}$ representing the immediate volume around the reactor. The entire reactor bay was not included due to the possibility of having someone located close to the reactor at the time of the accident.

4. The effective ventilation decay constants for noble gases and other chemical groups (i.e., $4.9 \times 10^{-2}$ and $5.5 \times 10^{-2} \mathrm{~min}^{-1}$, respectively).

5. Release fractions for the chemical groups are from (Restrepo, 1992), Table 14.

6. In-building transport and the release fractions to the environment are from (Restrepo, 1992), Table 15. 
7. Filter factors: For this limiting accident sequence, the form and energy of the postulated release from the reactor is such that all filters are performing within their designed operating/environmental conditions. Scenarios outside these conditions could reduce filter performance, but no accident scenarios have been identified which would result in both a source term and loss of filter systems.

a. High Bay Filters.

The ACRR High Bay ventilation system and the co-located GIF ventilation system are modeled with an efficiency of $99.98 \%$, even though the acceptance criteria for HEPA filters is $99.99 \%$. The corresponding removal factor is $\mathbf{5 0 0 0}$ for a single HEPA filter and $10 \%$ efficiency for halogens and vapors (noble gases are assumed to pass unfiltered through all the ventilation filtration systems). High Bay filter factors are:

$\begin{array}{ll}5000 & \text { particulates } \\ 10 & \text { halogens } \\ 1 & \text { noble gases }\end{array}$

b. Cavity Purge Filters

The cavity purge ventilation system contains a prefilter, two HEPA filters, and two charcoal filters. The acceptance criterion for the HEPA filters is $99.99 \%$ for the first stage and $99.98 \%$ for subsequent stages for aerosols. To obtain an upper bound on releases to the environment, an efficiency of $99.98 \%$ is used for the first stage and $50 \%$ for the second stage, for an overall removal factor of 10,000 for particulates. The latter efficiency is selected based on the uncertainty of the effectiveness of filters in series. The charcoal filters are assumed to have an efficiency of $99 \%$ for each of the filters in series, leading to an overall removal factor of 10,000 for halogens. Cavity purge filter factors are:

$$
\begin{array}{ll}
10,000 & \text { particulates } \\
10,000 & \text { halogens } \\
1 & \text { noble gases }
\end{array}
$$

8. An input file identifying over 300 radionuclides, their half lives, decay constants, their location in the decay chain, their branching ratios, chemical groups, etc.

9. The initial time intervals and final times for evacuation purposes, i.e., the time when the alarms sound and the times when personnel are expected to evacuate from the reactor bay, are used to calculate the integrated concentrations and the ingrowth/decay of the radionuclides released.

10. An average decay time of $\mathbf{3 0}$ minutes in the reactor building for all radionuclides before they are released to the environment. The time for releasing over $99.9 \%$ of the radionuclides is estimated to be as long as $\mathbf{5 0 0 0}$ seconds; thus the $\mathbf{3 0}$ minutes have been selected as an average decay or delay time for conservative purposes.

11. Assumed evacuation time of personnel from the reactor room is 2 minutes.

12. No fuel/coolant interaction.

13. Weather type $F$ and $1 \mathrm{~m} / \mathrm{s}$ wind speed. 
Complete discussions of the development of the fuel inventory and building release source terms are given in Restrepo, 1992.

The Abnormal Events discussed in Section 14.2 of (Restrepo, 1992), can be evaluated against the Limiting Event dose consequences by applying a linear factor to estimate the source term. This factor is the ratio of the fission product inventory of the abnormal event to the Limiting Event. This provides a relative estimation of the change in the source term and while it may not be applicable in an absolute manner to all abnormal events the linear multiplier can be used to provide an initial assessment of the event.

TABLE F-2 CENTERLINE TOTAL LIFE COMMITMENT CONSEQUENCES FOR INDIVIDUALS AS A FUNCTION OF DISTANCE FROM THE ACRR (USES WEATHER BIN SAMPLING)

\begin{tabular}{|c|c|c|c|c|c|}
\hline \multirow[b]{2}{*}{ Distance $(\mathrm{Km})$} & \multirow[b]{2}{*}{ Ground $\times 1 Q$} & \multicolumn{4}{|c|}{ Organ Dose (Sv) } \\
\hline & & Lungs & Thyroid & R. Marrow & Whole Body \\
\hline $0.0-0.1$ & $2.28 E-4$ & $2.03 E-4$ & $2.51 E-4$ & $2.02 E-4$ & $2.02 E-4$ \\
\hline $0.1-0.5$ & $7.25 E-5$ & $1.35 \mathrm{E}-4$ & $1.46 \mathrm{E}-4$ & $1.07 E-4$ & $1.07 E-4$ \\
\hline $0.5-1.7$ & $1.36 \mathrm{E}-5$ & $7.90 \mathrm{E}-5$ & $7.90 E-5$ & $7.90 E-5$ & $5.80 E-5$ \\
\hline $1.7-3.1$ & 4.05E-6 & $3.08 \mathrm{E}-5$ & $5.57 \mathrm{E}-5$ & $3.74 E-5$ & $3.74 \mathrm{E}-5$ \\
\hline $3.1-4.0$ & $2.14 \mathrm{E}-6$ & $3.08 \mathrm{E}-5$ & $3.11 E-5$ & $3.07 \mathrm{E}-5$ & $2.38 \mathrm{E}-5$ \\
\hline $4.0-5.6$ & $1.31 E-6$ & 2.06E-5 & $2.08 E-5$ & 2.06E-5 & 2.02E-5 \\
\hline $5.6-6.0$ & $9.63 E-7$ & $1.12 \mathrm{E}-5$ & $1.54 \mathrm{E}-5$ & $1.12 E-5$ & $1.11 \mathrm{E}-5$ \\
\hline $6.0-6.4$ & $8.75 E-7$ & $1.09 \mathrm{E}-5$ & $1.14 \mathrm{E}-5$ & $1.09 E-5$ & $1.07 E-5$ \\
\hline $6.4-9.3$ & $7.54 \mathrm{E}-7$ & $9.39 E-6$ & $1.04 \mathrm{E}-5$ & $9.39 E-6$ & $9.23 \mathrm{E}-6$ \\
\hline $9.3-20.0$ & $2.21 \mathrm{E}-7$ & $3.58 \mathrm{E}-6$ & $4.01 \mathrm{E}-6$ & $3.57 \mathrm{E}-6$ & $3.38 \mathrm{E}-6$ \\
\hline
\end{tabular}

Table F-3 lists the calculated fission product inventory for the ACRR limiting event. Table F-4 lists the actinides inventory for the ACRR limiting event. Table F-5 summarizes the ACRR building concentration and dose consequences to radiation workers. 


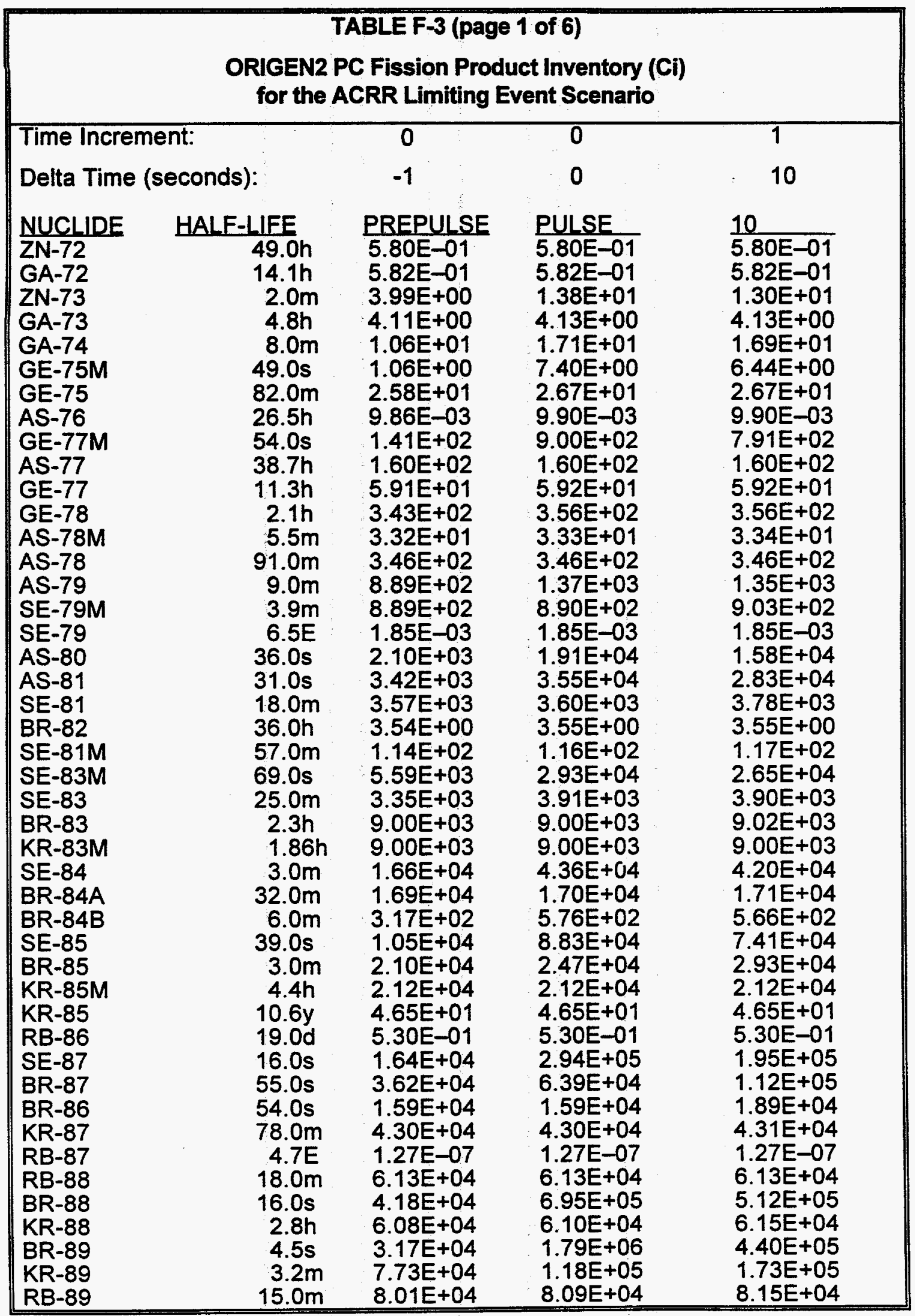




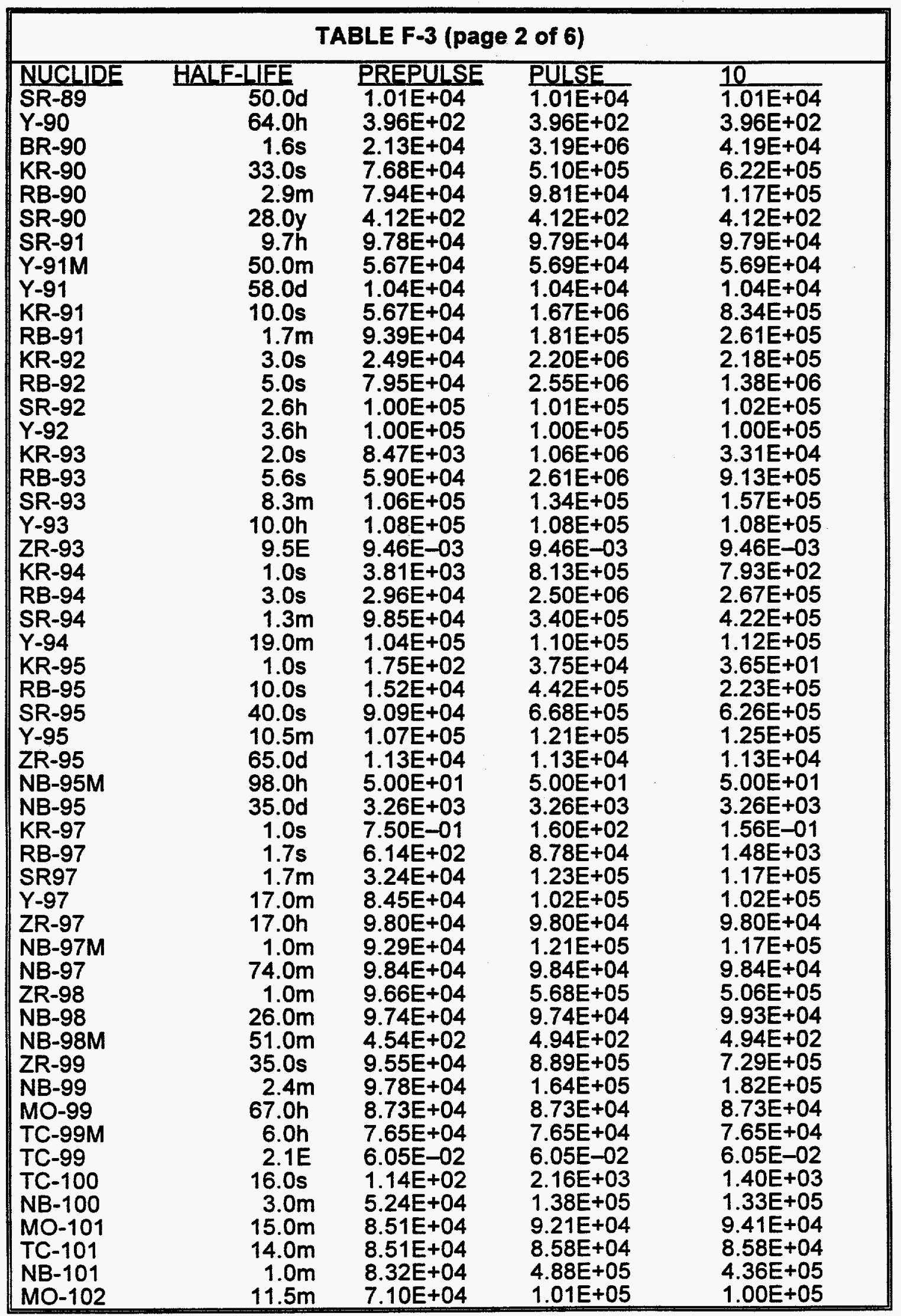




\begin{tabular}{|c|c|c|c|c|}
\hline \multicolumn{5}{|c|}{ TABLE F-3 (page 3 of 6 ) } \\
\hline $\begin{array}{l}\text { NUCLIDE } \\
\text { TC-102M } \\
\text { RB-88 } \\
\text { BR-88 } \\
\text { KR-88 } \\
\text { BR-89 } \\
\text { KR-89 } \\
\text { RB-89 } \\
\text { SR-89 } \\
\text { Y-90 } \\
\text { TC-102 } \\
\text { TC-103 } \\
\text { RU-103 } \\
\text { RH-103M } \\
\text { RH-104M } \\
\text { RH-104 } \\
\text { MO-104 } \\
\text { TC-104 } \\
\text { MO-105 } \\
\text { TC-105 } \\
\text { TC-105 } \\
\text { RH-105 } \\
\text { RH-106B } \\
\text { RH-105M } \\
\text { RU-106 } \\
\text { RH-106 } \\
\text { TC-107 } \\
\text { RU-107 } \\
\text { RH-107 } \\
\text { PD-107 } \\
\text { PD-109 } \\
\text { AG-109M } \\
\text { AG-110 } \\
\text { AG-110M } \\
\text { RH-107M } \\
\text { RU-108 } \\
\text { RH-108 } \\
\text { RH-109 } \\
\text { PD-109M } \\
\text { RH-111 } \\
\text { PD-111 } \\
\text { AG-111 } \\
\text { AG-111M } \\
\text { PD-111M } \\
\text { PD-112 } \\
\text { AG-112 } \\
\text { PD-113 } \\
\text { AG-113M } \\
\text { AG-113 } \\
\text { PD-114 } \\
\text { AG-114 } \\
\text { PD-115 } \\
\text { AG-115 }\end{array}$ & $\begin{array}{r}\text { HALF-LIFE } \\
4.5 \mathrm{~m} \\
18.0 \mathrm{~m} \\
16.0 \mathrm{~s} \\
2.8 \mathrm{~h} \\
4.5 \mathrm{~s} \\
3.2 \mathrm{~m} \\
15.0 \mathrm{~m} \\
50.0 \mathrm{~d} \\
64.0 \mathrm{~h} \\
5.0 \mathrm{~s} \\
1.2 \mathrm{~m} \\
40.0 \mathrm{~d} \\
57.0 \mathrm{~m} \\
4.4 \mathrm{~m} \\
42.0 \mathrm{~s} \\
1.6 \mathrm{~m} \\
18.0 \mathrm{~m} \\
2.0 \mathrm{~m} \\
10.0 \mathrm{~m} \\
4.4 \mathrm{~h} \\
36.0 \mathrm{~h} \\
2.2 \mathrm{~h} \\
30.0 \mathrm{~s} \\
1.0 \mathrm{y} \\
30.0 \mathrm{~s} \\
1.5 \mathrm{~m} \\
4.0 \mathrm{~m} \\
22.0 \mathrm{~m} \\
7.0 \mathrm{E} \\
14.0 \mathrm{~h} \\
40.0 \mathrm{~s} \\
24.0 \mathrm{~s} \\
253.0 \mathrm{~d} \\
10.0 \mathrm{~s} \\
4.5 \mathrm{~m} \\
17.0 \mathrm{~s} \\
25.0 \mathrm{~s} \\
4.7 \mathrm{~m} \\
0.5 \mathrm{~s} \\
22.0 \mathrm{~m} \\
7.5 \mathrm{~d} \\
1.2 \mathrm{~m} \\
5.5 \mathrm{~h} \\
21.0 \mathrm{~h} \\
3.2 \mathrm{~h} \\
1.4 \mathrm{~m} \\
1.2 \mathrm{~m} \\
5.3 \mathrm{~h} \\
24.0 \mathrm{~m} \\
5.0 \mathrm{~s} \\
45.0 \mathrm{~s} \\
21.0 \mathrm{~m}\end{array}$ & $\begin{array}{l}\text { PREPULSE } \\
2.16 E+01 \\
6.13 E+04 \\
4.18 E+04 \\
6.08 E+04 \\
3.17 E+04 \\
7.73 E+04 \\
8.01 E+04 \\
1.01 E+04 \\
3.96 E+02 \\
7.10 E+04 \\
5.29 E+04 \\
8.08 E+03 \\
7.28 E+03 \\
1.77 E+01 \\
2.38 E+02 \\
3.07 E+04 \\
3.16 E+04 \\
1.58 E+04 \\
1.74 E+04 \\
1.75 E+04 \\
1.65 E+04 \\
3.22 E+01 \\
4.89 E+03 \\
2.75 E+02 \\
3.39 E+02 \\
3.22 E+03 \\
3.30 E+03 \\
3.30 E+03 \\
6.83 E-05 \\
7.77 E+02 \\
7.76 E+02 \\
3.84 E+00 \\
8.22 E-03 \\
5.15 E+02 \\
1.58 E+03 \\
1.58 E+03 \\
7.75 E+02 \\
3.88 E+02 \\
4.53 E+02 \\
4.56 E+02 \\
2.45 E+02 \\
4.54 E+02 \\
3.90 E+00 \\
3.28 E+02 \\
3.31 E+02 \\
2.69 E+02 \\
2.71 E+01 \\
2.42 E+02 \\
2.92 E+02 \\
2.95 E+02 \\
2.64 E+02 \\
2.00 E+02 \\
\end{array}$ & $\begin{array}{l}\text { PULSE } \\
2.33 E+01 \\
6.13 E+04 \\
6.95 E+05 \\
6.10 E+04 \\
1.79 E+06 \\
1.18 E+05 \\
8.09 E+04 \\
1.01 E+04 \\
3.96 E+02 \\
7.14 E+04 \\
2.68 E+05 \\
8.08 E+03 \\
7.28 E+03 \\
3.74 E+01 \\
1.07 E+03 \\
1.24 E+05 \\
3.28 E+04 \\
5.44 E+04 \\
1.87 E+04 \\
1.75 E+04 \\
1.65 E+04 \\
3.25 E+01 \\
4.89 E+03 \\
2.75 E+02 \\
3.39 E+02 \\
1.36 E+04 \\
3.71 E+03 \\
3.30 E+03 \\
6.83 E-05 \\
7.77 E+02 \\
7.76 E+02 \\
4.83 E+01 \\
8.22 E-03 \\
5.17 E+02 \\
3.29 E+03 \\
1.61 E+03 \\
9.78 E+03 \\
3.94 E+02 \\
1.44 E+05 \\
5.02 E+02 \\
2.45 E+02 \\
4.54 E+02 \\
3.92 E+00 \\
3.30 E+02 \\
3.31 E+02 \\
1.14 E+03 \\
2.71 E+01 \\
2.42 E+02 \\
3.52 E+02 \\
2.99 E+02 \\
1.97 E+03 \\
2.00 E+02 \\
\end{array}$ & $\begin{array}{l}10 \\
2.35 E+01 \\
6.13 E+04 \\
5.12 E+05 \\
6.15 E+04 \\
4.40 E+05 \\
1.73 E+05 \\
8.15 E+04 \\
1.01 E+04 \\
3.96 E+02 \\
7.55 E+04 \\
2.43 E+05 \\
8.08 E+03 \\
7.28 E+03 \\
3.64 E+01 \\
9.43 E+02 \\
1.15 E+05 \\
3.33 E+04 \\
5.13 E+04 \\
1.91 E+04 \\
1.75 E+04 \\
1.65 E+04 \\
3.25 E+01 \\
4.89 E+03 \\
2.75 E+02 \\
3.39 E+02 \\
1.27 E+04 \\
3.95 E+03 \\
3.30 E+03 \\
6.83 E-05 \\
7.77 E+02 \\
7.76 E+02 \\
3.64 E+01 \\
8.22 E-03 \\
5.60 E+02 \\
3.21 E+03 \\
2.16 E+03 \\
7.40 E+03 \\
4.88 E+02 \\
1.38 E-01 \\
5.54 E+02 \\
2.45 E+02 \\
4.63 E+02 \\
3.95 E+00 \\
3.30 E+02 \\
3.31 E+02 \\
1.06 E+03 \\
2.71 E+01 \\
2.42 E+02 \\
3.51 E+02 \\
3.40 E+02 \\
1.68 E+03 \\
2.07 E+02\end{array}$ \\
\hline
\end{tabular}




\begin{tabular}{|c|c|c|c|c|}
\hline \multicolumn{5}{|c|}{ TABLE F-3 (page 4 of 6 ) } \\
\hline $\begin{array}{l}\text { NUCLIDE } \\
\text { CD-115 } \\
\text { IN-115M } \\
\text { IN-115 } \\
\text { IN-116 } \\
\text { AG-115M } \\
\text { CD-115M } \\
\text { AG-116 } \\
\text { AG-117 } \\
\text { CD-117 } \\
\text { IN-117 } \\
\text { CD-117B } \\
\text { IN-117M } \\
\text { CD-118 } \\
\text { IN-118 } \\
\text { SN-119M } \\
\text { IN-118B } \\
\text { CD-119B } \\
\text { IN-119M } \\
\text { IN-119 } \\
\text { IN-120 } \\
\text { IN-121 } \\
\text { SN-121 } \\
\text { SB-122 } \\
\text { SB-122M } \\
\text { IN-123 } \\
\text { SN-123M } \\
\text { SB-124 } \\
\text { TE-125M } \\
\text { SB-124A } \\
\text { SB-124B } \\
\text { SN-125 } \\
\text { SB-125 } \\
\text { SN-125M } \\
\text { SN-126 } \\
\text { SB-126M } \\
\text { SB-126 } \\
\text { SN-127 } \\
\text { SB-127 } \\
\text { TE-127 } \\
\text { I-128 } \\
T E-127 M \\
\text { SN-128 } \\
\text { SB-128 } \\
\text { TE-129 } \\
\text { SB-130A } \\
\text { SB-130B } \\
\text { SN-131A } \\
\text { SB-131 } \\
T E-131 \\
\text { I-131 } \\
\text { TE-131M }\end{array}$ & $\begin{array}{r}\text { HALF-LIFE } \\
2.3 \mathrm{~d} \\
4.5 \mathrm{~h} \\
6.0 \mathrm{E} \\
54.0 \mathrm{~m} \\
20.0 \mathrm{~s} \\
43.0 \mathrm{~d} \\
2.5 \mathrm{~m} \\
1.1 \mathrm{~m} \\
2.9 \mathrm{~h} \\
45.0 \mathrm{~m} \\
50.0 \mathrm{~m} \\
1.9 \mathrm{~h} \\
50.0 \mathrm{~m} \\
5.0 \mathrm{~s} \\
250.0 \mathrm{~d} \\
4.5 \mathrm{~m} \\
11.0 \mathrm{~m} \\
18.0 \mathrm{~m} \\
2.3 \mathrm{~m} \\
50.0 \mathrm{~s} \\
30.0 \mathrm{~s} \\
27.0 \mathrm{~h} \\
2.8 \mathrm{~d} \\
3.5 \mathrm{~m} \\
30.0 \mathrm{~s} \\
41.0 \mathrm{~m} \\
60.0 \mathrm{~d} \\
58.0 \mathrm{~d} \\
21.0 \mathrm{~m} \\
1.3 \mathrm{~m} \\
9.4 \mathrm{~d} \\
2.7 \mathrm{y} \\
9.7 \mathrm{~m} \\
1 \mathrm{Es} \mathrm{y} \\
19.0 \mathrm{~m} \\
125.0 \mathrm{~d} \\
2.6 \mathrm{~h} \\
3.7 \mathrm{~d} \\
9.3 \mathrm{~h} \\
25.0 \mathrm{~m} \\
105.0 \mathrm{~d} \\
57.0 \mathrm{~m} \\
10.0 \mathrm{~m} \\
67.0 \mathrm{~m} \\
7.1 \mathrm{~m} \\
33.0 \mathrm{~m} \\
1.6 \mathrm{~h} \\
23.0 \mathrm{~m} \\
25.0 \mathrm{~m} \\
8.1 \mathrm{~d} \\
1.2 \mathrm{~d}\end{array}$ & $\begin{array}{l}\text { PREPULSE } \\
2.33 E+02 \\
2.33 E+02 \\
3.94 E-14 \\
3.17 E+00 \\
7.69 E+01 \\
3.45 E+00 \\
1.42 E+02 \\
5.62 E+01 \\
7.32 E+01 \\
6.73 E+01 \\
3.94 E+01 \\
8.54 E+01 \\
3.08 E+02 \\
3.08 E+02 \\
1.94 E-01 \\
6.73 E-02 \\
1.45 E+02 \\
2.18 E+02 \\
8.40 E+01 \\
1.52 E+02 \\
2.45 E+02 \\
3.10 E+02 \\
1.87 E-01 \\
2.66 E-03 \\
2.56 E+02 \\
3.04 E+02 \\
3.78 E-02 \\
3.21 E+00 \\
1.00 E-01 \\
4.63 E-02 \\
1.19 E+02 \\
1.61 E+01 \\
4.09 E+02 \\
1.65 E-03 \\
7.93 E+00 \\
6.31 E+00 \\
1.72 E+03 \\
2.04 E+03 \\
1.78 E+03 \\
1.79 E+00 \\
1.76 E+01 \\
6.22 E+03 \\
2.67 E+02 \\
1.05 E+04 \\
2.09 E+04 \\
2.97 E+04 \\
1.19 E+04 \\
4.31 E+04 \\
4.34 E+04 \\
2.40 E+04 \\
6.03 E+03 \\
\end{array}$ & $\begin{array}{l}\text { PULSE } \\
2.33 E+02 \\
2.33 E+02 \\
3.94 E-14 \\
3.45 E+00 \\
8.55 E+01 \\
3.45 E+00 \\
4.21 E+02 \\
3.05 E+02 \\
7.33 E+01 \\
6.73 E+01 \\
3.96 E+01 \\
8.54 E+01 \\
3.38 E+02 \\
3.10 E+02 \\
1.94 E-01 \\
1.40 E-01 \\
2.09 E+02 \\
2.18 E+02 \\
8.44 E+01 \\
1.03 E+03 \\
2.62 E+03 \\
3.10 E+02 \\
1.87 E-01 \\
6.40 E-03 \\
5.47 E+04 \\
3.15 E+02 \\
3.78 E-02 \\
3.21 E+00 \\
1.24 E-01 \\
2.20 E-01 \\
1.19 E+02 \\
1.61 E+01 \\
6.15 E+02 \\
1.65 E-03 \\
7.93 E+00 \\
6.31 E+00 \\
1.77 E+03 \\
2.04 E+03 \\
1.78 E+03 \\
2.14 E+00 \\
1.76 E+01 \\
6.75 E+03 \\
3.01 E+02 \\
1.05 E+04 \\
2.67 E+04 \\
3.15 E+04 \\
1.25 E+04 \\
4.75 E+04 \\
4.60 E+04 \\
2.40 E+04 \\
6.03 E+03\end{array}$ & $\begin{array}{l}10 \\
2.33 E+02 \\
2.33 E+02 \\
3.94 E-14 \\
3.45 E+00 \\
2.16 E+02 \\
3.45 E+00 \\
4.02 E+02 \\
2.75 E+02 \\
7.34 E+01 \\
6.73 E+01 \\
3.99 E+01 \\
8.54 E+01 \\
3.37 E+02 \\
3.30 E+02 \\
1.94 E-01 \\
1.37 E-01 \\
2.08 E+02 \\
2.19 E+02 \\
8.59 E+01 \\
9.01 E+02 \\
2.08 E+03 \\
3.12 E+02 \\
1.87 E-01 \\
6.18 E-03 \\
5.35 E+01 \\
3.40 E+02 \\
3.78 E-02 \\
3.21 E+00 \\
1.23 E-01 \\
2.01 E-01 \\
1.19 E+02 \\
1.61 E+01 \\
6.07 E+02 \\
1.65 E-03 \\
7.93 E+00 \\
6.31 E+00 \\
1.77 E+03 \\
2.04 E+03 \\
1.78 E+03 \\
2.12 E+00 \\
1.76 E+01 \\
6.73 E+03 \\
3.00 E+02 \\
1.05 E+04 \\
2.69 E+04 \\
3.16 E+04 \\
1.25 E+04 \\
4.75 E+04 \\
4.60 E+04 \\
2.40 E+04 \\
6.03 E+03\end{array}$ \\
\hline
\end{tabular}




\begin{tabular}{|c|c|c|c|c|}
\hline \multicolumn{5}{|c|}{ TABLE F-3 (page 5 of 6 ) } \\
\hline 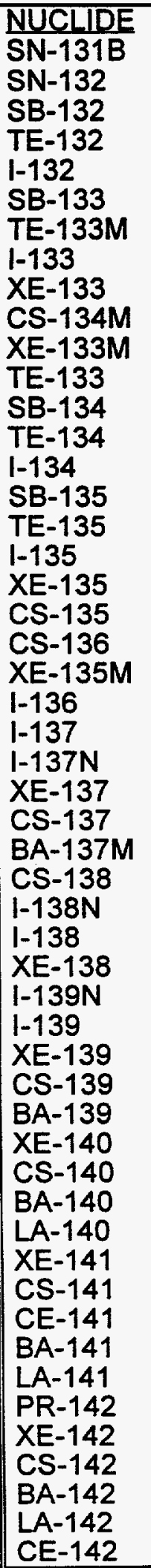 & $\begin{array}{r}\text { HALFLIFE } \\
3.4 \mathrm{~m} \\
2.2 \mathrm{~m} \\
2.1 \mathrm{~m} \\
78.0 \mathrm{~h} \\
2.3 \mathrm{~h} \\
4.1 \mathrm{~m} \\
53.0 \mathrm{~m} \\
21.0 \mathrm{~h} \\
5.3 \mathrm{~d} \\
2.9 \mathrm{~h} \\
2.3 \mathrm{~d} \\
2.0 \mathrm{~m} \\
48.0 \mathrm{~s} \\
42.0 \mathrm{~m} \\
53.0 \mathrm{~m} \\
24.0 \mathrm{~s} \\
1.4 \mathrm{~m} \\
6.7 \mathrm{~h} \\
9.1 \mathrm{~h} \\
2.0 \mathrm{E} \\
13.0 \mathrm{~d} \\
16.0 \mathrm{~m} \\
83.0 \mathrm{~s} \\
24.0 \mathrm{~s} \\
24.0 \mathrm{~s} \\
3.9 \mathrm{~m} \\
30.0 \mathrm{y} \\
2.6 \mathrm{~m} \\
32.0 \mathrm{~m} \\
6.0 \mathrm{~s} \\
6.0 \mathrm{~s} \\
17.0 \mathrm{~m} \\
2.0 \mathrm{~s} \\
2.0 \mathrm{~s} \\
41.0 \mathrm{~s} \\
9.5 \mathrm{~m} \\
85.0 \mathrm{~m} \\
16.0 \mathrm{~s} \\
66.0 \mathrm{~s} \\
13.0 \mathrm{~d} \\
40.0 \mathrm{~h} \\
2.0 \mathrm{~s} \\
18.0 \mathrm{~s} \\
33.0 \mathrm{~d} \\
18.0 \mathrm{~m} \\
3.8 \mathrm{~h} \\
19.3 \mathrm{~h} \\
1.5 \mathrm{~s} \\
1.0 \mathrm{~m} \\
11.0 \mathrm{~m} \\
85.0 \mathrm{~m} \\
5 \mathrm{E} 15 \\
\end{array}$ & $\begin{array}{l}\text { PREPULSE } \\
1.19 E+04 \\
9.97 E+03 \\
2.80 E+04 \\
5.89 E+04 \\
5.93 E+04 \\
3.77 E+04 \\
4.89 E+04 \\
1.12 E+05 \\
6.62 E+04 \\
1.54 E+01 \\
2.87 E+03 \\
6.53 E+04 \\
4.56 E+03 \\
1.13 E+05 \\
1.28 E+05 \\
3.32 E+03 \\
5.51 E+04 \\
1.05 E+05 \\
8.87 E+04 \\
6.21 E-03 \\
5.47 E+01 \\
1.90 E+04 \\
5.13 E+04 \\
5.46 E+04 \\
3.19 E+03 \\
1.00 E+05 \\
4.29 E+02 \\
4.10 E+02 \\
1.13 E+05 \\
1.59 E+03 \\
2.78 E+04 \\
1.05 E+05 \\
1.60 E+03 \\
1.24 E+04 \\
8.50 E+04 \\
1.07 E+05 \\
1.08 E+05 \\
5.96 E+04 \\
9.68 E+04 \\
3.83 E+04 \\
2.90 E+04 \\
1.99 E+04 \\
7.41 E+04 \\
1.70 E+04 \\
9.85 E+04 \\
9.88 E+04 \\
2.17 E+01 \\
6.44 E+03 \\
4.75 E+04 \\
9.67 E+04 \\
1.03 E+05 \\
2.77 E-12 \\
\end{array}$ & $\begin{array}{l}\text { PULSE } \\
2.89 E+04 \\
3.21 E+04 \\
6.72 E+04 \\
5.89 E+04 \\
5.93 E+04 \\
8.28 E+04 \\
5.07 E+04 \\
1.12 E+05 \\
6.62 E+04 \\
1.58 E+01 \\
2.87 E+03 \\
6.55 E+04 \\
3.23 E+04 \\
1.19 E+05 \\
1.29 E+05 \\
4.36 E+04 \\
1.87 E+05 \\
1.06 E+05 \\
8.94 E+04 \\
6.21 E-03 \\
5.49 E+01 \\
1.90 E+04 \\
2.22 E+05 \\
6.90 E+05 \\
4.18 E+04 \\
1.35 E+05 \\
4.29 E+02 \\
4.10 E+02 \\
1.14 E+05 \\
7.53 E+04 \\
1.28 E+06 \\
1.17 E+05 \\
2.00 E+05 \\
1.55 E+06 \\
4.74 E+05 \\
1.17 E+05 \\
1.08 E+05 \\
1.13 E+06 \\
2.74 E+05 \\
3.83 E+04 \\
2.90 E+04 \\
2.50 E+06 \\
8.59 E+05 \\
1.70 E+04 \\
1.04 E+05 \\
9.88 E+04 \\
2.17 E+01 \\
1.02 E+06 \\
2.57 E+05 \\
1.15 E+05 \\
1.03 E+05 \\
2.77 E-12 \\
\end{array}$ & $\begin{array}{l}10 \\
2.80 E+04 \\
3.04 E+04 \\
6.54 E+04 \\
5.89 E+04 \\
5.93 E+04 \\
8.02 E+04 \\
5.07 E+04 \\
1.12 E+05 \\
6.62 E+04 \\
1.58 E+01 \\
2.87 E+03 \\
6.84 E+04 \\
2.80 E+04 \\
1.20 E+05 \\
1.29 E+05 \\
3.26 E+04 \\
1.88 E+05 \\
1.06 E+05 \\
8.94 E+04 \\
6.21 E-03 \\
5.49 E+01 \\
1.90 E+04 \\
2.07 E+05 \\
5.31 E+05 \\
3.13 E+04 \\
1.55 E+05 \\
4.29 E+02 \\
4.10 E+02 \\
1.14 E+05 \\
2.37 E+04 \\
4.18 E+05 \\
1.29 E+05 \\
6.25 E+03 \\
4.82 E+04 \\
5.87 E+05 \\
1.23 E+05 \\
1.08 E+05 \\
7.33 E+05 \\
3.35 E+05 \\
3.83 E+04 \\
2.90 E+04 \\
7.80 E+04 \\
8.86 E+05 \\
1.70 E+04 \\
1.10 E+05 \\
9.88 E+04 \\
2.17 E+01 \\
1.00 E+04 \\
2.50 E+05 \\
1.18 E+05 \\
1.03 E+05 \\
2.77 E-12 \\
\end{array}$ \\
\hline
\end{tabular}




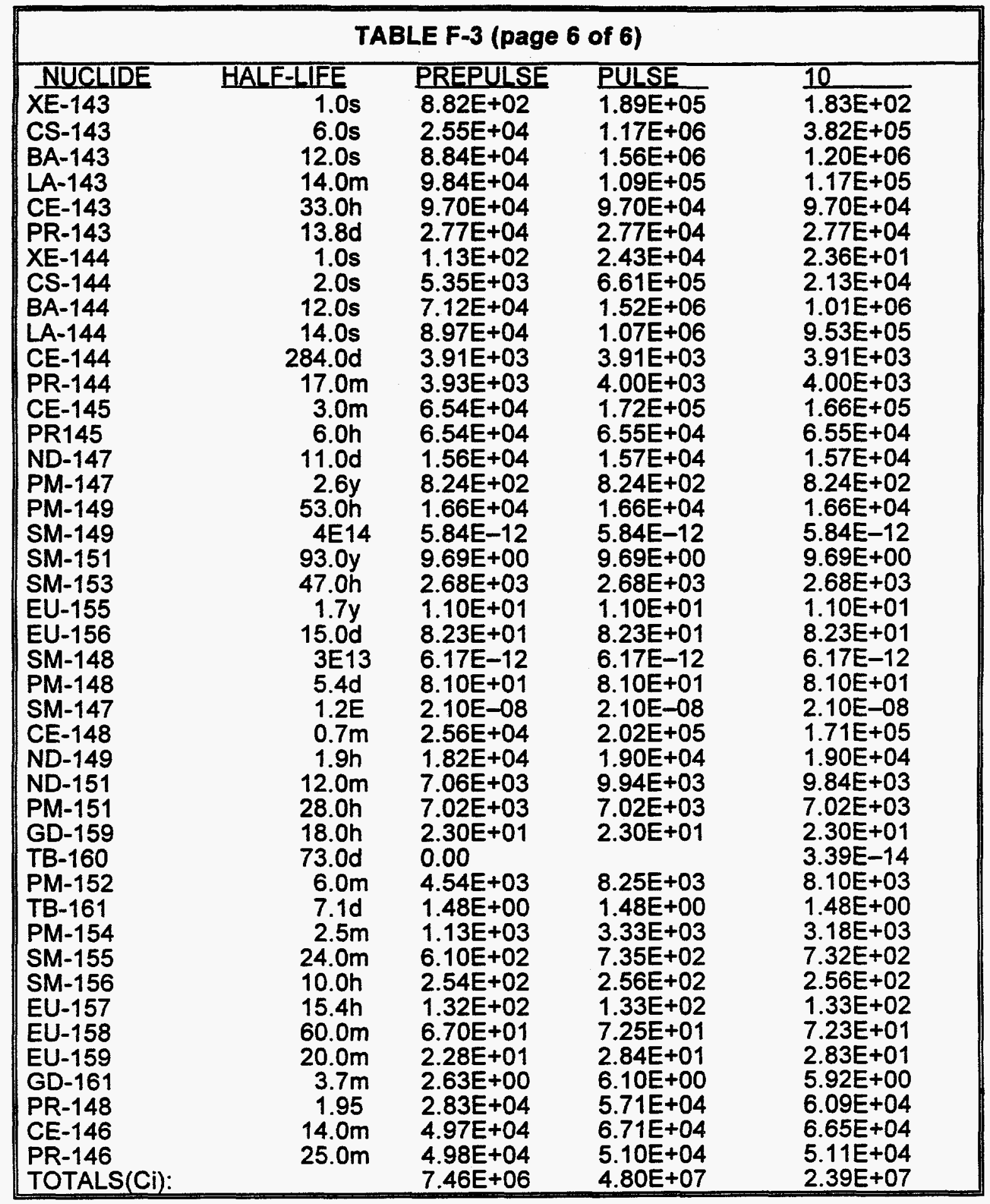

NOTE: Several parametric studies (i.e., computer runs) were made to determine the relationship between various periods and power levels. All inventories were found to be linear scales of the power level or irradiation time. 


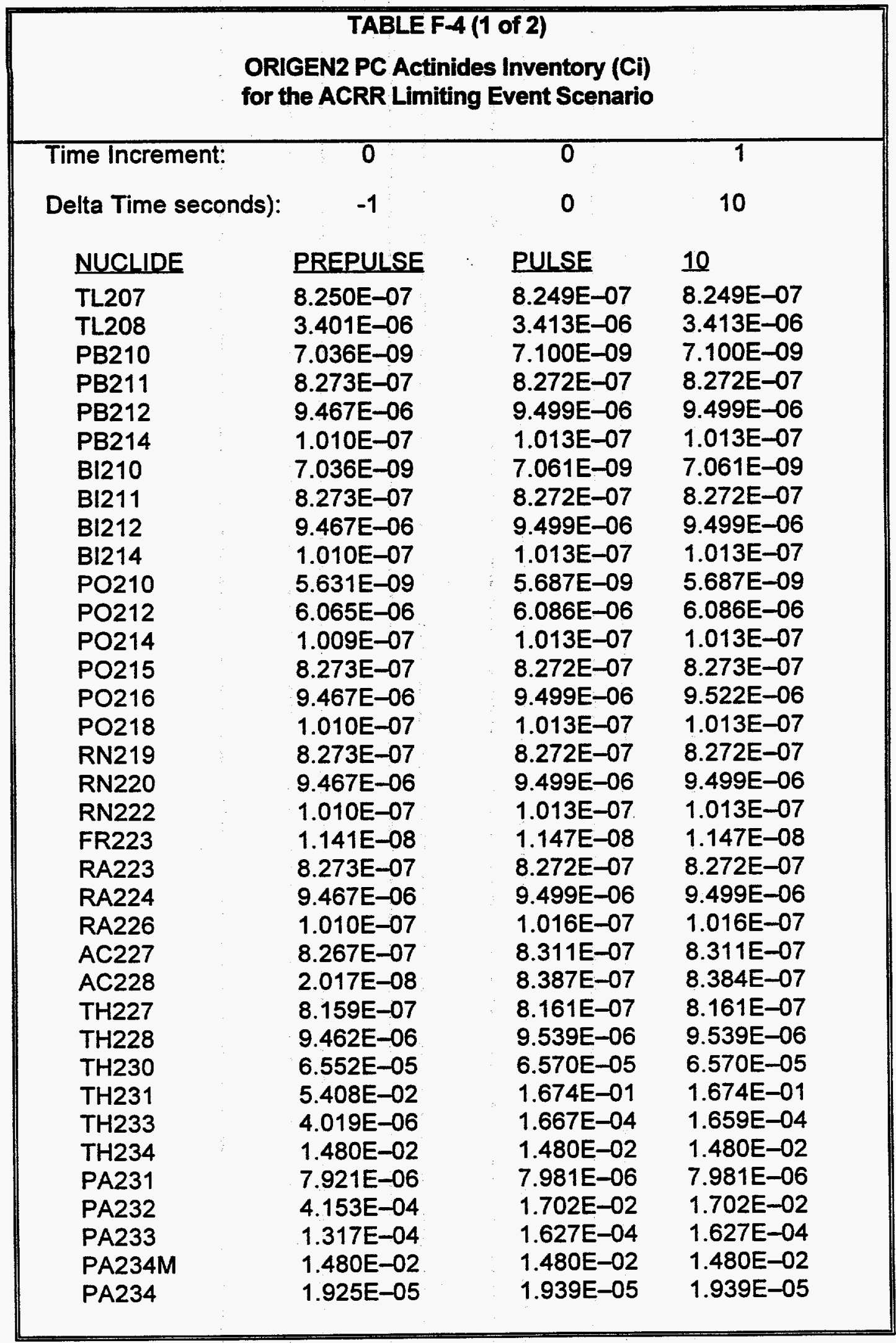




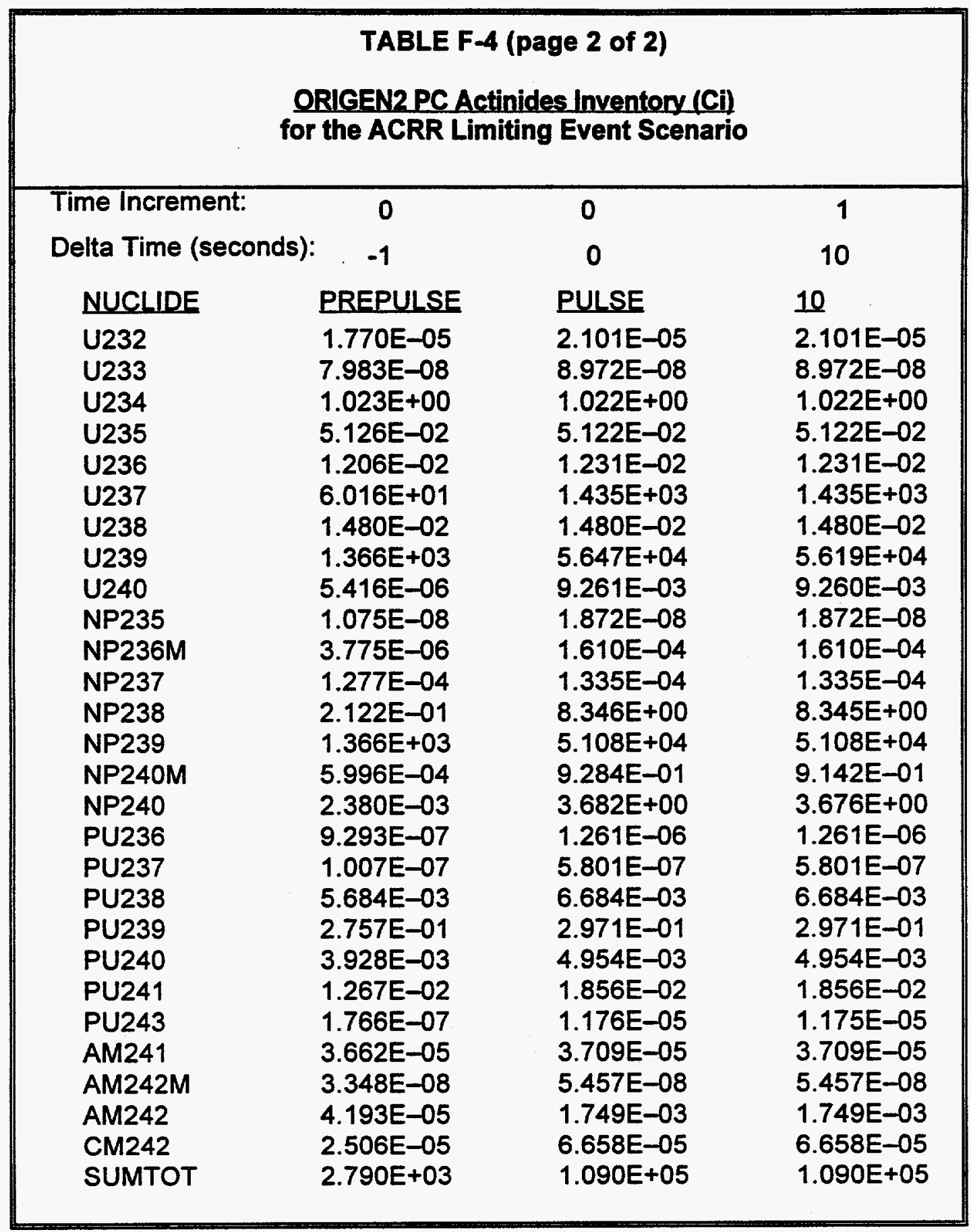


TABLE F-5 (Part 1 of 4)

SUMMARY OF BUILDING CONCENTRATION AND

DOSE CONSEQUENCES TO RADIATION WORKERS*

\begin{tabular}{|c|c|c|c|c|c|c|}
\hline \multirow{3}{*}{ NUCLIDE } & \multirow{3}{*}{$\frac{\text { QZERO* }}{\left(\mathrm{Ci} / \mathrm{m}^{3}\right)}$} & \multirow[b]{2}{*}{ LUNG } & \multicolumn{4}{|c|}{ WHOLE } \\
\hline & & & R.MARROW & B.SURFACE & IHYROID & BODY \\
\hline & & (Sv) & (Sv) & (Sv) & (Sv) & (Sv) \\
\hline $\mathrm{Zn}-7$ & 0.15E-09 & $0.59 E-09$ & $0.54 E-10$ & $0.65 E-10$ & $0.28 E-10$ & $0.15 E-09$ \\
\hline Ga-72 & $0.18 E-07$ & $0.28 E-07$ & $0.61 E-08$ & 0.59E-08 & $0.63 E-08$ & $0.11 E-07$ \\
\hline Ga-73 & $0.13 E-06$ & $0.57 E-07$ & $0.41 E-08$ & $0.53 E-08$ & $0.45 E-08$ & $0.13 E-07$ \\
\hline As-76 & 0.31E-09 & $0.12 E-08$ & $0.25 E-10$ & $0.25 E-10$ & $0.26 E-10$ & $0.25 E-09$ \\
\hline Ge-77 & $0.19 E-05$ & 0.30 E-05 & $0.23 E-06$ & $0.25 E-06$ & $0.26 E-06$ & $0.56 E-06$ \\
\hline As-77 & $0.45 E-07$ & $0.49 E-07$ & 0.42E-09 & 0.42E-09 & 0.41E-09 & $0.96 E-08$ \\
\hline Se-77m & $0.87 E-09$ & $0.60 E-11$ & $0.58 E-11$ & $0.88 E-11$ & $0.80 \mathrm{E}-11$ & $0.54 E-11$ \\
\hline Ge-78 & 0.11E-04 & $0.48 E-05$ & 0.30 E-06 & $0.38 E-06$ & $0.37 E-06$ & $0.86 E-06$ \\
\hline As-78 & $0.59 E-06$ & $0.29 E-06$ & $0.69 E-07$ & $0.74 E-07$ & 0.83E-07 & $0.92 E-07$ \\
\hline $\mathrm{Br}-82$ & $0.24 E-05$ & $0.36 E-05$ & $0.96 \mathrm{E}-06$ & $0.97 E-06$ & $0.11 E-05$ & $0.13 E-05$ \\
\hline $\mathrm{Br}-83$ & $0.60 E-02$ & $0.82 E-03$ & 0.90E-05 & $0.95 E-05$ & 0.99E-05 & $0.11 E-03$ \\
\hline $\mathrm{Kr}-83 \mathrm{~m}$ & $0.36 \mathrm{E}+00$ & $0.72 E-06$ & $0.25 E-06$ & $0.12 E-05$ & $0.96 E-06$ & $0.33 E-06$ \\
\hline $\mathrm{Br}-84$ & $0.10 \mathrm{E}-01$ & $0.30 \mathrm{E}-02$ & $0.18 E-02$ & $0.19 E-02$ & $0.22 E-02$ & $0.18 E-02$ \\
\hline $\mathrm{Kr}-85 \mathrm{~m}$ & $0.88 E+00$ & $0.11 E-01$ & $0.11 E-01$ & $0.16 \mathrm{E}-01$ & $0.15 E-01$ & $0.10 E-01$ \\
\hline$K r-85$ & $0.19 E-02$ & $0.36 E-06$ & $0.37 E-06$ & 0.42E-06 & $0.45 E-06$ & $0.33 E-06$ \\
\hline $\mathrm{Rb}-86$ & $0.64 E-08$ & $0.16 \mathrm{E}-07$ & 0.11E-07 & $0.20 E-07$ & 0.64E-08 & $0.86 E-08$ \\
\hline $\mathrm{Kr}-87$ & $0.17 E+01$ & $0.13 E+00$ & $0.13 E+00$ & $0.14 E+00$ & $0.16 E+00$ & $0.12 E+00$ \\
\hline $\mathrm{Kr}-88$ & $0.25 E+01$ & $0.48 E+00$ & $0.49 E+00$ & $0.51 E+00$ & $0.58 E+00$ & $0.44 E+00$ \\
\hline $\mathrm{Rb}-88$ & $0.52 E+00$ & $0.88 E-01$ & $0.32 E-01$ & $0.33 E-01$ & $0.38 E-01$ & $0.37 E-01$ \\
\hline $\mathrm{Rb}-89$ & $0.91 E+00$ & $0.22 E+00$ & $0.18 E+00$ & $0.19 E+00$ & $0.22 E+00$ & $0.17 E+00 \mathrm{Sr}-89$ \\
\hline $0.62 E-06$ & $0.13 E-02$ & $0.15 E-04$ & $0.33 E-04$ & $0.12 E-06$ & $0.16 E-03$ & \\
\hline$Y-90$ & $0.13 E-07$ & 0.91E-07 & $0.15 E-09$ & $0.15 E-09$ & $0.51 E-11$ & $0.22 E-07$ \\
\hline Sr-91 & $0.15 E-03$ & $0.24 E-03$ & $0.11 \mathrm{E}-04$ & $0.11 E-04$ & $0.12 E-04$ & $0.57 E-04$ \\
\hline Y-91m & $0.86 E-05$ & $0.83 E-06$ & $0.40 E-06$ & $0.45 E-06$ & $0.48 E-06$ & $0.41 E-06$ \\
\hline$Y-91$ & $0.35 E-06$ & $0.26 \mathrm{E}-04$ & $0.83 E-07$ & $0.83 E-07$ & $0.23 E-08$ & $0.34 E-05$ \\
\hline Sr-92 & $0.15 E-03$ & $0.14 E-03$ & $0.18 E-04$ & $0.19 E-04$ & $0.22 E-04$ & $0.40 E-04$ \\
\hline Y-92 & $0.62 E-05$ & $0.59 E-05$ & $0.15 E-06$ & $0.16 \mathrm{E}-06$ & $0.17 E-06$ & $0.11 E-05$ \\
\hline$Y-93$ & $0.36 \mathrm{E}-05$ & $0.67 E-05$ & $0.40 E-07$ & $0.40 \mathrm{E}-07$ & $0.38 E-07$ & $0.16 E-05$ \\
\hline$Y-94$ & $0.60 E-04$ & $0.13 E-04$ & $0.61 E-05$ & $0.65 E-05$ & $0.75 E-05$ & $0.63 E-05$ \\
\hline $\mathrm{Zr}-95$ & $0.38 E-06$ & $0.64 E-06$ & $0.37 E-05$ & $0.29 E-04$ & $0.44 E-06$ & $0.18 E-05$ \\
\hline $\mathrm{Nb}-95 \mathrm{~m}$ & $0.84 E-07$ & $0.19 E-06$ & 0.41E-08 & 0.47E-08 & $0.30 E-08$ & $0.42 E-07$ \\
\hline $\mathrm{Nb}-95$ & $0.55 E-05$ & $0.35 E-04$ & $0.22 E-05$ & $0.25 E-05$ & 0.19E-05 & $0.68 E-05$ \\
\hline$Z r-97$ & $0.33 E-05$ & $0.10 \mathrm{E}-04$ & $0.21 E-06$ & $0.14 E-06$ & $0.12 E-06$ & $0.29 E-05$ \\
\hline $\mathrm{Nb}-97 \mathrm{~m}$ & 0.61E-05 & $0.39 E-06$ & $0.39 E-06$ & 0.43E-06 & 0.49E-06 & $0.35 E-06$ \\
\hline $\mathrm{Nb}-97$ & $0.16 \mathrm{E}-03$ & $0.27 E-04$ & $0.92 E-05$ & $0.10 \mathrm{E}-04$ & $0.11 E-04$ & $0.11 E-04$ \\
\hline Mo-99 & $0.15 E-03$ & $0.47 E-03$ & 0.77E-05 & 0.67E-05 & $0.41 E-05$ & $0.12 E-03$ \\
\hline Tc-99m & $0.13 E-03$ & $0.35 E-05$ & $0.14 E-05$ & $0.23 E-05$ & $0.66 \mathrm{E}-05$ & $0.20 E-05$ \\
\hline
\end{tabular}




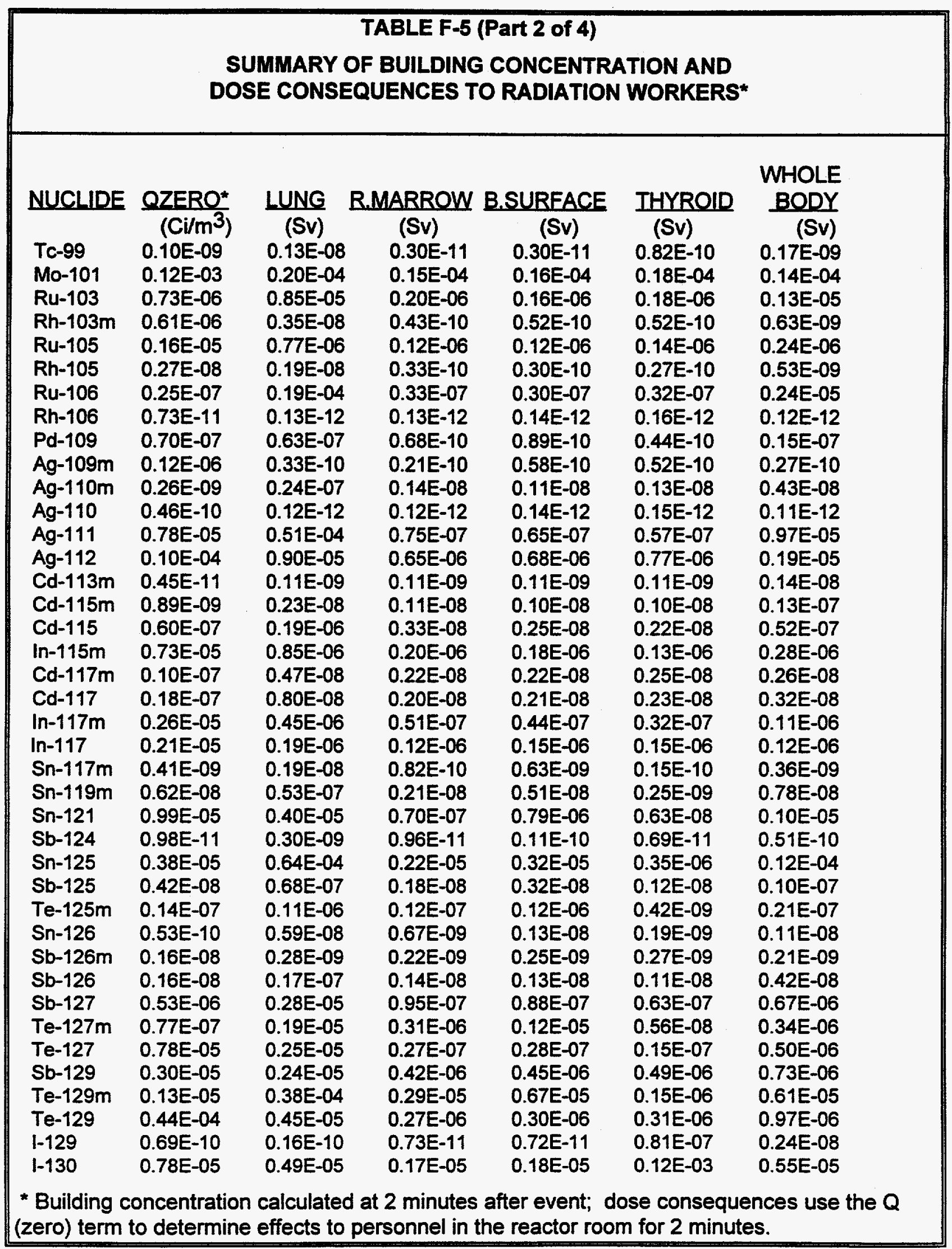


TABLE F-5 (Part 3 of 4)

SUMMARY OF BUILDING CONCENTRATION AND DOSE CONSEQUENCES TO RADIATION WORKERS*

\begin{tabular}{|c|c|c|c|c|c|c|}
\hline NUCLIDE & $\frac{\text { QZERQ* }}{\left(\mathrm{Ci} / \mathrm{m}^{3}\right)}$ & $\frac{\text { LUNG }}{(S V)}$ & $\frac{\text { R.MARROW }}{\text { (Sv) }}$ & $\frac{\text { B.SURFACE }}{(\text { SV) }}$ & $\frac{\text { THYROID }}{(\mathrm{Sv})}$ & $\begin{array}{l}\text { WHOLE } \\
\text { BODY } \\
\text { (Sv) }\end{array}$ \\
\hline $1 \mathrm{~m}$ & $0.26 \mathrm{E}-04$ & 0.47E-04 & 0.61E-05 & $0.82 E-05$ & $0.72 E-03$ & $0.37 E-04$ \\
\hline 131 & $0.17 E-03$ & $0.39 E-04$ & $0.68 E-05$ & $0.83 E-05$ & $0.35 E-03$ & $0.22 E-04$ \\
\hline $\mid-131$ & $0.16 E-01$ & $0.86 E-02$ & $0.13 E-02$ & $0.13 \mathrm{E}-02$ & $0.36 E+01$ & $0.11 E+00$ \\
\hline Xe-131m & $0.29 E-02$ & $0.12 E-05$ & 0.88E-06 & $0.19 E-05$ & $0.19 E-05$ & $0.96 E-06$ \\
\hline Te-132 & $0.26 E-03$ & $0.33 E-03$ & $0.87 E-04$ & $0.14 E-03$ & $0.12 E-01$ & $0.50 E-03$ \\
\hline $1-132$ & $0.40 E-01$ & $0.16 E-01$ & $0.84 E-02$ & $0.91 E-02$ & $0.61 E-01$ & $0.10 E-01$ \\
\hline Te-133m & $0.21 E-03$ & $0.70 \mathrm{E}-04$ & $0.44 E-04$ & $0.48 E-04$ & $0.46 E-03$ & 0.57E-04 \\
\hline Te-133 & $0.22 E-03$ & $0.25 E-04$ & $0.18 E-04$ & $0.20 E-04$ & $0.12 E-03$ & $0.20 E-04$ \\
\hline |-133 & 0.77 E-01 & 0.51E-01 & $0.56 E-02$ & $0.60 \mathrm{E}-02$ & $0.28 E+01$ & $0.94 E-01$ \\
\hline $\mathrm{Xe}-133 \mathrm{~m}$ & $0.30 \mathrm{E}-05$ & $0.62 E-08$ & $0.60 E-08$ & $0.86 E-08$ & $0.84 E-08$ & $0.55 E-08$ \\
\hline$X e-133$ & $0.28 E+01$ & $0.73 E-02$ & 0.49E-02 & $0.13 E-01$ & $0.11 E-01$ & 0.61E-02 \\
\hline Te-134 & $0.20 \mathrm{E}-03$ & $0.24 E-04$ & $0.17 E-04$ & $0.19 E-04$ & $0.10 E-03$ & $0.19 E-04$ \\
\hline $\mid-134$ & $0.82 E-01$ & $0.28 E-01$ & $0.20 E-01$ & $0.21 E-01$ & $0.41 E-01$ & $0.20 E-01$ \\
\hline Cs-134m & $0.19 E-06$ & $0.92 E-08$ & $0.75 E-09$ & $0.96 E-09$ & $0.88 E-09$ & $0.19 E-08$ \\
\hline Cs-134 & $0.42 E-07$ & $0.37 E-06$ & $0.37 E-06$ & $0.35 E-06$ & $0.35 E-06$ & $0.39 E-06$ \\
\hline $\mid-135$ & $0.72 E-01$ & $0.34 E-01$ & $0.12 E-01$ & $0.12 E-01$ & $0.47 E+00$ & $0.27 E-01$ \\
\hline $\mathrm{Xe}-135 \mathrm{~m}$ & $0.61 E+00$ & $0.22 E-01$ & $0.22 E-01$ & $0.25 E-01$ & $0.27 \mathrm{E}-01$ & $0.20 E-01$ \\
\hline $\mathrm{Xe}-135$ & $0.37 E+01$ & $0.75 E-01$ & 0.76E-01 & $0.10 E+00$ & $0.97 E-01$ & $0.68 E-01$ \\
\hline Cs-135 & $0.87 E-10$ & $0.92 E-10$ & $0.78 \mathrm{E}-10$ & $0.78 E-10$ & $0.78 E-10$ & $0.80 E-10$ \\
\hline Cs-136 & $0.66 \mathrm{E}-06$ & $0.13 E-05$ & $0.10 E-05$ & $0.98 E-06$ & $0.10 E-05$ & $0.11 E-05$ \\
\hline Cs-137 & $0.62 E-05$ & $0.41 E-04$ & $0.38 E-04$ & $0.37 E-04$ & $0.37 E-04$ & $0.40 E-04$ \\
\hline $\mathrm{Ba}-137 \mathrm{~m}$ & $0.12 \mathrm{E}-06$ & $0.61 E-08$ & $0.63 E-08$ & 0.69E-08 & $0.77 \mathrm{E}-08$ & $0.56 E-08$ \\
\hline$X e-138$ & $0.42 E+01$ & $0.45 E+00$ & $0.46 E+00$ & $0.49 E+00$ & $0.55 E+00$ & $0.41 E+00$ \\
\hline Cs-138 & $0.56 E+00$ & $0.19 E+00$ & $0.12 E+00$ & $0.13 E+00$ & $0.15 \mathrm{E}+00$ & $0.12 E+00$ \\
\hline $\mathrm{Ba}-139$ & $0.50 E-01$ & $0.97 E-02$ & $0.29 E-03$ & $0.34 E-03$ & $0.32 E-03$ & $0.19 E-02$ \\
\hline $\mathrm{Ba}-140$ & $0.39 E-03$ & $0.49 E-03$ & $0.39 E-03$ & $0.72 E-03$ & $0.83 E-04$ & $0.30 E-03$ \\
\hline La-140 & $0.14 \mathrm{E}-05$ & $0.46 E-05$ & $0.50 E-06$ & $0.45 E-06$ & $0.42 E-06$ & $0.16 E-05$ \\
\hline $\mathrm{Ba}-141$ & $0.13 E-03$ & $0.21 E-04$ & 0.99E-05 & $0.12 E-04$ & $0.12 E-04$ & $0.11 E-04$ \\
\hline La-141 & $0.58 E-05$ & $0.28 E-05$ & $0.15 E-06$ & $0.54 E-06$ & $0.68 E-07$ & $0.70 E-06$ \\
\hline $\mathrm{Ce}-141$ & $0.57 E-06$ & $0.72 E-05$ & $0.41 E-07$ & 0.11E-06 & $0.16 \mathrm{E}-07$ & $E-05$ \\
\hline $\mathrm{Ba}-142$ & $0.38 E-03$ & $0.50 E-0.4$ & $0.35 E-04$ & $0.39 E-04$ & $0.44 E-04$ & $0.34 E-04$ \\
\hline La-142 & $0.24 E-04$ & $0.12 E-04$ & $0.68 \mathrm{E}-05$ & $0.69 E-05$ & $0.78 E-05$ & $0.70 \mathrm{E}-05$ \\
\hline La-143 & $0.31 E-05$ & $0.27 E-06$ & $0.29 E-07$ & 0.31E-07 & $0.34 E-07$ & $0.62 E-07$ \\
\hline $\mathrm{Ce}-143$ & $0.33 E-05$ & $0.96 E-05$ & $0.14 E-06$ & $0.13 E-06$ & $0.11 E-06$ & $0.23 E-05$ \\
\hline Pr-143 & $0.92 E-06$ & 0.91E-05 & $0.10 \mathrm{E}-07$ & $0.10 E-07$ & $0.20 E-14$ & $0.15 E-05$ \\
\hline Ce-144 & $0.13 E-06$ & $0.78 E-04$ & $0.28 E-06$ & $0.47 E-06$ & $0.29 E-07$ & $0.10 E-04$ \\
\hline Pr-144 & $0.10 \mathrm{E}-06$ & $0.76 E-08$ & $0.32 E-09$ & $0.34 E-09$ & $0.38 E-09$ & $0.12 E-08$ \\
\hline Nd-147 & $0.52 E-06$ & 0.41E-05 & 0.41E-07 & $0.13 E-06$ & $0.14 E-07$ & $0.72 E-06$ \\
\hline
\end{tabular}

* Building concentration calculated at 2 minutes after event; dose consequences use the $Q$ (zero) term to determine effects to personnel in the reactor room for 2 minutes. 


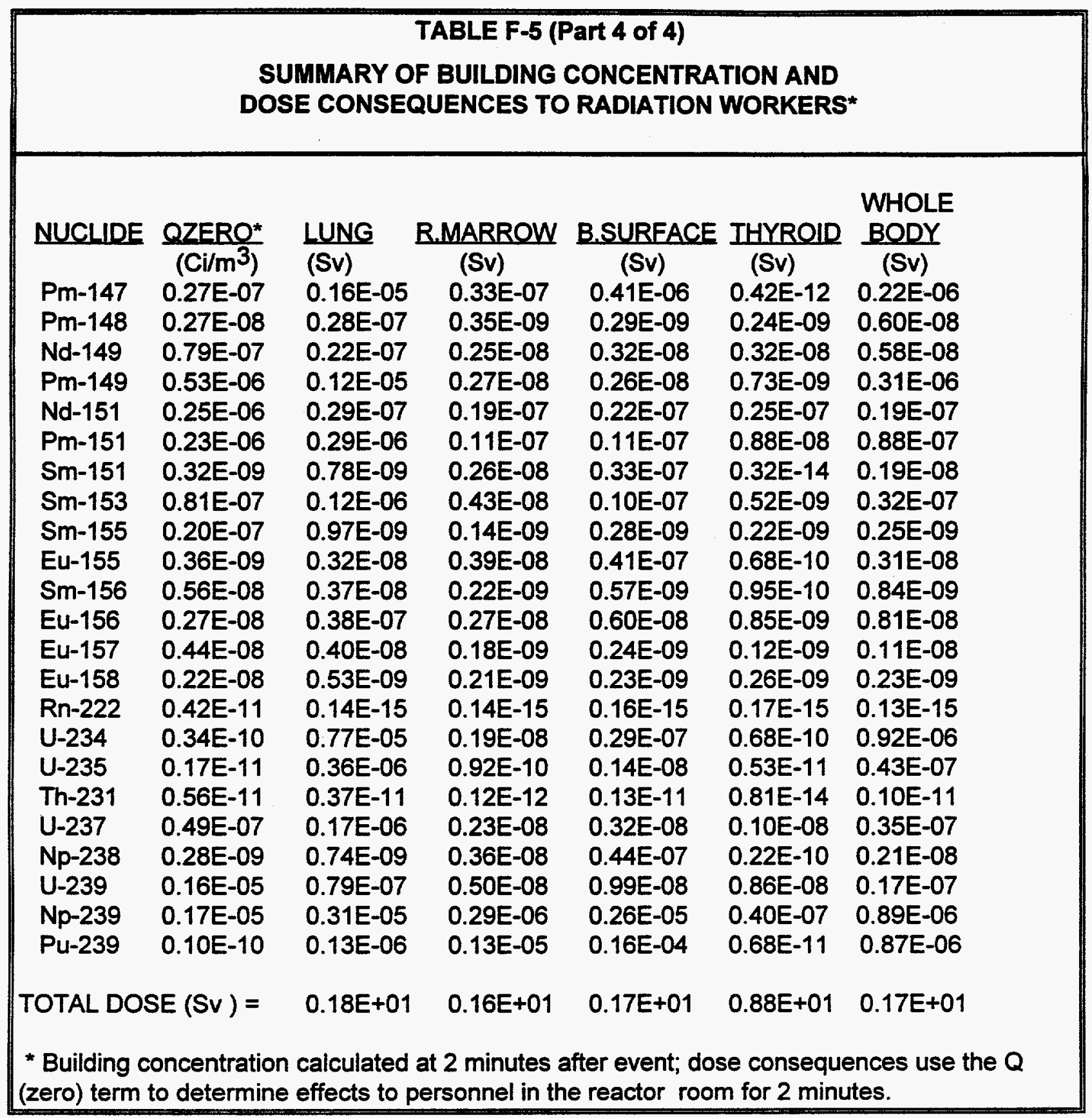




\section{References}

1. Bennett, D. E., 1979, Sandia ORIGEN Users Manual, Sandia National Laboratories, NUREG/CR-0987, SAND79-0299, October 1979.

2. Bonzon, L. L. and J. B. Rivard, 1970, Computational Methods for Calculation of Radiological Dose Resulting from Hypothetical Fission Product Release, SC-RR-70338, Sandia National Laboratories, Albuquerque, NM, July 1970.

3. Bowen, T. L., 1976, Hazards Associated with Hydrogen Fuel, 11th Intersociety Energy Conversion Engineering Conference, September 1976.

4. Pickard, P. S., and J. P. Odom, 1978, Sandia Reactor Kinetics Codes: SAK and PK1D, SAND77-1211, Sandia National laboratories, Albuquerque, NM, January 1978.

5. Restrepo, L. F., 1992, The Annular Core Research Reactor (ACRR) Postulated Limiting Event Initial and Building Source Terms, SAND91-0571, Sandia National Laboratories, Albuquerque, NM, August 1992. 
HCF RADIONUCLIDE RELEASE CALCULATIONS 


\section{APPENDIX G \\ HCF RADIONUCLIDE RELEASE CALCULATIONS}

In order to estimate radionuclide release, the radionuclide flow during ${ }^{99} \mathrm{Mo}$ extraction and purification can be modeled as shown in Figure G-1.

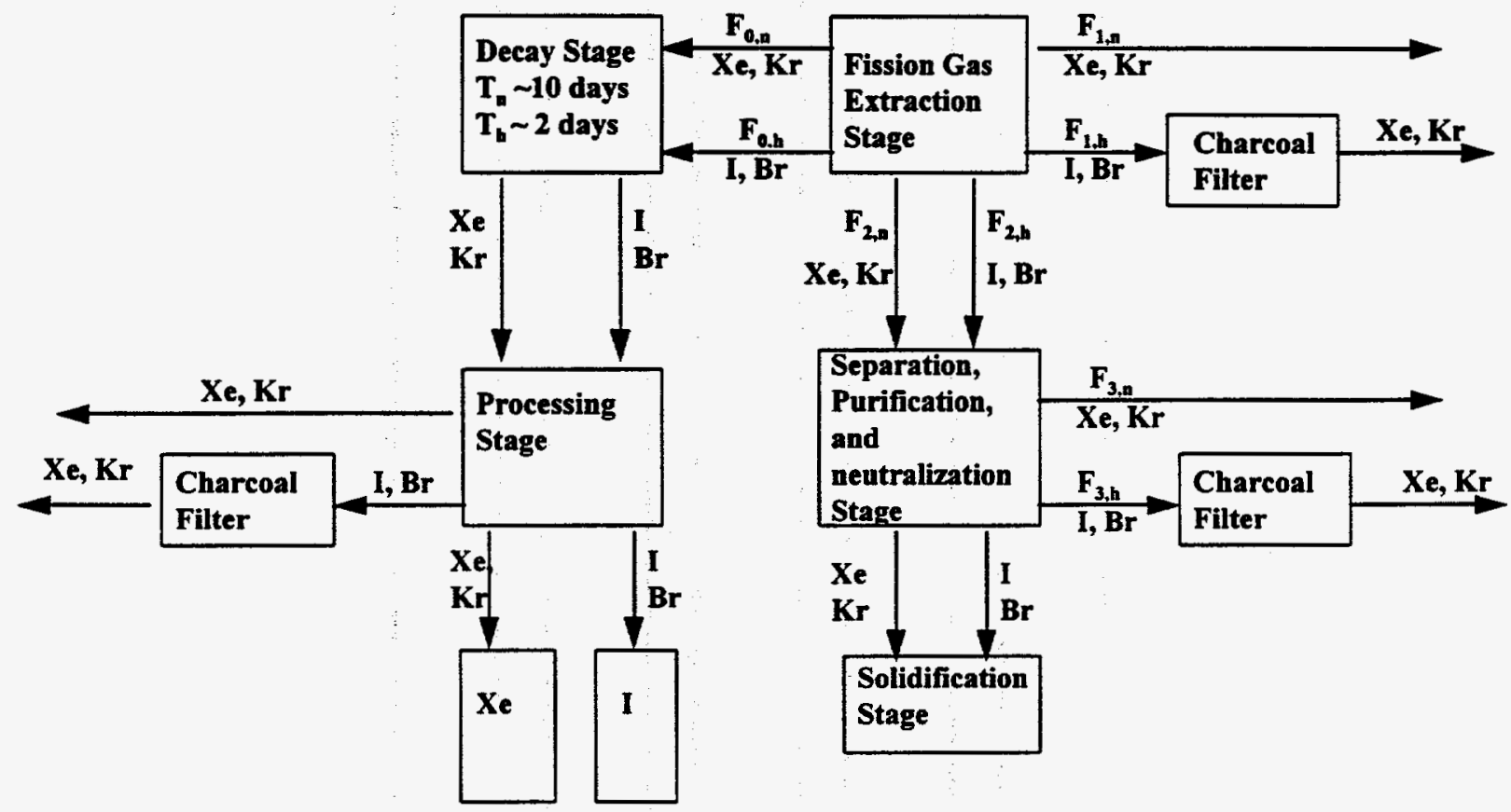

Figure G-1. Model for Estimating Noble Gas Release During Normal Process Operations.

The fractions $\mathrm{F}_{0, \mathrm{n}}$ and $\mathrm{F}_{0, \mathrm{~h}}$ are the respective fractions of the noble gases and halogens that are extracted and maintained within sealed containers for further processing. $F_{1, n}$ and $F_{1, h}$ are the fractional losses directly to the process box during the extraction process and $F_{2, n}$ and $\mathrm{F}_{2, \mathrm{~h}}$ are the fractions remaining in the liquid process material after the extraction stage. All noble and halogen precursors such as selenium, antimony and tellurium are assumed to be retained in the process liquid. $F_{3, n}$ and $F_{3, h}$ are the respective fractional losses of the nobles and halogens from the process liquid to the process box during the various separation, purification and neutralization steps prior to solidification of the waste liquid. The losses of gaseous fission products following solidification are insignificant.

By using the above fractions to give the dose from release of a given noble gas population at a specific point in the process, the dose due to the complete processing sequence can be determined. Total estimated release from the processing of one target can be expressed analytically by the following equation:

$$
\text { Dose }=a_{1} F_{1, n}+a_{2} F_{1, h}+a_{3} F_{2, n} F_{3, n}+a_{4} F_{2, h} F_{3, n}\left(1-F_{3, h}\right)+a_{5} F_{2, h} F_{3, h}
$$

where $a_{i}$ is the dose kernal for release type $i$ and is a function of the time between irradiation and the start of extraction, process times and the distance to the dose point; $i$. e., off-site workers or the general public: 
$a_{1} F_{1, n}=$ dose due to the loss of nobles directly from the extraction phase.

${ }_{a_{2}} F_{1, h}=$ dose due to the loss of nobles resulting from the decay of halogens deposited in the process box or box filters during the extraction process .

$a_{3} F_{2, n} F_{3, n}=$ dose due to the loss of nobles present in the process liquid during postextraction processing from the decay of halogens remaining in the process liquid.

$$
\begin{aligned}
\text { a4 } F_{2, h} F_{3, n}\left(1-F_{3, h}\right)= & \begin{array}{l}
\text { dose due to the loss of nobles produced in the process } \\
\text { liquid during post-extraction processing from the decay } \\
\text { of halogens remaining in the process liquid. }
\end{array}
\end{aligned}
$$

$a_{5} F_{2, h} F_{3, h}=$

dose due to the loss of nobles resulting from the decay of halogens deposited in the process box or filters from post-extraction processing.

The quantities of radioactive noble gases and their precursors present during processing depend strongly on the time allowed for radioactive decay prior to start of the gas extraction and separation process. ORIGEN2 calculations were performed to determine the fission product inventory in a target as a function of time following a 20-kW, 7-day irradiation.

The relative fractions of the radioactive noble gases available for release at any given time are a function of time following irradiation and the separation processes occurring up to that time. Table G-1 gives the individual dose per curie of radionuclide released from the HCF stack for each of the radionuclides of interest. Doses were calculated in the NW direction, since these values are among the highest and the highest population density is in the direction of the city.

For the HCF, a stack height of $38.1 \mathrm{~m}$, a stack diameter of $1.8 \mathrm{~m}$, a flow velocity of $8.7 \mathrm{~m} / \mathrm{s}$, and a volumetric flow rate of $22.14 \mathrm{~m} 3 / \mathrm{s}$ were assumed. Stack exit temperature was assumed to be $21.0^{\circ} \mathrm{C}$. Other data inputs were:

$\begin{array}{ll}\text { Average air temperature } & 13.0^{\circ} \mathrm{C} \\ \text { Annual precipitation } & 21.0 \mathrm{~cm} / \mathrm{y} \\ \text { Mixing height } & 2055 \mathrm{~m} \\ \text { Closest Receptor/Sector } & 1610 / \mathrm{NW} \\ \text { Run type } & \text { Individual } \\ \text { Wind file } & \text { ABQ0282 } \\ \text { Source type } & \text { Stack } \\ \text { Agricultural data } & \text { Imported }\end{array}$




\section{Table G-1. Dose to an Individual per Curie of Radionuclide}

Released from the HCF Stack, NW Direction

Isotope

Dose/Ci (mrem)

\begin{tabular}{|c|c|c|c|c|c|}
\hline & $300 \mathrm{~m}$ & $1610 \mathrm{~m}$ & $3000 \mathrm{~m}$ & $6000 \mathrm{~m}$ & $20,000 \mathrm{~m}$ \\
\hline $\mathrm{Kr}-83 \mathrm{~m}$ & 2.1 E-8 & 8.4 E-9 & 6.5 E-9 & 3.3 E-9 & 4.7 E-10 \\
\hline $\mathrm{Kr}-85 \mathrm{~m}$ & 1.5 E-5 & 6.2 E-6 & 5.0 E-6 & 2.9 E-6 & $4.9 \mathrm{E}-7$ \\
\hline$K r-87$ & 7.9 E-5 & 3.2 E-5 & $2.3 \mathrm{E}-5$ & 1.1 E-5 & 1.2 E-6 \\
\hline$K r-88$ & $2.1 E-4$ & 8.5 E-5 & 6.8 E-5 & 3.7 E-5 & 6.8 E-6 \\
\hline $\mathrm{Xe}-133$ & 3.2 E-6 & 1.4 E-6 & 1.2 E-6 & 7.4 E-7 & 2.4 E-7 \\
\hline $\mathrm{Xe}-133 \mathrm{~m}$ & 2.8 E-6 & 1.2 E-6 & $1.0 \mathrm{E}-6$ & 6.4 E-7 & $2.0 \mathrm{E}-7$ \\
\hline $\mathrm{Xe}-135$ & $2.3 \mathrm{E}-5$ & 9.7 E-6 & 8.1 E-6 & 4.9 E-6 & 1.3 E-6 \\
\hline $\mathrm{Xe}-135 \mathrm{~m}$ & 8.9 E-6 & 1.7 E-6 & 4.1 E-7 & 3.8 E-8 & 8.2 E-12 \\
\hline
\end{tabular}

\section{Sample Calculation}

To provide a reference estimate of the radioactive gas release to the environment from normal operations, the following assumptions were made.

- The target has been subjected to a $10-\mathrm{kW}$ irradiation for 7 days.

- The fission gas extraction steps begin 6 hours after completion of target irradiation.

- The extraction step is instantaneous and the waste stabilization step takes place 8 hours later.

- $90 \%$ of the nobles and $90 \%$ of the halogens present at the time of extraction are collected in a sealed container. $10 \%$ of the nobles and $10 \%$ of the halogens are retained in the process liquid.

- $0.1 \%$ of the nobles and $0.1 \%$ of the halogens are lost during disconnect steps during the extraction stage.

- $100 \%$ of the noble gases initially present or subsequently produced by the radioactive decay of their precursors are released prior to waste stabilization.

- $100 \%$ of the halogens are retained in the process liquid.

Under these assumptions, immediately following the fission gas extraction stage, the significant noble gases and their precursors would be partitioned as shown in Table G-2. 
Table G-2. Partitioning of Significant Noble Gases and Their Precursors

\begin{tabular}{|l|l|l|c|l|c|c|}
\hline Nuclide & Half-life & $\begin{array}{l}\text { Beginning } \\
\text { Inventory (Ci) }\end{array}$ & $\begin{array}{c}\text { Extracted } \\
\text { (Ci) }\end{array}$ & $\begin{array}{l}\text { Retained in } \\
\text { Liquid (Ci) }\end{array}$ & $\begin{array}{l}\text { Released } \\
\text { Directly (Ci) }\end{array}$ & $\begin{array}{l}\text { In Box or } \\
\text { Charcoal Filter (Ci) }\end{array}$ \\
\hline Se-83 & $22.3 \mathrm{~m}$ & 0.000255 & 0 & 0.000255 & 0 & 0 \\
\hline $\mathrm{Br}-83$ & $2.4 \mathrm{~h}$ & 8.5 & 7.6 & 0.844 & 0 & 0.0084 \\
\hline $\mathrm{Kr}-83 \mathrm{~m}$ & $1.86 \mathrm{~h}$ & 19.4 & 17.5 & 1.940 & 0.0194 & 0 \\
\hline $\mathrm{Kr}-85$ & $10.73 \mathrm{y}$ & 0.0277 & 0.025 & 0.00277 & 0.0000277 & 0 \\
\hline $\mathrm{Kr}-85 \mathrm{~m}$ & $4.48 \mathrm{~h}$ & 42.6 & 38.34 & 4.26 & 0.0426 & 0 \\
\hline $\mathrm{Kr}-87$ & $1.27 \mathrm{~h}$ & 8.23 & 7.41 & 0.823 & 0.00823 & 0 \\
\hline $\mathrm{Kr}-88$ & $2.84 \mathrm{~h}$ & 70.3 & 63.3 & 7.03 & 0.0703 & 0 \\
\hline $\mathrm{Sb}-13$ & $123 \mathrm{~m}$ & 0.0042 & 0 & 0.0042 & 0 & 0 \\
\hline $\mathrm{Te}-131$ & $25 \mathrm{~m}$ & 5.92 & 0 & 5.92 & 0 & 0 \\
\hline $\mathrm{Te}-131 \mathrm{~m}$ & $1.35 \mathrm{~d}$ & 26.8 & 0 & 26.8 & 0 & 0 \\
\hline $\mathrm{I}-131$ & $8.04 \mathrm{~d}$ & 104.0 & 93.6 & 10.4 & 0 & 0.104 \\
\hline $\mathrm{Xe}-131 \mathrm{~m}$ & $11.5 \mathrm{~d}$ & 0.2361 & 0.212 & 0.02361 & 0.000236 & 0 \\
\hline $\mathrm{Te}-133$ & $12.4 \mathrm{~m}$ & 0.465 & 0 & 0.465 & 0 & 0 \\
\hline $\mathrm{Te}-133 \mathrm{~m}$ & $55.4 \mathrm{~m}$ & 2.77 & 0 & 2.77 & 0 & 0 \\
\hline $\mathrm{l}-133$ & $20.8 \mathrm{~h}$ & 471.0 & 424.0 & 7.1 & 0 & 0.471 \\
\hline $\mathrm{Xe}-133$ & $5.24 \mathrm{~d}$ & 300.0 & 270.0 & 30.0 & 0.300 & 0 \\
\hline $\mathrm{Xe}-133 \mathrm{~m}$ & $2.19 \mathrm{~d}$ & 13.6 & 12.24 & 1.36 & 0.0136 & 0 \\
\hline $\mathrm{l}-135$ & $6.57 \mathrm{~h}$ & 281.0 & 253.0 & 28.1 & 0 & 0.281 \\
\hline $\mathrm{Xe}-135$ & $9.1 \mathrm{~h}$ & 206.0 & 185.4 & 20.6 & 0.206 & 0 \\
\hline $\mathrm{Xe}-135 \mathrm{~m}$ & $15.3 \mathrm{~m}$ & 45.0 & 40.5 & 4.5 & 0.045 & 0 \\
\hline & & & & & & \\
\hline
\end{tabular}

During the processing steps following the fission gas extraction step, the noble gas precursors continue to decay, producing more noble gases. The relevant decay schemes are shown in Figure G-2.

Conservative approximations of the noble gases produced in the process liquid during the 8 hours prior to waste solidification are given below.

$\begin{array}{lc}\text { Nuclide } & \text { Curies Produced } \\ \text { Kr-83m } & 0.98 \\ \text { Xe-131m } & 0.00237 \\ \text { Xe-133 } & 1.801 \\ \text { Xe-133m } & 0.126 \\ \text { Xe-135 } & 9.66 \\ \text { Xe-135m } & 68.18\end{array}$




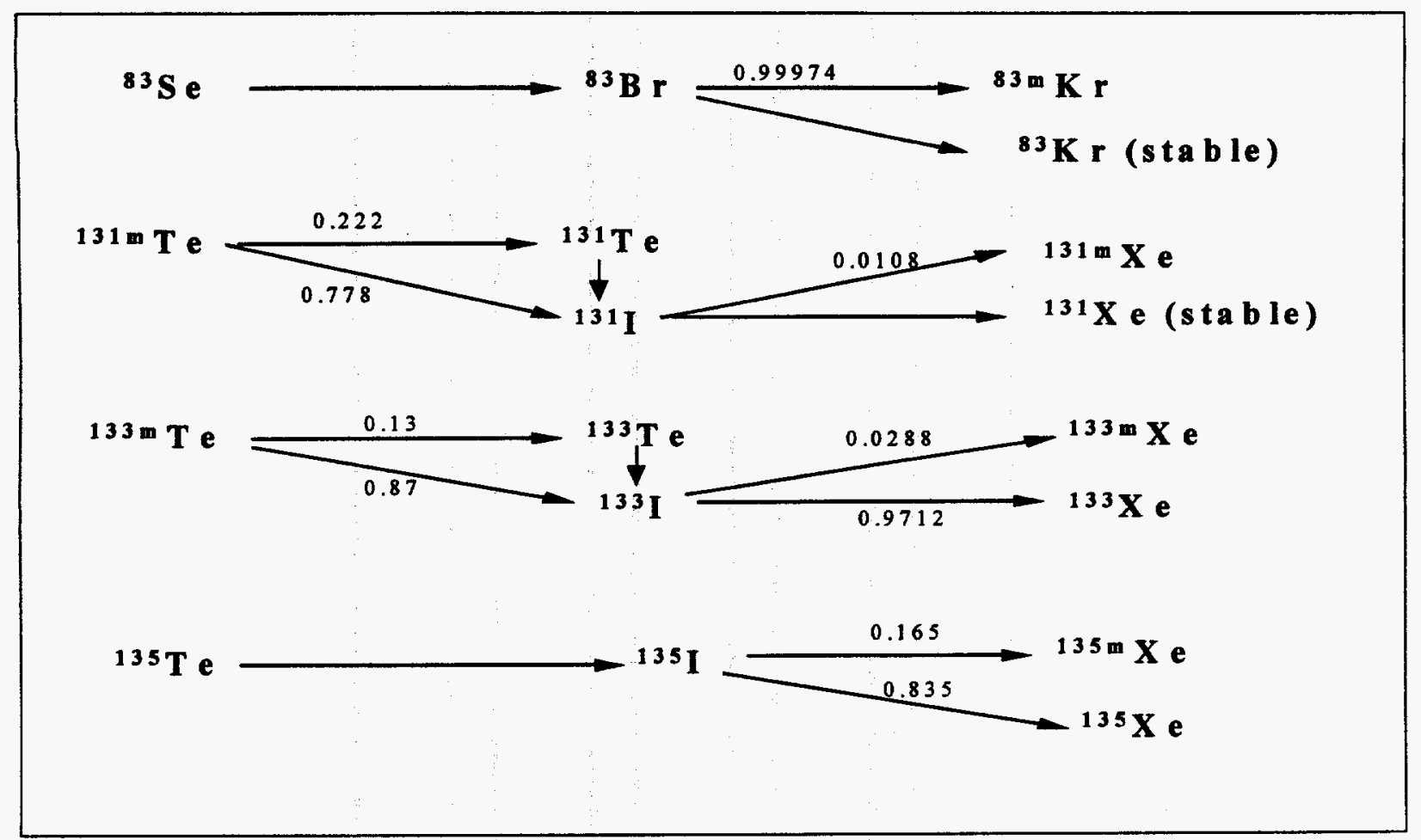

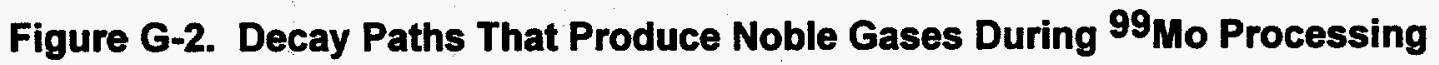

The halogens that have plated out within the process box or the charcoal filters will ultimately decay to noble gases. The activity of species $i$ resulting from the decay of its parent species $j$ is given by:

$$
\text { Act } i=\text { Act }_{j}\left(\frac{\text { half-life }}{j}\right)(f j-->i)
$$

where $f_{j->i}=$ the decay fraction of species $j$ that results in species $i$.

The dose fractions/Ci released given in Table G-1 were used to determine the dose contribution at the various stages of processing. Results are shown in Table G-3. 
Table G-3. Downwind Dose Estimates at $3000 \mathrm{~m}$ for Sample Case

Nuclide Process Dose (mrem)

\begin{tabular}{|c|c|c|c|c|}
\hline & $\begin{array}{l}0.1 \% \text { Direct } \\
\text { Release }\end{array}$ & $\begin{array}{l}0.1 \% \text {, Filters } \\
\text { \& Plate-Out }\end{array}$ & $\begin{array}{l}10 \text { Release } \\
\text { Erom Liquid }\end{array}$ & $\begin{array}{c}\text { Delayed Release } \\
\text { From Liquid }\end{array}$ \\
\hline $\mathrm{Kr}-83 \mathrm{~m}$ & $1.26 E-10$ & 7.15 E-10 & 1.26 E-8 & 6.37 E-9 \\
\hline $\mathrm{Kr}-85$ & $3.08 \mathrm{E}-12$ & 0 & $3.08 \mathrm{E}-10$ & 0 \\
\hline $\mathrm{Kr}-85 \mathrm{~m}$ & $2.13 \mathrm{E}-7$ & 0 & $2.13 \mathrm{E}-5$ & 0 \\
\hline $\mathrm{Kr}-87$ & $1.89 \mathrm{E}-7$ & 0 & 1.89 E-5 & 0 \\
\hline $\mathrm{Kr}-88$ & $4.78 \mathrm{E}-6$ & 0 & $4.78 E-4$ & 0 \\
\hline $\mathrm{Xe-131m}$ & 1.71 E-8 & $2.52 E-10$ & 1.71 E-6 & 1.82 E-9 \\
\hline Xe-133 & $3.60 \mathrm{E}-7$ & 9.12 E-8 & 3.6 E-5 & 2.16 E-6 \\
\hline $\mathrm{Xe-133m}$ & 1.36 E-8 & 5.40 E-9 & $1.36 \mathrm{E}-6$ & 5.11 E-8 \\
\hline Xe-135 & $1.67 \mathrm{E}-6$ & 1.37 E-6 & $1.67 E-4$ & 7.78 E-5 \\
\hline $\mathrm{Xe-135m}$ & 2.21 E-7 & 5.85 E-6 & 2.21 E-5 & $3.34 E-4$ \\
\hline
\end{tabular}



APPENDIX H

CHEMICALS USED IN THE HCF 


\section{APPENDIX H}

The inventory of chemicals that would be used during $99^{9}$ Mo purification is shown in Table $\mathrm{H}-1$. All but six of these chemicals have established exposure limits that are used to regulate employee exposure. These exposure limits are listed in Table H-2. The limits referenced are the Permissible Exposure Limits (PELs), published by the Occupational Safety and Health Administration (OSHA), the Threshold Limit Values (TLVs) published by the American Conference of Governmental Industrial Hygienists (ACGIH) and the Immediately Dangerous to Life and Health limit (IDLH) published by the National Institute for Occupational Safety and Health (NIOSH). The PELs and TLVs are generally defined as the time-weighted average concentration for a normal 8-hour workday and a 40-hour workweek, to which nearly all workers may be repeatedly exposed, day after day, without adverse effect. Excursions above these exposure standards are allowable and a rationale for excursions is supplied by the aforementioned sources. The IDLH represents the maximum concentration from which, in the event of respirator failure, one could escape within 30 minutes without a respirator and without experiencing any escape-impairing (i.e., severe eye irritation) or irreversible health effects. 
Room 106

10 liters $98 \% \mathrm{H}_{2} \mathrm{SO}_{4}$

20 liters waste acid[1]

$2 \mathrm{~kg}$ Ammonium Oxalate

5 liters $28-30 \% \mathrm{NH}_{4} \mathrm{OH}$

2.5 liters $88 \%$ Formic Acid

$500 \mathrm{~g} \mathrm{U}_{3} \mathrm{O}_{8}$

2.5 liters $70 \% \mathrm{HNO}_{3}$

2.5 liters Methanol

$100 \mathrm{ml} \mathrm{H} \mathrm{SO}_{4} / \mathrm{HNO}_{3}$ sol'n[2]

$100 \mathrm{~g} \mathrm{NaOH}$

$100 \mathrm{~g} \mathrm{Nal}$

$100 \mathrm{~g} \mathrm{MoO}_{3}$

$50 \mathrm{ml} 0.375 \mathrm{~g} \mathrm{MoO}_{3}$ in $1.0 \mathrm{~N} \mathrm{NaOH}$

$50 \mathrm{ml} 2 \% \mathrm{RhCl}_{3} \cdot 3 \mathrm{H}_{2} \mathrm{O}$ in $\mathrm{H}_{2} \mathrm{O}$

$100 \mathrm{~g} \mathrm{RhCl}_{3} \cdot 3 \mathrm{H}_{2} \mathrm{O}$

$200 \mathrm{~g} \mathrm{~K}_{3} \mathrm{RuCl}_{6}$

$100 \mathrm{ml} \mathrm{30 \%} \mathrm{H}_{2} \mathrm{O}_{2}$

$50 \mathrm{ml}$ Ruthenium Carrier sol'n[3]

$100 \mathrm{~g}$ Benzoin a Oxime

$50 \mathrm{ml} 2 \%$ Benzoin a Oxime in $0.4 \mathrm{~N} \mathrm{NaOH}$

$100 \mathrm{ml} 1 \% \mathrm{H}_{2} \mathrm{O}_{2}$ in $0.4 \mathrm{~N} \mathrm{NaOH}$

2 liters $0.4 \mathrm{~N} \mathrm{NaOH}$

2 liters $0.2 \mathrm{~N} \mathrm{NaOH}$

$100 \mathrm{ml} 1 \% \mathrm{H}_{2} \mathrm{O}_{2}$ in $0.2 \mathrm{~N} \mathrm{NaOH}$

$100 \mathrm{ml} 1 \mathrm{mg} / \mathrm{ml} \mathrm{Nal} \mathrm{sol'n}$

$500 \mathrm{~g} \mathrm{AgNO}_{3}$

2 liters $\mathrm{AgNO}_{3}$ in $0.1 \mathrm{~N} \mathrm{HNO}_{3}$

3 liters $0.1 \mathrm{~N} \mathrm{HNO}_{3}$

1 liter $4 \mathrm{~N} \mathrm{H}_{2} \mathrm{SO}_{4}$

1 liter $2 \mathrm{~N} \mathrm{H}_{2} \mathrm{SO}_{4}$

1 liter $1 \mathrm{~N} \mathrm{HCl}$

2.5 liters $38 \% \mathrm{HCl}$
Chemical Storage Area

20 liters $38 \% \mathrm{HCl}$

20 liters $98 \% \mathrm{H}_{2} \mathrm{SO}_{4}$

$4 \mathrm{~kg}$ Ammonium Oxalate

5 liters $28-30 \% \mathrm{NH}_{4} \mathrm{OH}$

2.5 liters $88 \%$ Formic Acid

$1 \mathrm{~kg} \mathrm{U}_{3} \mathrm{O}_{8}$

2.5 liters $70 \% \mathrm{HNO}_{3}$

2.5 liters Methanol

$100 \mathrm{~g} \mathrm{Nal}$

$100 \mathrm{~g} \mathrm{NaOH}$

$100 \mathrm{~g} \mathrm{MoO}_{3}$

$500 \mathrm{~g} \mathrm{KMnO}_{4}$

$100 \mathrm{~g} \mathrm{RhCl}_{3} \cdot 3 \mathrm{H}_{2} \mathrm{O}$

$200 \mathrm{~g} \mathrm{~K}_{3} \mathrm{RuCl}_{6}$

$100 \mathrm{~g}$ Benzoin a Oxime

$500 \mathrm{~g} \mathrm{AgNO}_{3}$

[1] Waste will consist of $\mathrm{H}_{2} \mathrm{SO}_{4}, \mathrm{HNO}_{3}$, $\mathrm{HCl}$ in various concentrations.

[2] $95 \% 2 \mathrm{~N} \mathrm{H}_{2} \mathrm{SO}_{4}, 5 \%$ conc. $\mathrm{HNO}_{3}$.

[3] Aqueous sol'n. Each $50 \mathrm{ml}$ contains $250 \mathrm{mg} \mathrm{K}_{3} \mathrm{RuCl}_{6}, 5 \mathrm{ml}$ conc. $\mathrm{H}_{2} \mathrm{SO}_{4}$, and $1 \mathrm{ml}$ conc. $\mathrm{HNO}_{3}$. 
Table H-2. Exposure Limits for Mo-99 Chemicals 


\section{APPENDIX I}

ACCIDENT ANALYSIS 


\section{APPENDIX 1 \\ ACCIDENT ANALYSIS FOR THE ACRR AND HCF FACILITIES}

Because they are operating facilities, Sandia's Annular Core Research Reactor and Hot Cell Facility have extensive accident analyses performed in support of their existing missions. These analyses are reported in the Safety Analysis Reports (SARs) for the respective facilities. To comply with recently revised regulatory requirements, the SAR for each facility has been updated and a draft version of the updated SAR is currently being reviewed by the DOE. The accident analyses presented in this appendix are based on analyses contained in the approved SARs, analyses performed and presented in the draft SARs currently in review, and specific analyses performed for the proposed isotope production mission.

Accidents for each facility are grouped into three categories based on their cause as follows:

1. Operational accidents caused by internal events include spills of toxic or radioactive materials, fires, explosions, and nuclear criticalities.

2. Natural-phenomena events that affect the HCF include earthquakes, flooding, tornadoes, and extreme winds.

3. External events include nearby transportation accidents (e.g., aircraft and vehicle crashes), explosions in the propane tank farm, and accidents in other facilities within Technical Area V.

For each category, the accident resulting in the worst consequence is reported in Section 5 of Volume I. Simultaneous accidents between the ACRR and HCF are not considered because no common mode failure has been identified which could result in an accident of worse consequence than the single facility scenarios.

The accidents presented in this Appendix are considered to result in the worst consequence for the public and workers. The methodology used to screen the accidents was developed in accordance with DOE-STD-3009-93. This methodology is described in detail in the HCF SAR which is currently being reviewed by DOE (Restrepo, L. F., Hot Cell Facility Safety Analysis Report, SAND94-2650, SNLNM, 1994). Section 1.1 of this Appendix is the methodology discussion extracted directly from the HCF SAR. Accidents satisfying the screening process and representing the worst overall risk are presented in Sections 1.2 and 1.3 for the ACRR and HCF, respectively. Section 1.4 describes the worst case radiological accident for workers at both facilities.

\section{I.1 Methodology}

\subsubsection{Operational Accidents}

This section identifies the methods and computer codes used in the assessment of the operational accident scenarios, including:

- Identification of initiating events and preventive/mitigating systems or actions.

- Relationships between the preventive/mitigating systems and the accident initiators.

- Identification of accident scenarios or accident-sequence analysis including quantification of frequencies of occurrence.

- Source terms from each of the scenarios or limiting events within each accident category. 
- Dispersion and transport of radioactive and toxic (nonradioactive) material inside the facility and to the environment.

- Consequences from each of the accident scenarios or limiting events.

- Public, worker, and facility risk from all the accident scenarios or limiting events.

Based on the HCF's hazard classification of 2 (HC-2) and on the fact that the frequency of occurrence of the limiting postulated events and their respective consequences are based on conservative assumptions, the results of the risk calculations will bound all other accident scenarios. Therefore, based on the graded approach and on the hazard classification of the facility, only order-of-magnitude (upper-bound) estimates of frequencies are provided and no formal uncertainty analysis is performed herein.

A new DOE standard on the format and content guidance for SARs, DOE-STD-3009-93 (DOE, 1994b) has been issued in draft and is likely to become the standard throughout the DOE complex. The HCF SAR incorporates as many of the recommendations of the newer standard as possible. That is, the hazard analysis will be an integral part of this appendix. Most of the differences between the format of this appendix and that given in the DOE-STD-3009-93 are a result of the fact that most of the HCF SAR was written before the standard was developed.

\section{I.1.1.1 Accident-Sequence Initiating Event (IE) Analysis}

This section identifies the methods used in the identification of possible initiating events and mitigating systems or actions. Initiating events are divided into four major accident categories: fires, explosions, spills, and nuclear criticalities. Other potential events caused by transientinitiated events will not cause any severe consequences to any of the cohorts evaluated nor will they cause any major damage to the facility.

As part of the initiating-event analysis, a plant familiarization with the facility and each of the process systems within the facilities was required. This plant familiarization included, among other things, the acquisition of plant documentation (e.g., existing SARs, piping and instrumentation drawings (P\&IDs), wiring diagrams, and operating procedures), system-process walk throughs, and interviews with operating personnel.

In accordance with SNL/NM ES\&H requirements, the HCF is required to maintain and update preliminary hazard assessments (PHAs) for the facility. These preliminary hazard assessments are designed to help only in the identification of hazardous materials in both radiological and nonradiological operations. PHAs provide only a "snapshot" of the inventory of hazardous materials within the facility at the time they are prepared; they do not define the bounding inventories for the facility. No additional information is provided by these PHAs that could be used to support the hazard or accident analysis. Nonreactor operational Preliminary Hazards Checklists (PHCs) for the HCF are designed to complement the identification of major hazards (radiological or toxic); to establish their maximum inventories; and to identify past accidents, accident initiators, and preventive/mitigating systems or actions for each type of hazard.

\section{I.1.1.2 Plant-System Analysis}

To estimate the frequency of occurrence of an accident scenario, the frequency of occurrence of the initiating event (IE) and the unavailability of each of the mitigating systems identified in the accident-sequence IE analysis was determined. A mitigating system is any system or operator response that would mitigate the consequences of an accident scenario should the IE occur. 
Failure Modes and Effects Analyses (FMEAs), fault- and event-tree analyses, and other accepted modeling techniques were used to analyze the availability of some of the mitigating or supporting systems. FMEAs have been prepared for most safety-related systems described in Chapter 4, Safety Structures, Systems, and Components of the draft HCF SAR. Moreover, information from Human Factors, Chapter 13, of the same unapproved draft HFC SAR identifies various human interactions at the system and component level.

When available, historical information or plant-specific information on the occurrence of IEs or primary events or the availability of mitigating systems or mitigating actions was used. When sufficient historical data were not available, conservative (upper) estimates of generic failure rates and human-error probability (HEP) were used in the quantification of primary events. Fault-tree analyses (FTA) were used when plant-specific unavailability or failure-rate data was not available on the occurrence of IEs or on the availability of safety or support systems. When needed, FTAs were used to identify the possible ways in which the IEs, or mitigating systems, could occur (i.e., cut sets) and their frequencies of occurrence or unavailability.

Boolean algebra and quantification computer codes like SETS (Worrel, 1985), SIPRA (SNL, 1993), FTAP (Willie, 1978), and IMPORTANCE (Lambert, 1975) were used to identify the cut sets and quantify the frequency of occurrence of IEs or the unavailability of mitigating systems or actions in such fault trees. Graphical representation of the fault trees was done with the help of SEATree (SEA, 1994)

\subsubsection{Accident-Sequence Analysis}

Accident sequences that could lead to uncontrolled release (radioactive or nonradioactive) to working areas or to the environment were modeled, identified, and quantified by the use of event trees. In this task, all the safety and support systems responding to each of the IEs identified in the initiating-event analysis were identified along with all the accident-mitigating requirements. The sequential ordering of safety-system response to each IE was modeled by the use of event trees. These event trees provided the accident-sequence logic or accident scenarios that could result.

The computer codes EVNTRE (Griesmeyer, 1989b) along with ETPRE (Griesmeyer, 1989a), PSTEVNT (SNL, 1988), SANET (Camp, 1991), or plain spreadsheets were used in the construction, quantification, and drawing of the event trees.

Components that serve to prevent the IE from happening at the process level were modeled in the system analysis. Generally, separate event trees were generated for different IE groups or accident categories. These event trees were designed to depict the interrelationships between the mitigating systems (or actions) and the IE. These relationships determined the phenomenological information necessary to determine the damage from each of the accident scenarios. For each set of IEs, all the mitigating systems or actions were clearly identified and appeared as headings in the event tree. Support systems appeared in the event tree only if they were common to more than one mitigating system or action. Otherwise, they were modeled as part of the mitigating system unavailability (plant-system analysis).

Where system operation requires operator control, the operators were considered support systems and therefore were modeled in the system analysis. However, if human interactions are performed as emergency responses, these were modeled in the event tree (e.g., fire suppression by operators or the fire department). 
The frequency of occurrence of all accident scenarios identified in the accident-sequence analysis was quantified with the help of the results of the system analysis and the event-tree analyses. Because of the hazard classification of the facility (i.e., HC-2), all frequency calculations are considered order-of-magnitude (upper-bound) estimates. Each initiating event and accident scenario within each accident category was assigned to the frequency plant conditions (PC) as specified in Appendix $3 A$ to the accident analysis methodology chapter of the draft HCF SAR.

PC-1 events, which according to Appendix A are normal events, are those planned or deliberate events expected to occur at regular intervals during normal operations of the facility; they are evaluated and documented in those portions of Chapters 7 and 8 of the draft SAR dealing with the assessment of normal operations. This appendix evaluates only abnormal events or accident conditions, i.e., PC-2, PC-3, and PC-4 events.

Accidents caused by initiating events that can be reasonably shown to have nominal occurrence frequencies of less than $10^{-6}$ per year are not considered credible and need not be analyzed.

The dominant cut sets, if needed, were identified and quantified with the help of any of the Boolean algebra and quantification computer codes listed in the system analysis. Quantification of the frequency of occurrence for each accident scenario in the accidentsequence analysis was obtained by multiplying each system availability or unavailability in the event tree by the frequency of occurrence of the IE, when the mitigation system responses are independent from each other, or by the use of computer codes previously mentioned. From the accident-sequence analysis, all credible accident scenarios were evaluated for each accident category, including the most limiting accident scenarios; these accidents include design-basis accidents (DBAs) or evaluation-basis accidents (EBAs) if information on DBAs was not available, and beyond DBAs (BDBAs) or beyond EBAs (BEBAs). Note that since the HCF was not designed to any particular DBA, all accidents to be analyzed in this appendix are considered EBAs. According to the draft standard DOE-STD-3009 (DOE, 1994b), EBAs are those accidents that are postulated for the purpose of confirming that safety structures, systems, and components (SSCs) can limit accident consequences to less than evaluation guidelines (EG) values.

\section{I.1.1.4 Source-Term Analysis}

This section identifies the methods and codes used to assess the source terms from each of the limiting events or accident scenarios being evaluated. This includes the methods and codes used to determine the initial and building source terms (IST and BST, respectively).

\section{a. Initial Source Terms}

To determine the IST, it is necessary to determine the inventory or material-at-risk (MAR), airborne release fraction (ARF), respirable fraction (RF), and initial leak path factor (ILPF) from a containment area to working areas. The IST gives the respirable amount of dispersible (airborne) material inside working areas or facilities. For hand calculations, the IST was calculated from the following four-factor equation (DOE, 1991).

$$
\text { IST }\left(\mathrm{Ci} \text { or g) }=\text { MAR(Ci or g) } \cdot \text { ARF } \cdot \text { RF } \cdot \text { LPF }_{\text {IST }}\right.
$$

To the extent applicable, the methodologies used in NUREG-1320 (Ayer, 1988) or the suggested ARFs and RFs in the draft DOE standard on release fractions, DOE-STD-SAFT- 
0013 (DOE, 1993) were used to determine the ISTs for each accident scenario or limiting event. For explosion scenarios inside glove boxes or confinement areas, the release fractions, leak path factors, and damage levels documented by Restrepo (Restrepo, 1991) were used to supplement the above references.

The inventory and initial source-term models or codes to be used will depend on the type of accident category being evaluated. For example, the inventory of fission products generated in nuclear criticalities was obtained through the use of the computer code ORIGEN2 (ORNL, 1989). The initial source terms for fire-accident scenarios were obtained through the use of the computer code FIRIN (Ayer, 1988) which directly incorporated the methods outlined in NUREG1320 (DOE, 1993).

\section{b. In-Building Transport and Building Source-Term Analysis}

The building source terms or amount of material released to the environment was determined by taking into account the fraction of the IST that will be reduced due to engineered and natural removal mechanisms before leaving the building, also called the building leak path factor (LPF $\left.{ }_{B S T}\right)$. The methods and codes to be used to determine the BST will depend on the type of accident category being analyzed. For hand calculations the following equation was used to determine the BST:

$$
\mathrm{BST}(\mathrm{Ci} \text { or } \mathrm{g})=\mathrm{IST}(\mathrm{Ci} \text { or } \mathrm{g}) \cdot \mathrm{LPF}_{\mathrm{BST}}
$$

The LPF material by engineered safety features like HEPA filters. For fire accidents the computer code FIRAC (Nichols, 1986) was used to determine both the LPF BST $_{\text {and }}$ ane BST. Because of the hazard classification of the HCF (HC-2) and the relatively low inventories of radioactive materials present in the HCF, more sophisticated or more costly to run in-building transport codes like MELCOR (Summers, 1990), CONTAIN (Murata, 1989), and EXPAC (Nichols, 1990) were not used. Instead, for accident categories other than fires, equation I-2 was used.

Each accident-category section provides its own documentation of the methodology and codes used to determine the source terms, and the assumptions and input used. This includes release characteristics, such as rates and forms.

\section{I.1.1.5 Consequence Analysis}

\section{a. On-site and Off-site Consequences}

The MELCOR Accident Consequence Code System (MACCS) (Chanin, 1990) computer code was used to calculate the on-site and off-site radiological consequences to on-site personnel, to the Maximum-exposed Off-site Individual (MOI), and to the general public from postulated BSTs from the HCF. MACCS uses plant-specific meteorological data, representing 1 year of hourly meteorological data. For hand calculations, equations identified in Chapter 1 of the unapproved draft HCF SAR were used when needed. For radiological exposures, the consequences or dose received off site, on site, or locally were calculated using the following assumptions and input:

- ICRP-30 committed effective dose equivalent (CEDE) or DOE dose conversion factors (DCF) (DOE-0070, DOE-0071) were used in all consequence calculations. 
- For hand calculations, only inhalation and immersion exposures were calculated. (These are the predominant exposure pathways for the HCF.)

- Consequence calculations using the MACCS computer code (Chanin, 1990) were done using Albuquerque site-specific meteorological conditions and data.

- A breathing rate (BR) of $3.47 \times 10^{-4} \mathrm{~m}^{3} / \mathrm{s}$ for all cohorts was used.

- Specific activities (SA) for each radionuclide being analyzed or each representative radionuclide (Ci/g). Specific activities of radioactive materials are calculated from (Nuclear Lectern Association, 1984):

$$
S A=1.3 \times 10^{8} /\left(T_{1 / 2} \cdot M_{a}\right)
$$

Where:

$\mathrm{SA}$ is the radionuclide specific activity (Ci/gram).

$T_{1 / 2}$ is the radionuclide half-life (days).

$M_{a}$ is the radionuclide atomic mass.

To properly assess the impact of radioactive materials on the public and workers, all radionuclides, fission products, and actinides are grouped into 12 chemical groups, based on similar chemical properties. When it was impractical to calculate the consequences for each radionuclide released individually, the maximum hazard potential or dose conversion factor (both inhalation and immersion) for the isotope representing each chemical group was used to assess the consequences off site, on site, and locally. Dose conversion factors for these representative radionuclides along with their respective specific activities are listed in Table 1-1.

\begin{tabular}{|l|l|l|l|}
\hline \multicolumn{4}{|c|}{$\begin{array}{l}\text { Table 1-1. EDE-Dose Conversion Factors and Specific } \\
\text { Activities for Representative Radionuclides }\end{array}$} \\
\cline { 2 - 4 } $\begin{array}{l}\text { Representative } \\
\text { Radionuclide }\end{array}$ & $\begin{array}{l}\text { EDE-Dose Conversion Factor (DCF) } \\
\text { (rem/Ci) }\end{array}$ & $\begin{array}{l}\text { Immersion } \\
\text { (rem-m }\end{array}$ & $\begin{array}{l}\text { Specific Activity } \\
\text { (Ci/g) }\end{array}$ \\
\hline Kr-85 & 0 & $3.6 \times 10^{-4}$ & $3.9 \times 10^{2}$ \\
\hline Cs-137 & $3.2 \times 10^{4}$ & 0 & $8.7 \times 10^{1}$ \\
\hline Sr-90 & $1.3 \times 10^{6}$ & 0 & $1.4 \times 10^{2}$ \\
\hline I-131 & $3.2 \times 10^{4}$ & $6.0 \times 10^{-2}$ & $1.2 \times 10^{5}$ \\
\hline Po-210 & $8.1 \times 10^{6}$ & $1.4 \times 10^{-6}$ & $4.5 \times 10^{3}$ \\
\hline Ru-106 & $4.4 \times 10^{5}$ & 0 & $3.3 \times 10^{3}$ \\
\hline Mo-99 & $3.6 \times 10^{3}$ & $2.5 \times 10^{-2}$ & $4.7 \times 10^{5}$ \\
\hline Pu-239 & $3.3 \times 10^{8}$ & $1.3 \times 10^{-5}$ & $6.1 \times 10^{-2}$ \\
\hline La-140 & $4.4 \times 10^{3}$ & $3.9 \times 10^{-1}$ & $5.6 \times 10^{5}$ \\
\hline Bi-214 & $5.8 \times 10^{3}$ & $2.6 \times 10^{-1}$ & $1.0 \times 10^{3}$ \\
\hline Ag-110m & $5.3 \times 10^{4}$ & $4.5 \times 10^{-1}$ & $4.7 \times 10^{3}$ \\
\hline C-14 & $2.1 \times 10^{6}$ & 0 & $4.5 \times 10^{3}$ \\
\hline
\end{tabular}

For hand calculations, the consequences from the inhalation of a radionuclide can be readily calculated by multiplying the time-integrated air concentrations (i.e., $\chi / Q$ of the SAR by the 
appropriate breathing rate (BR) and the effective dose conversion factor (DCF) for the radionuclide in question.

The following equation was used to calculate the consequences (dose) from the inhalation of radionuclides released to the environment:

$$
\begin{aligned}
& C E D E_{\text {inhalation }}=Q \cdot S A \cdot \chi / Q \cdot B R \cdot D C F_{\text {inhalation }} \\
& \text { Where }
\end{aligned}
$$

CEDE $_{\text {inhalation }}$ is the CEDE received by the cohor from inhalation of the radionuclide at $a$ downwind distance $X$ from the release point (rem).

Q is the source activity (Ci or $\mathrm{g}$ ).

$\chi / Q \quad$ is the time-integrated air concentration $\left(\mathrm{s} / \mathrm{m}^{3}\right)$.

SA is the specific activity (Ci/g) which may be used to convert grams to curies $(\mathrm{Ci})$; if $\mathrm{Q}$ is given in $\mathrm{Ci}$ already, $\mathrm{SA}$ is not used.

BR is the breathing rate $\left(\mathrm{m}^{3} / \mathrm{s}\right)$.

DCF inhalation is the committed DCF from inhalation of a given radionuclide $(\mathrm{rem} / \mathrm{Ci})$.

The following equation was used to calculate the consequences (dose) from the immersion in the plume containing the radionuclides released to the environment:

$$
\mathrm{CEDE}_{\mathrm{immersion}}=\mathrm{Q} \cdot \mathrm{SA} \cdot \chi / \mathrm{Q} \cdot \mathrm{DCF} \mathrm{F}_{\mathrm{immersion}}
$$

Where

$$
\begin{aligned}
& \mathrm{CEDE}_{\text {immersion }} \begin{array}{l}
\text { is the committed effective dose equivalent received by the } \\
\text { cohort immersed in a radioactive plume (rem). } \\
\text { is the } D C F \text { from immersion in a plume containing a given } \\
\text { radionuclide (rem } \cdot \mathrm{m}^{3} / \mathrm{Ci} \cdot \mathrm{s} \text { ). }
\end{array} \\
& \mathrm{Q}, \mathrm{SA} \text {, and } \chi / \mathrm{Q} \text { are as defined above. }
\end{aligned}
$$

The overall dose received by the receptor (i.e., locally, on site or off site) from airborne radioactive sources is calculated by adding the doses received from the two exposure pathways (i.e., inhalation and immersion). In other words, the total dose received is given by:

$$
\mathrm{CEDE}_{\text {Total }} \quad=\mathrm{CEDE}_{\text {inhalation }}+\mathrm{CEDE}_{\text {immersion }}
$$

Where

$$
\begin{aligned}
& \text { CEDE }_{\text {Total }} \text { is the total committed effective dose equivalent (rem) from } \\
& \text { the inhalation of a radionuclide in the plume and immersion } \\
& \text { in it. }
\end{aligned}
$$


The methodology for calculating the consequences to individuals located in the vicinity of the accident (i.e., local receptors) will depend on whether or not the accident category can cause the radioactive material to become airborne or not.

For radioactive material that becomes airborne, the consequences or dose from the inhalation of or immersion in radioactive material can be calculated by using the following equation:

$$
\begin{aligned}
& \mathrm{CEDE}_{\text {inhalation }}=\mathrm{C}^{\prime} \cdot \mathrm{SA} \cdot \mathrm{BR} \cdot \mathrm{DCF} \mathrm{F}_{\text {inhalation }} \cdot \mathrm{T} \\
& \mathrm{CEDE}_{\text {immersion }}=\mathrm{C}^{\prime} \cdot \mathrm{SA} \cdot \mathrm{DCF} \mathrm{F}_{\text {immersion }} \cdot \mathrm{T}
\end{aligned}
$$

Where

$\mathrm{C}^{\prime}$ is the local concentration of airborne radioactive material release $\left(\mathrm{Ci} / \mathrm{m}^{3}\right.$ or $\mathrm{g} / \mathrm{m}^{3}$ ).

T is the exposure time. All other variables have been previously defined.

The overall dose received by the receptor (i.e., locally) from airborne radioactive sources is calculated using Equation I-6.

For non-airborne radionuclides, or for the accident category of inadvertent exposure to highly penetrating radiation (i.e., gamma or energetic beta radiation), the dose received from directpenetrating radiation sources like $\mathrm{Co-60}$ or $\mathrm{Cs-137}$ was calculated using shielding models. That is, all direct radiation exposures from gamma sources were calculated using the MICROSHIELD® computer code (Grove Engineering, Inc., 1987). Other, more sophisticated shielding codes like QADMOD-GP (ORNL, 1990) were not used because of the uncertainties in the geometrical configurations postulated. If these codes were not available, the following equation was used to calculate the dose rate $\left(D^{\prime}\right.$ in rem/h) received by a receptor a distance $d$ from a point gamma source (Chilton, 1984).

$$
D^{\prime}=\left(6.81 \times 10^{4} Q_{0} E_{i} B_{f}(-\mu x) /\left(4 \pi d^{2}\right)\right.
$$

Where

$6.81 \times 10^{4}$ is a constant conversion factor (rem. $\left.\mathrm{cm}^{2} / \mathrm{h} \cdot \mathrm{MeV} \cdot \mathrm{Ci}\right)$, based on the energy flux to dose-rate conversion factor (i.e., $1.84 \times 10^{-6}$ ) and the conversion from $\mathrm{Ci}$ to disintegrations per second (dps) (i.e., $3.7 \times 10^{10}$ ).

$\mathrm{QO}_{\mathrm{i}} \quad$ is the source (gamma) activity (Ci).

$E_{i} \quad$ is the weighted average photon energy, i.e., decay energy weighted by the percent of decay of the isotope, (MeV).

$B_{\mathrm{f}} \quad$ is the buildup factor (unitless).

$\mu \quad$ is the linear attenuation coefficient for the energy and composition $\left(\mathrm{cm}^{-1}\right)$.

$x \quad$ is the shield thickness (cm).

d is the distance from the source to the receptor location, $\mathrm{cm}$. 
The total dose $(D$, in rem) received by the receptor from the point gamma source is calculated by multiplying the dose rate ( $\left.D^{\prime}\right)$ by the total exposure time $(T)$, i.e.:

$$
D=D^{\prime} \cdot T
$$

For these calculations (using computer codes or Equation 1-9) the following assumptions were made:

- Point, isotropic sources.

- No shielding, except standard air.

- When the percent decay for the isotope is not available, use the energy $\left(E_{i}\right)$ in Equation $1-9$ as the weighted average energy for the isotope in question to calculate the attenuation coefficient in air. Use Table of Nuclides or similar reference to identify the percent abundance and the decay energy.

- The distance to the receptor is equal to the thickness of the shield (air) (i.e., $x=d)$.

- The Geometric Progression (ANSI/ANS-6.1) (ANSI, 1977) method or standard tables when available to determine the buildup factor $\left(B_{f}\right)$. If data for geometric progression are not available, use the Taylor method (Chilton, 1984) to calculate the buildup factor.

- For direct irradiation from a point source (gamma), the exposure time will be dependent on the accident scenario

The dose calculated by the computer codes mentioned above or by the use of equations $1-9$ and $\mathrm{I}-10$ is equivalent to the committed effective dose equivalent (CEDE) received.

The computer codes HAZCON (Spectral Research Institute, 1981) or SLAB (Ermak, 1988) or the Canadian Portable Computing System for Use in Toxic Gas Emergencies (ISBN 0-77438932-X, OMERAB, 1983) were not used to assess the concentrations of toxic pollutants at offsite locations where either the MOI or the public are postulated to be located because of the low levels of toxic materials postulated to be released. The methods for estimating toxic concentrations of toxic materials by hand are presented in the section on spills, if applicable.

\section{b. Local or Worker Consequences}

In addition to hand or spreadsheet calculations of consequence estimates, the DOSES computer code (Restrepo, 1992) may be used if needed (that is, if short-lived radionuclides are assumed to be released within the HCF) and if results from MELCOR (Summers, 1990) are available to support the calculations of consequences to personnel postulated to be located in the HCF (inside the facility) from radiological releases. FIRAC (Nichols, 1986) can also be used to estimate the concentrations of airborne radioactive material within the facility.

All local radiological-consequence calculations involved only the exposure from the inhalation and immersion in the contaminated volume. Consequence calculations from nonradiological releases involved the calculation of the concentration of toxic materials in the local area, or of 
the pressures resulting from pressurized releases (i.e., explosions). The equations and models to be used will be documented in their respective sections.

\section{c. Facility Damage}

Facility damage was estimated by considering the percentage of the facility that would be damaged to the point that it would require replacement, including interruption of operations. To facilitate this estimate, the facility cost/damage impact has been divided into four categories, the first three addressing the physical value of the building (replacement), and the fourth the contribution from the potential for interruption of operations: (1) building structure, (2) process equipment, (3) utilities and support equipment, and (4) interruption of operations. Percent facility damage estimates are made using engineering judgment and were based on a lower limit of 0.1 percent damage (Stone \& Webster Engineering, 1991). No dollar amount is assigned to damage so as to provide a continuous damage estimate which could be easily translated into cost estimates at any time without having to worry about inflation or other factors that may change the present estimates of the damages.

\section{d. Environmental Impacts}

The results of the airborne dispersion analysis (i.e., ground concentrations) using the MACCS computer code (Chanin, 1990) were used to determine the environmental impacts from radiological releases. Other nonradiological environmental impacts were evaluated on a caseby-case basis.

\subsubsection{Risk Analysis and HCF Comparison to Guidelines}

This section summarizes the frequency, consequences, and risks (single-point estimates) to the public, on-site co-located workers, local workers, and the facility from the bounding EBAs (or maximum credible accidents) and BEBAs; no risk curves are presented. It also compares calculated consequences for these various accident scenarios with the consequence EGs in Appendix $3 A$ to the draft HCF SAR for public, on-site, and local workers.

The calculated frequency was correlated to the appropriate frequency category outlined in Appendix $3 A$ referenced above. The frequency categorization for each of the bounding EBAs and BEBAs was correlated to acceptable radiological and toxicological evaluation guidelines (i.e., threshold values) to show that the more likely the event, the lower the potential consequences, and, conversely, the higher the potential consequences, the lower the probability of occurrence. This is achieved by requiring that all exposures be scaled as a function of the frequency of occurrence of the accident scenario in order to maintain a constant acceptable risk. This also ensures that facilities are designed so they can be operated without undue risk to the public or the workers. Appendix $3 A$ of the draft HCF SAR summarizes the proposed radiological threshold Evaluation Guidelines for Radiological Exposures as a function of frequency category (or plant condition).

\subsubsection{Natural Phenomena and External Events}

Natural phenomena events include, but may not necessarily be limited to, the following categories: earthquakes, tornadoes or other extreme winds, and flooding. External events will include, but may not be limited to, the following categories: nearby transportation accidents and accidents at nearby facilities. 
No DOE-approved site-specific natural-phenomenon hazard assessments have been conducted pursuant to DOE Order 5480.28 (DOE, 1993) and its implementation standards (Kennedy, 1989). Therefore, the DOE-defined criteria for the site (or facility) were used (i.e., UCRL-15910) (Kennedy, 1989). That is, since the methods defined in DOE Order 5480.28 and its applicable standards have not been used, the methods used to define the design or evaluation basis natural-phenomena events for the HCF (or site), including the return periods and loads in the University of California Research Laboratory (UCRL) reports, were used. The frequency or return period for such events is presented quantitatively, along with the expected consequences to the public, workers, and the facility itself.

\subsubsection{Design-Basis Events}

Since DOE Order 5480.28 (DOE, 1993a) and its applicable standards were not available at the time this SAR was being prepared, the requirements in other DOE Orders were used in the assessment of natural-phenomena events. In accordance with DOE Order 6430.1A (Section 0111-99.0.4), the modeling techniques presented in the natural-phenomena modeling project for both seismic hazards (Coats, 1984) and extreme-wind/tornado hazards (Coats, 1985) were used to establish the design-basis earthquake and extreme-wind/tornado characteristics consistent with the approach specified in Kennedy, 1989. The procedures and approaches presented in Kennedy, 1989 were used to determine the maximum horizontal and vertical ground surface accelerations at the facility, the wind speeds for design loads, and the probability of occurrence of such event loads.

\subsubsection{Frequency of Occurrence or Return Periods}

As a minimum, the procedures and approaches presented in Kennedy, 1989 will be used to determine the probability of occurrence or return periods for each of the applicable naturalphenomena events affecting the facility.

\section{I.1.2.3 Facility and Equipment Response}

Once the design loads for the various design-basis natural-phenomena events were established, the facility and equipment response to the various loads postulated was determined. The methods presented in the reports mentioned above provided the methodologies recommended to be used in assessing the facility and equipment responses. The section on natural phenomena describes the method used to evaluate such analyses.

Damage ratios based on the response of the facility and equipment will be determined. These damage ratios correspond to the percentage of the facility, SCBs, glove boxes, and equipment containing hazardous materials that is damaged, resulting in an unfiltered or unconfined release of these hazards.

\subsubsection{Source-Term Analysis}

Equations used to determine the IST and the BST from natural-phenomena events are documented by Foppe (Rocky Flats, 1993, Foppe, 1988, and DOE, 1991). Data on release fractions and additional methodology to determine IST and BST are also contained in NUREG1320 (Ayer, 1988) or in the DOE draft Standard on Release Fractions, DOE-STD-SAFT-0013 (DOE, 1993). 


\subsubsection{Consequence Analysis}

The same methodology and computer codes identified in Section 1.1.1.5 were used in assessing the consequences from postulated releases from natural-phenomena events for the HCF.

\subsubsection{Risk Analysis}

As with operational accidents, single-point risk estimates from each of the design- or evaluation-basis natural events were obtained; this includes also a comparison to Evaluation Guidelines (EG) in Appendix 3A of the HCF SAR, even though the draft DOE-DP-STD-3005 (DOE, 1994a) does not require such a comparison for natural-phenomena events. This comparison is included for risk-management purposes only, providing comparisons between operational, external, and natural-phenomena events.

\section{I.1.3 External Events}

External events include those events outside the HCF that could impact the operation of the facility and could potentially result in releases from the facility itself and, therefore, contribute to the consequences from the facility itself.

\section{I.1.3.1 Identification of External Events}

The following external event categories have been identified as having some potential for causing releases or damage to the HCF: airplane crashes, transportation or handling accidents, accidents at the ACRR or the SPR facilities as documented in their respective SARs, and an explosion at the propane gas tank farm north of the facility.

\subsubsection{Event-Frequency Estimation}

When data were not available, the methodology and codes identified in Section I.1.1.2 or specific methodology to be presented in their respective sections were used to determine the frequency or probability of occurrence of such external events.

\section{I.1.3.3 Facility-Damage Assessment}

The facility damage assessment was based on the energy released from the postulated external events. This assessment determined the extent of the damage to the HCF.

\section{I.1.3.4 Source-Term Analysis}

The methods and computer codes identified, outlined, and documented in NUREG-1320 were used to assess the source-term estimates from external events; any other methods or computer codes used will be documented in their respective sections.

\subsubsection{Consequence Analysis}

The same methodology and computer codes identified in Section I.1.1.5 were used to assess the consequences from postulated releases from external events for the HCF. 


\subsubsection{Risk Analysis}

As with operational accidents and natural-phenomena events, single-point risk estimates were performed for each of the postulated external events affecting the HCF; this also included a comparison with Evaluation Guidelines in Appendix 3A of the HCF SAR.

\subsection{ACRR Accident Analysis}

The ACRR accident analysis has been performed for two distinct modes of operation: pulse mode for the current mission and steady-state production mode for the proposed action. For the steady-state production mode, the pulse capabilities of the reactor will be physically disabled. For this mode, pulsing accidents which were previously analyzed in detail in the ACRR Safety Analysis, are not considered credible. For completeness of this analysis, the worst-case pulsing accident is included as part of this document. This accident (a \$10.25 reactivity insertion in $80 \mathrm{msec}$ ) serves as the Design Basis Accident for the ACRR. The DBA is the upper bounding case for postulated credible accidents. However, the $\$ 10.25$ reactivity insertion in $80 \mathrm{msec}$ is not a credible event for ${ }^{99}$ Mo operations because the reactor will not be run in a pulse mode. Therefore, analyses and consequences for this accident are presented separately in Appendix $F$.

Table I-2 gives a summary of the accident scenarios analyzed in detail for the ACRR. For each accident, the estimated probability of occurrence and mechanical consequences to the reactor are listed. Accidents highlighted by an asterisk are considered the worst case for consequences and a detailed descriptions of these scenarios are contained in Section 5 of the main body of this report. All other accident scenarios are described in the following discussion.

\section{I.2.1 ACRR Operational Accidents}

ACRR operational accidents are defined as potential accident situations due to system failure or operator error within the ACRR facility.

Fuel element accident scenarios are discussed in the context of the existing fuel elements. Facility modifications call for new uranium fuel elements that do not contain $\mathrm{BeO}$ to be installed after about two years of ${ }^{99}$ Mo operations. Replacement fuel elements would have the same physical form as existing elements, and would contain the same amount of ${ }^{235} \mathrm{U}$, i.e., about 100 gm/element. The new elements would differ from the existing fuel in that their ${ }^{235} \mathrm{U}$ enrichment would be less than 20 percent, the heat transfer between fuel and cladding would be larger, and they would not be able to operate in the pulse mode.

It is expected that $130-180$ elements would be required for a complete core loading. A complete core would last about 5 years, with one-fifth of the elements being replaced each year. While any replacement element would be expected to have comparable performance characteristics, since the exact design and composition of replacement fuel elements have not been finalized, the data presented here apply only to the existing fuel elements.

\section{Dry Fuel Element Rupture}

The ACRR fuel element mechanical design is dominated by the criterion that fuel element cladding integrity be maintained for all normal operations during the expected reactor lifetime. The $\mathrm{UO}_{2}-\mathrm{BeO}$ fuel has been tested to $1500^{\circ} \mathrm{C}\left(2732^{\circ} \mathrm{F}\right)$ without observable degradation such 
as cracking or powdering. Melting of the $\mathrm{UO}_{2}-\mathrm{BeO}$ fuel starts at $2150^{\circ} \mathrm{C}\left(3902^{\circ} \mathrm{F}\right)$ and the $\mathrm{BeO}$ melting is complete at about $2450^{\circ} \mathrm{C}\left(4442^{\circ} \mathrm{F}\right)$. On the basis of the thermal/hydraulic performance of the reactor core, a peak fuel temperature of $1800^{\circ} \mathrm{C}\left(3272^{\circ} \mathrm{F}\right)$ was established as the maximum operating temperature for maintaining cladding integrity. The peak fuel temperature is about $900^{\circ} \mathrm{C}\left(1652^{\circ} \mathrm{F}\right)$ at $2 \mathrm{MW}$ steady-state operation, and maximum pulse operations yield peak fuel temperatures of about $1350^{\circ} \mathrm{C}\left(2462^{\circ} \mathrm{F}\right)$. 
Table 1-2. Estimated Annual Probability of Occurrence and Mechanical Consequences for ACRR Accident Scenarios

\begin{tabular}{|c|c|c|}
\hline $\begin{array}{l}\text { Accident } \\
\text { Scenario }\end{array}$ & $\begin{array}{l}\text { Estimated Probability of } \\
\text { Occurrence/Year }\end{array}$ & $\begin{array}{l}\text { Mechanical Consequences to } \\
\text { Reactor }\end{array}$ \\
\hline \multicolumn{3}{|l|}{ OPERATIONAL ACGIBENTS } \\
\hline $\begin{array}{l}\text { Rupture of undamaged fuel } \\
\text { element }\end{array}$ & $<10^{-6}$ & $\begin{array}{l}\text { May damage other rods and/or } \\
\text { targets. Possible fission product } \\
\text { release. }\end{array}$ \\
\hline $\begin{array}{l}\text { Uncontrolled fuel rod withdrawal - } \\
\text { subcritical (Safety system fails) }\end{array}$ & $10^{-4}-10^{-6}$ & $\begin{array}{l}\text { Partial fuel melt. Cap and } \\
\text { cladding integrity maintained; no } \\
\text { fission product release. }\end{array}$ \\
\hline $\begin{array}{l}\text { Uncontrolled fuel element } \\
\text { withdrawal - high power (Safety } \\
\text { system fails) }\end{array}$ & $10^{-4}-10^{-6}$ & None expected. \\
\hline $\begin{array}{l}\text { Waterlogged fuel element } \\
\text { rupture }\end{array}$ & $10^{-4}-10^{-6}$ & $\begin{array}{l}\text { May damage other rods and/or } \\
\text { targets. Possible fission product } \\
\text { release. }\end{array}$ \\
\hline Waterlogged target rupture & $10^{-4}-10^{-6}$ & $\begin{array}{l}\text { May damage other rods and/or } \\
\text { targets. Possible fission product } \\
\text { release. }\end{array}$ \\
\hline $\begin{array}{l}\text { Fuel/target element dropped and } \\
\text { ruptures }\end{array}$ & $10^{-4}-10^{-6}$ & $\begin{array}{l}\text { May damage other rods and/or } \\
\text { targets. Possible fission product } \\
\text { release. }\end{array}$ \\
\hline Leak in reactor coolant system & $10^{-4}-10^{-6}$ & $\begin{array}{l}\text { Reactor shutdown. Coolant loss. } \\
\text { No fission product loss. } \\
\end{array}$ \\
\hline Total loss of coolant & $<10^{-6}$ & $\begin{array}{l}\text { Reactor shutdown. No fission } \\
\text { product release. }\end{array}$ \\
\hline Cold water injection & $<10^{-6}$ & None expected. \\
\hline \multicolumn{3}{|c|}{ NATURAL PHENOMENA ACCIDENTS } \\
\hline Floods & $10^{-2}-10^{-4}$ & None expected. \\
\hline High winds and tornadoes & $10^{-1}-10^{-3}$ & $\begin{array}{l}\text { Damage may be equivalent to } \\
\text { bridge crane collapse. Possible } \\
\text { fission product release. Reactor } \\
\text { shutdown. }\end{array}$ \\
\hline Earthquakes & $10^{-2}-10^{-4}$ & $\begin{array}{l}\text { Damage may be equivalent to } \\
\text { bridge crane collapse. Possible } \\
\text { fission product release. Reactor } \\
\text { shutdown. } \\
\end{array}$ \\
\hline $\begin{array}{l}\text { *Earthquake bridge crane } \\
\text { collapse }\end{array}$ & $<10^{-6}$ & $\begin{array}{l}\text { Reactor shutdown; } \\
\text { superstructure crushed. Possible } \\
\text { fission product release. }\end{array}$ \\
\hline \multicolumn{3}{|l|}{ EXTERNAL EVENT ACGIDENTS } \\
\hline *Airplane/projectile impact & $10^{-4}-10^{-5}$ & $\begin{array}{l}\text { Damage may be equivalent to } \\
\text { bridge crane collapse. Possible } \\
\text { fission product release. Reactor } \\
\text { shutdown. } \\
\end{array}$ \\
\hline Explosion & $<10^{-6}$ & N/A; not a credible event. \\
\hline Fire & $10^{-2}-10^{-4}$ & $\begin{array}{l}\text { Minimal damage in high bay. } \\
\text { Possible fission product release } \\
(<1 \text { mCi) if HEPA filters } \\
\text { damaged. }\end{array}$ \\
\hline
\end{tabular}

*Worst-case accident scenario in this category. 
Under steady-state operating conditions of $4 \mathrm{MW}$, cladding integrity is expected to be maintained for the reactor lifetime. While it is possible that individual fuel elements may be damaged prior to the end of the reactor life, to date no evidence (i.e., changes in coolant radioactivity and/or resistivity) has been found that indicates damage is occurring. The estimated probability of occurrence for spontaneous rupture of a fuel element is $1 \times 10^{-4}$ to $1 \times 10^{-6}$.

\section{Uncontrolled Control Rod Withdrawal - Subcritical or Low Power Delayed Critical}

All movements of fuel within the pool area, and especially in the core region, would require that the reactor be shut down. An uncontrolled withdrawal of the control rod bank while subcritical or operating at a low power condition is an abnormal event, and the control system is designed, constructed, tested and inspected to minimize failures that could result in the uncontrolled addition of reactivity to the system.

To estimate an upper bound on the amount of fuel above the melt temperature, a bounding scenario is again assumed - concentrated temperature distribution with the fuel element located at that point. Using these assumptions, for a $\mathrm{T}_{\max }$ of $2284^{\circ} \mathrm{C}\left(4143^{\circ} \mathrm{F}\right)$, the fraction of fuel in the element at or above $2150^{\circ} \mathrm{C}\left(3902^{\circ} \mathrm{F}\right)$ is about 0.32 (32 percent). This is a conservative estimate of the fraction of fuel/element from which fission products could escape if the cladding were breached. Since the average fuel temperature is less than the cladding melting point range of $1400-1454^{\circ} \mathrm{C}\left(2552-2649^{\circ} \mathrm{F}\right)$, and the niobium liner would maintain its integrity at $2284^{\circ} \mathrm{C}\left(4143^{\circ} \mathrm{F}\right)$, it is expected that the cladding would be undamaged under these conditions, and no fission products would be released.

\section{Uncontrolled Control Rod Withdrawal - High Power Delayed Critical}

As in the case of control rod bank withdrawal from low power, uncontrolled withdrawal of the control rod bank while operating at high power results in a transient increase in reactor power and fuel element temperature to new equilibrium conditions that are dependent upon the amount of reactivity added. If reactivity addition rates are evaluated for the maximum uncontrolled withdrawal rate for assumed operational power levels of $2 \mathrm{MW}$ and $4 \mathrm{MW}$, the core-averaged fuel temperatures are about $600^{\circ} \mathrm{C}$ and $1000^{\circ} \mathrm{C}\left(1112^{\circ} \mathrm{F}\right.$ and $\left.1832^{\circ} \mathrm{F}\right)$, respectively, with maximum temperatures of $1068^{\circ} \mathrm{C}$ and $1780^{\circ} \mathrm{C}\left(1954^{\circ} \mathrm{F}\right.$ and $\left.3236^{\circ} \mathrm{F}\right)$. No damage is expected for the $4 \mathrm{MW}$ case. Localized boiling may occur for the $4 \mathrm{MW}$ case, but the mechanical integrity of the niobium cup and the stainless steel cladding would not be degraded to a failure point.

\section{Waterlogged Target Element Rupture}

Since target exposure time is only about 7 days, resulting in a lower fission product inventory relative to fuel elements, and the power level per element is smaller than the maximum fuel element power, target element rupture due to mechanical stress created by excessive radiation flux density is not a credible accident scenario. The most likely abnormal event is a pinhole leak.

At $4 \mathrm{MW}$ steady-state power, for a target element containing about $20 \mathrm{gm}$ of 93 percent enriched $\mathrm{U}_{3} \mathrm{O}_{8}$, the power level/target can be as high as $17.5 \mathrm{~kW}$. The expected maximum target equilibrium temperature for this condition is $100^{\circ} \mathrm{C}\left(212^{\circ} \mathrm{F}\right)$. At this temperature, neither the mechanical integrity of the $\mathrm{U}_{3} \mathrm{O}_{8}$ nor the stainless steel cladding would be challenged. 
Reactor fuel elements and targets would be handled during removal from the reactor core, transfer to temporary storage in the GIF pool, and eventual return to the core (fuel elements) or packaging for transfer (targets). While fuel or target element rupture due to a hot spot or a departure from nucleate boiling during reactor operation is possible, but unlikely, a rupture could occur due to dropping the element during an element change-out. A target rupture could occur in the GIF pool as a result of being dropped or being crushed by an object falling into the pool, such as the transfer cask. Estimated probability of occurrence for these events is $1 \times 10^{-4}$ to $1 \times 10^{-6}$.

Fuel elements and targets would be moved out of the reactor one at a time and only when the reactor is not operating. All transfers would take place under water at the depth of the passthrough ports between the ACRR pool and the GIF pool. A credible accident would be to drop the fuel element or target during one of these transfer operations. Since fuel elements and targets would be designed to survive a drop through $20 \mathrm{ft}$ of air with subsequent impact on a stainless steel surface, it is expected that element structural integrity would be maintained during this event.

The worst-case scenario would be to drop either item such that it impacts the reactor core, causing a perturbation in reactivity. However, the shutdown margin in the core is significantly large and negative such that the reactivity perturbation (if fuel element structural integrity is maintained) would be negligible. The probability of a fuel element drop into the core causing criticality is estimated to be less than $1 \times 10^{-6}$.

\section{Damaged Fuel/Target Transfer Cask}

The possibility of a release of radioactive material or damage to the reactor core as a result of damage to a container used to transfer fuel elements or targets is unlikely (estimated probability of occurrence $=10^{-4}-10^{-6} / \mathrm{yr}$ ). Heavy loads such as shipping casks would not be handled over the reactor; they are moved into the reactor room by manned transporter and placed on the floor. Irradiated ${ }^{99} \mathrm{Mo}$ targets and spent fuel would be loaded into transfer containers in the GIF pool. If a cask were to be dropped during this operation, the reactor would be unaffected. Since both fuel elements and targets have been designed and tested to withstand a $20-\mathrm{ft}$ drop onto a stainless steel surface, elements inside a transfer cask that was dropped back into the storage pool would not be affected. If any fuel elements were in storage in the pool, they would be in racks along the side of the pool and it is extremely unlikely they would be damaged by a vertical drop of a large object such as the transfer cask. Since, at any one time, up to four targets may be in the GIF pool, the worst case for this type of drop would be if all four targets were impacted.

\section{Primary Heat Exchange Leak}

The discharge pressure on the secondary side of the heat exchanger is higher than the pressure on the primary side. If a leak were to occur in the heat exchanger, water would flow to the primary side from the secondary. Contamination of the secondary water would be highly unlikely. The water makeup rates for both the primary and secondary sides are monitored for consistency. Any deviations from normal are investigated to determine the source of the additional water makeup demand. 


\section{Reactor Coolant System Failure}

The reactor coolant tank and piping operate at ambient pressure and temperature. Core cooling is achieved by natural convective flow in all modes of operation. A bulk coolant system extracts coolant at about $2.4 \mathrm{~m}$ (7.9 ft) from the reactor tank top, passes the coolant through two heat exchangers, and returns the coolant to the reactor tank through a pipe at the bottom of the tank. Along with a secondary evaporative cooling tower, the system is capable of rejecting $4 \mathrm{MW}$ of heat while maintaining the primary coolant temperature at $60^{\circ} \mathrm{C}$ or less. As part of the ${ }^{99}$ Mo facility modifications, this cooling capacity would be doubled.

The system components outside the reactor tank have a low probability of serious leakage or of gross failure that would propagate. Any piping malfunction that would cause a siphon effect and drain the pool would at worst lower the tank water level to about $2.4 \mathrm{~m}$ above the core. It is virtually impossible for the reactor tank to break because of reinforced concrete supports on the bottom and side. The tank is connected to the GIF pool through two ports in the common wall; draining the GIF by any means would not lower the reactor tank coolant level past the ports, and the core would still be under about $4 \mathrm{~m}$ of water.

In case of a loss of cooling, i.e., instantaneous loss of all coolant during 2 MW steady-state operation, resulting in immediate reactor shutdown, the calculated maximum fuel temperature is about $1550^{\circ} \mathrm{C}\left(2882^{\circ} \mathrm{F}\right)$, and occurs about 13 hours after loss of coolant. At $4 \mathrm{MW}$, maximum fuel temperature would occur several hours earlier, but still with sufficient time for response.

Less severe incidents, such as total or partial loss of coolant flow, would have little effect. If loss of flow is due to a power outage, the reactor would also shut down. Decay heat would be removed from the core by convection heat transfer with the reactor tank water. If a partial coolant flow loss were to occur due to blockage of some of the coolant flow channels, localized boiling could occur in the flow channels adjacent to fuel elements in the peak flux regions. This would have several effects:

- The change in coolant density would aggravate the already existing under-moderated condition and most likely result in localized reactivity decreases that would lower the power level in the affected fuel element. Tests conducted at $4 \mathrm{MW}$ have confirmed that formation of voids due to coolant boiling results in a decrease in reactor power.

- Boiling would enhance heat transfer in the vicinity of the fuel elements.

- Coolant blockage is prevented by the availability of ample cross flow paths throughout the core.

In summary, the cumulative effect of any coolant system abnormal event other than complete loss of coolant would be, at most, to raise the fuel element cladding temperature a few degrees above its steady-state value for normal operations.

\section{Criticality}

Storage requirements for Special Nuclear Material are based on the attractiveness level, chemical form, and quantity of material. Category III material, $<20 \mathrm{~kg}{ }^{235} \mathrm{U}$, is required to be stored in a locked and alarmed room or on a 2-hour patrol. Category IV material, $<6 \mathrm{~kg}{ }^{235} \mathrm{U}$, requires only a locked storage area. 
Each target would contain approximately $25 \mathrm{gm}$ of ${ }^{235} \mathrm{U}$ in the form of $\mathrm{U}_{3} \mathrm{O}_{8}$. To remain a Category IV quantity, the number of targets stored cannot exceed 240. To remain a Category III quantity, the number of targets stored cannot exceed 800 . Approximately 40 targets per week are expected to be required for full production ( $200 \%$ of North American demand) of about 2080 targets/yr.

At least two locations within TA-V would be used to store the targets; one near the reactor that would contain Category IV material ( $<240$ targets) and one at a separate location that would contain Category III material ( $<800$ targets). If more targets are required, other storage locations within TA-V can be utilized. For storage of SNM quantities greater than $700 \mathrm{gm}$, a criticality assessment would be performed on the storage configuration.

Replacement unirradiated fuel elements would be stored in a separate TA-V location. Fuel elements typically contain $100 \mathrm{gm}$ of ${ }^{235} \mathrm{U}$. A full core loading will require 130 to 180 elements, equaling 15 to $20 \mathrm{~kg}$ of ${ }^{235} \mathrm{U}$, i.e., Category III quantities.

Irradiated fuel elements would be stored in the GIF pool in criticality-safe storage racks. The storage racks would be stowed under the GIF cells so that the transfer cask cannot come in contact with the racks. The GIF pool has enough protected storage space for several cores of irradiated fuel.

\section{I.2.2 ACRR Natural Phenomena Accidents}

Natural phenomena that could impact the ACRR are floods, tornadoes, high winds, and earthquakes.

\section{Floods}

The maximum observed precipitation in 24 hours in the Albuquerque area occurred in 1994, when $56 \mathrm{~mm}$ (2.2 in) were recorded at the Albuquerque International Airport measuring station. Since thunderstorms move with the prevailing winds aloft, they can produce significant precipitation upland from the reactor complex. Localized flooding may result from this concentrated activity, and water may run high in arroyos in the area. Since TA-V is situated on ground higher than the surrounding terrain, precipitation tends to run off rather than collect in the area. Arroyo del Coyote to the east collects runoff from the mountains and diverts it from the area; therefore, normal precipitation would not cause flooding at TA-V. In the past, there has been only minor localized flooding due to rainfall within TA-V itself, such as in the HCF, which is below grade. This has never affected ACRR operations, since all below-grade areas are equipped with sump pumps.

\section{High Winds and Tornadoes}

During the time that meteorological records have been maintained for KAFB East, no tornadoes have been observed at TA-V. Only two tornadoes have been reported in the Albuquerque area for the 20-year period from 1970 to 1990 . On a point probability basis, the reactor site lies in a zone of $2 \times 10^{-4}$ or less annual tornado probability.

Based on the small probability of occurrence, postulated low intensity, the remote location of $T A-V$, and the low fission product inventory, criteria for tornadoes were not included in the design; however, since high winds in excess of $30 \mathrm{~m} / \mathrm{sec}(70 \mathrm{mph})$ do occur, Building 6588 was designed and constructed to withstand this wind load. Wind speeds as high as $45 \mathrm{~m} / \mathrm{sec}$ have been recorded at the reactor site, with no resultant structural or architectural damage. 
Assuming damage onset, but not destruction onset, at a wind speed of $60 \mathrm{~m} / \mathrm{sec}$, the statistics of small numbers estimates that damage onset would occur about every 5000 years at the reactor site.

Although the probability of a tornado occurring at the reactor site is extremely low, it is still possible to estimate the resultant damage to the reactor building. Building response to a tornado (disregarding missile impact) can be summarized by (1) anticipating that the roof will blow off due to aerodynamic lift and pressure differential, followed by (2) a collapse of the walls caused in part by wind loading. It is anticipated that the worst consequences of high wind damage would be bounded by those estimated for the collapse of the bridge crane into the reactor.

Structural damage resulting from a direct tornado strike would be significant; however, dose hazard would be insignificant compared to the direct loss of life which could be expected from the tornado itself. The resultant downwind dose hazard associated with a tornado or high winds would be minimal, although it is conceivable that radioactive debris could be carried in the tornado and deposited away from the site, thereby creating localized pockets of radioactive sources.

\section{Earthquakes}

Beginning in 1960, instrumented seismic records for New Mexico indicate the pattern of seismic activity for earthquakes with a magnitude $\leq 2.7$ has shifted such that the center of activity is now in the northeast quadrant of the state. Although Richter magnitudes $\leq 2.7$ have been recorded for seven earthquakes centered near Albuquerque during the last 20 years, there is no geological evidence for intensive earthquakes in the Albuquerque area within recent geologic history. Strong earthquakes have not affected the area within the last 300 years, and the area has been relatively stable for possibly as long as thousands of years.

\section{Earthquake with Collapse of the Bridge Crane}

The Albuquerque area is located in Seismic Zone 2, which, by definition, is a region that can be expected to receive moderate damage from earthquakes, corresponding to a value of 5 to 6 on the Richter scale. An earthquake of intensity sufficient to collapse this bridge crane onto the reactor is considered as the worst consequence and is described in Section 5, Volume I.

\subsubsection{ACRR External Event Accidents}

External events that could cause an accident situation include man-made disasters such as an external explosion, fire or airplane crash, and natural disasters such as an earthquake, tornado or flood. Table 1-2 contains risk information for events that could result in a release of radioactive materials.

\section{Airplane/Projectile Impact}

The airplane/projectile impact accident is considered the scenario with the worst consequence for the external event category. Detailed analysis is presented in Section 5, Volume I. 


\section{Explosion}

${ }^{99}$ Mo production would not require the use of explosives; therefore, no explosive materials would be stored within the perimeter of TA-V. A propane tank farm is located on the north side of the facility. An explosion at the tank farm poses no threat to ACRR operations.

\section{Fire}

Since the ACRR room is built of steel, concrete and concrete block, it is fire-resistant. However, because materials such as wood and solvents within the room are flammable, standard fire safety precautions are enforced. Periodic safety inspections are made by SNL/NM Fire Safety Engineers, and quarterly in-house inspections are made to minimize the inventory of combustible materials. Fusible link sprinkler systems are installed in the ceilings of the High Bay, Low Bay, and control room. If this system is activated, or a fire alarm is tripped, the KAFB East fire department is automatically alerted and, based on actual drill times, would respond to TA-V within 8 minutes.

Even an extremely intense fire in the reactor room would cause only moderate damage to certain reactor components, and none at all to the core itself. The components subject to the most damage are those situated at the top of the reactor pool: the regulating rod drives, and the control instrumentation cables. The large volume of water in the reactor tank protects the rest of the reactor. It is estimated that available heat from burning of the combustibles present would not be sufficient to boil away more than 20 percent to 30 percent of the reactor water.

\section{I.3 HCF Accident Analyses}

The estimated facility damage resulting from the accident and natural disaster scenarios discussed in the preceding sections are summarized in Table I-3. The only scenarios that could produce facility or equipment damage would be a major chemical spill, fire, explosion, or flood.

\section{I.3.1 HCF Operational Accidents}

\section{Fire}

Room 109 is proposed as the primary storage area for process wastes and contaminated equipment from the HCF Zone 2A. This room consists entirely of a concrete and steel structure devoid of combustible materials in the structure itself. Hence the items stored in the facility represent the only source for combustible materials. The only combustible materials in the process waste stream are organic materials containing hydrocarbons such a plastics and rubber-like materials. These materials have a relatively high combustion temperature. Since these materials would be packaged in sealed containers they are well separated both from sources of heat and a sustained supply of oxygen. Therefore, multiple events would have to occur for this fuel to be involved in a fire. Propagation of the fire from one container to the other would require sufficient heat to rupture adjacent waste containers.

\section{Waste Storage Accidents}

The waste storage area would contain only remote handled process waste and contaminated equipment (such as contaminated SCB and associated process equipment) from Zone $2 A$ of the HCF. This storage area would not contain items such as personal protective equipment (PPE) or other waste that has activity levels that allow for contact handling procedures. These lower activity wastes would be stored in other areas either within the HCF or another SNL/NM 
Table 1-3. Estimated Probability of Occurrence for HCF Accident Scenarios

\begin{tabular}{|c|c|c|}
\hline $\begin{array}{l}\text { Accident } \\
\text { Scenario }\end{array}$ & $\begin{array}{c}\text { Estimated Probability of } \\
\text { Occurrence/Year }\end{array}$ & $\begin{array}{c}\text { Mechanical Consequences } \\
\text { to HCF }\end{array}$ \\
\hline \multicolumn{3}{|l|}{ OPERATIONAL ACOLENTS } \\
\hline *Fire & $\begin{array}{l}10^{-2}-10^{-4} \text { (small) } \\
10^{-4}-10^{-6} \text { (large) }\end{array}$ & $\begin{array}{l}\text { Damage will vary as a } \\
\text { function of fire intensity and } \\
\text { duration. Possible fission } \\
\text { product and/or chemical } \\
\text { releases. }\end{array}$ \\
\hline $\begin{array}{l}\text { Manned transport accident, } 1 \\
\text { target ruptures }\end{array}$ & $10^{-4}-10^{-6}$ & $\begin{array}{l}\text { None, other than forklift and } \\
\text { cask damage. Fission } \\
\text { product release. }\end{array}$ \\
\hline $\begin{array}{l}\text { *Spill in SCB; ventilation filter } \\
\text { not isolated }\end{array}$ & $10^{-3}-10^{-5}$ & $\begin{array}{l}\text { None expected. Fission } \\
\text { product release }\end{array}$ \\
\hline $\begin{array}{l}\text { Release of cold trap contents; } \\
\text { ventilation filter not isolated }\end{array}$ & $10^{-3}-10^{-5}$ & $\begin{array}{l}\text { None expected. Fission } \\
\text { product release. }\end{array}$ \\
\hline Major chemical spill & $10^{-2}-10^{-4}$ & $\begin{array}{l}\text { Possible damage to nearby } \\
\text { materials/equipment if } \\
\text { corrosive material spilled. }\end{array}$ \\
\hline Explosion & $<10^{-6}$ & $\begin{array}{l}\text { Minimal damage from } \\
\text { explosion. Possible damage } \\
\text { from subsequent fire. }\end{array}$ \\
\hline \multicolumn{3}{|c|}{ WATURAL PHENOMENA AOOIOENTS } \\
\hline $\begin{array}{l}\text { Heavy rain, pumps operate } \\
\text { properly }\end{array}$ & $10^{-2}-10^{-4}$ & None expected. \\
\hline Flood (One pump fails) & $10^{-4}-10^{-6}$ & $\begin{array}{l}\text { Approximately } 3^{\prime \prime} \text { water in the } \\
\text { truck ramp area and Room } \\
114 .\end{array}$ \\
\hline High winds and tornadoes & $10-1-10^{-3}$ & None expected. \\
\hline Earthquakes & $10^{-2}-10^{-4}$ & $\begin{array}{l}\text { Possible minor damage and } \\
\text { possible minor fission product } \\
\text { release. }\end{array}$ \\
\hline \multicolumn{3}{|l|}{ EXTERNAL EVENT ACODENTS } \\
\hline *Airplane/projectile impact & $10^{-4}-10^{-5}$ & $\begin{array}{l}\text { Minimal damage expected } \\
\text { from impact. Possible } \\
\text { damage from subsequent fire. } \\
\text { No fission product release } \\
\text { expected. }\end{array}$ \\
\hline $\begin{array}{l}\text { Lightning strike - propane tank } \\
\text { farm }\end{array}$ & $10^{-4}-10^{-6}$ & $\begin{array}{l}\text { Possible HEPA filter damage. } \\
\text { Possible minor fission product } \\
\text { release. }\end{array}$ \\
\hline
\end{tabular}

Worst-case accident scenario in this category. 
facility until shipment for packaging and/or disposal. Accidents in the process waste storage area that could result in the release of radioactive materials are mechanical failures and fire.

Mechanical failures include events such as damage during movement or storage and container failure under design conditions. The movement and storage failures could be a result of dropping the waste containers or from the failure of a piece of equipment such as lifting fittings or hardware, a punctured waste container, failure of the lift/ransport device, or failure of the storage rack. The process wastes would be contained in small metal cans which serve as a primary passive confinement barrier. These metal cans would be placed into waste containers that will provide a secondary confinement barrier. High energy impacts are not plausible since lift height would be limited to about four feet and movement device speeds will be low. The waste containers would be ductile; therefore, low energy impacts are not likely to rupture the container, i.e., would not result in a loss of container integrity. In the event that a container is damaged or ruptured, the waste may need to be repackaged. However, such incidents would not result in large releases of radioactive materials.

Heat would be generated by the decay of the fission products present in the process wastes. However, this heat would not be sufficient to generate temperatures high enough to cause combustion within the waste containers. Sparks are another source of heat that could cause combustion. However, sparks could only start combustion in highly volatile fuels, which would limit the possibility of ignition to gases present in the storage area. The storage room monitors and ventilation systems would preclude hazardous levels of combustible gases in this area.

Volatile gases could be present in the storage area in small quantities. These gases, primarily hydrogen, could result from the heat induced and radiolytic decomposition of the hydrocarbons in the waste containers. These gases would be vented from the containers to prevent package rupture. Any gases that are vented from the waste containers are exhausted from the storage room by means of continuous ventilation systems. In addition, hydrogen monitors would be used to ensure that a dangerous situation would be discovered and appropriate mitigating actions taken.

In all of the above cases, fire propagation would be precluded by the operation of fire detectors and suppression equipment. Hence, a fire in the waste storage area that could result in a significant amount of radioactive material is not a credible event.

\section{Criticality}

Criticality is not an issue for HCF purification of ${ }^{99}$ Mo for several reasons. All fissionable materials currently stored in the HCF would be permanently removed prior to beginning facility modifications. It is estimated that 1 year's worth of solidified target waste (assuming 200 percent production of roughly 2080 targets/yr) could be stored in the HCF storage area.

Assuming each ${ }^{99}$ Mo target would contains about $20 \mathrm{gm}$ of 93 percent enriched uranium, the maximum amount of fissionable (e.g., $\left.{ }^{238} \mathrm{U}\right)$ or fissile (e.g., $\left.{ }^{235} \mathrm{U}\right)$ material that could be in storage would be about $42 \mathrm{~kg}$. This is well below the current HCF storage limit of $500 \mathrm{~kg}$ for fissionable or fissile material.

Each SCB currently has a limit of $5 \mathrm{~kg}$ of solid fissile material. Since a maximum of only one target in either solid or dissolved form would be present in each of the process SCBs at any one time, the probability of a critical event occurring during ${ }^{99} \mathrm{Mo}$ purification would be negligible. 


\section{Explosion}

Accident scenarios considered in the current HCF SAR produced only two initiating events, a spill of acetone and a reaction between a reactive metal such as sodium or potassium with water, that could potentially result in an explosion within an SCB. Since there are no potentially explosive solvents or reactive metals used in the ${ }^{99}$ Mo purification process, this accident scenario would no longer be credible.

Hydrogen peroxide is the only potentially explosive chemical required for ${ }^{99} \mathrm{Mo}$ isolation and purification; however, this would only be used in very small quantities (less than $2 \mathrm{ml} /$ day) and at dilute concentration ( 0.3 percent). At this concentration, hydrogen peroxide is not explosive; therefore, there is no scenario that could provide an explosive situation in a process SCB. The dilute reagent would be prepared from a commercial 30 percent stock solution. Because of the small quantities required, it is not reasonable to keep more than $500 \mathrm{ml}$ of the stock solution in inventory. This solution would be stored in an explosion-proof refrigerator and replaced at least 30 days prior to its expiration date.

\section{Spills within the SCBs - Filter Not Isolated}

There are many spill scenarios postulated for the processing operation in the SCB. In each case, it is assumed that, should a spill occur in an SCB, established procedures would be followed, and the charcoal filters for that area would be isolated from the exhaust system to prevent release of secondary krypton and xenon produced from the decay of bromine and iodine. If the filters are not isolated, these additional quantities of noble gases would be released. Detailed analysis of this accident scenario is presented in Section 5, of the main text.

\section{Major Chemical Reagent Spills}

Chemical reagent spills of more than 1 quart of a hazardous liquid or $1 \mathrm{lb}$ of a hazardous solid could occur during reagent preparation, in the chemical storage room, or in transit between these areas. The consequences of these spills, which are discussed in Section 5, Volume I, would be toxicological rather than radiological.

\section{Chemical Release-Major Spills}

Worker exposure hazards from chemical spills greater than $237 \mathrm{ml}$ (one pint) of liquid were evaluated using a scenario that assumes that 2.5 liters of each of the following chemicals were spilled: concentrated ( 88 percent) formic acid, methanol, concentrated nitric ( 70 percent) acid, and concentrated (38 percent) hydrochloric acid. The scenario further assumed that $237 \mathrm{ml}$ of each chemical vaporized, a reasonable assumption based on the equilibrium vapor pressures at standard temperature and pressure of these materials. These chemicals were chosen based on their frequency of use, amount used, and relative hazard.

Exposure hazard calculations were performed using a mathematical model for indoor dispersion of chemical vapors. The equations associated with this model are found in the 21st Edition of the Industrial Ventilation Manual published by the American Conference of Governmental Industrial Hygienists (ACGIH). One of the model variables is the volumetric flow rate of ventilation air through the laboratory. Since the ventilation systems for the HCF are to be redesigned, the flow rate used was that which is recommended by several sources relative to chemical laboratory safety and health. Assuming the chemical laboratory will be located in Room 106, an air flow rate of $7 \mathrm{cfm} / \mathrm{ft}^{2}$ of floor area, corresponding to a vent flow rate of 2538 
$\mathrm{cfm}$, was used to calculate the dispersion rates. Since flow rate requirements are less for isolated storage areas, a rate of $0.1 \mathrm{~cm} / \mathrm{ft}^{2}$, corresponding to a vent rate of $6.3 \mathrm{cfm}$, was used for the chemical storage area.

The limits referenced are the Threshold Limit Values (TLVs) published by the American Conference of Governmental Industrial Hygienists (ACGIH) and the Immediately Dangerous to Life and Health limit (IDLH) published by the National Institute for Occupational Safety and Health (NIOSH). TLVs are generally defined as the time-weighed average concentration for a normal 8-hour workday and a 40-hour workweek, to which nearly all workers may be repeatedly exposed, day after day, without adverse effect. The IDLH represents the maximum concentration from which, in the event of respirator failure, one could escape within 30 minutes without a respirator and without experiencing any escape-impairing (i.e., severe eye irritation) or irreversible health effects.

Results of these calculations are shown in Table 1-4. The data show that acceptable occupational exposure levels would be exceeded during a spill scenario in a very short period of time as will, in some cases, exposure levels immediately dangerous to life and health (IDLH). Spill control and cleanup would be completed by personnel who are equipped and trained to enter and work in an IDLH environment.

Although the immediate area of a major spill would have to be evacuated, this would not be a toxic hazard for personnel outside Building 6580 , since the neutralization filters in the exhaust stack would trap and neutralize exiting vapors.

Table 1-4. Time Required to Reach TLV and IDLH in HCF Rooms 106, 203 and the Chemical Storage Area (CSA) After A 2.5-Liter Chemical Spill, Assuming $473 \mathrm{ml}$ Evaporates

\begin{tabular}{|l|c|c|c|c|c|c|c|c|c|c|c|}
\hline \multirow{2}{*}{ Chemical } & \multicolumn{2}{|c|}{$\begin{array}{c}\text { Time to TLV } \\
\text { (min) }\end{array}$} & \multicolumn{2}{c|}{$\begin{array}{c}\text { Time to IDLH } \\
\text { (min) }\end{array}$} & \multicolumn{2}{c|}{$\begin{array}{c}\text { Time to } \\
\text { Saturation } \\
\text { (min) }\end{array}$} & \multicolumn{3}{c|}{$\begin{array}{c}\text { Saturation Conc. } \\
\text { (ppm) }\end{array}$} \\
\cline { 2 - 12 } & $\mathbf{2}$ & \multicolumn{2}{|c|}{ Room/Area } & \multicolumn{2}{c|}{ Room/Area } & \multicolumn{2}{c|}{ Room/Area } & \multicolumn{3}{c|}{ Room/Area } \\
\hline
\end{tabular}

* IDLH levels never reached; saturation concentration is lower. 


\section{Chemical Release-Fire}

In the event of a fire within the HCF, the heat generated may cause chemical containers to fail, with the subsequent release of toxic vapors. Of primary concern are those hazardous materials that, if released to the environment may:

- Immediately threaten those who are in close proximity to the release.

- Have the potential for dispersal beyond the immediate vicinity in quantities that threaten the health and safety of on-site personnel or the public in co-located facilities and/or off site.

- Have a rate of transport and dispersion sufficient to require prompt emergency response to implement protective actions.

The 55 chemicals required for ${ }^{99}$ Mo processing were evaluated to determine whether they represent a toxic threat in the event of fire. Details of this analysis are presented in Appendix K. Model results demonstrated that while the immediate area of a chemical release would have to be evacuated, chemical dispersion from a fire in the HCF would pose no threat to the nearest permanent population group, KUMSC, at $1610 \mathrm{~m}$ (1 mi).

Any large fire would be expected to have a serious impact on the HCF facility. The 83 fire accident scenarios analyzed in the current HCF SAR produced facility damage ranging from less than 1 percent to over 60 percent. Facility damage on the order of 20 percent or more could provide bases for curtailing or stopping all operations within the HCF. Of the 56 credible fire scenarios (probability of occurrence greater than $1 \times 10^{-6}$ ), 10 were predicted to produce facility damage of $\mathbf{2 0}$ percent or more. The highest probability of occurrence within these 10 scenarios was $3.3 \times 10^{-5}$ for a fire in Room 108 that was predicted to produce 20 percent facility damage.

The explosion of a 5-gal solvent container has been conservatively estimated to produce facility damage of 25 percent. Only very local damage is expected from the blast itself; most of the damage would be caused by the accompanying deflagration and potential contamination.

\subsubsection{HCF Natural Phenomena Accidents}

\section{Facility Flooding}

Because the HCF is located in the basement, flooding is a potential problem. Trenches and a sump collect rainwater that may collect at the bottom of the HCF truck ramp. Two $50 \mathrm{gpm}$ pumps, powered both by line current and an emergency diesel generator, pump the water out of the sump and away from the buildings into a neighboring arroyo. (Liquid discharged by this system is not hazardous.) Discharge pump \#1 activates automatically once a nominal quantity of water enters the sump; discharge pump \#2 automatically activates if the water level in the sump reaches $4 \mathrm{ft}$. If these pumps failed, the sump would overflow into the HCF. In this event, or if the fire protection sprinkler system were to activate, a floor drain system would divert the water to holding tanks. If the capacity of this drain system were exceeded, the large pits for the hydraulic system of the fissionable material storage vault and other vaults would capture the excess.

The level of rainfall in the Albuquerque area can vary widely with storm conditions and proximity to the mountains. The largest "official" rainfall in 24 hours ever recorded at the airport 
measuring station was about 2.2 inches in 1994. Because the HCF's susceptibility to rainfall closely approximates that of the airport, it is conservatively assumed that 2 inches of rain could fall in 1 hour in the vicinity of the HCF with an annual probability of 0.01 . This is considered the evaluation basis flood for the HCF. Failure analyses of this event produced the following conclusions: (1) flooding is not possible if both discharge pumps operate properly, (2) it is extremely unlikely that both pumps would fail simultaneously with the rainfall event $\left(3.0 \times 10^{\circ}\right.$ $\left.{ }^{7} / \mathrm{yr}\right)$, and $(3)$ it is also extremely unlikely, yet credible, that one sump pump could fail simultaneously with the rainfall event $\left(9.7 \times 10^{-5} / \mathrm{yr}\right)$. The latter event would produce a maximum water depth of 2.8 inches (truck ramp and Room 114) within the facility. Worker consequences would be limited to minor exposure during cleanup and only if the water picked up contamination adsorbed to facility surfaces. Although facility surfaces are generally free of contamination, procedures dictate that the water would first be sampled to determine the level of contamination prior to cleanup. Based on this information, doses received by cleanup workers could be easily controlled to below the HCF ALARA goal of $500 \mathrm{mrem} / \mathrm{yr}$. There would be no doses to other on-site or off-site personnel or the general public.

Flood damage would be limited to direct water damage to affected equipment. In addition, some surfaces may become slightly contaminated if contaminated water infiltrates noncontaminated areas. Facility damage estimates range from 1 percent for the least probable (probability of occurrence $=3.0 \times 10^{-7} / \mathrm{yr}$ ) scenario to 0.1 percent for the most likely situation where the sump pumps operate properly (probability of occurrence estimated at $1.0 \times 10^{-2} / \mathrm{yr}$.)

\section{High Winds and Tornadoes}

Since the HCF is below ground, it is not vulnerable to tornado and wind-generated loadings and missiles. Tornadoes are not likely to affect the ductwork and internal pressures would remain negative with respect to the outside.

\section{Earthquakes}

The HCF structure, along with the SCBs, glove boxes, blister, fume hood, and the ventilation system perform confinement functions. Elements of the HCF have been analyzed with respect to the adequacy of bracing and support to survive a Seismic Zone 2 event. The analysis is based on Uniform Building Code requirements, 1985 Edition, and concludes that if there were any release of radioactive material from the HCF as a result of any magnitude earthquake possible in Seismic Zone 2, it would be small. The HCF ventilation system would survive the design-basis earthquake without structural failure or catastrophic loss of confinement, and the fire protection system would survive without mechanical failure.

\subsubsection{HCF External Event Accidents}

Events external to the HCF that could affect ${ }^{99}$ Mo production are discussed in the following sections.

\section{Airplane Crash}

This accident scenario is postulated to result in the worst consequence for the external event category for the HCF and is therefore presented in detail in Section 5, Volume I.

\section{Lightning Strike - TA-V Propane Tank Farm}


The TA-V propane tank farm provides fuel for space heating. A lightning strike is considered the most likely initiating event for a tank explosion or fire. The consequences of an assumed lightning strike on or near the tanks have been evaluated in the current HCF SAR. The probability of occurrence of a tank explosion was calculated to be about $6.0 \times 10^{-5} / \mathrm{yr}$. The explosion could potentially damage the HCF HEPA filters, creating the possibility of a release of material trapped in the filters; however, the force of the explosion would blow the filters back into the ductwork. This would be expected to reduce the amount of radioactivity released to minimal levels. Facility damage is estimated at 2 percent and would consist of the damaged filter bank and any associated structural damage.

\section{ACRR Accident}

None of the accidents discussed for the ACRR would result in an incident at the HCF other than worker exposure within occupational limits and some contamination. Worker exposure would most likely occur during personnel evacuation. If the HCF heating and ventilating system were not secured during an event at the ACRR that led to release of radioactive material, airborne contaminants could be pulled into the facility. However, the Area $V$ Emergency Plan provides for safe shutdown of all HCF activities as a part of an orderly evacuation. The level of exposure would be well within ALARA guidelines; however, subsequent decontamination of the facility would probably be required.

\subsection{Accident Analysis for Worker Impact}

\section{Worker Impact}

To determine the radiological impacts to workers from postulated accidents, the approach is to assess accidents with the worst consequences for both the ACRR or HCF. The hazard which would lead to accidents with the worst consequences to workers is direct personnel exposure to irradiated targets.

Accidents with the greatest potential for direct whole body radiation exposure would be those associated with the handling of the fission target either in the ACRR, during transfer between the ACRR and HCF, or in processing at the HCF. Unshielded targets would be handled individually and remotely at all times. The postulated accident with the worst consequences to workers is inadvertent personnel exposure to a target when it has the highest radioactivity and with no shielding between the worker and the target. Numerous and redundant engineered safety features, personnel training and administrative controls (both by design and administrative control) are incorporated in the facilities and facility operations to preclude such an accident; however, for the purposes of this analysis, these are assumed to fail and the worker is assumed to be directly exposed to the target.

Worker dose estimates have been calculated for both 6 hours after irradiation, which is the anticipated minimum period for targets to radioactively cool underwater before transfer. Worker dose estimates have also been calculated for 2 hours after irradiation, which would bound the analysis for transferring targets to cool before handling for transfer between the facilities. When irradiated targets are first removed from the reactor they are handled remotely and underwater to place them in a temporary storage rack in the GIF. Since these operations are performed entirely underwater, exposure accidents during this period are not evaluated.

The postulated accident scenarios for direct exposure assumes that all safety features fail, a worker is inadvertently exposed to an irradiated target, and the exposed worker retreats to a 
safe distance from the target. No shielding, other than the target cladding and air, is present. Two scenarios are assumed:

1. Anticipated accident scenario: The target is allowed to cool for its normal time of 6 hours. Since targets are handled remotely, an exposure distance of 3 meters is assumed. The amount of time before the worker becomes aware of the danger, either visually or from audio/visual radiation alarms, is estimated to be 5 seconds. The worker retreats at a running speed of $3 \mathrm{~m} / \mathrm{s}$. The total dose received is calculated to be $1.1 \mathrm{rem}$ or a 1 in 2272 chance of developing a latent fatal cancer.

2. Bounding accident scenario: The target is allowed to cool only 2 hours. An exposure distance of 1 meter is assumed. The amount of time before the worker becomes aware of the danger, either visually or from audio/visual radiation alarms, is estimated to be 10 seconds. The worker retreats at a walking speed of $2 \mathrm{~m} / \mathrm{s}$. The total dose received is calculated to be 28.6 rem or 1 in 100 chances of developing a latent fatal cancer. 


\section{References}

1. ANSI, 1977, Neutron and Gamma-Ray Flux-to-Dose-Rate Factors, ANSI/ANS 6.1, 1977.

2. Ayer, J. E., et al., 1988, Nuclear Fuel Cycle Facility Accident Analysis Handbook, NUREG1320, U.S. Nuclear Regulatory Commission, May 1988.

3. Camp, A. L., 1991, SANET User's Guide and Reference Manual, SAND91-1445, Sandia National Laboratories, Albuquerque, New Mexico, 1991.

4. Chanin, D. I., et al., 1990, MELCOR Accident Consequence Code System (MACCS), NUREG/CR-4691, U.S. Nuclear Regulatory Commission, February 1990.

5. Chilton, A. B., et al., 1984, Principles of Radiation Shielding, Prentice-Hall, Inc., Englewood, New Jersey, 1984.

6. Coats, D. W. and R. C. Murray, 1984, Natural Phenomena Hazards Modeling Project: Seismic Hazard Models for Department of Energy Sites, UCRL-53582, Lawrence Livermore National Laboratory, Livermore, California, 1984.

7. Coats, D. W. and R. C. Murray, 1985, Natural Phenomena Hazards Modeling Project: Extreme WindTornado Hazard Models for Department of Energy Sites, UCRL53526, Lawrence Livermore National Laboratory, Livermore, California, 1985.

8. DOE Order 6430.1A, General Design Criteria, U.S. Department of Energy, April 6, 1981.

9. Ermak, E. L., 1988, SLAB: A Denser-than-Air Atmospheric Dispersion Model, UCRL99882, Lawrence Livermore National Laboratory, Livermore, California, October 1988.

10. Foppe, T. L., 1988, Natural Phenomena Risk Assessment at Rocky Flats Plant, Rockwell International, Golden, Colorado, 1988.

11. Griesmeyer, J. M. and L. N. Smith, 1989a, A Reference Manual for the Event Tree Processor (ETPRE), Sandia National Laboratories, Albuquerque, New Mexico, 1989.

12. Griesmeyer, J. M. and L. N. Smith, 1989b, A Reference Manual for the Event Progression Analysis Code (EVNTRE), NUREG/CR-5174, SAND88-1607, U.S. Nuclear Regulatory Commission, September 1989.

13. Grove Engineering, Inc., 1987, MICROSHIELD Computer Code, Version 1.0, Grove Engineering, Inc., Rockville, Maryland, October 1987.

14. Kennedy, R. P., et al., 1989, Design and Evaluation Guidelines for Department of Energy Facilities Subjected to Natural Phenomena Hazards, UCRL-15910, Lawrence Livermore National Laboratory, Livermore, California, May 1989.

15. Lambert, H. E., 1975, Fault Trees for Decision-Making in System Analysis, (Computer Code IMPORTANCE), PhD Thesis, URCL-51929, Lawrence Livermore National Laboratory, Livermore, California, 1975. 
16. Murata, K. K., et al., 1989, User's Manual for CONTAIN 1.1: A Computer Code for Severe Nuclear Reactor Accident Containment Analysis, NUREG/CR-5026, U.S. Nuclear Regulatory Commission, November 1989.

17. Nichols, B. D. and W. S. Gregory, 1986, FIRAC user's Manual: A Computer Code to Simulate Fire Accidents in Nuclear Facilities, NUREG/CR-4561, U.S. Nuclear Regulatory Commission, April 1986.

18. Nichols, B. D. and W. S. Gregory, 1990, EXPAC User's Manual: A Computer Code to Simulate Explosive Accidents in Nuclear Facilities, Los Alamos National Laboratory, Los Alamos, New Mexico.

19. Nuclear Lectern Association, 1984, The Health Physics and Radiological Health Handbook, Nuclear Lectern Association, 1984.

20. Oak Ridge National Laboratory (ORNL), 1989, ORIGEN2, Isotope Generation and Depletion Code - Matrix Exponential Method, RSIC Computer Code Collection, CCC-371, Version 1.1 (Release 2), Oak Ridge National Laboratory, Oak Ridge, Tennessee, September 1989.

21. Oak Ridge National Laboratory (ORNL), 1990, Point Kernel Gamma-Ray Shielding Code (QADMOD-GP with Geometric Progression Buildup Factors, CCC-494, RSIC Computer Code Collection, Oak Ridge National Laboratory, Oak Ridge, Tennessee, November 1990.

22. OMEARB, 1983, Toxic Gas - Portable Computer System for Use in Toxic Gas Emergencies, ISBN 0 7743-8932-X, (ARB-162-83-ARSP), Ontario Ministry of the Environment Air Resource Branch, Ontario, Canada, 1981.

23. Restrepo, L. F., 1991, A Revised Risk Assessment Guide for Explosions at Rocky Flats, Proceedings of the International Conference on Probabilistic Safety Assessment and Management (PSAM), Volume 1, July 1991.

24. Restrepo, L. F., 1992, The Annular Core Research Reactor (ACRR) Limiting Event Workers and Public Consequences (Draft), SAND91-0572, Sandia National Laboratories, Albuquerque, New Mexico, 1993.

25. Rocky Flats, 1993, Rocky Flats Risk Assessment Guide, Version 2, Rocky Flats Plant, Golden, Colorado, September 30, 1991.

26. Science \& Engineering Associates, Inc. (SEA), 1994, SEATree Version 2.2, Functional Specifications, SEA Report \#92-592-01-0.0, for Los Alamos and Sandia National Laboratories, Albuquerque, New Mexico, 1994.

27. SNL, 1988, A User's Manual for the Post Processing Program PSTEVNT, SAND88-2988, Sandia National Laboratories, Albuquerque, New Mexico, 1988.

28. SNL, 1993, SABLE Users Manual, Sandia National Laboratories, Albuquerque, New Mexico (to be published), 1991.

29. Spectral Research Institute, 1981, HAZCON User's Manual, Spectra Research Institute, for Sandia National Laboratories, Albuquerque, New Mexico, May 1981. 
30. Stone \& Webster Engineering, 1991, Final Safety Analysis Report (FSAR) Review Team Report on Rocky Flats Plant Building 707, prepared by Stone \& Webster Engineering for the U.S. Department of Energy, July 1991.

31. Summers, R. M., et al., 1990, A Computer Code for Severe Nuclear Reactor Accidents (MELCOR), NUREG/CR-5531, U.S. Nuclear Regulatory Commission, April 1990.

32. U.S. Department of Energy (DOE), 1991a, Special Task Force Report on the Rocky Flats Plant Final Safety Analysis Report-Building 559, U.S. Department of Energy, Rocky Flats Office, February 25, 1991.

33. U.S. Department of Energy (DOE), 1993b, Recommended Values and Technical Bases for Airborne Release Fractions (ARFs), Airborne Release Rates (ARRs), and Respirable Fractions (Rfs) for Materials in Accidents in DOE Fuel Cycle, Ex-Reactor Facilities, DOE Handbook-3010, U.S. Department of Energy, 1993.

34. U.S. Department of Energy (DOE), 1993, DOE Order 5480.28 Natural Phenomena Hazards Mitigation, U.S. Department of Energy, January 15, 1993.

35. U.S. Department of Energy (DOE), 1994a, Evaluation Guidelines for Accident Analysis and Safety Structures, Systems, and Components, DOE-DP-STD-3005 (Draft), U.S. Department of Energy, February 1994.

36. U.S. Department of Energy (DOE), 1994b, Preparation Guide for U.S. Department of Energy Nonreactor Nuclear Facility Safety Analysis Reports, DOE-STD-3009-93, U.S. Department of Energy, April 1994 (Draft).

37. Willie, R. R., 1978, Computer-Aided Fault Tree Analysis (FTA), ORC 78-14, University of California, Berkeley, California, August 1978.

38. Worrel, R. B., 1985, SETS Reference Manual, NUREG/CR-4213, U.S. Nuclear Regulatory Commission, May 1985. 


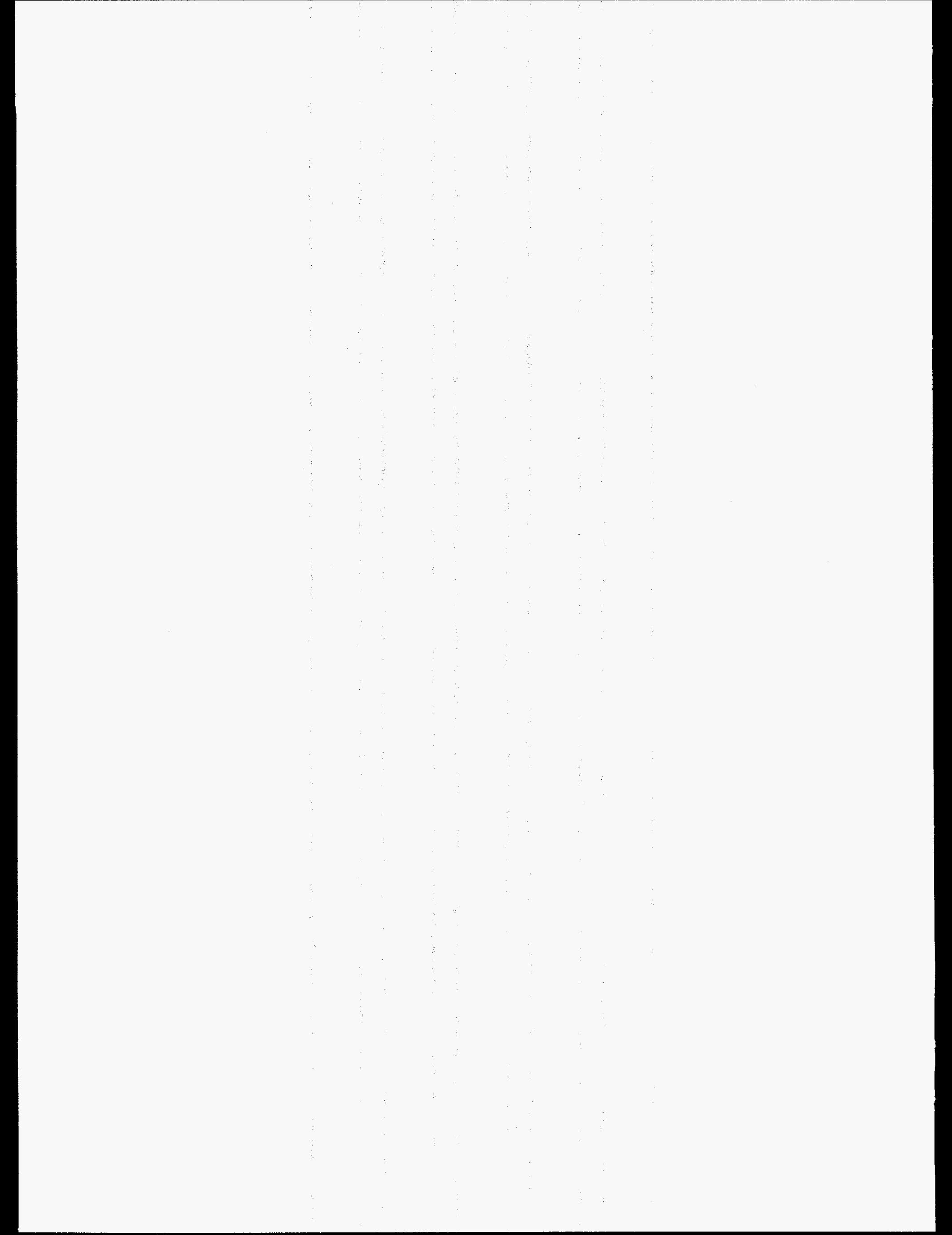




\section{APPENDIX J \\ HOT CELL FACILITY EVALUATION GUIDELINES (EG)}




\section{APPENDIX J \\ HOT CELL FACILITY EVALUATION GUIDELINES (EG)}

This appendix presents the criteria employed at the HCF to ensure that it can be safely shut down and maintained in a safe shutdown condition following any postulated accident. That is, it identifies the applicable set of Evaluation Guidelines (EG) using a combination of exposure criteria found in the applicable regulations and DOE orders and exposure criteria developed specifically for the HCF in areas not addressed in the applicable regulations and orders. This section also provides a description of each of the plant conditions (PCs) that are expected to occur during the operational lifetime of the facility. Finally, it presents a correlation between these PCs and the applicable exposure criteria in the areas of public and worker exposures to hazardous materials, including radioactive material (i.e., radiological and toxicological dose criteria). This correlation between PCs and applicable exposure criteria will be defined as the EGs for the facility.

\section{J.1 Plant Conditions}

DOE Order AL 5481.1B, Safety Analysis and Review ${ }^{1}$ and LA-10924-MS, A Guide to Radiological Accident Considerations for Siting and Design of DOE Nonreactor Nuclear Facilities, ${ }^{2}$ presents the following qualitative accident-frequency categorization scheme or plant conditions that can be used to assess the likelihood of accident scenarios or events that are expected or postulated to occur during the operation of a facility:

- Likely: Those events expected to occur with a probability $>10^{-2} / y r$.

- Unlikely: Those events expected to occur with a frequency range between $10^{-2}$ and $10^{-4} / \mathrm{yr}$.

- Extremely Unlikely: Those events expected to occur with a frequency range between $10^{-4}$ and $10^{-6} / \mathrm{yr}$.

- Incredible: Those events expected to occur with a frequency $<10^{-6} / \mathrm{yr}$.

Several similar frequency categorization schemes have been introduced by the nuclear power industry [e. g., 10 CFR 50, ${ }^{3}$ Regulatory Guide (RG) $1.48,{ }^{4}$ RG $1.70,{ }^{5}$ ANSI/ANS-51.1, ${ }^{6}$ ANSI/ANS-52.1, and ANSI/ANS-53.1 ${ }^{8}$, although some of these documents are no longer in effect (e.g., ANSI/ANS-53.1). Table J-1 presents a recommended scheme and compares it to other categorizations, including those recommended for use in non-reactor facilities by DOE (DOE/TIC-11603, ${ }^{9}$ RFP $-4384^{10}$ ). Most of the categorizations do not use definitions that precisely indicate the relationships between event categories and the quantified frequency of occurrence scale. The dashed lines in the table represent a judgment as to where those definitions could be located on the frequency scale.

To assign the frequency of occurrence of accident scenarios to a particular frequency range or PC, the frequency of occurrence must be first quantified. This study uses probabilistic risk assessment (PRA) techniques to assign PCs based on conservative estimates of the frequency of occurrence. 


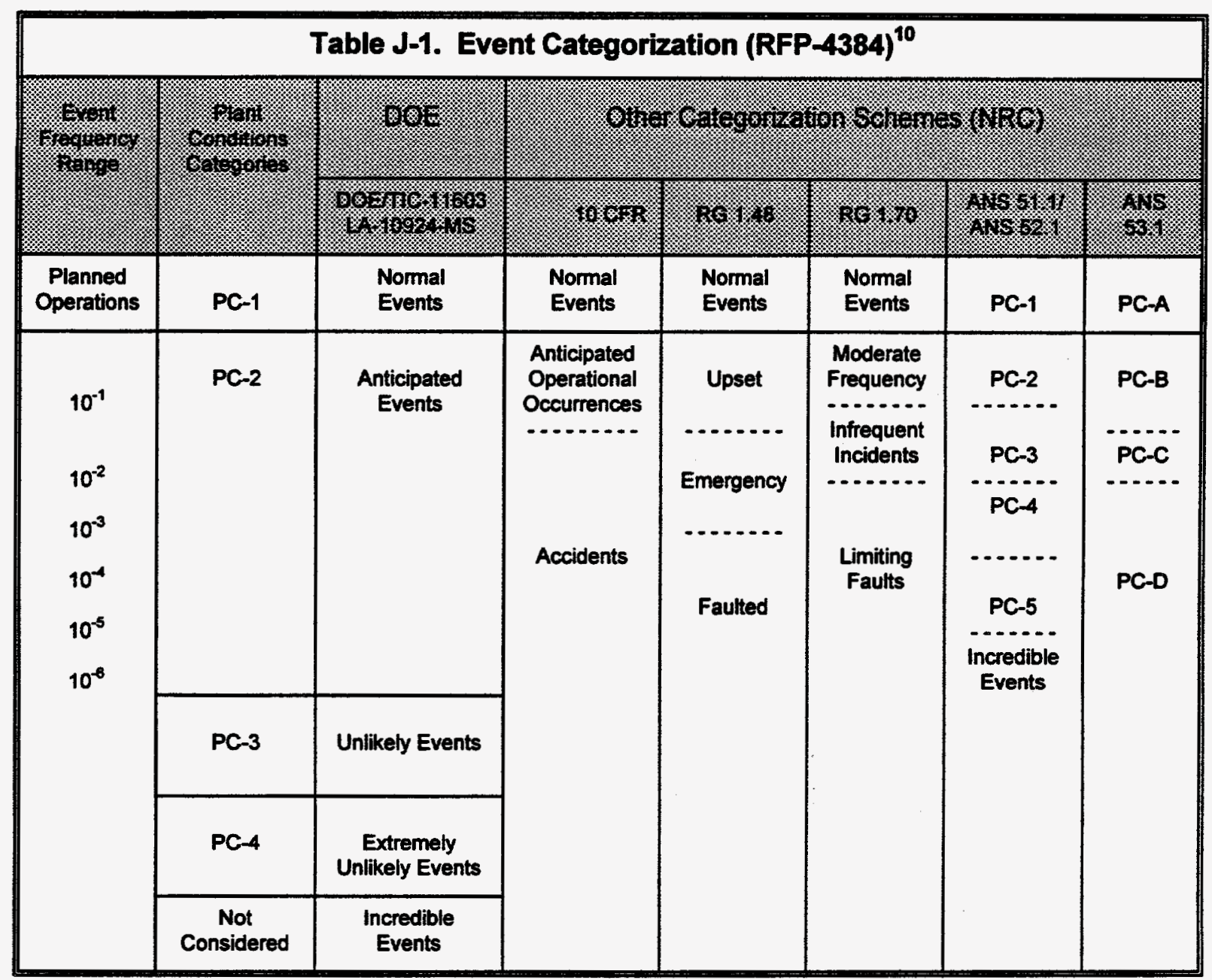

The exposure criteria for PCs include consideration of the cause of the event; expected frequency of occurrence; radiological or toxicological exposure criteria for each PC for off-site population, on-site personnel, and the immediate workers; and the need for particular protection function(s). Exposure criteria are established for each PC (EG) with the objective that the more likely the event, the lower the potential consequences, and, conversely, the higher the potential consequences, the lower the probability of occurrence. Criteria for various PCs are established with the goal of having a constant risk for all combinations of accident frequencies and their associated consequences (ANSI/ANS-51.1, ${ }^{6}$ ANSI/ANS-52.1 ${ }^{7}$ ).

\section{J.2 Radiological Evaluation Guidelines}

Secretary of Energy Notice SEN-35-91 11 established safety goals for DOE nuclear facilities to limit the risk to nearby members of the public from nuclear operations. These goals apply to the total risk posed by the nuclear facility, and not to individual equipment, operations, or postulated accident sequences. Furthermore, these goals apply only to members of the public and not to on-site workers at DOE nuclear facilities.

To have a standard by which to judge calculated risk to on-site personnel and off-site public from individual equipment, operations, or postulated accident sequences, the following radiological exposure criteria have been adopted. These safety-decision thresholds could be used in conjunction with unreviewed safety question (USQ) determinations and safety analyses to judge whether additional prevention or mitigation of hazards needs to be considered to 
reduce the risk from a specific hazard. Risks that cannot reasonably be reduced below the radiological EGs would be submitted to SNL and DOE management for their acceptance or for further direction. These radiological EGs do not imply that any risk or exposure below the thresholds established by the criteria is acceptable.

To promulgate consistency among non-reactor nuclear facilities, DOE has proposed a frequency/consequence categorization for off-site radiological doses as shown in Figure J-1, which is derived from Reference 9.

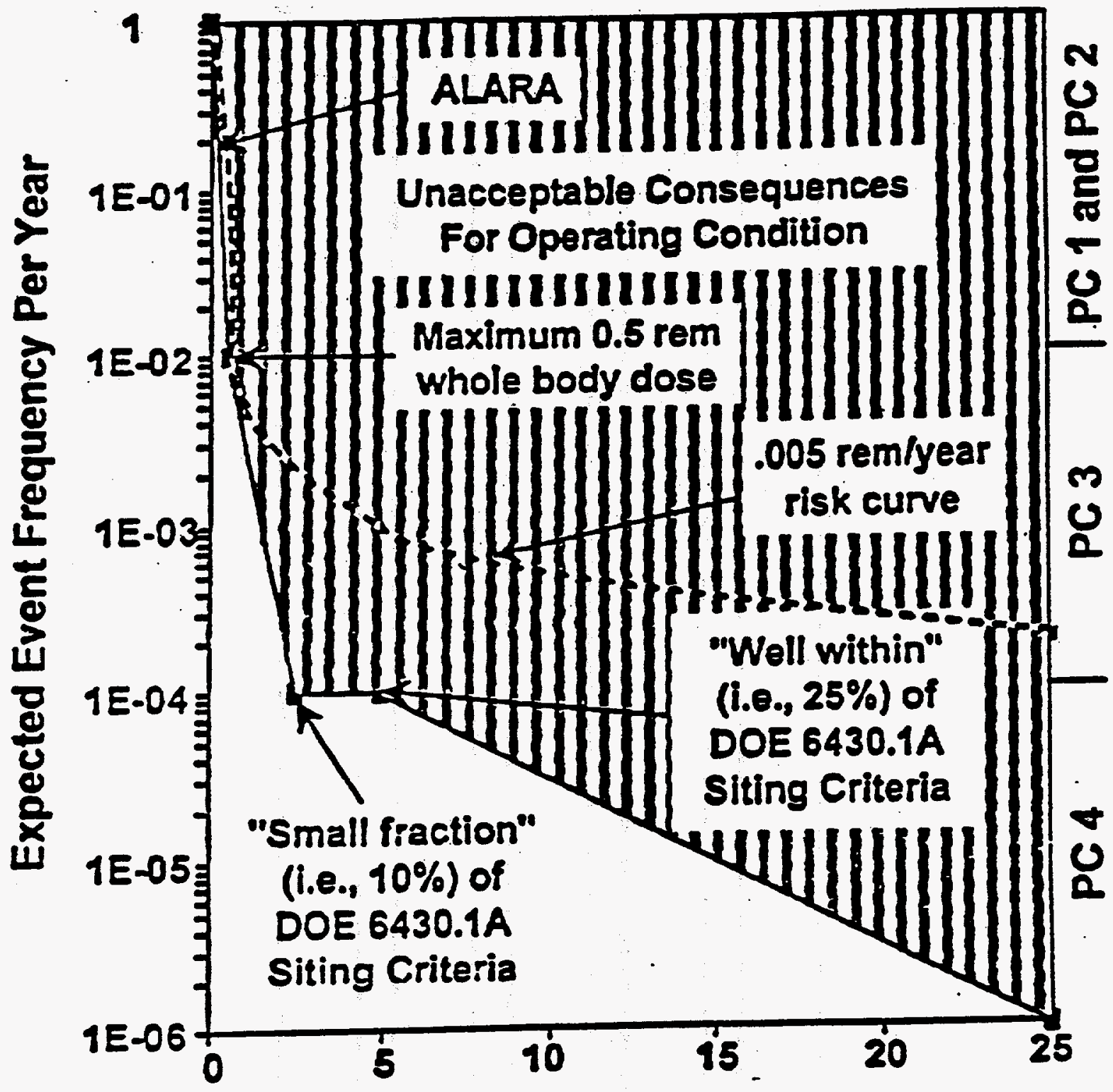

Figure J-1. Radiological Dose Criteria (rem EDE) 
New facilities or major modifications to existing facilities should be designed to accommodate the accident conditions within the recommended radiological dose criterion for each PC. PC determination can be done as stated previously by using, for example, Level 1 PRA techniques to quantify the likelihood or probability of occurrence of the postulated accident sequences. Based on the results of the frequency quantification, events then can be categorized into PCs according to their respective frequency ranges, and the applicable EG shall apply. As indicated in DOE Order $6430.1 \mathrm{~A}^{12}$ and DOE/TIC-11603, ${ }^{9}$ facility design and accident analyses should not consider events that have a conservative estimate of their frequency of occurrence of less than $10^{-6} /$ year.

The overall intent of the radiological dose guidelines, as they relate to plant conditions, is to ensure that facilities are designed to be operated without undue risk to the public or to the workers. This is achieved by requiring that all exposures from normal operations remain as low as reasonably achievable (ALARA), and that all other exposures from abnormal or accidental conditions be scaled as a function of the likelihood of occurrence of the initiating event or as a function of plant-condition classification.

Consequences from radiological exposures are expressed as roentgen-equivalent-man (rem) from one or more predominant exposure pathways. All consequence calculations are based on 50-year dose commitments for the effective dose equivalent (EDE) or critical organ dose equivalent if necessary.

For safety analysis or USQ-determination purposes, recommended EGs are shown in Table J2. The EGs for "immediate worker" apply to all workers within the building or within $100 \mathrm{~m}$ (328 $\mathrm{ft}$ ) of a postulated accident. The EGs for "on-site collocated personnel" apply to the most affected worker outside the building or more than $100 \mathrm{~m}$ from a postulated accident. The EGs for "off-site individual" apply to the most affected individual located at or outside the site boundary. Credit may be taken for reasonable mitigating actions (such as donning respirators, evacuating the area, or taking shelter) for on-site workers, but no such credit may be taken for off-site individuals. Any credit for mitigating actions must be carefully justified.

\begin{tabular}{|c|c|c|c|c|}
\hline \multirow{2}{*}{ Receptor: } & \multicolumn{4}{|c|}{ 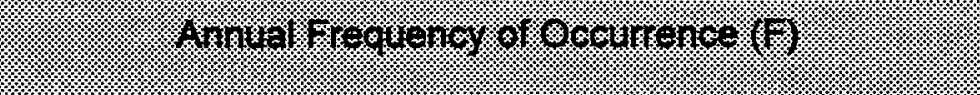 } \\
\hline & ? & 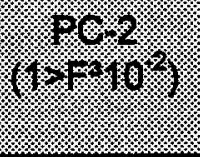 & 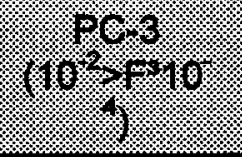 & 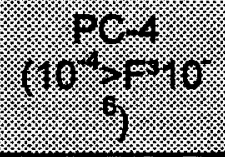 \\
\hline Off-site Individual & $0.01 \mathrm{rem}$ & $0.5 \mathrm{rem}$ & $2.5 \mathrm{rem}$ & $25 \mathrm{rem}$ \\
\hline $\begin{array}{l}\text { On-site Collocated } \\
\text { Personnel }\end{array}$ & $0.5 \mathrm{rem}$ & $5 \mathrm{rem}$ & 25 rem & $100 \mathrm{rem}$ \\
\hline Immediate Worker & $5 \mathrm{rem}$ & $25 \mathrm{rem}$ & $100 \mathrm{rem}$ & $200 \mathrm{rem}$ \\
\hline
\end{tabular}

The radiological exposure criteria represent external effective dose equivalents (EDEs) plus committed effective dose equivalents (CEDE) from all significant pathways (inhalation, air submersion, ingestion, and direct exposure). These dose criteria were selected to be consistent with current regulations (DOE 6430.1A, ${ }^{12} 10$ CFR 20, ${ }^{14} 10$ CFR 50 Appendix I, ${ }^{15} 10$ CFR $100,{ }^{16}$ DOE $5400.5,{ }^{17}$ DOE $5480.11^{18}$ ). For PC-1 and PC-2, these criteria are to be 
applied to the summation of consequences from all postulated events with frequencies greater than or equal to $10^{-2} / \mathrm{yr}$. The dose consequences for these PCs should be calculated using best-estimate source-term, dispersion (meteorology), and dose models. In other words, for all events with a frequency of occurrence greater than $10^{-2} / y r$ (i.e., PC-2), the sum of the consequences from all of these events or scenarios shall not exceed the consequence levels specified (i.e., 500 mrem for off-site, 5 rem for on-site, and 25 rem for immediate worker).

For other PCs (i.e., PC-3 and PC-4), these criteria are applied to individual postulated accident scenarios or events. That is, for accident scenarios with frequency $<10^{-2} / \mathrm{yr}$, the consequences for each accident scenario are to be within the appropriate EGs in Table J-2. The doses should be calculated using best-estimate source terms and conservative dispersion and dose models (References 6 and 7).

The factors considered in the selection of values for the radiological exposure criteria include:

a. The EG shall be consistent with DOE and NRC requirements and regulations.

b. The EG shall be more restrictive for high-probability events than for low-probability events.

c. EGs for off-site individuals shall be more restrictive than for on-site personnel. Setting off-site EGs lower than on-site EGs is consistent with common practice within the nuclear industry (e.g., annual dose limits and radiological concentration guides).

d. The "expected risk" associated with a range of off-site criteria (i.e., the product of the highest frequency in the range and the maximum permissible consequences for the range) is to be less than a constant-risk estimate. This constant-risk estimate is indexed to the 10 CFR 50 Appendix $1^{15}$ guidance on design-objective value of $5 \mathrm{mrem}$ whole body or EDE at a frequency of 1 per plant year as indicated by the dashed line in Figure $\mathrm{J}-1$ (i.e., $5 \times 10^{-3} \mathrm{rem} / \mathrm{yr}$ ). Also shown in the figure is the DOE $/ \mathrm{TIC}-11603^{\circ}$ interpretation of this criterion. The goal is to have the consequences for each of the operating conditions fall to the left side of the curve. The dose criteria imposed on all PCs lead to a level of risk for each event or type of event that is comparable to the one posed by normal operations. ${ }^{6,7}$

e. For off-site calculations, the maximum exposed off-site individual (MEOI) assumed to be located at the plant boundary (or greater distance with maximum dose) is to be used as the dose/risk receptor criterion.

f. The criterion for the use of conservative versus realistic dose consequences is based on the concept that for frequent events, consequence modeling is to be as realistic as possible in order not to weigh the risk from these events more heavily than risk from less likely events. $A$ combination of source-term estimation based on realistic models and conservative dispersion and dose models is used to prevent over conservatism, but still provide compliance with Siting guidelines on the design basis or maximum credible accidents for a facility. ${ }^{12}$

g. Immediate workers within the building or within 100 meters of a postulated accident are subject to greater consequences than on-site collocated personnel.

A 25-rem ceiling for off-site individuals is well established in the nuclear industry as a Siting Criterion (e.g., DOE Order 6430.1A, DOE/TIC-11603, and 10 CFR 100) and is also suggested in the DOE nonreactor nuclear-facilities accident-analysis guide (LA-10294-MS) ${ }^{2}$ as an off-site risk acceptance criterion for low probability events. The endpoint for off-site criteria is thus 
established at the point corresponding to an annual probability of $10^{-6}$ and a dose consequence of 25 rem external EDE plus CEDE. The $10^{-4} /$ year event is selected as $10 \%$ of this limit, as indicated in DOETIC-11603.

DOE Order $5400.5^{17}$ limits public exposure to 0.5 rem/year external EDE plus CEDE as a result of a planned noncontinuous exposure. Since the order states that a continuous exposure is one that is predicted to last longer than 5 years, it can be deduced that a noncontinuous exposure can last up to 5 years. It is therefore conservative to apply this criterion to events with an annual probability of $10^{-2}$. This provides a midpoint for the off-site goal at an annual probability of $10^{-2}$ and 0.5 rem external EDE plus CEDE.

DOE Order $5400.5^{17}$ also specifies an annual limit of 0.1 rem external EDE plus CEDE for continuous exposure of the public. It is conservative to set this as the limit for events with an annual probability approaching one, which provides an endpoint for the off-site goal at an annual probability of one and 0.1 rem external EDE plus CEDE. However, recent reviews have suggested that the more restrictive annual limit (DOE 5400.5, 40 CFR $61^{19}$ ) of 0.01 rem EDE from airborne emissions for normal operations should be applied to postulated accident conditions.

Due to dispersion phenomena, consequences of any given accident will usually be higher onsite than off-site. However, credit for protective measures may be taken in the evaluation of consequences to collocated workers. Industrial accident statistics indicate approximately $10^{\circ}$ $4 /$ year fatality rate. The probability of latent cancer fatalities is approximately $10^{-4} / \mathrm{rem}$ according to the International Commission of Radiation Protection (ICRP) Publication $26^{20}$ and $10^{-3} / \mathrm{rem}$ according to ICRP $60 .^{21}$ Using the higher latent-cancer value with a $0.1 \%$ reduction (i.e., offsite SEN-35-91 safety goal ${ }^{11}$ ) and the industrial fatality rate results in $100 \mathrm{rem}$ at $10^{-6} / \mathrm{year}$. This value is being proposed as an acceptable risk criterion for DOE high-level waste tanks safety analyses. 22

DOE Order $5480.11^{18}$ specifies an annual limit of 5 rem EDE for occupational exposure. For collocated workers, it is therefore conservative to apply a criterion of 5 rem external EDE plus CEDE to events with an annual probability of $10^{-2}$.

DOE Order 5480.11 specifies a maximum dose of 0.5 rem to the unborn child of a worker. For collocated workers, it is therefore conservative to set 0.5 rem external EDE plus CEDE as the criterion for events with an annual probability of 1 .

Radiological exposure criteria for immediate workers are set to range from the annual limit of 5 rem to $200 \mathrm{rem}$ at $10^{-6}$ /year. The larger doses are based on the emergency dose criteria of DOE Order 5480.11 for voluntary exposures.

\section{J.3 Toxicological Evaluation Guidelines}

DOE Order $5480.23^{23}$ and DOE/AL Order $5481.1 B^{1}$ also require that nonradiological toxic hazards be assessed as part of the safety-analysis documentation. To assess whether the facility could be operated without undue risk to the public or workers, based on the results of the accident analysis involving toxic hazardous materials, and even to be able to assess whether a USQ exists due to proposed modifications to the facility, an acceptable toxicological exposure guideline needs to be established. This section proposes toxicological exposure guidelines as functions of PCs for the public and for on-site collocated and local workers. 
Exposure guidelines for the public and for local workers are based on exposure limits proposed or introduced by various regulatory and advisory agencies. Since most of these guidelines have one or more caveats associated with their use (e.g., some guidelines apply only to public exposures and not to workers, and vice versa), the following definitions are provided to serve as a basis for the selection of the recommended exposure levels proposed in this guideline:

a. The following are public exposure limits associated with short-term, accidental exposure:

- Level of Concern (LOC) - LOCs were developed by the Environmental Protection Agency to aid community emergency planning for accidental releases. LOCs are defined as those concentrations of an extremely hazardous substance (EHS) in air, above which there may be serious irreversible health effects or death as a result of a single exposure for a relatively short period of time. LOCs were estimated by using one-tenth of the Immediately Dangerous to Life and Health (IDLH) level published by the National Institute for Occupational Safety and Health (NIOSH) ${ }^{24}$. LOCs for EHS are found in the EPA document titled Technical Guidance for Hazard Analysis: Emergency Planning for Extremely Hazardous Substances. ${ }^{25}$

- Emergency Response Planning Guidelines (ERPGs) - ERPGs were developed by a consortium of chemical firms based on the National Research Council Emergency Exposure Guidance Levels (EEGL) and Short-Term Exposure Guidance Levels (SPEGL), with oversight and review from the American Industrial Hygiene Association (AlHA). ${ }^{26}$ Presently, ERPGs exist for only a few dozen chemicals. Three concentration levels have been identified for several chemicals of concern:

ERPG-1 - The maximum airborne concentration below which it is believed that nearly all individuals could be exposed for up to one hour without experiencing other than mild, transient adverse health effects or perceiving a clearly defined objectionable odor.

ERPG-2 - The maximum airborne concentration below which it is believed that nearly all individuals could be exposed for up to one hour without experiencing or developing irreversible or other serious health effects or symptoms which could impair an individual's ability to take protective action.

ERPG-3 - The maximum airborne concentration below which it is believed that nearly all individuals could be exposed for up to one hour without experiencing or developing life-threatening health effects.

- Short-Term Exposure Guidance Level (SPEGL) - SPEGLs were developed by the National Research Council's Committee on Toxicology (NRCCT). ${ }^{27}$ SPEGLs are acceptable ceiling concentrations for a single, unpredicted, short-term exposure to the public, normally of 1 hour or less, but never more than 24 hours.

b. The following are public exposure limits associated with long-term chronic or routine exposures:

- Integrated Risk Information System (EPA-IRIS) - The EPA in its EPA-IRIS database provides information on hazard identification, dose-response assessment, and exposure levels which, when combined with specific exposure information, can be used for characterization of the public health risks of a given chemical. 
The levels in the EPA-IRIS database (EPA 88$)^{28}$ are intended to be protective for chronic lifetime exposures rather than for exposure to accidental releases. Two airborne exposure levels are presented in the database system:

(1) Reference Dose (RfD) - The RfD represents an estimate of an environmental exposure at which no adverse effect is expected to occur.

(2) Carcinogen Assessment (CA) - For those chemicals that may cause human cancer, the CA is a quantitative assessment of the likelihood of an individual within a large population to develop cancer over a lifetime exposure. Generally, three CA exposure levels are given for each chemical corresponding to three risk ratios of $10^{-4}$, $10^{-5}$, and $10^{-6}$ probability of developing cancer.

c. The following are occupational exposure limits for short-term, accidental exposures:

- Immediately Dangerous to Life and Health (IDLH) - IDLHs were developed by the $\mathrm{NIOSH}$ exclusively for respirator selection in the workplace. IDLHs are the maximum concentration from which one could escape within 30 minutes without any escapeimpairing symptoms or any irreversible health effects. IDLHs can be found in the NIOSH Pocket Guide to Chemical Hazards (NIOSH 90). ${ }^{29}$

- Emergency Exposure Guidance Level (EEGL) - EEGLs are also developed and are available from the NRCCT.

d. The following are occupational exposure limits for routine or normal operations:

- Permissible Exposure Limit (PEL) - PELs are OSHA workplace exposure standards listed in 29 CFR 1910, Subpart Z, General Industry Standards for Toxic and Hazardous Chemicals (29 CFR 1910). ${ }^{30}$ PELs are the maximum airborne concentration of a contaminant to which an employee may be exposed over the duration specified by the type of PEL assigned to the contaminant. Three types of PELs are provided:

(1) Time-Weighted Average (TWA): PEL-TWA is the average exposure in any 8-hour shift of a 40-hour work week, that shall not be exceeded.

(2) Short-Term Exposure Limit (STEL): PEL-STEL is the employee's 15-minute time-weighted average exposure that shall not be exceeded at any time during a workday unless another time limit is specified in a parenthetical notation below the limit.

(3) Ceiling (C): PEL-C is the exposure that shall not be exceeded during any part of the workday.

- Threshold Limit Values (TLVs) - TLVs are published annually by the American Conference of Governmental Industrial Hygienists (ACGIH). ${ }^{31}$ TLVs are airborne concentrations of substances representing conditions under which it is believed that nearly all workers may be repeatedly exposed day after day without adverse effects. Three TLV limits categories are published: 
(1) Time-Weighted Average: TLV-TWA is the time-weighted average concentration for a normal 8-hour workday and a 40-hour work week, to which nearly all workers may be repeatedly exposed, day after day, without adverse effect.

(2) Short-Term Exposure Limit: TLV-STEL is the concentration to which workers can be exposed continuously for a short periods of time without suffering from irritation; chronic or irreversible tissue damage; or narcosis of sufficient degree to increase the likelihood of accidental injury, impair self-rescue, or materially reduce work efficiency, provided that the daily TLV-TWA is not exceeded.

(3) Ceiling: TLV-C is the concentration that should not be exceeded during any part of the working exposure.

Another measure proposed but not listed above is the lethal concentration low (LCLO) which is the lowest concentration of a material in air, other than the lethal concentration fifty $\left(L_{50}\right)$, that has been reported to cause death in humans or animals.

As with radiological consequence guidelines, nonradiological guidelines are intended to ensure that the operation of the facility will not result in undue risk to the public or to workers.

To develop a correlation between exposures and PCs like that provided for radiological exposures, the exposure guidelines are ranked in descending order of exposure as follows:

LCLO > IDHL $\approx E R P G-3>L O C \approx E R P G-2 \approx T L V-C \approx P E L-C \approx S P E G L \approx E E G L>E R P G-1$

$\approx$ TLV-STEL $\approx$ PEL-STEL $>$ TLV-TWA $\approx$ PEL-TWA $>$ CA $>$ RfD

Table J-3 presents the correlation between PCs and toxicological exposure guidelines for the public and workers (local and collocated on-site).

\begin{tabular}{|l|l|l|l|l|l|l|}
\hline \multicolumn{7}{|c|}{ Table J-3. Toxicological Exposure Criteria } \\
\hline
\end{tabular}

For PC-1 and PC-2, these criteria are applied to the summation of consequences from all postulated events with frequencies greater than or equal to $10^{-2} / \mathrm{yr}$. The toxicological consequences are to be calculated using best-estimate source term, dispersion (meteorology), and exposure models. In other words, for all events and postulated accidents with a frequency of occurrence greater than $10^{-2} / \mathrm{yr}$, the sum of the consequences from all of these events or scenarios shall not exceed the consequence levels specified. 
The other PCs (i. e., PC-3 and PC-4), are applied to individual postulated accident scenarios or events. That is, for accident scenarios with frequency $<10^{-2} / y r$, the consequences of each accident scenario are to be within the appropriate toxicological criteria in Table 3 . The toxicological consequences are to be calculated using best-estimate source terms and conservative dispersion and dose models.

Values for these toxicological exposure criteria have been selected based upon the principle that the exposure criteria for nonradioactive toxic hazardous materials are to be set at levels equivalent to those associated with the corresponding radiological-exposure guidelines. 


\section{References}

1. DOE/Albuquerque Operations Office Order 5481.1B-AL, Safety Analysis and Review System.

2. LA-10924-MS, A Guide to Radiological Accident Considerations for Siting and Design of DOE Nonreactor Nuclear Facilities.

3. Title 10, Code of Federal Regulations, Part 50 (10 CFR 50), Domestic Licensing of Production and Utilization Facilities.

4. Regulatory Guide (RG) 1.48 .

5. Regulatory Guide (RG) 1.70 .

6. American National Standards Institute/American Nuclear Society (ANSI/ANS) Standard 51.1.

7. ANSI/ANS Standard 52.1.

8. $\quad$ ANSI/ANS Standard 53.1.

9. DOE/TIC-11603.

10. RFP-4384.

11. Secretary of Energy Notice (SEN) 35-91.

12. DOE Order 6430.1A.

13. Restrepo-92.

14. 10 CFR 20, Standards for Protection Against Radiation.

15. 10 CFR 50, Appendix I.

16. 10 CFR 100, Reactor Site Criteria.

17. DOE Order 5400.5

18. DOE Order 5480.11

19. 40 CFR 61 , Protection of the Environment.

20. International Commission on Radiation Protection (ICRP) Publication 26 (ICRP 26).

21. ICRP 60.

22. Hallinan 92.

23. DOE Order 5480.23. 
24. National Institute for Occupational Safety and Health Publication 73 (NIOSH 73).

25. Environmental Protection Agency Publication 87 (EPA 87), Technical Guidance for Hazard Analysis: Emergency Planning for Extremely Hazardous Substances.

26. American Industrial Hygiene Association (AIHA).

27. National Research Council Committee on Toxicology (NRCCT).

28. Environmental Protection Agency Publication 88 (EPA 88), Integrated Risk Information System.

29. NIOSH Pocket Guide to Chemical Hazards (NIOSH 90).

30. 29 CFR 1910, Occupational Safety and Health Standards.

31. American Conference of Governmental Industrial Hygienists (ACGIH) Publication 92 (ACGIH 92) 



\section{APPENDIX $K$}

CHEMICAL DISPERSION ANALYSIS FOR A RELEASE FROM THE HCF DURING 99MO PROCESSING 


\section{APPENDIX K \\ CHEMICAL DISPERSION ANALYSIS FOR A RELEASE FROM \\ THE HCF DURING $9_{\text {MO PROCESSING }}$}

The chemicals required for 99 Mo processing were evaluated to determine whether they represent a toxic threat in the event of fire using the following screening criteria:

- In accordance with 40CFR, Part 355.20, "Any substance used for personal, family or household purposes, or is present in the same form and concentration as a product packaged for distribution and use by the general public" is not considered a hazardous material. Therefore, chemicals such as methanol were eliminated from further consideration.

- In accordance with 40CFR, Part 302, and 40CFR, Part 355, Appendix A, the quantity at which a chemical does not require dispersion analysis is one pound. $A$ total of 17 chemicals were eliminated from further consideration based on this criterion.

- For chemicals whose quantity exceeds one pound, occupational exposure limits were reviewed. Metrics used were the Emergency Response Planning Guidelines (ERPGs) published by the American Industrial Hygiene Association. ERPG levels in ascending order of severity are ERPG-1, ERPG-2, and ERPG-3. These are defined as follows:

- ERPG-1 - The maximum airborne concentration below which it is believed that nearly all individuals could be exposed for up to 1 hour without experiencing other than mild transient adverse health effects or perceiving a clearly defined objectionable odor.

- ERPG-2 - The maximum airborne concentration below which it is believed that nearly all individuals could be exposed for up to 1 hour without experiencing or developing irreversible or other serious health effects or symptoms that could impair their abilities to take protective action.

- ERPG-3 - The maximum airborne concentration below which it is believed that nearly all individuals could be exposed for up to 1 hour without experiencing or developing life-threatening health effects.

Based on the fact that they did not exceed ERPG-1 at 30 meters, silver nitrate in $0.1 \mathrm{~N}$ nitric acid and $0.1 \mathrm{~N}$ nitric acid were removed from further consideration.

- Chemicals that are considered non-dispersible were removed from further consideration. In order for a chemical to be non-dispersible, it must meet at least one of the following criteria:

- Have a boiling point $>100^{\circ} \mathrm{C}$

- Be a powder of $>10 \mu \mathrm{m}$

- Cannot conceivably be involved in a high energy event such as a fire or explosion. 
- Three chemicals, ammonium oxalate, uranium oxide, and potassium permanganate, met one or more of the criteria for non-dispersability.

Chemical screening resulted in 2 bases, 8 acids and the plating solution that could present at least an ERPG-1 hazard level in the event of a fire. The dispersion characteristics of each solution were modeled using the following assumptions:

- Chemical locations were assumed to be Rooms 106, 203 and an unspecified chemical storage area.

- The entire inventory of a particular chemical (i.e, 20 liters of waste acid in Room 106) was released into the room.

- Release duration was assumed to be one minute, an extremely conservative time frame for sprinkler activation.

- Building air exchanges were estimated at $60 / \mathrm{hr}$.

- The following meteorological parameters were used:

Wind speed: $1 \mathrm{~m} / \mathrm{sec}$ from $0^{\circ}$ true

Air temperature: $20^{\circ} \mathrm{C}$

Relative humidity: $5 \%$

Stability class: $\mathrm{F}$

Cloud cover: $10 \%$

These values are considered "worst case", i.e., ideal conditions for maximum chemical dispersion.

Dispersion characteristics were calculated using the Aerial Locations of Hazardous Atmospheres (ALOHA) model developed by the U.S. EPA and the National Oceanic and Atmospheric Administration. ALOHA allows two types of dispersions: heavy gas and Gaussian. If unsure which dispersion type should be used, ALOHA gives the option to let the model decide.

Model results are shown in Table K-1. It can be seen that chemical dispersion from a fire in the HCF would pose no threat to the nearest permanent population group, KUMSC, at 1610 meters. 
Table K-1. Dispersion Characteristics of HCF Chemicals.

Release Duration: 1 Minute

\begin{tabular}{|c|c|c|c|c|c|}
\hline \multirow[t]{2}{*}{ Chemical } & \multirow[t]{2}{*}{ Location } & \multirow[t]{2}{*}{$\begin{array}{c}\text { Max } \\
\text { Quantity (I) }\end{array}$} & \multicolumn{3}{|c|}{ Maximum Hazard Distance $(\mathrm{m})$} \\
\hline & & & ERPG-1 & ERPG-2 & ERPG-3 \\
\hline $98 \% \mathrm{H}_{2} \mathrm{SO}_{4}$ & 106 & 10 & 404 & 136 & 64 \\
\hline Waste Acid & 106 & 20 & 554 & 186 & 90 \\
\hline $4 \mathrm{~N} \mathrm{H}_{2} \mathrm{SO}_{4}$ & 106 & 1 & 87 & 31 & 15 \\
\hline $98 \% \mathrm{H}_{2} \mathrm{SO}_{4}$ & Chem St & 20 & 550 & 184 & 89 \\
\hline $2 \mathrm{~N} \mathrm{H}_{2} \mathrm{SO}_{4}$ & 106 & 2 & 62 & 22 & 11 \\
\hline $70 \% \mathrm{HNO}_{3}$ & 106 & 2.5 & 84 & 30 & 21 \\
\hline $70 \% \mathrm{HNO}_{3}$ & 203 & 2.5 & 84 & 30 & 21 \\
\hline $70 \% \mathrm{HNO}_{3}$ & Chem St & 2.5 & 84 & 30 & 21 \\
\hline $0.4 \mathrm{~N} \mathrm{NaOH}$ & 106 & 2 & 47 & 27 & 18 \\
\hline $0.2 \mathrm{~N} \mathrm{NaOH}$ & 106 & 2 & 47 & 27 & 18 \\
\hline $38 \% \mathrm{HCl}$ & Chem St & 20 & 644 & 214 & 72 \\
\hline $1 \mathrm{~N} \mathrm{HCl}$ & 106 & 1 & 158 & 52 & 21 \\
\hline $38 \% \mathrm{HCl}$ & 106 & 2.5 & 208 & 69 & 25 \\
\hline $38 \% \mathrm{HCl}$ & 203 & 10 & 700 & 238 & 80 \\
\hline Plating Solution & 203 & 64 & 216 & 122 & 78 \\
\hline $88 \% \mathrm{HCOOH}$ & 106 & 2.5 & 42 & 24 & 16 \\
\hline Waste Plating Sol'n & 203 & 64 & 216 & 122 & 78 \\
\hline $88 \% \mathrm{HCOOH}$ & Chem St & 2.5 & 42 & 24 & 16 \\
\hline $28-30 \% \mathrm{NH}_{4} \mathrm{OH}$ & 106 & & 116 & 30 & 11 \\
\hline $28-30 \% \mathrm{NH}_{4} \mathrm{OH}$ & 203 & 2.5 & 88 & 22 & 11 \\
\hline $28-30 \% \mathrm{NH}_{4} \mathrm{OH}$ & Chem St & 5 & 116 & 30 & 11 \\
\hline
\end{tabular}




\section{APPENDIX L}

INPUT PARAMETERS FOR TRANSPORTATION RISK ANALYSIS 


\section{APPENDIX L INPUT PARAMETERS FOR TRANSPORTATION RISK ANALYSIS}

Transportation risk analysis with the RADTRAN 4 computer code requires that the user develop a number of input parameter values that describe the particulars of the shipments being analyzed. These input parameters and the sources of the values used in this analysis are described in this appendix.

\section{L.1 Potentially Exposed Population Groups}

During routine transportation operations, individuals located near the spent fuel casks would receive low levels of external exposure to radiation (gamma and x-rays). However, no internal exposures would be received since the radioactive material would be contained within the shipping containers. Population exposure models are described in detail in the RADTRAN 4 technical manual (Neuhauser and Kanipe, 1991). The various groups of persons potentially at risk from routine operations resulting from transportation activities would be:

- Workers and Handlers: Workers who load the packages onto trucks for transportation are modeled based on specific aspects of procedures for loading and unloading the packages (see Section L.2). Workers who do not handle, but share the work space with the packages, are also modeled for potential exposures.

- Truck Crew: Dose rates in the cabs of tractor trucks carrying radioactive material are required by regulation to be less than $2 \mathrm{mrem} / \mathrm{hr}$ ( 49 CFR 173). All trucks are modeled as having two-person crews.

- Aircraft Crew: Dose estimates for cargo aircraft crews are modeled by assuming $3 \mathrm{crew}$ members sitting at a distance of 9.14 meters $(30 \mathrm{ft})$ from the radioactive material. No shielding from internal structures is modeled.

- Persons along the Highway Route: This group, often referred to as the off-link population, generally receives the smallest doses. Population doses to persons within $800 \mathrm{~m}(0.5 \mathrm{mi})$ on each side of the transport route are estimated.

- Persons Sharing the Highway Route: Population doses to persons in vehicles traveling in the same direction (including passing vehicles) and in the opposite direction (collectively referred to as the on-link population) are estimated, although their doses, too, are usually very small.

- Persons at Highway Stops: Population doses to persons at fuel and rest stops, tire inspection stops, etc. along the route are estimated. In this analysis the stop time was derived by using $0.011 \mathrm{hr} / \mathrm{km}$ as the stop rate for truck shipments (based on national trucking data for long haul shipments), the general public population exposed during each stop was estimated at 50 persons, and the average exposure distance for these persons was $20 \mathrm{~m}(65 \mathrm{ft})$. 
- Maximum Individual: An individual member of the public who is modeled as living beside the highway route and who is exposed to every shipment at a distance of 30 meters.

- "Traffic Jam" Individual: An individual member of the public who is sharing the highway with the conveyance vehicle during a traffic stoppage resulting in traffic jam conditions. The exposure to this individual is modeled with a 2-hour traffic stoppage and with an exposure distance of $2 \mathrm{~m}(6.6 \mathrm{ft})$. This dose estimate is performed for a single truck shipment to establish an estimate of a potential dose resulting from a realistic traffic situation.

\section{L.2 Handler Dose Models}

Transfer of a 20-WC cask from the point at which the product isotope is packaged (SNL/NM, TA-V) to an air-cargo carrier's loading dock at the Albuquerque, NM International airport would be modeled as one RADTRAN "Handling". The 20-WC casks are of a size and weight that require a heavy forklift or overhead crane for handling; only forklifts are known to be available for handling these large packages at both locations. RADTRAN models doses resulting from a forklift handling as 2 handlers at a distance of 1 meter ( $3.3 \mathrm{ft}$ ) from the package for 15 minutes.

Air transport of the casks from Albuquerque to the pharmacological generator suppliers is expected to be accomplished by commercial air-cargo transport. Discussion of operating procedures with an air-cargo carrier (Wheeler, 1994) has indicated that there would be one forklift operator at a distance of 2 meters $(6.6 \mathrm{ft})$ for 1 minute, one cargo tow tug driver at a distance of 2 meters for 1 minute, and 2 cargo handlers (in the aircraft) 2 meters $(6.6 \mathrm{ft}$ ) from the package for 3 minutes in the course of moving the package from the loading dock into the aircraft. The reverse of this procedure takes place during unloading. Each shipment was assumed to be transferred at the carrier's central distribution hub to a second flight to the final destination, thus, two loading and unloading procedures were included in the analysis of each air shipment. The sum of these two procedures was modeled in RADTRAN as one handling.

In addition to the loading and unloading of aircraft, transit of the package through the distribution hub was modeled as a stop involving 300 workers at a distance of 10 meters (32.8 $\mathrm{ft}$ ) for 0.1 hour. This model addresses $\mathbf{2 5 0}$ to 300 workers (number specified by one carrier's representative) assumed to be uniformly and randomly distributed about a 50 by 100 meter (328 ft) sorting dock; the inverse-distance-squared-weighted average distance of the workers from the package was calculated to be approximately 10 meters. The amount of time each worker might be located at this average distance was estimated to be 6 minutes, based on the ratio of the area of a 10-meter $(328 \mathrm{ft})$ radius circle to the total area and the total time the package resides on the sorting dock.

For small packages (maximum dimension less than 0.5 meter [1.6 ft]) such as the ${ }^{133}$ Xe gas bottle the dose to workers is modeled as $2.5 \mathrm{E}-4 \mathrm{rem} / \mathrm{handling} / \mathrm{TI}$ (Shapiro, 1977). Otherwise, the RADTRAN calculations were the same as described above.

\section{L.3 Accident Severity Category Data}

Potential accident environments are defined and their likelihood of occurrence are modeled using an approach that divides the entire spectrum of accident environments (from minor to 
catastrophic) into six "accident severity" categories. The severity categories are based on event trees originally developed for spent fuel shipped by truck and rail (Wilmot, 1981). The conditional probabilities of occurrence of each accident severity were developed from these data. A conditional probability is defined as the probability, given that an accident has occurred, that it will be of a certain severity. In order to calculate overall probability of an accident of a particular severity, the base accident probability (accident rate) must be multiplied by the conditional probability. Accident rate data are shown in Table L-1. The accident severity categories and their frequency values are shown in Table L-2. Accident rate data for the air accidents are taken from the Ross air safety study (Ross, 1994). Truck accident data are taken from DOT national data on tractor-trailer accidents on interstate highways (U.S. DOT, 1985).

Other researchers have used eight-category (U.S. NRC, 1977) and 20-category schemes (Fischer et al., 1987) to describe the same spectrum of highway accidents. All give approximately the same results when applied to similar problems and are essentially interchangeable (Fischer et al., 1987; Whitlow and Neuhauser, 1992). Consistent with the general principles of probabilistic risk assessment, extremely low probability events (Helton, 1991) are not considered reasonably foreseeable and, therefore, are not included among the accident-severity categories. Thus, for example, a "worst case" accident, although physically possible, is so remote (i.e., improbable) as to render it not reasonably foreseeable to occur. The six severity categories include all accidents with a probability of occurrence of one in a million or greater, well within the levels found acceptable by EPA and other agencies (Hallenbeck and Cunningham, 1986).

The source term from which members of the public could receive a dose in the event of an accident depends on three factors in the event that a package fails and its protection is compromised. Release fractions define the quantity of the package inventory that would be released into the environment. Aerosol fraction defines the quantity of released material that would be lofted into the plume, and respirable fraction defines the quantity of aerosolized material that could be inhaled by human beings. These parameters are quantified for each type of radioactive material that would be shipped as part of an isotope production program and are shown in Table L-3.

\section{L.4 Highway Routes}

Data on highway routes were obtained from the HIGHWAY routing code (ORNL, 1992), which also gives population densities for each route segment derived from 1990 Census Bureau data. The nature of the data as structured for input into the RADTRAN computer analysis is illustrated in Table $L-4$ for the truck shipments of isotope product from SNL/NM Technical Area $V$ to Albuquerque International Airport in Table $L-5$ for representative routes for the highway shipments of unirradiated targets, and in Tables L-6 and L-7 for Hot Cell Facility wastes. Each route segment is labeled as to whether it is rural, suburban, or urban according to the following breakdown: rural population densities range from 0 to 54 persons $/ \mathrm{km}^{2}\left(0-139\right.$ persons $\left./ \mathrm{mi}^{2}\right)$; the suburban range is 55 to 1284 persons $/ \mathrm{km}^{2}$ (140-3326 persons $\left./ \mathrm{mi}^{2}\right)$; and urban is classified as all population densities above 1284 persons $/ \mathrm{km}^{2}$ (3326 persons $/ \mathrm{mi}^{2}$ ) (Neuhauser and Kanipe, 1992). The total population is given for persons within $800 \mathrm{~m}(0.5 \mathrm{mi})$ on each side of the route.

Certain areas along these routes are designated by EPA as air quality nonattainment areas. The representative route from SNLNM to NTS passes through three nonattainment counties. Table L-8 identifies these counties and provides the lowest average annual daily traffic (AADT) 
count along the route in each county. Along the representative route from SNLNM to Hanford there are 10 nonattainment counties. The same traffic count information is provided for these counties in Table L-9. The tables also identify the pollutant(s) upon which the nonattainment designation is based.

\section{L.5 Radionuclide Inventory For Waste Shipments}

The radionuclide inventory of each shipment of HCF waste was modeled as being equivalent to the inventory of fourteen $25 \mathrm{~kW}, 7$-day irradiated targets 180 days out of the reactor. The radionuclides that are included in the transportation analysis are limited to those radionuclides that have an inventory level of $10 \%$ of the $A_{2}$ packaging limit as defined in 49 CFR 173.435 . The radionuclide inventory is shown in Table $\mathrm{L}-10$. 
Table L-1. Highway and Air Accident Probability Data by Mode

\begin{tabular}{|c|c|c|}
\hline \multirow{4}{*}{$\begin{array}{l}\text { RADTRAN Input Parameter } \\
\text { Accident Rate - Aircraft Take Off and Landing } \\
\text { Accident Rate - Aircraft In-flight } \\
\text { Truck Accident Rates }\left(\mathrm{km}^{-1}\right)\end{array}$} & \multirow{2}{*}{\multicolumn{2}{|c|}{\begin{tabular}{|l|} 
Values Used in This \\
Study \\
$2.8 e-06 /$ Flight \\
\end{tabular}}} \\
\hline & & \\
\hline & $\begin{array}{l}2.8 \mathrm{e}-06 / \text { Flight } \\
6.9 \mathrm{e}-10 / \mathrm{km}\end{array}$ & \\
\hline & $\begin{array}{l}\text { Access } \\
\text { Road }\end{array}$ & Interstate \\
\hline $\begin{array}{ll}\text { Arizona } & \text { Urban } \\
& \text { Suburban } \\
& \text { Rural }\end{array}$ & $\mathrm{NA} A^{*}$ & $\begin{array}{l}2.8 e-07 \\
2.6 e-07 \\
2.8 e-07\end{array}$ \\
\hline $\begin{array}{l}\text { Urban } \\
\text { Suburban } \\
\text { Rural } \\
\end{array}$ & NA & $\begin{array}{l}3.7 e-08 \\
1.5 e-07 \\
1.5 e-07\end{array}$ \\
\hline $\begin{array}{l}\text { Urban } \\
\text { Suburban } \\
\text { Rural }\end{array}$ & $\overline{\mathrm{NA}}$ & $\begin{array}{l}2.9 e-07 \\
2.7 e-07 \\
2.7 e-07\end{array}$ \\
\hline $\begin{array}{l}\text { Urban } \\
\text { Suburban } \\
\text { Rural }\end{array}$ & $\overline{\mathrm{NA}}$ & $\begin{array}{l}3.4 e-07 \\
3.2 e-07 \\
3.2 e-07\end{array}$ \\
\hline $\begin{array}{ll}\text { Nevada } & \text { Urban } \\
& \text { Suburban } \\
& \text { Rural }\end{array}$ & $\begin{array}{l}4.5 e-07 \\
4.5 e-07 \\
4.5 e-07\end{array}$ & $\begin{array}{l}3.6 e-07 \\
3.3 e-07 \\
3.3 e-07\end{array}$ \\
\hline $\begin{array}{ll}\text { New Mexico } & \text { Urban } \\
& \text { Suburban } \\
& \text { Rural }\end{array}$ & $\begin{array}{l}7.4 e-06 \\
2.1 e-07 \\
2.1 e-07\end{array}$ & $\begin{array}{l}3.2 e-07 \\
2.7 e-07 \\
2.7 e-07\end{array}$ \\
\hline $\begin{array}{l}\text { Urban } \\
\text { Suburban } \\
\text { Rural }\end{array}$ & NA & $\begin{array}{l}2.8 \mathrm{e}-07 \\
3.0 \mathrm{e}-07 \\
3.0 \mathrm{e}-07\end{array}$ \\
\hline $\begin{array}{l}\text { Urban } \\
\text { Suburban } \\
\text { Rural }\end{array}$ & NA & $\begin{array}{l}1.7 e-07 \\
3.2 e-07 \\
3.2 e-07\end{array}$ \\
\hline $\begin{array}{ll}\text { Washington } & \text { Urban } \\
& \text { Suburban } \\
& \text { Rural }\end{array}$ & $\begin{array}{l}2.3 e-08 \\
2.3 e-08 \\
2.3 e-08\end{array}$ & $\begin{array}{l}\text { NA } \\
3.0 \mathrm{e}-07 \\
3.0 \mathrm{e}-07\end{array}$ \\
\hline $\begin{array}{ll}\text { Wyoming } & \text { Urban } \\
& \text { Suburban } \\
& \text { Rural }\end{array}$ & NA & $\begin{array}{l}1.9 e-07 \\
6.6 e-07 \\
6.6 e-07\end{array}$ \\
\hline
\end{tabular}

*Not applicable to the route modeled. 
Table L-2. RADTRAN Accident Severity Category Conditional Probability Data by Mode

\begin{tabular}{|c|c|c|}
\hline RADTRAN Input Parameter & \multicolumn{2}{|c|}{$\begin{array}{l}\text { Values Used in This } \\
\text { Study }\end{array}$} \\
\hline $\begin{array}{l}\text { Category } 1 \\
\text { Conditions do not exceed those for a Type A package; no release } \\
\text { of contents }\end{array}$ & $\begin{array}{l}\text { Air Takeoff/ } \\
\text { Landing } \\
\text { Air In-flight } \\
\text { Urban } \\
\text { Suburban } \\
\text { Rural }\end{array}$ & $\begin{array}{l}.208 \\
.230 \\
.604 \\
.602 \\
.603\end{array}$ \\
\hline $\begin{array}{l}\text { Category } 2 \\
\text { Conditions equal to those for Type B certification tests; no release } \\
\text { of contents. Type A package contents would be released. }\end{array}$ & $\begin{array}{l}\text { Air Takeoff/ } \\
\text { Landing } \\
\text { Air In-flight } \\
\text { Urban } \\
\text { Suburban } \\
\text { Rural }\end{array}$ & $\begin{array}{l}.504 \\
.130 \\
.395 \\
.394 \\
.394\end{array}$ \\
\hline $\begin{array}{l}\text { Category } 3 \\
\text { Seal damage creates leak path, special form material undamaged; } \\
\text { normal form material could be expelled from package }\end{array}$ & $\begin{array}{l}\text { Air Takeoff/ } \\
\text { Landing } \\
\text { Air In-flight } \\
\text { Urban } \\
\text { Suburban } \\
\text { Rural }\end{array}$ & $\begin{array}{r}.050 \\
.385 \\
3.8 e-04 \\
4.0 e-03 \\
3.0 e-06\end{array}$ \\
\hline $\begin{array}{l}\text { Category } 4 \\
\text { Impact damage great enough to cause damage to special form } \\
\text { material; particulates and gases may be released }\end{array}$ & $\begin{array}{l}\text { Air Takeoff/ } \\
\text { Landing } \\
\text { Air In-flight } \\
\text { Urban } \\
\text { Suburban } \\
\text { Rural }\end{array}$ & $\begin{array}{r}.060 \\
.014 \\
3.8 \mathrm{e}-07 \\
4.0 \mathrm{e}-06 \\
3.0 \mathrm{e}-06\end{array}$ \\
\hline $\begin{array}{l}\text { Category } 5 \\
\text { Impact damage to seals plus fire severe enough to cause thermal } \\
\text { burst with release of fission gases, volatiles, and particulates }\end{array}$ & $\begin{array}{l}\text { Air Takeoff/ } \\
\text { Landing } \\
\text { Air In-flight } \\
\text { Urban } \\
\text { Suburban } \\
\text { Rural }\end{array}$ & $\begin{array}{r}.128 \\
.217 \\
2.5 e-07 \\
3.0 e-06 \\
5.0 e-06\end{array}$ \\
\hline $\begin{array}{l}\text { Category } 6 \\
\text { Severe impact damage plus fire severe enough to cause oxidation } \\
\text { with release of greater amounts of particulates than Category } 5\end{array}$ & $\begin{array}{l}\text { Air TakeoffI } \\
\text { Landing } \\
\text { Air In-flight } \\
\text { Urban } \\
\text { Suburban } \\
\text { Rural }\end{array}$ & $\begin{array}{r}.014 \\
.024 \\
1.3 e-07 \\
2.0 e-06 \\
7.0 e-06\end{array}$ \\
\hline
\end{tabular}


Table L-3. RADTRAN Source Term Parameters

\begin{tabular}{|c|c|c|c|c|c|c|c|}
\hline \multirow{2}{*}{ Material } & \multicolumn{7}{|c|}{ Source Term Fractions } \\
\hline & $\begin{array}{l}\text { Accident Severity } \\
\text { Category }\end{array}$ & 1 & 2 & 3 & 4 & 5 & 6 \\
\hline Unirradiated Targets & $\begin{array}{l}\text { Release From Cask } \\
\text { Aerosolized } \\
\text { Respirable } \\
\end{array}$ & $\begin{array}{l}0 \\
0 \\
0 \\
\end{array}$ & $\begin{array}{l}0.01 \\
1.0 \\
1.0 \\
\end{array}$ & $\begin{array}{l}0.1 \\
1.0 \\
1.0 \\
\end{array}$ & $\begin{array}{l}0.1 \\
1.0 \\
1.0 \\
\end{array}$ & $\begin{array}{l}1.0 \\
1.0 \\
1.0\end{array}$ & $\begin{array}{l}1.0 \\
1.0 \\
1.0\end{array}$ \\
\hline Isotopic Products & \begin{tabular}{|c|} 
Released From \\
Cask \\
${ }_{99} \mathrm{Mo}^{131} \mathrm{I}$ \\
${ }^{133} \mathrm{Xe}$ \\
${ }^{125} \mathrm{I}$ \\
Aerosolized \\
${ }_{99}^{9} \mathrm{Mo},{ }^{131} \mathrm{I}$ \\
${ }^{133} \mathrm{Xe}$ \\
${ }^{125} \mathrm{I}$ \\
Respirable \\
${ }^{99} \mathrm{Mo},{ }^{131} \mathrm{I}$ \\
${ }^{133} \mathrm{Xe}$ \\
${ }^{125} \mid$
\end{tabular} & $\begin{array}{l}0 \\
0 \\
0\end{array}$ & $\begin{array}{c}0 \\
1.0 \\
1.0 \\
0 \\
1.0 \\
0 \\
0 \\
0 \\
1.0 \\
0\end{array}$ & $\begin{array}{c}1.0 \\
1.0 \\
1.0 \\
0 \\
0 \\
1.0 \\
0 \\
0 \\
0 \\
1.0 \\
0\end{array}$ & $\begin{array}{c}1.0 \\
1.0 \\
1.0 \\
\\
0 \\
1.0 \\
0 \\
0 \\
0 \\
1.0 \\
0\end{array}$ & $\begin{array}{c}1.0 \\
1.0 \\
1.0 \\
1.0 \\
1.0 \\
1.0 \\
\\
0.05 \\
1.0 \\
0.05\end{array}$ & $\begin{array}{c}1.0 \\
1.0 \\
1.0 \\
\\
1.0 \\
1.0 \\
1.0 \\
\\
0.05 \\
1.0 \\
0.05\end{array}$ \\
\hline Hot Cell Wastes & $\begin{array}{l}\text { Released From } \\
\text { Cask } \\
\text { Aerosolized } \\
\text { Respirable }\end{array}$ & $\begin{array}{l}0 \\
0 \\
0\end{array}$ & $\begin{array}{l}0 \\
0 \\
0\end{array}$ & $\begin{array}{l}0 \\
0 \\
0\end{array}$ & $\begin{array}{l}1.0 \mathrm{e}-08 \\
1.0 \\
0.05\end{array}$ & $\begin{array}{c}5.0 e-08 \\
1.0 \\
0.05\end{array}$ & $\begin{array}{c}5.0 \mathrm{e}-08 \\
1.0 \\
0.05\end{array}$ \\
\hline
\end{tabular}

Table L-4. A Representative Transportation Route From TA-V, SNLINM to Albuquerque International Airport

\begin{tabular}{|l|c|c|c|c|}
\hline \multicolumn{5}{|c|}{ TA-V, SNLNM to Albuquerque International Airport } \\
\hline Route Segment* & $\begin{array}{c}\text { Distance } \\
(\mathbf{k m})\end{array}$ & $\begin{array}{c}\text { Population } \\
\text { Density } \\
\left(\# / \mathbf{k m}^{2}\right)\end{array}$ & Type $^{* *}$ & $\begin{array}{c}\text { Potentially } \\
\text { Exposed } \\
\text { Population }\end{array}$ \\
\hline \multirow{2}{*}{$\begin{array}{l}\text { TA-V to Albuquerque } \\
\text { International Airport }\end{array}$} & 7.5 & 10 & $\mathrm{R}$ & 120 \\
\hline & 6.3 & 591 & $\mathrm{~S}$ & 5957 \\
\hline Total & 4.7 & 2333 & $\mathrm{U}$ & 17,544 \\
\hline
\end{tabular}

* Route segments are sequential segments of highway route, beginning with the site access road for the origin and ending with the destination.

** $R, S$, and $U$ symbolize rural, suburban, and urban, respectively. 
Table L-5. Highway Route for Shipments Of Unirradiated Targets From LANL To SNLNM and Albuquerque

\begin{tabular}{|c|c|c|c|c|}
\hline \multicolumn{5}{|c|}{ Los Alamos, NM to Sandia National Laboratory } \\
\hline Route Segment & $\begin{array}{l}\text { Dist } \\
(\mathrm{km})\end{array}$ & $\begin{array}{l}\text { Pop den } \\
\left(\mathrm{km}^{-1}\right)\end{array}$ & Type & $\begin{array}{c}\text { Exposed } \\
\text { Population }\end{array}$ \\
\hline \multirow{2}{*}{ Los Alamos, NM to Pojoaque, NM } & $2.850 \mathrm{e}+01$ & $1.360 \mathrm{e}+01$ & $\mathbf{R}$ & 620 \\
\hline & $2.100 e+00$ & $3.122 \mathrm{e}+02$ & $\bar{s}$ & 1049 \\
\hline \multirow[t]{3}{*}{ Pojoaque, NM to Santa Fe, NM } & $2.400 e+01$ & $1.100 e+01$ & $\mathbf{R}$ & 422 \\
\hline & $6.300 e+00$ & $6.246 e+02$ & $\overline{\mathbf{S}}$ & 6296 \\
\hline & $1.900 \mathrm{e}+00$ & $2.228 e+03$ & $\bar{U}$ & 6772 \\
\hline \multirow[t]{3}{*}{ Santa Fe, NM to Albuquerque, NM } & $7.830 e+01$ & $6.200 \mathrm{e}+00$ & $\overline{\mathbf{R}}$ & 777 \\
\hline & $1.550 e+01$ & $3.439 e+02$ & $\bar{S}$ & 8529 \\
\hline & $6.000 e+00$ & $2.120 e+03$ & $\bar{U}$ & 20355 \\
\hline \multirow[t]{3}{*}{ Albuquerque, NM to SNL } & $1.300 e+00$ & $2.200 \mathrm{e}+00$ & $\overline{\mathbf{R}}$ & 5 \\
\hline & $3.000 e+00$ & $5.529 \mathrm{e}+02$ & $\overline{\mathbf{S}}$ & 2654 \\
\hline & $5.000 \mathrm{e}-01$ & $1.765 \mathrm{e}+03$ & $\bar{U}$ & 1412 \\
\hline \multirow[t]{2}{*}{ SNL, TA-I to TA-V } & $3.00 e+00$ & 1250 & $\bar{S}$ & 6000 \\
\hline & $6.00 e+00$ & 250 & $\mathbf{S}$ & 2400 \\
\hline Total & $1.76 e+02$ & & & 57290 \\
\hline
\end{tabular}


Table L-6. Highway Route for Shipments Of Hot Cell Facility Wastes From SNLNM To NTS

\begin{tabular}{|c|c|c|c|c|}
\hline \multicolumn{5}{|c|}{ Sandia National Laboratory to NTS } \\
\hline Route Segments & $\begin{array}{l}\text { Dist } \\
(\mathrm{km})\end{array}$ & $\begin{array}{c}\text { Pop den } \\
\left(\mathrm{km}^{-1}\right)\end{array}$ & Type & $\begin{array}{l}\text { Exposed } \\
\text { Population }\end{array}$ \\
\hline \multirow[t]{2}{*}{ SNL, TA-V to TA-I } & $6.00 e+00$ & 250 & $\mathrm{~S}$ & 2400 \\
\hline & $3.00 \mathrm{e}+00$ & 1250 & $\mathrm{~S}$ & 6000 \\
\hline \multirow[t]{3}{*}{ SNL to Albuquerque, NM } & $1.300 \mathrm{e}+00$ & $2.200 \mathrm{e}+00$ & $\overline{\mathbf{R}}$ & 5 \\
\hline & $3.000 \mathrm{e}+00$ & $5.529 e+02$ & $\mathbf{S}$ & 2654 \\
\hline & $5.000 e-01$ & $1.765 e+03$ & $\bar{U}$ & 1412 \\
\hline \multirow{3}{*}{$\begin{array}{l}\text { Albuquerque, NM to } \\
\text { Arizona/New Mexico Border on } \\
\text { Interstate } 40\end{array}$} & $2.377 e+02$ & $7.500 e+00$ & $\mathbf{R}$ & 2852 \\
\hline & $2.120 \mathrm{e}+01$ & $4.903 e+02$ & $\bar{S}$ & 16631 \\
\hline & $8.300 \mathrm{e}+00$ & $2.046 e+03$ & $\bar{U}$ & 27168 \\
\hline \multirow{3}{*}{$\begin{array}{l}\text { Arizona/California Border on } \\
\text { Interstate } 40\end{array}$} & $5.645 e+02$ & $1.800 \mathrm{e}+00$ & $\overline{\mathbf{R}}$ & 1626 \\
\hline & $2.350 \mathrm{e}+01$ & $3.826 e+02$ & $\mathrm{~S}$ & 14386 \\
\hline & $2.700 \mathrm{e}+00$ & $2.313 e+03$ & $\mathrm{U}$ & 9991 \\
\hline \multirow{3}{*}{$\begin{array}{l}\text { Arizona/California Border on } \\
\text { Interstate } 40 \text { to } \\
\text { California/Nevada Border on } \\
\text { Interstate } 15\end{array}$} & $4.145 e+02$ & $2.400 \mathrm{e}+00$ & $\overline{\mathbf{R}}$ & 1592 \\
\hline & $1.180 \mathrm{e}+01$ & $3.514 e+02$ & S & 6634 \\
\hline & $1.700 \mathrm{e}+00$ & $2.445 e+03$ & $\mathrm{U}$ & 6650 \\
\hline \multirow{3}{*}{$\begin{array}{l}\text { California/Nevada Border on } \\
\text { Interstate } 15 \text { to Las Vegas, NV }\end{array}$} & $5.780 \mathrm{e}+01$ & $2.500 e+00$ & $\mathbf{R}$ & 231 \\
\hline & $9.400 \mathrm{e}+00$ & $3.525 e+02$ & $\mathrm{~S}$ & 5302 \\
\hline & $4.000 \mathrm{e}-01$ & $2.380 \mathrm{e}+03$ & $\mathrm{U}$ & 1523 \\
\hline \multirow[t]{3}{*}{ Las Vegas, NM to Mercury, NV } & $9.230 \mathrm{e}+01$ & $1.800 e+00$ & $\overline{\mathbf{R}}$ & 266 \\
\hline & $9.700 \mathrm{e}+00$ & $5.444 \mathrm{e}+02$ & $\mathrm{~S}$ & 8449 \\
\hline & $2.600 \mathrm{e}+00$ & $2.421 e+03$ & $\mathrm{U}$ & 10073 \\
\hline Total & $1.472 e+03$ & & & 125844 \\
\hline
\end{tabular}


Table L-7. Highway Route for Shipments of Hot Cell Facility Wastes From SNLNM to Hanford

\begin{tabular}{|c|c|c|c|c|}
\hline Route Segment & $\begin{array}{l}\text { Dist } \\
(\mathbf{k m})\end{array}$ & $\begin{array}{c}\text { Pop den } \\
\left(\mathrm{km}^{-1}\right)\end{array}$ & Type & $\begin{array}{c}\text { Exposed } \\
\text { Population }\end{array}$ \\
\hline \multirow[t]{2}{*}{ SNL, TA-V to TA-I } & $6.00 e+00$ & 250 & $\mathbf{S}$ & 2400 \\
\hline & $3.00 e+00$ & 1250 & $\mathbf{S}$ & 6000 \\
\hline \multirow[t]{2}{*}{ SNLNM to Albuquerque, NM } & 1.40 & 915.70 & $\mathbf{S}$ & 2051 \\
\hline & 1.80 & 2684.70 & $\mathbf{U}$ & 7732 \\
\hline \multirow[t]{3}{*}{$\begin{array}{l}\text { Albuquerque, NM to New Mexicol } \\
\text { Colorado Border on Interstate } 25\end{array}$} & 355.00 & 4.10 & $\overline{\mathbf{R}}$ & 2329 \\
\hline & 26.60 & 349.10 & $\mathbf{S}$ & 14858 \\
\hline & 3.00 & 2450.90 & $\mathbf{U}$ & 11764 \\
\hline \multirow[t]{3}{*}{$\begin{array}{l}\text { New Mexico/Colorado Border on Interstate } \\
25 \text { to Colorado/Wyoming Border on } \\
\text { Interstate } 25\end{array}$} & $\mathbf{3 7 9 . 3 0}$ & 5.60 & $\overline{\mathbf{R}}$ & 3399 \\
\hline & 83.60 & 406.40 & $\mathbf{S}$ & 54360 \\
\hline & 18.20 & 2067.30 & $\mathbf{U}$ & 60200 \\
\hline \multirow{3}{*}{$\begin{array}{l}\text { Colorado Wyoming Border on Interstate } 25 \\
\text { to Wyoming/Utah Border on Interstate } 80\end{array}$} & 557.80 & 2.00 & $\overline{\mathbf{R}}$ & 1785 \\
\hline & 32.50 & 392.50 & $\mathbf{S}$ & 20410 \\
\hline & 0.30 & 1764.70 & $\mathbf{U}$ & 847 \\
\hline \multirow[t]{3}{*}{$\begin{array}{l}\text { Wyoming/Utah Border on Interstate } 80 \text { to } \\
\text { Utah/ldaho Border on Interstate } 84\end{array}$} & 212.30 & 4.30 & $\overline{\mathbf{R}}$ & 1461 \\
\hline & 23.30 & 319.00 & $\mathbf{s}$ & 11892 \\
\hline & 2.30 & 2394.20 & $\mathbf{U}$ & 8811 \\
\hline \multirow[t]{3}{*}{$\begin{array}{l}\text { Utah/ldaho Border on Interstate } 84 \text { to } \\
\text { Idaho/Oregon Border on Interstate } 84\end{array}$} & 404.70 & 5.90 & $\mathbf{R}$ & 3820 \\
\hline & 31.80 & 344.80 & $\mathbf{S}$ & 17543 \\
\hline & 5.90 & 2095.10 & $\mathbf{U}$ & 19778 \\
\hline \multirow[t]{3}{*}{$\begin{array}{l}\text { Idaho/Oregon Border on Interstate } 84 \text { to } \\
\text { Oregon/Washington Border on Interstate } 82\end{array}$} & 316.20 & 4.40 & $\mathbf{R}$ & 2226 \\
\hline & 16.40 & 360.90 & $\mathbf{S}$ & 9470 \\
\hline & 2.10 & 1930.80 & $\mathbf{U}$ & 6487 \\
\hline \multirow[t]{2}{*}{$\begin{array}{l}\text { OregonMashington Border on Interstate } 82 \\
\text { to Richland, WA }\end{array}$} & 52.50 & 4.90 & $\overline{\mathbf{R}}$ & 412 \\
\hline & 3.80 & 218.80 & $\mathbf{s}$ & 1330 \\
\hline \multirow[t]{3}{*}{ Richland, WA to Hanford LLW Repository } & 46.40 & 2.10 & $\overline{\mathbf{R}}$ & 156 \\
\hline & 4.40 & 459.70 & $\mathbf{S}$ & 3236 \\
\hline & 2.40 & 1995.10 & $\mathbf{U}$ & 7661 \\
\hline Total & 2593.00 & & & 282418 \\
\hline
\end{tabular}


Table L-8. EPA Nonattainment Counties Along a Representative Route from SNLNM to the NTS

\begin{tabular}{|c|c|c|c|c|c|c|}
\hline \multirow{2}{*}{ COUNTIES } & \multicolumn{4}{|c|}{ CRITERIA POLLUTANTS } & \multicolumn{2}{|c|}{ TRAFFIC DATA } \\
\hline & $\begin{array}{l}\text { CARBON } \\
\text { MONOXIDE }\end{array}$ & OZONE & TSP & PM-10 & AADT & $\begin{array}{l}\text { YEAR OF } \\
\text { DATA }\end{array}$ \\
\hline \multicolumn{7}{|l|}{ NEW MEXICO } \\
\hline Bernalililo & $x$ & & & & 13,300 & 1993 \\
\hline \multicolumn{7}{|l|}{ ARIZONA } \\
\hline Mojave & & & & $x$ & 7,100 & 1992 \\
\hline \multicolumn{7}{|l|}{ CALIFORNIA } \\
\hline $\begin{array}{l}\text { San } \\
\text { Bernardino }\end{array}$ & $x$ & & & $x$ & & 1993 \\
\hline \multicolumn{7}{|l|}{ NEVADA } \\
\hline Clark & $\bar{x}$ & & & $\bar{x}$ & 1,390 & 1992 \\
\hline
\end{tabular}

PM-10 = Total suspended particulate with standards measured as particulate matter with an aerodynamic diameter less than or equal to a nominal 10 micrometers.

\section{Table L-9. EPA Nonattainment Counties Along a Representative Route from SNL/NM to the Hanford Site}

\begin{tabular}{|c|c|c|c|c|c|c|}
\hline \multirow{2}{*}{ COUNTIES } & \multicolumn{4}{|c|}{ CRITERIA POLLUTANTS } & \multicolumn{2}{|c|}{ TRAFFIC DATA } \\
\hline & $\begin{array}{c}\text { CARBON } \\
\text { MONOXIDE }\end{array}$ & OZONE & TSP & PM-10 & AADT & $\begin{array}{l}\text { YEAR OF } \\
\text { DATA }\end{array}$ \\
\hline \multicolumn{7}{|l|}{ NEW MEXICO } \\
\hline Bernalillo & $x$ & & & & 35,200 & 1993 \\
\hline \multicolumn{7}{|l|}{ COLORADO } \\
\hline EI Paso & $x$ & & & & 20,600 & 1992 \\
\hline Douglas & $x$ & $x$ & & $x$ & 28,300 & 1992 \\
\hline Denver & $\underline{x}$ & $x$ & $x$ & $x$ & 123,200 & 1992 \\
\hline Adams & $x$ & $x$ & & $x$ & 50,000 & 1992 \\
\hline Arapahoe & $x$ & $x$ & & $x$ & 79,000 & 1992 \\
\hline Weld & $x$ & & & & 10,300 & 1992 \\
\hline Larimer & $x$ & & & & 10,600 & 1992 \\
\hline \multicolumn{7}{|l|}{ UTAH } \\
\hline Weber & $x$ & & $x$ & & 7,065 & 1993 \\
\hline \multicolumn{7}{|l|}{ IDAHO } \\
\hline Ada & $x$ & & & $x$ & 15,000 & 1992 \\
\hline
\end{tabular}

PM-10 = Total suspended particulate with standards measured as particulate matter with an aerodynamic diameter less than or equal to a nominal 10 micrometers 
Table L-10. HCF Waste Shipment Radionuclide Inventory For RADTRAN 4 Accident Analysis

\begin{tabular}{|l|c|}
\hline \multicolumn{1}{|c|}{ Isotope } & Activity (Curies) \\
\hline${ }^{\mathrm{T}} \mathrm{Cr}$ & 20.1 \\
\hline${ }^{55} \mathrm{Fe}$ & 27.1 \\
\hline${ }^{59} \mathrm{Fe}$ & 1.0 \\
\hline${ }^{89} \mathrm{Sr}$ & 109.0 \\
\hline${ }^{90} \mathrm{Sr}$ & 7.6 \\
\hline${ }^{91} \mathrm{Y}$ & 163 \\
\hline${ }^{95} \mathrm{Zr}$ & 195.0 \\
\hline${ }^{95} \mathrm{Nb}$ & 348.0 \\
\hline${ }^{103} \mathrm{Ru}$ & 44.7 \\
\hline${ }^{106} \mathrm{Ru}$ & 11.0 \\
\hline${ }^{137} \mathrm{Cs}$ & 7.9 \\
\hline${ }^{141} \mathrm{Ce}$ & 51.6 \\
\hline${ }^{144} \mathrm{Ce}$ & 174.0 \\
\hline${ }^{147} \mathrm{Pm}$ & 29.9 \\
\hline
\end{tabular}




\section{References}

1. Fischer, L. E., et al., 1987, Shipping Container Response to Severe Highway and Railway Accident Conditions, NUREG/CR-4829, USNRC, Washington, DC, 1987.

2. Hallenbeck, W. H. and K. M. Cunningham, 1986, Quantitative Risk Assessment for Environmental and Occupational Health, Lewis Publ., Chelsea, MI, 1986.

3. Helton, J. C., 1991, Performance Assessment Overview, in Preliminary Comparison with 40 CFR Part 191, Subpart B, for the Waste Isolation Pilot Plant, December 1991, SAND91-0893, Sandia National Laboratories, Albuquerque, NM, 1991.

4. Neuhauser, K. S. and Kanipe, F. L., 1991, RADTRAN 4 - Volume II: Technical Manual, Draft SAND89-2370, Sandia National Laboratories, Albuquerque, NM, 1991.

5. Neuhauser, K. S. and F. L. Kanipe, 1992, RADTRAN 4 - Volume III: User Guide, SAND892370, Sandia National Laboratories, Albuquerque, NM, January 1992.

6. ORNL (Oak Ridge National Laboratory), 1992, P. Johanson, Highway 5.0 - An Expanded Highway Routing Model: Program Description, Methodology and Revised User's Manual, ORNL/TM-12124, Oak Ridge National Laboratory, Oak Ridge, TN, 1992.

7. Ross, 1994, Transportation Evaluation Report, Ross Aviation, Inc., Albuquerque, NM, February 1, 1994.

8. Shapiro, J., 1977, Exposure of Airport Workers to Radiation from Shipments of Radioactive Material, NUREG-0154, U.S. Nuclear Regulatory Commission, Washington, DC.

9. U.S. Department of Transportation, 1985, Annual Report of Bureau of Motor Carrier Safety, Washington DC, 1985

10. U.S. Nuclear Regulatory Commission, 1977, Final Environmental Statement on the Transportation of Radioactive Material by Air and Other Modes, NUREG-0170, Vols. I and II, Office of Standards Development, USNRC, Washington, DC, 1977.

11. Wheeler, T., 1994, Telephone conversation between Timothy Wheeler (SNL, Department 6626) and Timothy Crume (Federal Express, Albuquerque, NM), November, 1994

12. Whitlow, J. D. and K. S. Neuhauser, 1992, "A Methodology for the Transfer of Probabilities Between Accident Severity Classification Schemes," Proceedings of 1st International Consensus Conference of the Risks of Transporting Dangerous Goods, Institute for Risk Research, Waterloo, Ontario, Canada, 1992.

13. Wilmot, E. L., 1981, Transportation Accident Scenarios for Commercial Spent Fuel, SAND80-2124, Sandia National Laboratories, Albuquerque, NM, February 1981. 


\section{APPENDIX $M$ \\ IMPACT AND RISK ASSESSMENT METHODOLOGY}

\section{M.1 Measurements of Radiation Exposure}

An individual may be exposed externally to ionizing radiation from a radioactive source outside the body, and/or internally, from ingesting or inhaling radioactive material. In calculating an external dose, one may assume that the dose is distributed uniformly over the body. An external dose is delivered only during the actual time of exposure to the radiation source. However, when radionuclides are deposited in various body tissues and organs, the dose and effects are not uniform. A few organs in the body may receive a large dose; others may receive none. An internal dose continues to be delivered as long as the radioactive source is in the body, although both radioactive decay and elimination of the radionuclide by ordinary metabolic processes decrease the dose rate with the passage of time. An internal dose is calculated for 50 years following the initial exposure, and the result is expressed as the committed effective dose equivalent (CEDE). The effective dose equivalent is the sum of the external dose and the committed effective dose from internal sources.

Potential radiological impacts are measured by estimating the highest radiation exposure any single person might receive, as well as the collective exposure of a particular population (for example, all those living in the vicinity of a transportation route). Two primary units of radiation measurement are used to estimate these impacts, the rem and person-rem. The rem (roentgen equivalent man) is a measure of absorbed dose to biological tissue. The rem is defined as the absorbed radiation (rad) multiplied by a quality factor (see below). Quantitatively, it is the amount of damage done when 1 gram of biological tissue absorbs 100 ergs of $x$-ray (or gamma-ray). Absorbed radiation is measured directly in rad (radiation absorbed dose); one rad is the absorption of 100 ergs of energy by 1 gram of absorbing substance. Thus, one rem is the biological damage done when one rad of $x$-ray or gamma rays is absorbed. Radiation doses are usually measured in millirems (mrem, or 1/1000 of a rem) or millirads (mrad, or $1 / 1000$ of a rad).

The concept of dose equivalent accounts for the different amounts of biological damage done by various types of ionizing radiation (alpha, gamma, and so on). The ratio of dose equivalent (rem or mrem) to absorbed energy (rad or mrad) is called the quality factor (QF). For gamma radiation and $\mathrm{X}$-rays, the QF is 1.0; thus, the dose equivalent in mrem is equal to the dose in mrad (Shleien, 1992).

In this study, dose equivalents from incident-free operations and CEDE risks from accidents are the basis for calculated health effects. For brevity, however, they are referred to as "doses" and "dose risks."

It is estimated that the average individual in the United States receives a dose of about 360 mrem per year from all sources, including natural and medical sources of radiation. (NAS, 1990). For perspective, a modern chest $x$-ray results in an approximate dose of 8 mrem, while a diagnostic hip $x$-ray results in an approximate dose of 83 mrem (Shleien, 1992). For further perspective, an individual must receive an acute exposure of approximately 600 rem $(600,000$ mrem) before there is a high probability of near-term death (NAS, 1990). To protect individual members of the general public, the maximum annual allowable radiation exposure from operational activities is established by DOE, as well as by the NRC, to be $100 \mathrm{mrem}$ (DOE, 
1990). DOE Order 5480.11 has established the maximum annual whole-body dose for radiological workers as 5 rem (SNL, 1994). SNL policy dictates that, during normal operations, the annual whole-body dose to a worker shall not exceed 500 mrem. Requests to exceed this self-imposed limit must be approved by upper-level SNL management.

Radiation exposure to a population or a group of persons is measured in person-rem. The total population exposure (expressed in person-rem) is derived by adding up all the individual doses in the exposed group. This measurement is particularly important when trying to take into account the potential impacts of very small doses on very large populations.

Health effects may be calculated from doses by multiplying the dose by an appropriate conversion factor known as a risk factor. This risk factor has the dimensions of health effect per unit dose per person and may include a time factor. The National Academy of Sciences study on the biological effects of ionizing radiation includes a number of examples of such risk factors. These risk factors have been developed from epidemiological studies of health effects in populations exposed to ionizing radiation, primarily the Atomic Bomb Survivors Life Study (NAS, 1990) and occupational exposures.

Using such a conversion factor, the estimated exposures can be converted into estimated numbers of health effects. Because the exposures predicted in this study are far below those known to cause immediate illness or fatality, only delayed health effects are estimated. A delayed effect is measured in latent cancer fatalities (LCFs), defined as a fatal malignancy that may occur after 10 years or more and that has a probability of occurrence that increases with exposure. The conversion factor is 0.0005 LCFs/person-rem for the general public and 0.0004 LCFs/person-rem for workers (FR, 1991). Worker groups tend to be healthy adults and do not represent as broad a spectrum of susceptible people (for example, children) as does the general population. Applying the conversion factor to the general population, a collective dose of 2,000 person-rem is estimated to result in one additional LCF.

Genetic effects in subsequent generations are another type of health effect that may occur as a result of low-level radiation exposure such as that associated with the proposed action in this EA. The conversion factor is smaller, and the uncertainty is greater than for LCFs. The International Committee on Radiation Protection (ICRP) has recommended a conversion factor about five times lower than that used to estimate cancer fatalities (ICRP, 1991). For comparison with the latter, one can state that in a general population, a collective dose of 10,000 person-rem is estimated to result in one additional genetic effect in all subsequent generations.

\section{M.2 Operations Dose Calculations and Risk Assessment}

Dose estimates and associated risk data are presented for ACRR and HCF operations in Sections 4.3 and 4.4. Estimated whole-body doses were calculated for normal operations and all accident scenarios that could result in a release of radioactivity to the atmosphere. For each case, doses were calculated for the following distances from the facility: $300 \mathrm{~m}(0.2 \mathrm{mi}), 1610$ $\mathrm{m}$ (1 mi), $3000 \mathrm{~m}$ (1.9 mi), $6000 \mathrm{~m}$ (3.7 mi) and $20,000 \mathrm{~m}$ (12.4 mi). Three hundred meters is a representative distance for other workers within TA-V, $1610 \mathrm{~m}$ is the location of KUMSC (the closest population group outside the immediate area of the ACRR and HCF), $3000 \mathrm{~m}$ is the TA$V$ exclusion zone, $6000 \mathrm{~m}$ represents the closest public living are (an on-base cluster of military housing) and $20,000 \mathrm{~m}$ is a representative distance for the population centers of Albuquerque. 
Dose data at the exclusion zone boundary $(3000 \mathrm{~m})$ and $20,000 \mathrm{~m}$ were used to calculate LCF data for the maximally exposed off-site individual (MOI) and the general population. The population figure used for the metropolitan Albuquerque area was 496,065 (Parks, 1992).

\section{M.3 Incident-Free Transportation}

The transportation risk analysis was performed using the RADTRAN 4 computer code (Neuhauser, 1992). RADTRAN 4 models have been developed to yield estimates that tend to overstate the impact. RADTRAN 4 postulates that, in the event of an accident, people would not be evacuated for 24 hours. In actuality, people would most likely be evacuated sooner, thereby reducing the time of exposure. In addition, the RADTRAN accident dispersal characteristics of flammable materials were used to yield conservative estimates of accident dose risk.

Detailed information regarding truck routes and associated population distributions for the fresh (unirradiated) target shipments between LANL and SNL/NM, the isotopic product shipments between SNL/NM and the Albuquerque International Airport, and the waste shipments between SNLINM and NTS and Hanford was obtained using the HIGHWAY computer program (ORNL, 1992). HIGHWAY is essentially a computerized atlas that can be used to minimize a combination of distance and driving time for a highway route between two points while maximizing use of interstate system highways. This feature allows the user to establish baseline routes for shipments of radioactive materials that conform to DOT routing regulations, which require that interstate system highways be used to the maximum extent possible. The population density distribution is calculated for several segments of the highway route, representing rural, suburban, and urban population densities. Similar information regarding the air transportation routes between Albuquerque and the three U.S. distribution centers (Boston, Chicago, St. Louis) and the Canadian producer of ${ }^{99} \mathrm{Mo}$ (Nordion, near Ottawa, Ontario) was developed using HIGHWAY. Air routes over the continental U.S. and Canada are bounded by ground highway routes. This allows HIGHWAY to accumulate information regarding the population densities along the air routes.

Population densities from HIGHWAY are determined using 1990 federal Census Bureau data. The Census Bureau updates the census data once every 10 years. There is no other national database available for population densities. Use of the Census Bureau's decennial data is consistent with the practice in government and private industry when there is a need to model population characteristics.

The routes that might ultimately be taken cannot be predicted with 100 percent precision because of routing variables such as weather, construction, or accidents involving other vehicles. Moreover, if consistent with DOT regulation, state authorities can change highway routes that must be used for ground transportation. The representative routes analyzed, based on conformity with general DOT criteria, provide a basis for comparing potential impacts associated with using different disposal sites for the SNL/NM waste. These routes are described in Section 4.6.

During routine transportation operations, individuals near the transportation packages would receive low levels of external exposure to radiation (gamma and $x$-rays). No internal exposures would be received since the product and waste would be contained within the shipping containers. Population exposure models are described in detail in the RADTRAN 4 technical 
manual (Neuhauser, 1991). The various groups potentially at risk from routine operations resulting from overland transportation would be the truck crew and the general public:

- Iruck Crew: Dose rates in the cabs of tractor trucks carrying radioactive material are required by regulation to be less than $2 \mathrm{mrem} / \mathrm{hr}$ (49 CFR 173). All trucks are modeled as having two-person crews.

- Aircraft Crew: Dose estimates for cargo aircraft crews are modeled by assuming 3 crew members sitting at a distance of 9.14 meters $(30 \mathrm{ft})$ from the radioactive material. No shielding from internal structures is modeled.

- Persons along the Highway Route: This group, often referred to as the off-link population, generally receives the smallest doses. Population doses to persons within $800 \mathrm{~m}(0.5 \mathrm{mi})$ on each side of the transport route are estimated.

- Persons Sharing the Highway Route: Population doses to persons in vehicles traveling in the same direction (including passing vehicles) and in the opposite direction (collectively referred to as the on-link population) are estimated, although their doses are usually very small.

- Persons at Highway Stops: Population doses to persons at fuel and rest stops, tire inspection stops, etc. along the route are estimated. In this analysis the stop time was derived by using $0.011 \mathrm{hr} / \mathrm{km}(0.018 \mathrm{hr} / \mathrm{mi})$ as the stop rate for truck shipments (based on national trucking data for long haul shipments), the general public population exposed during each stop was estimated at 50 persons, and the average exposure distance for these persons was $20 \mathrm{~m}$ (66ft).

- Maximum Individual: An individual member of the public who is modeled as living beside the highway route and who is exposed to every shipment at a distance of $30 \mathrm{~m}$ (100 ft).

- "Traffic Jam" Individual: An individual member of the public who is sharing the highway with the LLW conveyance during a traffic stoppage resulting in traffic jam conditions. The exposure to this individual is modeled with a 2-hour traffic stoppage with an exposure distance of $2 \mathrm{~m}$ (6.6 ft). This dose estimate is performed for a single truck shipment to establish an estimate of a potential dose resulting from a realistic traffic situation.

\section{M.4 Highway Accidents}

\section{Methodology}

Risk analysis of potential accidents differs from calculations for incident-free transportation because the analyst must account for the probability of an accident occurring. In the incidentfree scenario, some exposure is expected from radiation emitted from the casks. In the case of accidents, the probability of exposure is only an estimate of a hypothetical event. Probabilities are derived from published accident rates for truck and rail transportation modes. 
Because accidents can be of any severity from a "fender-bender" to one involving severe impact and prolonged fire, the RADTRAN 4 code allows the analyst to divide the severity spectrum into a number of accident-severity categories. Each category is assigned a probability of occurrence-that is, a probability, given that an accident occurs, that it will be of that particular severity. The more severe the accident, the more remote the chance of such an accident. In this analysis, the accident severity spectrum is divided into six categories for highway transportation (NRC, 1977). The six severity categories include all accidents with a probability of occurrence of one in a million or greater for the entire campaign of truck or rail shipments, a figure well within the levels found acceptable by the EPA and other agencies (Hallenbeck, 1986).

Atmospheric dispersion is usually the primary mechanism for dispersing any radioactive material that might be released in a severe accident. Weather conditions cannot be predicted with any certainty far in advance, and transportation analyses must consider the fact that weather may vary from one point on a route to another. Therefore, national average weather conditions are used for transportation by highway.

\section{Materials and Waste Packaging}

The behavior of the package in each accident severity category is accounted for in this analysis. "Type $A$ " containers are intended to provide a safe, economical means for transporting relatively small quantities of radioactive materials such as the uranium loaded targets. These are expected to retain their integrity under the kind of abuse considered "normal," or likely to occur during transport: falling from vehicles or being dropped from similar heights, being exposed to rain, being struck by a sharp object that may penetrate their surface, or having other cargo stacked on top. They must also satisfy stringent additional dimensional, ambient environment, internal pressure, and containment specifications. It is assumed that Type A packages would be damaged in a severe accident and that a fraction of their contents may be released. The regulations therefore prescribe limits on the maximum amounts of radionuclides that can be transported in such packages. These limits ensure that in the event of a release the risks from external radiation or contamination are low.

Federal regulations require that for Type A packages to be used, each package design must be certified by the appropriate agency. The DOE proposes to use only DOT-certified packages for ${ }^{99}$ Mo shipments. The certification process for a package design includes extensive documentation that the package can pass certain performance-based test criteria. Passing is defined as maintaining specified shielding and containment capabilities after being subjected to appropriate test conditions. Type A packages must be able to withstand test conditions that simulate the stress of normal, incident-free conditions of transport. The test standards for Type A packages as established in 49 CFR 173.463 through 173.469 are as follows:

- Water spray for one hour,

- Free-fall drop onto a flat surface from a height of 4 feet, if the package weighs 11,000 pounds or less;

- Compression five times the package's weight for 24 hours; and

- Dropping a 13-pound bar on end onto the package from a height of 3.3 feet. 
"Type B" containers (such as the B-3 shipping cask for the waste and the 20WC package for the ${ }^{99} \mathrm{Mo}$ and ${ }^{131} \mathrm{I}$ isotopes) are massive, highly damage-resistant packagings. Type $B$ packages are required to pass two series of rigorous tests: those associated with normal or routine transportation and those associated with hypothetical accident conditions that might be encountered. The sequence of accident conditions is defined in 10 CFR Part 71, Subpart F:

- Drop test, a free drop through a distance of 30 feet $(9 \mathrm{~m})$ onto a flat unyielding surface, striking the surface in a position for which maximum damage is expected; followed by

- Puncture test, a free drop through a distance of 40 inches $(1 \mathrm{~m})$ in a position in which maximum damage is expected onto upper end of solid steel bar; followed by

- Thermal test, exposure for not less than 30 minutes to thermal environment of $1475^{\circ}$ F $\left(800^{\circ} \mathrm{C}\right)$; followed by

- Immersion test, subjected to water pressure equivalent to immersion under a head of water at least 50 feet $(15 \mathrm{~m})$ for at least eight hours.

These certification tests were developed by the International Atomic Energy Agency (IAEA) and promulgated as model regulations (IAEA, 1990). These model regulations have been adopted by the United States and all of the nations proposing to ship foreign research reactor spent nuclear fuel to the United States.

\section{Accident Risks During Overland Transportation}

The radiological accident risks from the shipping campaign described in Appendix $L$ were calculated assuming that a group of people were exposed to a contaminated airborne plume that might result from an accident. The number of persons potentially exposed varied by route segment and was based on the segment population density and downwind travel of the radioactive cloud (plume). In the event of a severe transportation accident and fire within an urban area, the radioactive cloud is assumed to travel over the urban area and out to a distance of $80 \mathrm{~km}(50 \mathrm{mi})$ of the accident site. In reality, the plume would be subject to prevailing winds and might blow away from populated areas. In addition, although the urban population is typically much greater than the population in surrounding outlying areas, the accident model treats the urban population density as constant for the full $80 \mathrm{~km}$ (50 mi). Another conservative assumption incorporated into the risk assessment is that the entire population remains in the area for 24 hours and therefore is exposed to the greatest extent possible to radioactive material deposited on the ground from the plume. In reality, individuals close to an accident would probably be evacuated in less than 24 hours.

\section{M.5 Air Accidents}

Risk associated with air shipments of the fresh targets to Canada and of the isotopic products to Boston, Chicago, and St. Louis are estimated based on modeling the air flights as two segments: (1) a takeoff and landing leg in which air accident data specific to takeoff and landing operations (Ross, 1994) and population data specific to each airport were used, and (2) an inflight leg in which air accident data specific to inflight operations were used. Population 
data for the inflight legs were modeled using the HIGHWAY code as discussed above. All other aspects of the air accident methodology are the same as the highway accident methodology.

\section{M.6 Nonradiological Health Effects and Risks}

A series of unit-risk factors (that is, risk per kilometer traveled) have been developed based on national statistics for accident-related deaths for highway and rail modes (Wilmot, 1983). These have been used to calculate the expected numbers of nonradiological fatalities associated with highway transportation of the SNL/NM LLW shipments to each of the options for the proposed action.

Health effects related to vehicle emissions are estimated in terms of LCFs. Recovery rates for cancer are far more variable and depend on the site of the cancer. In part because of the large variation in relative incidence of nonfatal health effects, fatalities are the only measure of harm that allows direct comparison between radiological and nonradiological consequences. An estimate of consequences of incident-free transportation (latent cancer fatalities associated with release of pollutants by trucks in urban areas) is presented for completeness. These estimates include very large uncertainties. The incident-free estimates were calculated with published nonradiological risk factors (Wilmot, 1983) used in combination with the truck transportation distances associated with each LLW disposal option. The nonradiological impact estimates include the contribution from the return trip of the truck to SNL/NM. 


\section{References}

1. DOE see U.S. Department of Energy.

2. FR see U.S. Federal Register.

3. Hallenbeck, W.H. and Cummingham, K.M., 1986, Quantitative Risk Assessment for Environmental and Occupational Health, Lewis Publ., Chelsea, Michigan.

4. IAEA (International Atomic Energy Agency), 1990, Regulations for the Safe Transport of Radioactive Material, Safety Series No. 6, IAEA, Vienna, Austria.

5. ICRP (International Commission on Radiological Protection), 1991, 1990 Recommendation of the International Commission on Radiological Protection, Publication 60.

6. NAS (National Academy of Sciences Committee on the Effects of lonizing Radiation), 1990 Health Effects of Exposure to Low Levels of lonizing Radiation (BEIR V), National Academy of Sciences, Washington, D.C.

7. Neuhauser, K.S. and Kanipe, F.L., 1991, RADTRAN 4 - Volume II: Technical Manual, DRAFT SAND89-2370, Sandia National Laboratories, Albuquerque, New Mexico.

8. Neuhauser, K.S. and Kanipe, F.L., 1992, RADTRAN 4 - Volume Ili: User Guide, SAND892370, Sandia National Laboratories, Albuquerque, New Mexico.

9. NRC see U.S. Nuclear Regulatory Commission.

10. ORNL (Oak Ridge National Laboratory), 1992, P. Johanson, Highway 5.0 - An Expanded Highway Routing Model: Program Description, Methodology and Revised User's Manual, ORNLTM-12124, Oak Ridge National Laboratory, Oak Ridge, Tennessee.

11. Parks, B.S. 1992, User's Guide for CAP88-PC, 402-B-92-001, U.S. Environmental Protection Agency, Las Vegas, NV.

12. Ross, 1994, Transportation Evaluation Report, Ross Aviation, Inc., Albuquerque, New Mexico, February 1, 1994.

13. Sandia National Laboratories (SNL), 1994, ES\&H Manual Supplement - Radiological Protection Procedures Manual, E9407465A, Sandia National Laboratories, Albuquerque, New Mexico.

14. Shleien D., 1992, The Health Physics and Radiological Health Handbook, Scinta Inc., Silver Spring, Maryland.

15. U.S. Department of Energy (DOE), 1990, Radiation Protection of the Public and the Environment, DOE Order 5400.5, U.S. Department of Energy, Washington, DC. 
16. U.S. Federal Register (FR), 1991, Standards for Protection Against Radiation, Final Rule, U.S. Nuclear Regulatory Commission, Title 10, Part 20 et al, Washington D.C., May 21, 1991.

17. U.S. NRC (U.S. Nuclear Regulatory Commission), 1977, Final Environmental Statement on the Transportation of Radioactive Material by Air and Other Modes, NUREG-0710, Vols. I and II, Office of Standards Development, USNRC, Washington, D.C.

18. Wilmot, E.L. et al., 1983, A Preliminary Analysis of the Cost and Risk of Transporting Nuclear Waste to Potential Candidate Repository Sites, SAND83-0867, Sandia National Laboratories, Albuquerque, NM, June 1982. 
Distribution:

Pacific Northwest (Batelle) Lab

Michael McKinney

(4 copies)

Box 999 M/N K8-03

Richland, WA 99336

Los Alamos National Lab

Jim Kedbetter, MSG-742

P.O. Box 1163

( 3 copies)

Los Alamos, NM 87545

US Department of Energy

Wade Carroll, NE-70

19901 Germantown Road

( 5 copies)

Germantown, MD 20874-1290

1 Copy to the following:

MS 0184 Stan Brown, DOE/KAO

MS 0184 Terry Wallace, DOE/KAO

MS 0717 Anthony Trennel, 6642

MS 0717 Scott Mills, 6624

MS 0720 Dennis Miller, 6626

MS 0720 Susan Carson, 6626

MS 0720 Timothy Wheeler, 6626

MS 0736 Nestor Ortiz, 6400

MS 1137 Ed Parma, 9361

MS 1137 Milt Vernon, 9361

MS 1137 Susan Bourcier, 9361

MS 1137 Susan Longley, 6626

MS 1141 Jim Bryson, 9361

MS 1141 Marion McDonald, 9361

MS 1141 Ken Boldt, 9363

MS 1145 Paul Pickard, 9360

MS 1165 Jim Powell, 9300

MS 1137 Richard Coats, 9360 (2copies)

MS 0720 Charles Massey, 6626 ( 2 copies)

MS 9018 Central Technical Files, 8523-2 (1 copy)

MS 0899 Technical Library, 4414 (5 copies)

MS 0619 Print Media, 12615 (1 copy)

MS 0100 Document Processing, 7613-2 (2 copies)

for DOE/OSTI 